\title{
Urban Form and Passive Design for High Performance Buildings in the Christchurch Rebuild
}

By

Tavis Creswell-Wells

\author{
A thesis submitted to the \\ School of Architecture, Victoria University of Wellington \\ In fulfilment of the requirements for the degree of \\ Master of Building Science
}

Victoria University of Wellington

2014 

"One of the most basic and fundamental questions in urban master planning and building regulations is "how to secure common access to sun, light and fresh air?" (Stromann-Andersen \& Sattrup, 2011).

Daylighting and natural ventilation can have significant benefits in office buildings. Both of these 'passive' strategies have been found to reduce artificial lighting and air-conditioning energy consumption by as much as $80 \%$ (Ministry for the Environment, 2008); (Brager, et al., 2007). Access to daylight and fresh air can also be credited with improved occupant comfort and health, which can lead to a reduction of employee absenteeism and an increase of productivity (Sustainability Victoria, 2008).

In the rebuild of Christchurch central city, following the earthquakes of 2010 and 2011, Cantabrians have expressed a desire for a low-rise, sustainable city, with open spaces and high performance buildings (Christchurch City Council, 2011). With over $80 \%$ of the central city being demolished, a unique opportunity to readdress urban form and create a city that provides all buildings with access to daylight and fresh air exists.

But a major barrier to wide-spread adoption of passive buildings in New Zealand is their dependence on void space to deliver daylight and fresh air - void space which could otherwise be valuable built floor space. Currently, urban planning regulations in Christchurch prioritize density, allowing and even encouraging low performance compact buildings.

Considering this issue of density, this thesis aimed to determine which urban form and building design changes would have the greatest effect on building performance in Central City Christchurch.

The research proposed and parametrically tested modifications of the current compact urban form model, as well as passive building design elements. Proposed changes were assessed in three areas: energy consumption, indoor comfort and density. Three computer programs were used: EnergyPlus was the primary tool, simulating energy consumption and thermal comfort. Radiance/Daysim was used to provide robust daylighting calculations and analysis. UrbaWind enabled detailed consideration of the urban wind environment for reliable natural ventilation predictions.

Results found that, through a porous urban form and utilization of daylight and fresh air via simple windows, energy consumption could be reduced as much as $50 \%$ in buildings. With automatic modulation of windows and lighting, thermal and visual comfort could be maintained naturally for the majority of the occupied year. Separation of buildings by as little as $2 \mathrm{~m}$ enabled significant energy improvements while having only minimal impact on individual property and city densities.

Findings indicated that with minor alterations to current urban planning laws, all buildings could have common access to daylight and fresh air, enabling them to operate naturally, increasing energy efficiency and resilience. 


\section{Author/Supervisor}

\section{Author:}

Tavis Creswell-Wells

School of Architecture

Victoria University of Wellington

Email: tavis.creswellwells@gmail.com

\section{Supervisor:}

Dr Michael Donn

Director of Centre for Building Performance Research

School of Architecture

Victoria University of Wellington

Email: michael.donn@vuw.ac.nz 


\section{Acknowledgements}

Firstly, I would like to thank my supervisor, Mike Donn, whose expertise and guidance has helped me to develop as a building scientist and has been most appreciated over the last few years.

Thank you to the Building Research Association New Zealand (BRANZ) and the 'Building Research Levy' for providing a scholarship for this research.

A very big thank you to Stephane Sanquer and Meteodyn for providing the UrbaWind software and operating the CFD computations. Without your generosity, the all-important wind pressure coefficients could not have been generated in such appropriate detail.

Particular gratitude is sent to Vasilis Maheras and $\mathrm{Yi}$ Zhang for your time and assistance in attempting to develop the three program coupling method. Although we could not find the solution, I was able to learn some very useful computer modelling skills that I will certainly continue to use and develop in the future.

Cheers to Shaan Cory for your help in setting up the EnergyPlus cross natural ventilation models; for teaching me how to operate GenOpt; and for always being approachable and helpful.

Cheers also to Brian Berg for your constant quest for technical detail which kept me on my toes; and for your general comradery which helped us to keep our sanity over these long months!

To my family, thank you for your interest, concern and help throughout the course of this degree. I am very lucky to have such strong love and support.

Finally, a big thank you to the wonderful Sarah Mokhtar for your unwavering support, encouragement and patience.

This research was supported by: 


\section{Contents}

Abstract

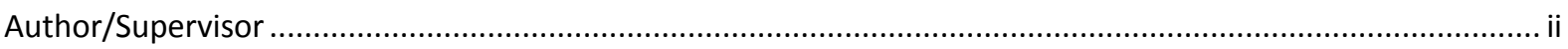

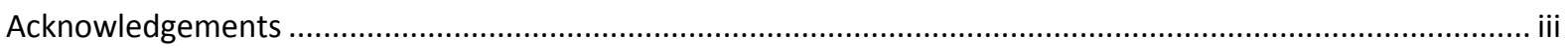

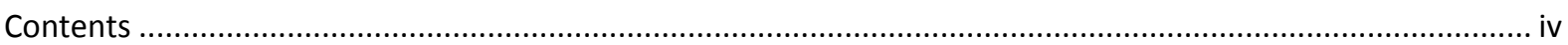

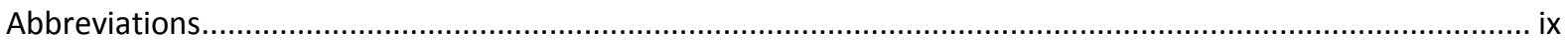

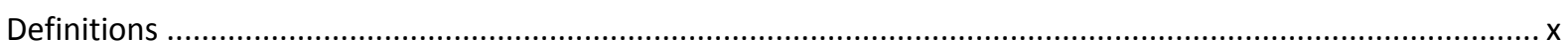

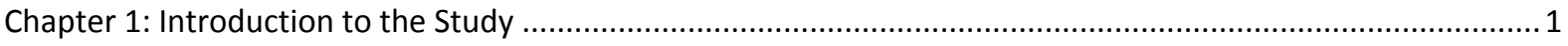

1.1 Context, Motivation and Problem Statement..................................................................................... 1

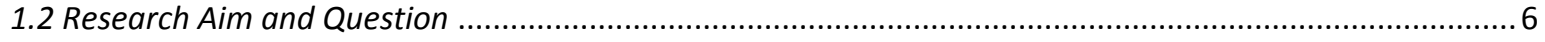

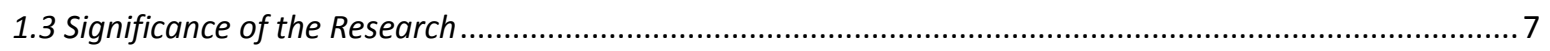

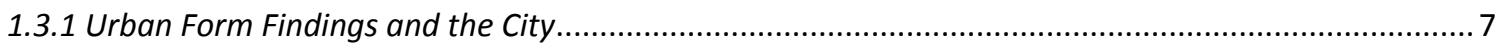

1.3.2 Building Design Findings and Individual Buildings .................................................................

1.3.3 Christchurch Urban Form and Energy Pilot Study .................................................................... 7

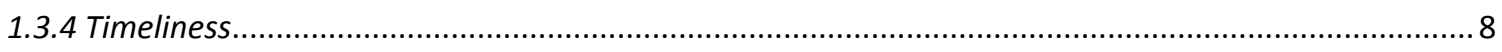

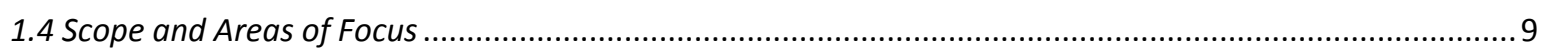

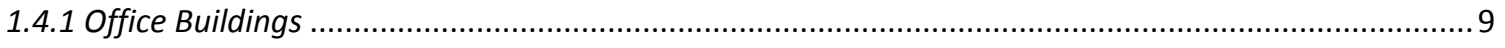

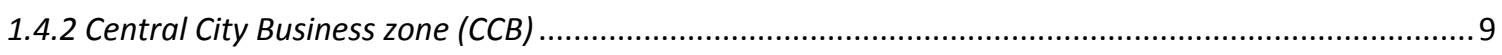

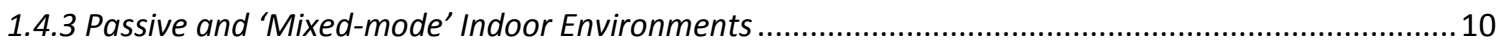

1.4.4 Performance Areas - Energy, Comfort and Density; Not Cost ....................................................... 10

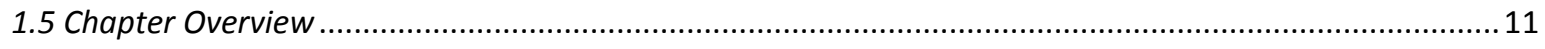

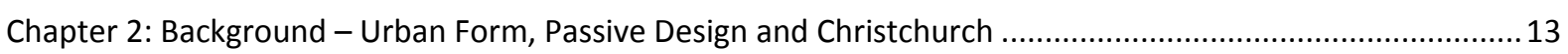

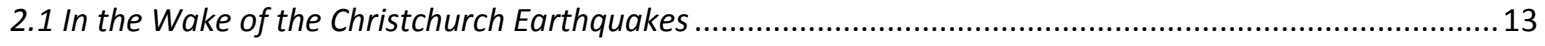

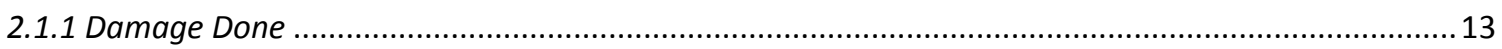

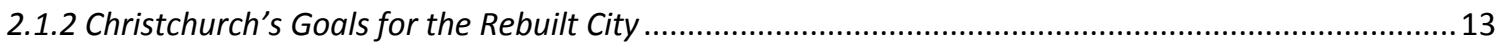

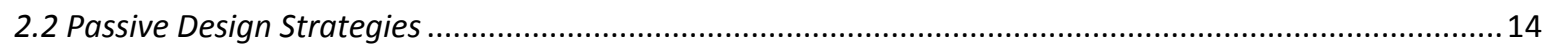

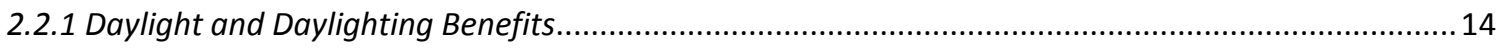

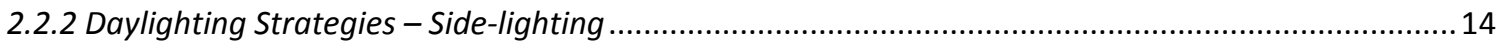

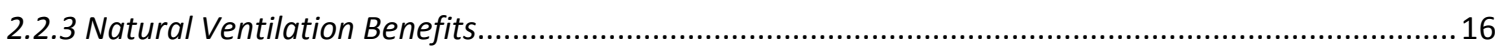

2.2.4 Natural Ventilation Strategies - Cross Ventilation .................................................................. 17

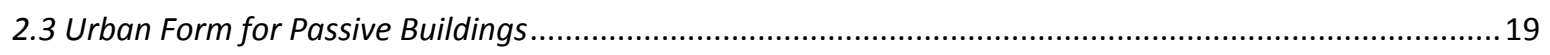

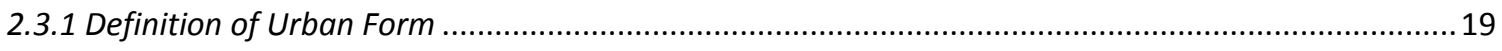

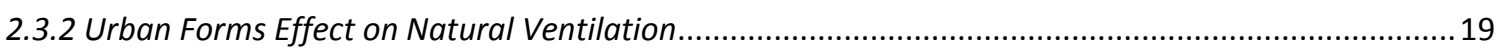

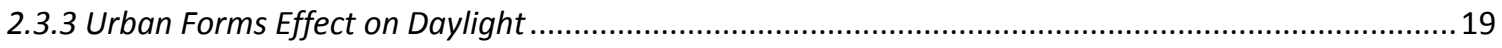

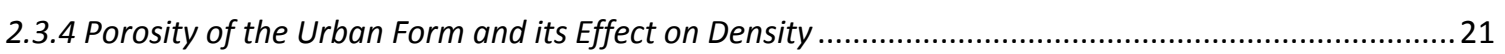

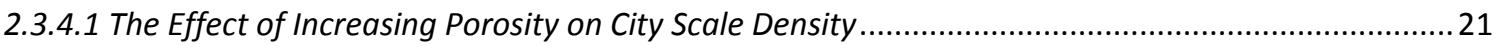

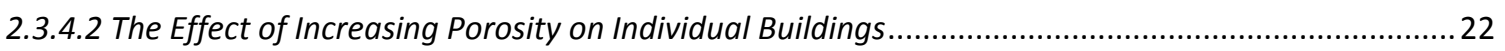

2.4 Changing Times - Green Buildings for Commercial Advantage ..........................................................2 23

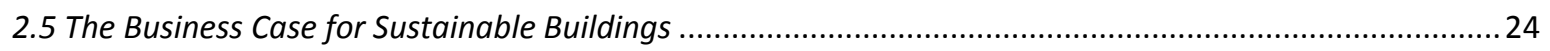

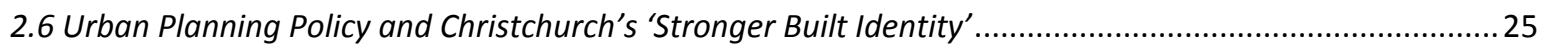

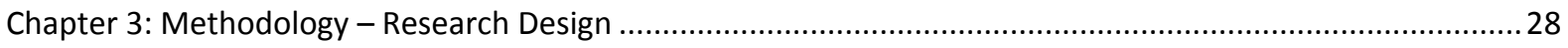




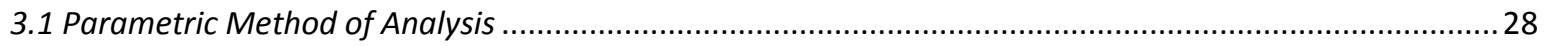

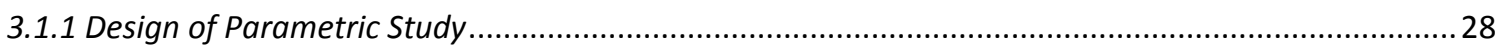

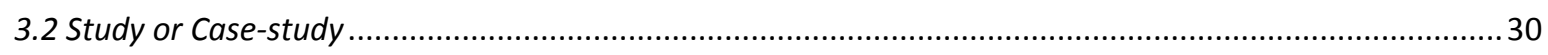

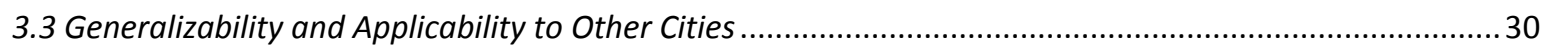

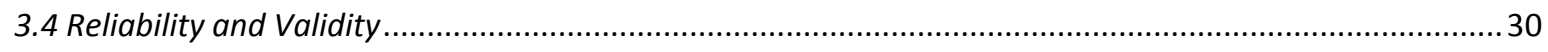

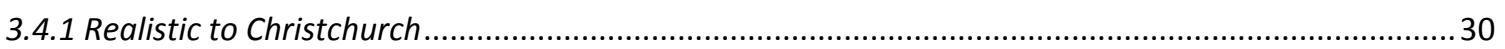

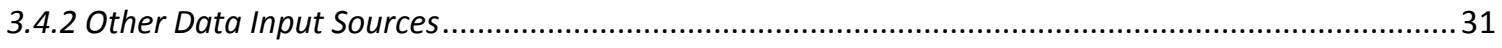

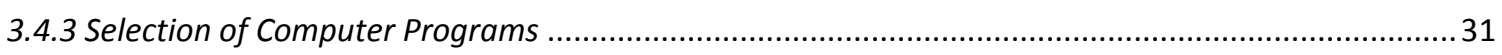

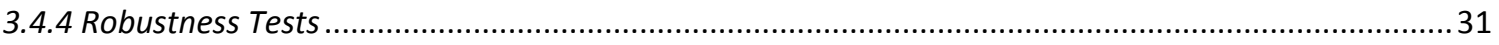

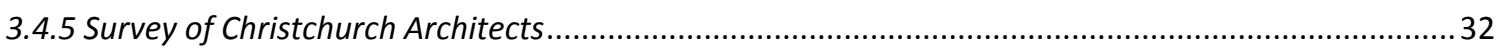

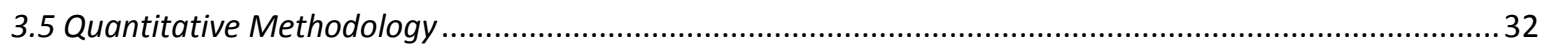

Chapter 4: Method - Development of Modelling Metrics, Tools and Methods .............................................34

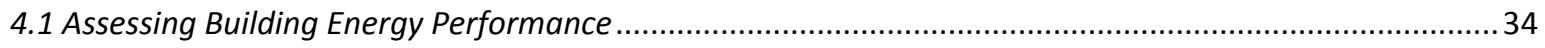

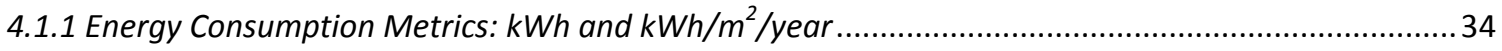

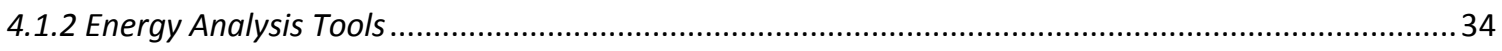

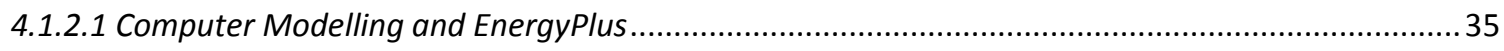

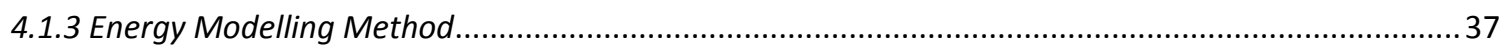

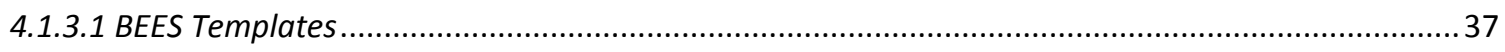

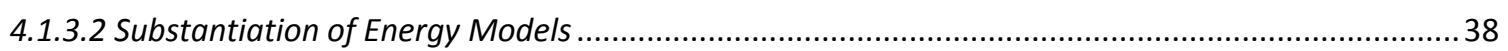

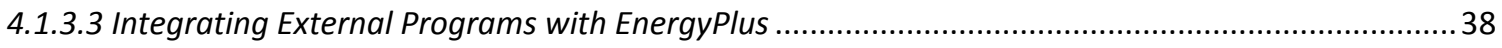

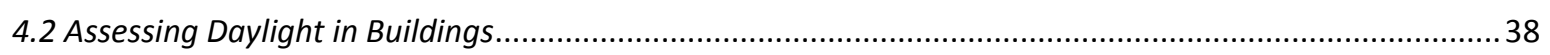

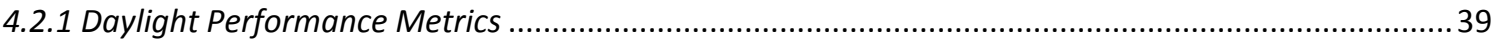

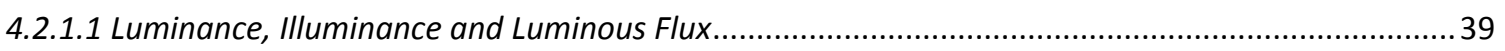

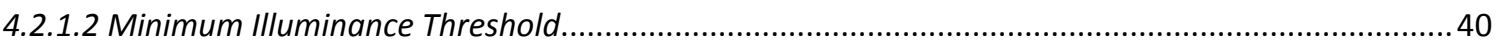

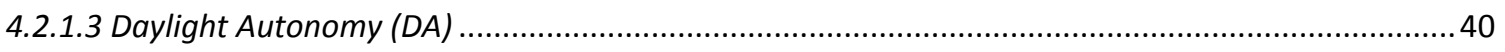

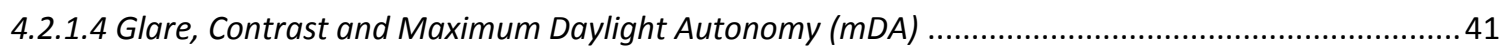

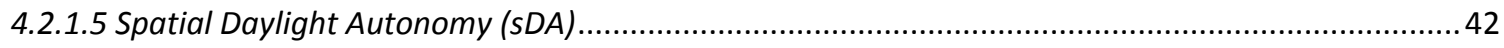

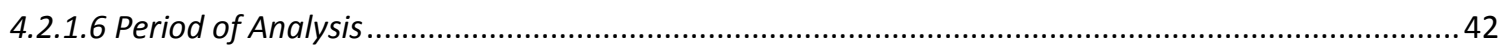

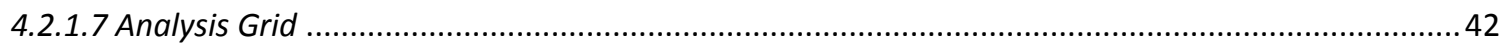

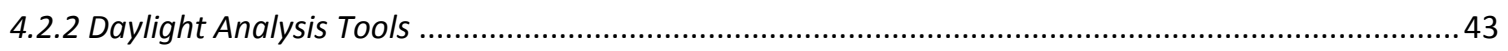

4.2.2.1 EnergyPlus and the Split-flux Daylight Calculation Method .........................................................43

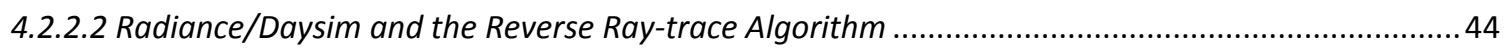

4.2.3 Daylight for Energy Consumption Method .................................................................................. 45

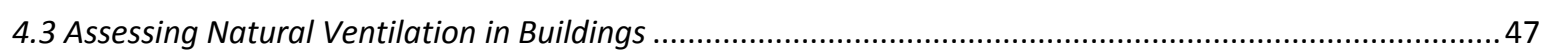

4.3.1 Natural Ventilation Performance Metrics ............................................................................ 47

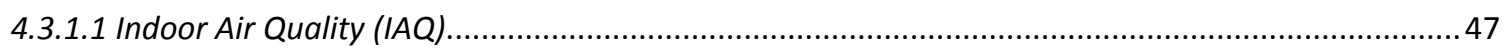

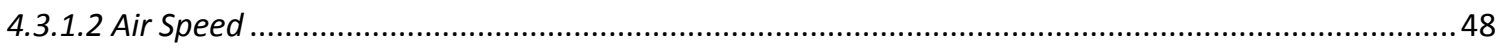

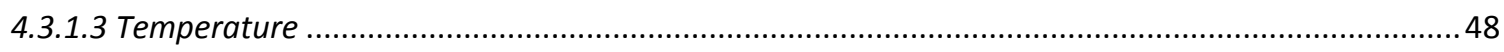

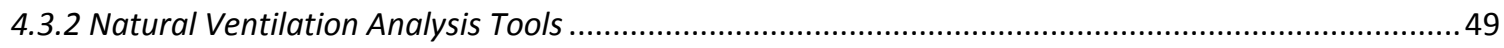

4.3.2.1 EnergyPlus and the Airflow Network for Natural Ventilation ....................................................49

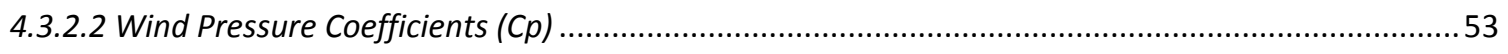

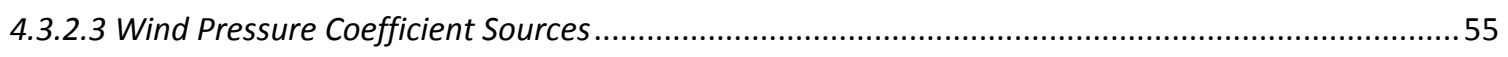

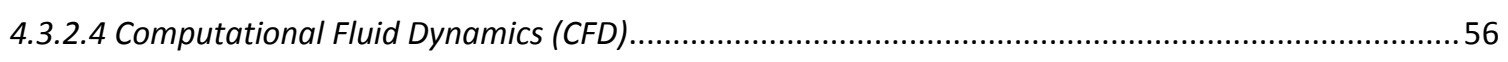


4.3.2.5 UrbaWind. 57

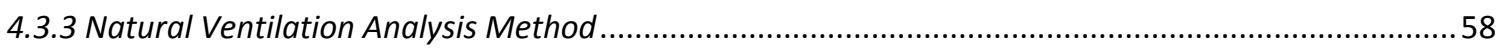

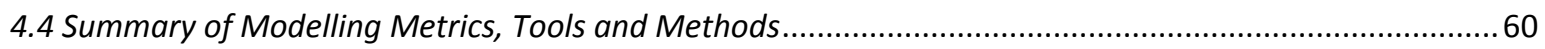

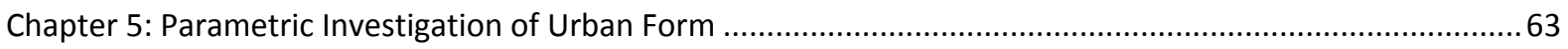

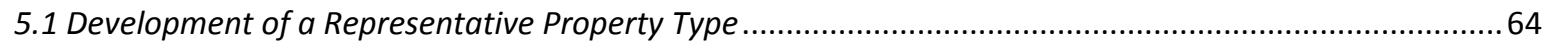

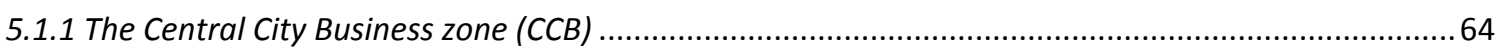

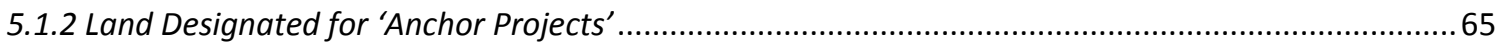

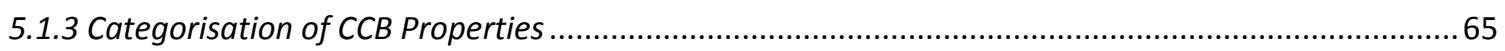

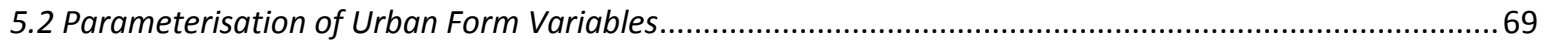

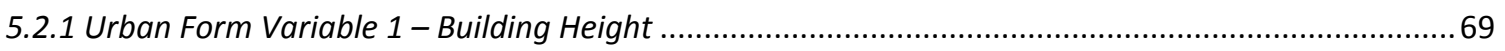

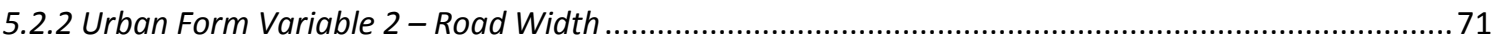

5.2.3 Urban Form Variable 3 - Gaps between Buildings.................................................................... 71

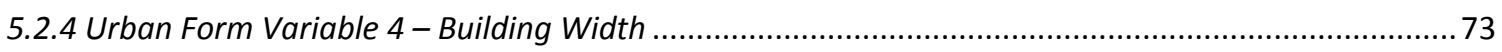

5.2.5 Urban Form Variable 5 - Continuous Frontage Height ............................................................. 75

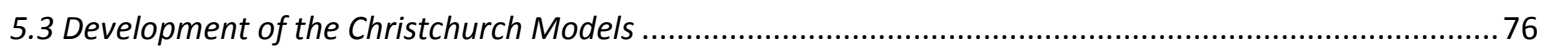

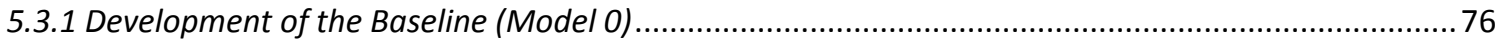

5.3.2 Development of Proposed Urban Form Variation Models (Model 1)............................................. 78

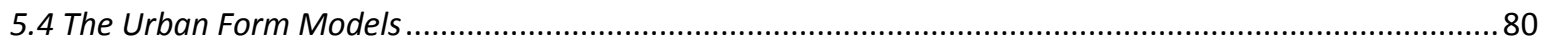

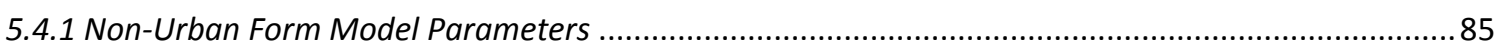

Chapter 6: Parametric Investigation of Passive Building Design ................................................................ 87

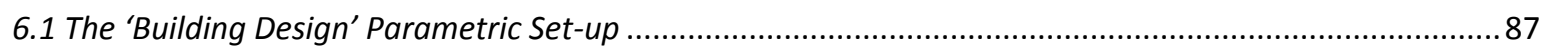

6.2 Parameterization - Daylighting Design Variables Tested ................................................................ 89

6.2.1 Daylighting Design Variable 1 - Window to Wall Ratio (WWR) .......................................................89

6.2.2 Daylighting Design Variable 2 - Glazing Type ...........................................................................9 91

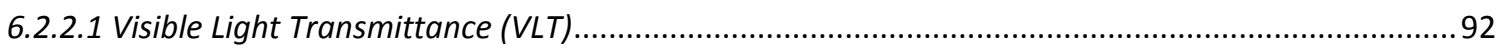

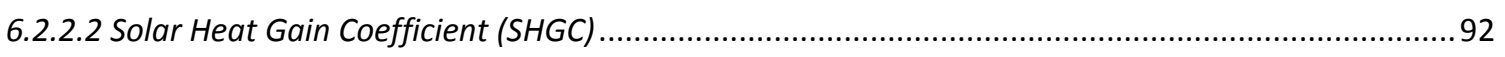

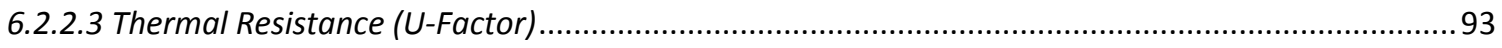

6.2.3 Daylighting Design Variable 3 - Solar Shading .......................................................................... 95

6.3 Parameterization - Ventilation and Thermal Design Variables Tested ...............................................97

6.3.1 Ventilation and Thermal Design Variable 1 - Construction Type....................................................97

6.3.2 Ventilation and Thermal Design Variable 2 - Roof Insulation Level ...............................................98

6.3.3 Ventilation and Thermal Design Variable 3 - Wall Insulation Level ................................................99

6.3.4 Ventilation and Thermal Design Variable 4 - Openable Window Area ......................................... 100

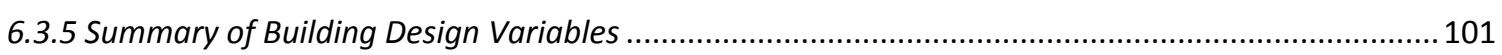

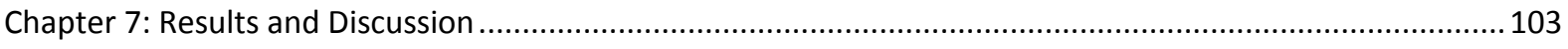

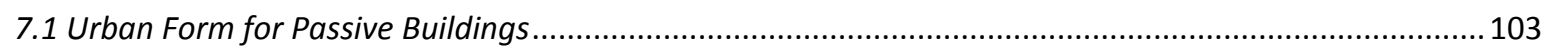

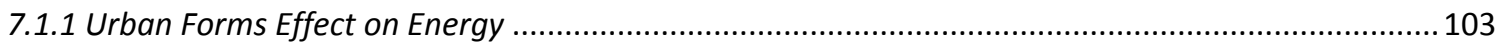

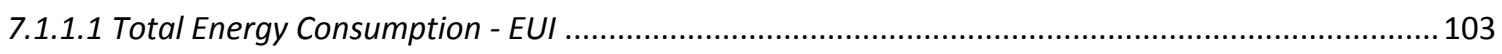

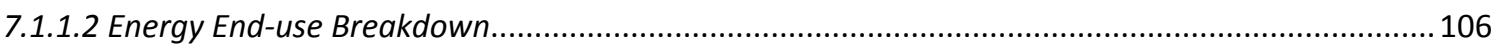

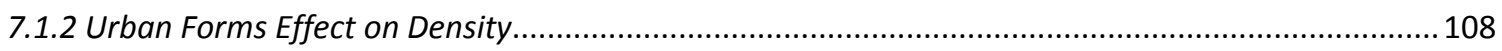

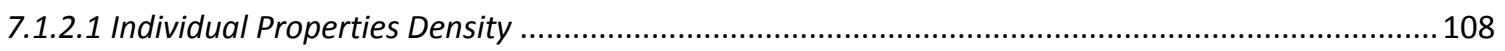

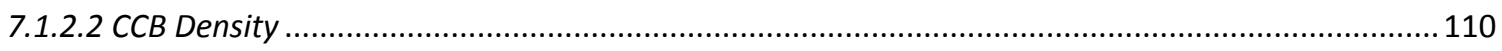

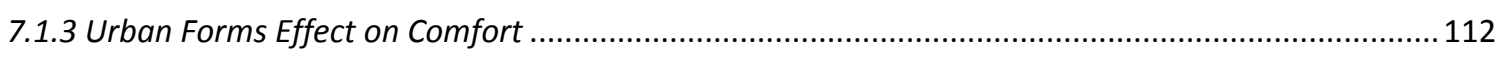


7.1.3.1 Environmental Performance Criteria 1 - Temperature. 112

7.1.3.2 Environmental Performance Criteria 2 - Air Change Rates ...................................................... 114

7.1.3.3 Environmental Performance Criteria 3 - Air Speed ....................................................................... 115

7.1.3.4 Environmental Performance Criteria 4 - Daylight Autonomy (DA).............................................115

7.1.3.5 Environmental Performance Criteria 5 - Maximum Daylight Autonomy (mDA) ......................... 117

7.2 Building Design for Improved Passive Performance .............................................................................. 119

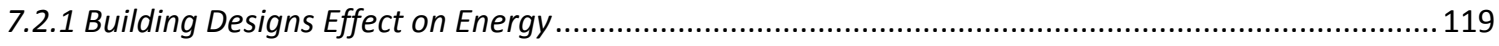

7.2.1.1 Daylighting Design - Energy Use Intensities (EUI's) .............................................................. 119

7.2.1.2 Ventilation and Thermal Design - Energy Use Intensities (EUI's) ............................................ 122

7.2.1.3 'Daylighting Design' and 'Ventilation and Thermal Design' - Energy End-uses .......................... 124

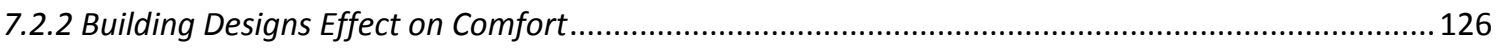

7.2.2.1 Environmental Performance Criteria 1 - Temperature .................................................................. 126

7.2.2.2 Environmental Performance Criteria 2 - Air Change Rates ...................................................... 127

7.2.2.3 Environmental Performance Criteria 3 - Air Speed ................................................................... 127

7.2.2.4 Environmental Performance Criteria 4 - Daylight Autonomy..................................................... 128

7.2.2.5 Environmental Performance Criteria 5 - Maximum Daylight Autonomy ..................................... 129

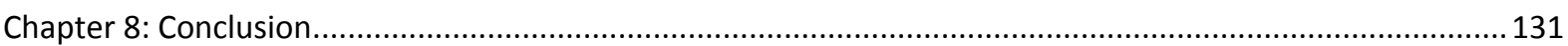

8.1 Artist's Impression of Proposed Urban Environment ..................................................................... 134

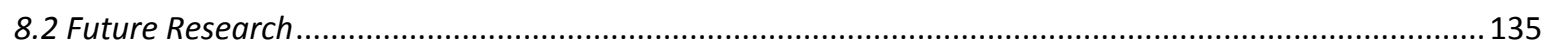

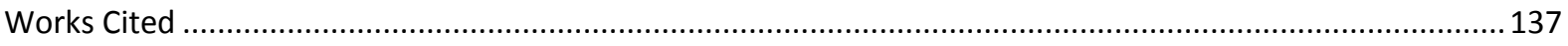

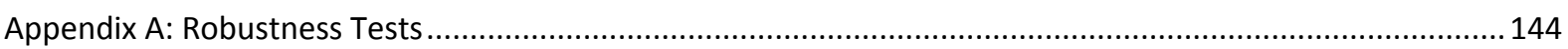

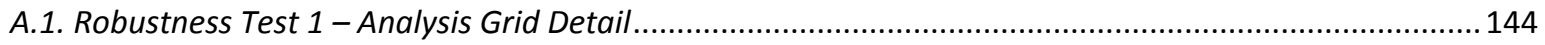

A.2. Robustness Test 2 - Analysis Grid Frequency (across storeys) ........................................................... 146

A.3. Robustness Test 3 - Daylight Calculation Methods ........................................................................... 150

A.4. Robustness Test 4 - Wind Angle Increment (WAI) Frequency......................................................... 152

A.5. Robustness Test 5 - Surrounding Buildings Effect on Natural Ventilation ............................................. 155

A.6. Robustness Test 6 - Validation of UrbaWind ................................................................................. 159

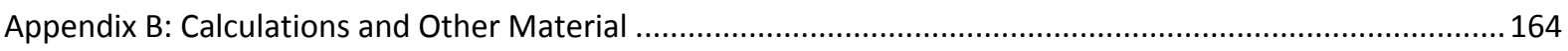

Appendix B.1 - Plot Ratio Calculations (individual property density analysis) .......................................... 164

Appendix B.2 - Hectares and CCB Blocks Calculations (CCB density analysis) ............................................ 165

Appendix B.3 - Minimum Air Change Rate Calculations ........................................................................... 166

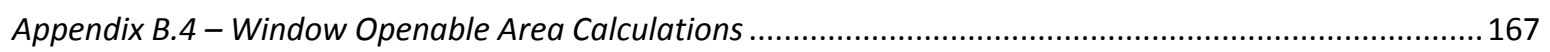

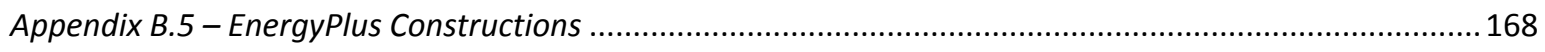

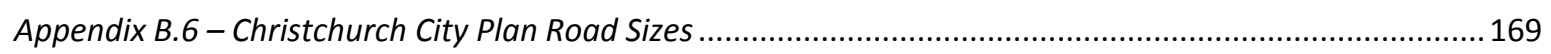

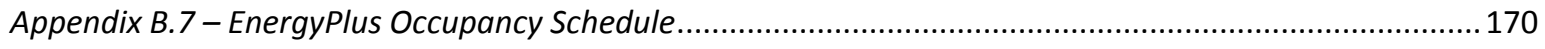

Appendix B.8 - Central City Business zone (CCB) Area and Block Calculation ............................................ 171

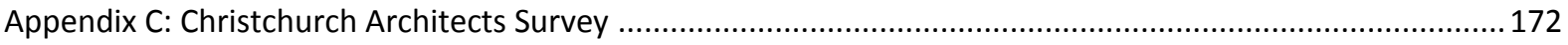

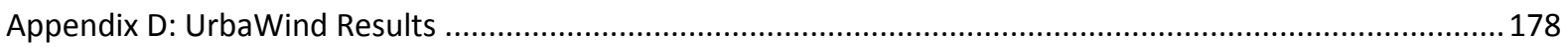


Urban Form and Passive Design for High Performance Buildings in the Christchurch Rebuild 


\section{Abbreviations}

ASHRAE - American Society of Heating, Refrigeration, and Air-conditioning Engineers

BEES - Building Energy End-use Study

BRANZ - Building Research Association of New Zealand

CBD - Central Business District. In Christchurch's case confined by...

CCB - Central City Business zone

CCC - Christchurch City Council

CCDU - Christchurch Central Development Unit

CCPo - Christchurch City Plan online

dCCP - draft Central City Plan

CFD - Computational Fluid Dynamics

CIBSE - Chartered Institution of Building Services Engineers

$\mathrm{Cp}$ - Wind pressure coefficient

HVAC - Heating Ventilation and Air Conditioning

IES - Illuminating Engineering Society

NZBC - New Zealand Building Code

NZGBC - New Zealand Green Building Council

R-value - Thermal resistance

SHGC - Solar Heat Gain Coefficient

SLL - Society of Light and Lighting

U-value - Thermal resistance (inverse of R-value)

VLT - Visible Light Transmittance (also Tvis) 


\section{Definitions}

Christchurch Central City - The geographic area bound by- Deans, Bealey, Fitzgerald and Moorehouse Avenues (also known as the 'Four Avenues') - refer Figure 1.8.

Urban Form - Physical manifestation of an urban environment created by buildings and voids between buildings.

Building Form - Physical geometry/shape of an individual building.

Plot Ratio - Buildings total floor area against land parcel area on which it is built.

Time-step - the period of time between calculations in simulation programs - every 10 minutes in this study.

Lighting Power Density - Measured in watts per square meter $\left(\mathrm{W} / \mathrm{m}^{2}\right)$, represents the concentration of artificial lighting power per surface area.

Urban Form variables - the individual features of urban form that were tested in this study: 'building height', 'gap between buildings', 'street width', 'building width' and 'continuous frontage'.

Gap between buildings - the separation distance in meters $(m)$ between facades of two neighbouring buildings.

Continuous frontage - refers to the number of levels that must be built to $100 \%$ of the property width. 
Urban Form and Passive Design for High Performance Buildings in the Christchurch Rebuild 


\section{Chapter 1: Introduction to the Study}

"One of the most basic and fundamental questions in urban master planning and building regulations is "how to secure common access to sun, light and fresh air?" (Stromann-Andersen \& Sattrup, 2011).

Right now, in Christchurch, a rare and unique opportunity exists to develop a world-leading, sustainable city.

With the rebuild process still in early stages, Christchurch has a chance to redevelop its buildings to be high performance- energy efficient with high quality indoor environments.

This thesis investigates whether providing all Central City buildings common access to daylight and fresh air enables high performance buildings; and determines the changes to urban form and building design that would be required to achieve it.

\subsection{Context, Motivation and Problem Statement}

In September 2010, and February 2011, Christchurch City was rocked by magnitude 7.1 and 6.3 earthquakes, killing 185 people (New Zealand History Online, 2011) and causing 80\% of the Central City to be demolished (OPUS, 2011).

In response to the earthquakes, the Christchurch City Council (CCC) set-up the 'Share an Idea' scheme to gather the thoughts and desires of Cantabrian's in the development of a rebuild blueprint. A strong theme identified through the scheme was a world-leading 'green' city with low-rise sustainable buildings - "Enforce eco-friendly and sustainable buildings to promote a clean green garden city with unique and innovative architecture." (Christchurch City Council, 2011).

These sentiments were reflected in the 'draft Central City Plan' (dCCP) prepared by the CCC as a blue-print for the rebuild. A central initiative of the dCCP was the 'Stronger Built Identity' directive which aims to create a unique and high performance city with emphasize on sustainable buildings as a feature of its character (Christchurch City Council, 2011).

Sustainability of a building is often associated with tangible pieces such as photovoltaic panels on the roof, or high-tech LED lighting. Figure 1.1 illustrates that while energy efficiency and energy generation measures can contribute to overall sustainability of a building, they are more expensive to implement, yet less effective than early stage passive design efforts. 


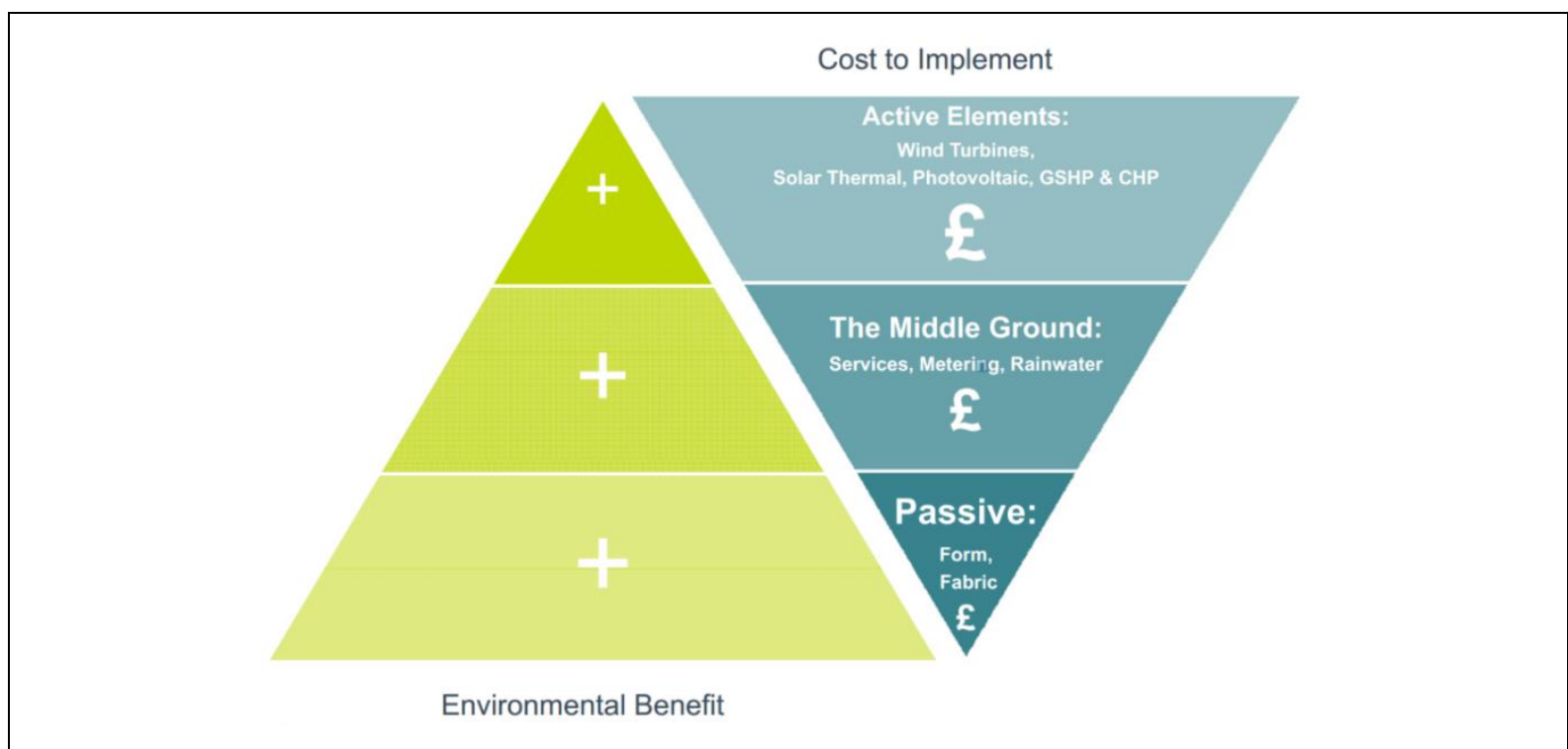

Figure 1.1.The significance of passive design in comparison to energy efficiency and generation measures. (Brown, 2010).

Passive design enables a building to respond to local climate conditions and maintain occupant comfort with minimal reliance on energy intensive mechanical systems like artificial lighting and Heating Ventilation and Air Conditioning (HVAC) (BRANZ, n.d.). Passive strategies aim to deliver daylight, fresh air and thermal comfort to internal spaces, naturally, minimizing energy consumption, thus reducing utility expenses and emissions. Additional benefits associated with passive architecture are improved occupant health and comfort, which can enhance employee satisfaction and productivity (Ministry for the Environment, 2008); and even greater marketability due to public perception of 'social responsibility' (The Dominion Post, 2012).

Passive design is the first aspect necessary in the creation of an energy efficient building as it defines the 'base-building'. It involves the initial design decisions made in the project - site selection, orientation, building form and fabric, etc. Figure 1.2 illustrates how, in comparison to energy efficient systems (Middle Ground) and energy generation systems (Active Elements), passive design strategies have the greatest impact on environmental benefits, while costing less to implement. Every project begins with a design process. Passive design is inexpensive because it is simply a more thorough execution of the already existing design process.

Passive strategies' can address the two major energy end-use areas of an office building - 'Cooling' and 'Lighting'. Demand on mechanical Cooling due to heat generated by high occupant and equipment densities and solar gains typically accounts for around $1 / 3^{\text {rd }}$ of total energy consumption. Artificial lighting also typically accounts for $1 / 3$ of total energy (Ministry for the Environment, 2008).

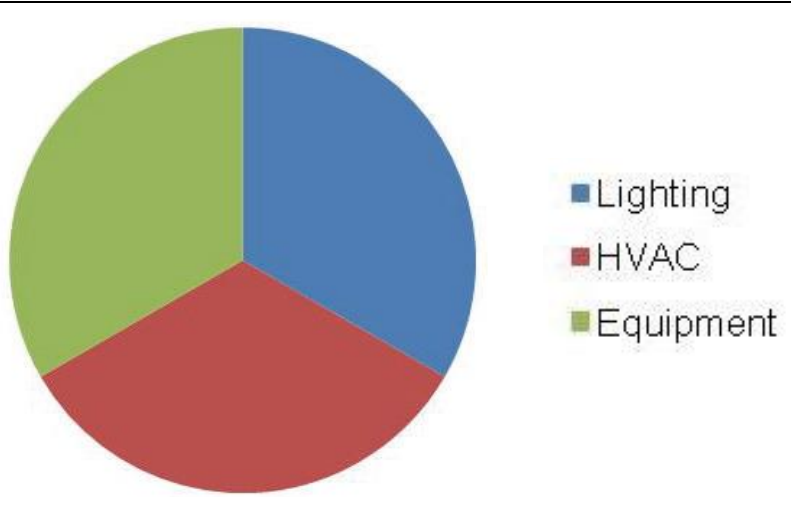

Figure 1.2. Typical energy end-use breakdown for a New Zealand office building. (Ministry for the Environment, 2008). 
Energy consumed through both of these systems can be reduced with two common passive strategies - natural ventilation and daylighting.

Natural ventilation replaces over-heated or 'old' air by using wind to force fresh air into building spaces through openings in the thermal envelope. When combined with a supplementary HVAC system (known as 'mixed-mode' or 'hybrid' ventilation) natural ventilation has been found to reduce Cooling loads by up to $79 \%$ (Brager, et al., 2007).

Using the sky as the light source, daylighting aims to deliver target illuminance levels with minimal assistance from artificial lights. When used in conjunction with automatic dimming and illuminance sensors, daylighting can reduce artificial Lighting loads by up to $80 \%$ (Ministry for the Environment, 2008). Both of these strategies can be applied to a building through standard vertical windows, on the external walls (refer Figure 1.3).

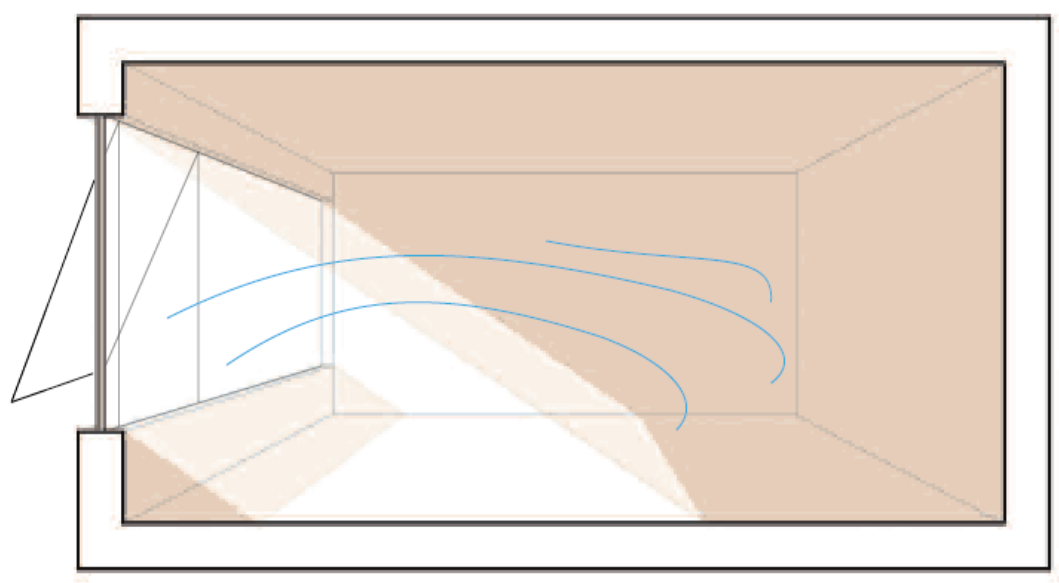

Figure 1.3. Depiction of the study's focus passive strategies - daylighting and natural ventilation Adapted from (The Scottish Government, 2007).

The effectiveness of passive strategies depends on the 'microclimate' created by the urban form surrounding that building. Wind-driven cross ventilation is dependent on wind pressures acting on the building's facades to force air through an internal space. High density urban environments can interrupt wind-flow, diminishing pressures and the potential for ventilation. Similarly, if buildings are in close proximity, shading will impact on daylighting.

A previous study conducted by the author (refer Section 1.3.3) concluded that a porous urban form enabled more building surface area, and therefore more internal spaces, to have access to daylight and fresh air. This concept is portrayed in Figure 1.4 where rules of thumb are used to demonstrate daylight and natural ventilation penetration into a space with access to daylight and fresh air on both sides. Figure 1.5 then illustrates how a non-porous, or compact urban fabric (buildings sharing party walls) only provides exposure to sunlight and wind on the street facing wall of the building. 


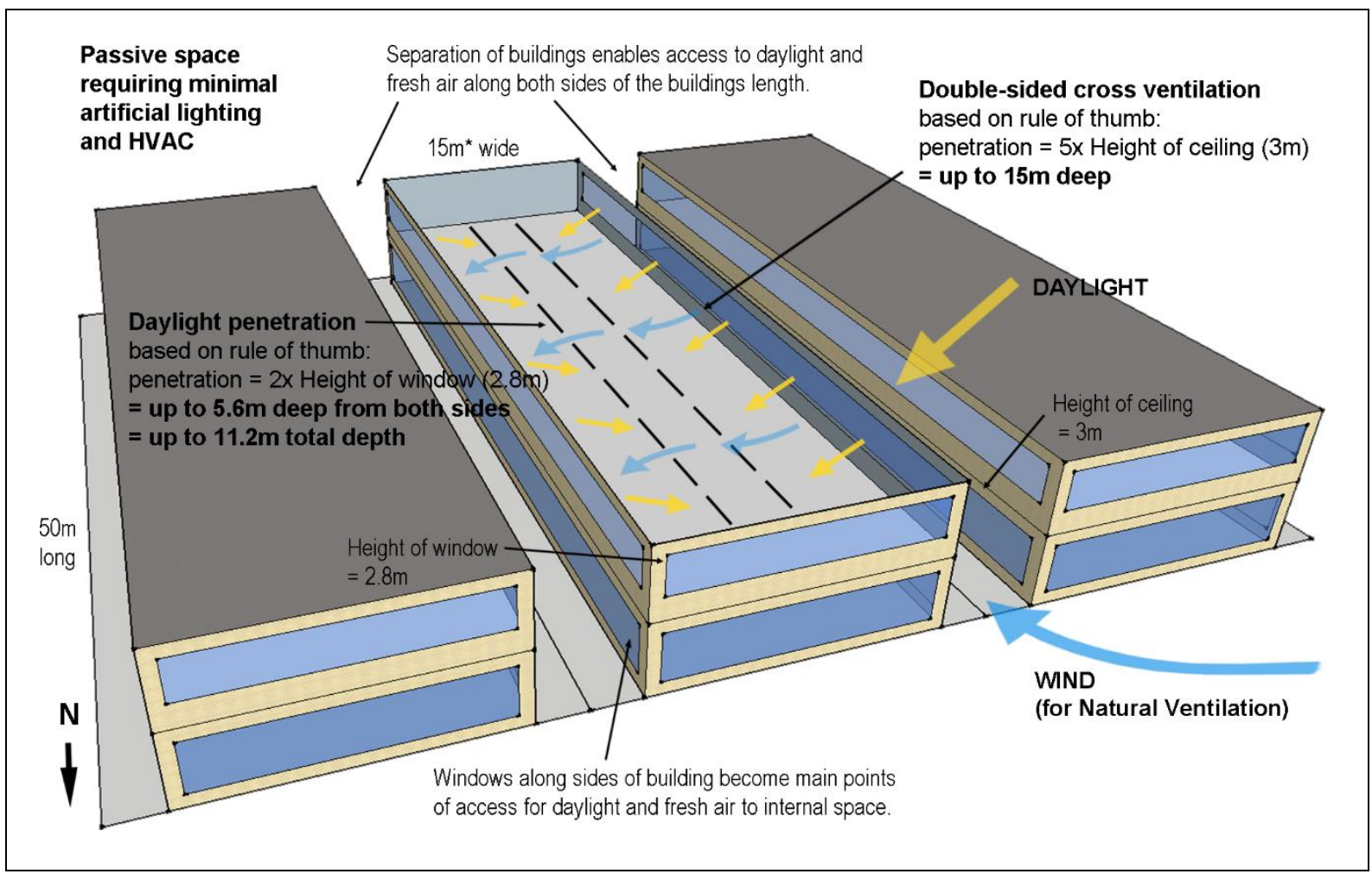

Figure 1.4. Diagram illustrating improved effectiveness of passive strategies when applied along the two sides of a building. (Author).

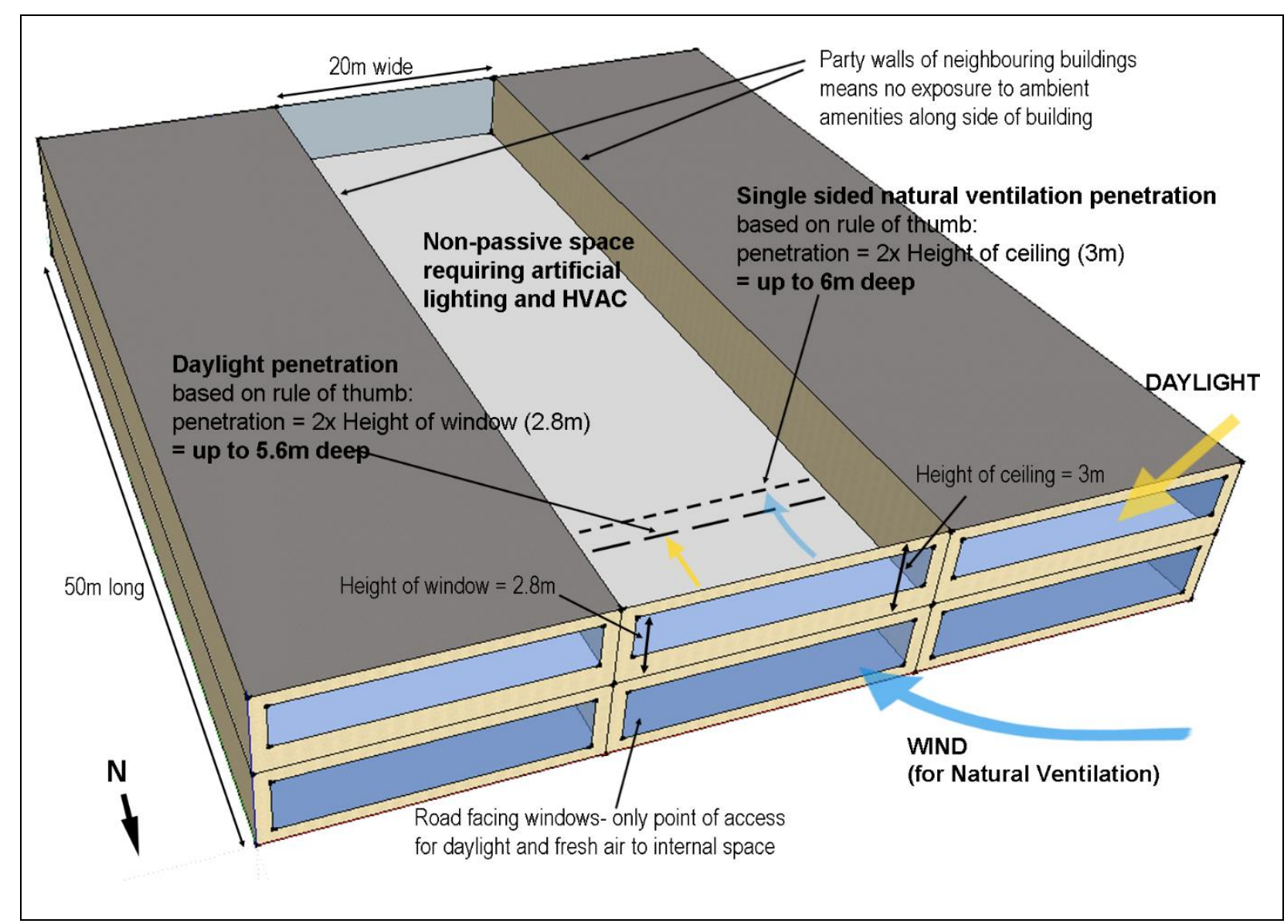

Figure 1.5. Diagram illustrating the ineffectiveness of daylighting and natural ventilation with only a single delivery point. (Author). 
The compact urban form seen in Figure 1.5 above is reminiscent of Christchurch's urban form prior to the earthquake. Figure 1.6 shows how buildings were 'butted' up against each other, offering no opportunity for daylighting and natural ventilation along either side of the building.

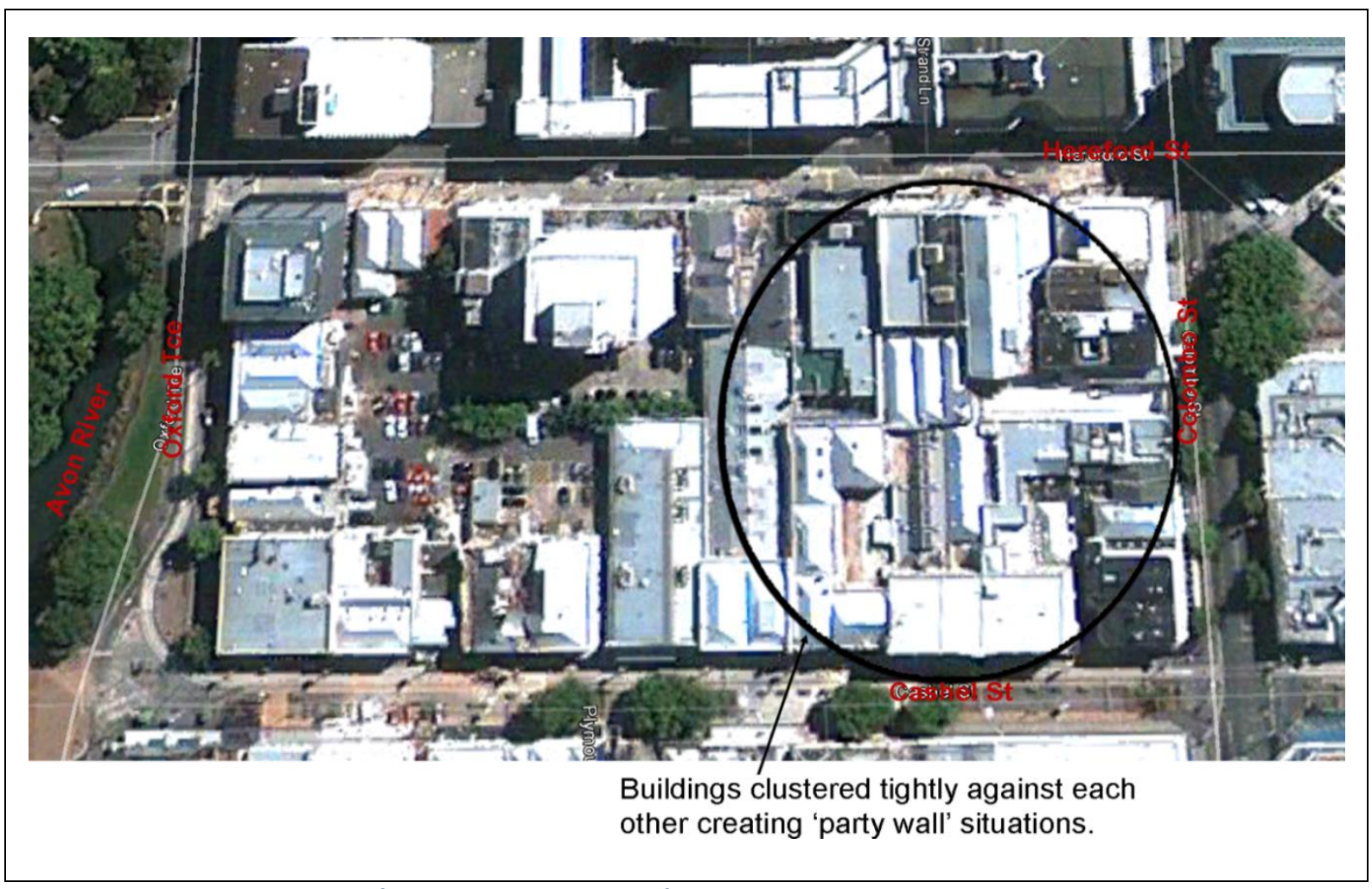

Figure 1.6. Aerial view of a typical compact urban form central city block in pre-earthquake Christchurch.

Adapted from (New Zealand Planning Institute, 2013).

There are two primary barriers to a porous urban form in Christchurch:

1) Effect on built floor area. Net Lettable Area (NLA) is a highly valuable commodity, especially in central city markets where land costs and lease rates are high. In 2013, office space leased for between $\$ 250-\$ 420 / \mathrm{m}^{2} /$ year in Christchurch's CBD (Bayleys Realty Group, 2013). By contrast, typical energy consumption could be calculated at anywhere between $\$ 17.60 / \mathrm{m}^{2} /$ year and $\$ 53 / \mathrm{m}^{2} /$ year based on an average electricity cost of $17.63 \mathrm{c} / \mathrm{kWh}$ (Ministry of Business Innovation and Employment, 2014) and Energy Use Intensities (EUIs) of 100 and $300 \mathrm{kWh} / \mathrm{m}^{2} /$ year, respectively (Bishop \& Isaacs, 2012). Considering this, the concept of 'sacrificing' valuable floor area to void space may be difficult to accept for some building investors.

2) Continuous frontage. 'Section 3.3.2.2.1: Building Set-back and Continuity' of the Christchurch City Plan online (CCPo) requires that the Ground and first floors of all buildings in the CCB are built to $100 \%$ of the property width (Christchurch City Council, 2013). This 'continuous frontage' concept is a common urban planning regulation which is intended to create a well-defined street edge and distinct central city character.

Here lies the problem this research addresses:

Current urban planning laws prioritize built floor area over access to daylight and fresh air, and therefore impede high-performance buildings in Central City Christchurch. 


\subsection{Research Aim and Question}

The study adopts the view that to improve building performance, porosity needs to be increased but acknowledges the need to limit the loss of built floor area for commercial plausibility. In other words, the increase of porosity needs to be sufficient to provide enough access to daylight and wind but limited as much as possible. A range of changes can be made to a building to alter built volume, such as reducing width, height or depth. However, it is not known which type and to what extent of change is most effective.

Therefore, the aim of this research is:

To determine which changes to urban form and building design would have the greatest effect on building performance, but smallest impact on density in Central City Christchurch.

Further- how much impact do these changes have on building performance? The question this research asks is:

Compared to conventional urban form and building design, how far can the use of daylighting and natural ventilation through porous urban form and passive design improve energy efficiency in CCB buildings? 


\subsection{Significance of the Research}

This research is designed to contribute directly to the Christchurch rebuild. It aims to provide valuable urban form and passive building design information that can be immediately implemented in Christchurch.

\subsubsection{Urban Form Findings and the City}

The city-scale, urban form investigation of this research is one that can rarely be explored with the possibility of implementation. The porous urban form proposed to facilitate passive buildings would not be plausible in normal circumstances where a city's urban fabric is already established. But in the context of the current rebuild process in Christchurch, a new urban form model can be developed and applied to all new buildings being built. Now is when the results from this study will have most impact.

It is intended that the research's findings inform local planners of the potential (or lack thereof) for an alternative, porous, high-performance urban form to provide daylight and fresh air to ALL buildings, and the changes that would be required to realize that potential. Greatest effect will be realized if findings are applied as mandatory regulations at the city-scale.

\subsubsection{Building Design Findings and Individual Buildings}

Findings can also be used by private property owners/developers to guide the design of their own buildings. Sustainable architecture is a growing trend and many investors want to capitalize on the associated benefits. However, minimal information is available regarding passive office buildings, which is a major reason why they have not been embraced in New Zealand. This research aims to contribute to the knowledge base in this area, particularly in terms of energy savings potential and design requirements, so that building investors can make informed decisions on sustainable building development. The passive design methods and systems investigated in this research are relatively simple techniques. This means that results are more feasible than high-tech, complex systems which are less likely to be understood or afforded.

\subsubsection{Christchurch Urban Form and Energy Pilot Study}

This research continues from the pilot study 'BEES Interim Report: Christchurch Urban Form and Energy', which investigated the effect of urban form features (lanes, courtyards and façade stepbacks - proposed by the $\mathrm{CCC}$ ) on building performance. It found that office building energy efficiency could be improved by almost $50 \%$ through a porous urban form and naturally ventilation and daylighting (refer Figure 1.7) (Creswell-Wells, 2012). This was an exciting finding, which demonstrated a potential for significant benefits, and was met with great interest in the Christchurch building design and policy communities.

However, the study was based on substantial assumptions (such as the effectiveness of natural ventilation in reducing cooling loads), and unrealistic urban form scenarios (buildings assumed to be monolithic, covering a full block). The current study looks to investigate similar issues but at far greater detail, with considerably more robust methods. It is intended that this research is rigorous and can be considered for implementation in the rebuild. 


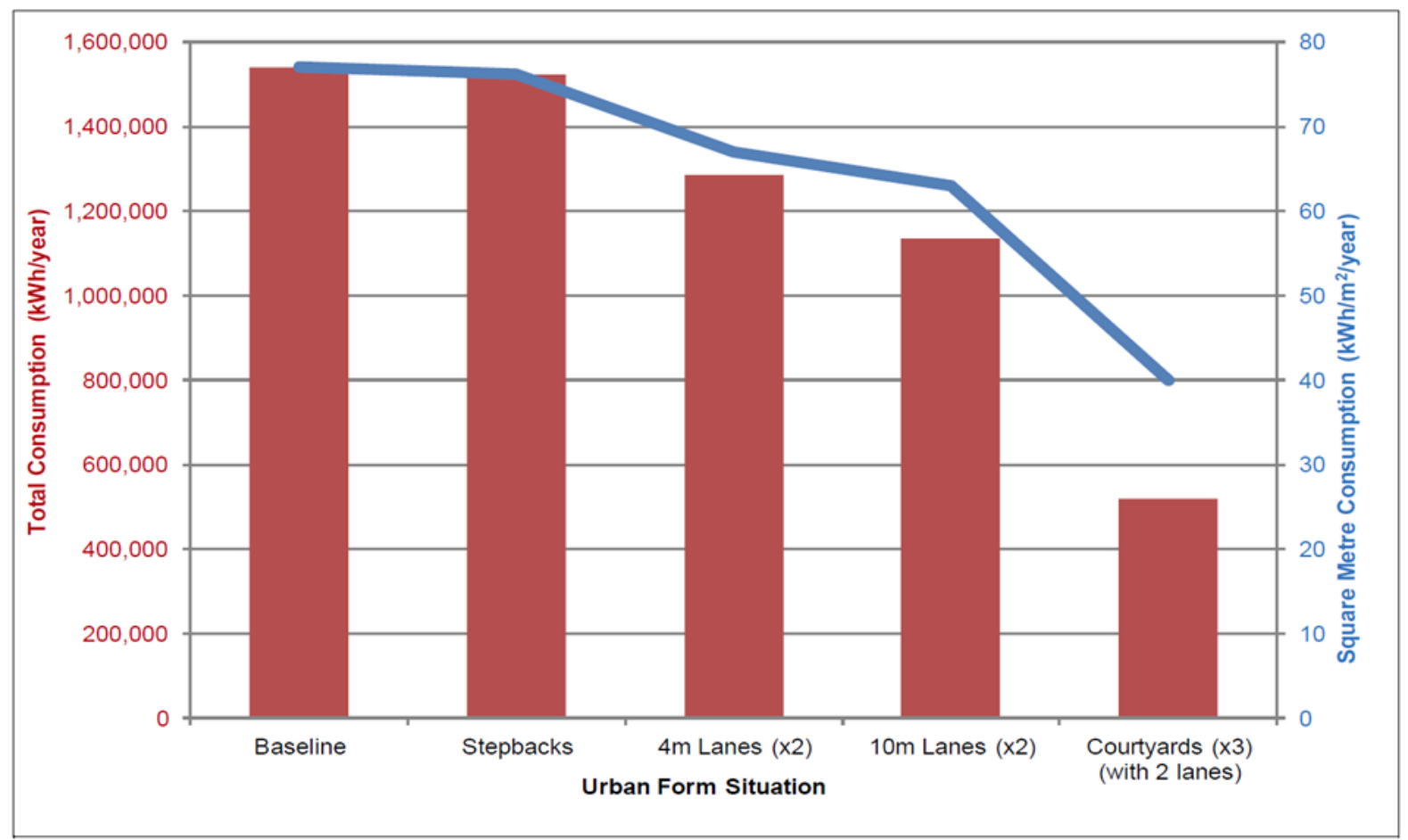

Figure 1.7. Pilot study results - 'Energy Consumption for each Urban Form Scenario'. (Creswell-Wells, 2012).

\subsubsection{Timeliness}

At the time of writing this thesis, most of the 1,000 CBD buildings that required demolition had been demolished (The Treasury, 2013) and around 200 private-sector building projects were being designed or constructed in the Central City (New Zealand Government, 2014). Evidently, there is a considerable amount of rebuilding yet to be done. Now, before the central city's physical fabric is reinstated, is the ideal time to address urban design and planning issues and to ask some afflictive questions: Was the old urban planning model working? What aspects could be improved in terms of pursuing high performance buildings? And, critically- does the urban planning model Christchurch intends to rebuild its city on, enable them to realize the world-leading green city they aspire to? 


\subsection{Scope and Areas of Focus}

\subsubsection{Office Buildings}

"The reasons for studying office buildings are that they perhaps are the most important building type of the 20th century. Just as factories were the symbols of the industrialisation at the start of the 19th century, office buildings are emblematic of the current post-industrial era. Office buildings are all around us. They dominate the contemporary city, they accommodate more than half of the working population in the western world and they represent a large share of the building stock's total use of energy." (Kleiven, 2003).

\subsubsection{Central City Business zone (CCB)}

Christchurch Central City consists of five zone categories (refer Figure 1.8). The Central City Business zone (CCB - blue area) is selected as the geographical focus of the study as it is the core business district, comprising the city's largest concentration of commercial infrastructure and, most importantly, office buildings. The CCB also represents the highest building and population densities in Christchurch (Christchurch City Council, 2000), maximizing significance and applicability of the study's findings.

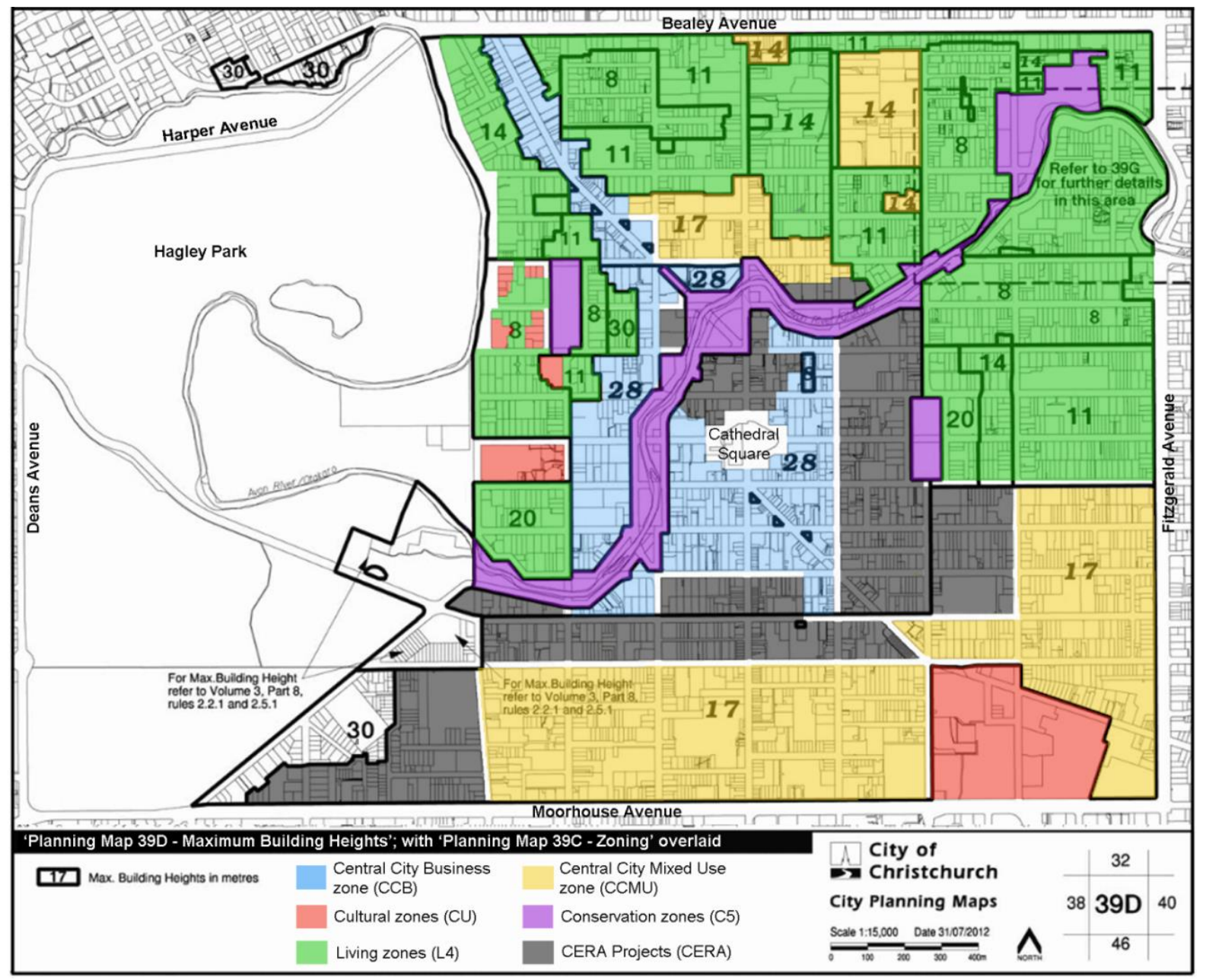

Figure 1.8. Christchurch City Plan Map 39D identifying the (blue) Central City Business zone (CCB). Adapted from (Christchurch City Council, 2013). 


\subsubsection{Passive and 'Mixed-mode' Indoor Environments}

In this thesis, the term 'passive' implies 'mixed-mode'. Indoor environments of office buildings are demanding in terms of comfort. Instances where there is no wind and therefore no natural ventilation; or dark winter evenings and therefore no daylighting, are inevitable and mechanical systems (i.e. HVAC, artificial lighting) must be present to maintain comfort at these times. This is a mixed-mode system. The term 'passive' is used in this study to emphasize passive strategies as the primary means of delivering a comfortable environment. Mechanical systems are supplementary.

\subsubsection{Performance Areas - Energy, Comfort and Density; Not Cost}

This research proposes changes to urban form and building design. Successfulness of changes is assessed primarily on energy efficiency with consideration of indoor environments and density. Table 1.1 presents the performance areas investigated. The focus of the study is on environmental and energy performance; NOT financial cost.

\begin{tabular}{|l|l|}
\hline Performance Area & Significance \\
\hline Energy Consumption & Efficiency of the design \\
\hline Indoor Environmental Comfort & Suitability of environment for occupancy \\
\hline- Temperature & Thermal comfort \\
\hline- Air change rate & Air quality \\
\hline- Air speed & Excessive movement- disruption \\
\hline- Daylight sufficiency & Daylighting effectiveness \\
\hline- Daylight over-exposure & Likelihood of glare/visual discomfort \\
\hline Density & Ability to provide floor area \\
\hline
\end{tabular}

Table 1.1. Performance Areas assessed. 


\subsection{Chapter Overview}

\section{Chapter 1: Introduction}

Chapter 1 introduces the thesis topic and the motivations that instigated the research. It presents the aim and question to be answered.

\section{Chapter 2: Background}

Chapter 2 outlines the context and factors behind this research, such as Christchurch's situation and goals; passive design as a method of obtaining goals; urban forms influence; and planning priorities and laws in Central City Christchurch

\section{Chapter 3: Methodology}

Chapter 3 outlines the underpinning methodological approaches taken to conduct the research, and explains the measures taken to ensure the research and its findings are valid and reliable.

\section{Chapter 4: Metrics, Tools and Methods}

Chapter 4 determines which metrics enable the most telling results; which tools enable required data to be generated or analysed; and how these tools and metrics fit together in a functional method. It also comprehensively explains daylighting and natural ventilation operation and assessment.

Chapter 5: Parametric Investigation of Urban Form

Chapter 5 establishes the parametric investigation including the underpinning land situation and the parameters and variations of those parameters tested. It presents the Urban Form Models tested in this study.

Chapter 6: Parametric Investigation of Building Design

Chapter 6 is similar to Chapter 5 but with focus on building design aspects.

\section{Chapter 7: Results and Discussion}

Chapter 7 presents and discusses results from the Urban Form and Building Design parametric investigations in terms of energy, density, and indoor environmental performance.

\section{Chapter 8: Conclusions}

Chapter 8 summarizes the study highlighting the findings that have been produced and determining whether the research aim and question have been met. 
Urban Form and Passive Design for High Performance Buildings in the Christchurch Rebuild 


\section{Chapter 2: Background - Urban Form, Passive Design and Christchurch}

Chapter 2 outlines the background context that formed the foundation of this research. Section 2.1 establishes the post-earthquake situation in Christchurch and its vision of becoming a world-leading, sustainable city. Section 2.2 explains passive design with particular focus on the specific passive strategies targeted in the study. Section 2.3 illustrates the influence urban form has on a building's passive performance and density. Section 2.4 discusses the state of current planning laws in Christchurch and how they prioritize density, rather than sustainability - bringing us back to the research problem and aim presented in Chapter 1.

\subsection{In the Wake of the Christchurch Earthquakes}

\subsubsection{Damage Done}

In September 2010 and again in February 2011, earthquakes of magnitude 7.1 and 6.3 respectively, struck New Zealand's second largest city, Christchurch, killing 185 people (New Zealand History Online, 2011). These earthquakes resulted in over $80 \%$ of the central city requiring demolition (OPUS, 2011). Estimates indicate the cost to rebuild the central city would total over $\$ 40$ billion (The Treasury, 2013). It is expected to take around 20 years to rebuild the central city completely (Christchurch City Council, 2011).

At the time of writing, most of the 1,000 CBD buildings that required demolition had been demolished (The Treasury, 2013) and around 200 new building projects (commercial and residential) were underway in the Central City (New Zealand Government, 2014). This is the 'clean-slate' that enables urban form to be revisited.

\subsubsection{Christchurch's Goals for the Rebuilt City}

Through the 'Share an Idea' scheme undertaken by the CCC at the beginning of the rebuild process, it became clear that the people of Canterbury wanted the rebuilt Christchurch to be a world leading 'green' city - "Aim high. Develop a world-class, sustainable, modern green city... Establish a benchmark." Five key initiatives were developed to ensure the rebuilt city is vibrant and prosperous: 'Green City'; 'Accessible City'; 'Compact City'; 'Live, Work, Play'; and, 'Stronger Built Identity' (Christchurch City Council, 2011). The 'Stronger Built Identity' initiative is of particular interest in this thesis as it aims to facilitate-

"A low-rise city with safe, sustainable buildings that look good and function well, supported by urban design controls, new regulation and incentives..."

The 'urban design controls and regulations' aspects of this initiative are relevant to the desired outcomes of this research. If passive buildings are to be realized on a city-wide scale, urban planning directives must mandate an urban form which facilitates them. Issues of a 'Stronger Built Identity' are discussed in Section 2.6. 


\subsection{Passive Design Strategies}

Section 1.1 established why passive design is targeted in this thesis. This section outlines the benefits of the two specific passive strategies - daylighting and natural ventilation - and explains how they work and how they will be implemented in the research.

\subsubsection{Daylight and Daylighting Benefits}

An important point to establish is the difference between 'daylighting'- the means used to deliver daylight to a space, and 'daylight'- the resulting light delivered - each having different associated benefits. This research looks at both daylighting design strategies; and daylight performance.

Artificial lighting and resulting requirement for cooling, contributes an estimated $30-40 \%$ of a commercial building's energy use. The most prominent benefit of daylighting is that it can reduce these artificial lighting loads by $40-80 \%$ in office buildings (Ministry for the Environment, 2008).

Exposure to daylight can improve people's health and well-being. Benefits include regulation of melatonin which can cause sleepiness, fatigue and increased levels of stress hormones; and increase visual stimulation which can increase metabolism and even improve energy levels (Stewart, 2008).

A well-documented explanation for these benefits is the relationship between daylight and human circadian cycles which determine daily eating and sleeping patterns. This cycle is modulated by external cues like daylight, and can be modified by interruptions to those cues. The constant nature of artificial lighting disturbs circadian rhythms', while the presence of daylight helps to maintain them (Czeisler, et al., 1980).

Similarly significant to the benefits of daylight, are those associated with daylight-ing. A number of studies (Hunter, et al., 2003) have found that a view is just as important as daylight, or possibly even more important (Collins, 1976). The value of a view comes back to the basic human desire for a connection with the outside world - simply having the option of a view and daylight will improve a person's perception of a space and its lighting (Sullivan, 2013).

Existing research establishes a strong consensus that people prefer day-lit spaces over artificially lit spaces. Farley and Veitch (2001) found that $65-95 \%$ of people prefer to complete typical office tasks under daylight. Peter Boyce states in his book 'Human Factors in Lighting' that people's desire for daylight is evident across three distinct sources: advertising (good electric luminaires are "like daylight"); behaviour observation (those in executive positions are given offices with windows/views); and, finance (rent charged for day-lit offices is more than for non-day-lit offices) (Boyce, 2003).

\subsubsection{Daylighting Strategies - Side-lighting}

Many daylighting strategies exist that can deliver daylight to a space but in consideration of the points made in the previous section, there is only one strategy that provides both daylight and views - 'side-lighting'.

Side-lighting, the most common means of daylighting in office buildings (Advanced Lighting Guidelines, 2010), introduces daylight to an indoor space through vertical windows in perimeter walls of a building (refer Figure 2.1). It has the advantage of being applicable to all levels of a building, whereas top-lighting methods (e.g. skylights) can only be applied to the top level. A view is also possible when windows are placed around mid-height of a wall. 
A significant limitation of daylighting is the distance it can infiltrate a space. Penetration distance can be loosely calculated using a rule of thumb. Depending on the source, the rule of thumb can vary from 1.5 to 2.5 times the window height (Reinhart \& LoVerso, 2010) but, on average, can be expected to reach around $2 x$ the height of the window it enters through (refer Figure 2.1).

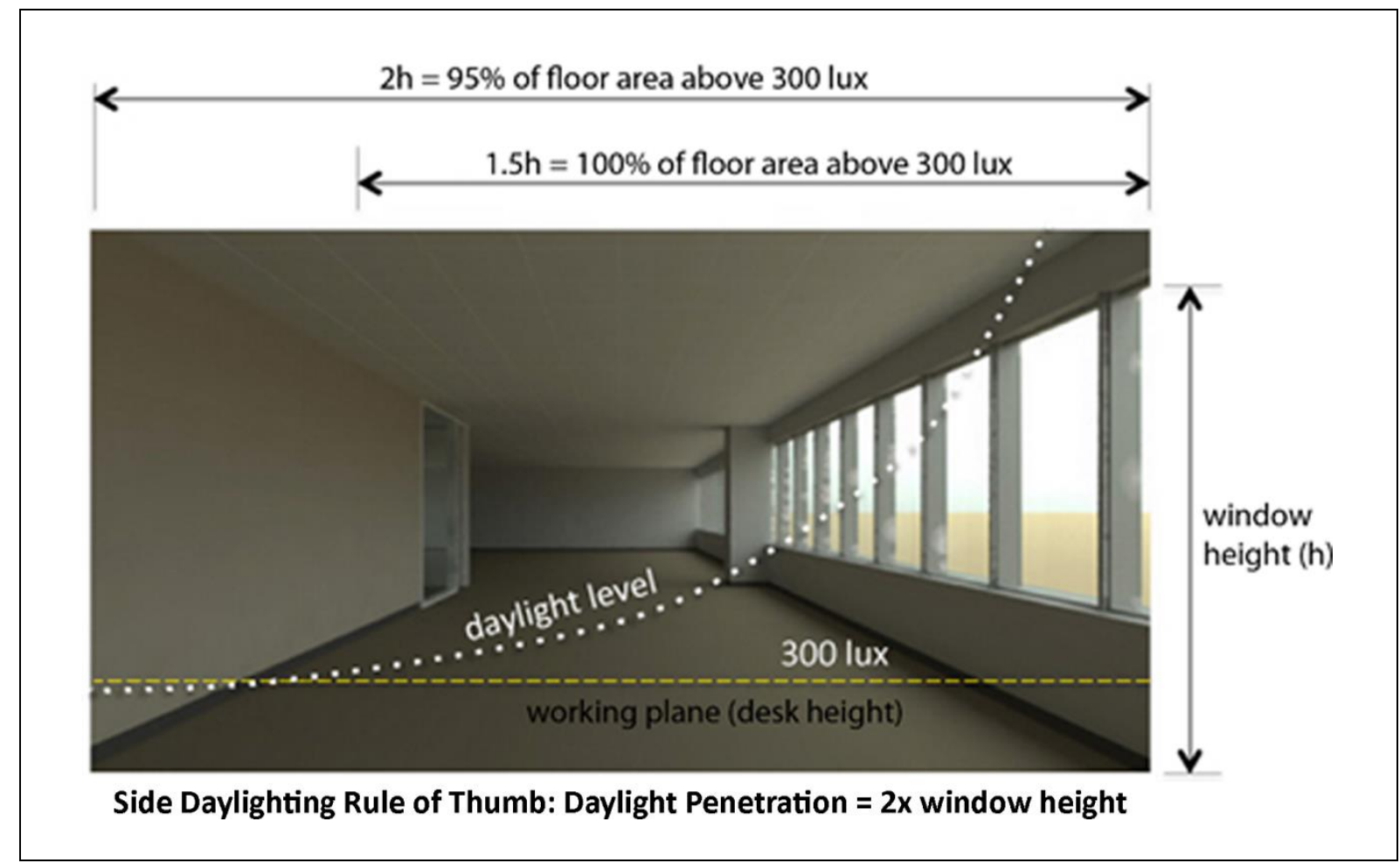

Figure 2.1. Diagram depicting the side-lighting penetration rule-of-thumb. Adapted from (2030 Palette, 2013).

Other factors such as the size of windows, known as 'Window to Wall ratio' (WWR) influence daylight levels and penetration. Adding devices like light-shelves can increase penetration into the space (up to $2.5 \mathrm{x}$ window height). Conversely, shading systems like louvers or fins, which are used to control over-exposure, can reduce penetration. Glazing properties such as Visible Light Transmittance (VLT or $\mathrm{T}_{\text {vis }}$ ) and Solar Heat Gain Coefficient (SHGC) are also particularly influential. Due to their effect on daylight penetration and on thermal performance of a building, WWR, shading systems and glazing properties are critical components of passive design, and are investigated in detail in Chapter 6.

The assumption that daylight will illuminate a space up to $2 x$ the height of the window (along with the natural ventilation rule of thumb, refer Section 2.2.4) will be used as a starting point in the development of scenarios tested in this research (refer Chapter 5).

The environment surrounding the building is the other significant factor affecting daylight (discussed in Section 2.3). 


\subsubsection{Natural Ventilation Benefits}

"Ventilation of occupied spaces in buildings has two primary purposes. One purpose is to provide an acceptable indoor air quality (IAQ), which essentially is based on the supply of fresh air and the removal or dilution of indoor pollution concentration. The other is to provide thermal comfort by providing a heat transport mechanism." (Kleiven, 2003).

Through the $20^{\text {th }}$ century, office buildings typically employed mechanical HVAC systems to deliver conditioned air to spaces. Mechanical HVAC systems were popular as they enabled incoming air to be treated (heated or cooled) as required providing control of indoor environments (Kleiven, 2003).

The alternative to mechanical ventilation is natural ventilation. Natural ventilation relies on wind or buoyancy (or both) as driving forces. By allowing air to be forced through openings in the building envelope (wind driven), or sucked through vertically (buoyancy/ stack effect), a buildings spaces can be ventilated, without energy intensive HVAC systems.

Natural ventilation also acts as a heat transport mechanism enabling natural cooling of spaces. In offices, air tends to overheat due to heat generated by electrical equipment and human bodies. Replacing this warm indoor air with cooler outdoor air helps to regulate temperatures, reducing the dependence on mechanical cooling systems. Volume and temperature of air moving through a space is critical to natural ventilations success. For this reason, environmental performance aspects - 'air speed', temperature' and 'air change rates' are addressed in Section 4.3.

Advantages of natural ventilation over mechanical ventilation include:

- Less likelihood of Sick Building Syndrome (Kleiven, 2003).

- Air-conditioned buildings have been found to have higher prevalence of 'work-related headache', lethargy and respiratory symptoms (Mendell \& Smith, 1990).

- Less noise from fans.

- Natural ventilation systems have the same service life as the building; whereas HVAC systems typically require earlier replacement (Kleiven, 2003).

- Little equipment and associated space required.

- Installation costs - up to $30 \%$ of the construction budget (Ministry for the Environment, 2008).

- Operation costs.

The 'Summary Report: Control Strategies for Mixed-mode Buildings' found that natural ventilation can produce air conditioning savings of up to $79 \%$, depending on climate and HVAC system/operation (Brager, et al., 2007).

A significant barrier to natural ventilation is the perceived lack of control over indoor environment. However, modern technology developments such as Building Management Systems (BMS) and automated windows regulate ventilation based on human comfort factors (Kleiven, 2003). For example, natural ventilation would be allowed if outdoor temperatures are slightly cooler than indoor temperatures. But if outdoor temperatures become too cold (or hot), the BMS will close windows and engage the HVAC system to maintain comfort until conditions become suitable for natural ventilation once more. This is the 'mixed-mode' ventilation concept that is adopted in this research (refer Section 1.4.3). These benefits and improvements have contributed to a 'comeback' of natural ventilation since the 1990's (Kleiven, 2003). 


\subsubsection{Natural Ventilation Strategies - Cross Ventilation}

Natural ventilation strategies can be described using the framework set-out in Figure 2.2.

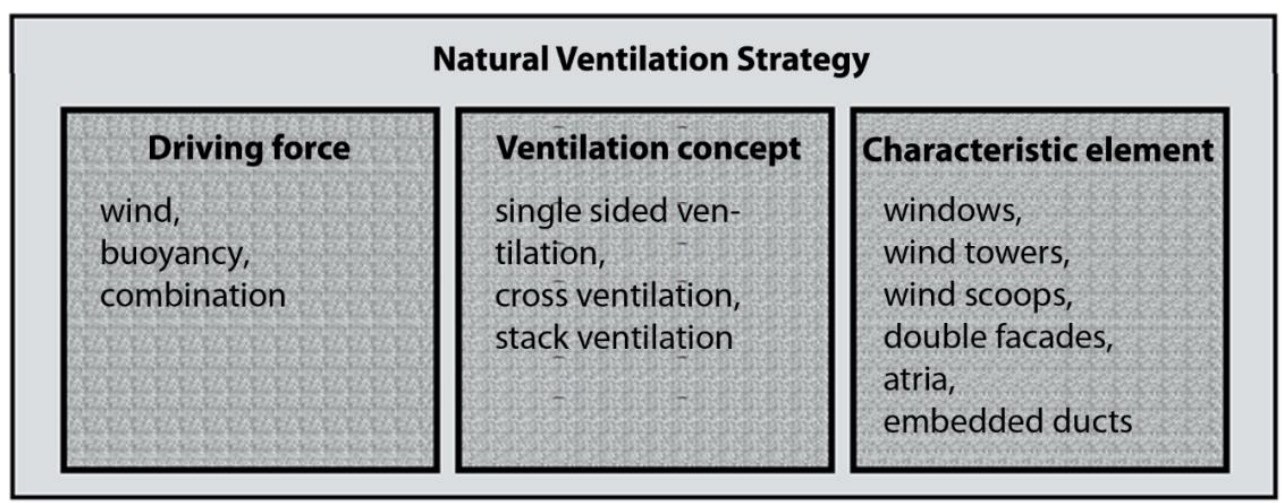

Figure 2.2. Natural ventilation strategy framework. Adapted from (Kleiven, 2003).

In order to align the natural ventilation strategy with the daylighting strategy established in Section 2.2.4, wind driven cross ventilation through vertical windows is selected. Cross ventilation can be applied to all levels of a building through the same windows used to deliver daylight. It requires two sides of the space to be on external walls of the building. The exchange of air between inside and outside is propagated by the pressure at the two venting windows (refer Section 4.3.2.2).

As with daylight, cross ventilation only penetrates so far into a space. According to CIBSE (1999) the double sided rule of thumb is $5 x$ the ceiling height (refer Figure 2.3).

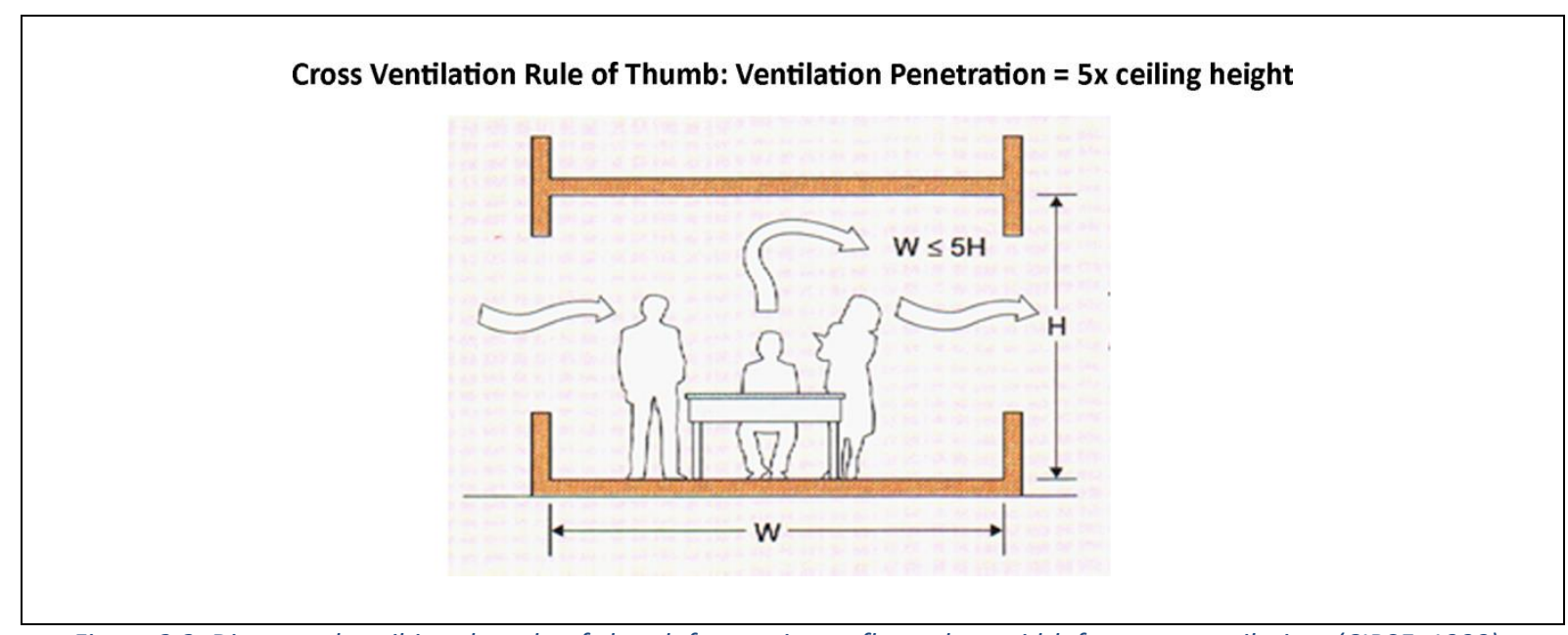

Figure 2.3. Diagram describing the rule-of-thumb for maximum floor-plate width for cross ventilation. (CIBSE, 1999).

Importantly, the effectiveness of cross ventilation is influenced by the layout of a space. Flows across a space will not be possible if there are full height partitions perpendicular to the flow direction, open-plan spaces are therefore the most effective (refer Figure 2.4). 


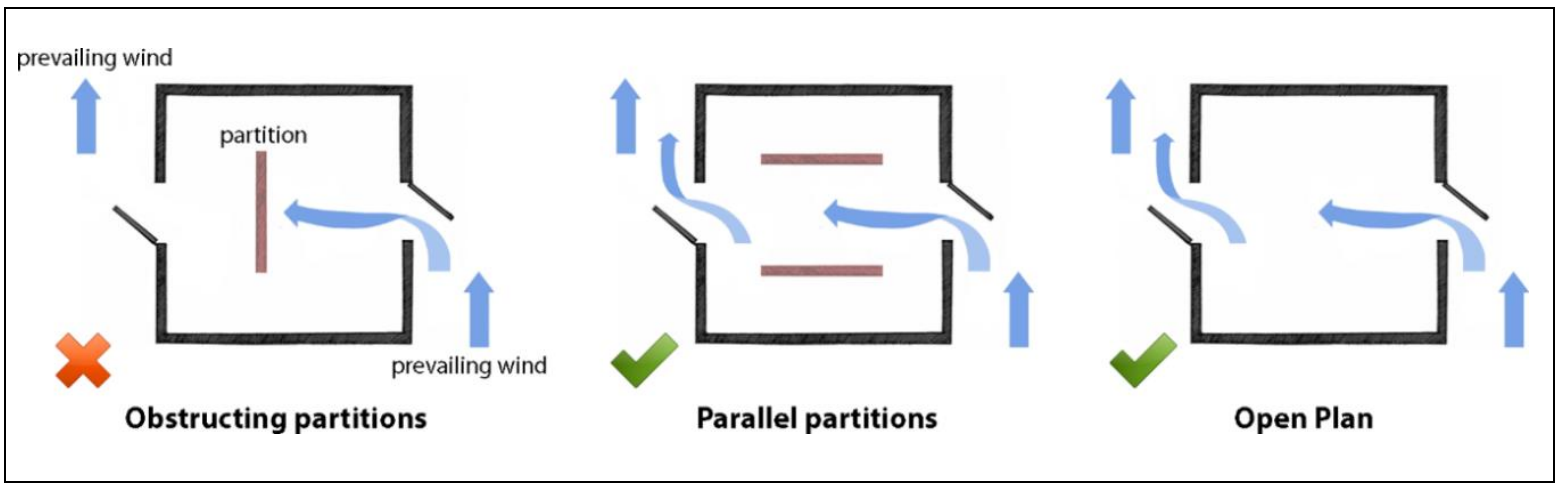

Figure 2.4. The effect of space configuration on cross ventilation. Adapted from (Autodesk, 2011).

Other factors that influence effectiveness of cross ventilation include 'openable window area', 'extent of openness' and positioning of windows. These are all investigated in depth in Section 4.3.2.1.

As with daylight, the natural ventilation rule of thumb will be used as a starting point for the design of scenarios tested in this research.

Urban form also has a significant impact on cross ventilation because it drastically modifies wind flows and pressures acting around/on the building (which propagate the cross ventilation). The following section establishes the importance of urban form in the design of cross ventilation and daylighting systems. 


\subsection{Urban Form for Passive Buildings}

Urban environments, such as cities, have a substantial effect on the natural environment in and around them. The physical form of a city creates a 'microclimate' which comprises aspects of temperature, humidity, rain, wind, fog, insolation and general air quality (Santamouris, 2006).

Following is an explanation of how a microclimate is influenced by built form and the resulting effect on natural ventilation and daylight.

\subsubsection{Definition of Urban Form}

This study adopts the simple but clear 'Towards Building Better Cities' definition of Urban Form as "the physical structure of the built environment in urban areas" (Roberti \& Helm, 2011).

\subsubsection{Urban Forms Effect on Natural Ventilation}

Cross ventilation is dependent on wind pressure on the buildings facades/windows. Figure 2.5 shows how wind pressures are reduced where there are interruptions to the flow - larger buildings and denser environments have a greater effect - "The airflow in street canyons has much lower values as compared with the undisturbed wind. Lower wind velocity means reduced wind pressure on the building façade and less effective cross ventilation." (Ghiaus, et al., 2006).

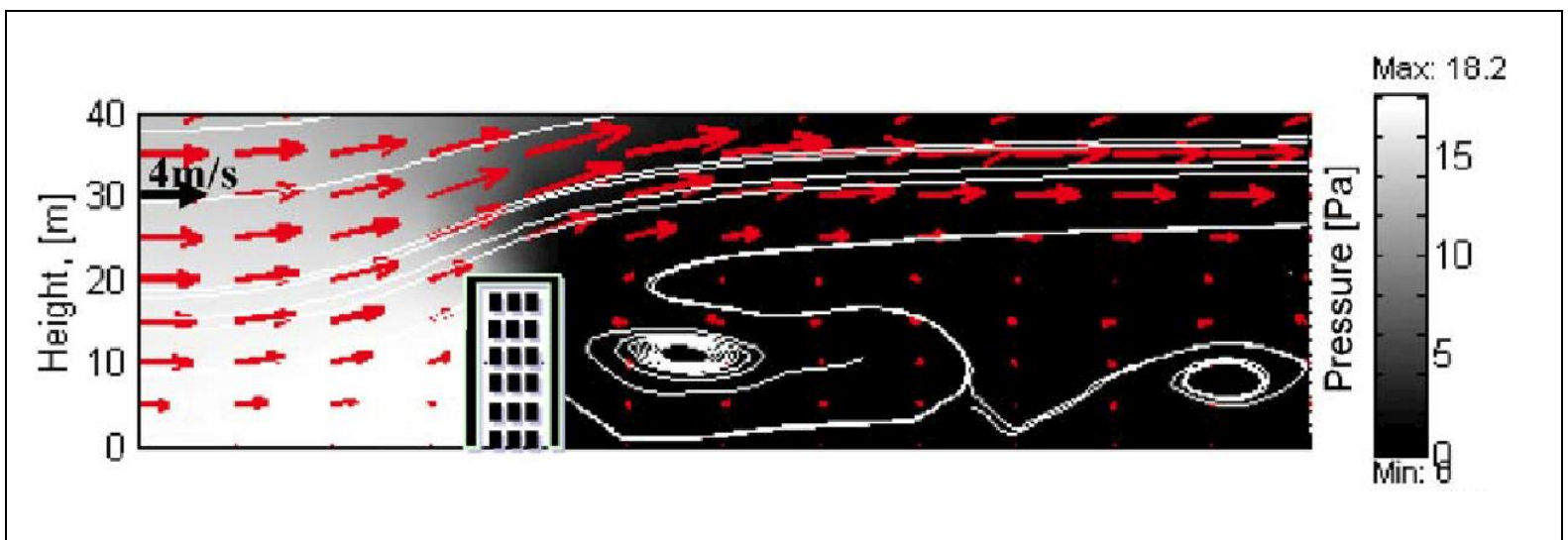

Figure 2.5. CFD analysis of wind flow and pressures around an urban environment. (Ghiaus, et al., 2006).

Studies have found that even low-density urban environments can reduce wind pressures acting on a building by over $80 \%$ (Change \& Meroney, 2003). However, few studies quantify the effect of urban form density on natural ventilation performance in terms of energy savings and fresh air volume turn-over. This effect is the focus of this thesis research.

\subsubsection{Urban Forms Effect on Daylight}

A significant concept in urban design for solar access is the relationship between building height and street width, known as 'aspect ratio'.

$$
\text { Aspect ratio }=\frac{\text { building height }(m)}{\text { street width }(m)}
$$


Generally, the higher the aspect ratio, the greater the urban form's impact on microclimate, and the lower the potential for daylighting. Many studies have investigated the impact aspect ratio has on daylighting and energy in buildings. Stromann-Andersen and Sattrup (2011) tested the performance of office buildings in aspect ratio scenarios of $0-3.0$ (building three times higher than street width). Figure 2.6 demonstrates how the highest density aspect ratio 3.0 scenario (far right) severely limited the amount of solar radiation entering the canyon, when compared to the lowest density aspect ratio 0.5 scenario (far left).

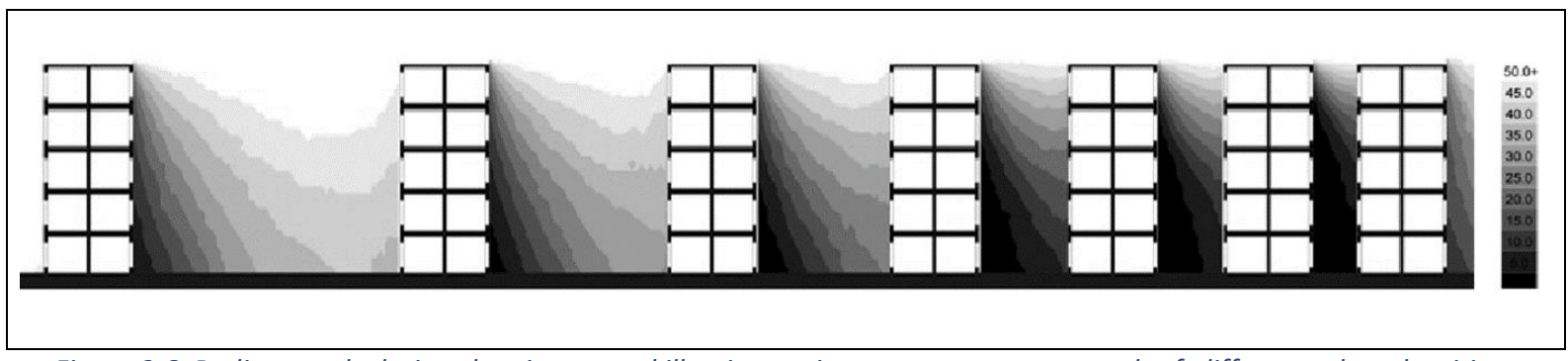

Figure 2.6. Radiance calculation showing annual illuminance in street canyon as a result of different urban densities. (Stromann-Andersen \& Sattrup, 2011).

Figure 2.7 then illustrates that this difference in access to daylight can cause a building in a dense urban environment to require up to $30.2 \%$ more energy than an isolated building.

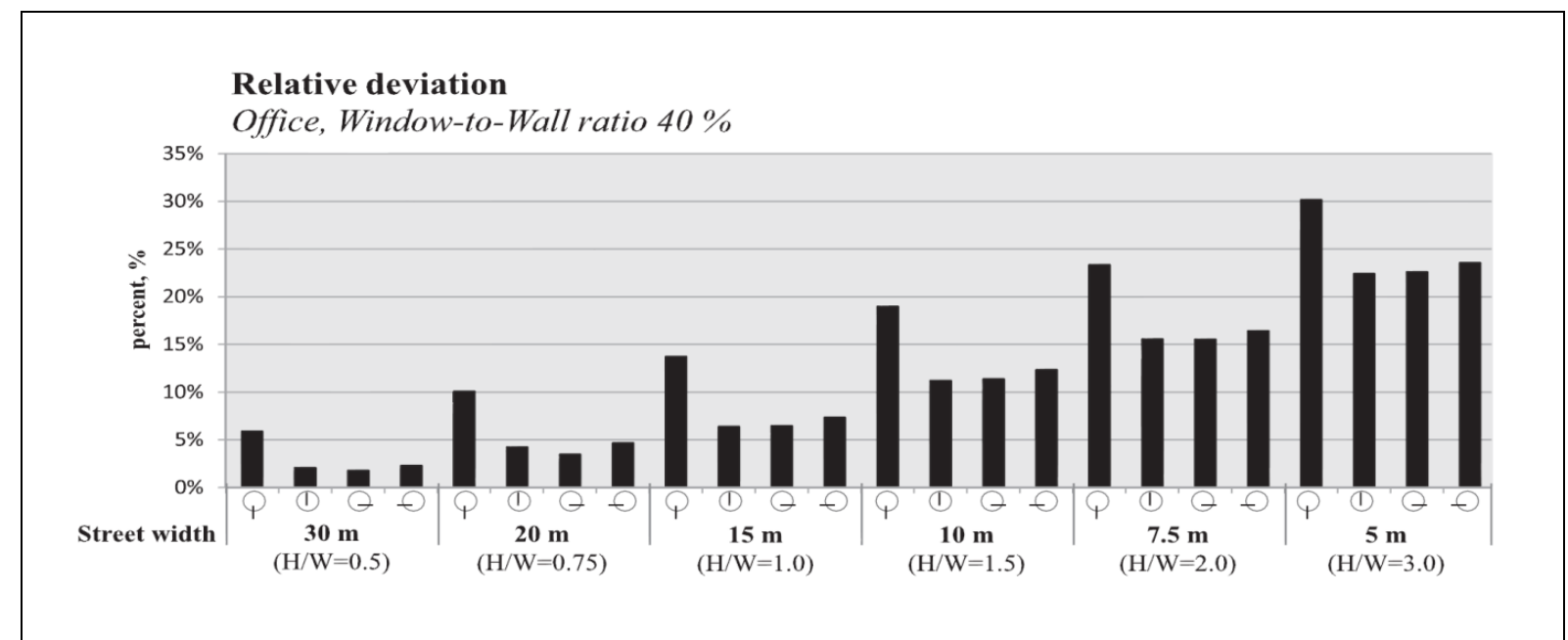

Figure 2.7. Increase (\%) in energy consumption for an office building in different $\mathrm{W} / \mathrm{H}$ scenarios, compared to a free horizon. (Stromann-Andersen \& Sattrup, 2011).

Evidently, the relationship between built form and void space has a significant influence on microclimate and passive potential of buildings. The following quote from the book 'Great Streets' by Allan Jacobs forms the basis from which the main urban form questions in this thesis were formed:

"Is there some point, some proportions or absolute height, at which the buildings are so high in relation to street that the building wall becomes oppressive? It may be that the upper limit is more appropriately determined by the impact of height on comfort and liveability of the street, as measured by sunlight, temperature and wind, than by absolute or proportional height." (Santamouris, 2006). 
In other words- where is the tipping point? At what aspect ratio does passive performance deteriorate? This research intends to identify maximum building height to 'separation' ratios in Christchurch by the impact on daylight in building spaces. Variations of building height and street width that will be tested are discussed and determined in Section 5.2.

\subsubsection{Porosity of the Urban Form and its Effect on Density}

If void space between buildings is fundamental to daylighting and natural ventilation, why is it only provided in the form of streets? Only the building façade facing the street can gain any benefit from its microclimate in this scenario. Passive performance could be improved by increasing porosity of the urban fabric, for example by adding secondary urban canyons between each building.

As was identified in Section 1.1, the barrier to increased porosity is the reduction of density, which is an issue at two levels- city scale; and the individual building scale.

\subsubsection{The Effect of Increasing Porosity on City Scale Density}

The problem with increasing porosity at the city scale is whether enough built floor space remains for the City Centre to remain the economic hub of the region. To help determine how much space will be needed in the rebuilt City Centre, the 'CERA Christchurch Central City Commercial Property Market Study' report was produced to determine likely supply and demand of commercial building space. It found that only $266,000 \mathrm{~m}^{2}$ of space is likely to be needed in the rebuilt city (compared to $446,000 \mathrm{~m}^{2}$ before the earthquakes) (Ernst \& Young, 2012). Another similar report, 'The Impacts of the Canterbury Earthquake on the Commercial Office Market', found that only $180,000 \mathrm{~m}^{2}$ of space is likely to be needed (CBRE and Lincoln University, 2012). The 'Architecture NZ' article 'The Emergence of Christchurch' has depicted this latter information in terms of built city blocks. Figure 2.8 shows that at 3 storeys only 5 CCB blocks would be required, and only 2.5 at 6 storeys (Webby \& Hoare, 2012).

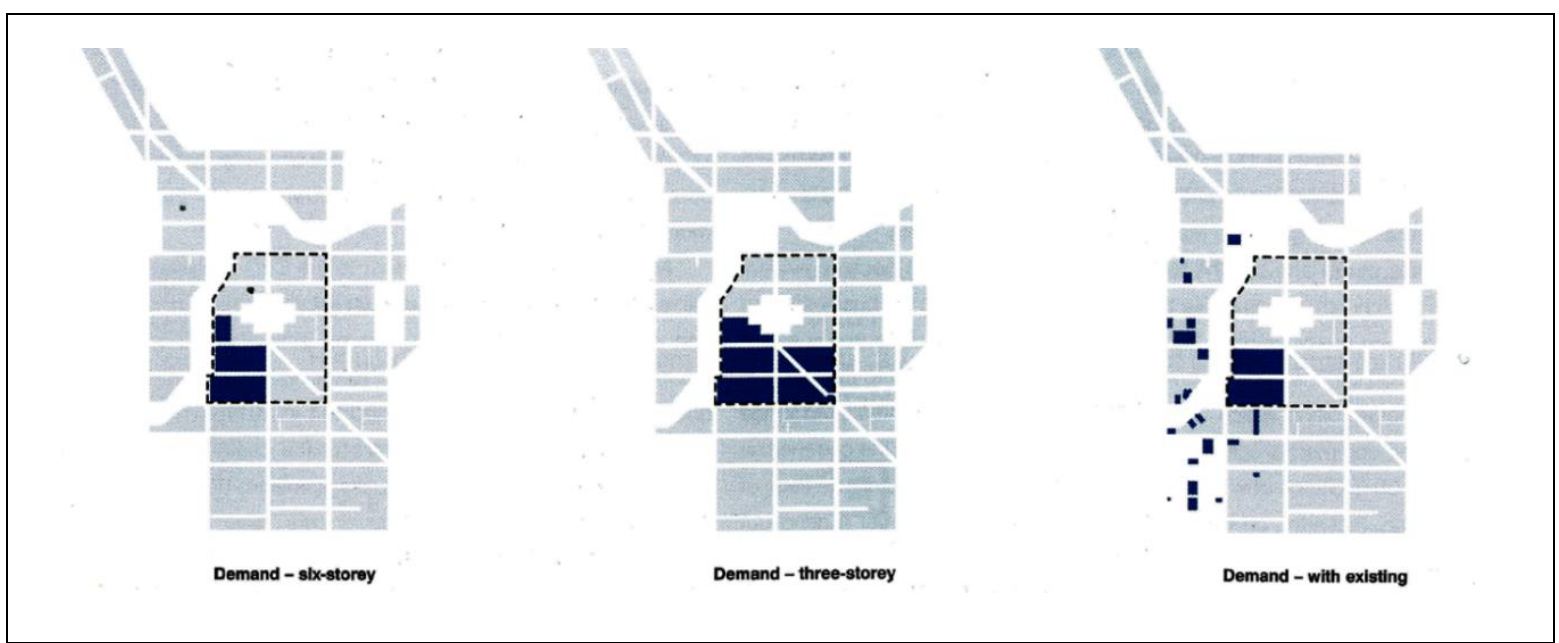

Figure 2.8. Diagram illustrating projected demand for floor area at varying levels of density (building heights). (Webby \& Hoare, 2012).

While this may suggest increasing porosity is not of serious concern at the city scale, proposed urban form scenarios need to prove they can provide ample room for buildings and growth. For this

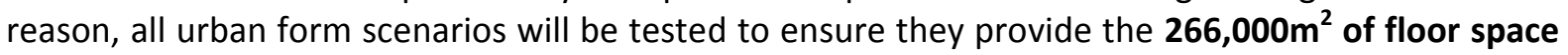
projected by CERA (this being the more demanding of the two predictions). 


\subsubsection{The Effect of Increasing Porosity on Individual Buildings}

A building's value is heavily dependent on its size- the more Net Leasable floor area (NLA), the more it is worth - so it is more economically advantageous to have large buildings. This is a primary reason for deep-plan and tall buildings, which aim to maximize plot ratio (floor area / land parcel area) and return on investment for developers and owners. Essentially, this means building to the property plot's boundaries. In a confined urban environment, where plots are often small and rates are high, it is almost inevitable plot ratios will be maximized.

As identified in Section 1.1, office floor area in Christchurch CCB is expected to lease for between $\$ 250-420 / \mathrm{m}^{2} /$ year (Bayleys Realty Group, 2013), whereas energy costs are between $\$ 17.60 / \mathrm{m}^{2} /$ year and $\$ 53 / \mathrm{m}^{2} /$ year.

Clearly, the cost of floor area outweighs energy expenses and so increasing porosity by converting profitable NLA to void space is not likely to be readily adopted by building developers and owners.

This reality is reflected in the following quote from architecture Professor Ralph Knowles:

So far, there has been little incentive for developers to worry about the long-term energy costs of keeping our buildings comfortable and repaired. Pressures are so enormous to build fast and move on quickly to the next project that construction techniques emphasize rapid assembly over the effects of long-term wear and tear. Developers do not pay the bills for heating, cooling and lighting over time and seasons. Consequently they have demanded that architects specify energyintensive systems rather than make the effort to design with nature. In the simplest ungrammatical terms, we "grow cheap" and "maintain expensive". (Knowles, 2003).

Developers and owners/owner-occupiers are the drivers and designers of buildings. But their priorities typically revolve around profit, achieved in part through maximization of NLA. It cannot be expected or assumed that developers or owners will create a building that is of more than just financial benefit.

If Christchurch is to realize the sustainable, green city it envisages, its urban development priorities need to be readdressed. A balance needs to be found between NLA and environmental performance. This endeavour can only be reliably achieved through policy; and this will only be realised if the business case of sustainable buildings is plausible. 


\subsection{Changing Times - Green Buildings for Commercial Advantage}

A survey by ACA Research and Colliers International found that sustainable buildings had become more important to New Zealand companies, with $40 \%$ of respondents identifying 'Social Responsibility' as a key factor (up from $28 \%$ in 2010). Other factors associated to the improved perception of sustainable buildings included:

- Operational cost savings

- Indoor Air Quality (IAQ) and daylight

- Improved staff acquisition and retention

- Productivity increases (The Dominion Post, 2012).

'Productivity' refers to output as a function of effort (Stang, et al., 2001) - i.e. the amount of work done by an employee vs the time taken to do so. Studies such as the post-occupancy evaluation of the retrofitted 500 Collins Street building in Melbourne have revealed a reduction in occurrences of issues like headaches $(-7 \%)$, cold and flu $(-21 \%)$, fatigue $(-26 \%)$ and poor concentration $(-20 \%)$. The value of this manifests in benefits such as reduction of average sick-leave costs (-44\%); and increases of productivity of up to $12 \%$ (Sustainability Victoria, 2008). Similar levels of productivity improvement have been associated with other sustainable building developments. The 'Melbourne Council House 2' building (6 Green Star rated) realized a $10.9 \%$ productivity increase, which is estimated to save $\$ 2$ million a year; and the Meridian building ( 5 Green Star) in Wellington which is perceived by its occupants to boost their productivity by $9 \%$ compared to their previous building (NZGBC, 2013).

These commercial benefits are beginning to be reflected in the increasing demand for sustainable buildings. The 'CERA Christchurch Central City Commercial Property Market Study' report outlines the projected supply and demand for commercial property, and the attractiveness of commercial property to investors and developers. The study identified that, as at 2010, the highest grade of office building, A+ (equivalent to 5 Green Star rating or higher), experienced the lowest tenancy vacancy rates at only $4 \%$, while Grades A and B came in at second and third respectively (refer Figure 2.9). This illustrates the demand for high quality, sustainable buildings. Furthermore, the remaining stock of Grade $C$ and below, is not expected to be financially viable following the rebuild (Ernst \& Young, 2012).

\begin{tabular}{lrrrr}
\hline Quality grade & Occupied sqm & Vacant sqm & Vacancy $(\%)$ & Total sqm \\
\hline A+ & 36,127 & 1,429 & 4 & 37,556 \\
\hline A & 31,181 & 3,417 & 10 & 34,598 \\
\hline B & 118,161 & 14,543 & 11 & 132,704 \\
\hline C & 126,310 & 28,723 & 19 & 155,033 \\
\hline D & 59,243 & 12,814 & 18 & 72,057 \\
\hline E & 11,069 & 2,985 & 21 & 14,054 \\
\hline Total & 382,091 & 63,911 & 14 & 446,002 \\
\hline
\end{tabular}

Figure 2.9. Vacancy rates by Quality grade. (Ernst \& Young, 2012). 


\subsection{The Business Case for Sustainable Buildings}

Sustainable buildings have been adopted for some years in Europe, North America and Australia but New Zealand is still in its relative infancy. There does however appear to be considerable interest in sustainable buildings in N.Z. The Investor Perception of the Business Case for Sustainable Office Buildings: Evidence from New Zealand' report surveyed developers, owners and occupiers about their perceptions and activity regarding sustainable buildings. It found that the majority of investors perceived sustainable buildings positively (Figure 2.10. left); and saw them as 'very important' or 'increasingly important' investments (right) (Myers, et al., 2008).

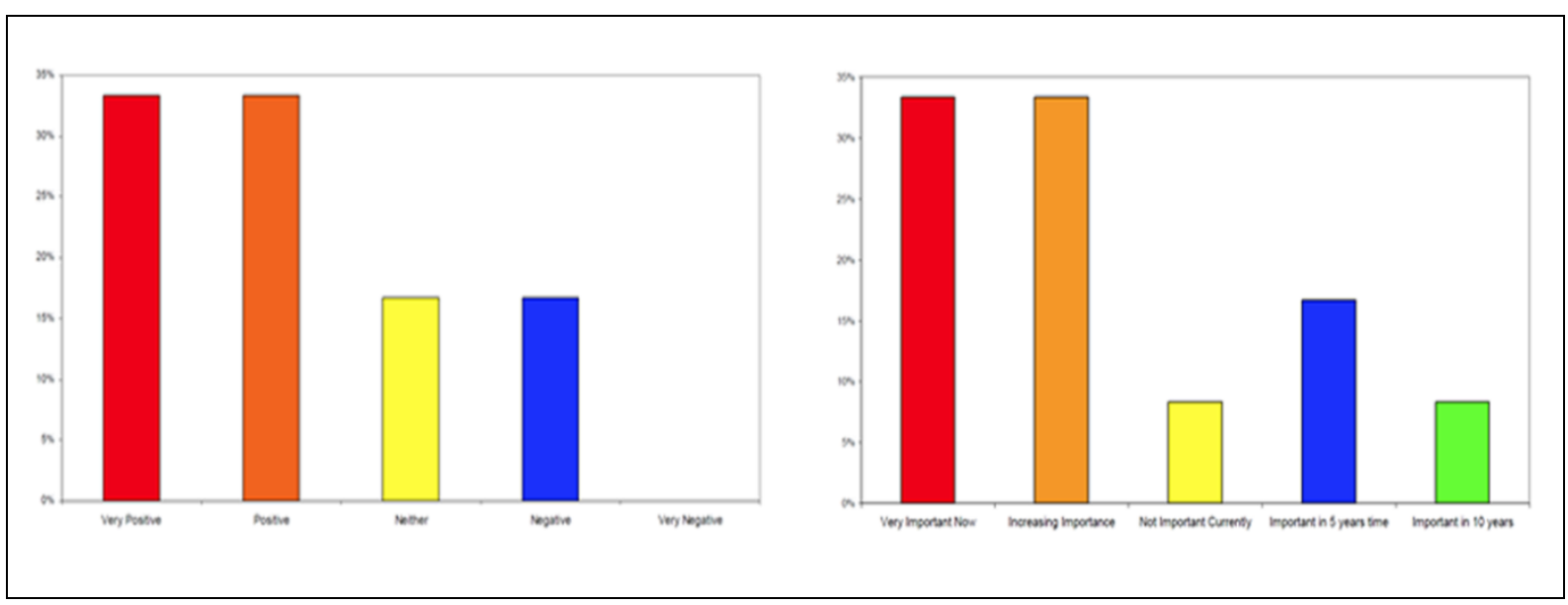

Figure 2.10. Investor perception of sustainable building (left); and Importance for Portfolios (right). (Myers, et al., 2008)

Despite this interest, and environmental, energy and health benefits presented in this Chapter, there still remains hesitation and scepticism in the market from investors. Much of the hesitation is due to uncertainty of the market and its direction. The report noted that investors tended to 'hold-back' and let other players lead the way, stepping in when the market was more certain. Christchurch cannot afford to take that attitude, as the opportunity to rebuild a city will soon be gone. Myers et al. summarizes the issue:

"...for sustainability to gain industry-wide acceptance, the majority of building owners and investors need to be assured of depth in the market as well as the financial certainty and viability of sustainable buildings... The lack of concrete evidence about the correlation between value and sustainability leaves the investment industry wondering and unsure of the financial benefits of sustainability" (Myers, et al., 2008).

A study that goes a long way to providing 'concrete evidence' is the 'Ministry for the Environment's' Value Case for Sustainable Building in New Zealand' (2006) which aimed to determine the economic benefits and disadvantages of sustainable buildings. In financial terms, the investigation found that:

- Capital costs of sustainable buildings varied from $15 \%$ less, to $11.5 \%$ more than conventional buildings, but on average were 2-6\% more expensive.

- Operational energy costs of the case study buildings were $35-50 \%$ less than conventional buildings.

- Resulting payback period of sustainable office buildings varied from 10-13 years.

- Residual value of a sustainable office building could be worth up to $40 \%$ more than a conventional building.

It has been argued there are no 'real' incentives to invest in sustainable buildings and that most of the benefits accrue to the occupier rather than the investor (Myers, et al., 2008). However, Figure 
2.11 illustrates the separate benefits for both developers/owners; and tenants. The left-hand graph shows that although a sustainable building will incur a higher capital cost (up to $\$ 200 / \mathrm{m}^{2}$ more than a conventional building), it will also yield higher rental returns (up to $\$ 350 / \mathrm{m}^{2}$ more). While this extra rent cost is picked up by the tenant, they enjoy other benefits. The right-hand graph shows how this extra $\$ 200 / \mathrm{m}^{2}$ rent pays off for the tenant through energy and productivity savings of up to $\$ 200 / \mathrm{m}^{2}$ and $\$ 900 / \mathrm{m}^{2}$ (20 year present value) respectively.

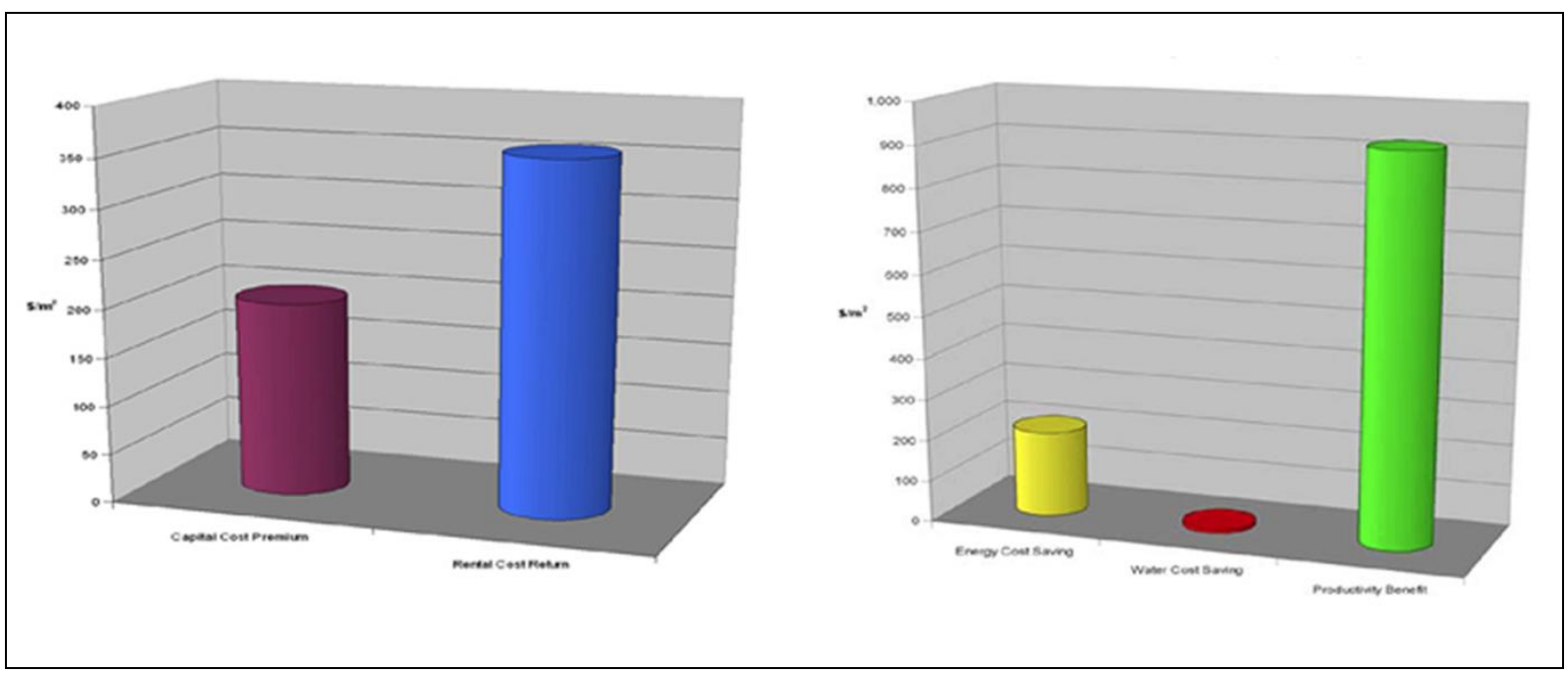

Figure 2.11. Twenty year Present Value for sustainable office buildings from the developers/owners perspective (left); and from Tenants perspective (right). (Myers, et al., 2008).

\subsection{Urban Planning Policy and Christchurch's 'Stronger Built Identity'}

The stronger built identity initiative aims to facilitate:

"A low rise city with safe, sustainable buildings that look good and function well, supported by urban design controls, new regulation and incentives..."

Christchurch's' Built Identity will reflect the values of Cantabrians. Policy makers need to decide whether sustainable buildings really are a priority or whether they are merely 'green-wash'. If sustainable buildings are central to their plans for the rebuilt city, the urban form will reflect this and will become part of the city's built identity. The question that must be asked then, is- What does Christchurch want their city's identity to reflect?

The current compact, party-walled urban form means that only street facing facades of a building have access to daylight and fresh air. While these buildings could still look good, and even appear 'sustainable' with some pretty greenery or timber louvers, in reality it cannot possibly function as efficiently as one with access to daylight and fresh air on all sides. This research intends to substantiate this hypothesis and determine just how much more energy efficient a building that has access to daylight and fresh air is than a building that does not. It concerns sustainable buildings, rather than sustainable frontages.

If this is indeed the case, urban design controls must support a porous urban form, which is equally important as the design of the building itself. New regulation indicates the CCC's intent to reform urban development laws in view of re-evaluated goals. Urban design controls regulating the size and 
juxtaposition of buildings is needed if the benefits of naturally lit and ventilated buildings are to be realized.

The following Chapters look at the effect a 'passive urban form' would have on building performance (comfort, energy and density) in Christchurch Central City. Results and findings aim to determine how much building performance can be improved with a more porous urban form and passive designed buildings; and how extreme the changes to urban planning and development regulations would have to be to achieve this. 
Urban Form and Passive Design for High Performance Buildings in the Christchurch Rebuild 


\section{Chapter 3: Methodology - Research Design}

This chapter discusses the methodological research techniques which underpin the implementation of the following methods chapters. The research aim the methodology must support is:

To determine which changes to urban form and building design would have the greatest effect on building performance, but smallest impact on density in Central City Christchurch.

\subsection{Parametric Method of Analysis}

"Variations in design are a fundamental part of the design process in the search for solutions to design problems. Design variations support improvement of design which in turn improves the quality of designed artefacts." (Hernandez, 2006).

When specific detail of a design variable is unknown - for example, how much void is needed adjacent to a façade to enable effective daylight and natural ventilation? - a parametric investigation enables the designer to systematically analyse and 'narrow down' the options. By methodically altering one design parameter (or 'variable') at a time, the effect of that parameter on the target performance criteria is determined. 'Parameterization' is the process of declaring which 'attributes' (of a design or model) are to be investigated (Hernandez, 2006).

Each parameter is tested at a range of variations to reveal patterns of effect. Initially, only one parameter is altered at any one time (isolated) to ensure results are comparable; then combinations of parameter variations are tested. Comparisons then reveal which changes and combinations had the most impact on the desired performance. This is how the parametric approach addresses the Research Aim.

\subsubsection{Design of Parametric Study}

This research conducts the parametric investigation in two main parts: 1) Urban Form (UF); and, 2) Building Design (BD). The benefits of this are:

- UF and BD parameters can be analysed completely separately. This enables a comparison between the general areas of UF, and BD; as well as comparisons of parameters within those two areas.

- Number of scenarios can be limited. In parametric analysis, tested scenarios grow exponentially with every variation added. For example, 3 variables of 3 variations each equals 27 scenarios $(3 \times 3 \times 3)$; whereas 3 variables of 4 variations each equals 64 scenarios ( $4 \times 4 \times 4)$. If UF parameters and BD parameters were tested simultaneously, an excessive number of scenarios would result.

The approaches taken for each of the UF and BD parametric investigation are slightly different. UF adopts the manually conducted, conventional parametric method described here, and is explained further in 'Chapter 5 - Parametric Investigation of Urban From'. BD, however, covered in 'Chapter 6 - Parametric Investigation of Building Design', is split into two further parts: 'Daylighting Design (DD)'; and 'Ventilation and Thermal Design' (VTD). DD uses the conventional parametric method, but VTD employs a computer program (GenOpt) to automate and streamline the parametric process. The different approach used for the final VTD part was possible, as complex daylight calculations were not required; and was necessary, to address the larger number of scenarios. 
Full Parametric Process

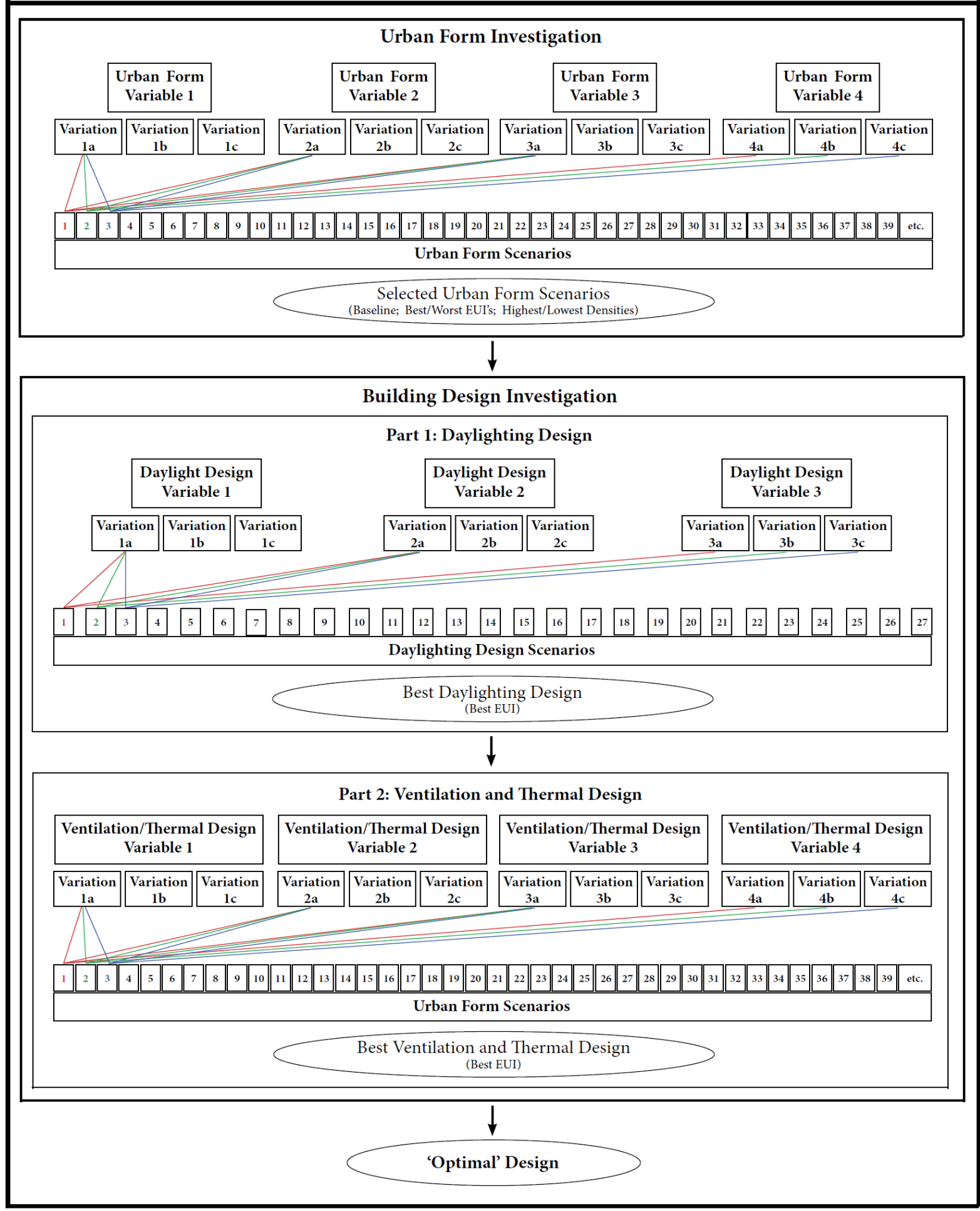

Figure 3.1. Flow-chart diagram illustrating the full parametric process. (Author).

Figure 3.1 presents the full parametric process used in the study. Each component of this flowchart is broken down and presented in greater detail in its associated chapter. Ultimately, 59 Urban Form scenarios were formulated and tested; 27 DD scenarios; and (up to) 192 VTD scenarios. This equals a total of up to 283 different combinations of urban form and building design tested in the study. As Figure 3.1 depicts, a single 'optimal' scenario is developed through this process and represents the 
final output of the parametric study. It is this minimized energy consumption scenario which addresses the research question:

\section{How far can the use of daylighting and natural ventilation through porous urban form and passive building design reduce energy consumption in Christchurch's CCB?}

\subsection{Study or Case-study}

Urban form, density, and, to a lesser extent, passive performance are characteristics of all cities. But because this research focuses on these urban design matters, specifically in Christchurch, an entirely unique rebuild situation, it is classified as a 'study-based' approach. This means that the focus is centred on Christchurch's urban design, rather than on urban design in general, using Christchurch as an example. The value of this 'study-based' approach is that findings are actually implementable because they have been generated using data and a methodology bespoke to Christchurch.

\subsection{Generalizability and Applicability to Other Cities}

The parametric method of investigation is a common method of research and design in architecture (Hernandez, 2006) and can be replicated for any similar study. The metrics and tools selected are also widely used in design analysis and, with the exception of the CFD software 'UrbaWind', are easily accessible.

This methodology is not, however, generalizable in terms of the inputs used, which are specific to the Christchurch rebuild. The investigation into urban form in particular is bespoke to Christchurch as it is based on Christchurch's urban planning model and property situation. As has been established, urban form influences a city's 'micro-climate' and potential for passive buildings, and can vary substantially between cities. For this reason results should not be presented as general or applicable to other New Zealand cities.

\subsection{Reliability and Validity}

To ensure the computer models developed in this research are reliable, and the results they produce are valid, the following measures were taken in the methodology.

\subsubsection{Realistic to Christchurch}

For findings produced through this study to have any chance of implementation, they must be representative of Christchurch conditions. To do this, tools like the Christchurch City Plan (CCPo) were used extensively to ensure urban design aspects of the models were realistic.

A range of other documents with varying purposes have been published for the Christchurch rebuild. For example, the 'CERA Christchurch Central City Commercial Property Market Study' provided valuable, current information regarding the commercial expectations of the rebuild (i.e. building supply and demand projections) (Ernst \& Young, 2012), and was used for density analyses.

The 'draft Central City Plan' (dCCP), discussed in the introduction chapter, was used as a representative of the Christchurch people, establishing their desires for the city.

Despite the use of city plan regulations, urban form is still highly variable with unlimited variations of building sizes and juxtapositions. So to model an 'unknown' environment, the study adopted a 'uniform city' approach (refer Section 5.3), meaning all buildings were as much as possible realistic but were identical in terms of size and separation. While this is not a likely scenario, it does enable an expedient and comparable parametric investigation of different design variables at varying scales. 


\subsubsection{Other Data Input Sources}

Additional to the Christchurch specific input data is the more general information required for reliable energy models. To accurately represent a typical New Zealand office building, data from the Building Energy End-use Study (BEES), conducted by the Building Research Association New Zealand (BRANZ), was used. The BEES project aggregated real building performance data of 3,000 New Zealand commercial buildings and produced outputs such as the energy modelling templates (BRANZ, 2012) used as the basis for computer models in this research. Obviously, to be feasible, results must abide by New Zealand Building Code (NZBC) regulations. Standards and clauses are referenced where necessary throughout the study, and in some cases form the basis of design parameters tested. Where NZBC standards do not cover a situation, international standards are used. Professional organisations such as the 'American Society for Heating, Refrigeration and Airconditioning' (ASHRAE), the 'Chartered Institution of Building Services Engineers' (CIBSE) and the 'Illuminating Engineering Society' (IES), provide rigorous tools and standards for environmental and energy performance and modelling in buildings and are used as required.

\subsubsection{Selection of Computer Programs}

In selecting computer programs for the study, three criteria were considered:

1) Validation. Validation provides assurance that the software is capable of accurate predictions and data, such as actual energy consumption in a building (Shrestha \& Maxwell, 2011). All programs used in this study have been officially validated for their purpose- this is discussed where relevant.

2) Outputs. This research addresses a range of building performance areas- daylighting, ventilation, urban design and energy efficiency. As no available program is proficient with all of these components, a range of packages needed to be integrated. Calculations made by some of these programs required inputs generated by the other programs. For example, EnergyPlus required wind pressure coefficients to calculate natural ventilation but cannot produce them itself. Therefore an external program was required to calculate urban wind flows and needed to produce pressure coefficients that could be integrated into EnergyPlus. Outputs also needed to enable the desired analysis of performance. For example, EnergyPlus can calculate daylight illuminances but cannot convert them into targeted performance metrics such as Daylight Autonomy. This is one reason why Daysim was employed. Metrics and Tools are covered in detail in Chapter 4.

3) User ability. A significant factor in building energy modelling is the ability of the modeller. To improve reliability of the models and results, programs with which the user had previous experience, were selected.

\subsubsection{Robustness Tests}

In some situations through this research, a question or issue was raised that could not be answered through existing literature. In the case of CFD program UrbaWind for example, where published validation reports were scarce, an internal validation exercise was conducted to determine the programs reliability for this study. This and a range of other quality assurance checks can be found in 'Appendix A - Robustness Tests'. 


\subsubsection{Survey of Christchurch Architects}

A notable measure taken to ensure model reliability was the 'Survey of Christchurch Architects' developed for this study. This survey aimed to identify typical and extreme architectural design patterns for Christchurch's central city commercial buildings, based on current local practice (e.g. WWR's, glazing properties, etc.). This data was intended to inform the development of computer models and variables tested. However, despite considerable effort to effectuate these surveys, response rates were too low ( 3 of 40 ) to draw any conclusive or defensible patterns from- and had to be abandoned. The survey can be found in Appendix $C$.

\subsection{Quantitative Methodology}

This research is a quantitative study, investigating a range of building performance areas (refer Table 3.1; full details in Chapter 4) through the generation and measurement of numerical data.

Quantitative data enables "the identification of evidence regarding specific cause and effect relationships." (Mora, 2010). The research aim of this study intended to determine which urban form and building design parameters contributed the most to high performance buildings. For this reason it is important to establish clear relationships between individual design parameters and resulting performance- which is made possible through quantitative analysis.

Quantitative research can be generalised from the scenarios tested in a study, to a wider range of scenarios (Sibanda, 2009). This is important for this study which intends for its findings to be applied to future building projects in Christchurch.

\begin{tabular}{|l|l|}
\hline Performance Area & Quantitative Metric \\
\hline Energy Consumption & kWh or kWh/m²/year \\
\hline Indoor Environmental Comfort & \\
\hline - Temperature & Degrees Celsius $\left({ }^{\circ} \mathrm{C}\right)$ \\
\hline - Air change rate & Air Changes per Hour, $\mathrm{ACH}^{\prime} \mathrm{s}\left(\mathrm{m}^{3} / \mathrm{hour}\right)$ \\
\hline - Air speed & Meters per second $(\mathrm{m} / \mathrm{s})$ \\
\hline - Daylight sufficiency & Daylighting Autonomy, DA (\% of occupied year) \\
\hline - Daylight overexposure & Maximum Daylighting Autonomy, mDA (\% of occupied year) \\
\hline Density & Built floor area vs. land area, Plot ratio $\left(\mathrm{m}^{2}: \mathrm{m}^{2}\right)$ \\
\hline
\end{tabular}

Table 3.1. Summary of study's performance areas and corresponding quantitative metrics. 
Urban Form and Passive Design for High Performance Buildings in the Christchurch Rebuild 


\section{Chapter 4: Method - Development of Modelling Metrics, Tools and Methods}

Chapter 4 focuses on 'how' testing was conducted. It discusses and establishes the techniques used to make and assess models tested in this research. The chapter is broken down into the study's three main 'Building Performance Areas' - Energy (Section 4.1); Daylight (Section 4.2); and, Natural Ventilation (Section 4.3). For each of these Building Performance Areas, a set of metrics, tools and methods are identified. 'Metrics' - "A system or standard of measurement" (Oxford Dictionaries, 2013) - are used to measure performance of the tested scenarios. 'Tools', with which the metrics are examined, are the equipment used to generate data, and, in this case, are all computer programs. Finally, the 'method', through which the metrics and tools are used to conduct the investigations, is established and explained.

\subsection{Assessing Building Energy Performance}

While this research is primarily concerned with passive design issues, there is an underlying factor that must be considered- money. As discussed in 'Chapter 2 - Background' the environmental and sustainability benefits of passive architecture, while palpable, are largely overshadowed by economic requirements. Commercial building investors need to see financial certainty in passive/sustainable architecture before it can be accepted and implemented in reality (Myers, et al., 2008). For this reason, energy, which can be easily translated to dollar terms, is the principal building performance area, over daylighting and natural ventilation metrics.

The selected metrics, tools and method used to assess energy performance need to:

- be simple enough to enable a large number of urban form and building design scenarios to be tested, yet comprehensive enough to ensure useful results;

- enable analogous performance results so models/scenarios can be compared;

- enable findings that are relatable and applicable to reality, so as to increase likelihood of implementation in the real world.

\subsubsection{Energy Consumption Metrics: $\mathrm{kWh}$ and $\mathrm{kWh} / \mathrm{m}^{2} /$ year}

A frequently used, and therefore familiar, system for measuring energy consumption in buildings is the kilowatt hour ( $\mathrm{kWh}$ ). However, because it only measures absolute energy consumption it cannot be used to compare different sized buildings. To do this the $\mathrm{kWh} / \mathrm{m}^{2} /$ year metric will be used as it represents energy consumption as a function of floor area, enabling comparisons. The 'year' aspect means all seasonal and daily cycles are considered in the figure- making it more comprehensive than a daily or monthly analysis. This unit is also referred to as Energy Use Intensity (EUI) which will be the system used to compare energy efficiency of scenarios in this study.

\subsubsection{Energy Analysis Tools}

To accurately calculate how much energy is incurred as a result of each of the urban form and passive building designs tested, a suitable energy analysis tool is required. Because the research investigates theoretical urban form and building designs, methods such as extrapolation of existing building data would not provide reliable representation. The selected tool would need to be able to support the small design alterations investigated in the research (e.g. changing glazing type); and would need to be sensitive to the resulting effects on energy performance. For these reasons, the 'responsiveness' and detail of computer modelling is considered the most suitable tool. 


\subsubsection{Computer Modelling and EnergyPlus}

A range of computer programs exist specifically for estimating energy consumption in buildings. Packages such as DOE-2, IES Virtual Environment, TRNSYS and EnergyPlus are all powerful, validated energy modelling tools (U.S Department of Energy, 2011). However, due to its ability to facilitate the research, and my previous user experience, EnergyPlus was selected as the energy analysis tool.

"EnergyPlus is an energy analysis and thermal load simulation program. Based on a user's description of a building from the perspective of the building's physical make-up, associated mechanical systems, etc., EnergyPlus will calculate the heating and cooling loads necessary to maintain thermal control set-points,... and the energy consumption of primary plant equipment; as well as many other simulation details that are necessary to verify that the simulation is performing as the actual building would." (Lawrence Berkeley National Laboratory, 2013).

EnergyPlus, developed by LBNL and NREL and funded by the US Department of Energy, is a rigorously tested and validated energy modelling package (U.S Department of Energy, 2011). EnergyPlus is capable of concept stage indications to complex final design compliance simulations. Its comprehensive range of 'outputs' are particularly useful for investigating specific aspects of building performance.

This study focuses on two types of outputs which cover a range of energy and environmental 'performance indicators'. In terms of energy, the program can breakdown building performance into different 'Energy End-use' categories, which inform how much energy a specific system is using to maintain comfort. Energy End-uses, or 'energy performance indicators', can be used to analyse how effective a passive system is. For example, high energy consumption under the 'Interior Lighting' end use would indicate daylighting is not terribly effective. The Energy End-use categories used in this study are outlined in Table 4.1 along with an explanation of their significance in terms of passive performance. 


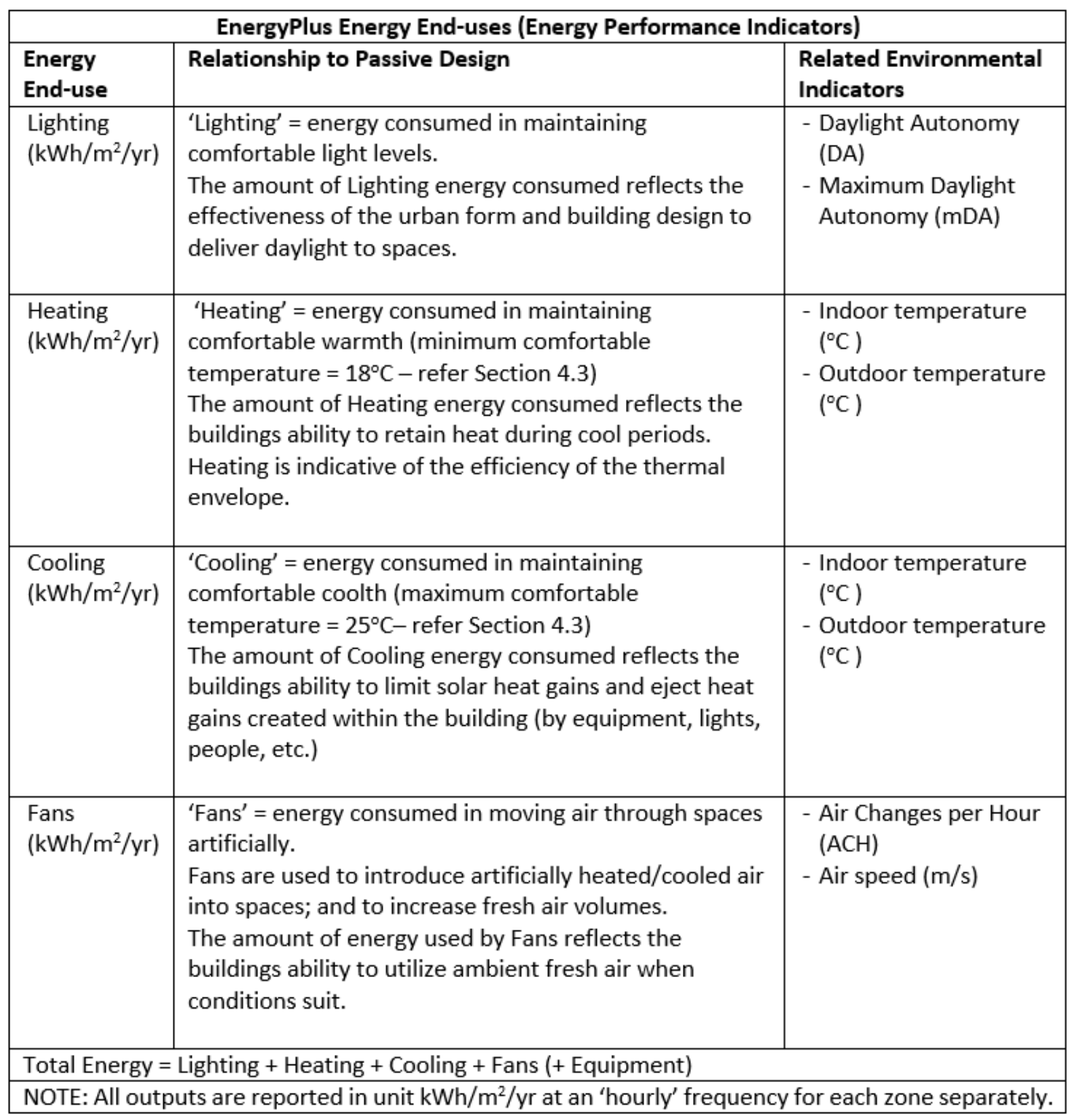

Table 4.1. Energy End-use Outputs generated by EnergyPlus used in building performance analysis.

It is all very well to make buildings energy efficient, but this is futile if the occupants are uncomfortable. For this reason the study also uses EnergyPlus' 'environmental performance indicators' outputs to analyse 'comfort' in spaces. These hourly data sets enable analysis of 'when' spaces are uncomfortable as a result of the building's design. From there it is possible to identify 'why' these patterns have emerged; and, which design parameters are responsible or could be changed to improve comfort - a primary goal of the research. When combined, energy and environmental performance indicators provide the framework for assessing scenarios.

Table 4.2 outlines the environmental outputs reported by EnergyPlus for this research, again with explanation of their significance in terms of passive performance. Each of these 'environmental performance indicators' will be discussed as they are addressed throughout this chapter. It must be noted that the daylight performance indicators (DA and $\mathrm{mDA}$ ) are not analysed in EnergyPlus but in the daylight analysis package, Daysim (refer Section 4.2.2.2). 


\begin{tabular}{|c|c|c|}
\hline \multicolumn{3}{|c|}{ EnergyPlus Environmental Outputs } \\
\hline $\begin{array}{l}\text { Environmental } \\
\text { Performance Indicators }\end{array}$ & Relationship to Passive Design & $\begin{array}{l}\text { Related Energy } \\
\text { Indicators }\end{array}$ \\
\hline $\begin{array}{l}\text { Air Changes per Hour } \\
\text { (ACH) }\end{array}$ & $\begin{array}{l}\text { The ACH performance indicator identifies whether } \\
\text { enough air is being delivered to spaces through the } \\
\text { natural ventilation system and therefore its } \\
\text { effectiveness in terms of IAQ. To avoid excess } \\
\text { accumulation of air-borne toxins (e.g. } \mathrm{CO}_{2} \text {, mildew, } \\
\text { etc.), a minimum air change rate must be achieved } \\
\text { (refer Section 4.3). }\end{array}$ & $\begin{array}{l}\text { - Fans } \\
\text { - Cooling }\end{array}$ \\
\hline $\begin{array}{l}\text { Air-speed inside } \\
\text { Windows } \\
(\mathrm{m} / \mathrm{s})\end{array}$ & $\begin{array}{l}\text { Wind driven natural ventilation can cause high } \\
\text { airspeeds as it enters through windows. This } \\
\text { performance indicator identifies times where cross } \\
\text { ventilation is causing discomfort through excessive } \\
\text { air movement. Air speed criteria is defined in Section } \\
\text { 4.3. }\end{array}$ & N/A \\
\hline $\begin{array}{l}\text { Indoor Temperature } \\
\left({ }^{\circ} \mathrm{C}\right)\end{array}$ & $\begin{array}{l}\text { Thermal conditions are a critical element of comfort. } \\
\text { A working environment must remain within a certain } \\
\text { range to maintain occupant comfort. } \\
\text { This performance indicator reflects the building's } \\
\text { (essentially the thermal envelope) ability to support } \\
\text { comfortable temperatures naturally. Thermal } \\
\text { comfort criteria is defined in Section 4.3. }\end{array}$ & $\begin{array}{l}\text { - Fans } \\
\text { - Cooling } \\
\text { - Heating }\end{array}$ \\
\hline $\begin{array}{l}\text { Outdoor Temperature } \\
\left({ }^{\circ} \mathrm{C}\right)\end{array}$ & $\begin{array}{l}\text { Not an absolute performance indicator but is useful } \\
\text { in assessing the buildings ability to regulate indoor } \\
\text { temperature despite outdoor conditions. }\end{array}$ & $\mathrm{N} / \mathrm{A}$ \\
\hline
\end{tabular}

Table 4.2. Environmental Performance Indicator Outputs generated by EnergyPlus used in building performance analysis.

EnergyPlus supports the study's selected energy metric $\left(\mathrm{kWh} / \mathrm{m}^{2} /\right.$ year) as well as the necessary range of environmental metrics. Following is a description of the measures taken to ensure processes and inputs used for energy modelling were reliable and appropriate to the scope and goals of the research.

\subsubsection{Energy Modelling Method}

\subsubsection{BEES Templates}

A useful tool available for EnergyPlus modelling is the set of 'BEES Templates' created by BRANZ. These templates include generic but detailed commercial building information such as typical equipment loads, occupancy schedules, material and construction definitions, HVAC systems, etc. derived from the study of over 3,000 commercial buildings (BRANZ, 2012). For this study the 'OP5' (Open Plan, Strata 5, refer Figure 4.1) template was selected, as buildings needed to be 'open-plan' to enable natural cross ventilation; and would be as large as $7,200 \mathrm{~m}^{2}$ (floor area). 


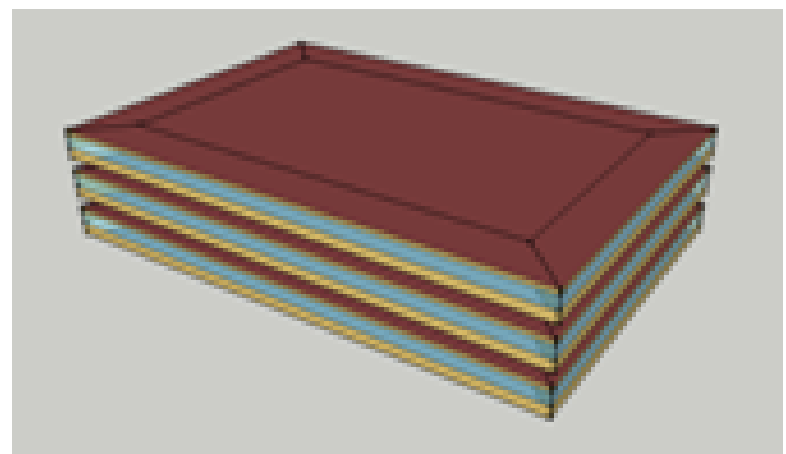

Figure 4.1 Open Plan, Strata 5 (OP5) BEES Energy Modelling Template. (BRANZ, 2012).

\subsubsection{Substantiation of Energy Models}

Because the research works with hypothetical buildings and scenarios based as much as possible on reality, but not on existing or specific buildings, the models cannot be calibrated against real building energy consumption figures. Instead, hypothetical models can be substantiated against typical building data using the aforementioned EUI, which is a standardised energy efficiency index based on the $\mathrm{kWh} / \mathrm{m}^{2} /$ year metric. The 'BEES Interim Report- Year 5: Energy Use Outliers' which investigates energy consumption patterns of New Zealand commercial buildings, found that office building energy efficiency ranged from 100-300 kWh/m²/year. This is consistent with NZS4220:1982, which specifies an energy consumption target of $100 \mathrm{kWh} / \mathrm{m}^{2} /$ year for new office buildings (Bishop \& Isaacs, 2012). This study's 'Baseline' (Model 0), which was created to represent a 'typical' office building located in Christchurch's CBD, and from which all other 'passive' models were developed, was simulated to have an EUI of $135 \mathrm{kWh} / \mathrm{m}^{2} /$ year (refer Section 7.1.1). This is within the expected $100-300 \mathrm{kWh} / \mathrm{m}^{2} /$ year range and is approaching the $100 \mathrm{kWh} / \mathrm{m}^{2} /$ year new building standard. This result substantiates the modelling process followed in this research.

\subsubsection{Integrating External Programs with EnergyPlus}

While EnergyPlus is proficient in estimating energy consumption, it is limited in some regards. Two of this study's main building performance areas - daylight and natural ventilation - which are critical aspects of passive architecture, are not calculated as adequately in EnergyPlus as was desired. The following Sections 4.2 and 4.3 explain how daylight and natural ventilation are addressed in the study, and how they have been integrated into EnergyPlus to improve robustness of calculations. A summary of the full modelling process is presented at the conclusion of this Chapter.

\subsection{Assessing Daylight in Buildings}

Daylighting metrics, tools and methods used for analysis are issues to which there is considerable debate. The research paper 'Current daylighting design and practice' outlines the most popular methods daylighting designers and researchers employ to measure and assess daylight performance:

When asked what criteria they used to assess the overall quality and performance of a daylighting design, $72 \%$ of 158 participants selected energy savings due to daylight as the main performance indicator. This choice was followed by the avoidance of glare (64\%), aesthetics (54\%), the assessment of solar heat gain (54\%), illuminances on selected work planes (46\%), the existence of a view (46\%), the presence of lighting controls (45\%), uniformity/variation of daylight (44\%), minimum/maximum levels for daylight factor (38\%), and daylight autonomy levels (17\%). (Galasiu \& Reinhart, 2008). 
This section aims to determine which daylighting assessment approach (set of methods, metrics and tools) is most suitable for this research. Specifically, the approach would need to:

- enable a comprehensive investigation of daylight 'quality';

- enable comprehensible, comparable results, and,

- enable the integration of daylight data into the EnergyPlus models where it could be translated into energy savings through reduction of artificial lighting loads.

\subsubsection{Daylight Performance Metrics}

\subsubsection{Luminance, Illuminance and Luminous Flux}

In photometry- the science of measuring light -metrics used to quantify light can be categorised into three groups:

Luminous flux measures how much light is emitted from the source (e.g. the sky or bulb) and does not indicate light levels at the point of interest in this study (the working plane) (The Society of Light and Lighting, 2002).

Luminance is the perceived brightness in a space but is subject to factors like colour/material of surfaces; and the observer's relative position, which can produce subjective perceptions of light.

Illuminance- 'the total luminous flux hitting a surface per unit area' measures the amount of light, in lumens per meter square $\left(\mathrm{Im} / \mathrm{m}^{2}\right)$ or lux $(\mathrm{Ix})$, received by the working plane surface. "The illuminance and its distribution on the task area and its surrounding area have a great impact on how quickly, safely and comfortably a person perceives and carries out a visual task." (The Society of Light and Lighting, 2002). Figure 4.2 illustrates the difference between these metrics and, importantly, how illuminance measures the amount of light penetrating the urban environment to reach the target working plane.

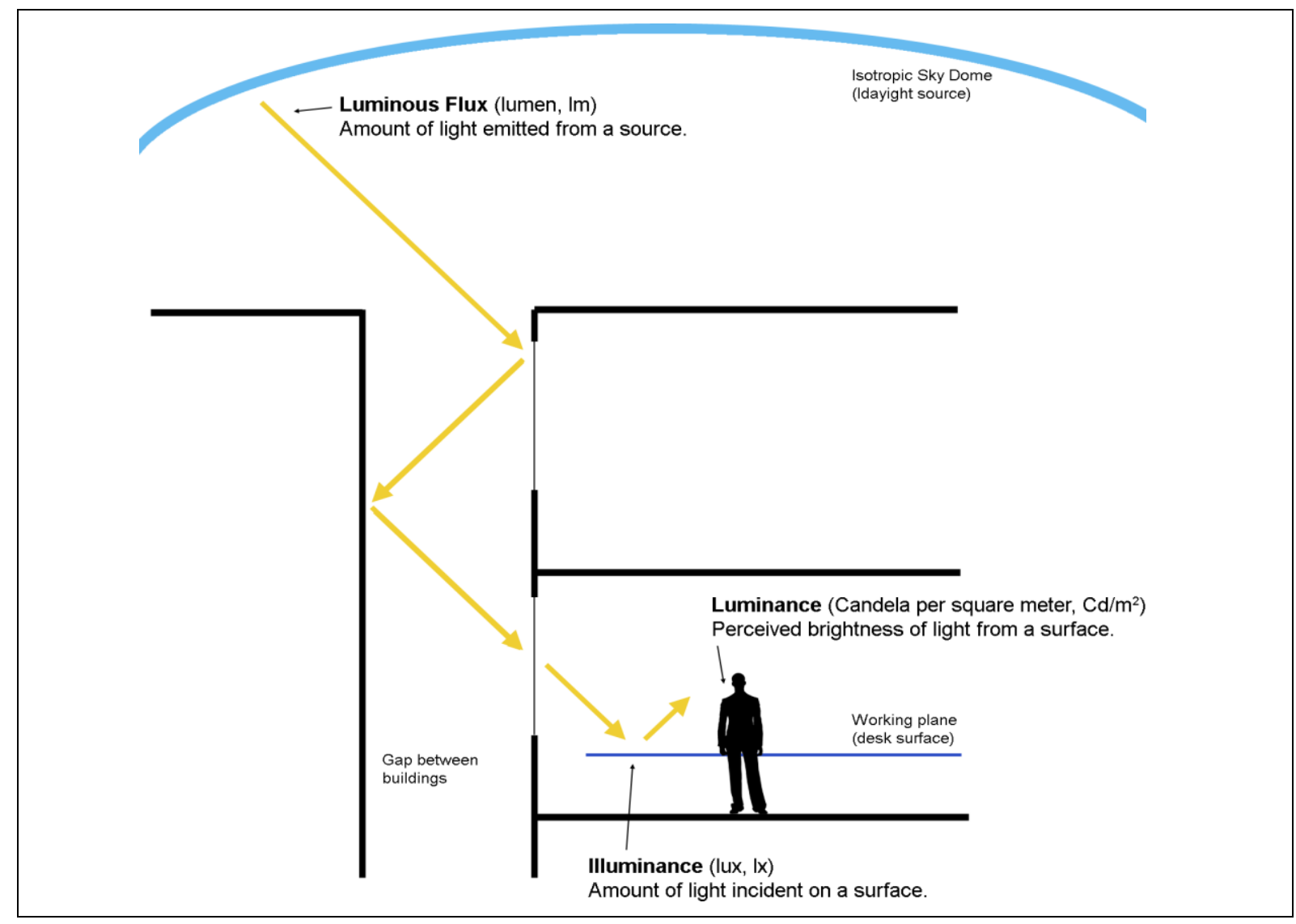

Figure 4.2. Depiction of lighting metrics and how Illuminance describes light reaching the target working plane. (Author). 
Illuminance quantifies the effectiveness of the urban form and building design to deliver daylight to the working plane- therefore facilitating this study's goal of determining urban and building design parameters for effective daylighting.

\subsubsection{Minimum Illuminance Threshold}

But what level of illuminance (lux) is required? There is some divergence on this topic. 'NZS1680.1:2006 - Interior and Workplace Lighting' recommends minimum illuminance levels of 320400lx for simple, typical office tasks (reading, writing, typing, etc.) (Standards New Zealand, 2006). The Illuminating Engineering Society (IES) (2012) suggest in the document 'Approved Method: IES Spatial Daylight Autonomy (sDA) and Annual Sunlight Exposure (ASE)' that any illuminance value in the range of $1001 x-1,0001 x$ could be used as a lighting performance indicator set-point due to the fluctuating nature of daylight (daily/seasonal cycles), but that $3001 x$ represents the best correlation to occupant preference. 'The Society of Light and Lighting' (SLL) (2002) suggest a more restrictive range with $500 \mathrm{~lx}$ as the upper end and stress that $300 \mathrm{~lx}$ should be the absolute minimum, as high contrast and visual discomfort is likely to become an issue (Section 4.2.1.4 discusses glare).

According to these standards it could be determined that $300-5001 \mathrm{x}$ is preferable; therefore, the mid-range value of $\mathbf{4 0 0 1 x}$, which is also the more demanding performance criteria under NZS1680, was selected as the minimum illuminance threshold.

\subsubsection{Daylight Autonomy (DA)}

"Daylight Autonomy is defined as the percentage of time over a year at which daylight can provide a given illuminance for a given point." (Architectural Energy Corporation, 2006). Following a simulation, times when $400 \mathrm{~lx}$ is exceeded are tabulated for each point on the analysis grid to identify daylight effectiveness in a space. This data can be effectively visualised through colour coded renders on the analysis grid (refer Figure 4.3).

DA is more useful than a metric like Daylight Factor (which is simply a ratio of outdoor to indoor light) because it is based on absolute illuminance levels and so informs how much time per year artificial lights can be turned off or dimmed. For example, Figure 4.3 illustrates how 'Good daylight' and 'Poor Daylight' would look in terms of DA. In the good daylight scenario, the lowest DA value is $60 \%$, meaning that for $60 \%$ of the year, ALL lights could be turned off. Immediately, one can see that this space can save $60 \%$ of its annual lighting costs - a very useful piece of information in the context of energy efficiency and passive design.

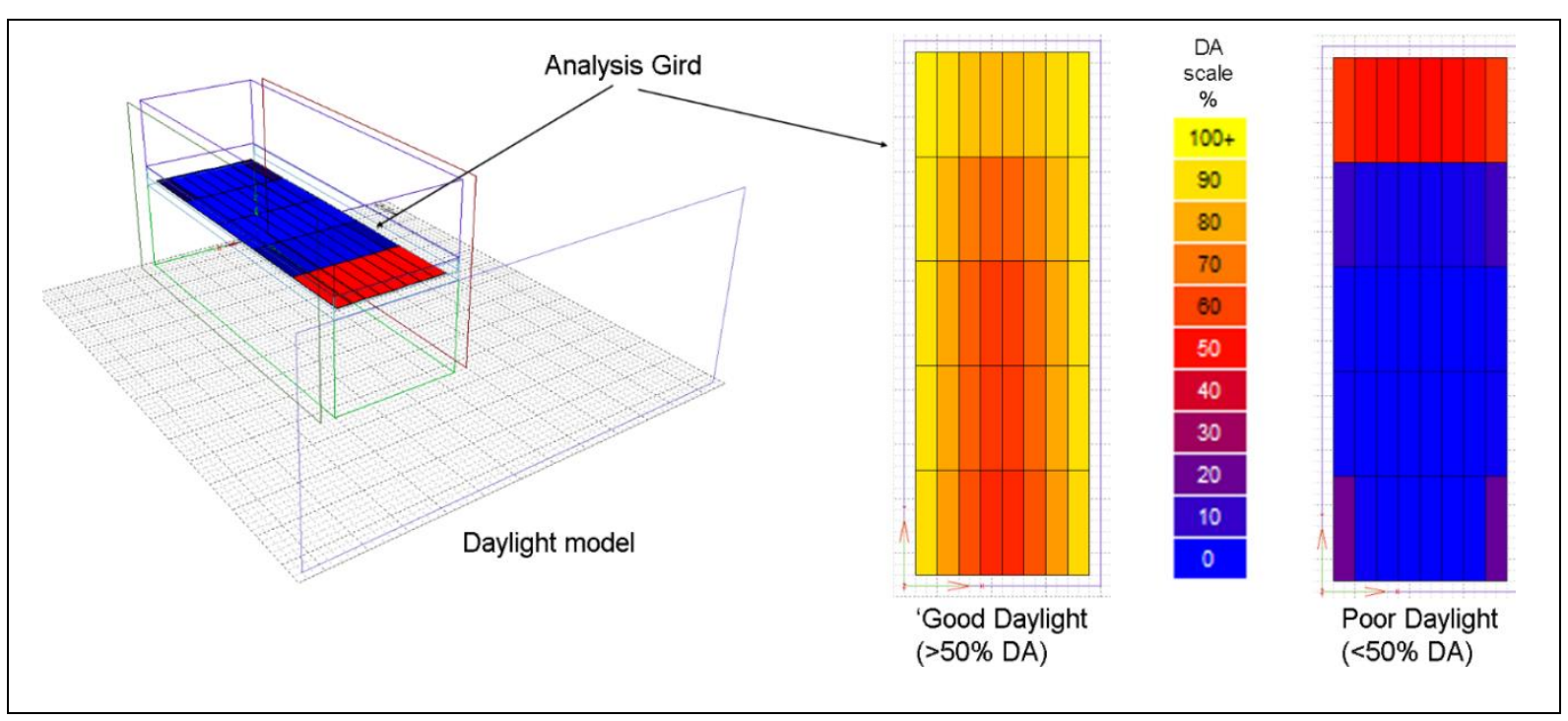

Figure 4.3. Example of Daylight Autonomy (DA) visualized on the Analysis Grid. (Author). 
Because people tend to be demanding of their working environment, daylight performance needs to be highly effective and reliable. If occupants believe daylight is too frequently insufficient they are likely to lose patience and revert back to more consistent artificial lighting- defeating any daylighting endeavours. To avoid this, the minimum $4001 x$ needs to be achieved for a minimum percentage of the year. Obviously, a DA of $100 \%$ would be preferable as it would mean that illuminance targets are met for the entire working year. However, this is not realistic and a more obtainable target should be set. Most studies agree that a DA of $50 \%$ is sensible, with the strongest correlation to occupant preference (Illuminating Engineering Society, 2012). Daylighting expert Christoph Reinhart also advocates a DA of $50 \%$ as acceptable and adds that spaces which reach a DA of $>70 \%$ can be considered to have 'very good' daylighting (Reinhart, 2012). Based on these sources, this study adopted a minimum DA target of $\mathbf{5 0 \%}\left(\mathbf{D A}_{\mathbf{4 0 0} 1 \times / 50 \%}\right)$ for 'adequate' daylight. Anything over $\mathbf{7 5 \%}$ $\left(\mathrm{DA}_{4001 \times / 75 \%}\right)$ will be considered 'very good' daylight performance ( $75 \%$ as 'three-quarters' is more relatable and has more impact than ' $70 \%$ ').

\subsubsection{Glare, Contrast and Maximum Daylight Autonomy (mDA)}

Glare- the result of direct or reflected sunlight, and contrast- exaggerated brightness in contrast to darker areas (Mead, 2011), represent a fundamental issue in daylighting design and potential barrier to its implementation and success. "Even a single occurrence of problematic direct sunlight for an occupant can result in complaints and an override of the daylighting resource..." (Architectural Energy Corporation, 2006). If efforts focus too heavily on delivering high levels of daylight to a space but neglect to account for the adverse effects of over-exposure, then occupants are likely to be dissatisfied with their visual environment. This could lead to blinds being closed, which can diminish daylight by up to $98 \%$ (Illuminating Engineering Society, 2012).

Just as with minimum lighting targets, maximum illuminances also need to be established to avoid these overexposure issues. A common daylight metric that accounts for glare is the Useful Daylight Index (UDI). This index establishes a range in which illuminances are considered beneficial to occupants (100-2,000lx), whereby Illuminances exceeding 2,000lx are considered too bright and likely to cause glare issues (Rogers, et al., 2006). However, UDI does not fully consider 'contrast'. The CIBSE 'Code for lighting' resource states that, in order to avoid contrast issues, illuminance ratios should not exceed 10:1 meaning maximum illuminances in a space are not more than 10x the illuminance of any other point (The Society of Light and Lighting, 2002). With the minimum illuminance threshold of $4001 x$, maximum illuminance threshold is therefore calculated as $4,0001 x$.

Another method to assess over-exposure is 'maximum Daylight Autonomy' (mDA), which identifies 'over-lit' areas of a space. Because it is based on the 10:1 ratio, mDA identifies spaces that are problematic in terms of both glare and contrast, making it more robust than UDI. The combination of $\mathrm{DA}$ and $\mathrm{mDA}$ provides a complimentary and compact means of analysing daylight performance and quality. The selected daylight analysis software, Daysim, can report both mDA and DA results.

As the metric assigned to assess over-exposure, mDA criteria must therefore be demanding. The study 'Dynamic Daylight Performance Metrics for Sustainable Design' applies a threshold of mDA 5\%, meaning over-exposure is an issue if occurrences exceed $5 \%$ of the year (Rogers, et al., 2006). The 'Architectural Energy Corporation' (2006) recommends an even more challenging criterion of $<1 \%$ $\mathrm{mDA}$ for $<5 \%$ of the work-plane. This means that illuminances cannot exceed $4,0001 \mathrm{x}$ for $99 \%$ of the year, across $95 \%$ of the space. This report provided the most comprehensive framework for mDA requirements and supports this research's goal of high quality environments. An mDA criteria of $<1 \% \mathrm{mDA}$ for $<5 \%$ of the work-plane will therefore be adopted for the study. 


\subsubsection{Spatial Daylight Autonomy (sDA)}

The sDA metric recognizes that if daylight is only present in part of a space it is likely to be ignored as a lighting option. The IES (2012) states that for a space to be acceptably daylit DA must be achieved for at least $55 \%$ of the analysis area. Further, they define 'preferred' daylight as $\mathbf{8 7 5 \%}$ of the analysis area, which is adopted as the SDA criteria for this study (consistent with its highperformance goals).

\subsubsection{Period of Analysis}

To ensure daylight is measured consistently, analysis will be based on 'work-day hours', rather than 'daylight hours', which are subject to seasonal variations. The IES (2012) recommends that, in order to account for flexible working hours, the assessment period should be extended from the more conventional ' 9 to 5 ' working day to $8 \mathrm{am}-6 \mathrm{pm}$. So while energy simulations and analysis will be conducted for all hours of the day and year ( 8,760 hours total), daylight analysis will only be performed between $8 \mathrm{am}-6 \mathrm{pm}$ on weekdays (3,650 hours total).

\subsubsection{Analysis Grid}

Depending on the investigation, light could be measured at a range of different locations, including eye level, points of interest or task areas (Heschong, et al., 2009). As this study is concerned with offices and therefore light available atop desks, an analysis grid was placed at working plane height, (desk height, $0.8 \mathrm{~m}$ above FFL according to NZS1680) across the entire space. Analysis grid extents are $1 \mathrm{~m}$ inside all walls, as required by 'AS/NZS 1680.1:2006 - Interior and Workplace Lighting' (Standards New Zealand, 2006).

The IES recommends that for daylight analysis of a full space, the grid should be uniformly spaced with grid point intervals of $0.6 \mathrm{~m}$ maximum in both the $X$ and $Y$ directions. However, as the tested spaces are large (up to $20 \times 50 \mathrm{~m}$ ) this would result in extensive computing times and will not necessarily produce 'more accurate' results than a 'reduced detail' analysis grid. To determine the required frequency of analysis points 'Robustness Test 1 -Analysis Grid Detail' was conducted (refer Appendix A.1). This investigation tested a $10 \times 50 \mathrm{~m}$ space twice: once using a $1 \times 1 \mathrm{~m}$ grid (441 grid points), then again using a $2 \times 10 \mathrm{~m}$ grid (30 points) and found that neither DA levels nor resulting energy consumption were significantly affected (both $<1 \%$ ), and computation times were halved. Grid points are therefore set at $2 \mathrm{~m}$ intervals in the X-direction and $10 \mathrm{~m}$ in the $\mathrm{Y}$-direction.

Another quality assurance test 'Robustness Test 2 -Analysis Grid Frequency' looked at whether an analysis grid was required for each level of the model (refer Appendix A.2). Daysim can only calculate daylight coefficients for a single analysis grid at any one time, so to generate illuminance data for each level would require multiple, time intensive, runs of the same model. Robustness Test 2 found that applying daylight levels from the mid-height storey to all levels resulted in artificial lighting loads, and total energy loads, of $<5 \%$ difference to a scenario in which daylight was calculated for all levels independently. Therefore a single representative daylighting grid is applied in all scenarios.

Section 4.2.3 explains how daylight calculations inform energy consumption calculations.

Table 4.3 summarizes the daylight metrics used to assess daylight performance in this study. 


\begin{tabular}{|l|l|l|}
\hline \multicolumn{3}{|c|}{ Daysim Environmental Outputs } \\
\hline $\begin{array}{l}\text { Environmental } \\
\text { Performance Indicators }\end{array}$ & Relationship to Passive Design & $\begin{array}{l}\text { Related Energy } \\
\text { Indicators }\end{array}$ \\
\hline $\begin{array}{l}\text { Daylight Autonomy, DA } \\
\text { (\% of occupied year) }\end{array}$ & $\begin{array}{l}\text { DA describes how adequate daylight levels are } \\
\text { across a space. It indicates the amount by which } \\
\text { artificial lighting loads can be reduced in a space. }\end{array}$ & - Lighting \\
\hline $\begin{array}{l}\text { maximum Daylight } \\
\text { Autonomy, mDA (\% of } \\
\text { occupied year) }\end{array}$ & $\begin{array}{l}\text { mDA describes the likelihood of over-exposure to } \\
\text { daylighting. It represents a likelihood of } \\
\text { occupants experiencing visual discomfort due to } \\
\text { excessive brightness and glare. }\end{array}$ & $\begin{array}{l}\text { - Lighting } \\
\text { - Cooling }\end{array}$ \\
\hline
\end{tabular}

Table 4.3. Daylight Performance Indicator Outputs generated by Daysim.

\subsubsection{Daylight Analysis Tools}

\subsubsection{EnergyPlus and the Split-flux Daylight Calculation Method}

While proficient in energy estimations, EnergyPlus can be limited in its daylight calculations and analysis. To calculate daylight, EnergyPlus uses the 'split-flux' method, which does not consider the 'Internally Reflected Component' (IRC) of daylight (refer Figure 4.4) (Ibarra \& Reinhart, 2009).

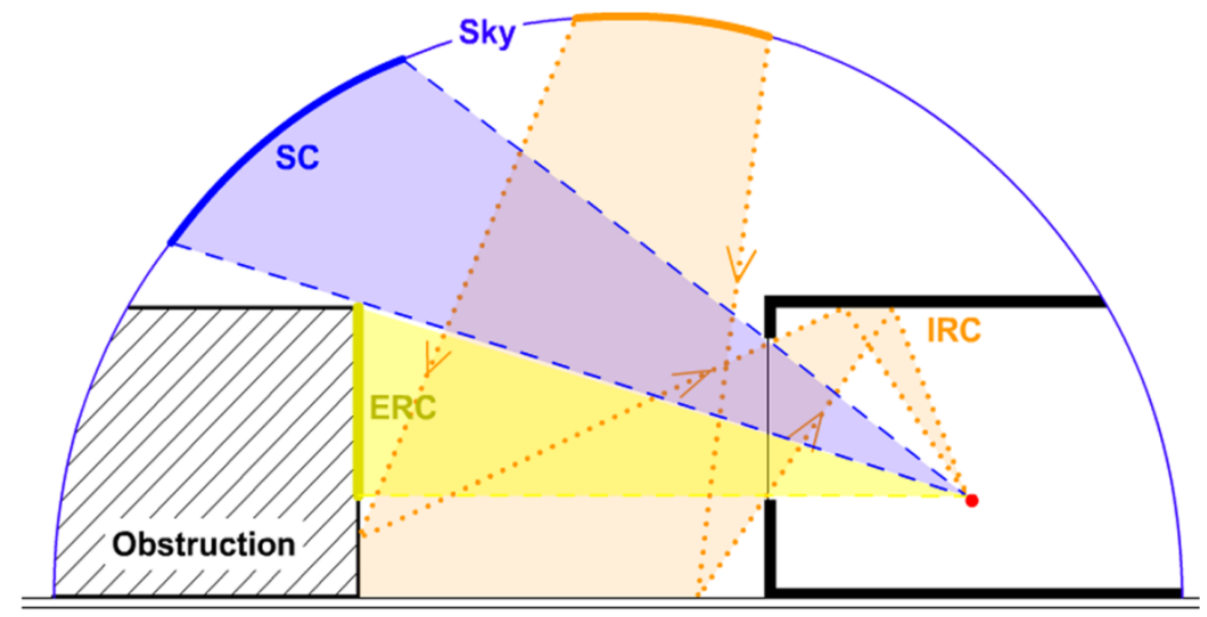

Components of the Split-flux method:

$\mathrm{SC}=$ Sky Component (Directly from the sky, through an opening such as a window).

$E R C=$ Externally Reflected Component (Light reflected off the ground, trees or other buildings).

IRC = Internally Reflected Component (The inter-reflection of SC and ERC off other surfaces within the room).

Figure 4.4. The components of daylight. Split flux method omits the Internally Reflected Component (IRC). (Ibarra \& Reinhart, 2009).

The result of this omission is a substantial under-prediction of daylight availability, and, therefore, an over-prediction of required artificial lighting loads. In the scenarios' tested by this study, where buildings are separated by small gaps, internal reflections could make a significant difference to illuminance levels. The split-flux method would likely cause significantly inaccurate results and so alternative daylight calculation engines are to be explored and tested. 


\subsubsection{Radiance/Daysim and the Reverse Ray-trace Algorithm}

Daysim is a validated advanced daylighting analysis program that uses Radiance's 'reverse raytracing algorithm' which calculates light levels based on the physical behaviour of light in a volumetric, three-dimensional model (Jakubiec \& Reinhart, 2011).

"...light rays are traced in the opposite direction to which they naturally flow. The process starts from the eye (the viewpoint) and then traces the rays up to the light sources taking into account all physical interactions (reflection, refraction) with the surfaces of the objects composing the scene." (Compagnon, 2001).

A geometrical description of the scene is based on boundaries of objects (i.e. building surfaces) using the Cartesian co-ordinate system (X, Y, Z) (Compagnon, 2001). Figure 4.5 illustrates a ray-trace from a building occupant's view-point, around the room and eventually to the light source- the sky. The 'sky dome' is modelled on the 'Perez All Weather Sky distribution' which uses data from the 'Typical Meteorological Year' (TMY) weather file (Lenoir, et al., 2013). The benefit of the ray-trace method over the 'split-flux method' is that it incorporates all three daylight components (SC, IRC, ERC) and so is a more complete interpretation of daylighting situations. Validation studies have found that Daysim can predict daylight autonomies to an accuracy of $2 \%$ (compared to measured data) (Reinhart \& Walkenhorst, 2001).

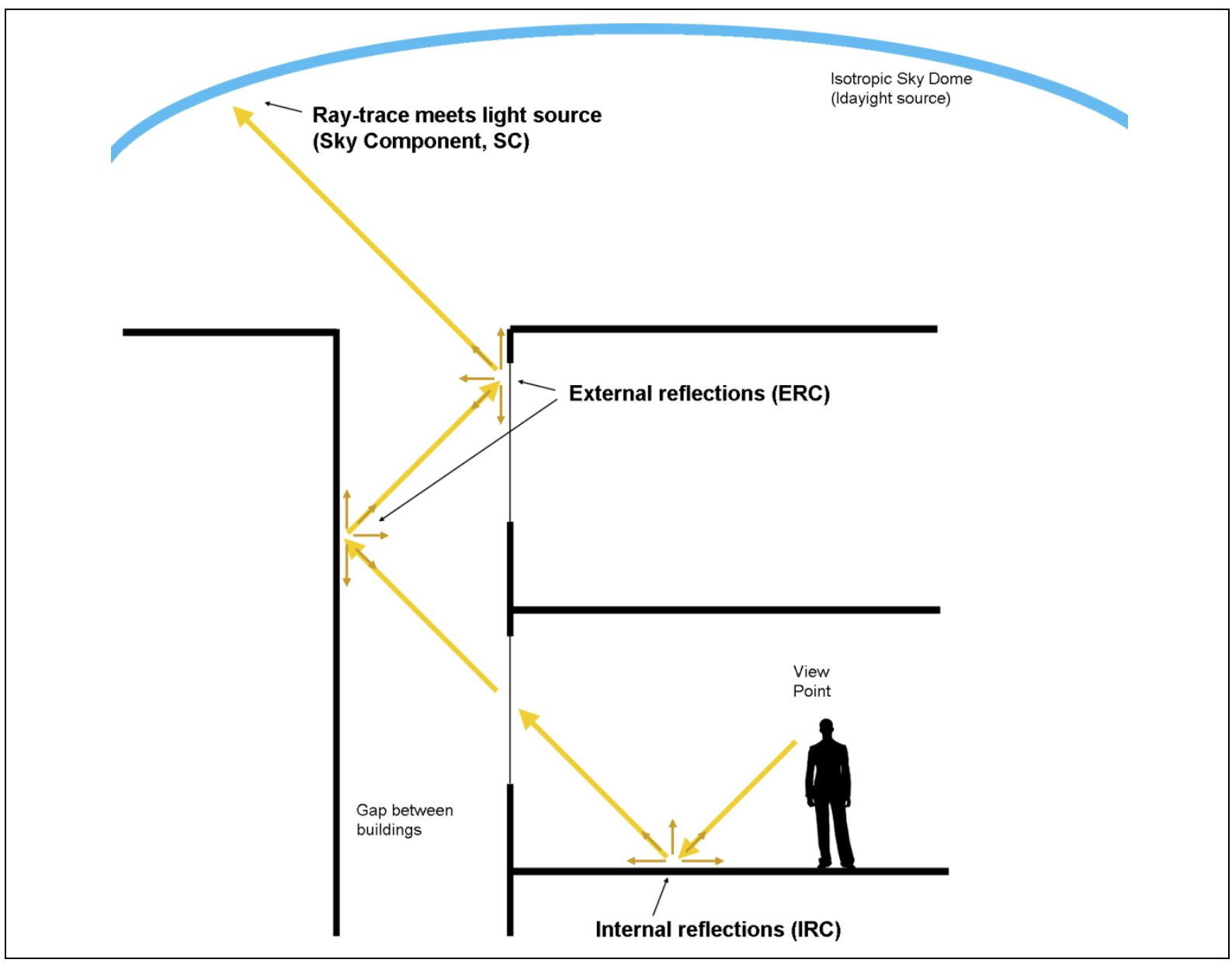

Figure 4.5. Section diagram illustrating how the 'ray-trace' method determines light at a point. Adapted from (Compagnon, 2001).

To confirm and quantify variance between the split-flux and ray-trace methods, 'Robustness Test 3 Daylight Calculation Method' (refer Appendix A3) was conducted. It found that EnergyPlus/split-flux 
underestimated daylight to the effect of $26 \%$ (in lighting energy terms) in comparison to the Radiance/ray-trace method. The test also simulated the same building with only artificial lighting (no daylighting) to demonstrate potential energy savings through daylighting. This preliminary investigation found that artificial lighting energy could be reduced by as much as $52 \%$ with the use of daylighting. These findings both verify Radiance/Daysim as the selected daylighting tool, and demonstrate the significance daylighting has as an energy conservation measure in this research.

\subsubsection{Daylight for Energy Consumption Method}

Once Daysim completes a daylight simulation it generates an 'artificial lighting reduction schedule' output which (using fractions) describes how much artificial lighting densities can be reduced to supplement daylight in the space and reach the minimum required illuminance (refer Figure 4.6). EnergyPlus references this schedule (through the 'Schedule:File' object, refer Figure 4.7) and adjusts artificial lighting loads accordingly.

For example, the artificial lighting coefficient for a 'time-step' (period of time between calculationshourly) might be 0.2 , which means daylight levels are high but not sufficient to reach $4001 \mathrm{x}$ across the space, and so artificial lights can be reduced to $20 \%$ of their 'installed lighting density' $\left(12 \mathrm{~W} / \mathrm{m}^{2}\right.$ down to $2.4 \mathrm{~W} / \mathrm{m}^{2}$ ), saving $80 \%$ lighting energy for that time-step. This method enables automatic light 'dimming' to be incorporated into the daylighting system, and enables a more accurate lighting energy calculation than EnergyPlus. Previous studies that have employed this method include (Didone \& Pereira, 2011) and (Jakubiec \& Reinhart, 2011) which both conclude it successfully compensates for EnergyPlus' limitation and produces a more reliable energy evaluation than using EnergyPlus alone.

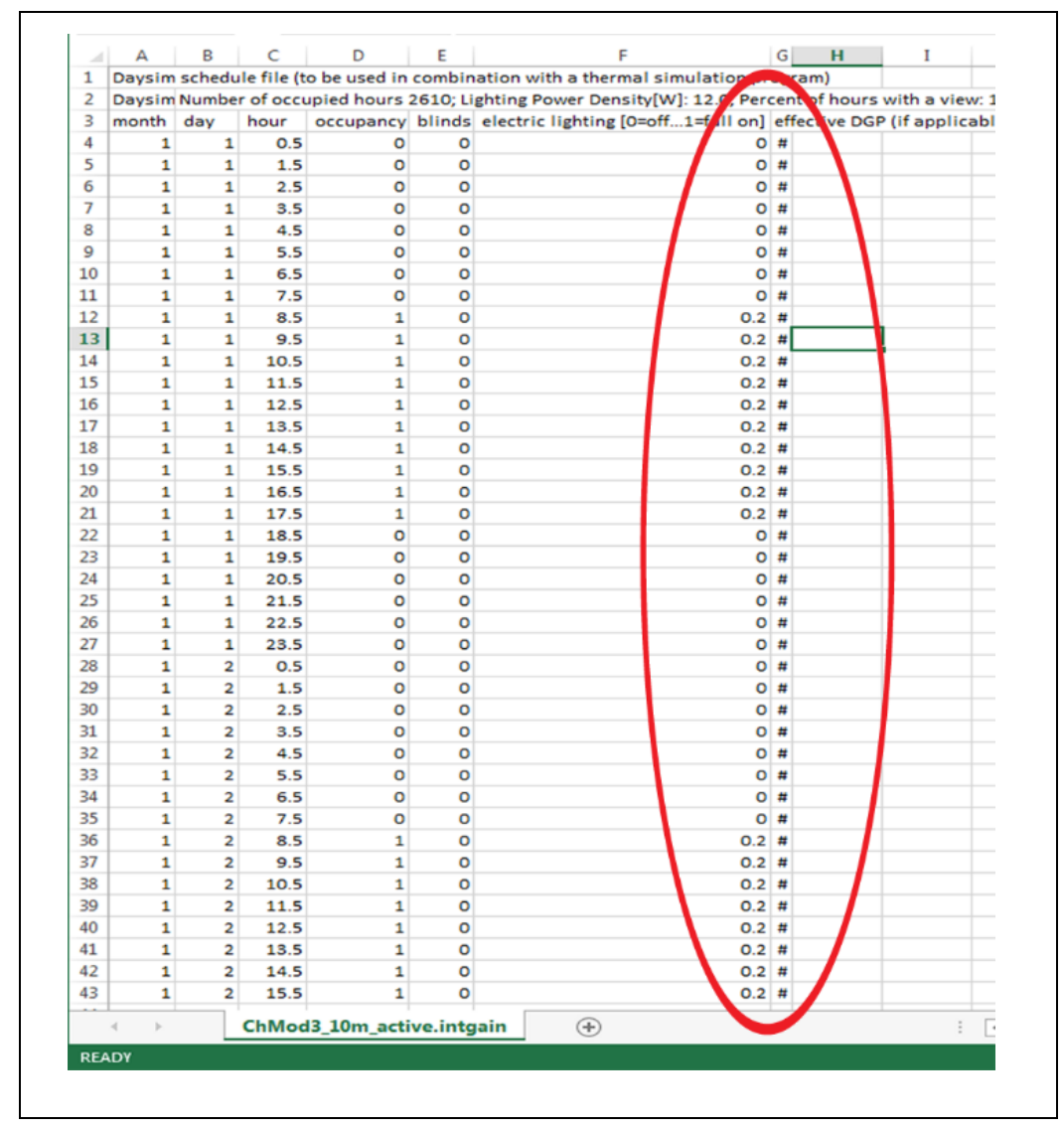

Figure 4.6 Example of an 'artificial lighting reduction schedule' produced by Daysim and referenced by EnergyPlus. (Author). 


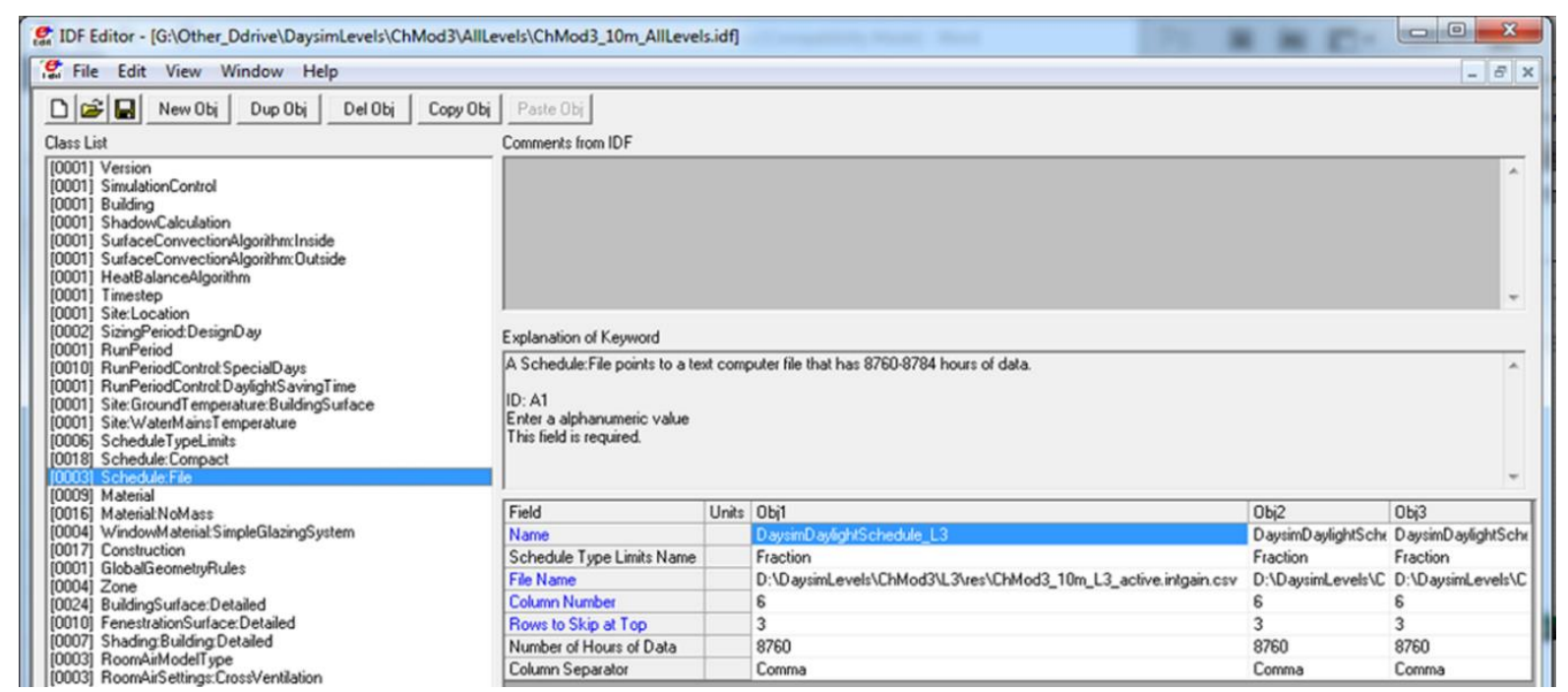

Figure 4.7. EnergyPlus referencing the Daysim 'lighting density reduction schedule' through its 'Schedule: File' object. (Author).

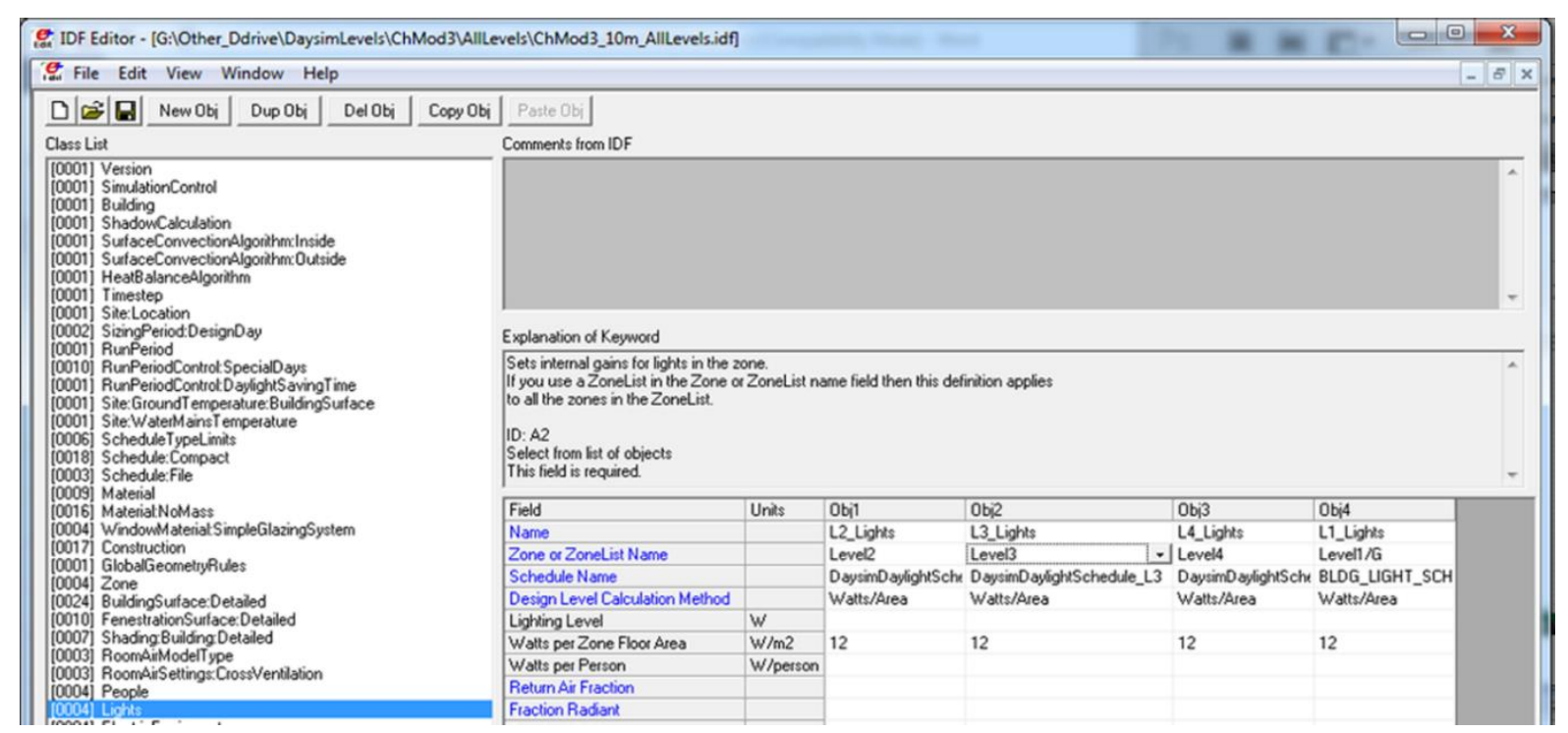

Figure 4.8. Linking of referenced Daysim schedule to the 'lighting density' input (Watts per Zone Floor Area) in EnergyPlus. (Author). 


\subsection{Assessing Natural Ventilation in Buildings}

This section establishes the metrics employed to quantify natural ventilations and evaluate its effect on the indoor environment. It identifies factors critical to the calculation of natural ventilation in an urban environment and selects the tools capable of conducting these calculations. Finally it develops an appropriate method for analysing environmental and energy performance of natural ventilation in the tested urban form and building design scenarios.

\subsubsection{Natural Ventilation Performance Metrics}

\subsubsection{Indoor Air Quality (IAQ)}

$\mathrm{IAQ}$, which reflects the level of contaminants (e.g. $\mathrm{CO}_{2}$, bacteria, etc.) in a space, is an important concept as it influences occupant comfort, health, attendance and productivity (Kleiven, 2003). Delivery of high quality air through effective natural ventilation would reduce energy consumed by HVAC systems to deliver artificially conditioned air.

$I A Q$ is an umbrella term that represents a range of different contaminants and design conditions, and so is not itself a measurable parameter. Instead, Carbon Dioxide $\left(\mathrm{CO}_{2}\right)$ concentration within the air is a preferred indicator of IAQ. NZS4303:1990 - Ventilation for Acceptable Indoor Air Quality' states that "Comfort (odour) criteria are likely to be satisfied if the ventilation rate is set so that 1,000ppm $\mathrm{CO}_{2}$ is not exceeded." (Standards New Zealand, 1990). In order to control contaminant build-up and maintain an environment of $<1,000 \mathrm{ppm} \mathrm{CO}_{2}$, air needs to be constantly vented (McIntosh, 2011). Figure 4.9 expresses the relationship between IAQ and air flow rate, illustrating how air-flow removes air-borne contaminants.

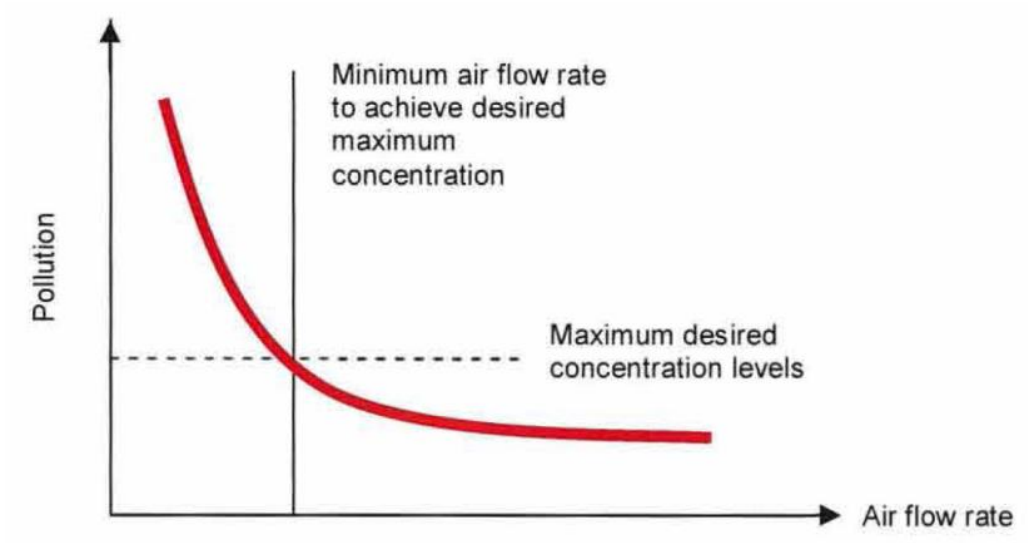

Figure 4.9. Relationship between indoor pollution rates and indoor air flow rates. (McIntosh, 2011).

A common ventilation design formula used in New Zealand, and which will be applied in this research, is the 'Ventilation Rate Procedure'. For office spaces, a ventilation rate of 10 Litres/second/person ( $\mathrm{L} / \mathrm{s} / \mathrm{p})$ is deemed sufficient to mitigate 'harmful levels of contaminants' (Standards New Zealand, 1990).

This air exchange rate can also be expressed in Air Changes per Hour (ACH), which is the number of times the volume of air in a space is replaced with fresh, outdoor air every hour. Assuming an occupancy density of $10 \mathrm{~m}^{2} /$ person, the above $10 \mathrm{~L} / \mathrm{s} / \mathrm{p}$ becomes $\mathbf{0 . 8 3} \mathbf{A C H}$ (refer Appendix B.3 for calculations). This will be the minimum air change rate for sufficient ventilation in the study. EnergyPlus produces an $\mathrm{ACH}$ output which will be used to assess natural ventilation performance. 
Ventilation can be used to cool a space as well as simply ventilate it. Higher air speeds associated to higher air changes (around $20 \mathrm{ACHs}$ ) can be used to increase moisture evaporation from people's skin, resulting in a cooling sensation (Givoni, 1994). However, this is only useful in hot, summer conditions and will likely be undesirable in cold winter months. So while Figure 4.9 suggests, 'more air changes is better', this cannot always be applied. The area of openable windows shouldn't simply be maximized to introduce large amounts of outdoor air, without consideration of conditions. Following is an explanation of the 'Thermal Comfort' factors - Air speed and Temperature - which contribute to a person's perception of comfort in a space temperature (Architectural Association Environment and Energy Programme, 2010).

\subsubsection{Air Speed}

'Air speed' is the rate of air movement within a space (as opposed to 'wind speed' which is the equivalent term for outdoors). Air must move to deliver fresh air to the space, however, if air movement is too fast, it can become a source of annoyance for inhabitants- by irritating the eyes, lifting papers on desks or feeling like a draft (Architectural Association Environment and Energy Programme, 2010). 'CIBSE: Guide A' (2006) suggests that air speeds up to $0.3 \mathrm{~m} / \mathrm{s}$ are acceptable in most situations. However in the case of naturally ventilated spaces, people have less stringent expectations of their environment. Air speeds in cross ventilated buildings, in particular, tend to be between $1-2 \mathrm{~m} / \mathrm{s}$. Studies have shown occupants are more willing to adapt in these situations and will accept an air speed of $2.0 \mathrm{~m} / \mathrm{s}$ in warmer conditions (Givoni, 1994). For assessment, air speeds will be considered 'comfortable' if they are below $0.3 \mathrm{~m} / \mathrm{s}$, and 'tolerable' between 0.3 and 2.0 $\mathrm{m} / \mathrm{s}$. Air speeds exceeding $2.0 \mathrm{~m} / \mathrm{s}$ will be considered uncomfortable.

\subsubsection{Temperature}

This study employs the simple 'comfort band' scale for thermal performance based on The World Health Organisation (1985), who define temperatures of $18-25^{\circ} \mathrm{C}$ to be comfortable for humans. To assess thermal comfort, EnergyPlus produces the output 'Mean Air Temperature' which is a combination of Air temperature and Radiant temperature (EnergyPlus, 2012). Each scenario will be assessed according to the percentage of the occupied year indoor temperatures lie between 18 and $25^{\circ} \mathrm{C}$.

Table 4.4 summarizes the metrics used to measure natural ventilation performance. Each of the performance indicators will be measured hourly across the occupied year (weekdays between 8am$6 \mathrm{pm}$ - same analysis period as for daylight).

\begin{tabular}{|l|l|l|}
\hline \multicolumn{3}{|c|}{ Summary of Ventilation Metrics } \\
\hline Performance Indicator & Unit & Performance Criteria \\
\hline Air Changes per Hour & ACH & $0.83 \mathrm{ACH}$ (minimum) \\
\hline Air speed & $\mathrm{m} / \mathrm{s}$ & $<0.3 \mathrm{~m} / \mathrm{s}$ (preferred); $2.0 \mathrm{~m} / \mathrm{s}$ (maximum) \\
\hline Indoor Temperature & ${ }^{\circ} \mathrm{C}$ & $18-25^{\circ} \mathrm{C}$ \\
\hline \multicolumn{2}{|c|}{ Table 4.4 Summary of metrics used for assessment of ventilation performance in the study. }
\end{tabular}




\subsubsection{Natural Ventilation Analysis Tools}

\subsubsection{EnergyPlus and the Airflow Network for Natural Ventilation}

EnergyPlus includes a ventilation system template called the 'Airflow Network' which can be used for wind-driven cross ventilation. Following is an outline of the Airflow Network model including identification of components and explanation of critical design settings. Figure 4.10 offers a visual summary of the systems described.

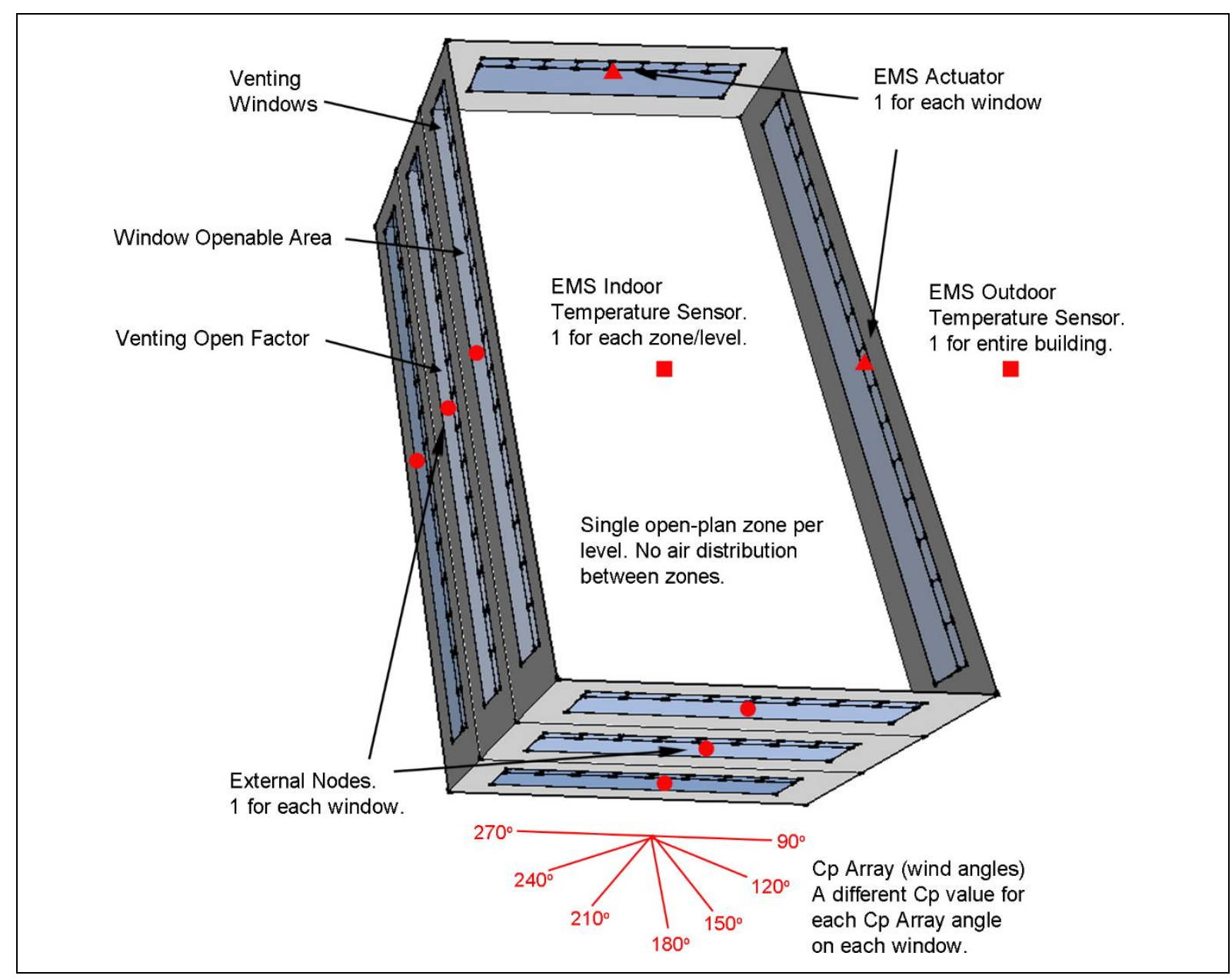

Figure 4.10. Diagram depicting important Airflow Network components. (Author).

\section{Venting Windows}

As has been established, designs tested in this research will deliver fresh air to spaces through windows on side facades rather than the street facing front facade. This enables double sided cross ventilation which is up to $3 x$ more effective than single sided delivery. Figure 4.11 presents an elevation from the example model shown in Figure 4.10. It identifies the 'Venting Window' as well as the 'Openable Window Area' and 'Venting Open Factor' components explained next. 


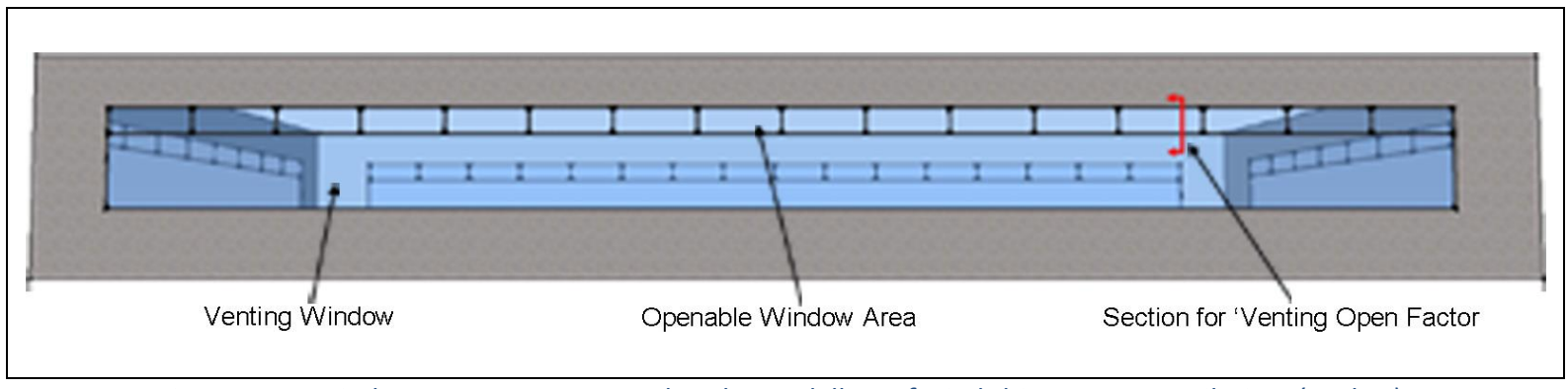

Figure 4.11. Window components central to the modelling of wind-driven cross ventilation. (Author).

\section{Openable Window Area}

The amount of air that can be delivered to a space depends on the 'Openable Window Area' - the portion of the window that physically opens. 'Clause G4- Ventilation' of the New Zealand Building Code (NZBC) states that "Natural ventilation of occupied spaces must be achieved by providing a net openable area of windows or other openings to the outside of no less than 5\% of the floor area." (1990). This standard will be used as a starting point for the Window Openable Area specification in the models.

Figure 4.12 depicts the method EnergyPlus uses to define the openable window area, with the following settings. 'Window Width' is the full length of the facade $(50 \mathrm{~m})$. 'Opening Width' is assumed to be $80 \%$ of the window width to account for frame area. 'Start Height' is set to the bottom of the glazed area to allow varying Opening Heights to be tested. 'Height Factor' describes the vertical percentage of the window that opens. Height Factor depends on the 'Opening Height', which varies depending on the desired openable window area and WWR. Variations of these settings are determined in Section 6.3.4. Window Openable Area calculations can be found in Appendix B.4.

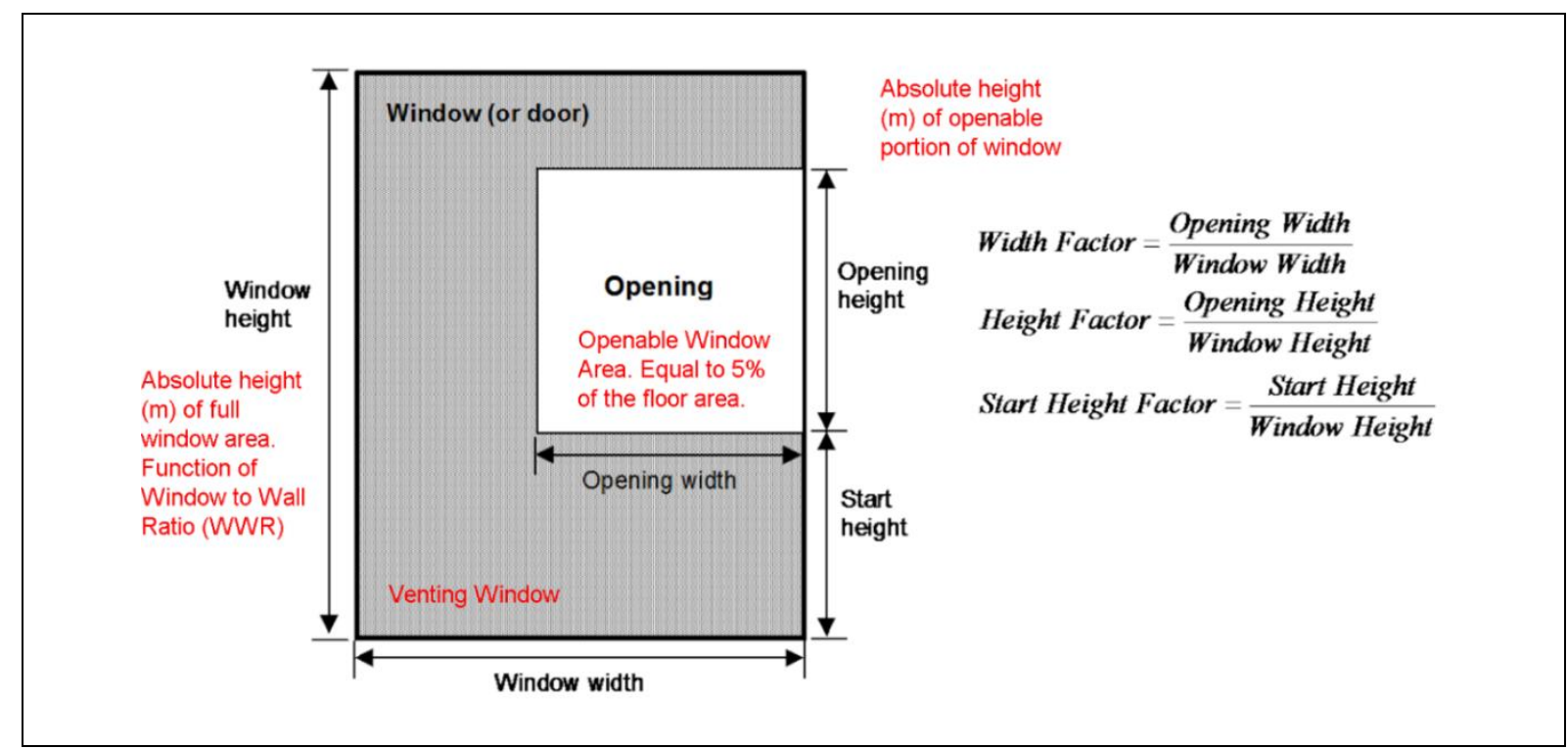

Figure 4.12. EnergyPlus diagram illustrating the Openable Window Area for ventilation. Adapted from (EnergyPlus, 2012).

\section{Venting Permitted Criteria}

Central to the design of a natural ventilation system is the criteria defining when venting is permitted. The BMS will only allow windows to open if outdoor conditions will improve the indoor environment. Table 4.5 outlines venting criteria definitions used in EnergyPlus models. All of the criteria must be meet for ventilation to be allowed and windows to open. 


\begin{tabular}{|c|c|c|c|}
\hline Rule Name & Description & Value & EnergyPlus Object \\
\hline Heating set-point & $\begin{array}{l}\text { Temperature at which } \\
\text { mechanical heating is required }\end{array}$ & $18^{\circ} \mathrm{C}$ & $\begin{array}{l}\text { Thermostat: } \\
\text { Heating Set-point. }\end{array}$ \\
\hline Cooling set-point & $\begin{array}{l}\text { Temperature at which } \\
\text { mechanical cooling is required }\end{array}$ & $25^{\circ} \mathrm{C}$ & $\begin{array}{l}\text { Thermostat: } \\
\text { Cooling Set-point. }\end{array}$ \\
\hline $\begin{array}{l}\text { HVAC Availability } \\
\text { Schedule }\end{array}$ & $\begin{array}{l}\text { Times which HVAC system is } \\
\text { available to operate }\end{array}$ & $\begin{array}{l}8 \mathrm{am}-6 \mathrm{pm} \\
\text { weekdays }\end{array}$ & Schedule: Compact \\
\hline $\begin{array}{l}\text { Natural Ventilation } \\
\text { Availability Schedule }\end{array}$ & $\begin{array}{l}\text { Times which window are } \\
\text { allowed to open }\end{array}$ & Always & Schedule: Compact \\
\hline $\begin{array}{l}\text { Maximum wind } \\
\text { speed }\end{array}$ & $\begin{array}{l}\text { Maximum wind speed for } \\
\text { venting, above which is likely to } \\
\text { cause discomfort so windows } \\
\text { close }\end{array}$ & $10 \mathrm{~m} / \mathrm{s}$ & $\begin{array}{l}\text { Availability Manager: } \\
\text { Hybrid Ventilation }\end{array}$ \\
\hline Precipitation & Windows close when raining & Yes & $\begin{array}{l}\text { Availability Manager: } \\
\text { Hybrid Ventilation }\end{array}$ \\
\hline $\begin{array}{l}\text { Minimum outdoor } \\
\text { temperature }\end{array}$ & $\begin{array}{l}\text { Temperature below which air is } \\
\text { too cold to bring into building }\end{array}$ & $10^{\circ} \mathrm{C}$ & $\begin{array}{l}\text { Availability Manager: } \\
\text { Hybrid Ventilation }\end{array}$ \\
\hline $\begin{array}{l}\text { Maximum outdoor } \\
\text { temperature }\end{array}$ & $\begin{array}{l}\text { Temperature above which air is } \\
\text { too warm to bring into building }\end{array}$ & $25^{\circ} \mathrm{C}$ & $\begin{array}{l}\text { Availability Manager: } \\
\text { Hybrid Ventilation }\end{array}$ \\
\hline $\begin{array}{l}\text { Minimum indoor } \\
\text { temperature }\end{array}$ & $\begin{array}{l}\text { Temperature below which } \\
\text { natural ventilation is likely to } \\
\text { cause mechanical heating (too } \\
\text { close to heating set-point) }\end{array}$ & $20^{\circ} \mathrm{C}$ & $\begin{array}{l}\text { Energy Management } \\
\text { System: Program }\end{array}$ \\
\hline $\begin{array}{l}\text { Outdoor } \\
\text { temperatures too } \\
\text { warm }\end{array}$ & $\begin{array}{l}\text { Indoor temperatures warmer } \\
\text { than } 25^{\circ} \mathrm{C} \text { and outdoor } \\
\text { temperatures higher than } \\
\text { indoor temperatures }\end{array}$ & $>25^{\circ} \mathrm{C}$ & $\begin{array}{l}\text { Energy Management } \\
\text { System: Program }\end{array}$ \\
\hline Venting allowed 1 & $\begin{array}{l}\text { Outdoor temperatures cooler } \\
\text { than indoor temperatures but } \\
\text { not less than } 10^{\circ} \mathrm{C}\end{array}$ & - & $\begin{array}{l}\text { Energy Management } \\
\text { System: Program }\end{array}$ \\
\hline Venting allowed 2 & $\begin{array}{l}\text { Indoor temperatures }<18^{\circ} \mathrm{C} \text { and } \\
\text { outdoor temperatures warmer } \\
\text { than indoor temperatures but } \\
<25^{\circ} \mathrm{C}\end{array}$ & - & $\begin{array}{l}\text { Energy Management } \\
\text { System: Program }\end{array}$ \\
\hline
\end{tabular}

Table 4.5. Conditions and criteria dictating ventilation operation in EnergyPlus models.

\section{Venting Open Factor}

Even when these venting rules are met, differences between indoor and outdoor temperatures can cause discomfort. In EnergyPlus this is addressed through the 'Venting Open Factor', which modulates the degree of 'openness' of windows. Windows will be allowed to open $100 \%$ of their capacity when the temperature difference between indoors and outdoors is $<1^{\circ} \mathrm{C}$. When the indoor/outdoor temperature difference is between $1^{\circ} \mathrm{C}$ and $15^{\circ} \mathrm{C}$ (maximum difference allowed) the openness of the window is modulated along a linear scale as illustrated in Figure 4.13. When temperature differences exceed $15^{\circ} \mathrm{C}$ windows are automatically closed. 


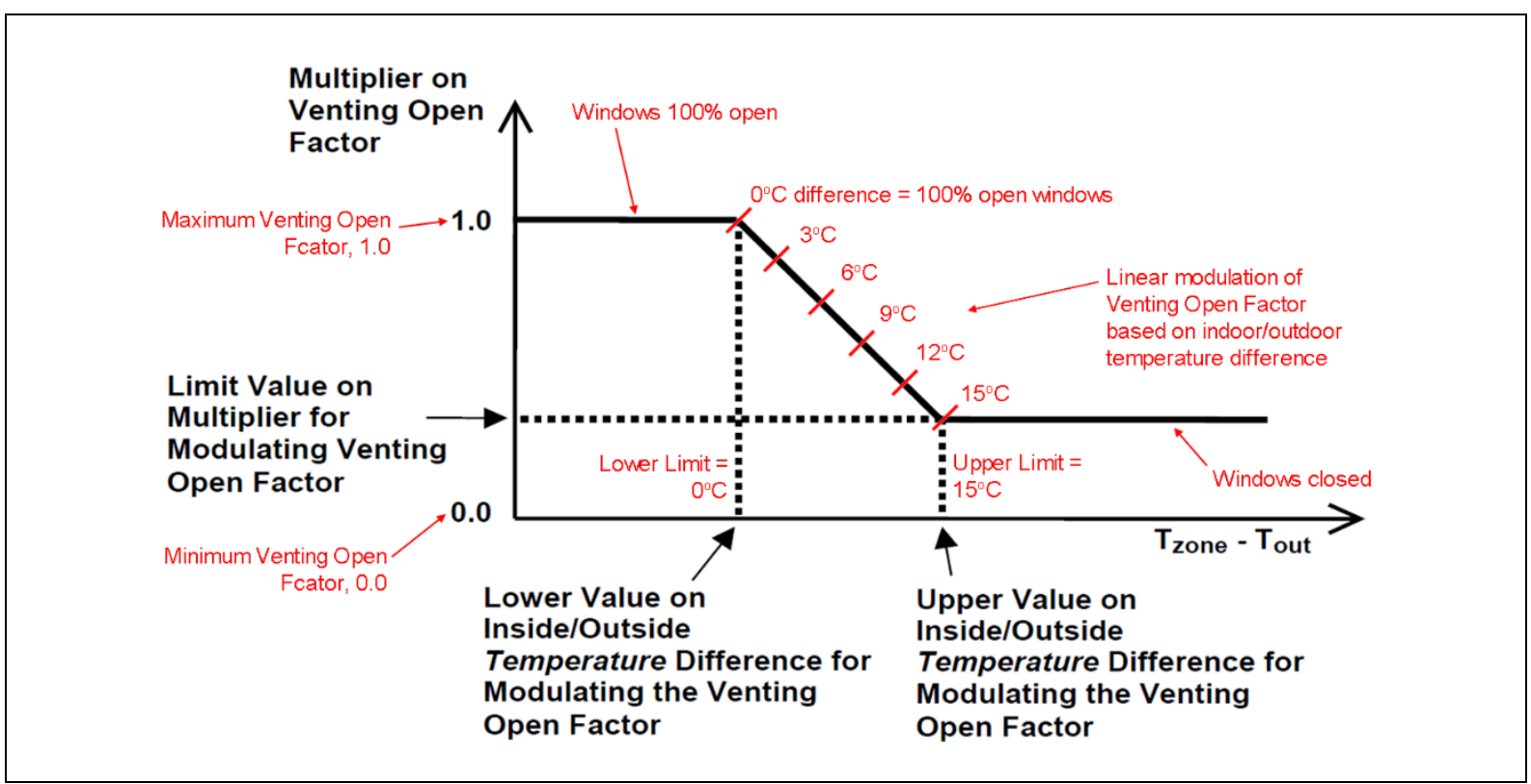

Figure 4.13. EnergyPlus modulation of window 'openness' based on indoor/outdoor temperature differences. Adapted from (EnergyPlus, 2012).

Figure 4.14 translates the concept illustrated in Figure 4.13 into a section diagram of a window. It shows the window 'ajar' when indoor/outdoor temperatures differences are large (e.g. $14^{\circ} \mathrm{C}$; and completely open when they are small (e.g. $\left.1^{\circ} \mathrm{C}\right)$.

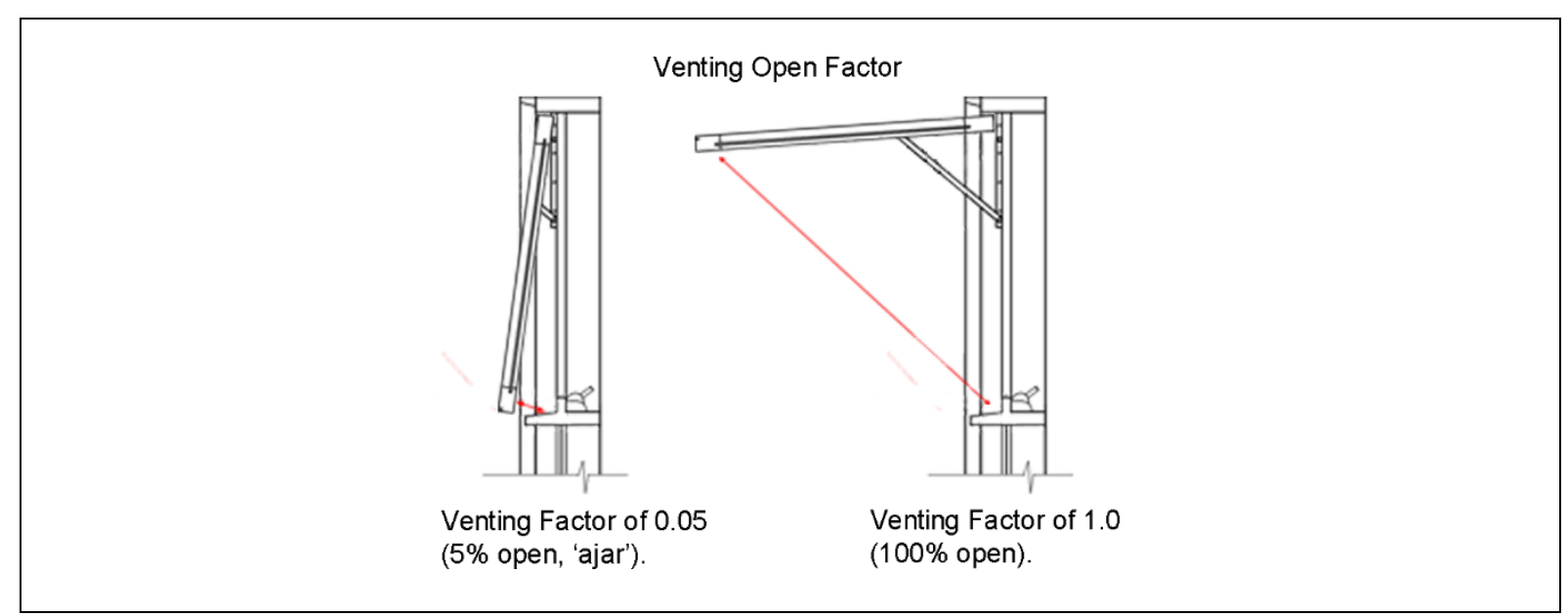

Figure 4.14. Section diagram illustrating window opening modulation. (Author).

\section{Wind Data}

Weather data used for simulations represents a location's macro-climate (e.g. 'Christchurch'), it does not reflect a micro-climate created by a specific urban form (i.e. the scenarios tested in this study). In the Airflow Network model, 'External Nodes' are used to inform the ventilation system of outdoor climatic conditions (e.g. wind speed, wind direction, precipitation) according to the weather file, for each time-step (every 10 minutes). Information gathered by these nodes is critical to the calculation of natural ventilation and so needs to incorporate the effects of the surrounding urban form. EnergyPlus cannot geometrically account for the effect on wind surrounding buildings will have However, the Airflow Network model does enable the user to manually enter 'Wind Pressure Coefficients (Cp's) values for a range of wind angles. 


\subsubsection{Wind Pressure Coefficients (Cp)}

The wind pressure coefficient, $C p$, is a dimensionless value which represents the exposure to wind pressure on a particular surface or point (Costola, et al., 2009). Cp values are influenced by a wide range of parameters, specifically- building geometry, surrounding urban form, wind direction, wind speed, position on the façade and even façade detailing (Costola, et al., 2009). Cp values are a single, all-encompassing, manifestation of ambient wind conditions, which is why they are critical in modelling of natural ventilation.

Wind-driven cross ventilation is dependent on pressure differences across indoor and outdoor boundaries, as well as between windward and leeward sides of the building, which force air into the building through openings (windows) in the building envelope (Muehleisen \& Patrizi, 2013). Laws of conservation of mass demand that the volume of air in a space must stay constant. Considering this, a pressure difference between two facades will cause air to be pushed into a space through the positive pressure openings, and sucked out through the negative pressure openings (Walker, 2010). These concepts of - positive and negative pressures; wind pressures as $\mathrm{Cp}$ values; and resulting ventilation - are illustrated in the following scenario (Figures $4.15-4.17$ ).

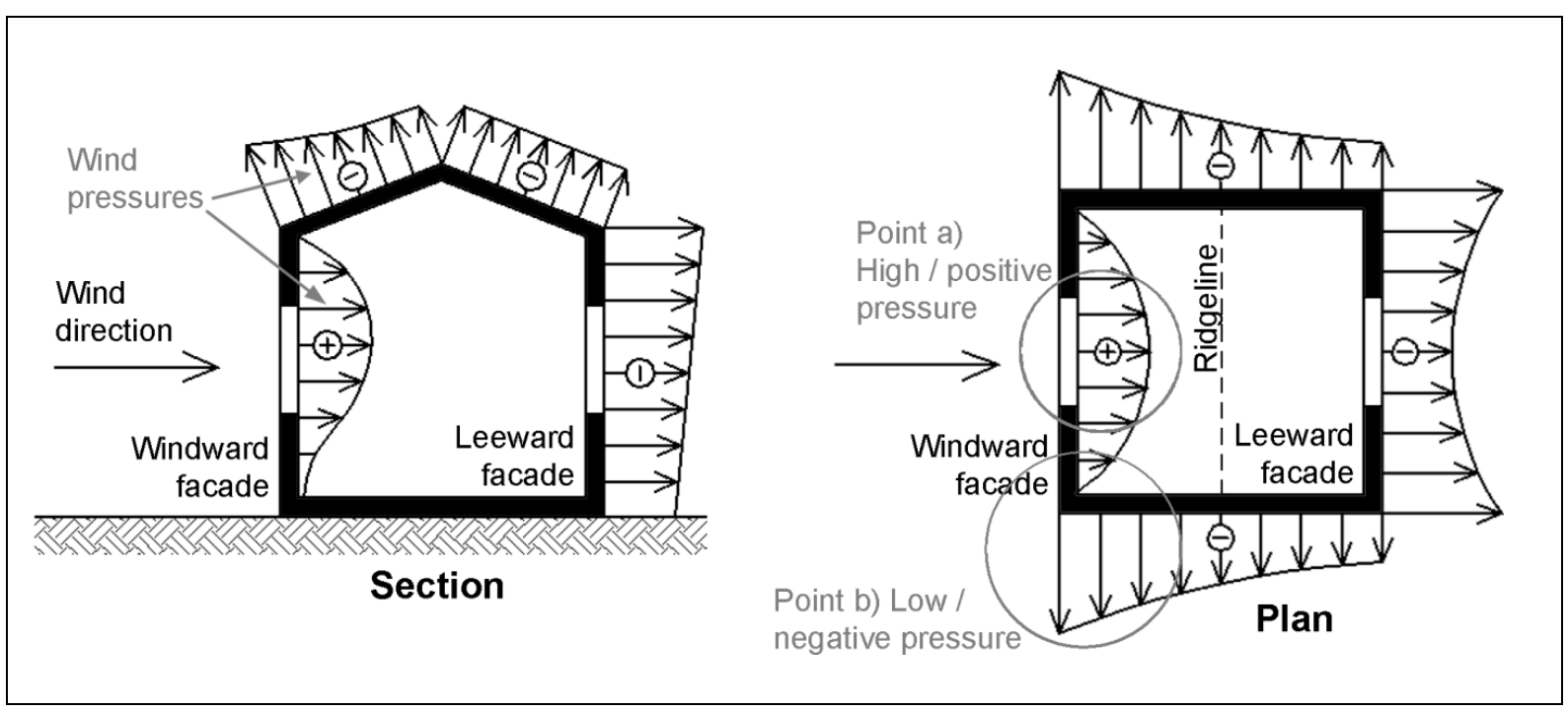

Figure 4.15. Diagram illustrating positive and negative wind pressure distributions on building surfaces. Adapted from (Hensen, 2013).

Firstly, Figure 4.15 demonstrates how wind acting on the facades of a building creates pressure differences between the positive windward side and negative leeward sides. In the plan view, extreme positive pressures are present at the centre of the windward facade (point a) and negative pressures are experienced on the leeward facades, especially at the corners (point $b$ ). These interest points ( $a$ and $b$ ) are referenced to Figure 4.16 which demonstrates how these wind pressures may translate to $\mathrm{Cp}$ data. It is these $\mathrm{Cp}$ values which are entered into the Airflow Network models. 


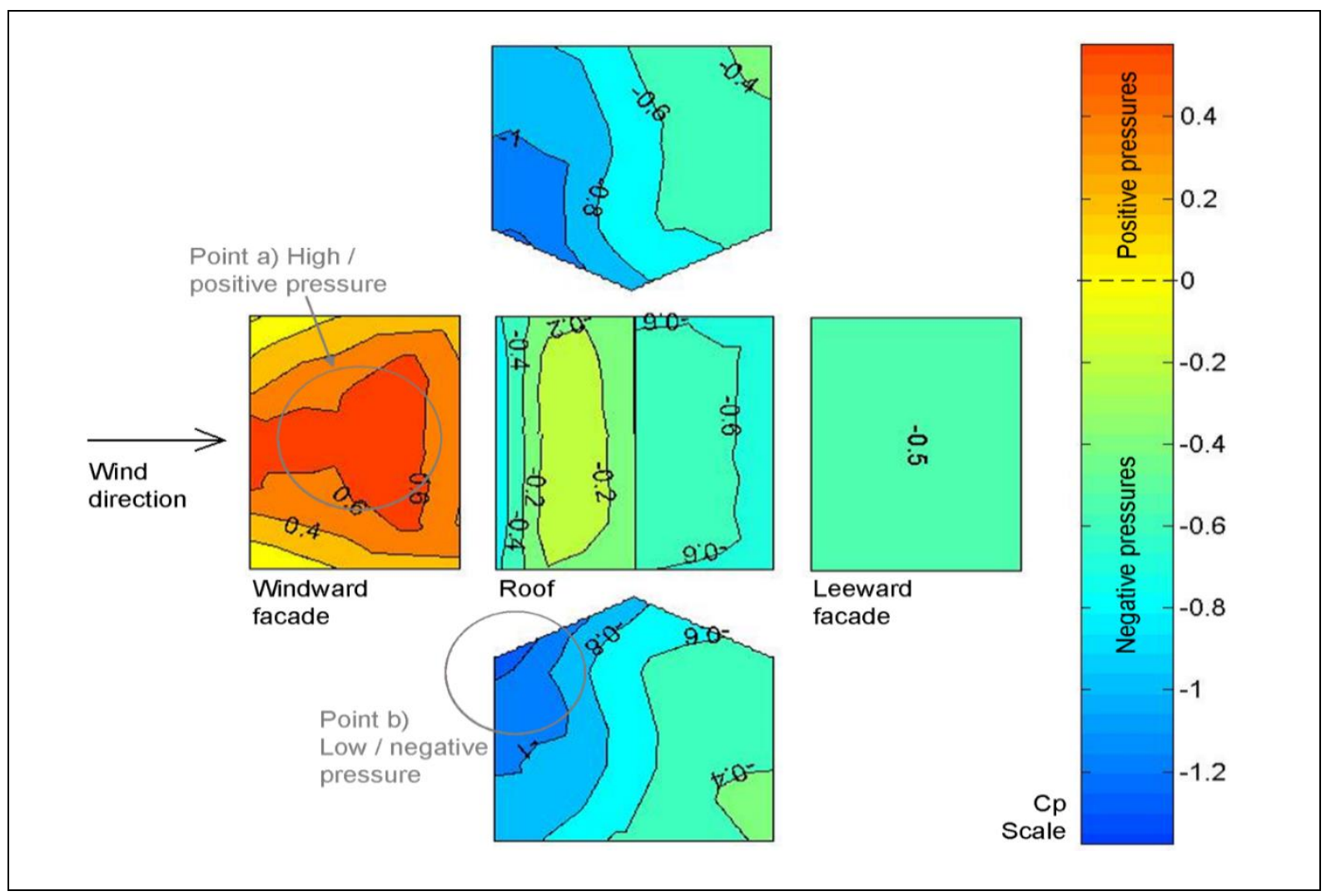

Figure 4.16. Diagram illustrating how the wind pressures in Figure 4.14 might manifest as Cp values. Adapted from (Tokyo Polytechnic University, 2007).

Figure 4.17 illustrates how those wind pressure differences draw fresh air into the internal spaces. Vector arrows represent varying wind-flow (external) and air-flow (internal) by their relative size. The cause of the extreme negative pressures seen in Figures 4.15 and 4.16 can be seen in the 'eddies' (swirling wind) at each corner of the building in Figure 4.17.

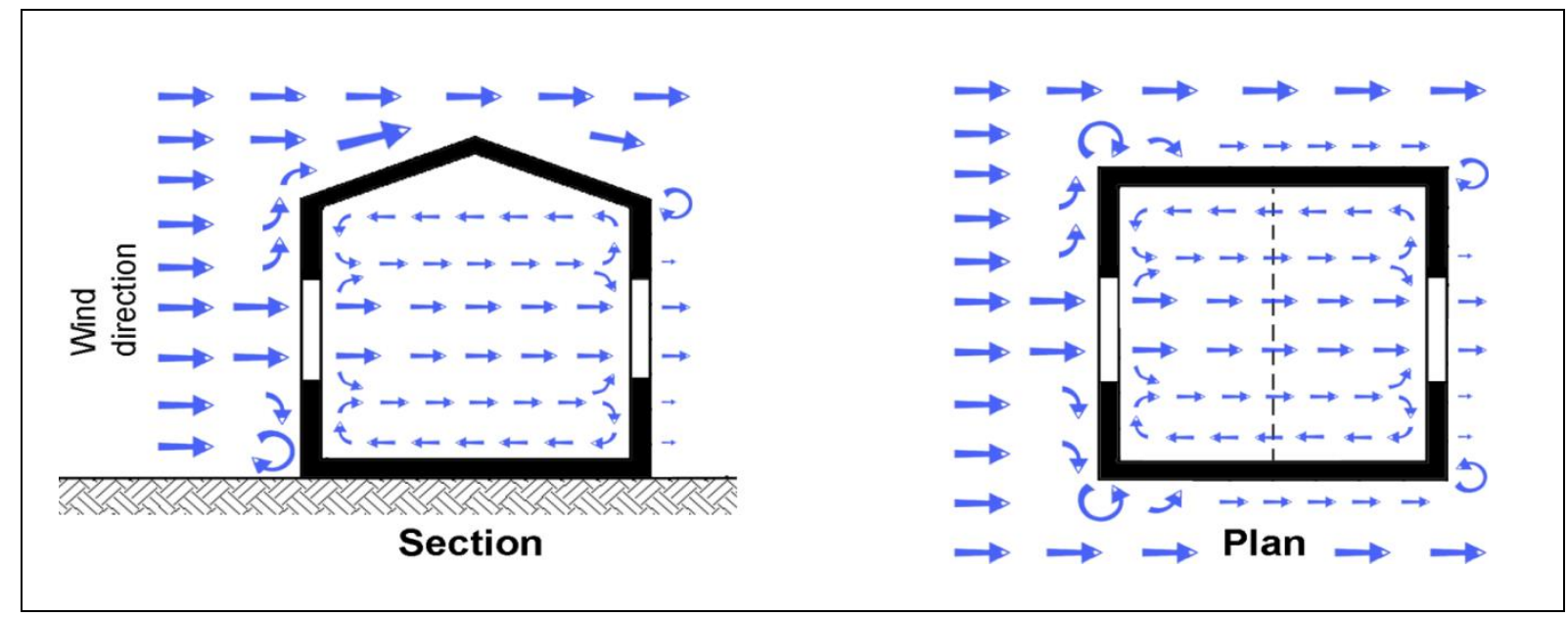

Figure 4.17. Air flow around and through building as a result of wind pressures in Figures 4.14 and 4.15. (Author).

Critically, $\mathrm{Cp}$ data considers the effect of surrounding physical forms. By taking the above example scenario (Figure 4.16) and adding surrounding buildings, a change in $\mathrm{Cp}$ data can be seen. Figure 4.18 compares the original isolated building (left) to the same building with surrounding urban forms added (right). Clearly, $\mathrm{Cp}$ distribution patterns (contours) have been altered due to the increased turbulence. Secondly, $\mathrm{Cp}$ values are less extreme. Not only are maximum pressures reduced from 
the isolated scenario ( 0.6 down to 0.1 ), but minimum values are also closer to neutral (-1.2 down to $0.5)$. Reduced positive and negative pressures, and thus smaller pressure differences, are a direct result of the shielding created by the surrounding buildings. As a consequence, natural ventilation potential will diminish.

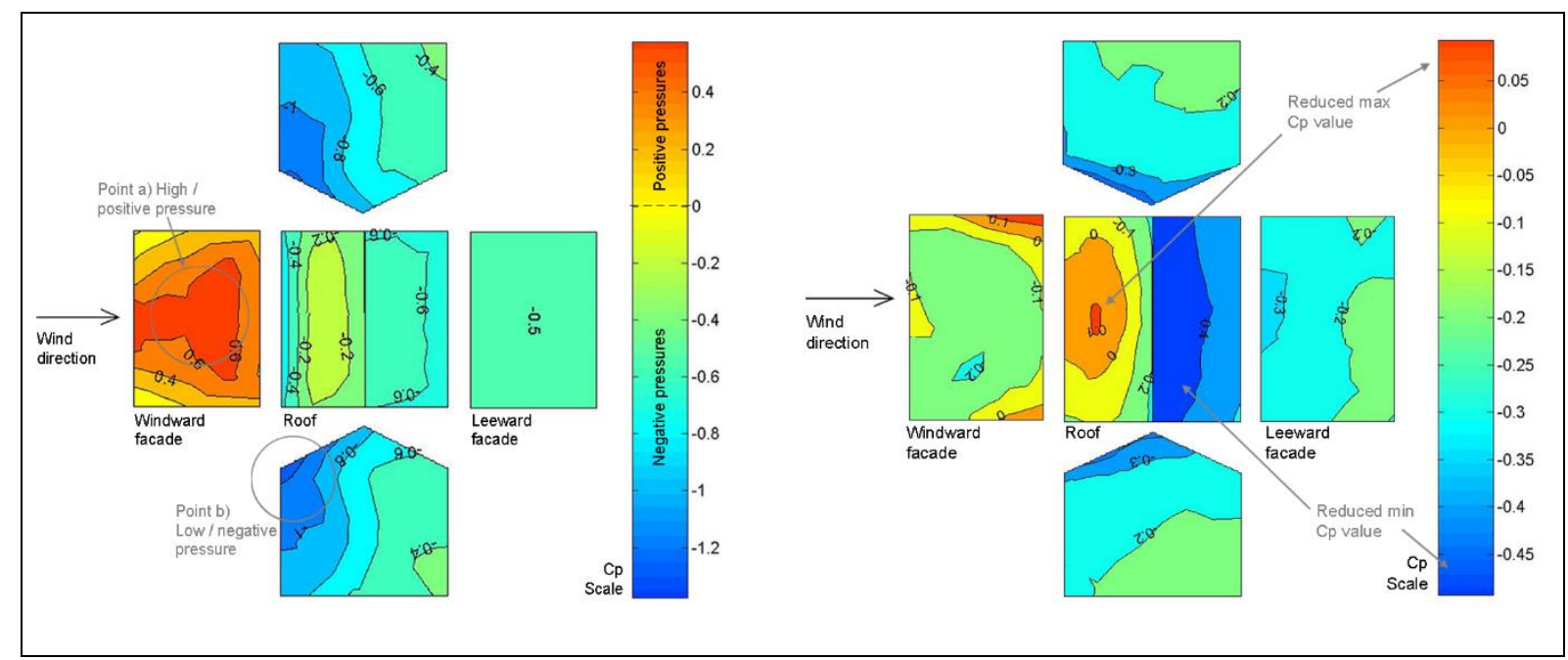

Figure 4.18. Diagram illustrating the effect surrounding buildings have on Cp values.

Adapted from (Tokyo Polytechnic University, 2007).

To quantify the effect adding urban form had on natural ventilation performance, substantiating the significance of the investigation, 'Robustness Test 5 - Surrounding Buildings Effect on Natural Ventilation' was conducted (refer Appendix A.5). Using the Tokyo Polytechnic University Aerodynamics Database (2007) the test found that a building in a non-isolated urban form would require $23 \%$ more HVAC energy than an isolated building, due to the lower and more turbulent wind pressures acting on the building. This is a significant amount of energy, substantiating natural ventilation as a potential energy conservation measure and demonstrating $\mathrm{Cp}$ values importance in natural ventilation modelling.

\subsubsection{Wind Pressure Coefficient Sources}

Because EnergyPlus cannot account for urban form in its pressure coefficient calculations, these values need to be determined externally. The source from which wind pressure coefficients are obtained can be crucial for accurate building energy simulations (Ramponi, et al., 2011). There are two types of $\mathrm{Cp}$ sources- Primary and Secondary. Primary sources - full scale measurements, wind tunnel tests and Computation Fluid Dynamics (CFD) - can generate wind data bespoke to a specific scenario, accounting for site factors such as urban form and so are more 'sensitive' than secondary sources. Secondary sources - databases and analytical models - are based on and generated by primary sources (e.g. databases are developed through wind tunnel testing) and are limited to a set range of scenarios (Costola, et al., 2009). Following is an outline of the criteria used to select a Cp source:

1) Accessibility and Operability. The method and tools used to generate $C p$ values need to be readily accessible and input data required could not be too complex or the task would become too time intensive. Set up and calibration of wind tunnel models (e.g. atmospheric qualities/scales, etc.) is complex and would require ongoing support from experts. As such, wind tunnel testing was omitted as an option.

2) Sensitivity to Small Urban Form Alterations. With the strong focus on the effect of urban form on passive performance, and the tested scenarios comprising small changes to the urban form, the $\mathrm{Cp}$ source needed to be highly sensitive. For this reason, generic databases 
could not be used, as they would not be able to generate data for the subtle changes in urban form scenarios tested.

Based on the above criteria, the most likely option was CFD, which can be used on any computer and enables models to be adjusted easily, to the desired level of detail, and for the preferred outputs.

\subsubsection{Computational Fluid Dynamics (CFD)}

CFD is an increasingly popular method for generating data such as $\mathrm{Cp}$ values and predicting natural ventilation performance (Chen, 2008).

"CFD numerically solves a set of partial differential equations for the conservation of mass, momentum, energy and other scalar quantities such as turbulence intensities and species concentration. The solution provides detailed information on the spatial distribution of air velocity, pressure and temperature. Despite simplifications in the simulation studies, the results given by the CFD analysis are normally a realistic approximation of a real-life system. Its flexibility and cost effectiveness makes the CFD software a very powerful tool in the engineering research field." (Teixeira, et al., 2012).

CFD is an approximation process which uses mathematical equations to estimate wind movement and forces in a specified environment (the 'domain'). A CFD simulation will iteratively adjust the equation variables until convergence is achieved (Thomas, 2007). Convergence is a point at which fluid conservation equations are obeyed in all cells of the computational domain to a specified tolerance. When convergence is reached (which may take thousands of iterations depending on level of accuracy/tolerance desired), the solution has been found and the computation is complete (FLUENT, 2011). Figure 4.19 displays an example CFD model labelling the key elements.

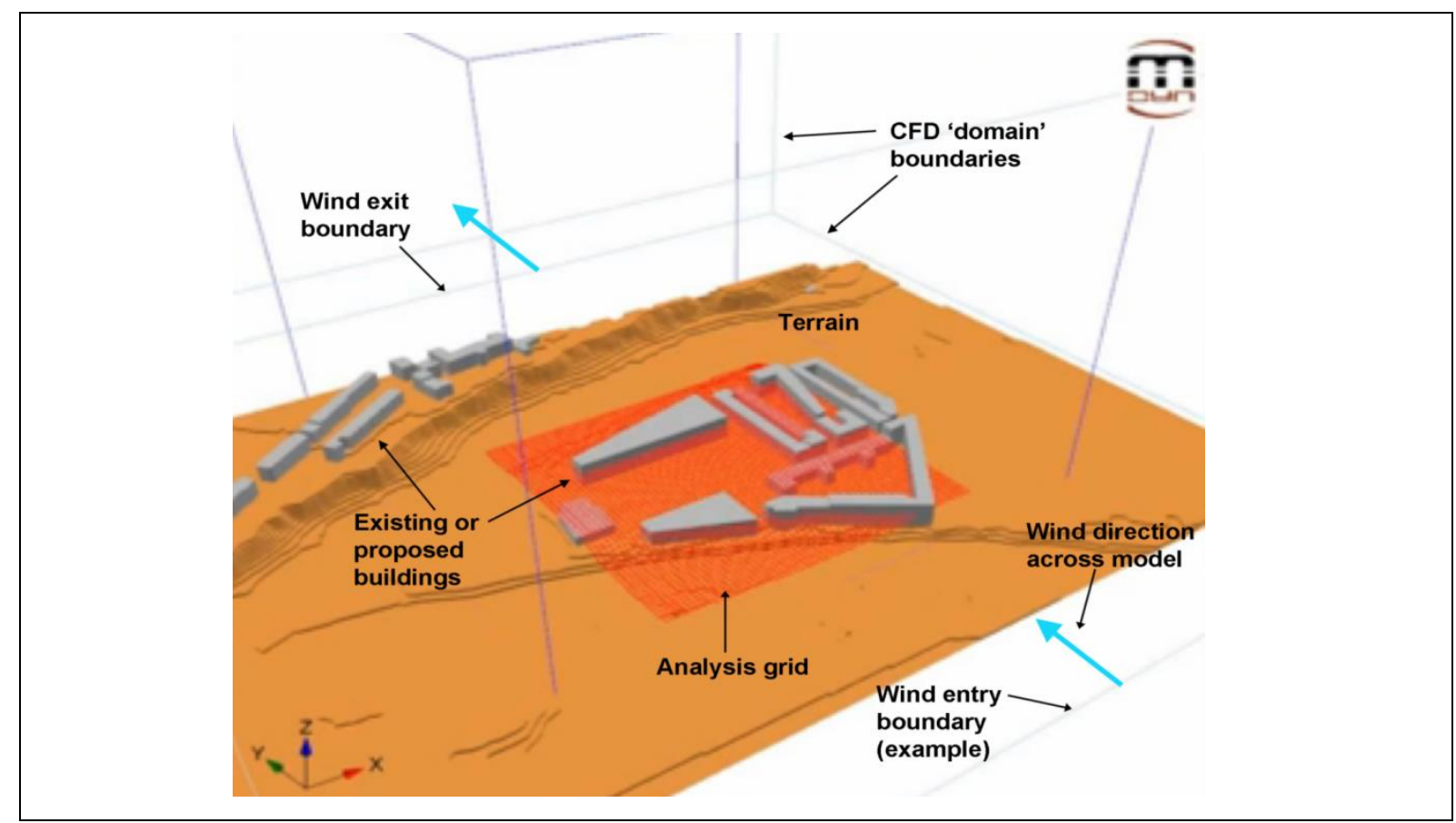

Figure 4.19. Example of a CFD model (in UrbaWind) with key elements labelled. Adapted from (Meteodyn, 2013).

Although fluid dynamics is a particularly unpredictable phenomenon for which mathematical algorithms are still being developed, they are largely considered sufficient to provide a 'realistic approximation' of expected wind conditions (Satwiko, et al., 1998). CFD's most advantageous 
attribute is its ability to model and generate data for any physical environment no matter how irregular (Costola, et al., 2009).

In theory, CFD is a promising tool for this study. But how accurate is the data generated through CFD compared to more reliable measured data? The research paper 'Reproducing the real pressure coefficient using a computational fluid dynamics program- How close is close enough?' states that there is no guide defining acceptable deviation between CFD Cp values and measured $C p$ values, and that deviations of up to $20 \%$ can still be considered 'good agreement' (Satwiko, et al., 1998). This is because real wind-flows fluctuate randomly but CFD calculates flow based on steady state conditions, and a small deviation in data should be expected. Another paper found that while a particular CFD program tended to overestimate absolute Cp values by up to $30 \%$, this only materialized in an overestimation of air-flow rate of $15 \%$ (Ramponi, et al., 2011).

This issue of CFD accuracy and reliability is addressed in terms of UrbaWind in the following section and in 'Robustness Test 6 - Validation of UrbaWind'.

\subsubsection{UrbaWind}

There is a range of CFD programs which can generate wind pressure data in building/urban environments, such as FLUENT and Vasari. However, barriers (in particular- high cost) to these products meant they weren't pursued. The program UrbaWind by MeteoDyn was identified for its ability to generate $\mathrm{Cp}$ values. Furthermore, during investigation into accessibility of this product, MeteoDyn offered use of the software for free, increasing its attraction.

UrbaWind's pre-processing procedure is simple. Geometry is built in SketchUp and imported into UrbaWind where analysis grids can then be assigned to facades and split into as many analysis points as desired. For this study, a grid system was set up to generate a $\mathrm{Cp}$ value for each level of each façade (refer 'Appendix D - UrbaWind Results').

Another important modelling consideration for natural ventilation is the Wind Angle of Incidence (WAI) frequency. More frequent WAl's enable more $\mathrm{Cp}$ detail which presumably would enable more accurate natural ventilation calculations in EnergyPlus. However more frequent WAI's also means longer computation and analysis times for each model. To determine an appropriate WAl frequency, 'Robustness Test 4 - Wind Angle Increment Frequency' was devised (refer Appendix A.4). It found that, considering this study's largely symmetrical Models, WAl's at every $45^{\circ}$ were sufficient to produce reliable natural ventilation calculations.

One of UrbaWind's most useful attributes is its post-processing capabilities and clarity of data. Figure 4.20 illustrates a scenario where $\mathrm{Cp}$ values have been generated for an entire building and the ground plane around it. $\mathrm{Cp}$ values for each grid point, at each simulated wind angle, can also be exported as a text file and plugged into EnergyPlus models to represent likely wind conditions (refer Section 4.3.3). 


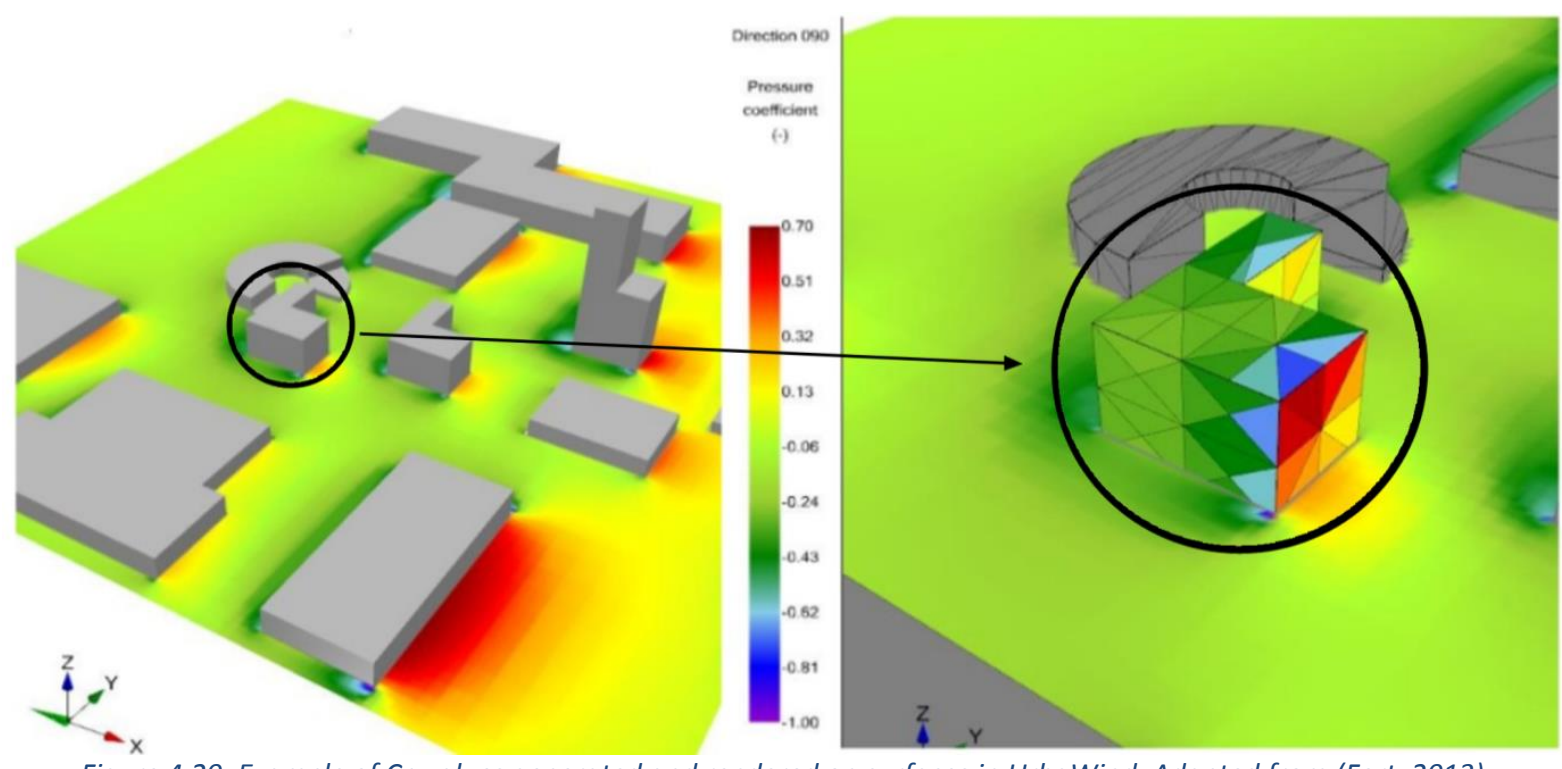

Figure 4.20. Example of Cp values generated and rendered on surfaces in UrbaWind. Adapted from (Fort, 2013).

The above information has demonstrated that UrbaWind is a malleable and suitable tool for its intended purposes, but how accurate is it? The only verification study found was MeteoDyn's 'Study cases - Validation File', (Leyronnas \& Dupont, 2009) which only considered wind-speed, not wind pressure coefficients. Therefore, it was deemed necessary to conduct a bespoke $\mathrm{Cp}$ data validation exercise of the software, in order to prove its reliability. 'Robustness Test 6 - Validation of UrbaWind' (refer Appendix A.6) found that UrbaWind's calculated $\mathrm{Cp}$ values differed, in some cases, from the Tokyo Polytechnic University's wind tunnel tested database $\mathrm{Cp}$ values (in identical models). However, these absolute $\mathrm{Cp}$ value differences equated to negligible $\mathrm{ACH}$ and mechanical cooling load differences when plugged into a corresponding EnergyPlus model. Therefore, it was determined that UrbaWind was accurate and reliable enough for application in this study.

The following section explains how UrbaWind $\mathrm{Cp}$ data was integrated into EnergyPlus' Airflow Network model to estimate likely natural ventilation performance in each urban form scenario.

\subsubsection{Natural Ventilation Analysis Method}

The EnergyPlus side of the natural ventilation calculations (Airflow Network) are explained in Section 4.3.2.1. Figure 4.21 illustrates the full modelling process (including UrbaWind input parameters) and how UrbaWind and its $\mathrm{Cp}$ outputs were integrated into EnergyPlus models. 'Appendix D - UrbaWind Results' presents CFD models and Cp results for each urban form scenario. 


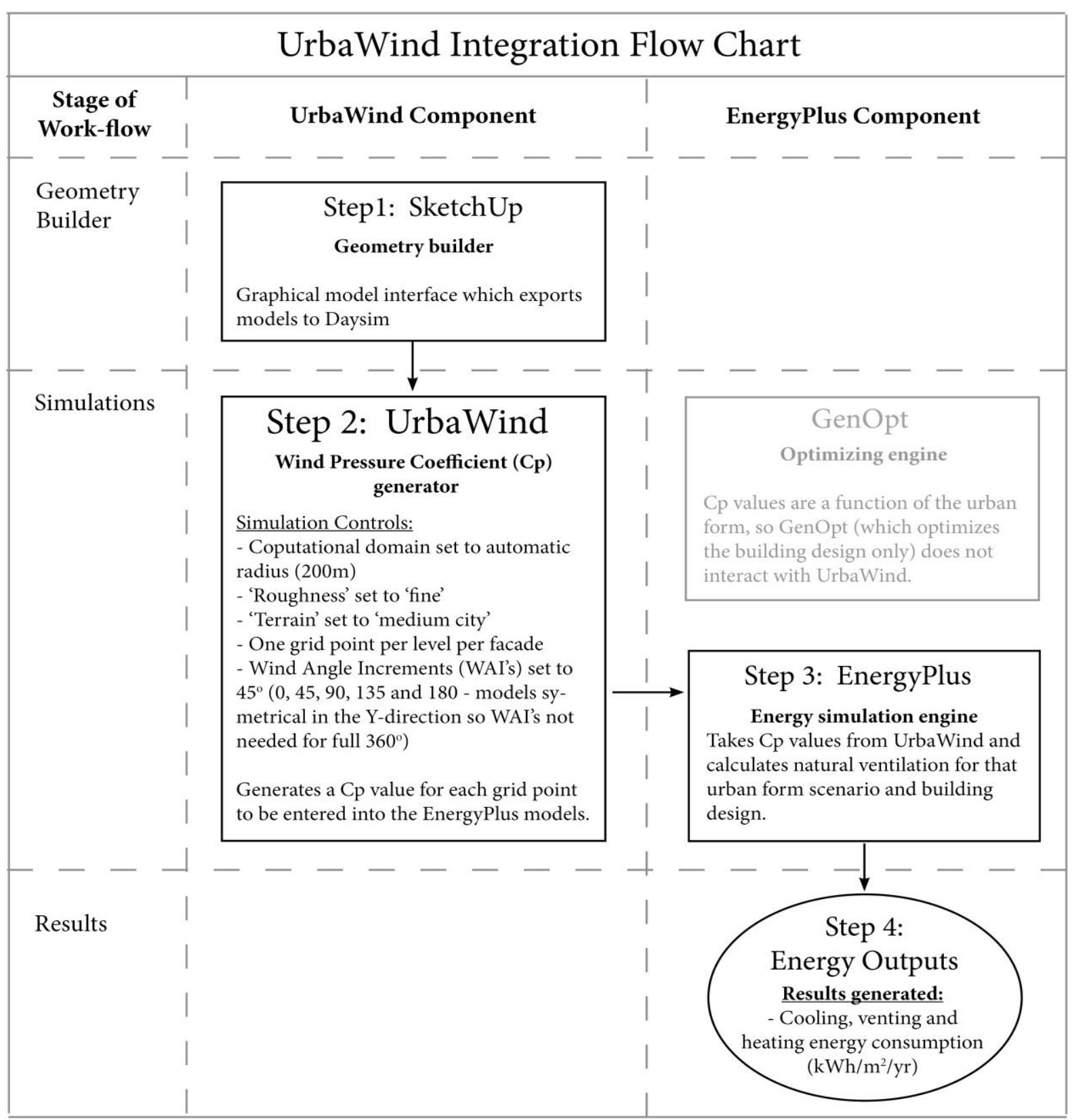

Figure 4.21. Flowchart illustrating UrbaWind's integration into EnergyPlus for natural ventilation calculations. (Author).

UrbaWind's Cp values are entered into EnergyPlus' 'Airflow Network: Multi Zone: Wind Pressure Coefficient Values' object. One $\mathrm{Cp}$ value is specified for each wind angle for both the east and west facades of each level of the tested building. Wind angles calculated in UrbaWind were $0,45,90,135$, and $180^{\circ}$. The remaining angles: 225,270 , and $315^{\circ}$ are derived based on the values calculated for the opposite façade (refer 'Appendix D - UrbaWind Results'). An example of Cp values as they are entered into an EnergyPlus model (Model 3) is presented in Figure 4.22. 


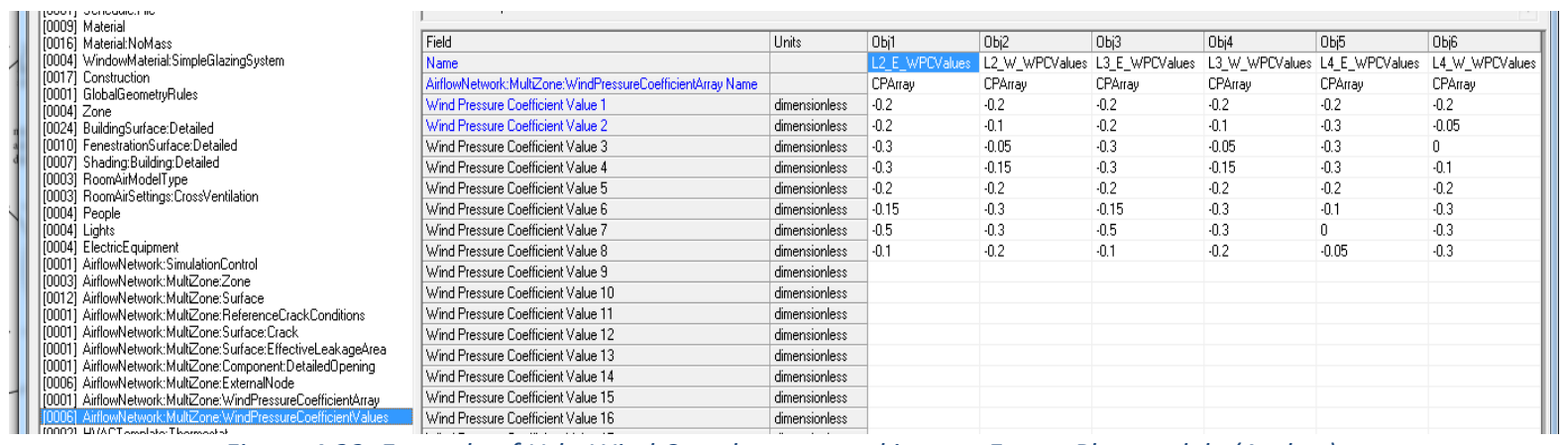

Figure 4.22. Example of UrbaWind Cp values entered into an EnergyPlus model. (Author).

\subsection{Summary of Modelling Metrics, Tools and Methods}

Following is a brief summary of the Tools (Table 4.6); the Metrics and Performance Indicators (Table 4.7); and the overall modelling process (Figure 4.23) used in this study.

\begin{tabular}{|l|l|}
\hline \multicolumn{2}{|c|}{ Tools Used in Study } \\
\hline Tool & Purpose \\
\hline EnergyPlus (with OpenStudio) & To calculate likely energy consumption in models \\
\hline Daysim (with Ecotect) & $\begin{array}{l}\text { To calculate daylight levels in building spaces and imported to } \\
\text { EnergyPlus }\end{array}$ \\
\hline UrbaWind & $\begin{array}{l}\text { To calculate wind pressure coefficient values to be used in } \\
\text { EnergyPlus natural ventilation calculations }\end{array}$ \\
\hline GenOpt & $\begin{array}{l}\text { To optimize EnergyPlus models to their most energy efficient } \\
\text { state }\end{array}$ \\
\hline
\end{tabular}

Table 4.6. Modelling and Optimisation Tools.

\begin{tabular}{|l|l|l|l|}
\hline \multicolumn{5}{|c|}{ Metrics (Performance Indicators) Used in Study } \\
\hline Output & Unit & To examine: & Program \\
\hline $\begin{array}{l}\text { Energy Performance } \\
\text { Indicators }\end{array}$ & & & \\
\hline Artificial Cooling & $\mathrm{kWh} / \mathrm{m}^{2} \mathrm{yr}$ & Performance- energy needed to cool & EnergyPlus \\
\hline Artificial Heating & $\mathrm{kWh} / \mathrm{m}^{2} \mathrm{yr}$ & Performance- energy needed to heat & EnergyPlus \\
\hline Artificial Venting & $\mathrm{kWh} / \mathrm{m}^{2} \mathrm{yr}$ & Performance- energy needed to vent & EnergyPlus \\
\hline Artificial Lighting & $\mathrm{kWh} / \mathrm{m}^{2} \mathrm{yr}$ & Performance- energy needed to light & EnergyPlus \\
\hline & & & \\
\hline $\begin{array}{l}\text { Environmental } \\
\text { Performance Indicators }\end{array}$ & & & \\
\hline Daylight Autonomy (DA) & $\%$ & Time per year space is adequately day-lit & Daysim \\
\hline $\begin{array}{l}\text { maximum Daylight } \\
\text { Autonomy (mDA) }\end{array}$ & $\%$ & Time per year space is subject to glare & Daysim \\
\hline $\begin{array}{l}\text { Zone Operative } \\
\text { Temperature }\end{array}$ & ${ }^{\circ} \mathrm{C}$ & Comfort as a function of temperature & EnergyPlus \\
\hline Air Change Rate (ACH) & volumes/h & Comfort as a function of IAQ & EnergyPlus \\
\hline Air Speed & $\mathrm{m} / \mathrm{s}$ & Comfort as a function of air speed & EnergyPlus \\
\hline & & & \\
\hline
\end{tabular}

Table 4.7. Performance Metrics and Performance Indicators. 


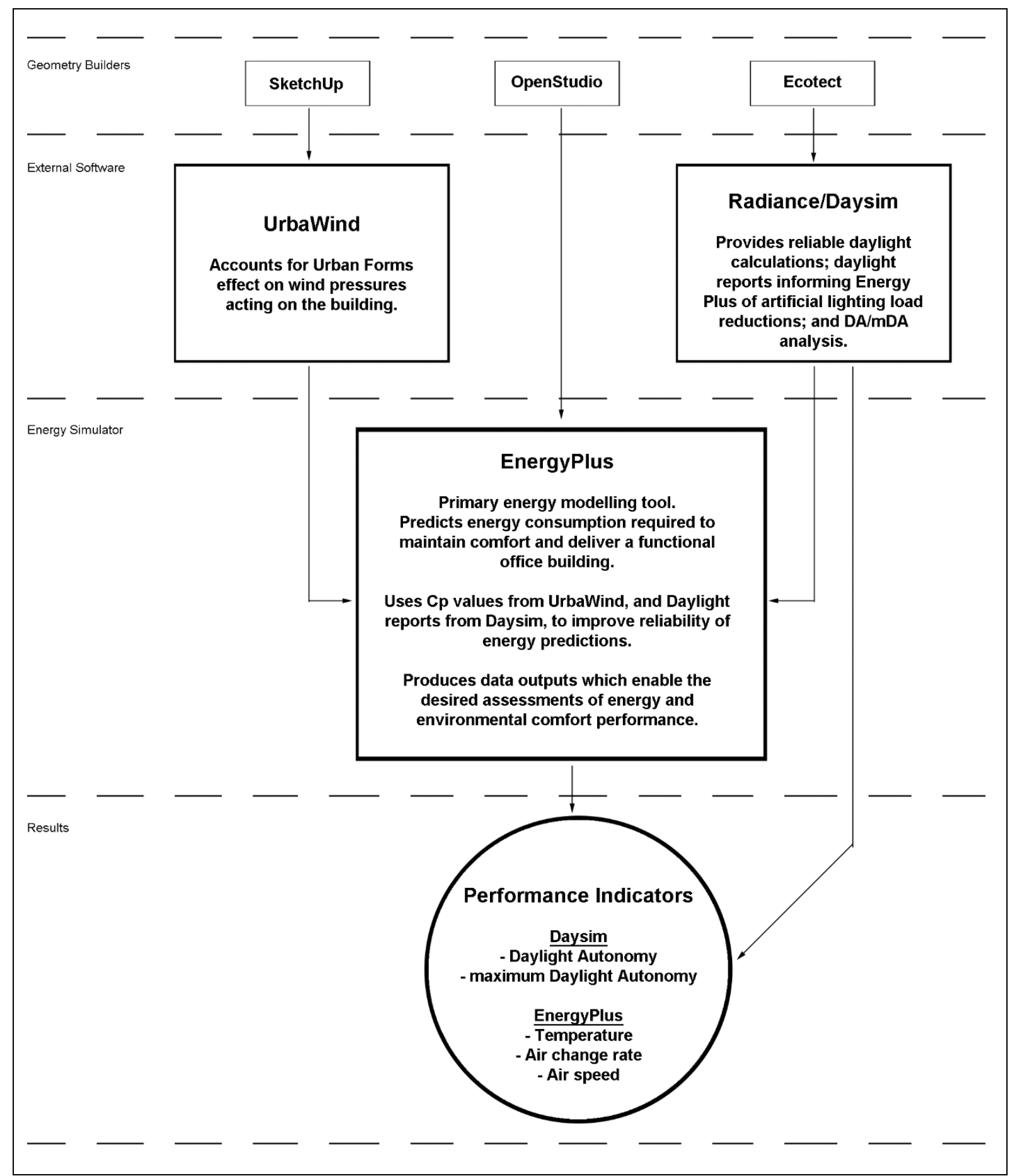

Figure 4.23. Flow-chart illustrating modelling process and interaction between computer programs. (Author). 
Urban Form and Passive Design for High Performance Buildings in the Christchurch Rebuild 


\section{Chapter 5: Parametric Investigation of Urban Form}

Chapter 5 develops scenarios which enable urban form features to be parametrically tested for their ability to deliver daylight and fresh air to buildings. The parametric study consists of three parts:

Firstly, Section 5.1 conducts a property categorisation study to decipher the varying property shapes, sizes and orientations of properties in Christchurch's CCB, and develops a single 'representative property type', to be used as the foundation of urban form scenarios in the parametric study.

Secondly, urban form features which are expected to enable passive performance are identified and variations developed ('parameterization') in Section 5.2.

Finally, Section 5.3 illustrates how the representative property type and selected urban form parameters/variations were developed into computer models, enabling each parameter to be isolated and analysed parametrically. Section 5.4 presents the final Urban Form Models.

Figure 5.1 depicts how the urban form parametric study moves through these parts to arrive at the Models, ready for testing.

Building design details that do not concern urban form (such as insulation levels, glazing properties, etc.) remain constant in all urban form scenarios to ensure comparability (refer Table 5.2 at conclusion of this Chapter). Chapter 6 then explores building design in depth.

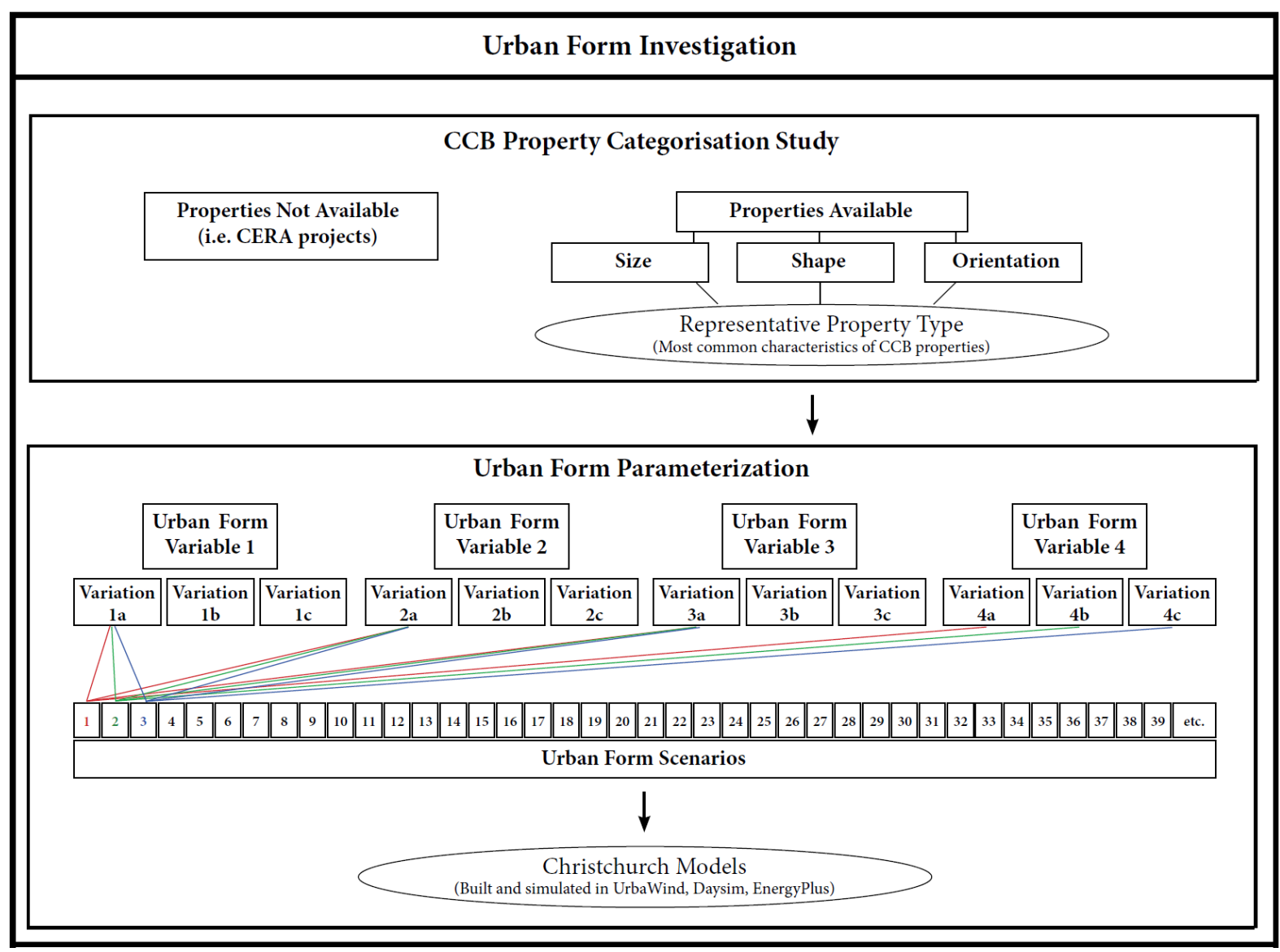

Figure 5.1. Flow-chart diagram illustrating the process of the Urban Form Investigation. (Author). 


\subsection{Development of a Representative Property Type}

Urban Form is dictated by property parcels- therefore so too is the potential for passive architecture. Ideally, if properties were identical, findings from this study could be applied to all. However, this is not the case, and rebuilt CCB property parcels will retain their former irregular configuration. Size, shape and orientation of properties vary greatly resulting in hundreds of different situations. Modelling and testing each of these scenarios is too time intensive and impractical. Instead, a single 'representative' scenario, which embodies common elements of CCB properties, will be used to simplify testing. While this approach will not produce results specific to any property or building, it will produce more general findings applicable to a wider sample of properties.

Property is not a parameter altered or tested in this study but must be considered as it lays the foundation for building shape, size and orientation. Section 5.1 establishes the current land situation in the CCB and develops a 'representative property type' to be used as the basis of the urban form scenarios.

\subsubsection{The Central City Business zone (CCB)}

The study focuses on the 'Central City Business zone' (CCB), denoted in blue in Figure 5.2, because it consists largely of the focus building type - office buildings - and is the highest built density area in the city (Christchurch City Council, 2013).

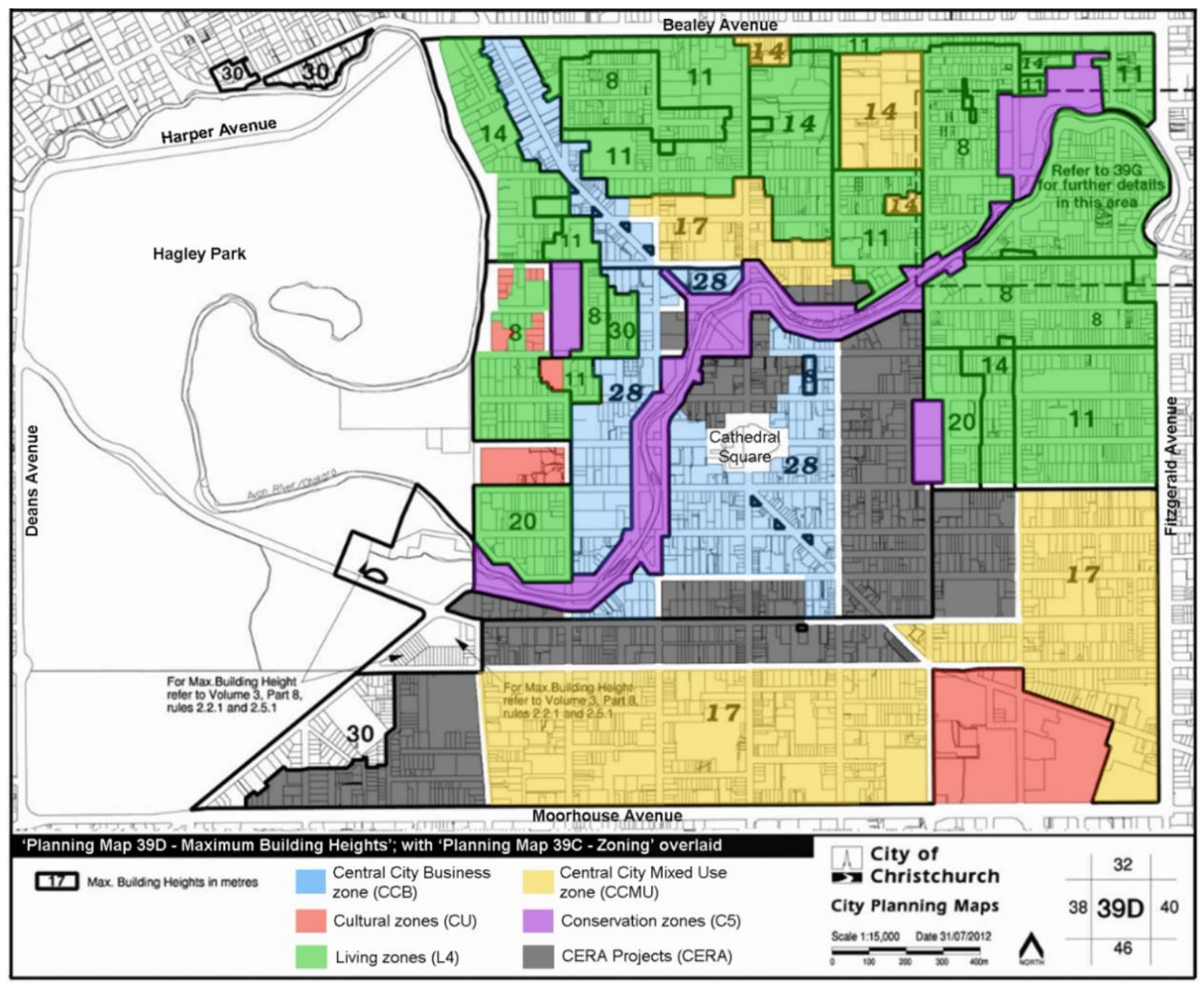

Figure 5.2. Christchurch City Plan Map 39D presenting CCB (blue) and maximum building heights. Adapted from (Christchurch City Council, 2013). 


\subsubsection{Land Designated for 'Anchor Projects'}

Land use and ownership has been a significant issue in the Christchurch rebuild. The CCC and CERA have purchased 350 properties from private owners, in order to develop a range of public facilities such as 'The Frame', 'Retail Precinct' and 'Health Precinct' known as 'Anchor Projects' (refer grey areas in Figure 5.2) (Canterbury Earthquake Recovery Authority (CERA), 2013). Most of the Anchor Projects are 'Civic buildings' containing highly specific activities, which are not necessarily practical for passive design strategies pursued in this study. For example, The Public Transport Precinct requires large indoor spaces to accommodate hundreds of commuters, making thin floor-plates impractical. For this reason, the study does not consider the Anchor Projects. However, they do occupy a considerable amount of land area and so must be included in the density equations (refer Section 7.1.2). For now, they are simply excluded from the following determination of which property type will be used for testing.

\subsubsection{Categorisation of CCB Properties}

To determine the 'representative property type', a 'property categorisation study' was conducted. Categorisation of properties was based on two criteria- property width; and orientation.

Property width criteria needed to reflect the issues central to this research- porosity and density which is represented by floor-plate width and void space. As a starting point, the maximum floorplate width of $15 \mathrm{~m}$ (based on daylight and natural ventilation rules of thumb established in Section 2.2 ) is assumed. Then, acknowledging that 'void' space will be required immediately outside the buildings, but not knowing exactly how much (one of the goals of this research) an estimate needed to be made. During dissemination of the pilot study, concerns over the $34 \%$ sacrificed NLA were expressed. $25 \%$ of the property width is therefore proposed as a starting point for void size. Assuming the $15 \mathrm{~m}$ wide building, this manifests in a $20 \mathrm{~m}$ wide property plot $(2.5 \mathrm{~m}$ gaps either side of the $15 \mathrm{~m}$ wide building).

Compared to the 'Living Zone' set-back requirement of $1.8 \mathrm{~m}$ either side of the building (no such requirement in the CCB) (Christchurch City Council, 2013), this slightly larger $2.5 \mathrm{~m}$ set-back is a logical starting point for an office building where occupant densities are higher and more fresh air is required. Therefore, to limit impact on density, $20 \mathrm{~m}$ was adopted as the width of the representative property ( $15 \mathrm{~m}$ wide building $+5 \mathrm{~m}$ wide gaps).

Property length is not a significant factor as both natural ventilation and daylight are intended to enter the building through the sides. In other words, the building can be infinitely long and still operate passively if its width and adjacent void are appropriate. Therefore, properties will be assumed to be $50 \mathrm{~m}$ long, which is half the depth of a CCB block and enables simple extrapolation to other lengths (e.g. a $20 \mathrm{~m}$ long building $=2 / 550 \mathrm{~m}$ long building).

Figure 5.3 illustrates how these principles resulted in the $20 \mathrm{~m}$ wide property threshold. 


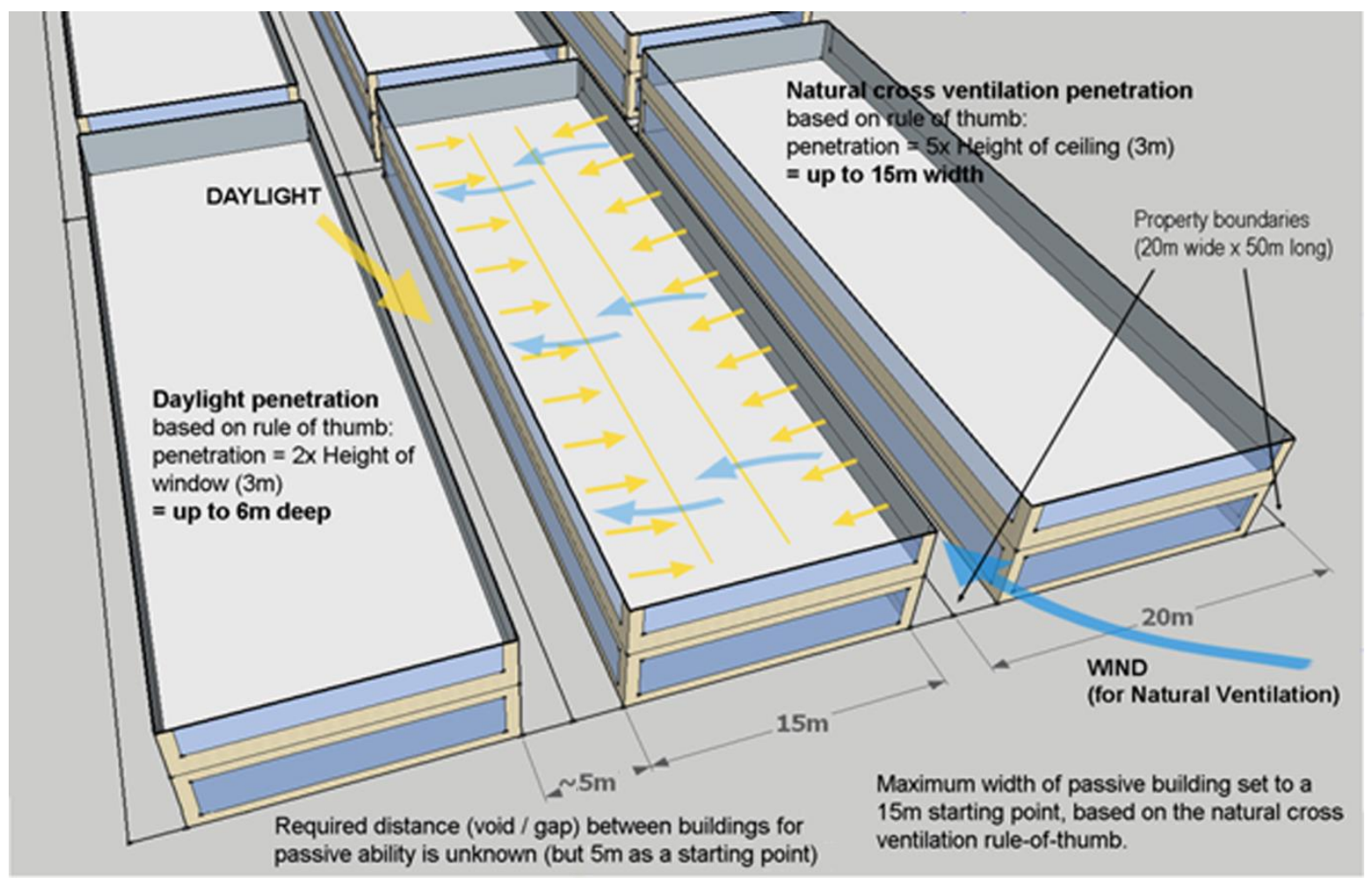

Figure 5.3. Diagram illustrating how the passive design rule-of-thumbs informed building and property sizes. (Author).

Orientation of property plots was also a necessary criterion because climatic considerations, such as sun paths and wind directions, which can influence design. For example, a north facing façade might benefit from an adjacent building casting shadow and reducing solar gains, where as a south facing facade isn't subject to solar gains and so a close neighbouring building would only reduce daylight.

Orientation was defined based on the direction of the street from that property. For example, a property sharing side boundaries with three other properties and one road-boundary to the North, would be classified as a North-facing property.

The goal of the categorisation study was to determine property types based on the width and orientation criteria. The most common property type would be taken forward to the development of urban form scenarios as the 'representative property type'.

Figure 5.4 presents the categorisation study. It identifies 11 different property types and their parameters and illustrates which properties fit under those categories. From this map, each property type was tabulated to determine which were the most common and therefore the most significant. 


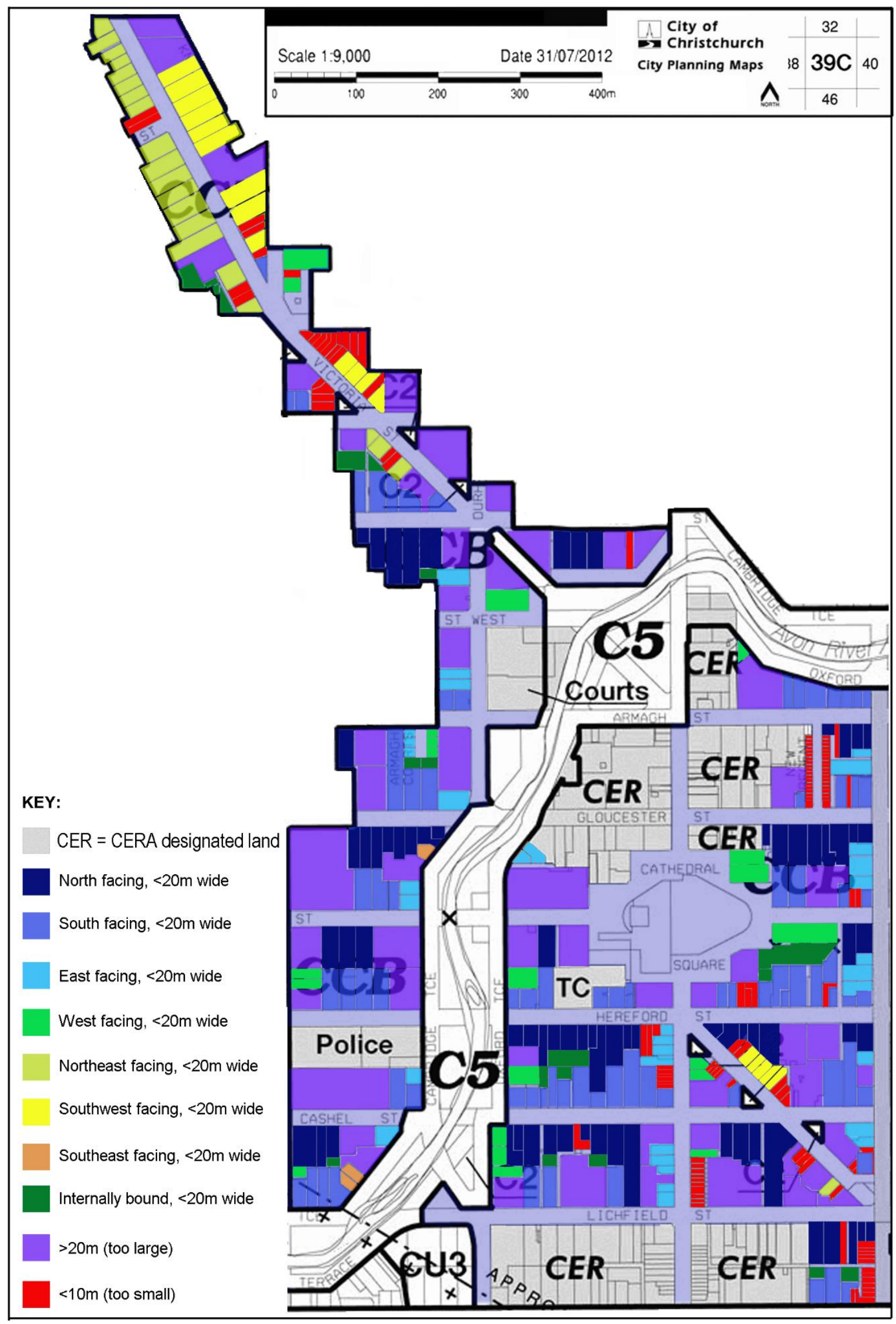

Figure 5.4. CCB 'Property Classification Study Map', derived from Planning Map 39C.

Adapted from (Christchurch City Council, 2013). 
Results of the categorisation study (refer Table 5.1) show that $61 \%$ of properties in the CCB are between 10 and $20 \mathrm{~m}$ wide. Furthermore, of the remaining $39 \%$ of properties, $12 \%$ are classified as 'too big' ( $>20 \mathrm{~m}$ wide). Findings from testing a property of $<20 \mathrm{~m}$ wide can easily be applied to larger properties, as they have more 'freedom' in their physical constraints. This means that $73 \%$ of properties in the CCB are wide enough for findings to be applied to.

Of the $10-20 \mathrm{~m}$ wide properties- ' $<20 \mathrm{~m}$ wide and north facing' and ' $<20 \mathrm{~m}$ wide and south facing' are the most common, representing $17 \%$ of the CCB each ( $34 \%$ total). Between these two (similar) property types, the north facing variation will be taken forward for testing. This is because a north facing building is subject to the added complexity of direct sunlight. Midday sunlight can cause substantial heat gains, requiring mechanical cooling if the building is not designed to mitigate it (Mead, 2011). This is an important consideration of passive solar design which would not be addressed if the south facing property type was selected.

One limitation encountered through this testing approach is the lack of data that will be generated for buildings with east and west facing /façade adjacent to the street- in particular issues of glare resulting from low sun angles. This limitation is only minimal however as only $12 \%$ (7\% east; $5 \%$ west) of buildings have facades exposed to the street in these directions.

\begin{tabular}{|l|l|l|}
\hline \multicolumn{3}{|c|}{ Results of Property Classification Study } \\
\hline Property Type & Count & Percentage of Total \\
\hline North facing, $<20 \mathrm{~m}$ wide & $\sim 76$ & $17 \%$ \\
\hline South facing, $<20 \mathrm{~m}$ wide & $\sim 77$ & $17 \%$ \\
\hline East facing, $<20 \mathrm{~m}$ wide & $\sim 31$ & $7 \%$ \\
\hline West facing, $<20 \mathrm{~m}$ wide & $\sim 21$ & $5 \%$ \\
\hline Northeast facing, $<20 \mathrm{~m}$ wide & $\sim 20$ & $5 \%$ \\
\hline Southwest facing, $<20 \mathrm{~m}$ wide & $\sim 18$ & $5 \%$ \\
\hline Southeast facing, $<20 \mathrm{~m}$ wide & $\sim 3$ & $0 \%$ \\
\hline Internally bound, $<20 \mathrm{~m}$ wide & $\sim 18$ & $5 \%$ \\
\hline$>20 \mathrm{~m}$ wide (too large) & $\sim 54$ & $12 \%$ \\
\hline$<10 \mathrm{~m}$ wide (too small) & $\sim 122$ & $27 \%$ \\
\hline TOTAL & $\sim 446$ & $100 \%$ \\
\hline
\end{tabular}

Table 5.1. Number of properties under each classification in tabulated and percentage form.

Figure 5.5 presents the property configuration, developed through the above categorisation study, which will be used as the basis of the urban form in testing. Based on the typical $100 \times 200 \mathrm{~m}$ Christchurch CBD block, properties are standardised into $20 \times 50 \mathrm{~m}$ plots running north-south. The central most property on the southern side of the street is highlighted as the subject property as it represents the most 'enclosed' (and therefore least access to daylight and wind pressures) north facing scenario. 


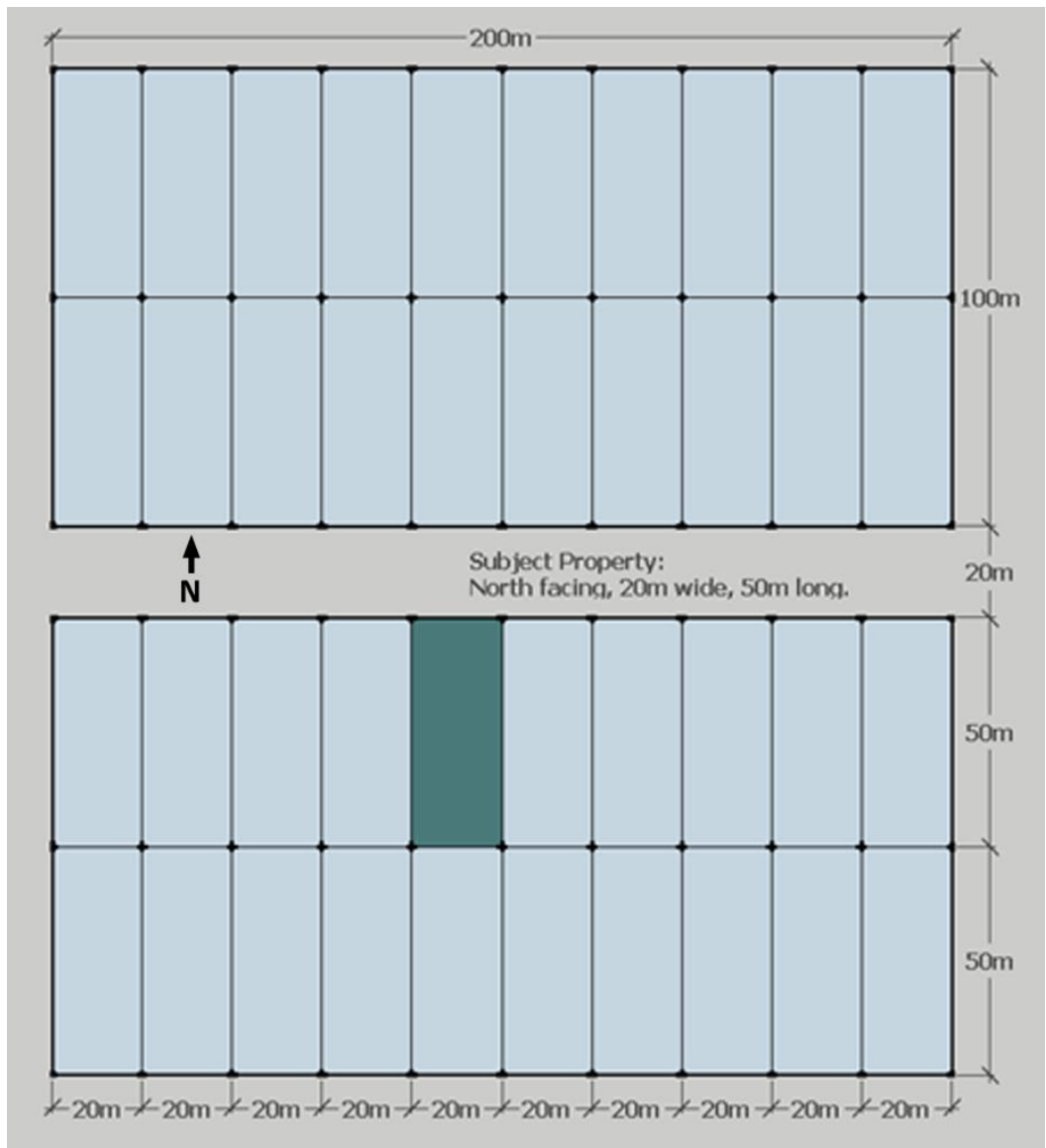

Figure 5.5. CCB Block and Property configuration to be used as the basis of urban form scenarios. (Author).

\subsection{Parameterisation of Urban Form Variables}

This section discusses and establishes the Urban Form parameters, and variations of those parameters, that are to be tested in the resulting Urban Form Models.

\subsubsection{Urban Form Variable 1 - Building Height}

The 'urban canyon' (refer Figure 5.6) is the void space created by a road cutting through blocks of buildings and is one of the most significant sources of solar energy to buildings and outdoor spaces. The effectiveness of the urban canyon to deliver light and heat from the sun (and wind for natural ventilation) depends on its proportions- this is known as the 'aspect ratio'. The aspect ratio denotes the ratio between the heights of buildings to the width of the street $(\mathrm{H} / \mathrm{W})$ (Ali-Toudert \& Mayer, 2006) and can have a significant effect on energy consumption in buildings. The paper 'The urban canyon and building energy use: Urban density versus daylight and passive solar gains' found that "the geometry of urban canyons has an impact on total energy consumption in the range of up to $+30 \%$ for offices and $+19 \%$ for housing, which shows that the geometry of urban canyons is a key factor in energy use in buildings." (Stromann-Andersen \& Sattrup, 2011). Figure 5.6 demonstrates how an urban canyon with an aspect ratio of 1:1 (top) creates shading across the entire street (at that particular time) and onto the building opposite; whereas an aspect ratio of 0.5:1 only shades half the street, meaning more light is present in the urban canyon for buildings to utilize. 

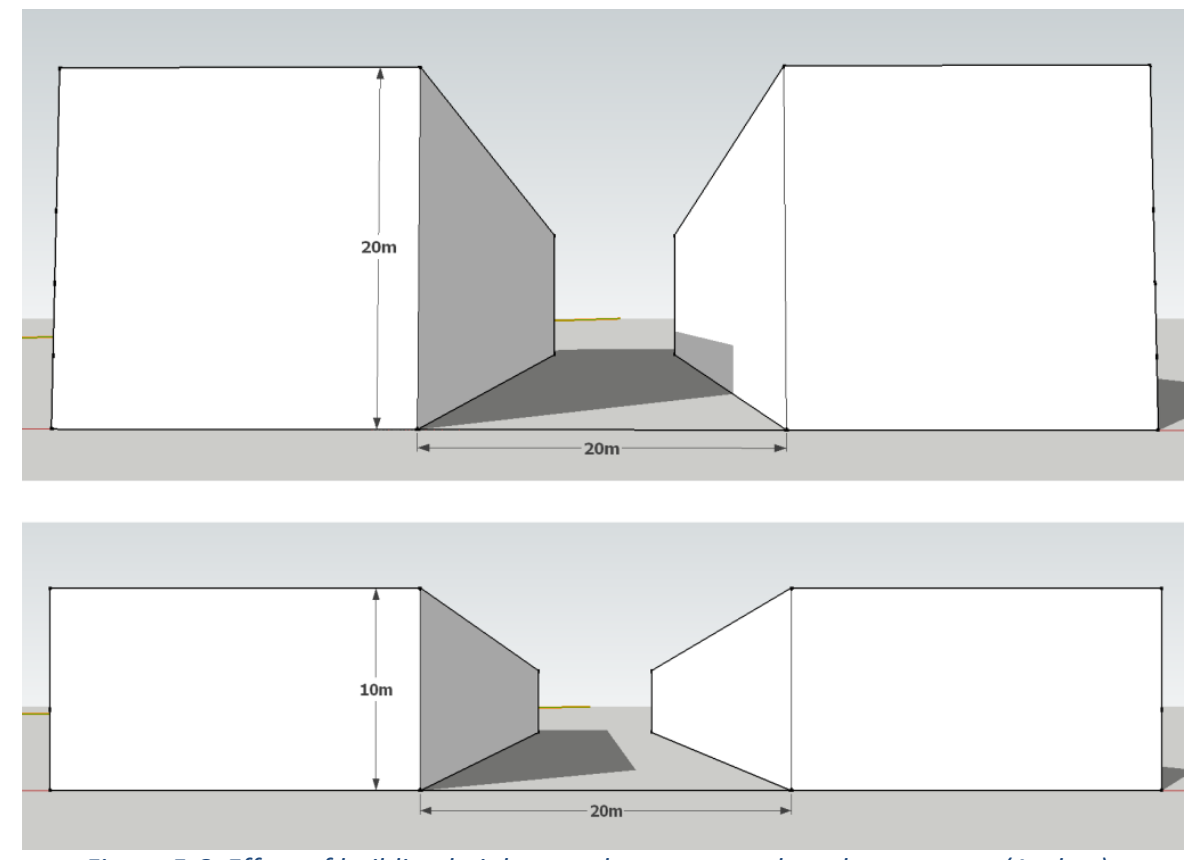

Figure 5.6. Effect of building height on solar access to the urban canyon. (Author).

'Section 3.3.2.2.8 - Minimum Number of Floors' of Christchurch's Town Plan requires CCB buildings to consist of at least two levels, ensuring the city centre remains the highest density area, retaining its status as the heart of the city (Christchurch City Council, 2013). However, two floors will not be tested as the minimum building height. The CCPo mandates that the Ground and first floors of CCB buildings must be built to $100 \%$ of the property width for 'continuous frontage' (Christchurch City Council, 2013). Therefore a two storey building cannot be designed to operate passively as it will consist of party-walls along its sides. Considering this, the minimum building height tested will be four storeys $(14 \mathrm{~m})$, which allows two 'passive levels'.

In the CCB the maximum building height allowed is $28 \mathrm{~m}$ (refer Figure 5.2 ).

Additional to the lowest building height (4 floors, $14 \mathrm{~m}$ ) and tallest building height (adjusted to $26 \mathrm{~m}$, 8 floors), a mid-height scenario of 6 floors $(20 \mathrm{~m})$ will be added. Testing three building heights at twostorey $/ 6 \mathrm{~m}$ increments enables a systematic investigation of the range of possible passive heights and their effect on energy efficiency. Furthermore, testing every second level will enable simple extrapolation of results to intermediate floors (e.g. energy consumed by a 5 floor building $=$ average consumption of 4 floor and 6 floor buildings).

The scenarios which test 4 storey buildings are Models $0,1,2,3$ and 13.6 storey buildings are Models 4, 5 and 6. And 8 storey buildings are Models 7, 8 and 9 (refer Section 5.4).

\section{Summary: Urban Form Variable 1 - Building Height}

Lower limit - 4 floors (assumed to be $14 \mathrm{~m}$ : ground and top floors $4 \mathrm{~m}$, intermediate floors $3 \mathrm{~m}$ )

Upper limit - 8 floors (assumed to be $26 \mathrm{~m}$ )

Increments - every 2 floors (4, 6 and 8 floors $=14,20$ and $26 \mathrm{~m}$ ) 


\title{
5.2.2 Urban Form Variable 2 - Road Width
}

The second component of the urban canyon and aspect ratio is road width.

"Traditional urban planning has sought to control the proportions of the streets, because the basic geometry of building heights and distances between buildings [urban canyon] regulates access to light and solar heat. Zoning laws and building regulations usually establish height-to-distance ratios that limit the overshadowing that buildings may cause for public spaces and other buildings.' (Stromann-Andersen \& Sattrup, 2011).

To determine which road widths should be tested, possible road widths need to first be identified. 'Section 3.8, Appendix 3 - List of Classified Roads' of the CCPo identifies 'Minor Arterial-Urban' and 'Collector Urban' to be the most common road types in the CCB (refer Appendix B.6) (Christchurch City Council, 2013). The minimum allowed width of 'Minor Arterial' roads is $20 \mathrm{~m}$ (from building to building, rather than curb to curb), and the maximum allowed width of 'Collector' roads. As the most common existing width, $20 \mathrm{~m}$ will be used as the baseline for the Road Width parameter.

Minor Arterial roads can be expanded up to a maximum of $30 \mathrm{~m}$ wide, and so will be the upper limit for the Road Width variable. As some buildings survived the earthquakes, it is difficult to alter the road width in reality, and would therefore be illogical to test many variations of road width. Testing only an upper and a lower limit enables a theoretical investigation into the potential effect of widening the streets. To determine the effect of Street Width on building performance, the hypothetical $30 \mathrm{~m}$ street width need only be applied to three scenarios - minimum density (Model 3), mid-range density (Model 5) and maximum density (Model 7) - to establish a pattern. This concise approach will enable an analysis of whether street width has the greater effect on low density, high porosity urban forms; or, high density, low porosity urban forms.

The scenarios which test alternative 30m wide streets are Models 10, 11 and 12 (simply Models 3, 5 and 7 with expanded streets, refer Section 5.4). All other models consist of a $20 \mathrm{~m}$ wide street.

\author{
Summary: Urban Form Variable 2 - Road Width \\ Lower limit - 20m (current situation) \\ Upper limit - 30m (widest possible) \\ Increments - none other ( $20 \mathrm{~m}$ and $30 \mathrm{~m}$ only)
}

\subsubsection{Urban Form Variable 3 - Gaps between Buildings}

There is no requirement in the CCPo to set buildings back from 'internal boundaries' (side boundaries), meaning they can extend to their boundary and share 'party-walls' with neighbouring buildings. As has been established, party-walls prohibit access to daylight and fresh air, making abutting buildings ineffective in terms of passive potential. It is for this reason that 'Gaps between Buildings' are proposed and are potentially one of the most significant urban form parameters tested in this research. Figure 5.7 re-presents the scenario presented in Figure 1.4 and asks- 'how wide does the gap between buildings have to be to deliver sufficient wind pressure and daylight to side facades?

It is expected that larger voids would enable buildings to have greater access to daylight and fresh air, but this of course affects density and floor area. Following is an investigation into 'gaps between buildings' and why they need to be limited to maintain density. 


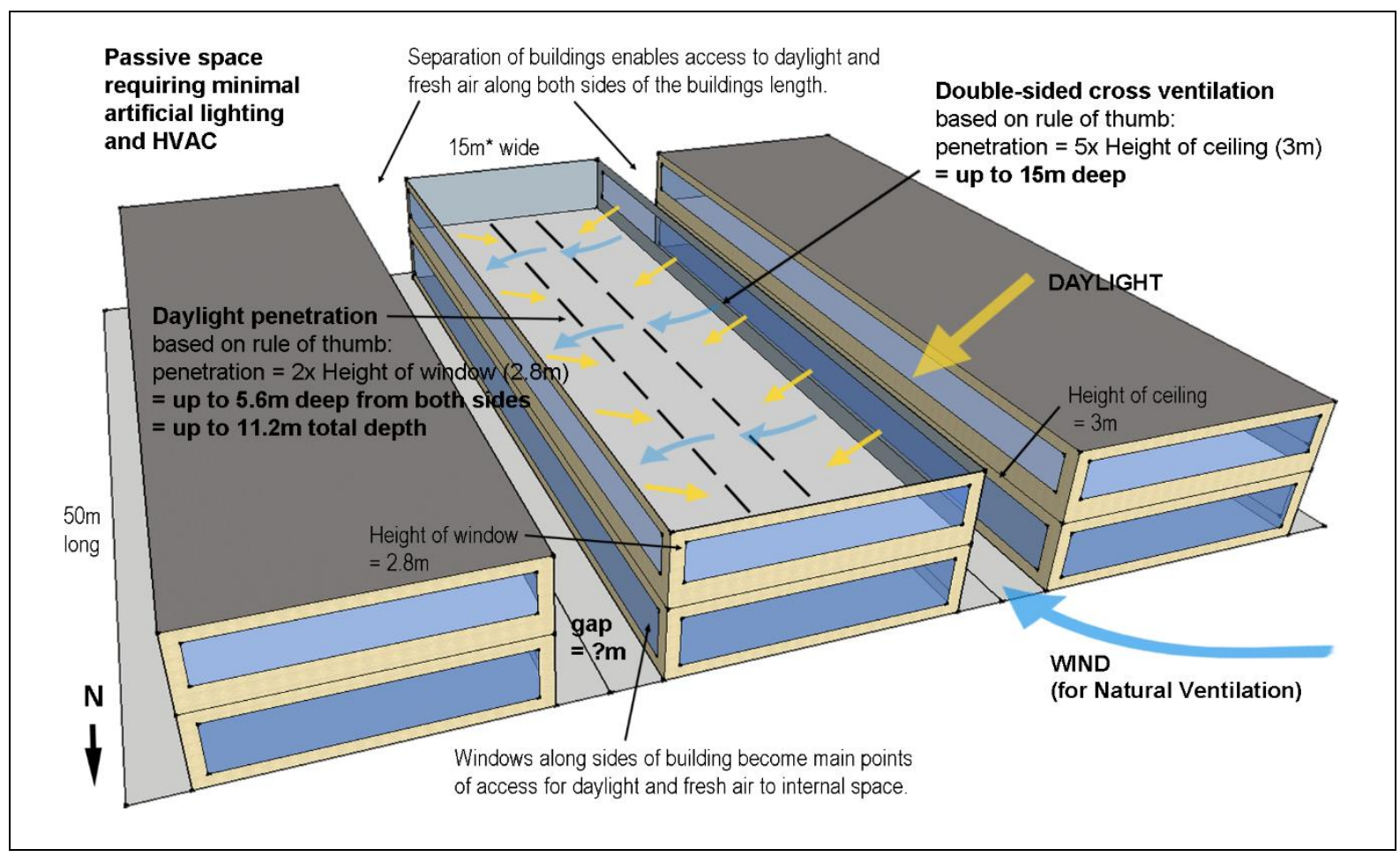

Figure 5.7. Scenario depicting the question of how much void between buildings is sufficient. (Author).

To determine the minimum possible set-back from an internal/side boundary, other building standards must be considered. A substantial factor in the Christchurch rebuild is structural security. Under the NZBC, the maximum allowed 'drift' to avoid 'pounding' between buildings in seismic activity is $0.02 \times$ the building height (Charleson, 2008). The largest building tested in this research would therefore require a set-back of $0.56 \mathrm{~m}(28 \mathrm{~m} \times 0.02)$.

Another issue concerning building proximity is fire safety. According to 'Clause C: Protection from Fire' of the NZBC, the minimum distance a 'non-fire rated' building façade can be from an internal/side boundary is $1 \mathrm{~m}$, to prevent the spread of fire (Department of Building and Housing, 2012).

As this fire related requirement specifies a larger set-back than the structural requirement, it takes precedence and will be adopted as the minimum set-back distance. Therefore, when applied to each building, either side of the boundary line, the minimum 'Gap between Buildings' distance will be $2 \mathrm{~m}$ ( $2 \times 1 \mathrm{~m}$ set-back).

The maximum 'Gap between Buildings' distance, on the other hand, is a matter dictated by what building owners regard as 'acceptable'. To discern an answer to this critical question, two points are raised:

1) Isolated precedence - Tony Gough, owner and developer of multiple CBD properties and buildings has begun design of a significant development in the CCB known as 'The Terrace', which comprises $45,000 \mathrm{~m}^{2}$ of commercial floor area. However, this is only around $50 \%$ of the floor area possible on the site. Gough (2013) states that 'We could have doubled the size of the development, but we wanted to let lots of light in. You have to give back to the city so it can give back to you."

2) CCB wide pattern - Another point that reinforces The Terrace precedent is the emerging patterns of building scale in central city Christchurch. The 'Emergence of Christchurch' article, presents 40 commercial building concepts planned for construction in and around the CBD. Of these projects, the average height was 3.15 levels, with only five buildings exceeding 4 storeys tall. (Webby \& Hoare, 2012). Reinforcing this expectation is the 'CERA 
Property Market Study' which found "There was strong preference towards new, low-rise buildings, with $75 \%$ of respondents' preferring to return to new buildings and $75 \%$ of respondents stating they would not return to a building over four storeys." (Ernst \& Young, 2012).

Considering buildings can be built up to $28 \mathrm{~m}$ ( 8-9 storeys) in the CCB it could be argued that, on average, buildings are only being built to $<50 \%$ of their potential area anyway.

Based on these two points it can be argued that developers might accept up to $50 \%$ of possible built volume be converted to void space to profit from natural amenities of daylight and fresh air. Although a 50\% reduction of NLA appears at first to be excessive and unfeasible, it is perhaps not as absurd as one might think. While it is not expected that land/building owners or developers will be particularly receptive to the concept (at least at first), there is sufficient justification to investigate a step-back of $50 \%$ of the property width. Therefore, gaps between buildings equal to $50 \%$ of the property plot ( $10 \mathrm{~m}$ of the $20 \mathrm{~m}$ wide property) will be adopted as the maximum void size.

Again, a third 'gap' size of $6 \mathrm{~m}$, the mid-point between the $2 \mathrm{~m}$ and $10 \mathrm{~m}$ wide scenarios, will be included to better reveal patterns. This set of gap sizes will enable a clear and comprehensive investigation of void-to-built volume ratios.

The scenarios which test $2 \mathrm{~m}$ gaps between buildings are Models $1,4,7$ and $12 ; 6 \mathrm{~m}$ gaps are tested in Models 2, 5, 8 and 11; and 10m gaps in Models 3, 6, 9 and 10. Model 13 is completely isolated with no surrounding buildings (refer Section 5.4).

\section{Summary: Urban Form Variable 3 - Gap between Buildings}

Lower limit $-2 m$ ( $10 \%$ of $20 m$ wide subject property)

Upper limit $-10 \mathrm{~m}$ (50\% of subject property)

Increments $-\mathbf{2 ,} 6$ and $10 \mathrm{~m}\left(1 / 10^{\text {th }}, 1 / 3^{\text {rd }}\right.$ and $1 / 2$ of subject property)

\subsubsection{Urban Form Variable 4 - Building Width}

A matter of building form linked to building separation is the width of the buildings themselves. To effectively light and ventilate a space naturally the floor-plate can only be so deep. Based on rules of thumb, it has been established that a building can be a maximum width of around $15 \mathrm{~m}$. But in what urban form circumstances? As established in Section 2.3, the potential for daylighting and windforced ventilation is likely to be higher in an 'uninterrupted' environment. So do the rules of thumb still apply in a high density urban setting? How far can daylight and ventilation penetrate with only 10,5 or even $2 \mathrm{~m}$ of gaps between buildings?

Urban Form Variable 4 aims to determine exactly how deep a 'passive floor-plate' can be in varying urban forms.

Using the $15 \mathrm{~m}$ theoretical maximum building width as a starting point, a range of building widths in this vicinity are proposed for testing. Firstly the research tests the relationship of building width against void size. By subtract

ing the intended 2, 6 and $10 \mathrm{~m}$ 'gaps between buildings' from the $20 \mathrm{~m}$ wide subject property, building widths of 18,14 and $10 \mathrm{~m}$, respectively, are produced. This enables an investigation of 'built to void' relationships of 1:10, 3:10 and 1:1. In other words, NLA sacrifices of $10 \%, 30 \%$ and $50 \%$. 
From here the research develops tested scenarios from the restrictive $20 \mathrm{~m}$ wide property 'starting point' to cover a wider range of building widths and void sizes. To do this it combines all identified gaps between buildings sizes $(2,6$ and $10 \mathrm{~m})$ with all identified building widths $(10,14$ and $18 \mathrm{~m})$. Furthermore, to enable a more detailed and insightful analysis, two more building widths of 12 and $16 \mathrm{~m}$ are added, meaning building widths are tested at $2 \mathrm{~m}$ increments $(10,12,14,16$ and $18 \mathrm{~m})$. This results in scenarios ranging from $12 \mathrm{~m}$ (10m building with $2 \mathrm{~m}$ gap) up to $28 \mathrm{~m}$ ( $18 \mathrm{~m}$ building with $10 \mathrm{~m}$ gap). This method enables a more comprehensive investigation of built-to-void ratios; and makes findings applicable to a wider range of properties than just a standardized $20 \mathrm{~m}$ wide plot. Figure 5.8 illustrates how building width ranges from $10-18 \mathrm{~m}$ and the gap between it and adjacent buildings ranges from $2-10 m$, all in $2 m$ increments.

Each of the five building widths are tested in Models 1-9 and 13 (isolated). Model 0 tests a building width of $20 \mathrm{~m}$, as this is the non-passive baseline assumed to be $100 \%$ of the $20 \mathrm{~m}$ wide property width. Models 10, 11 and 12 test building widths of $10 \mathrm{~m}, 14 \mathrm{~m}$ and $18 \mathrm{~m}$ respectively, in accordance with the lowest, middle and highest density investigation explained in 'Section 5.2.2 - Road Width'.

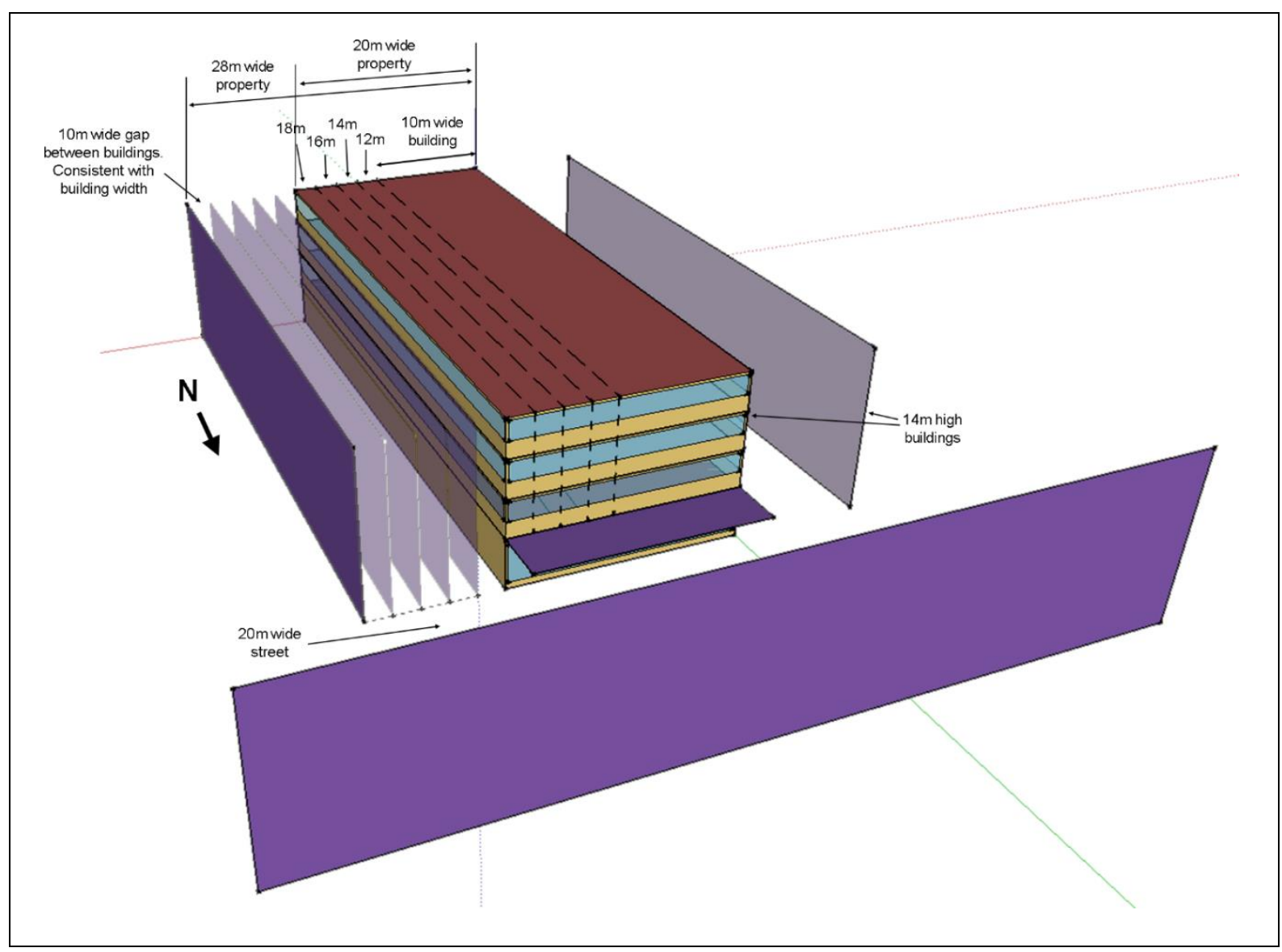

Figure 5.8. Example of ranging gaps between buildings being applied to all tested building widths. (Author).

\section{Summary: Urban Form Variable 4 - Building Width}

Lower limit $-10 \mathrm{~m}$ ( $50 \%$ of $20 \mathrm{~m}$ wide subject property)

Upper limit $-18 \mathrm{~m}$ (90\% of $20 \mathrm{~m}$ wide subject property)

Increments $-10,12,14,16$ and $18 m$ (every $2 \mathrm{~m}$ ) 


\title{
5.2.5 Urban Form Variable 5 - Continuous Frontage Height
}

'Section 3.3.2.2.1 - Building Setback and Continuity' of the CCPo states the Ground and First floors of all buildings in the CCB are to be built to $100 \%$ of the property width (refer Figure 5.9) (Christchurch City Council, 2013). This requirement has two purposes:

1) Security. Alleyways can be targeted for unlawful access to buildings, tagging and other criminal activity. Continuous frontage eliminates the opportunity for these kinds of activity.

2) 'Well defined street edge'. Continuous facades create a distinct urban canyon form and give substance to a strengthened urban structure (Rowland \& Moor, 2006).

These matters cannot be ignored. Security issues associated with dark lanes was identified as a potential barrier during dissemination of the pilot study. Additionally, a 'well defined street edge' is targeted by the CCC under their 'Stronger Built Identity' initiative, as discussed in Chapter 2. For these reasons continuous frontage is retained on the Ground floor in the proposed urban form scenarios. However, to maximize passive effect, the research proposes the $100 \%$ built width rule only be applied to the ground floor, to enable the first floor access to daylight and fresh air. Figure 5.9 illustrates this proposed alteration to the continuous frontage requirement.

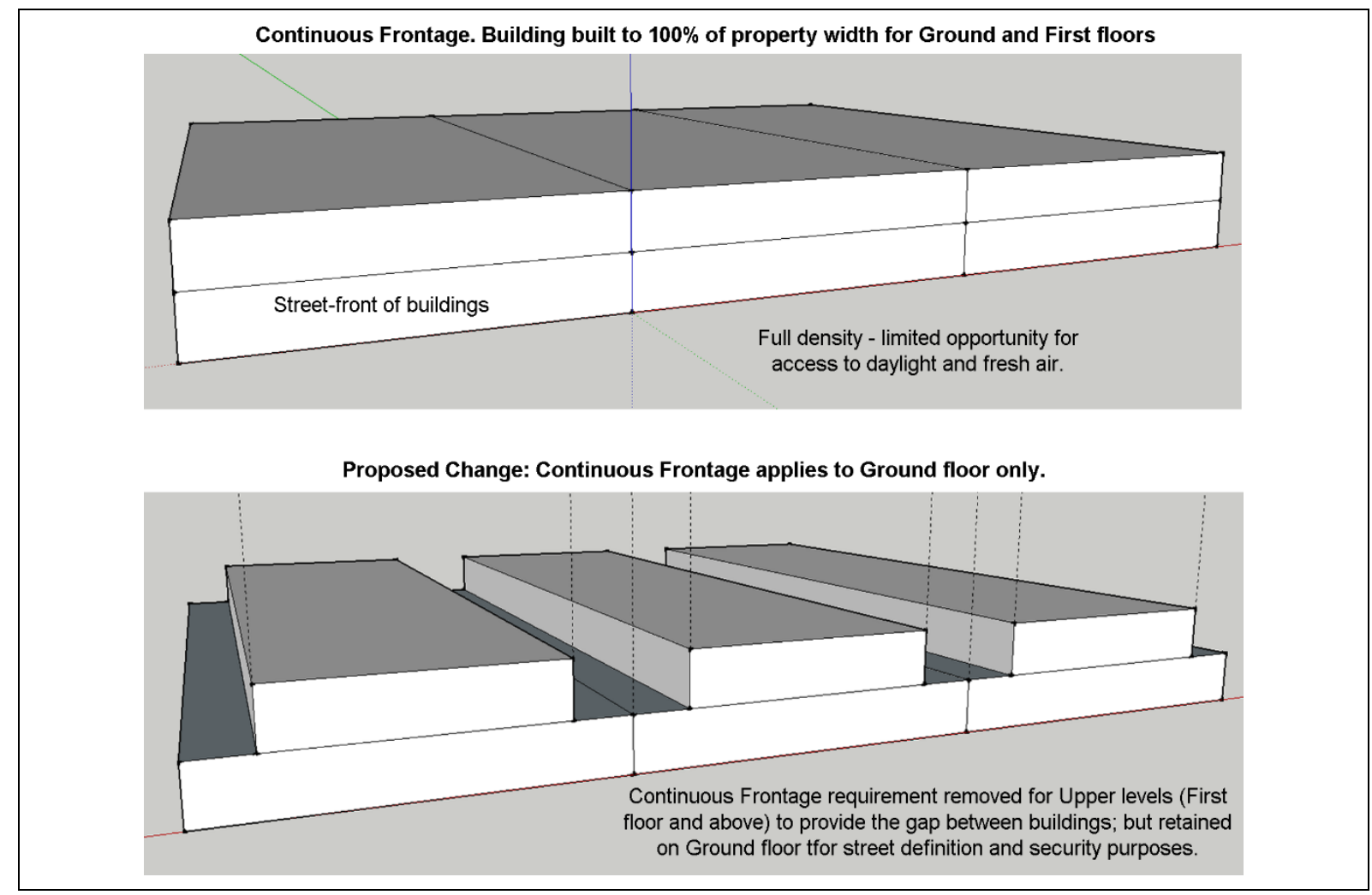

Figure 5.9. Continuous Frontage requirement in the CCB and the proposed change. (Author).

\author{
Summary: Urban Form Variable 5 - Continuous Frontage Height \\ Lower limit - 1 level (proposed minimum) \\ Upper limit - 2 levels (current CCPo minimum) \\ Increments - no other ( 1 and 2 levels)
}




\subsection{Development of the Christchurch Models}

Section 5.3 describes how the computer models of each scenario were developed from the property type analysis in Section 5.1 to incorporate the urban form variables identified in the previous Section 5.2. To do this two scenarios are used. Firstly, 'Model 0 ' (baseline scenario - non-passive) demonstrates the development process in full. Then 'Model 1 ' is used to demonstrate how urban form changes to the baseline were made. The method used for Model 1 is identical for all following Models (2-13), and so does not need to be repeated.

\subsubsection{Development of the Baseline (Model 0)}

Figure 5.10 ( $3 \mathrm{D}$ version of Figure 5.10) depicts the urban form of the entire baseline scenario (2 CCB Blocks) - labelled 'Model 0'. 'Model 0' was developed to represent Christchurch's urban form prior to the earthquakes and the likely form it will reassume if urban planning laws remain unchanged. This urban form is four storeys tall (refer Section 5.2.3) and built up to $100 \%$ of the property width and length. The model displayed in Figure 5.10 also represents the geometry that was used in CFD analysis software UrbaWind to generate the wind pressure coefficient data for Model 0.

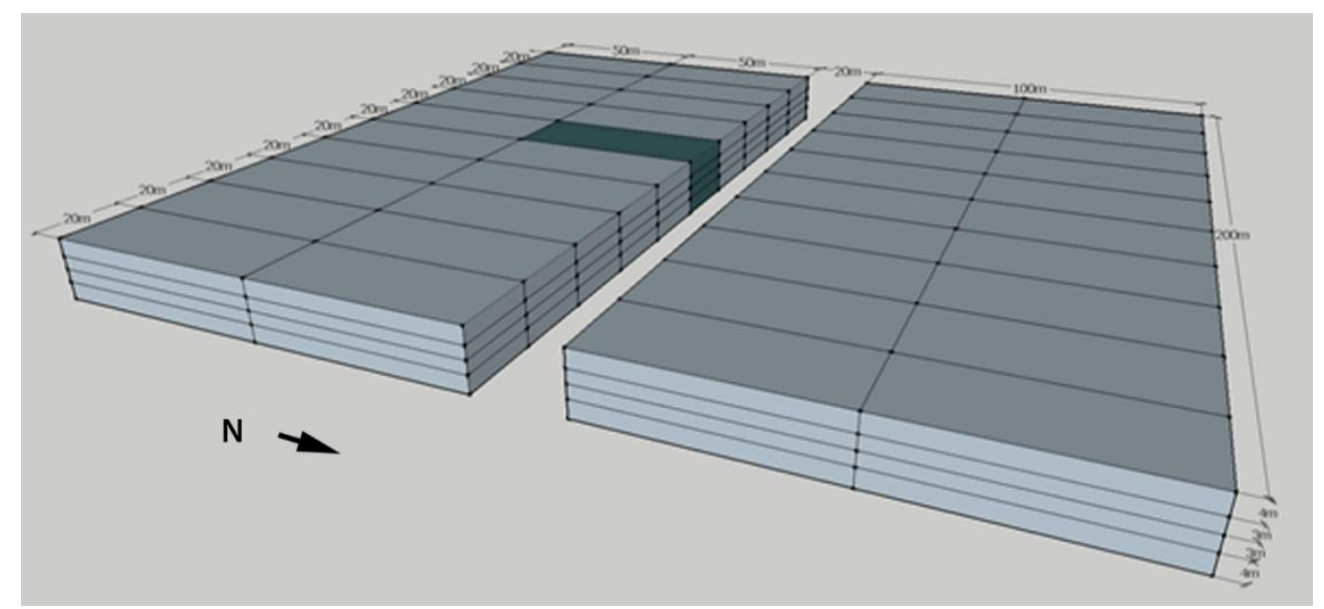

Figure 5.10. Final 'Model O' urban form. (Author).

Figure 5.11 focuses on the North-facing subject building (green), which is located in the centre of the southern block. This location was selected as it represents the most 'enclosed' position in the block, meaning it has the most restricted access to sun and wind pressures, and represents the worst-case scenario.

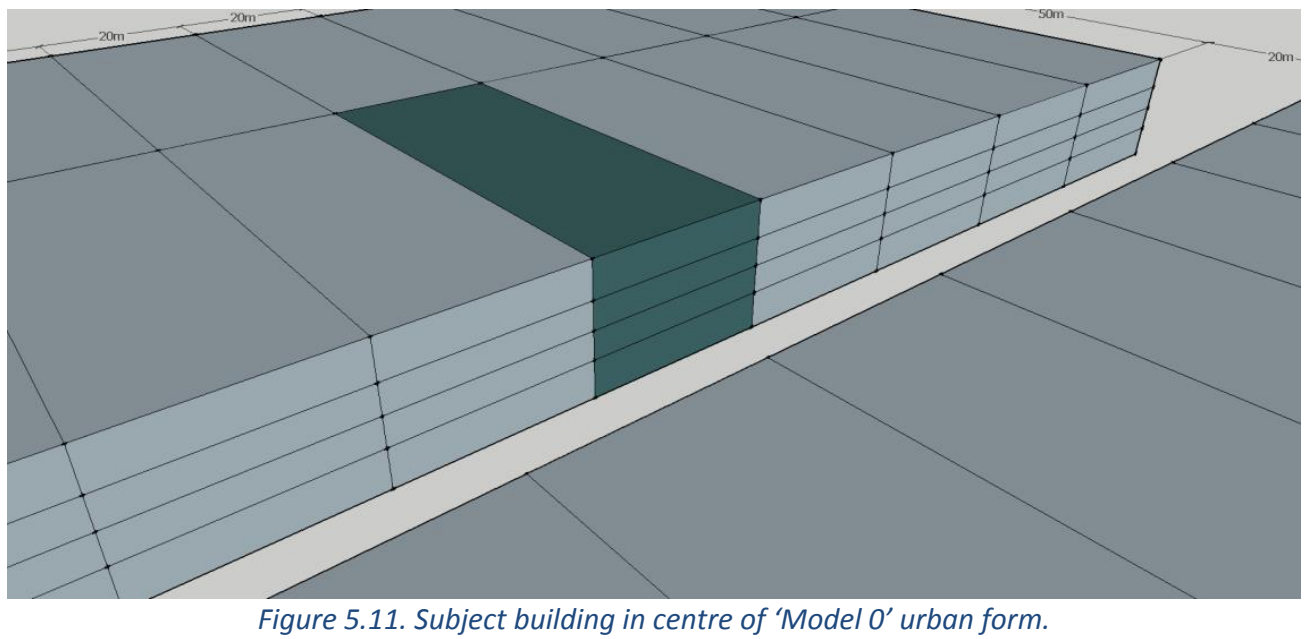


Figure 5.12 presents the OpenStudio/EnergyPlus version of the Model 0 baseline scenario. It shows the shading devices (purple surfaces) used to immitate the urban form surrounding the subject building. Shading surfaces were positioned adjacent to each of the subject buildings south, east and west walls to replicate the party-wall conditions seen in reality. For context, Figure 5.12 includes neighbouring buildings to better illustrate the neighbouring buildings represented by the purple shading devices. A large $(60 \mathrm{~m}$ long) shading surface is located to the North of the building representing the building frontage of three $20 \mathrm{~m}$ wide buildings on the opposite side of the street. Horizontal shading devices have also been positioned along the top of the Ground floor ( $4 \mathrm{~m}$ above street level) to represent Verandas, in accordance with the CCPo (Christchurch City Council, 2010).

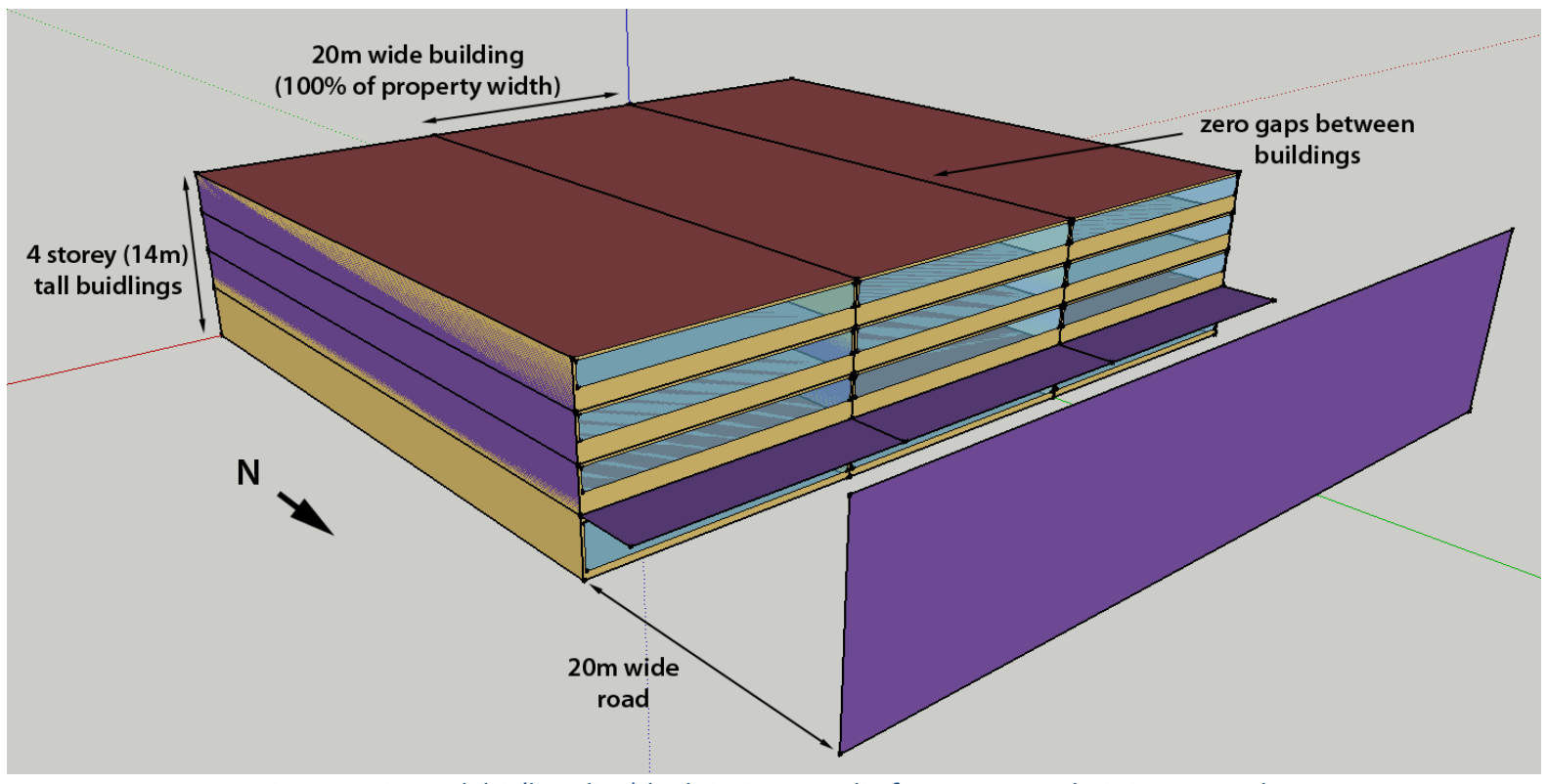

Figure 5.12. Model 0 (baseline) built in OpenStudio for energy analysis in EnergyPlus

Figure 5.13 presents the Ecotect model which is then simulated and analysed in Daysim. This model is identical to the OpenStudio/EnergyPlus model in Figure 5.12.

Only the single representative level and analysis grid is modelled and simulated for daylight, as discussed in Section 4.2.1.7. Illuminance levels calculated for this zone (Level 3) were also assumed for Levels 2 and 4 . Shading devices are not required along the side walls to represent neighbouring buildings, as only daylight data is taken from this model; solar gains and thermal interactions through these walls are irrelevant. All building design settings and inputs (e.g. materiality, WWR, etc.) for both the EnergyPlus and Daysim models are defined in Section 5.4.1 (Table 5.2).

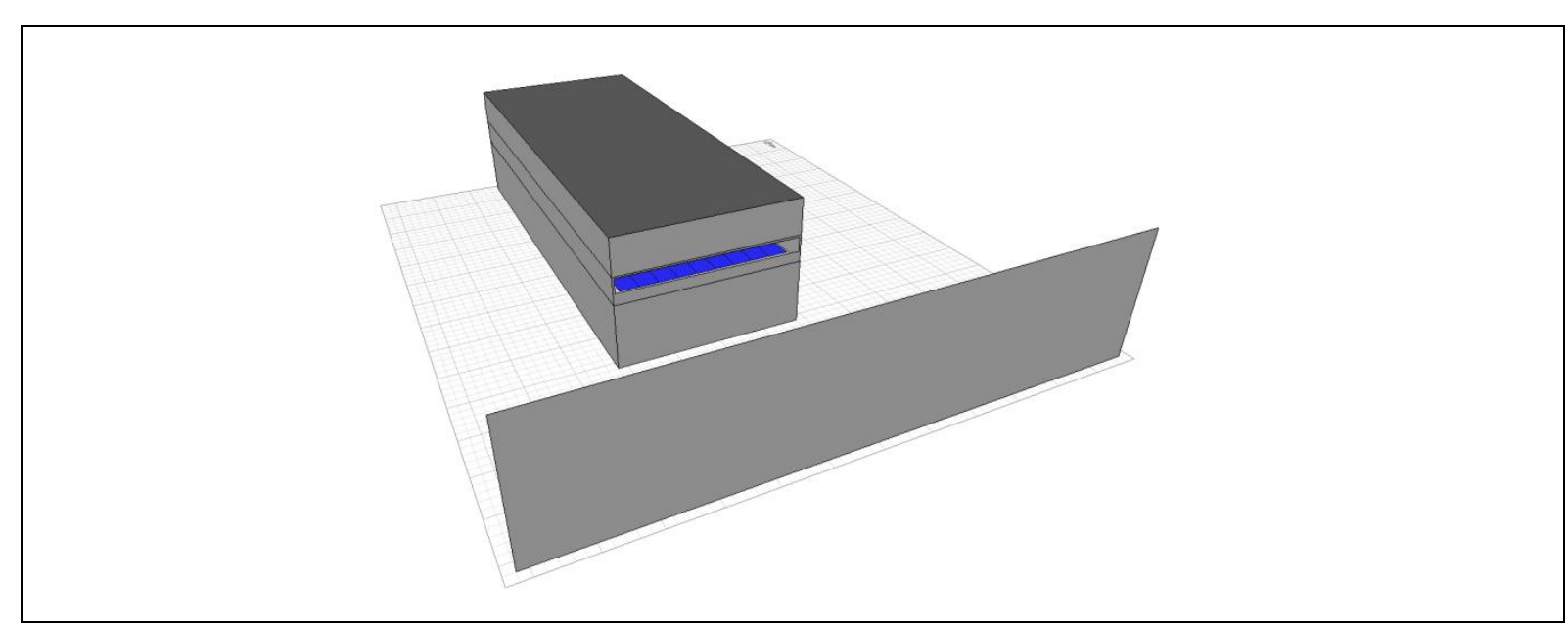

Figure 5.13. Model 0 (baseline) built in Ecotect for daylight analysis in Daysim 


\subsubsection{Development of Proposed Urban Form Variation Models (Model 1)}

Figure 5.14 illustrates the full urban form of 'Model 1', which embodies the first urban form change of a $2 \mathrm{~m}$ 'gap between buildings' ( $1 \mathrm{~m}$ gap between either side of the building and the property boundary). Apart from this variation, the model remains exactly the same as the Baseline to maintain comparability. As with the baseline, the model shown here represents the geometry exported to UrbaWind for wind pressure coefficient data.

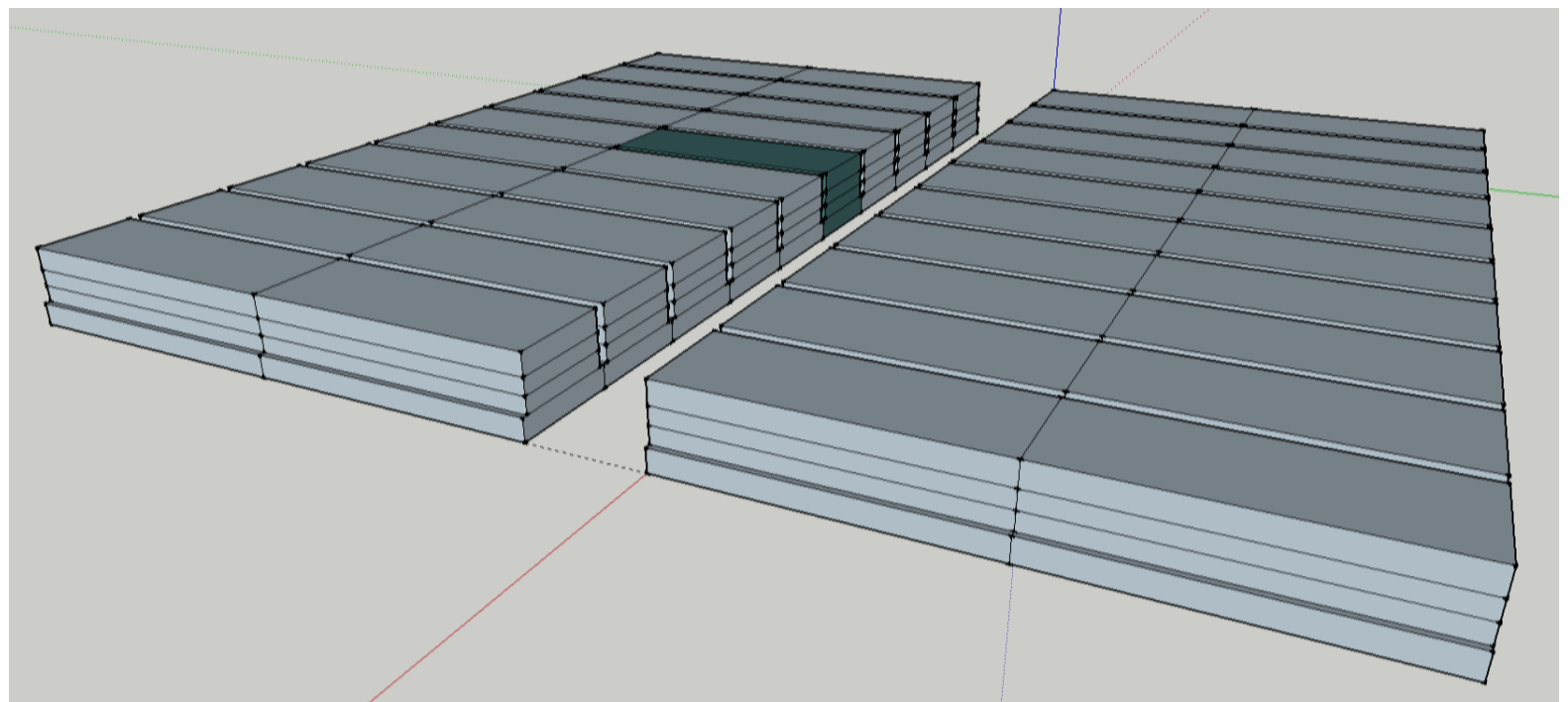

Figure 5.14. Full Model 1 urban form.

Figure 5.15 again focuses on the North-facing subject building (green). It shows how the width of the upper floors of the building have been reduced by $1 \mathrm{~m}$ (either side) down to $18 \mathrm{~m}$ to provide a $2 \mathrm{~m}$ gap between it and its neighbouring building on both sides. It is these gaps that are intended as the mechanism to deliver daylight and fresh air to internal building spaces. The Ground floor however remains built to the full $100 \%$ of the $20 \mathrm{~m}$ property width to retain continuous frontage.

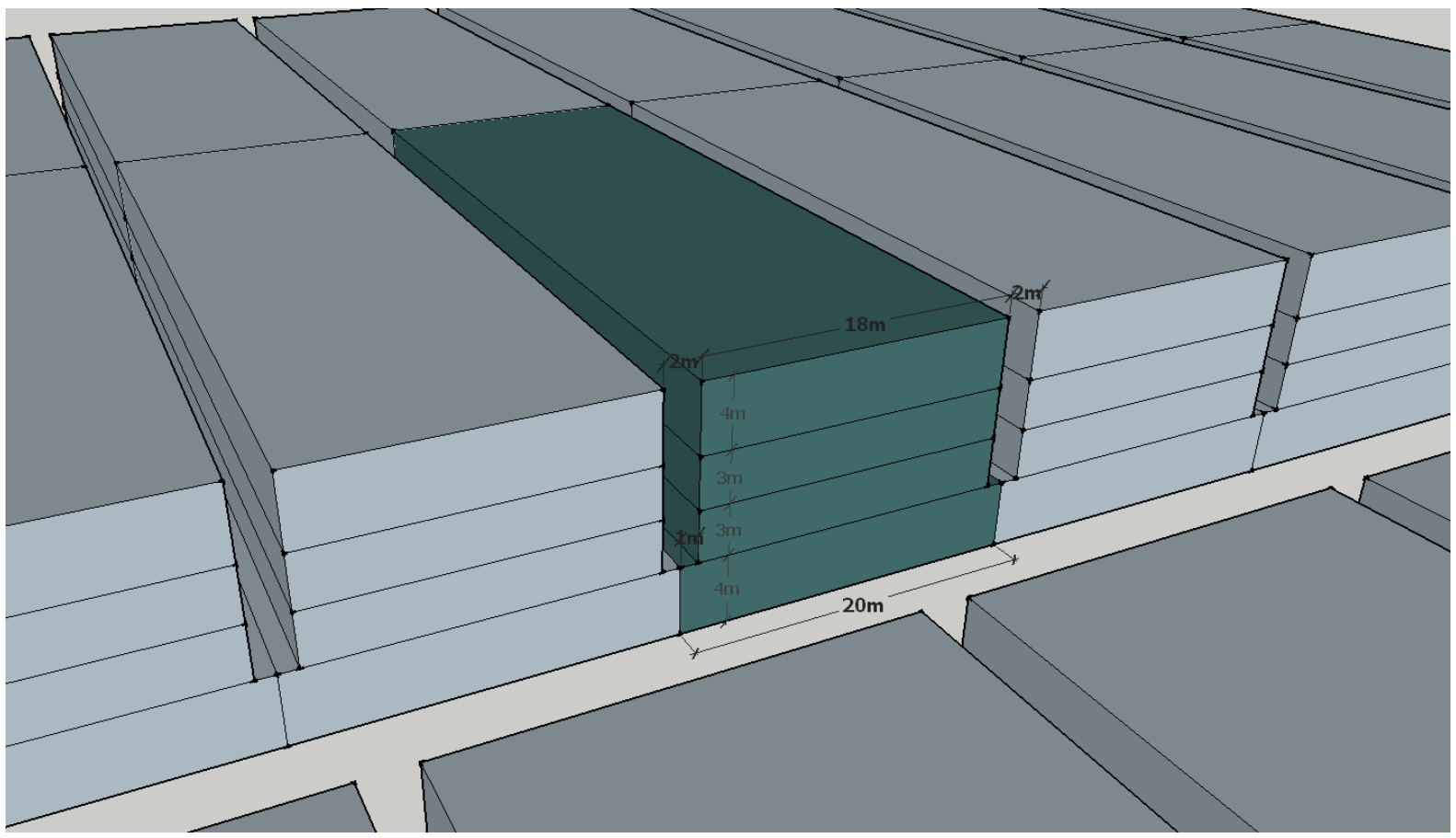

Figure 5.15. Altered subject building in centre of Model 1 urban form. 
Figure 5.16 translates the full urban form scenario into an EnergyPlus model. It shows how the shading devices along the sides (east and west) of the building have also been set back from the property boundary by $1 \mathrm{~m}$ (on either side) to represent the $2 \mathrm{~m}$ gap between buildings. Two more shading surfaces are applied to the side facades of the Ground floor so that no solar gains can occur through those walls (as would be the case if their was continuous frontage along the Ground floor. The shading surfaces representing the veranda and buildings on the far side of the road remain unchanged.

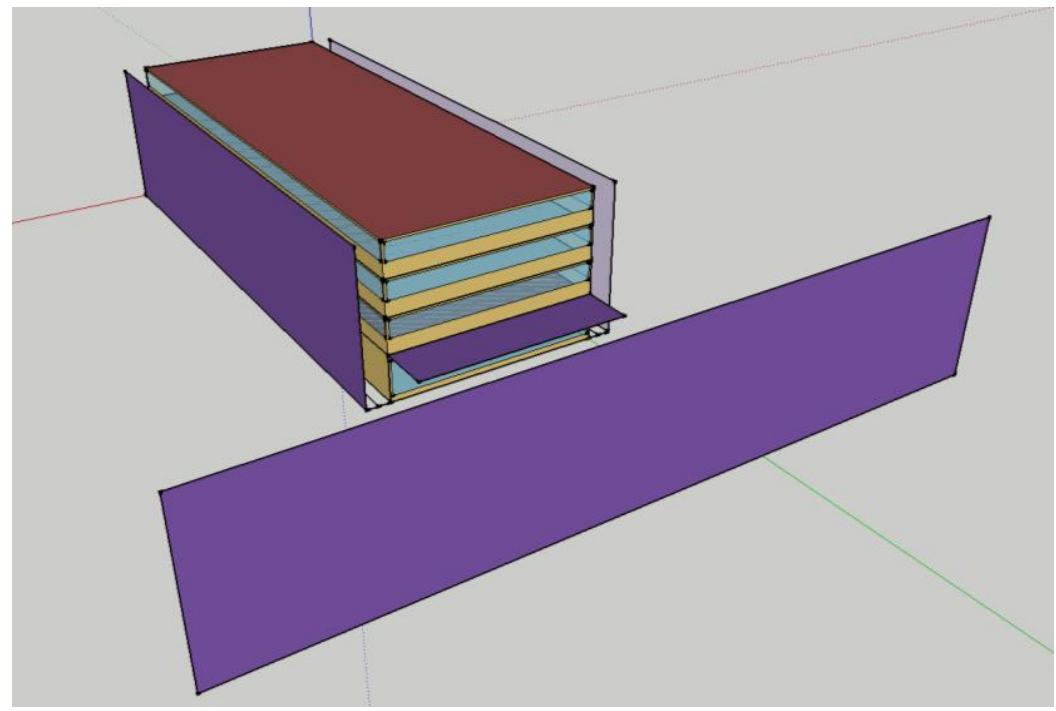

Figure 5.16. Model 1 built in OpenStudio for energy analysis in EnergyPlus.

Just with the baseline scenario, Model 1 is built identically for daylight analysis as it is for energy analysis. Figure 5.17 shows the same modifications to the building width and shading positioning along the sides of the building, but no changes to anything else.

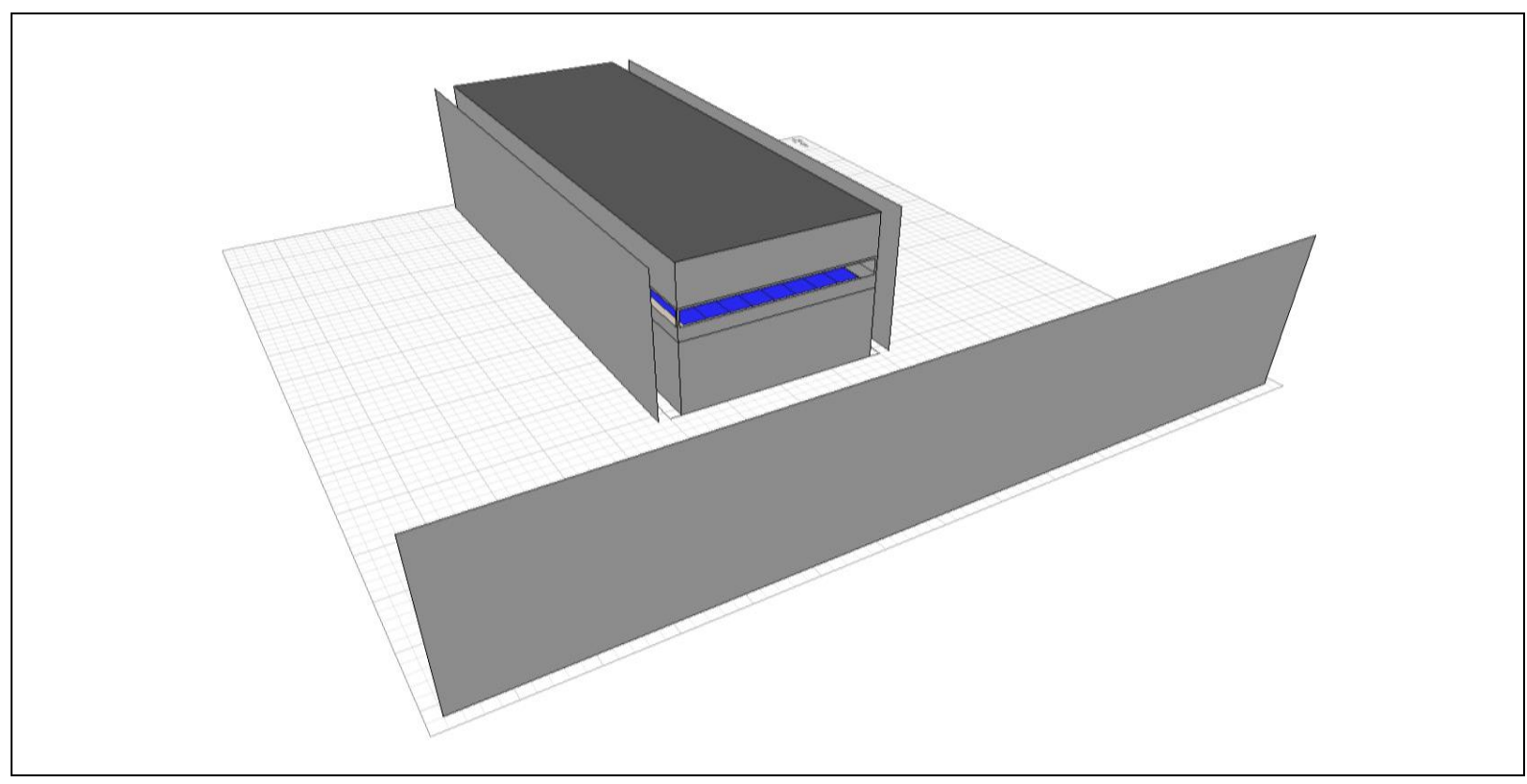

Figure 5.17. Christchurch Model 1 built in Ecotect for daylight analysis in Daysim. 


\subsection{The Urban Form Models}

Section 5.4 presents each of the 14 final 'Urban Form Models' used for testing in the Urban Form investigation part of this research. Illustrations of the models include a summary of the urban form variables that characterize that scenario. Section 5.4.1 establishes the building design inputs constant across each of the Christchurch Models.

\section{Model 0 (Baseline)}

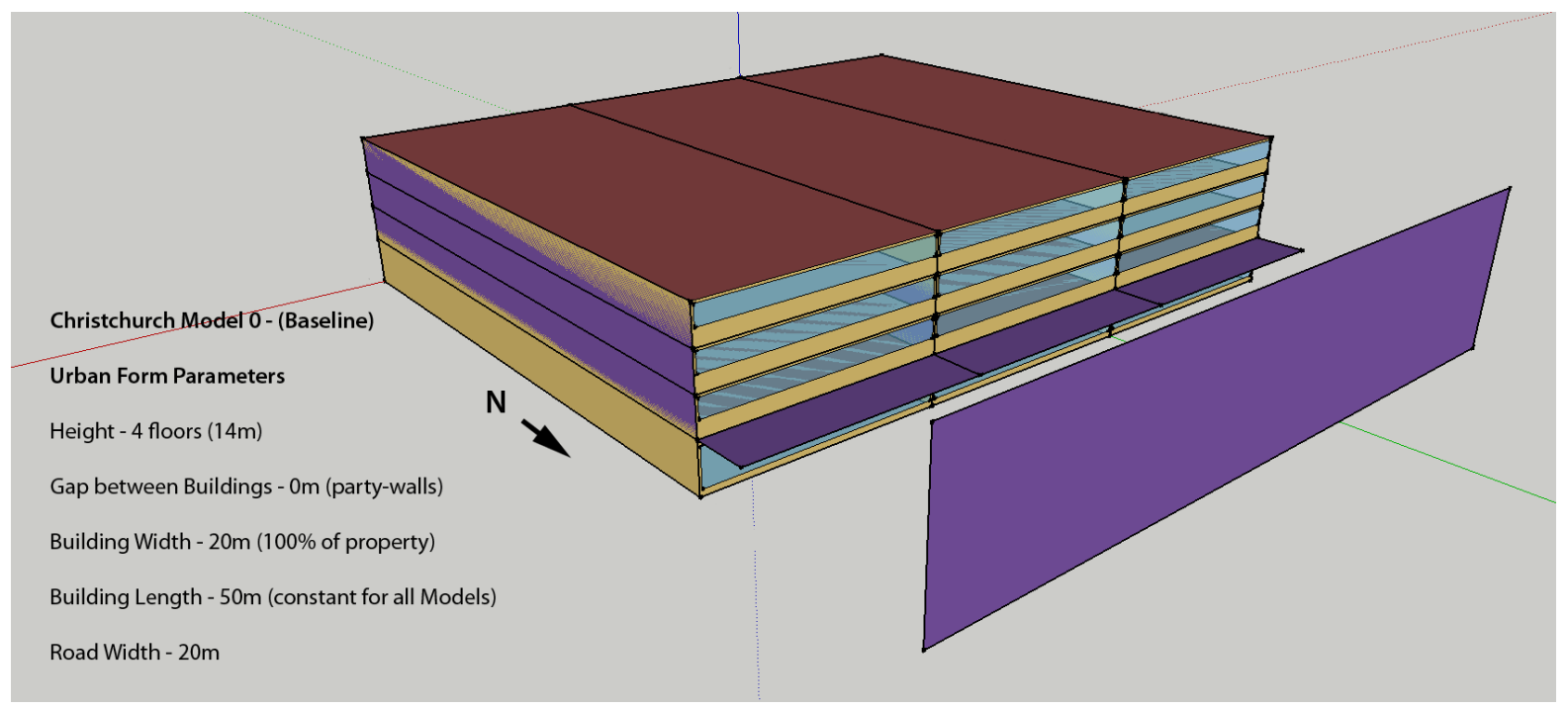

Figure 5.18. Model 0 (baseline)

\section{$\underline{\text { Model } 1}$}

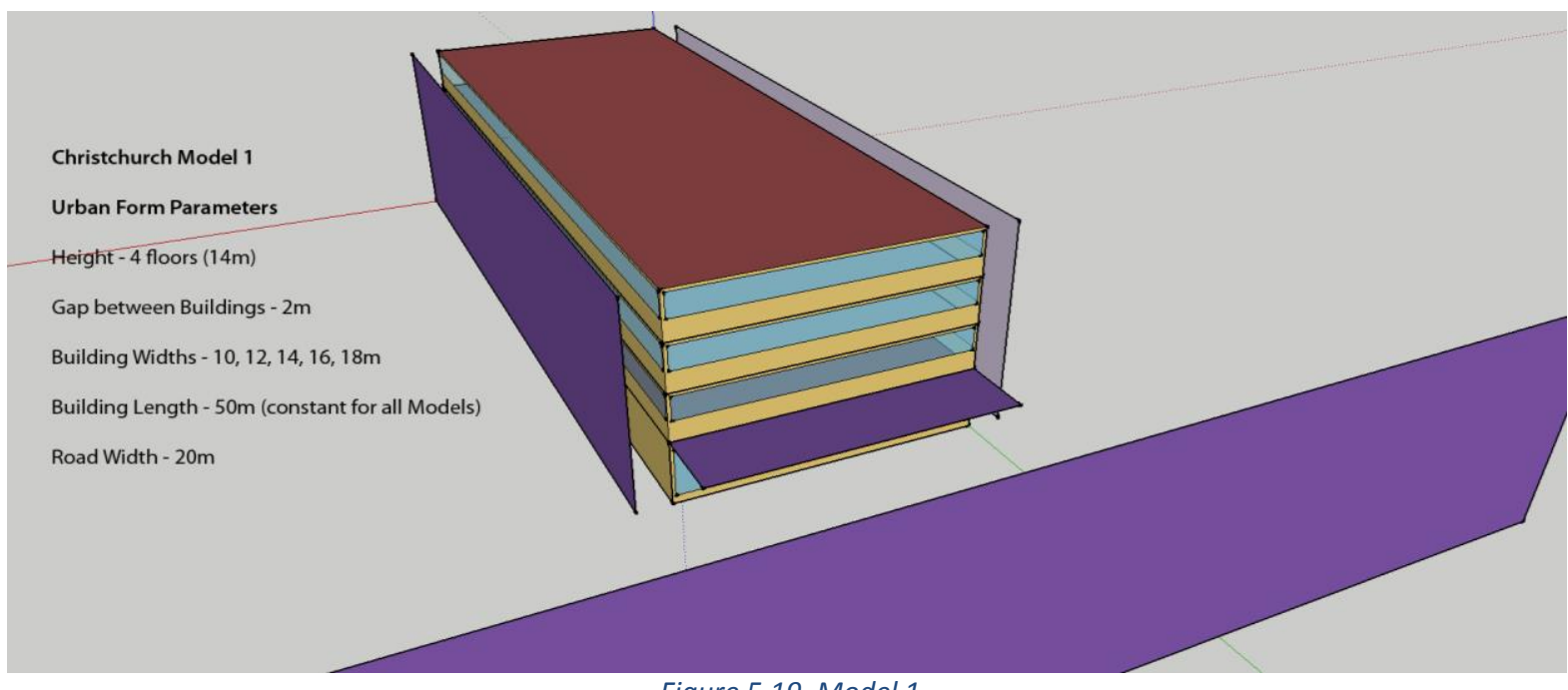

Figure 5.19. Model 1 


\section{Model 2}

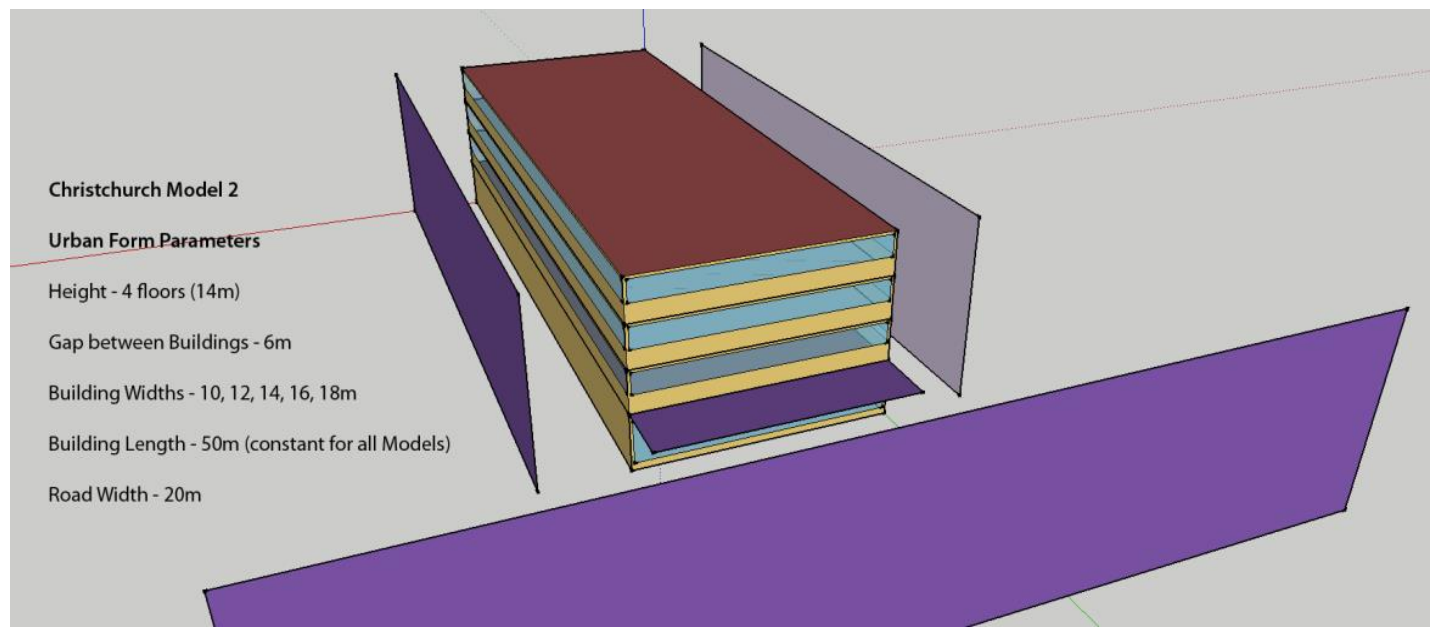

Figure 5.20. Model 2

\section{$\underline{\text { Model } 3}$}

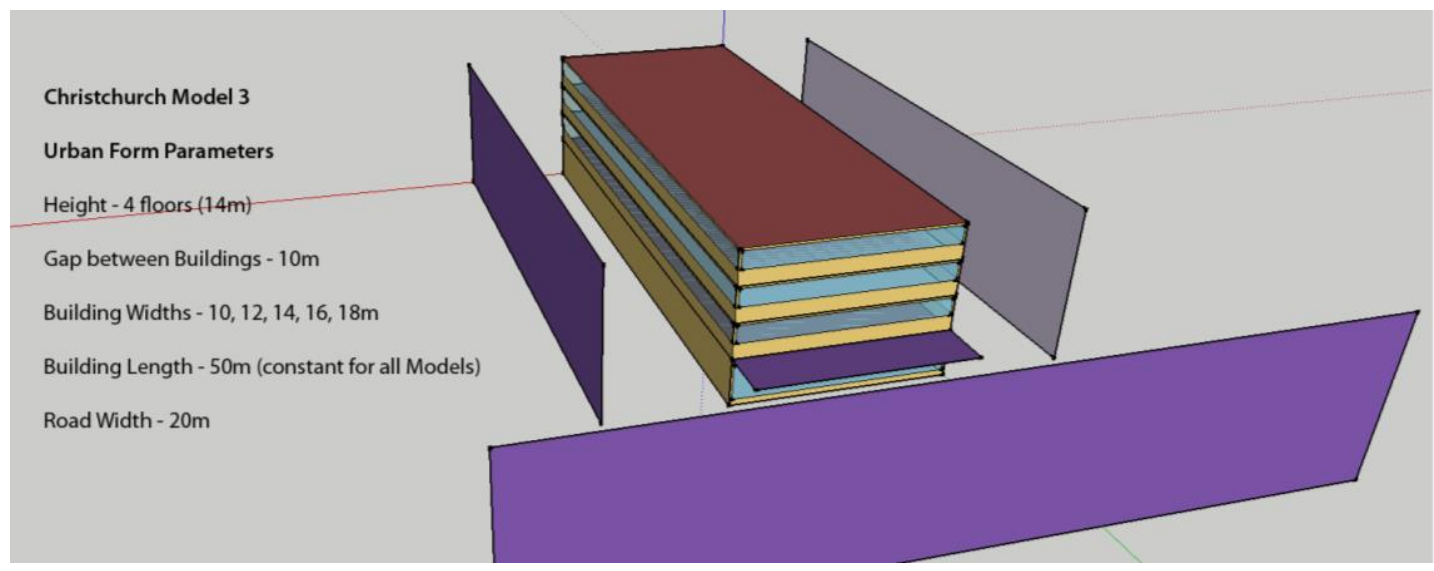

Figure 5.21. Model 3

\section{Model 4}

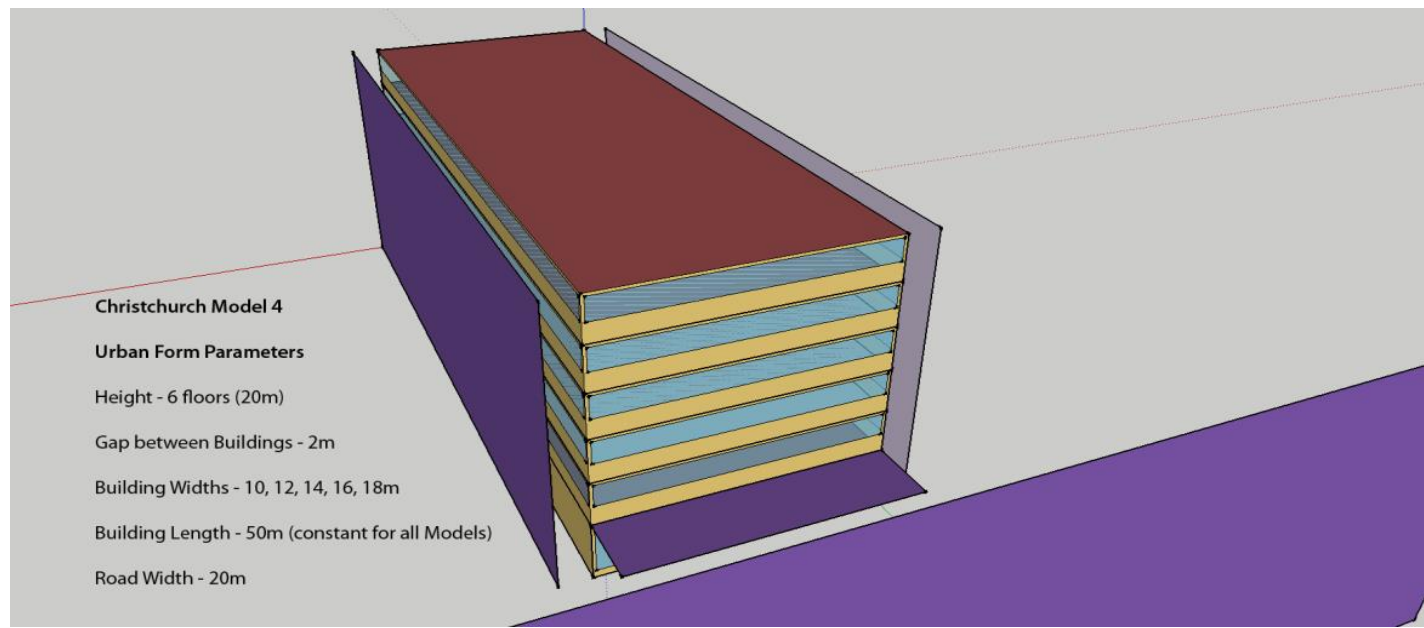

Figure 5.22. Model 4 


\section{$\underline{\text { Model } 5}$}

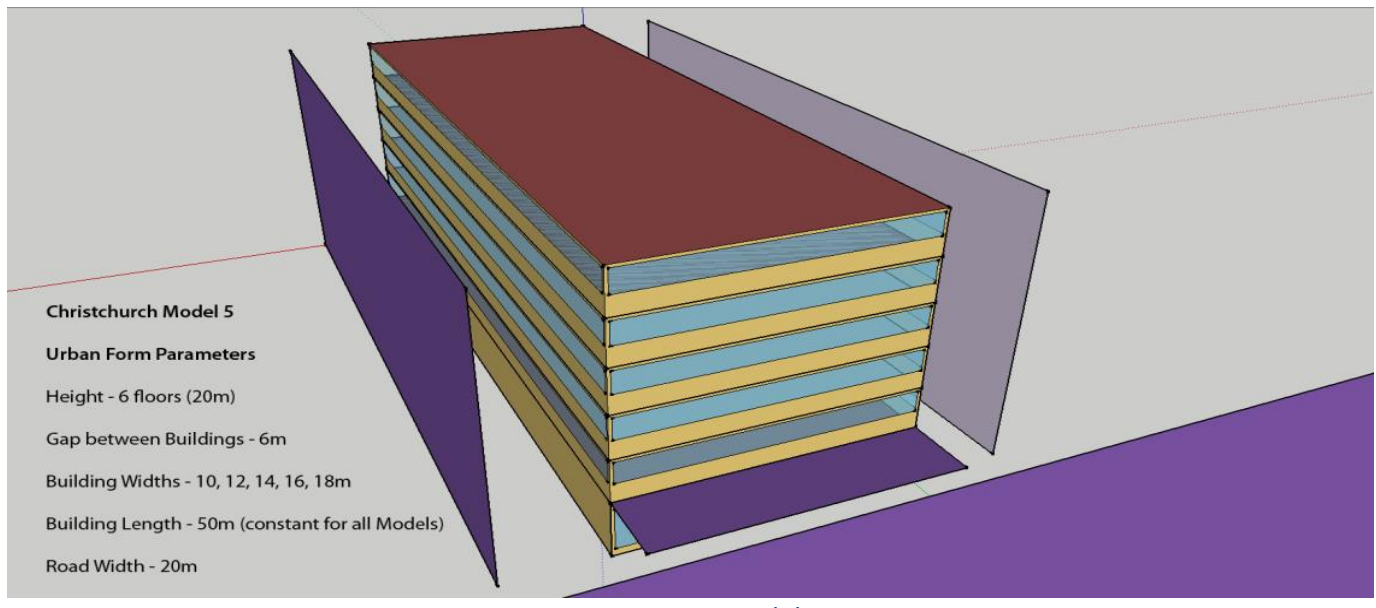

Figure 5.23. Model 5

\section{Model 6}

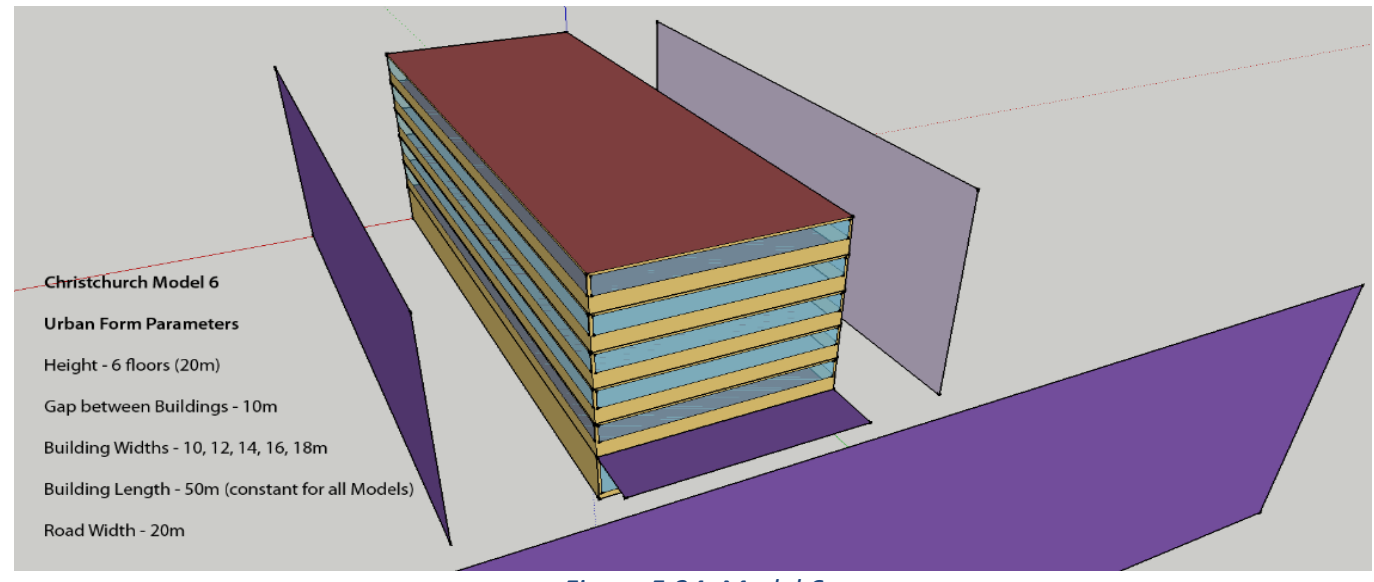

Figure 5.24. Model 6

\section{$\underline{\text { Model } 7}$}

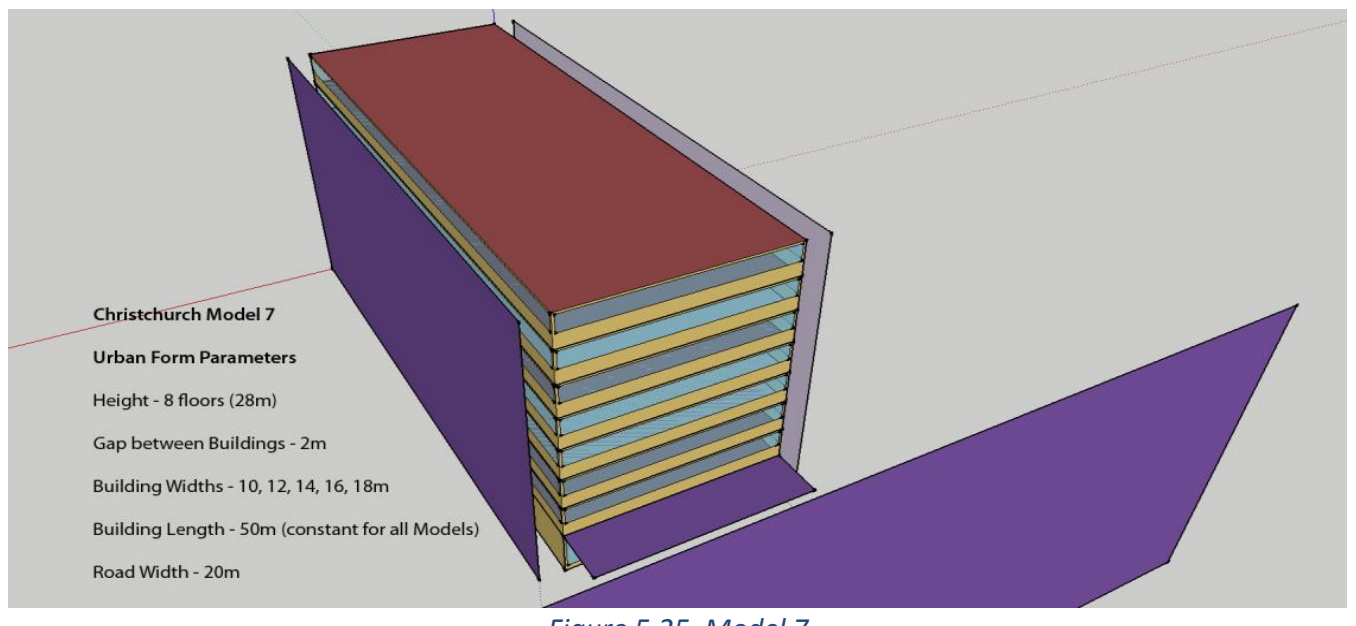

Figure 5.25. Model 7 


\section{Model 8}

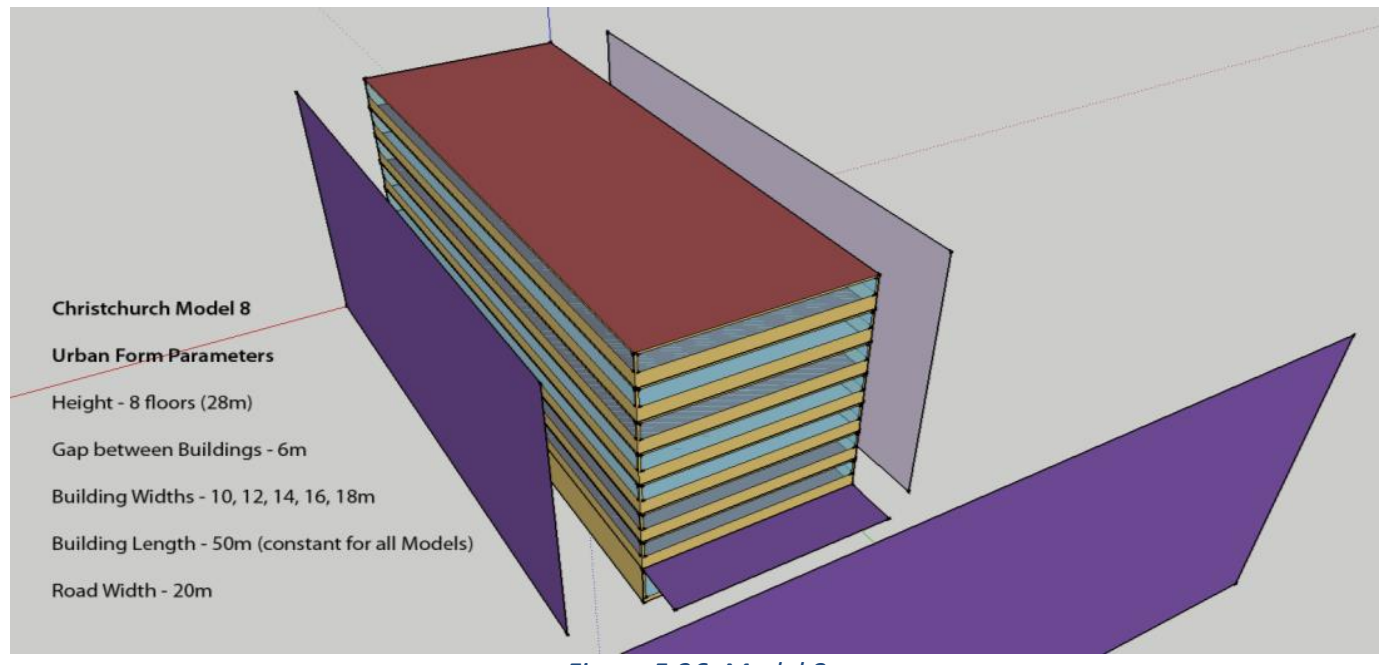

Figure 5.26. Model 8

\section{$\underline{\text { Model } 9}$}

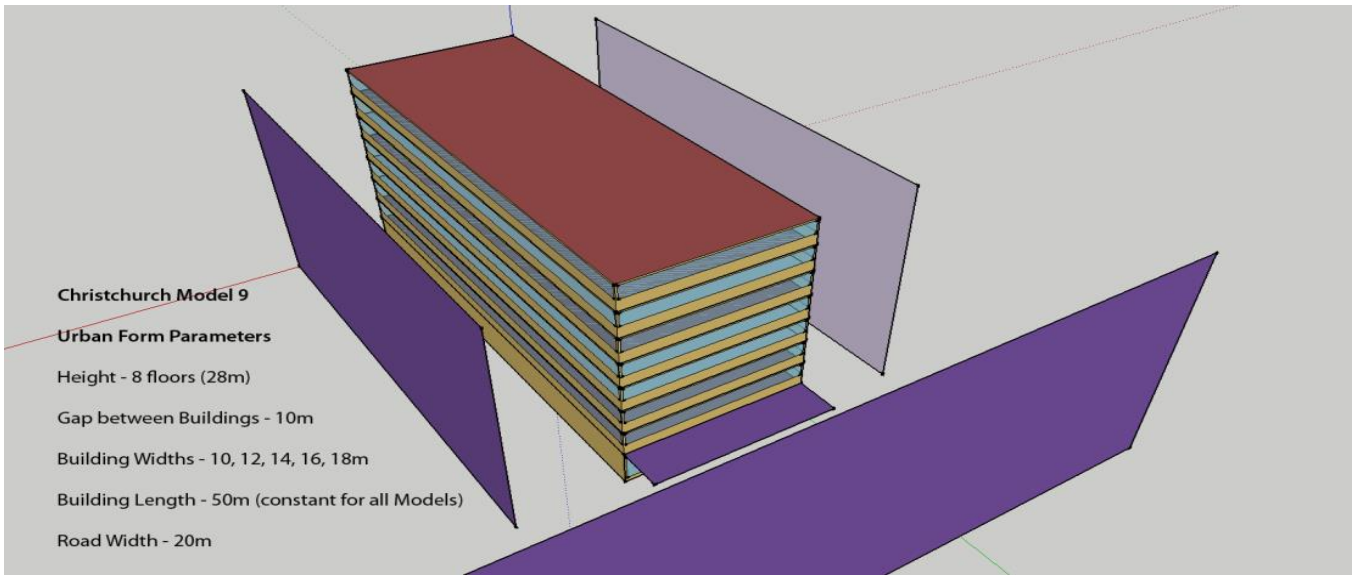

Figure 5.27. Model 9

\section{Model 10}

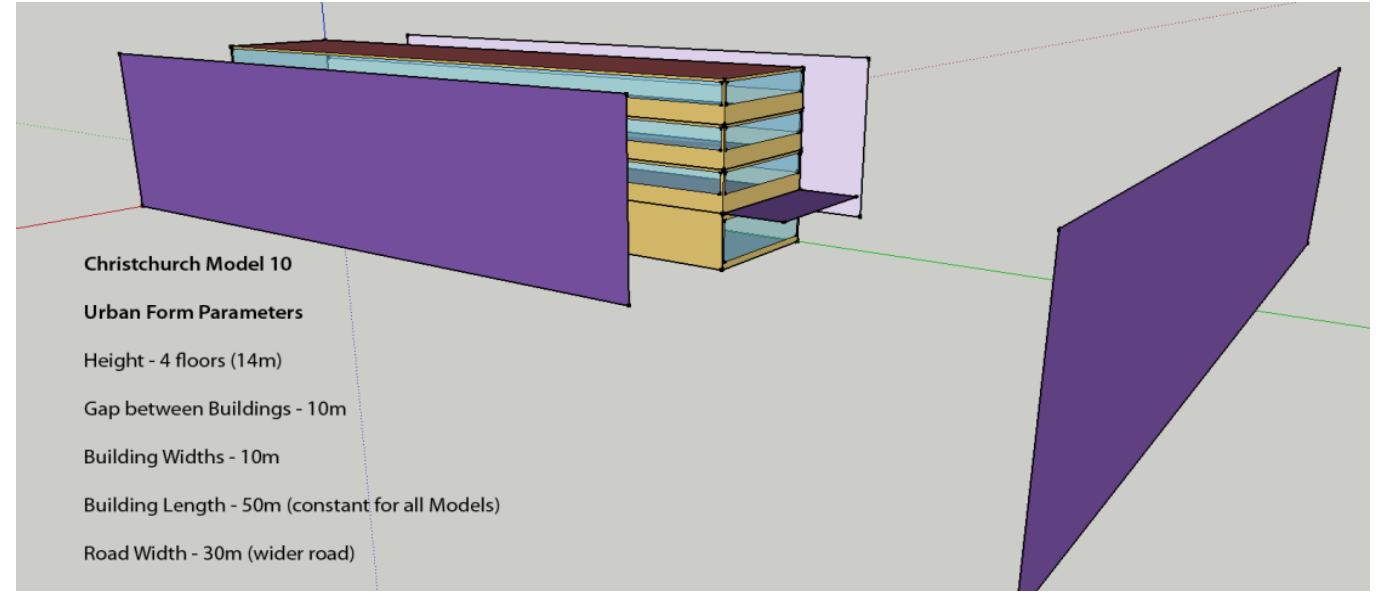

Figure 5.28. Model 10 


\section{Model 11}

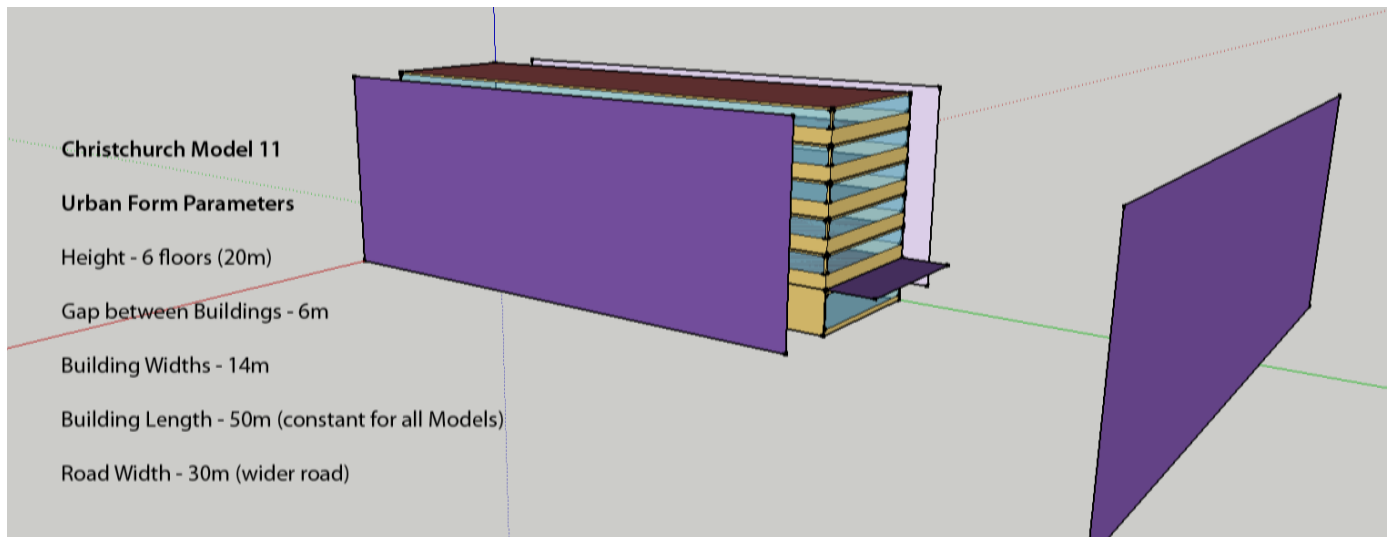

Figure 5.29. Model 11

\section{Model 12}

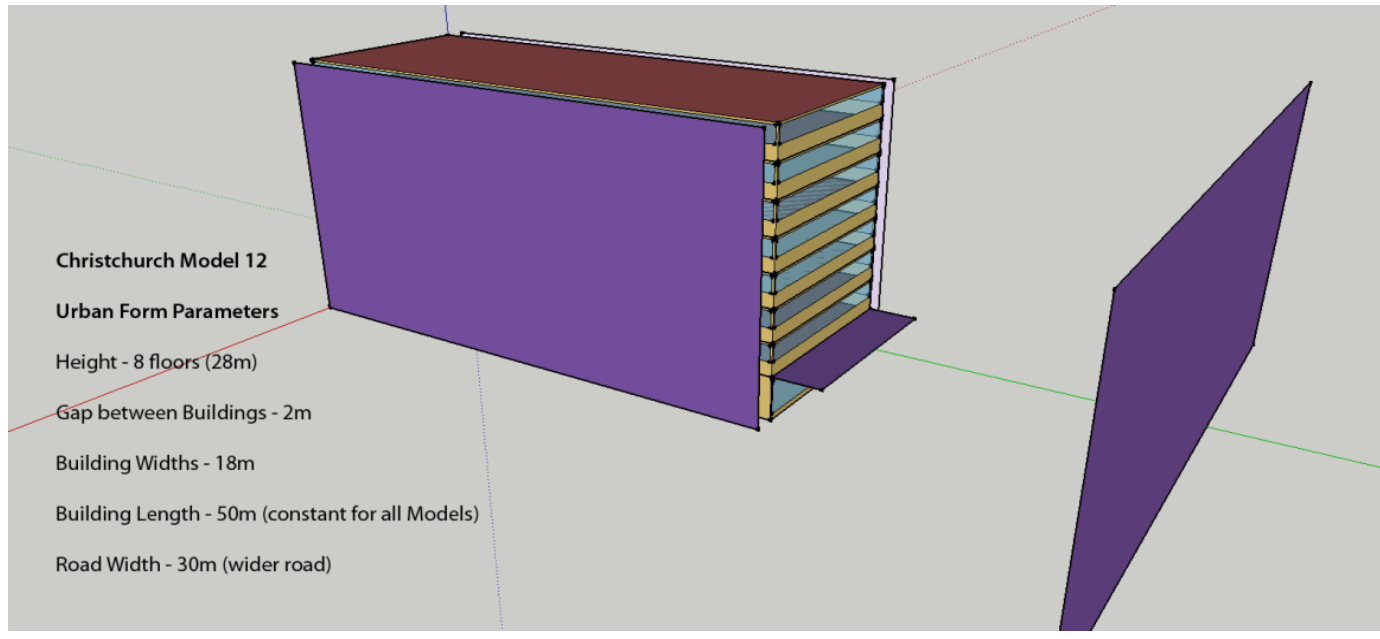

Figure 5.30. Model 12

\section{Model 13 (Isolated)}

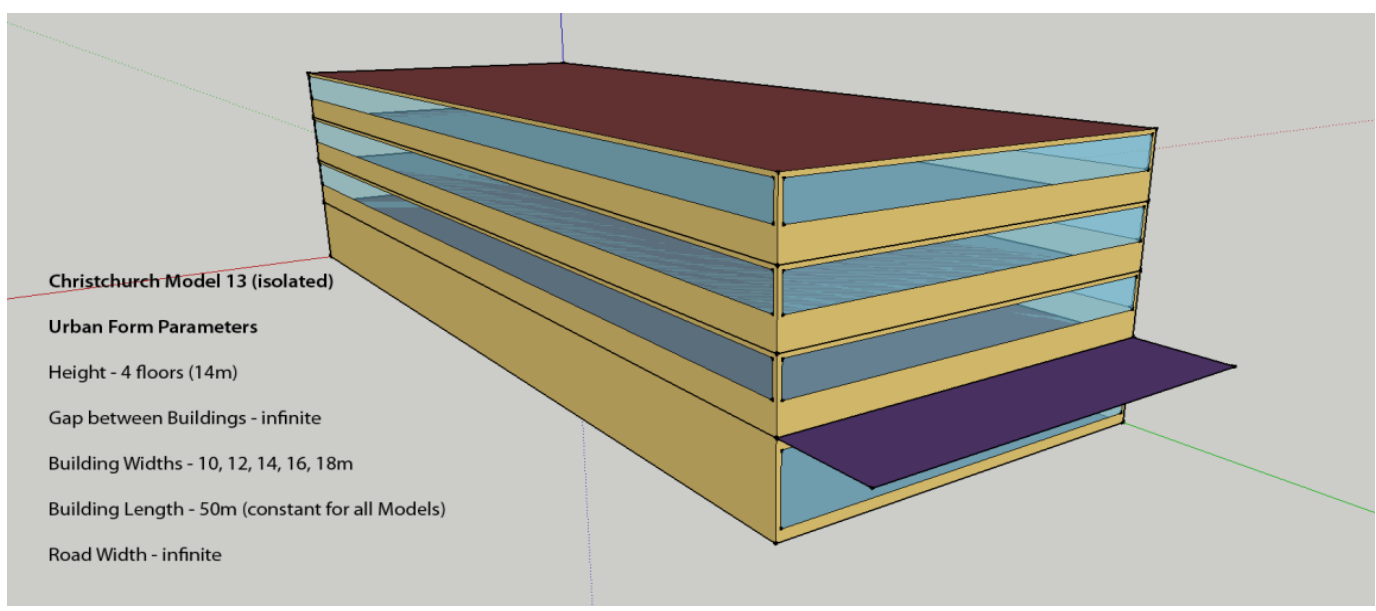

Figure 5.31. Model 13 


\subsubsection{Non-Urban Form Model Parameters}

The Models presented above test a single isolated urban form variable in each scenario. In terms of the design of the building itself, they all consist of identical and constant parameters, based on Building Code minimums, relevant published standards and literature (refer Table 5.2). Minimum design standards were used to produce legal, and therefore feasible, buildings that were not complex or expensive- ensuring the focus remained on urban form, and emphasizing that urban forms effect on performance does not require advanced building design. Building design parameters are investigated in depth in the following 'Chapter 6 - Parametric Investigation of Passive Building Design'.

\begin{tabular}{|c|c|c|}
\hline Parameter & Value & Reason/ Source \\
\hline Construction Type & $\begin{array}{l}\text { Concrete with } \\
\text { insulation on inside }\end{array}$ & BEES data. \\
\hline Insulation - Walls & $\mathrm{R}-1.2$ & Building Code minimum for Climate Zone 3 \\
\hline Insulation - Roof & R-1.9 & Building Code minimum for Climate Zone 3 \\
\hline $\begin{array}{l}\text { Window to Wall Ratio - } \\
\text { Upper floors }\end{array}$ & $50 \%$ (uniform) & Refer Section 6.1.1. \\
\hline $\begin{array}{l}\text { Window to Wall Ratio- } \\
\text { Ground floor }\end{array}$ & $80 \%$ & $\begin{array}{l}\text { Maximum realistic WWR (LoVerso \& Reinhart, } \\
2010 \text { ). } \\
\text { Ground floor WWR maximized for 'active } \\
\text { frontage' principle. }\end{array}$ \\
\hline Window Positioning & $\begin{array}{l}200 \mathrm{~m} \text { from top and } \\
\text { side of wall }\end{array}$ & $\begin{array}{l}\text { High on wall for best practice (National } \\
\text { Institue of Building Sciences, 2012) }\end{array}$ \\
\hline Window Openable Area & $5 \%$ of floor area & $\begin{array}{l}\text { Minimum allowed according to 'NZBC Clause } \\
\text { G4 - Ventilation', Section 1.2.2. (refer } \\
\text { Appendix B.4 for calculations) }\end{array}$ \\
\hline Glazing Type & $\begin{array}{l}4 \mathrm{~mm} \text { clear glass, single } \\
\text { layer. }\end{array}$ & $\begin{array}{l}\text { Maximum Visible Transmittance (0.9) glazing. } \\
\text { Cheapest option. }\end{array}$ \\
\hline Reflectivity - Ceiling & 0.8 & \multirow{4}{*}{$\begin{array}{l}\text { According to International Standards: CIBSE, } \\
\text { Society of Lighting; and 'The Daylighting } \\
\text { Dashboard' (Reinhart \& Wienold, 2011). }\end{array}$} \\
\hline Reflectivity - Walls & 0.6 & \\
\hline Reflectivity - Floor & 0.3 & \\
\hline $\begin{array}{l}\text { Reflectivity - Exterior } \\
\text { Surfaces }\end{array}$ & 0.5 (averaged) & \\
\hline Inter-floor Heights & $3.0 \mathrm{~m}$ & - \\
\hline Lighting Power Density & $12.0 \mathrm{~W} / \mathrm{m}^{2}$ & $\begin{array}{l}\text { BEES EnergyPlus modelling templates (BRANZ, } \\
\text { 2012) }\end{array}$ \\
\hline $\begin{array}{l}\text { Equipment Power } \\
\text { Density }\end{array}$ & $8.5 \mathrm{~W} / \mathrm{m}^{2}$ & $\begin{array}{l}\text { BEES EnergyPlus modelling templates (BRANZ, } \\
\text { 2012) }\end{array}$ \\
\hline Occupant Schedule & Refer Appendix B.8. & $\begin{array}{l}\text { BEES EnergyPlus modelling templates (BRANZ, } \\
\text { 2012) }\end{array}$ \\
\hline $\begin{array}{l}\text { Daylight Available } \\
\text { Schedule }\end{array}$ & 8am-6pm, all days & $\begin{array}{l}\text { Recommended by IES (Illuminating } \\
\text { Engineering Society, 2012). }\end{array}$ \\
\hline $\begin{array}{l}\text { Natural Ventilation } \\
\text { Available Schedule }\end{array}$ & Always available & \\
\hline $\begin{array}{l}\text { HVAC Available } \\
\text { Schedule }\end{array}$ & 8am-6pm, weekdays & $\begin{array}{l}\text { Conditioning on required during occupied } \\
\text { hours. }\end{array}$ \\
\hline
\end{tabular}

Table 5.2. Building design specifications and inputs for 'test building' in Urban Form investigation. 
Urban Form and Passive Design for High Performance Buildings in the Christchurch Rebuild 


\section{Chapter 6: Parametric Investigation of Passive Building Design}

Chapter 6 continues the parametric investigation conducted in Chapter 5, but with focus on building design. It aims to determine how much more building performance can be improved, from the basic design used in Chapter 5, through more detailed design of the building envelope. Section 6.1 explains the parametric methodology used for this 'Building Design' investigation and how it fits into the overall study. Sections 6.2 and 6.3 identify and discuss the 'Daylighting Design' variables and 'Thermal and Ventilation Design' variables that will be tested in the 'Building Design' investigation.

\subsection{The 'Building Design' Parametric Set-up}

This section describes the parametric 'Building Design' methodology used and how it was split into its two parts: 'Daylighting Design' and 'Ventilation and Thermal Design', with an accompanying diagram in Figure 6.1.

\section{Daylighting Design}

The first part of the Building Design investigation - Daylighting Design - takes the Urban Form scenario which produced the best energy performance results in terms of EUI (refer Section 7.1.1) and attempts to further develop its efficiency.

Daylighting Design variables and variations (Section 6.2) are tested parametrically and manually. Three Daylighting design features/variables with potential to improve daylight performance, and three variations of each, are identified and discussed. Each variation is isolated during testing to ensure results are clear and conclusive. This method will require $27(3 \times 3 \times 3)$ Daylighting Design scenarios to be built and simulated in both Daysim (daylight performance) and then EnergyPlus (energy performance). As modelling is done manually, scenarios needed to be limited. Three variations of each variable enables patterns to be identified, and so is considerably more informative than two variations. Any more than this (e.g. 4 variations) would incur a substantial increase in models $(4 \times 4 \times 4=64)$ but provide little more opportunity for analysis. Each of the 27 'Daylighting Designs' will then be compared against each other and the original Daylighting Design scenario to see which combination of variables produced the most energy efficient building. The best Daylighting Design will then be taken forward to the 'Ventilation and Thermal Design' stage for further development.

\section{Ventilation and Thermal Design}

The second part of the Building Design investigation - Ventilation and Thermal Design - takes the best Daylighting Design scenario (in terms of EUI) and attempts to further develop its efficiency.

Ventilation and Thermal Design variables (four) and variations (four of each variable) (Section 6.3), unlike Daylighting Design variables, are 'optimized' automatically using GenOpt. GenOpt alters userdefined design parameters of the EnergyPlus model until an 'optimum' solution is found. This optimum solution is defined by a 'cost-function', in this case- Total Energy Consumption (Lights+Heating+Cooling+Fans). The benefit of GenOpt is that not all combinations (potentially up to $4 \times 4 \times 4 \times 4=256$ ) need to be tested in a traditional parametric manner. GenOpt's algorithms identify which variables have the most positive impact on reducing energy consumption, and focuses on those parameters first (Wetter, 2008). This more direct, automated route to the solution enabled a much more efficient process than the manually conducted Daylight Design investigation- which consisted of fewer variables. GenOpt's use is possible here because Ventilation and Thermal Designs do not affect daylight, meaning Daysim did not have to be integrated for simulations and the conventional GenOpt with EnergyPlus optimisation process could be used. 
Ventilation and Thermal designs are applied only to the best Daylighting Design scenario as it has the highest potential for total energy savings. The 'optimized' design resulting from this procedure is the final product of the study and represents the best urban form plus passive design scenario for building performance. Analysis and results are presented in Chapter 7 following.

Technically, this research does not develop a true 'optimum' solution which varies non-discrete, variables continuously along a linear scale until performance cannot be improved any further. The parametric style employed here tests only a range of predefined, discrete variables which cannot reach the same degree of inquisition. However, the term 'optimized' is used to indicate the optimum solution of those scenarios tested has been reached- offering an element of finality.

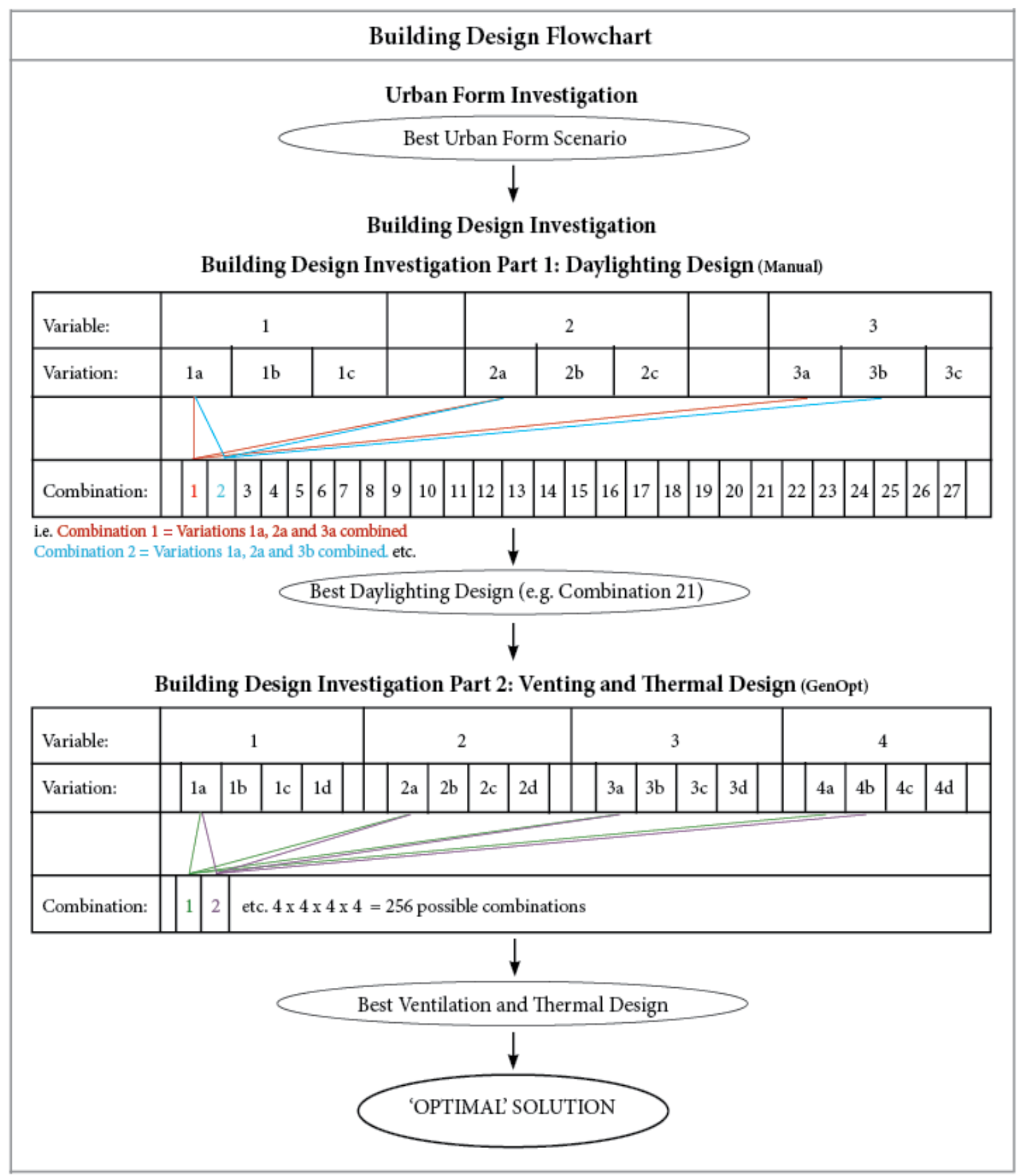

Figure 6.1. Flow-chart illustrating the 'Building Design' parametric investigation process. (Author). 


\subsection{Parameterization - Daylighting Design Variables Tested}

This section identifies significant Daylighting Design variables and, using relevant publications and standards, determines a range of variations to be tested parametrically.

\subsubsection{Daylighting Design Variable 1 - Window to Wall Ratio (WWR)}

WWR represents a windows size in relation to its parent wall surface, e.g. a WWR of 0.5 would signify a wall or façade that consists of $50 \%$ glazing (refer Figure 6.2). The sizing of glazed areas is of particular importance in daylighting and passive design. Larger WWR's offer better potential for daylighting, but also increase chances of solar gains (heat energy). In office buildings, overheating due to high occupant and equipment densities is already an issue and can be exacerbated when solar heat is added in an attempt to daylight.

Determining an appropriate WWR depends on factors like climate which can affect the amount of solar light and heat available to the building. Studies by Johnson et al. (1984) and Tian et al. (2008) attempted to determine the most effective aperture size for an office building in a moderately cold climate. In terms of effect on daylighting and thermal performance, they both found that a WWR of 0.4 was the most effective. A similar study by Tzempelikos and Athienitis (2005) found that, with the addition of exterior shading systems, WWR of $50-60 \%$ were optimal. The maximum WWR allowed under the Compliance Method of NZS4243 - Energy Efficiency of Large Buildings is $50 \%$. It is assumed that anything larger will be susceptible to excessive heat gain and/or heat loss (Department of Building and Housing, 2011). According to the literature, 50\% appears to be a reasonable starting point for WWR, with smaller and larger ratios to also be tested.

The report 'Development of Building Regulations and Guidelines to Achieve Energy Efficiency' aims to optimize window design for daylight, thermal comfort and energy performance. This study is particularly relevant as it tests WWR as a function of Height to Separation $(\mathrm{H} / \mathrm{S})$ ratio of buildings (TERI University, 2010), similar to the aspect ratio considerations of this research. It found the minimum WWR that could possibly daylight a building was $20 \%$, regardless of surrounding urban form.

In terms of maximum window sizes the same report states that the taller and closer buildings are, the larger WWR will need to be to deliver adequate light levels (TERI University, 2010). While this may point to glazed curtain walls as an option for daylighting, this style is particularly susceptible to heat transfers through the low resistance envelope. The study 'Design sequence for diffuse daylight' by LoVerso and Reinhart (2010) states that if a space requires a WWR of more than $80 \%$, then daylighting design, or even the use of daylighting, should be reconsidered. LoVerso and Reinhart also define an $80 \%$ WWR as the maximum realistic window size when considering ceiling space required by services and structure.

Based on the literature, minimum and maximum WWR limits for energy efficiency appear to be $20 \%$ and $80 \%$ respectively. This study adopted these values but alters them slightly to become $25 \%$ and $75 \%$. This enables a more systematic investigation of glazing areas as one quarter increments of the wall area- 25, 50 and 75\% (refer Figure 6.2). 


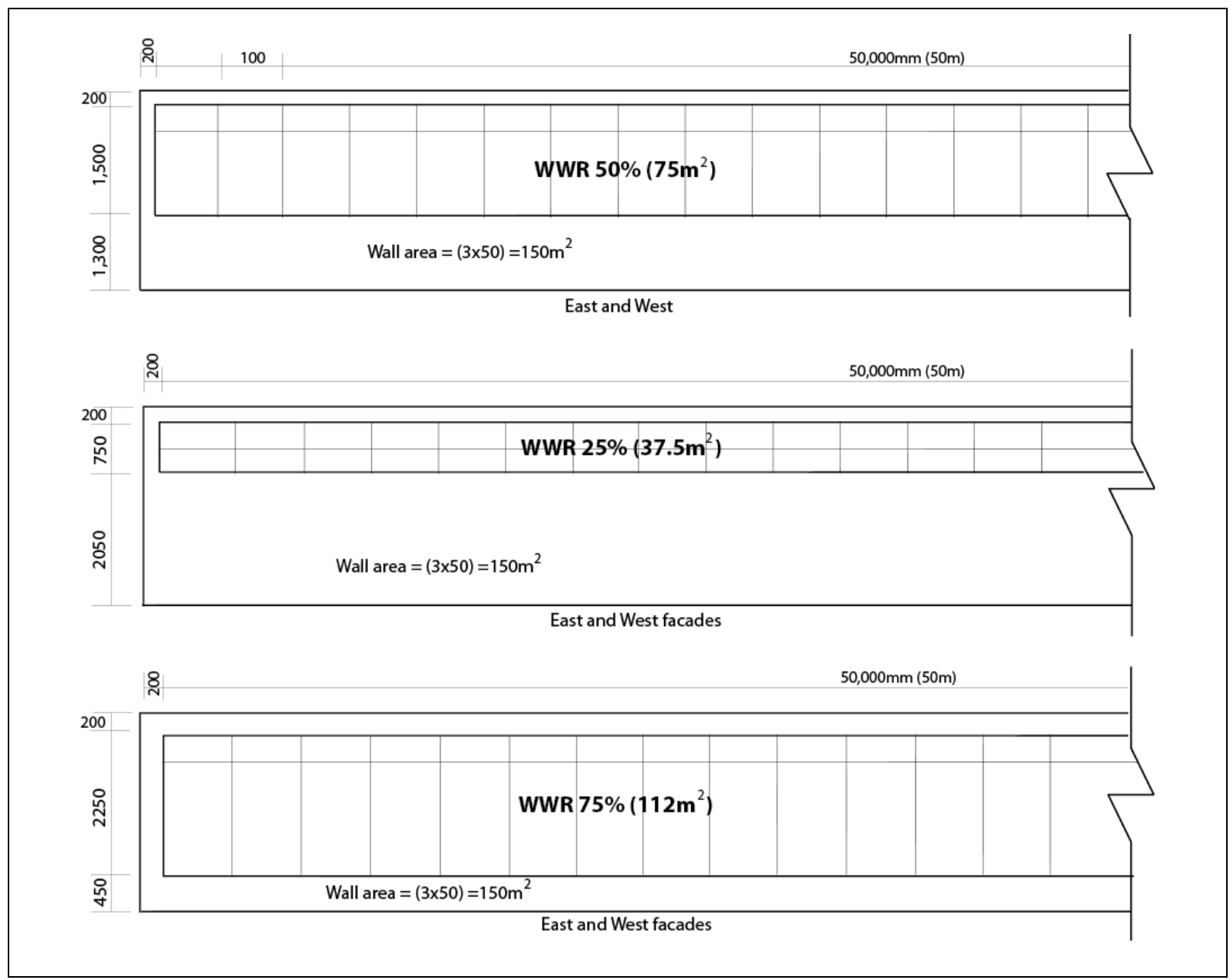

Figure 6.2. Window to Wall Ratios tested - starting (50\%); minimum (25\%); and maximum (75\%). (Author).

Best practice design of windows intended for daylighting is to install the window as high as possible on the wall to maximize daylight penetration (National Institue of Building Sciences, 2012). Therefore, in all cases, the window head will be placed $200 \mathrm{~mm}$ below the ceiling height $(2.8 \mathrm{~m}$ above floor level) to allow for construction components like top-plates.

Windows are continuous for the full length of the façade to maximize daylight uniformity. While some people prefer personal office spaces, internal partitioning walls would be detrimental to daylighting and natural ventilation and are not prioritized in the design of windows.

'Effective glazed area' is determined at 0.8 in EnergyPlus to account for the window framing area, which can block a significant amount of daylight from entering the space (refer Figure 6.3). 


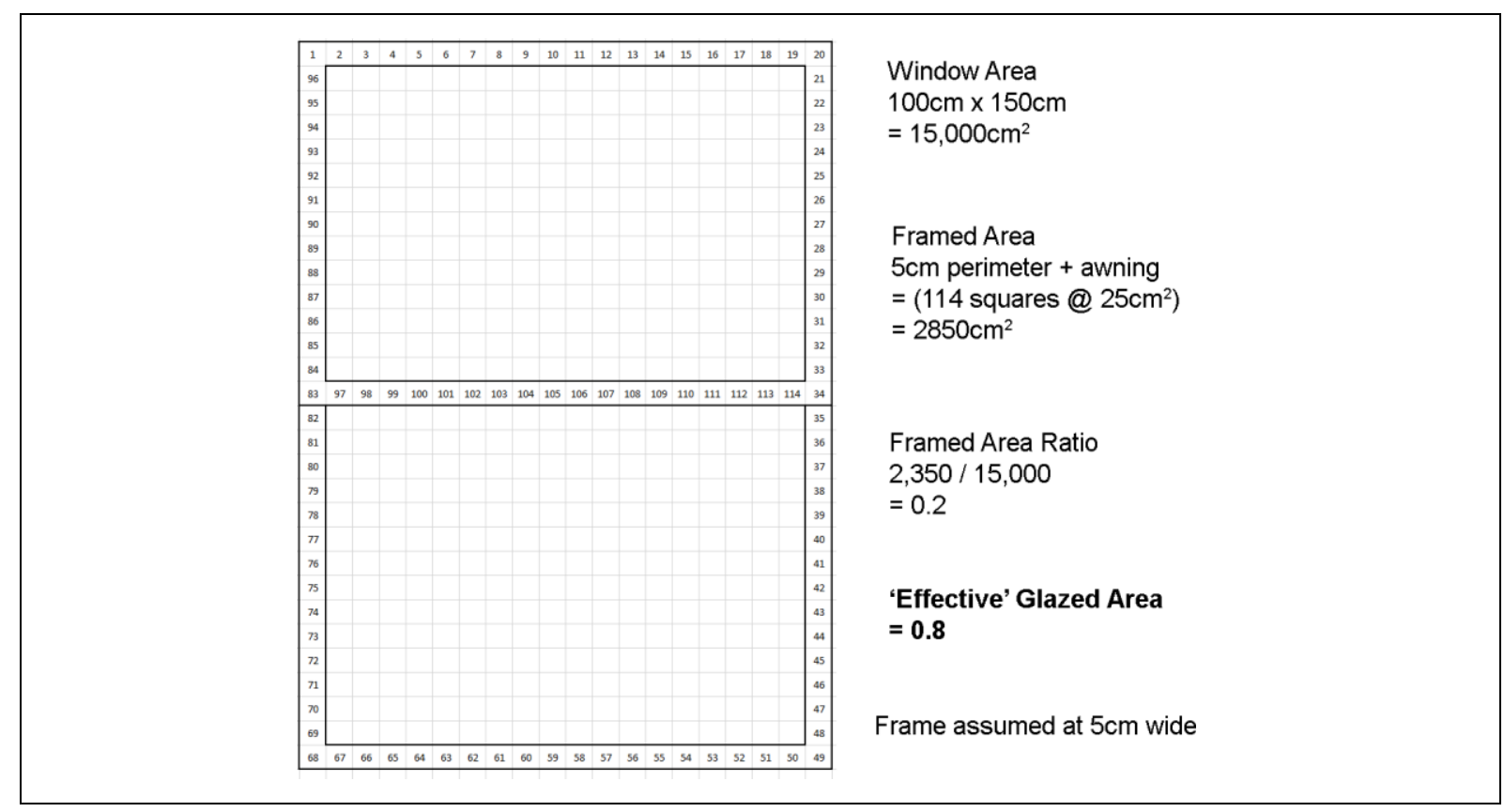

Figure 6.3. Window size and glazing to frame ratio assumed for modelling.

\author{
Summary: Daylighting Design Variable 1 - Window to Wall Ratio \\ Lower limit - 0.25 \\ Upper limit $\mathbf{- 0 . 7 5}$ \\ Increments - every $0.25(25 \%, 50 \%$ and $75 \%)$
}

\title{
6.2.2 Daylighting Design Variable 2 - Glazing Type
}

The material properties of glass can have a substantial effect on the amount of solar energy - light and heat - that enters a building envelope. Studies have shown that the selection of glazing alone can affect energy consumption by up to $15 \%$ (Beltran, et al., 2012). There are three predominant material properties that define a glazing type- Visible Light Transmittance (VLT), Solar Heat Gain Coefficient (SHGC) and Thermal Resistance (U-Factor) (refer Figure 6.4). Following is an explanation of each of these material properties, how it affects solar energy, and a determination of suitable values to be used in testing.

Importantly, glazing types cannot be treated in the same manner as other variables in parametric testing. For example, WWR can simply be increased or decreased along a linear scale between 0 and 1. Glazing type on the other hand consists of further internal parameters (material properties) which influence each other. For example- glass with a high VLT (allows most of light through) is likely to have low SHGC and U-Factors (thermal properties) because it also allows most of the heat energy through.

If the three material properties were tested separately from one another, the resulting ideal glass (for an office situation) would have a high VLT, high SHGC and low U-value as this would maximize light transmittance but minimize heat transfer. However, because these properties are physically entwined, this glass specification is not possible. Therefore, to test which property is the most influential in the selection of glazing, three glazing types will be selected, each prioritizing one of the three material properties. 


\subsubsection{Visible Light Transmittance (VLT)}

'Visible Light Transmittance' (VLT) (also known as Visible Transmission or $\mathrm{T}_{\text {vis }}$ ) of glass represents the percentage of a light-wave that is allowed to pass through. A VLT value of 0.9 (about maximum) signifies clear glass which will allow $90 \%$ of light that strikes it to pass through, while the other $10 \%$ is reflected and absorbed (refer Figure 6.5). The more light transmitted by the glass, the better the daylighting potential. Figure 6.4 indicates how, as the VLT of the glass increases, so too does the depth of daylight penetration.

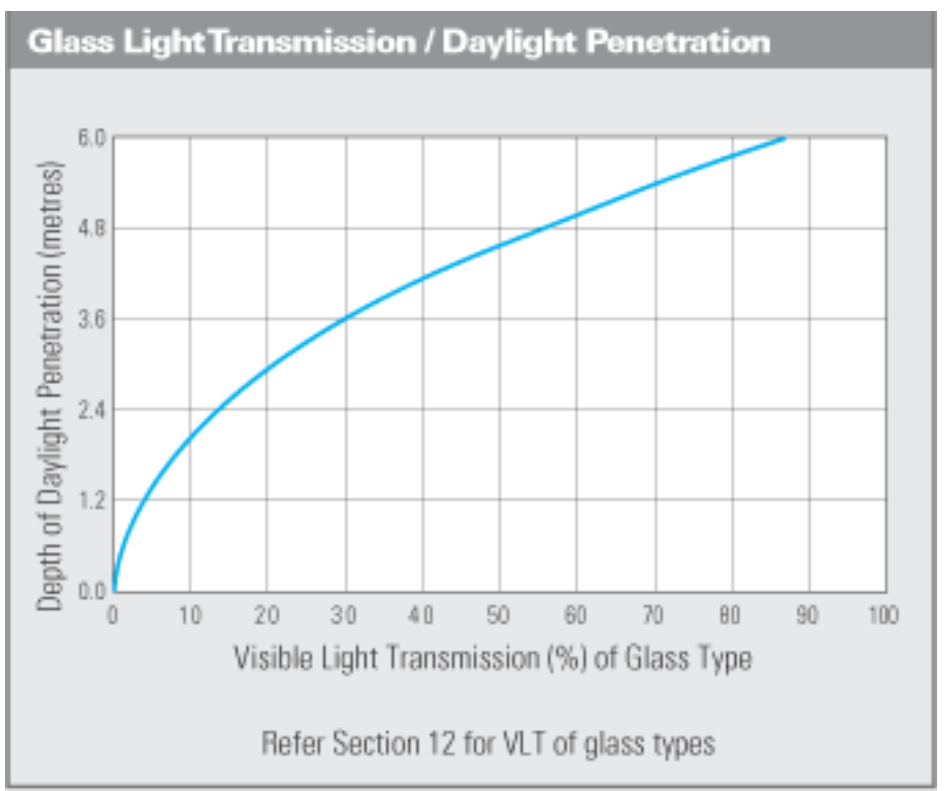

Figure 6.4. Relationship between VLT and depth of daylight penetrations. (Metro GlassTech, 2006).

There is no default or recommended VLT value for daylight and energy modelling in the NZBC. 'ASHRAE Standard 90.1:2004 - Energy Standard for Buildings Except Low-Rise Residential Buildings' (2004) recommends the minimum VLT for a clear, single glazed window should be 0.76 . However, because this is only a minimum value and because the daylighting design goal is to maximize daylight delivery, a high VLT value is sought. To do this, the 'Metro GlassTech' glazing/window database was used. Using manufacturers' data from a New Zealand based supplier means selections are readily available in New Zealand and therefore more feasible in the Christchurch rebuild. The highest VLT value glazing in the Metro GlassTech database is 'Starphire Low Iron', $5 \mathrm{~mm}$ at a VLT of 0.91. However, standard $4 \mathrm{~mm}$ clear glass possesses a VLT of 0.9 , essentially the same. Considering this, clear glass is selected as the high VLT product as it enables a comparison of the cheapest, most simple glazing option against other more expensive glasses.

Therefore, to test the VLT material property and the simplest glazing option, 'Glazing Type 1' will be clear glass with a VLT value of 0.9 .

\subsubsection{Solar Heat Gain Coefficient (SHGC)}

Solar Heat Gain Coefficient (SHGC), or 'Solar Factor', is "The measure of the total solar energy transmittance (direct solar beam; absorbed and radiated through glass) entering a building through the glazing as heat. The lower SHGC the better the glass restricts heat energy transmission." (Metro GlassTech, 2006). Solar heat gain can account for up to $50 \%$ of mechanical cooling loads in a coolingdominated office building (Lam \& Li, 1999), so a balance between daylight and thermal factors is required. The SHGC glazing property enables some control over the amount of solar heat entering 
through fenestrations. The maximum SHGC (least shading effect) must be 0.86 as this is the value associated with Glazing Type 1 - Clear glass. This glazing type prioritizes daylight transmission and has little solar shading effect.

The minimum permissible SHGC value can also be determined as a function of VLT. As identified in the previous section, the minimum VLT that should be specified for a daylighting window is 0.76 (ASHRAE, 2004). The Metro GlassTech glazing type that best meets this criteria is a single-glazed, green tinted glass (VLT 0.77), which has a corresponding SHGC value of 0.61 (Metro GlassTech, 2006).

To test the SHGC material property, 'Glazing Type 2' will be tinted glass with a SHGC value of 0.61 .

\subsubsection{Thermal Resistance (U-Factor)}

Just as thermal resistance (insulation) is important in a building's roof and walls, glazing areas also affect the thermal performance of a space. While SHGC concerns specifically the solar energy entering through an aperture, U-factor concerns glazing's ability to retain heat escaping from the space, as well as incoming heat transfer. A U-factor is the inverse $(x / 1)$ of an R-value.

The U-Factor for Glazing Types 1 and 2 are U-5.91 and U-5.88, respectively. These values are determined based on the VLT and SHGC values of those particular glazing's. Both these U-factors are high, which indicates poor resistance to heat flow.

A common window type which aims to increase thermal resistance is a double glazing unit (DGU), which is simply two layers of glass separated by a small (around $10 \mathrm{~mm}$ ) air-filled cavity. If the air in the cavity is replaced with a higher density, low conduction gas such as argon or krypton it improves the windows overall thermal resistance capacity and is known as an Insulated Glazing Unit (IGU). Standard double glazing typically improves a window's U-factor by 15\%; whereas IGU's can improve it by up to $27 \%$ (Glass Technology, 2013). Often included in an IGU is a Low-E (low emissivity) coating, which helps to reduce heat transfer across the window with minimal impact on translucency.

The lowest U-factor window in the Metro GlassTech database was U-1.6 (R-0.63). This is equal to half the thermal resistance offered by a standard wall built with minimum code insulation and is the selected U-Factor glazing type.

To test U-Factor, 'Glazing Type 3' will be a Low-E, IGU window with a U-factor value of 1.6 (R-0.63). 


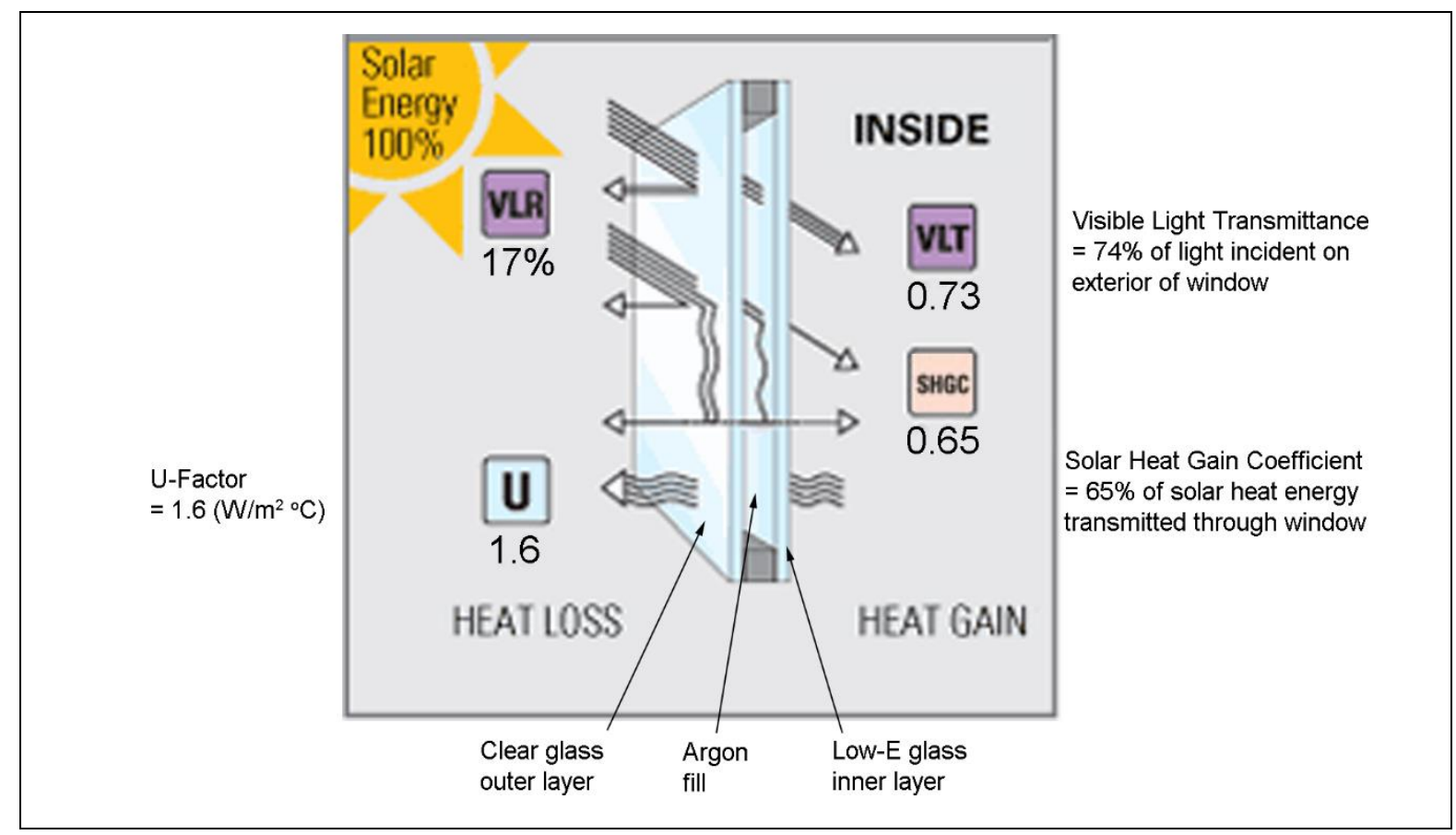

Figure 6.5. Diagram illustrating the three subject glazing properties (VLT, SHGC and U-Factor) in the form of the Low-E IGU 'Glazing Type 3'. Adapted from (Metro GlassTech, 2006).

\section{Summary: Daylighting Design Variable 2 - Glazing Type}

\begin{tabular}{|l|l|l|l|l|l|}
\hline Glazing Type & $\begin{array}{l}\text { Prioritized } \\
\text { Property }\end{array}$ & Common Name & VLT Value & SHGC Value & U-Factor Value \\
\hline Glazing Type 1 & VLT & Clear glass & 0.9 & 0.86 & U-5.91 (R-0.17) \\
\hline Glazing Type 2 & SHGC & Tinted glass & 0.76 & 0.61 & U-5.88 (R-0.17) \\
\hline Glazing Type 3 & U-Factor & $\begin{array}{l}\text { Double glazing, } \\
\text { or IGU }\end{array}$ & 0.73 & 0.65 & U-1.6 (R-0.63) \\
\hline
\end{tabular}

Table 6.1. Summary of Glazing Types tested and their values for the key material properties. 


\subsubsection{Daylighting Design Variable 3 - Solar Shading}

Solar shading involves an array of surfaces, or devices, to protect the building envelope - particularly fenestrations - from direct sunlight. The purpose of shading devices is to limit unwanted solar heat entering internal spaces. Shading devices have been demonstrated to reduce energy consumption in office buildings by between $8 \%$ and $20 \%$ depending on the orientation of the façade (Bellia, et al., 2013) and (Nielsen, et al., 2011). Examples of solar shading are overhangs, louvers and fins, meshes/grates, and internal blinds (refer Figure 6.6).

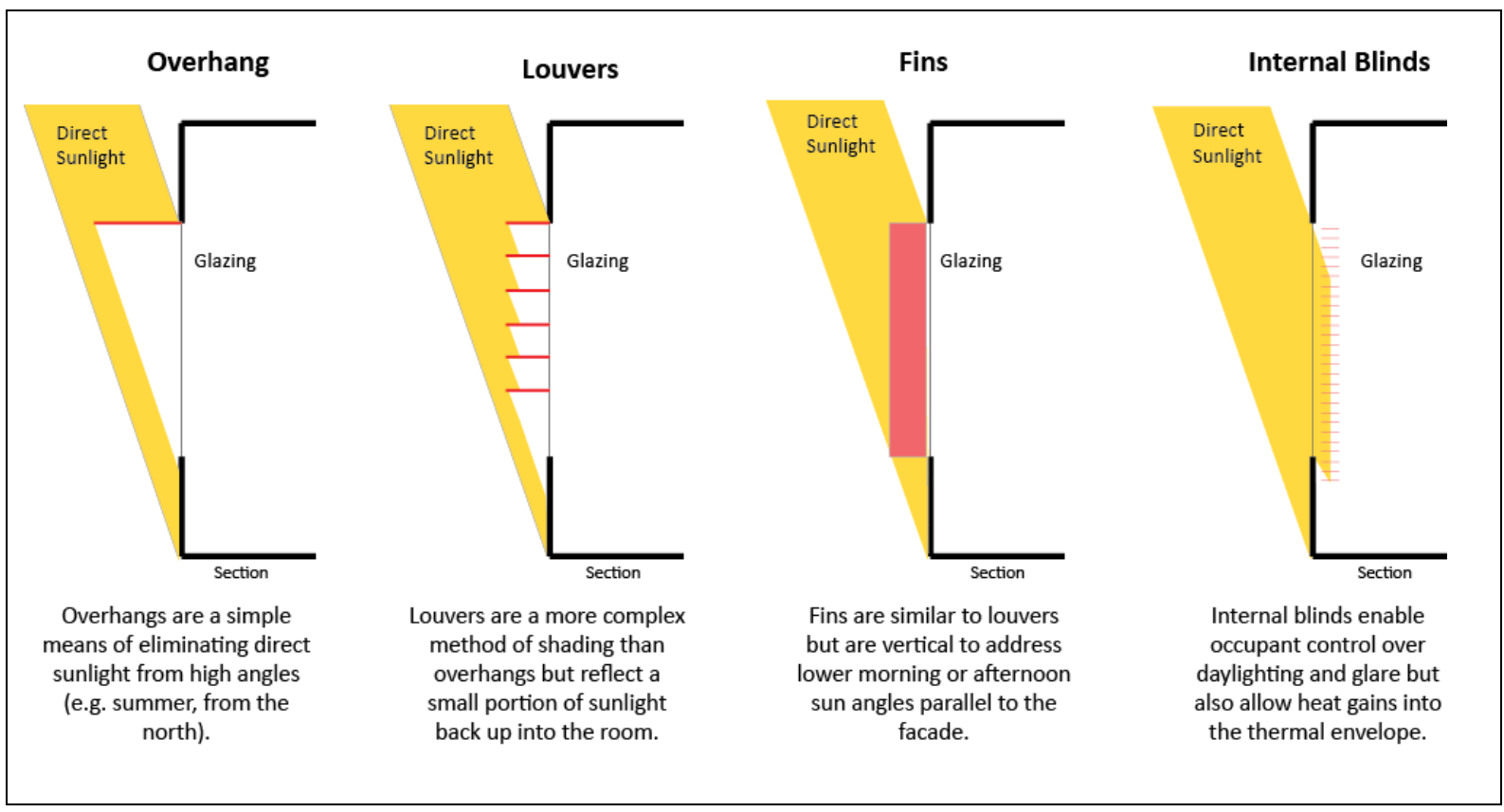

Figure 6.6. Examples of shading systems and how they address direct sunlight. (Author).

A common method of eliminating excess sun and daylight (over-exposure or glare) from office spaces is internal blinds. Blinds are popular because they give occupants control over their visual environment- adjusting them as required. However, this is also the reason why they are undesirable in a situation where daylight is intended as the primary lighting method.

Preference of some occupants may not coincide with daylighting design settings and tampering with blinds could disturb the daylighting system (Meek, 2013). Furthermore, blinds are not effective barriers to solar heat gains because they are inside the building's thermal envelope, meaning heat is already inside the space before it is addressed. External systems are preferred because they prevent solar heat reaching the envelope; and because they cannot be unwisely adjusted by occupants.

Of the external shading options presented above, overhangs are selected for investigation in this study. The research aims to investigate and analyse shading as a function of WWR. Sizes of overhangs, which are monolithic surfaces, can be simply derived as a percentage of the window height, enabling an analysis of the relationship between shading size to window size that would not be possible with multiple surface louvers or fins.

The WWR's tested $(25,50$ and $75 \%$ of a $3 \mathrm{~m}$ tall wall) equate to glazed heights of $750,1,500$ and $2,250 \mathrm{~mm}$, respectively. Based on this, overhang sizes tested were $750 \mathrm{~mm}$ and $1,500 \mathrm{~mm} .2,250 \mathrm{~mm}$ was omitted as this would be an unrealistically large overhang.

'No overhang' $(0 \mathrm{~mm})$ was also tested and is specified for the 'basic building design' used in the urban form investigation (refer Figure 6.7). The relationship between each of these overhang depths in relation to window size is presented in Table 6.2. 


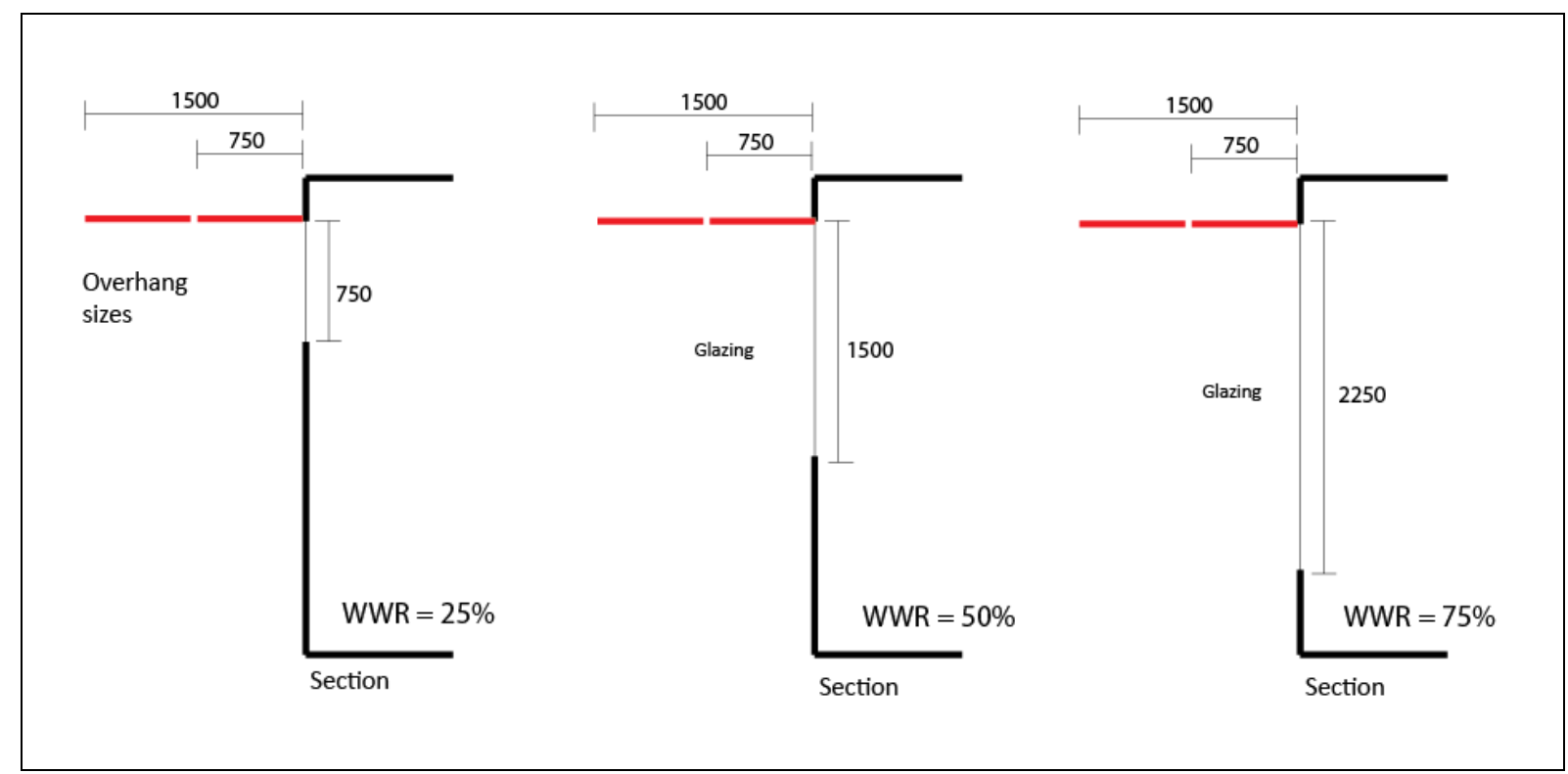

Figure 6.7. Illustration of overhang depths tested in the study, in relation to window size. (Author).

\begin{tabular}{|l|l|l|}
\hline WWR & Overhang Depth & Glazing to Overhang ratio \\
\hline \multirow{3}{*}{$25 \%$ (750mm high) } & $0 \mathrm{~mm}$ & N/A \\
\cline { 2 - 3 } & $750 \mathrm{~mm}$ & $1: 1$ \\
\cline { 2 - 3 } & $1,500 \mathrm{~mm}$ & $1: 2$ \\
\hline \multirow{3}{*}{$50 \%$ (1,500mm high) } & $0 \mathrm{~mm}$ & $\mathrm{~N} / \mathrm{A}$ \\
\cline { 2 - 3 } & $750 \mathrm{~mm}$ & $2: 1$ \\
\cline { 2 - 3 } & $1,500 \mathrm{~mm}$ & $1: 1$ \\
\hline \multirow{3}{*}{$75 \%(2,250 \mathrm{~mm}$ high) } & $0 \mathrm{~mm}$ & $\mathrm{~N} / \mathrm{A}$ \\
\cline { 2 - 3 } & $750 \mathrm{~mm}$ & $3: 1$ \\
\cline { 2 - 3 } & $1,500 \mathrm{~mm}$ & $3: 2$ \\
\hline
\end{tabular}

Table 6.2. Overhang depth to Window height ratio

Summary: Daylighting Design Variable 3 - Solar Shading

Lower limit - 0 (No overhang)

Upper limit $-1.5 \mathrm{~m}$ overhang

Increments - every $0.75 \mathrm{~m}$ 


\subsection{Parameterization - Ventilation and Thermal Design Variables Tested}

As with Daylighting Design, this section identifies significant Ventilation and Thermal Design parameters and variables.

\subsubsection{Ventilation and Thermal Design Variable 1 - Construction Type}

The structure or construction of a building can influence its reaction to outdoor temperature swings and regulate indoor temperatures. There are three predominant construction types in New Zealandconcrete, timber and steel (BRANZ, 2012). Concrete is a 'thermal mass' which is often used in residential settings to heat spaces in the evening using solar energy gathered during the day. Using concrete as a passive heat source is not beneficial in office buildings where overheating is an issue, but its 'thermal inertia' qualities can be useful. 'Thermal Inertia' is the ability (for a material) to resist temperature change. A building made with material of high thermal inertia, like concrete, will have slower and less severe temperature fluctuations than other materials like timber or steel (Reardon, 2013). This 'regulation' of internal temperatures thermal inertia provides means less heating or cooling energy is required when outdoor temperatures change (refer Figure 6.8).

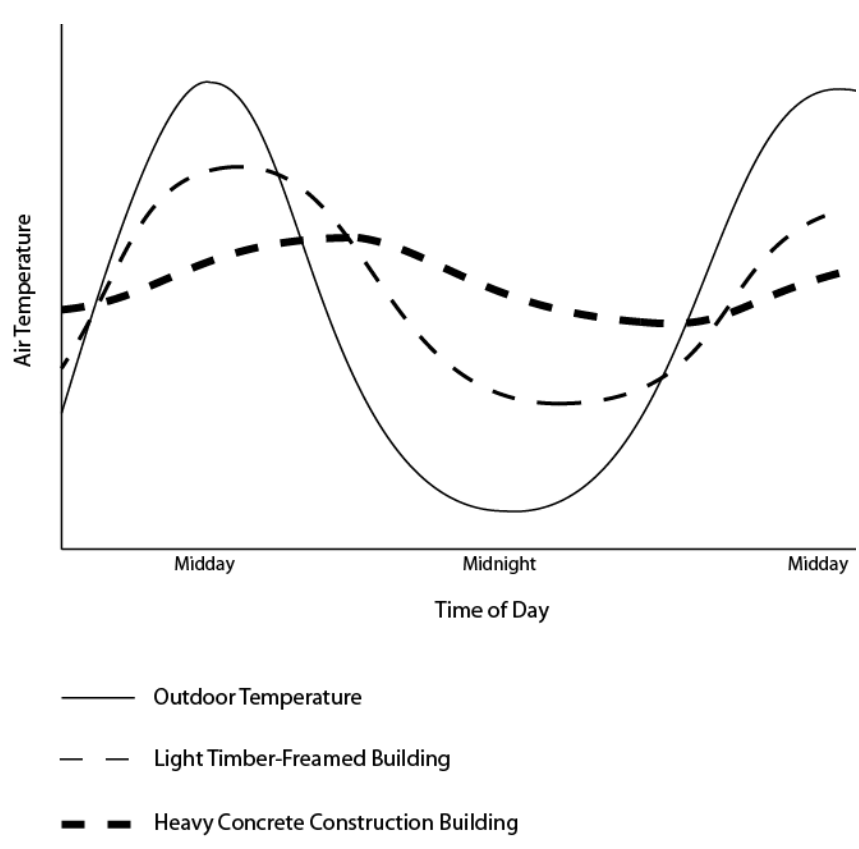

Figure 6.8. Graph indicating the thermal inertia effect building materiality has on temperature. Adapted from (Reardon, 2013).

Timber does not have the thermal inertia qualities of concrete but does possess many other attributes. Economically, timber is a feasible option as it is grown locally meaning it is abundant and affordable. Environmentally, timber boasts a 'negative embodied carbon' rating, meaning it absorbs carbon from the environment, rather than creating it like manufacturing concrete does. Since the Christchurch earthquakes, timber has also gained favour due to its structural flexibility and lightweight nature. While it is not expected to perform as well as concrete, timber has a strong presence in New Zealand's construction industry and will be tested to determine how it compares to concrete. For modelling, the timber structural system uses $90 \times 70 \mathrm{~mm}$ framing according to Table 8.2 of NZS3604. 
Another Construction Type consideration is the location of the insulation. The thermal inertia benefits of concrete are maximized when insulation is applied to its exterior, as this encapsulates the thermal mass within the thermal envelope. Positioning insulation on the inside of the walls is a cheaper option but effectively rejects the thermal inertia qualities of concrete construction. For timber construction, insulation is located within the framing cavity as usual.

Floor-plates offer more potential for thermal inertia than walls do as they provide larger volumes (Gratia \& De Herde, 2003). For this reason, not only construction of the thermal envelope is considered. The 'optimization' process was set-up so that when roof and wall construction type changed, the inter-floor ceilings/floors were also changed to reflect the envelope construction. This process ensured that the entire building consisted of the same construction type (i.e. all concrete; or, all timber).

Steel framing is not considered as it possesses none of concrete or timber's sustainable benefits.

EnergyPlus construction definitions for each Construction Type can be found in Appendix B.5.

\author{
Summary: Ventilation and Thermal Design Variable 1 - Construction Type \\ Construction Type 1 - Concrete, with insulation inside \\ Construction Type 2 - Concrete, with insulation outside \\ Construction Type 3 - Timber, with insulation in framing cavity
}

\title{
6.3.2 Ventilation and Thermal Design Variable 2 - Roof Insulation Level
}

Insulation is employed as a barrier to heat transfer through a buildings surface. Thermal resistance $\left(\mathrm{R}\right.$-value, $\left.\mathrm{W} / \mathrm{m}^{2} .{ }^{\circ} \mathrm{C}\right)$ is a rating of the effectiveness for a surface to limit the exchange of heat/coolth between internal spaces and the ambient environment.

Studies have found that between 30 and $50 \%$ of thermal energy loss is attributed to air leakage and heat transfer through the building envelope (Honeywell, 2008). Although these studies were conducted in colder North American climates, they still illustrate the importance of the thermal envelope in thermal energy transfer between indoors and outdoors.

The roof is a particularly important surface for heat transfer. Due to convective forces, heat from all levels of the building, rises through floor-plates and storeys to the top floor. If the roof is not sufficiently insulated, heat will continue to rise, and be lost. This is a significant point in residential situations where heat is a commodity but in office buildings, where over-heating is common, heat losses may be encouraged. However, heat does not only pass through the roof surface from the inside-out. The roof is also exposed to solar radiation, which can cause a dark coloured roof to reach temperatures of $80^{\circ} \mathrm{C}$ in summer, even in temperate climates (Castelton, et al., 2010). This exposure can cause significant heat gains if the roof section is not constructed to limit it. Both of these heating processes (convection and solar radiation) often result in the top floor experiencing hotter (and colder) temperatures than the rest of the building. Figure 6.9 illustrates these two heating processes and how insulation helps to mitigate heat transfer through the roof surface. 


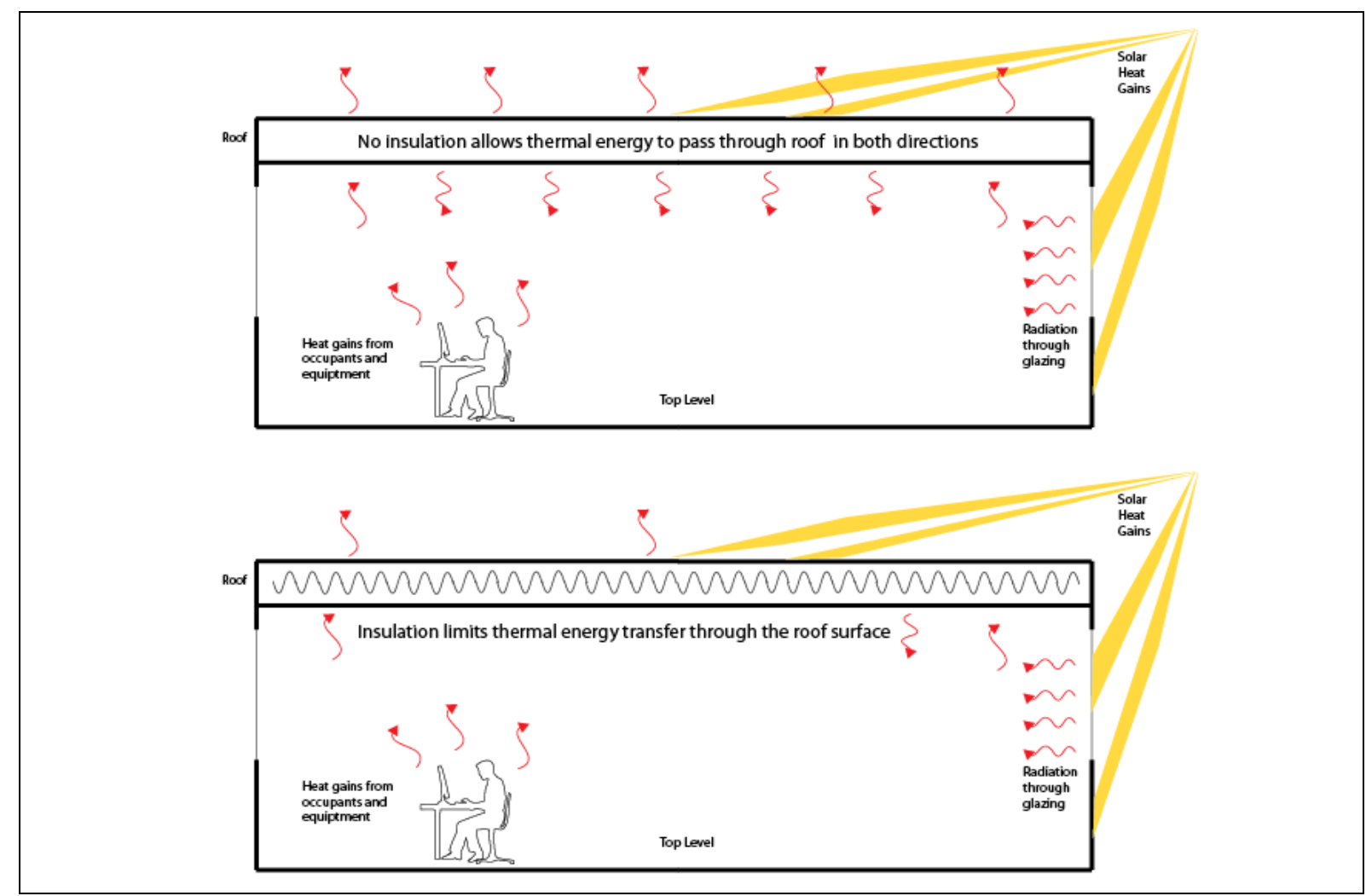

Figure 6.9. Insulated vs Uninsulated scenarios and the effect on thermal energy transfer. (Author).

'NZS4243.1:2007 - Energy Efficiency in Large Buildings' states the minimum average roof insulation should be R-1.9 for Climate zone 3 (Christchurch) (Department of Building and Housing, 2011). This value will therefore be set for all buildings in the testing of Urban Form scenarios; and as the starting point for the building design 'optimization' process. Double ( $R-3.8)$ and triple ( $R-5.7)$ this value will also be tested to determine what level of insulation produces best thermal and energy performance. Zero insulation will also be trialled to determine whether insulation is in fact necessary.

\section{Summary: Ventilation and Thermal Design Variable 2 - Roof Insulation Level}

Lower limit - R-0 (No insulation)

Upper limit - R-5.7 ( $3 x$ code minimum)

Increments - R-0; R-1.9 (NZBC minimum for roofs in climate zone 3); R-3.8 ( $2 x$ code); $\mathbf{R}-\mathbf{5 . 7}$ (3x code)

\subsubsection{Ventilation and Thermal Design Variable 3 - Wall Insulation Level}

Wall insulation is important for the same reason as roof insulation but not as significant in effect because walls are not subject to the same extent of convection and solar radiation as the roof surface. NZS4243.1:2007 requires minimum insulation for walls in Climate Zone 3 to be R-1.2, which will be applied for all urban form models; and as the starting point for building design 'optimization'. Again, double (R-2.4), triple (R-3.6) this minimum, and $\mathrm{R}-0$ will also be tested.

Summary: Ventilation and Thermal Design Variable 3- Wall Insulation Level

Lower limit - R-0 (No insulation)

Upper limit - R-3.6 ( $3 x$ code minimum)

Increments - R-0; R-1.2 (NZBC minimum for walls in climate zone 3); R-2.4 (2x code); R-3.6 (3x code) 


\subsubsection{Ventilation and Thermal Design Variable 4-Openable Window Area}

As explained in Section 2.3.4 the ventilation method used in this study is wind-driven cross ventilation. Therefore, because windows are the delivery mechanism of outdoor fresh air in this ventilation system, their sizing is critical to ventilation effectiveness.

To determine the area of glazing that can be opened for venting - 'openable window area' - the 'Acceptable Solution' of NZBC 'Clause G4 - Ventilation' was used. This states that 'Natural ventilation of occupied spaces must be achieved by providing a net openable area of windows or other openings to the outside of no less than 5\% of the floor area.' (Department of Building and Housing, 2011).

Just like insulation levels, openable window area is tested at double ( $10 \%$ of floor area) and triple (15\%) minimum code to enable more ventilation if air change rates are too low to meet the minimum required $0.84 \mathrm{ACH}$. The option of zero or no openable window area is again included to test all possible scenarios. This approach enables a systematic investigation of openable window area as a function of floor-plate depth (building length is constant at $50 \mathrm{~m}$ ); and comparable results.

EnergyPlus describes the openable area of a venting window as a percentage of the 'parent window' glazed area (under the 'Component: Detailed Opening' object) (refer Section 4.3.2.1 for explanation of Airflow Network in EnergyPlus). This means the 0, 5, 10 and 15\% of floor area values need to be converted into percentages of the glazed area (as seen in Table 6.3).

As explained in Section 6.1, the Ventilation and Thermal parametric testing will only be conducted on the most energy efficient urban form model, which is not yet known. When this best performing model is determined at the conclusion of Section 7.1, openable window areas can be calculated based on $0,5,10$ and $15 \%$ of that buildings floor area. These calculations can be found in Appendix B.4).

Summary: Ventilation and Thermal Design Variable 5 - Window Openable Area
Lower limit - 0 (No portion of the window can open for ventilation)
Upper limit - 15\% ( $3 \times$ code minimum = 15\% of floor area)
Increments - 0; 5\% (NZBC minimum 5\% of floor area); $10 \%$ ( $2 x$ code); 15\% ( $3 \times$ code) 


\subsubsection{Summary of Building Design Variables}

\begin{tabular}{|c|c|}
\hline Daylighting Parameters & Variations of Parameter \\
\hline \multicolumn{2}{|l|}{$\begin{array}{l}\text { Window to Wall Ratio, WWR } \\
\text { (Upper Floors) }\end{array}$} \\
\hline Minimum & $25 \%$ \\
\hline Maximum & $75 \%$ \\
\hline Increments & 25,50 , and $75 \%$ \\
\hline Starting Point & $50 \%$ \\
\hline \multicolumn{2}{|l|}{ Glazing Type } \\
\hline Glazing Type 1 & Clear glass [high VLT] \\
\hline Glazing Type 2 & Insulated Glazing Unit, IGU (double glazing) [high R-value] \\
\hline Glazing Type 3 & Reflective coating [high SHGC] \\
\hline \multicolumn{2}{|l|}{ Overhangs } \\
\hline Minimum & $0 \mathrm{~mm}$ \\
\hline Maximum & $1,500 \mathrm{~mm}$ \\
\hline Increments & 0,750 and $1,500 \mathrm{~mm}$ \\
\hline Starting Point & $0 \mathrm{~mm}$ \\
\hline Ventilation/Thermal Parameters & Variations of Parameter \\
\hline \multicolumn{2}{|l|}{ Construction Type } \\
\hline Construction Type 1 & Concrete, with interior insulation \\
\hline Construction Type 2 & Concrete, with exterior insulation \\
\hline Construction Type 3 & Timber, with insulation in framing \\
\hline \multicolumn{2}{|l|}{ R-Value - Walls } \\
\hline Minimum & $\mathrm{R}-0$ \\
\hline Maximum & $\mathrm{R}-3.6$ \\
\hline Increments & $\begin{array}{l}\text { R-0, R-1.2 [Building Code minimum], R-2.4, [2x Building Code], } \\
\text { and R-3.6 [3x Building Code] }\end{array}$ \\
\hline Starting Point & $\mathrm{R}-1.2$ \\
\hline \multicolumn{2}{|l|}{ R-Value - Roof } \\
\hline Minimum & R-0 \\
\hline Maximum & R-5.7 [3x Building Code] \\
\hline Increments & $\begin{array}{l}\text { R-0, R-1.9 [Building Code minimum], R-3.8 [2x Building Code], } \\
\text { R-5.7 [3x Building Code]. }\end{array}$ \\
\hline Starting Point & $\mathrm{R}-1.9$ \\
\hline \multicolumn{2}{|l|}{ Window Openable Area } \\
\hline Minimum & $0 \%$ \\
\hline Maximum & $15 \%$ \\
\hline Increments & $\begin{array}{l}5 \% \text { (of floor area) [Building Code minimum], 10\% [2x Building } \\
\text { Code], and } 15 \% \text { [3x Building Code] }\end{array}$ \\
\hline Starting Point & $5 \%$ \\
\hline
\end{tabular}

Table 6.3. Summary of Building Design Variables 
Urban Form and Passive Design for High Performance Buildings in the Christchurch Rebuild 


\section{Chapter 7: Results and Discussion}

Chapter 7 presents and discusses the results of the study. Section 7.1 addresses the effect the 'Urban Form' changes had on building performance with comparisons to the baseline scenario. Section 7.2 then takes a selection of the urban form scenarios forward to the 'Building Design' investigation, to determine how far energy consumption can be reduced. Combined results from these two sections will determine the answer to the research question and whether the research aim was satisfied.

\subsection{Urban Form for Passive Buildings}

The effects of urban form on the performance of a simply designed passive office building are presented in the following sections.

\subsubsection{Urban Forms Effect on Energy}

Through comparison, this section reports energy consumption results of the urban form changes.

\subsubsection{Total Energy Consumption - EUI}

Using the Energy Use Intensity (EUI) metric explained in Section 4.1.1, urban form scenarios are tested for their energy consumption performance on a square meter basis - $\mathrm{kWh} / \mathrm{m}^{2} / \mathrm{year}$ - enabling a comparison of scenarios despite varying building sizes.

Figure 7.1 presents the EUI of each of the 54 urban form scenarios (including the baseline model) developed in Chapter 5. Thumbnail images of each scenario are included for visual context. This graph groups scenarios in sets of three, based on number of floors. Within building height grouping, gaps between buildings, then street width are varied systematically. This enables a comparison of any urban form change with similar scenarios and instantly conveys the effectiveness of each change.

Figure 7.1 illustrates how energy consumption of the baseline scenarios (10-20m wide buildings) was between $128-136 \mathrm{kWh} / \mathrm{m}^{2} /$ year. Energy Consumption of all the passive scenarios, however, ranged from $68-81 \mathrm{kWh} / \mathrm{m}^{2} / \mathrm{year}$. This is a minimum improvement of $37 \%$, and as much as a $48 \%$ improvement in some corresponding scenarios. Following is a breakdown of the results according to the five Urban Form Parameters investigated.

\section{Urban Form Parameter 1: Building Height}

Height appears to have little effect on a building's ability to perform passively and that shorter buildings do not necessarily perform more efficiently than taller buildings, as was expected.

Models 1,4 and 7 (2m gaps) are identical except for height $(4,6$ and 8 floors respectively). Corresponding EUI's for each of these Models range between 74-78, 78-79 and 80-81 kWh/m $/ 2$ year, depending on building width. While there is a relative increase in energy as the building gets taller, this is only minimal, averaging $2 \mathrm{kWh} / \mathrm{m}^{2} /$ year difference between each building height.

Models 2, 5 and 8 (6m gaps) are also identical except for height and experience even less variation in EUI, all between $68-73 \mathrm{kWh} / \mathrm{m}^{2} /$ year. Conversely however, EUI's do not increase with building height. Instead a reduction of energy $\left(1 \mathrm{kWh} / \mathrm{m}^{2} /\right.$ year average) is seen between the four level and 6 level scenarios; then another $1 \mathrm{kWh} / \mathrm{m}^{2} /$ year average increase back up to the 8 level scenarios. $10 \mathrm{~m}$ gap scenarios show a similar pattern but at even smaller quantities. These patterns and values indicate energy performance is not proportional to building height, and that effect is minimal. 


\section{Urban Form Parameter 2: Road Width}

Street width also appears to have little or no effect on energy performance. The investigation into street width took the lowest, middle and highest density scenarios (Models 3, 5 and 7, respectively) and extended their streets from $20 \mathrm{~m}$ to $30 \mathrm{~m}$, to create Models 10,11 and 12 . Figure 7.1 shows an infinitesimal difference of less than $1 \mathrm{kWh} / \mathrm{m}^{2} /$ year in energy between $20 \mathrm{~m}$ and $30 \mathrm{~m}$ scenarios. These results indicate the current $20 \mathrm{~m}$ road width is sufficient to provide the light and wind required for passive buildings, and that expanding streets to $30 \mathrm{~m}$ wide would have no further benefit.

\section{Urban Form Parameter 3: Gaps between Buildings}

Gaps between buildings have a substantial effect on energy consumption. Model 1 is exactly identical to the Model 0 baseline- but with $2 \mathrm{~m}$ gaps separating buildings along their length. This small alteration to urban form reduced energy consumption from $135 \mathrm{kWh} / \mathrm{m}^{2} /$ year (Model $0,18 \mathrm{~m}$ wide) down to $78 \mathrm{kWh} / \mathrm{m}^{2} /$ year (Model $1,18 \mathrm{~m}$ ) - a profound $43 \%$ reduction.

When compared to the Model 0 average EUI of $132 \mathrm{kWh} / \mathrm{m}^{2} /$ year, $2 \mathrm{~m}$ gap scenarios enable an average energy reduction of $41 \%$ (based on an average EUI of $78 \mathrm{kWh} / \mathrm{m}^{2} /$ year); $6 \mathrm{~m}$ gap scenarios enable a $47 \%$ reduction (average EUI of $70 \mathrm{kWh} / \mathrm{m}^{2} /$ year); and $10 \mathrm{~m}$ gap scenarios enable an average energy reduction of $48 \%$ (average EUI of $69 \mathrm{kWh} / \mathrm{m}^{2} /$ year). Furthermore, the isolated Model 13 performed at $71 \mathrm{kWh} / \mathrm{m}^{2} /$ year, a reduction of $46 \%$ - less than both the 6 and $10 \mathrm{~m}$ gap scenarios.

Two clear results can be drawn from these comparisons: firstly, gaps between buildings have a significant impact on energy efficiency; and secondly, a modest $6 \mathrm{~m}$ gap is significantly more effective than $2 \mathrm{~m}$ gaps and just as effective as larger gaps.

\section{Urban Form Parameter 4: Building Width}

Building Width returned mixed results. For most of the tested scenarios, there are no clear patterns defining energy efficiency as a function of depth. In an effort to gain insight into the effect of floorplate width, a comparison between the four-storey Models 1, 2, 3 and 13 can be made. As expected, EUls increase proportionally as building width increases in Model 1 . This is because the small $2 \mathrm{~m}$ gap between buildings is not sufficient to supply a widening floor-plate with the required fresh air and daylight. In Model 2, EUls are largely unchanging, suggesting a $6 \mathrm{~m}$ gap is just as effective at delivering fresh air and daylight to an $18 \mathrm{~m}$ wide building as it is to a $10 \mathrm{~m}$ wide building. Conversely, Models 3 and 13 EUls decrease as the building widens, indicating larger gaps are better equipped to sustain larger buildings.

However, this pattern is not consistent across the other six and eight-storey scenarios. In most of these, EUls begin to decrease as floor-plates start to widen (i.e. between 10-14m) but begin to rise again as widening continues (between $14-18 \mathrm{~m}$ )- this can be seen in the gentle parabola-like shape of the data lines. This pattern is in line with the original rule-of-thumb based maximum floor-plate width of around $15 \mathrm{~m}$ but is not clear enough to offer any further detail to this design guideline.

\section{Urban Form Parameter 5: Continuous Frontage}

No tests directly investigated the effect of continuous frontage height. However, considering the 43\% EUI reduction between Models 0 and 1 enabled by transforming 3 of the 4 'non-passive levels' into 'passive levels', it can be assumed that only $2 / 3$ rds of those savings would be realized if 2 levels had remained continuous frontage (as would be required under current CCPo rules).

Performance differences between the 'non-passive' continuous frontage ground level, and 'passive' upper-levels are better defined in the following section.

\section{Best and Worst EUls}

The scenario that performed the 'best' in terms of Energy Intensity was Model 5 ( $12 \mathrm{~m}$ wide) at $67.8 \mathrm{kWh} / \mathrm{m}^{2} /$ year. The worst performer was Model 12 ( $18 \mathrm{~m}$ wide), at $81.3 \mathrm{kWh} / \mathrm{m}^{2} /$ year. These two scenarios will be analysed in depth in the following 'Energy End-use' section. 


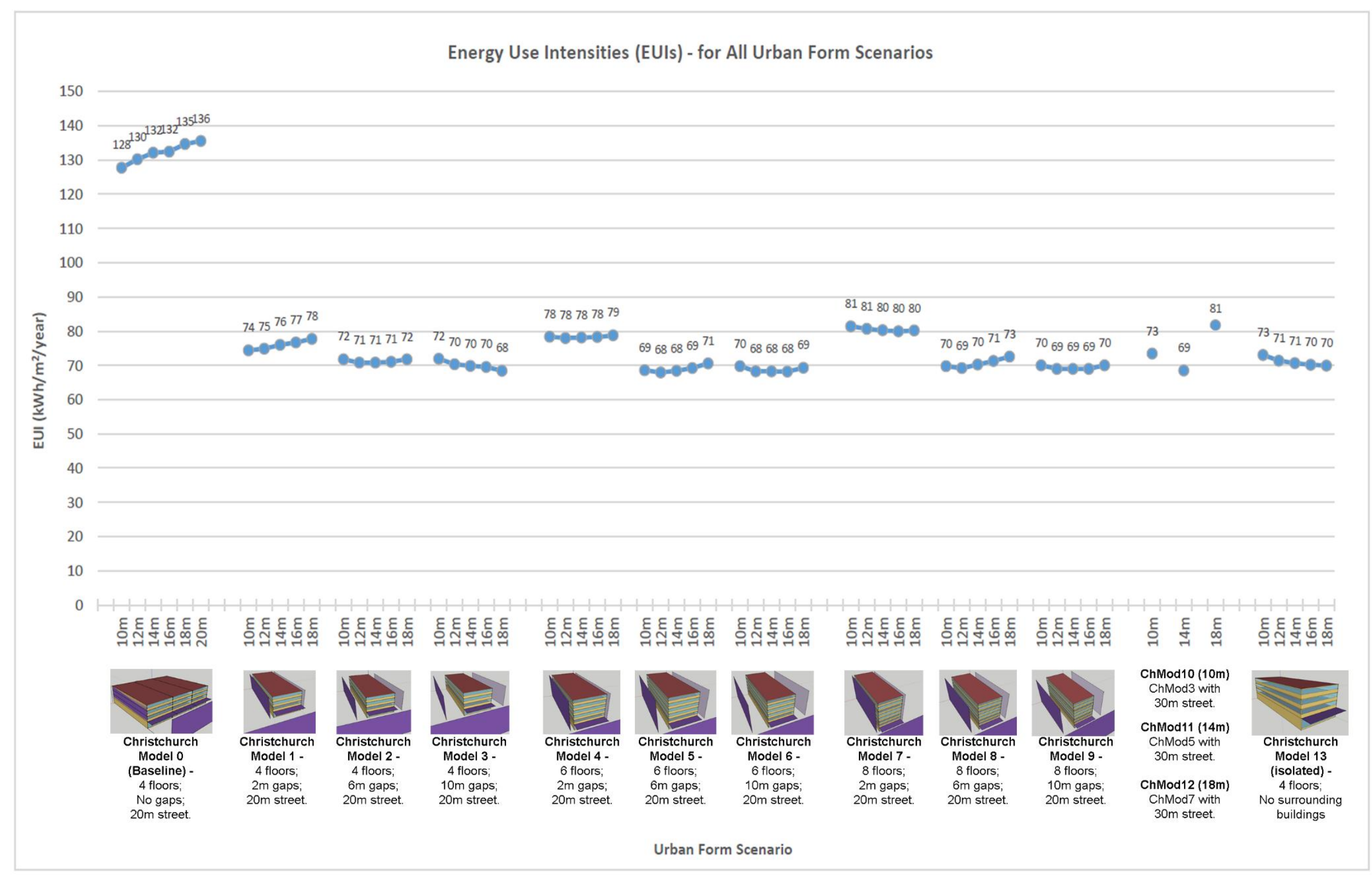

Figure 7.1. Energy Use Intensities (EUIs) for each urban form scenario. 


\subsubsection{Energy End-use Breakdown}

To determine, in more detail, what effect the urban form changes had on indoor environment, an analysis of the energy end-uses was conducted. Energy end-uses - 'lighting', 'heating', 'cooling', 'fans' (and 'equipment') - represent the building's mechanical systems which use energy to modify the environment to maintain occupant comfort.

Figure 7.2 presents the end-use proportions associated with Model 0 . The proportions seen here are similar to those expected of a conventional New Zealand office building, as was presented in Figure 1.2 (refer Section 1.1). A substantial dependency on cooling and lighting can be seen here- a result of the inability to utilize fresh air and daylight naturally. Conversely, Figure 7.3 illustrates the significant change in proportions of a passive building (Model 5, 12m wide). This graph shows the dramatic effect natural ventilation has on cooling loads, reducing them from $36 \%$ of the buildings consumption down to a mere $5 \%$. Electric equipment loads (e.g. computers, printers, etc.), are unaltered from the baseline but now represent almost $2 / 3$ rds of the buildings energy consumption (initially $1 / 3$ rd). Daylight appears not to have been affected in this graphic but this is only because overall energy consumption has dropped as well, this is better portrayed in Figure 7.4.

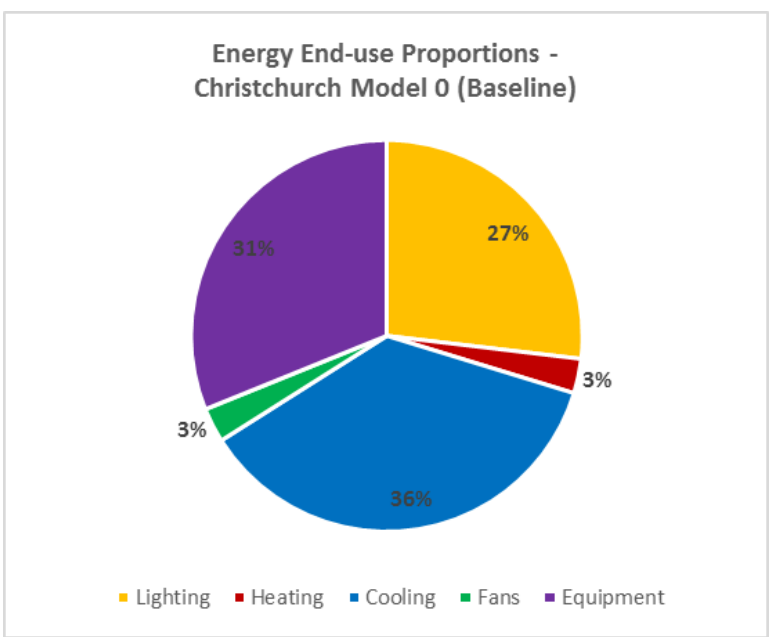

Figure 7.2. Energy End-use Proportions - Baseline (20m)

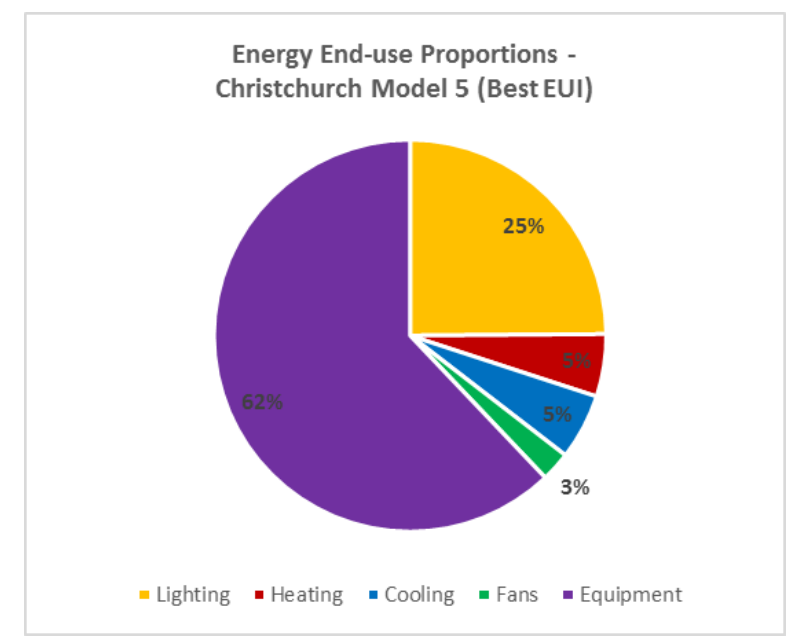

Figure 7.3. Energy End-use Proportions -Model 5 (12m)

Figure 7.4 presents the absolute energy consumption (per end-use and storey) of the best and worst performing Models in terms of EUI ('Model 5, 12m'; and 'Model 12, 18m' - refer Section 7.1.1) and density ('Model 3, 10m'; and 'Model 7, 18m' - refer Section 7.1.2). It also includes the baseline 'Model $0,20 \mathrm{~m}$ ' for comparison. Energy consumption in the $20 \mathrm{~m}$ wide baseline is based entirely on $\mathrm{m}^{2}$ rates so can be derived to $\mathrm{kWh} / \mathrm{m}^{2}$ for comparison against other sized models. This sample is selected to represent the extreme scenarios of the study, providing a basis for development toward the lowest energy, highest density scenario that is the goal of this study.

Here, a considerable difference can be seen between the non-passive baseline and the passive scenarios. As mentioned, the most prominent energy savings are to the 'cooling' loads, which are reduced to almost insignificant levels across all passive scenarios. For Model 0 , the average HVAC cooling intensity (per floor) was $36 \mathrm{kWh} / \mathrm{m}^{2} /$ year; whereas the average for 'Model $5,12 \mathrm{~m}$ ' was a mere $3 \mathrm{kWh} / \mathrm{m}^{2} /$ year - a considerable $92 \%$ reduction. The graph also illustrates how the lower density scenarios (Models 3 and 5) experience the lowest lighting energy loads, with 'Model 5, 12m' consuming at an intensity of $17 \mathrm{kWh} / \mathrm{m}^{2} /$ year, compared to $43 \mathrm{kWh} / \mathrm{m}^{2} /$ year for Model $0-$ a $60 \%$ reduction. 


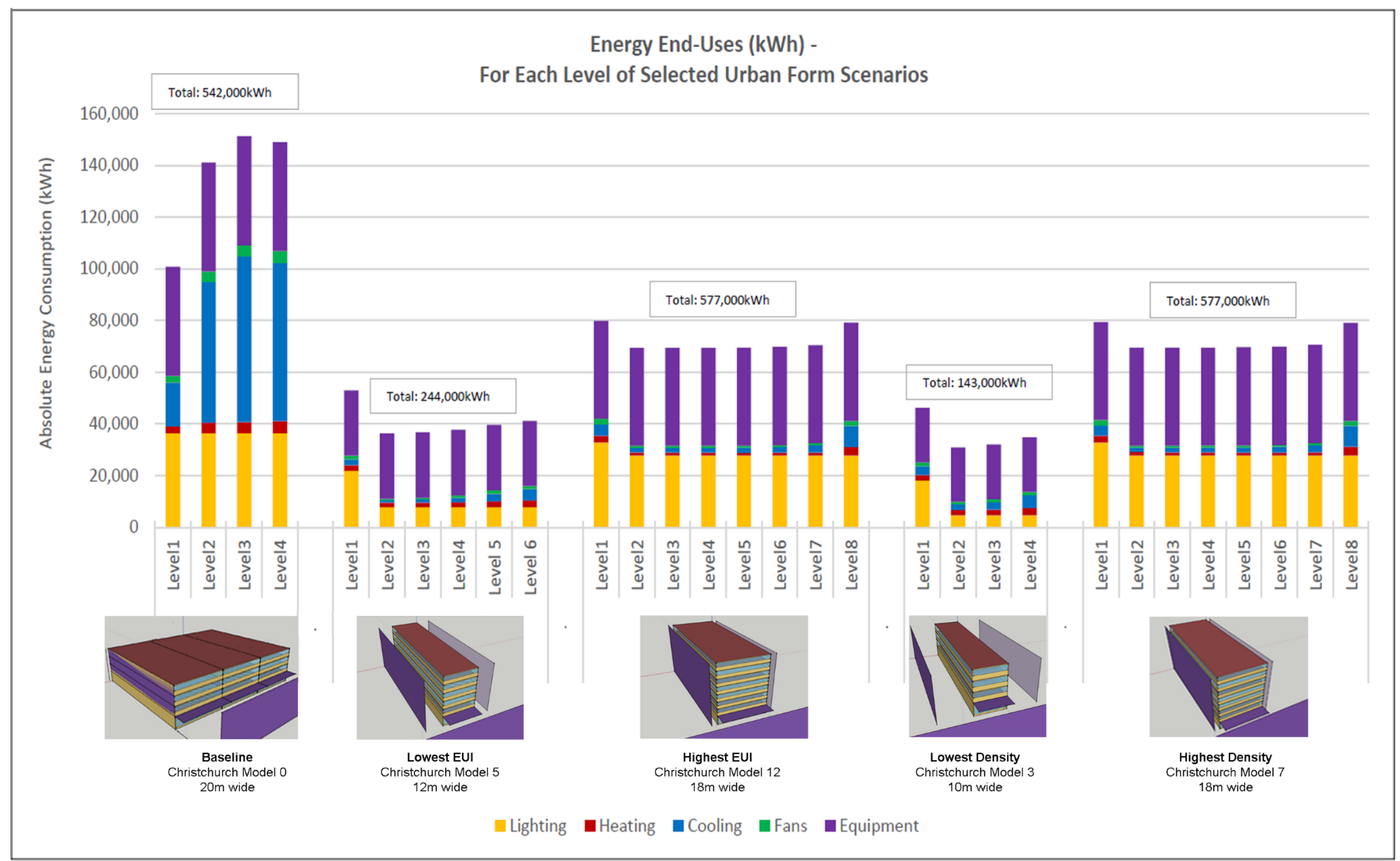

Figure 7.4. Energy End-use Breakdown for Each Level of Selected Scenarios. 


\subsubsection{Urban Forms Effect on Density}

One of the major considerations of this research is the effect the porous urban forms have on density. Density is discussed and assessed here at two scales- Individual property and CCB

\subsubsection{Individual Properties Density}

To quantify an urban forms effect on individual property density, the 'Plot Ratio' metric was used. Plot ratio (total floor area / property area) describes the maximum amount of floor area that can be built on a property plot according to building height and separation rules of each urban form scenario. Figure 7.5 presents an example (Model 3,10m) visualisation of how the calculation was made. Full plot ratio calculations can be found in Appendix B.1.

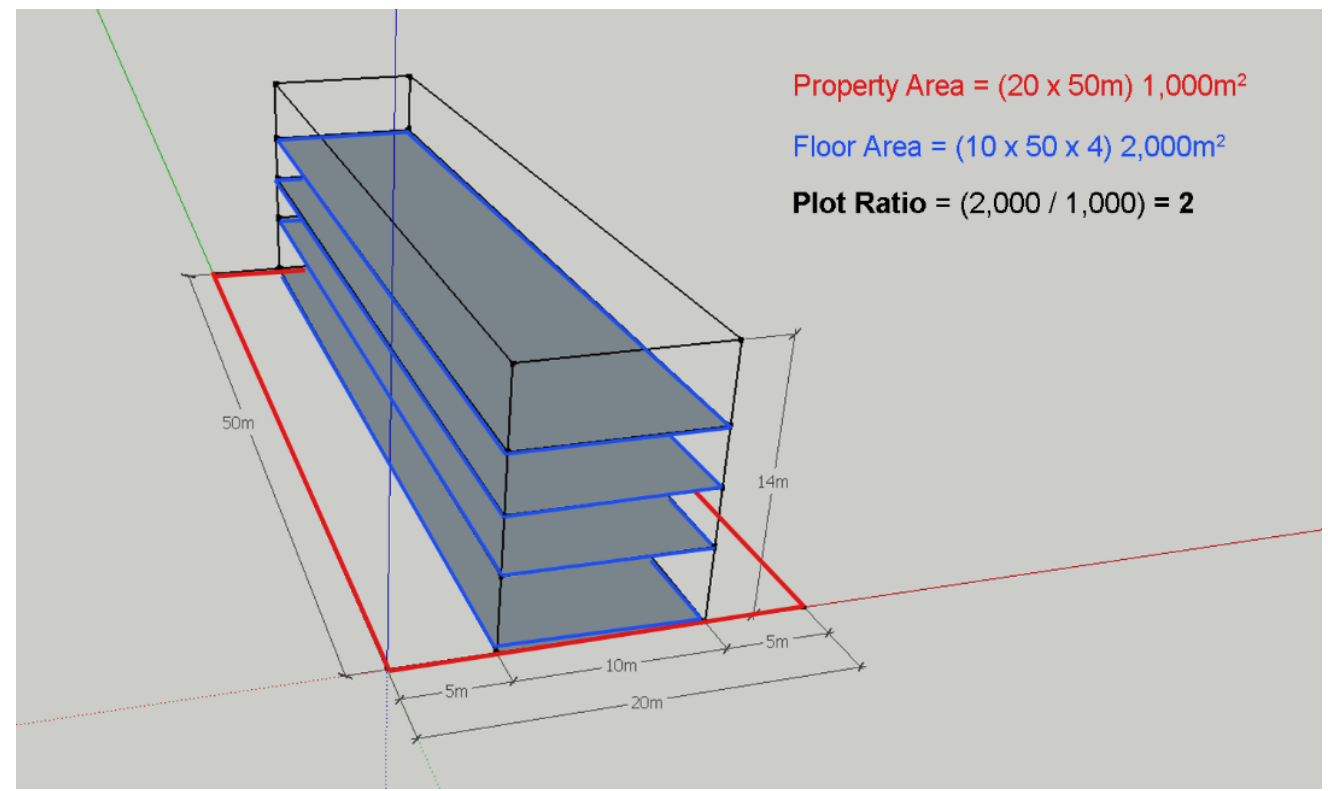

Figure 7.5. Visualization (Model 3, 10m) of the Plot Ratio calculation for individual property density.

Figure 7.6 presents the individual property Plot Ratio results. Lowest EUI 'Model 5, $12 \mathrm{~m}$ ' is in fact the same Plot Ratio as Model $0-4.0$. Three things have changed between these scenarios: $6 \mathrm{~m}$ gaps between buildings have been inserted; two levels have been added; and energy consumption has been reduced by $48 \%$. This change is possible with a simple rearrangement of the buildings geometry, retaining $100 \%$ of its NLA. It must also be acknowledged that this thinner but taller Model 5 would incur greater capital expenses due to extra façade area.

The highest EUI 'Model 12, 18m' and the highest Plot Ratio 'Model 7, 18m' have identical Plot Ratios of 7.2. However, because 'Model 7, $18 \mathrm{~m}$ ' includes $20 \mathrm{~m}$ roads it is higher density overall. Road width is not considered in plot ratio calculations as it does not affect property size. Road width is considered in the CCB scale calculations following.

The Lowest density 'Model 3,10m' has a Plot Ratio of 2.0, half that of Model 0. While this seems excessive, it remains within the 50\% NLA reductions that were argued as 'acceptable' in Section 5.2.3. Importantly, while Model $3,10 \mathrm{~m}$ is the lowest density, it is not the most energy efficient. This shows that energy and density are not necessarily proportional, and that higher density urban forms can in fact enable better building performance than low density urban forms.

Highest Plot Ratio 'Model 7, 18m' exemplifies the benefits of a porous urban form. While it is one of the highest EUls of the passive scenarios, it is still an improvement of $41 \%$ when compared to the non-passive baseline $\left(135 \mathrm{kWh} / \mathrm{m}^{2} /\right.$ year down to $80 \mathrm{kWh} / \mathrm{m}^{2} /$ year). 


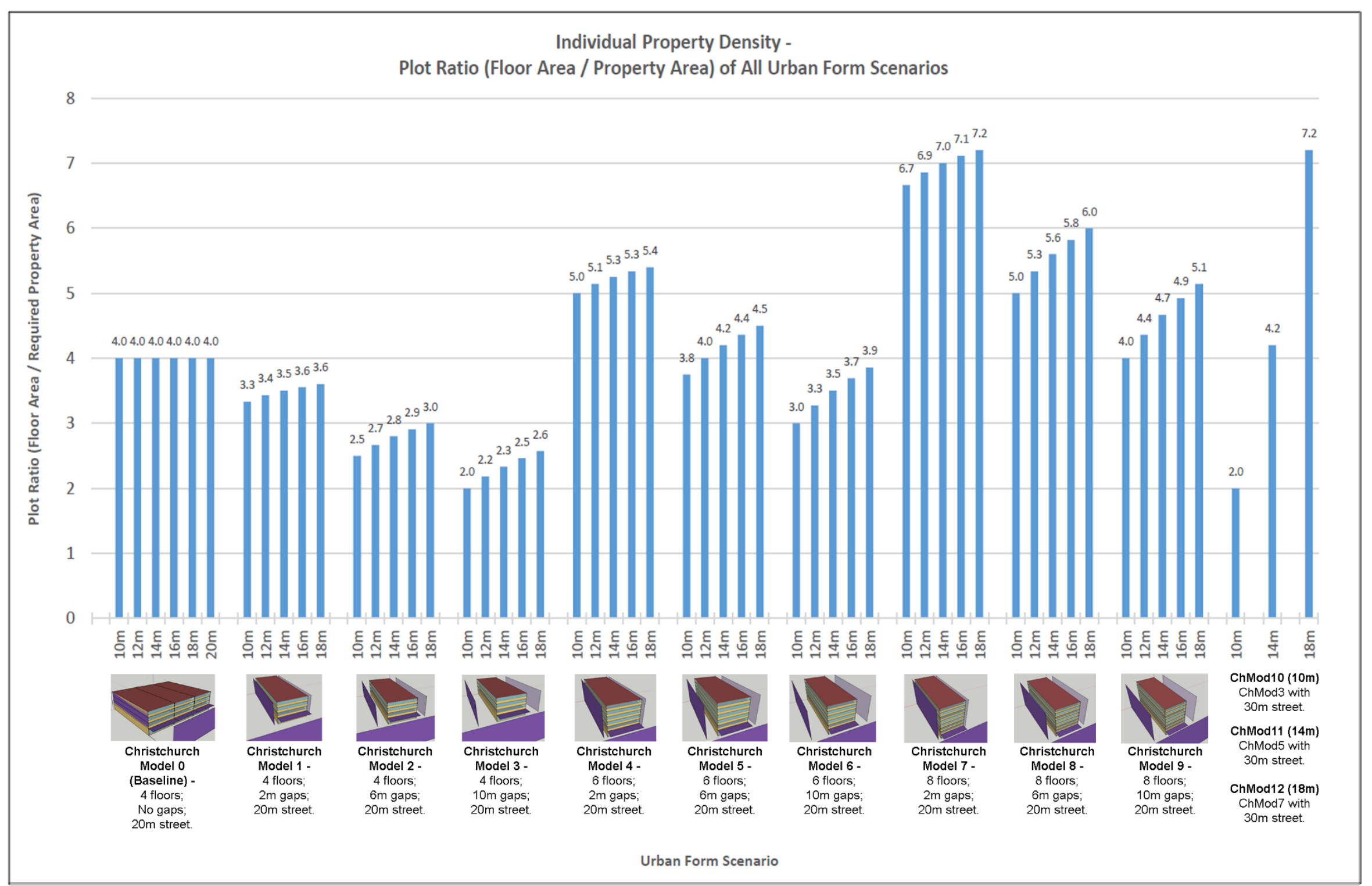

Figure 7.6. Plot Ratios (floor area / property area) for each Urban Form Scenario. 


\subsubsection{CCB Density}

Density is also analysed from the CCB scale perspective. Increasing porosity through 'passive urban forms' would restrict floor area potential in the CCB. Urban Forms must be assessed to determine whether they are capable of providing the $266,000 \mathrm{~m}^{2}$ projected demand for office space (refer Section 2.3.4.1). This section calculates how many of the 40 hectares/15 CCB blocks are required to achieve the $266,000 \mathrm{~m}^{2}$ demand for each urban form scenario. Figures are translated from hectares to 'CCB blocks' for context. A 'CCB block' is $110 \mathrm{~m}$ (north-south) by $210 \mathrm{~m}$ (east-west) including half the adjacent road. Figure 7.7 illustrates how the calculations were applied to each $20 \mathrm{~m}$ property (full calculations can be found in Appendix B.2).

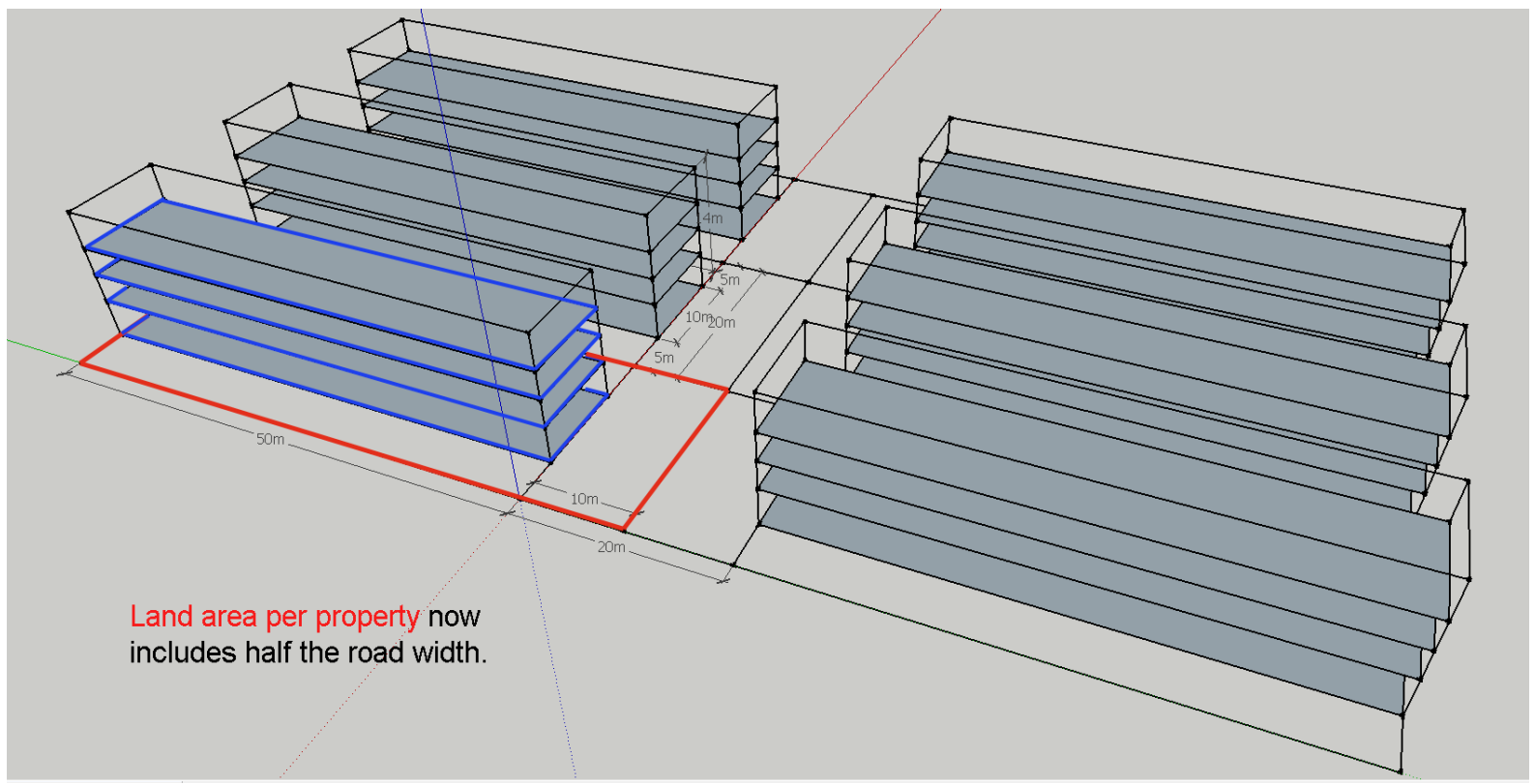

Figure 7.7. Visualization of the CCB Block calculation for city scale density.

Figure 7.8 shows that the best energy performing scenario 'Model $5,12 \mathrm{~m}$ ' is of equal density to the energy intensive baseline and would require only 4 CCB Blocks to achieve the $266,000 \mathrm{~m}^{2}$ projected demand for office space. The worst energy performing 'Model $12,18 \mathrm{~m}$ ' could achieve the required floor area in only 2.4 blocks.

The effect of road width on overall density can be seen in the difference between 'Model $3,10 \mathrm{~m}$ ' and 'Model $10,10 \mathrm{~m}$ ', the latter being expanded to $30 \mathrm{~m}$ wide roads, requiring an extra 0.6 ( 8.0 up to 8.6) blocks (over 1 hectare) to achieve the $266,000 \mathrm{~m}^{2}$ demand.

Highest density Model 7, 18m would only require 2.2 CCB blocks to achieve the required floor area. Figure 7.8 shows that all porous urban form scenarios easily provide the projected demand for office space within the 15 available CCB blocks. In fact, even the lowest density Model 10 would only cover $57 \%$ ( 8.6 out of 14.9 blocks) of the CCB.

Evidently, density at the CCB scale is not an issue. Increasing porosity of the urban fabric will still allow for both the projected demand for office space to be achieved following the rebuild; and continued growth in the future. At this scale there is no need for high density development, at the cost of building performance. 


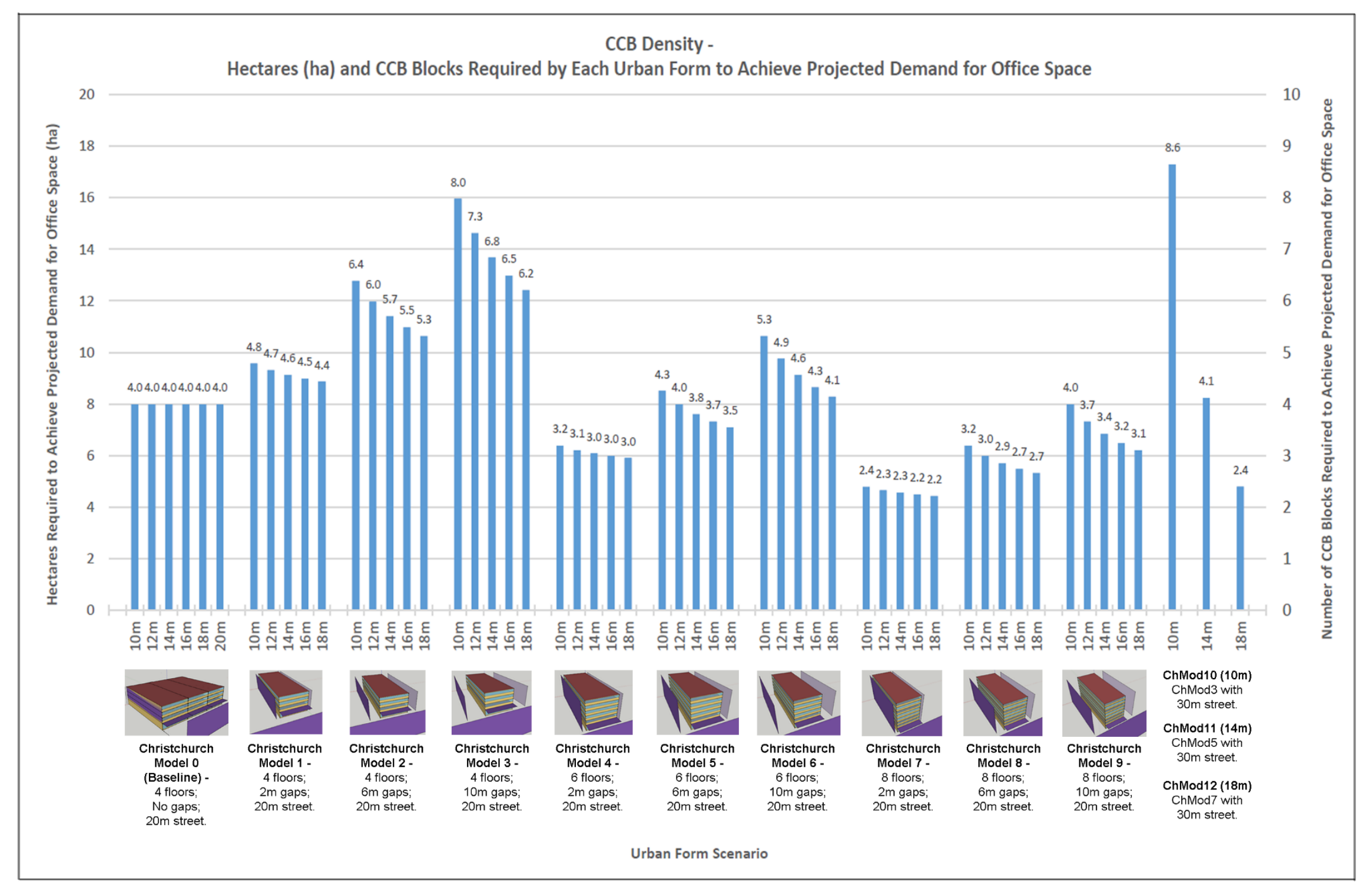

Figure 7.8. CCB Density (including streets) for each Urban Form Scenario 


\subsubsection{Urban Forms Effect on Comfort}

While minimizing energy consumption is valuable (and the primary goal of this research) it becomes a pointless, even detrimental exercise if user comfort is adversely affected. Section 7.1.3 reports the comfort performance of the 59 urban form scenarios tested, breaking them down into the five environmental performance areas: temperature, air change rates, air speed, Daylight Autonomy and maximum Daylight Autonomy (refer Chapter 4).

\subsubsection{Environmental Performance Criteria 1 - Temperature}

Section 4.3.1.3 established the range of comfort for temperature as $18-25^{\circ} \mathrm{C}$. Figures 7.9 and 7.10 illustrates how the five selected scenarios performed thermally, with and without any mechanical assistance (HVAC). The stacked bar-graphs show the percentage of the occupied year $(2,500$ hours, refer Section 4.2.1.6) that each level of the building was 'too cold' $\left(<18^{\circ} \mathrm{C}\right)$, 'comfortable' $\left(18-25^{\circ} \mathrm{C}\right)$, or 'too warm' $\left(>25^{\circ} \mathrm{C}\right)$.

Figure 7.9 presents unconditioned thermal performance. Clearly, the poorly designed baseline (Model 0 ) is constantly over-heated (100\% of occupied hours on upper floors), due to the sun, occupants and equipment. Because there are no windows to open, this over-heating can only be rectified with energy intensive, mechanical cooling, as was seen in Figure 7.4.

Conversely, the four passive scenarios only overheat for an average of $14 \%$ of the year, simply because they have the ability to release excess heat by opening windows. This comparison exemplifies the environmental benefits of naturally ventilation. Passive models are able to maintain a comfortable temperature for most of the occupied year without any HVAC assistance.

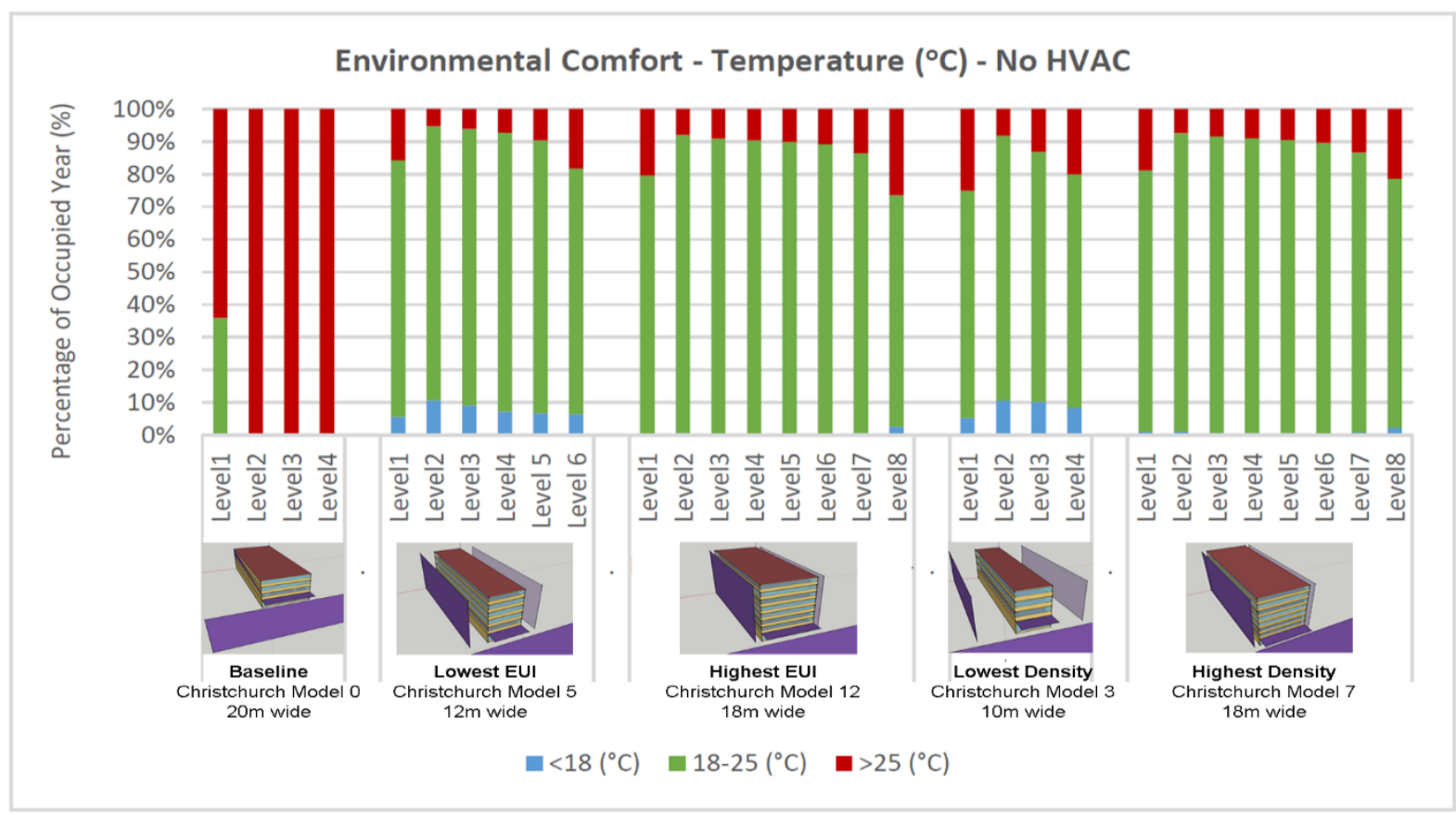

Figure 7.9. Thermal conditions in selected urban forms without HVAC.

When HVAC systems are applied (Figure 7.10), Model 0 is returned to comfortable temperatures, but at a significant energy cost. Furthermore, because the baseline was overheated so frequently, the mechanical cooling system is unable to satisfy cooling demand, leaving spaces still too hot for over $10 \%$ of the occupied year. With HVAC the passive scenarios now satisfy thermal criteria for $97 \%$ of the year on average. The remaining $3 \%$ of time where temperatures are still too warm could be resolved through further design development of the natural ventilation system (i.e. openable window sizes) which is addressed in the Building Design investigation reported in Section 7.2. 


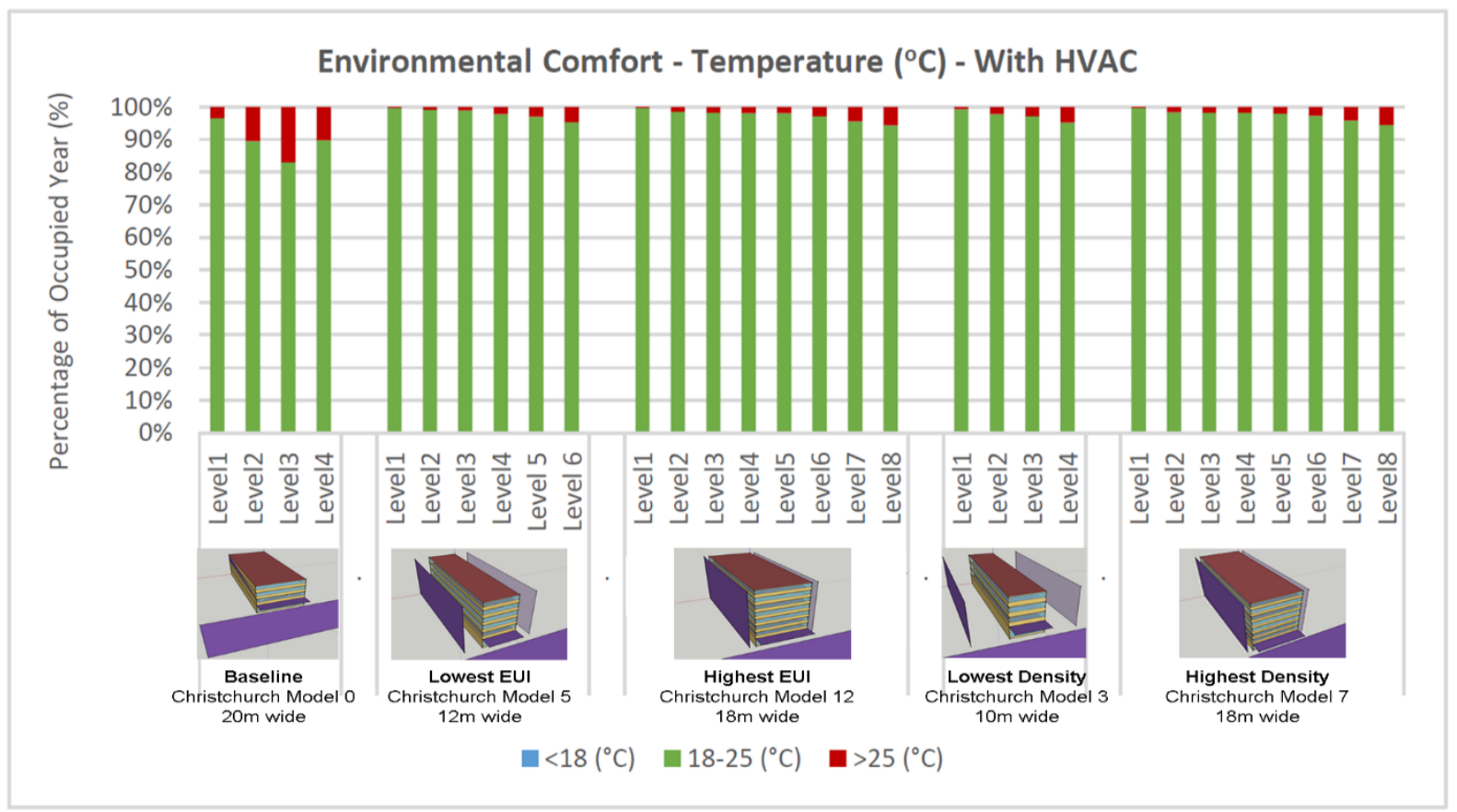

Figure 7.10. Thermal conditions in selected urban forms with HVAC

Where Figures 7.9 and 7.10 reported uncomfortable times, Figure 7.11 presents degree of discomfort. This analysis shows that minimum, average and maximum temperatures of each level of the baseline scenario are all we above the $18-25^{\circ} \mathrm{C}$ comfort band, whereas passive scenario temperatures are much lower, the average always falling within the comfort band.

Another clear pattern is that the top floor always experiences, by far, the hottest and coldest temperatures, up to $45^{\circ} \mathrm{C}$. This pattern indicates more protection (e.g. more insulation) is required in the roof to control thermal transfer. Insulation levels and construction type of the crucial roof surface are investigated in 'Ventilation and Thermal Design', reported in Section 7.2.

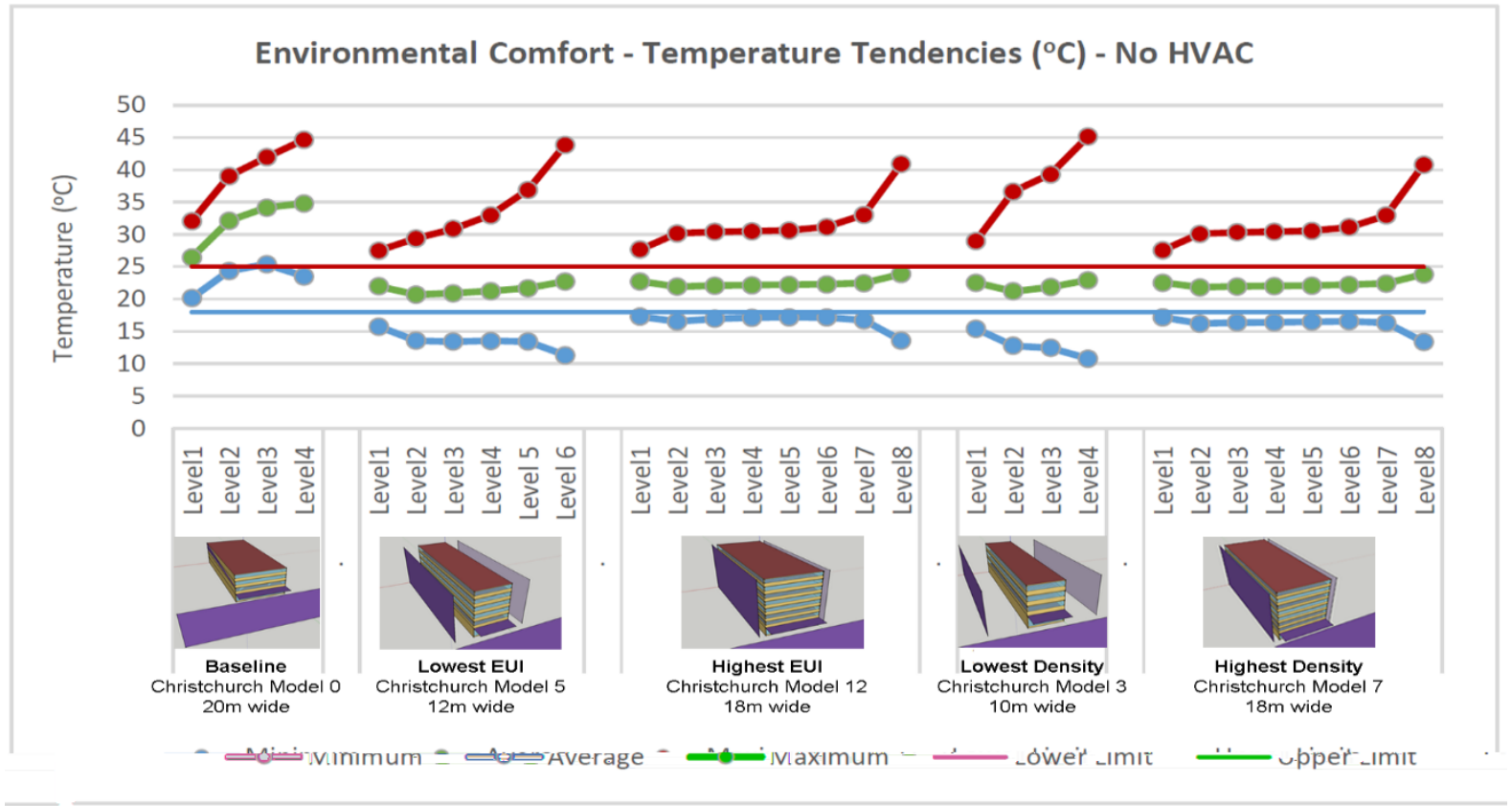

Figure 7.11. Minimum, average and maximum temperatures for selected scenarios. 


\subsubsection{Environmental Performance Criteria 2-Air Change Rates}

Figure 7.12 presents the ability for urban form scenarios to satisfy the minimum ventilation requirement, of 0.84 air changes per hour $(\mathrm{ACH})$ (refer Section 4.3.1.1), during the occupied year (refer Appendix B.3 for full calculations). Data is categorised as either: 'insufficient' $(<0.84 A C H)$, sufficient for ventilation' (0.84-20ACH); or 'sufficient for cooling' ( $>20 \mathrm{ACH})$. Model 0 , which has no openable windows, is omitted from this natural ventilation analysis.

Figure 7.12 shows that all passive scenarios and levels appear to deliver similar air change rates, achieving minimum ACH's for between 44 and $62 \%$ of the year. It was expected that lower density scenarios (wider gaps, shorter buildings) would create greater exposure to wind pressures and propagate more ventilation, or higher ACH's. Density of the urban form, however, does not appear to have much effect on natural ventilation with high density scenarios (Models 12 and 7) achieving minimum $\mathrm{ACH}^{\prime}$ s for $59 \%$ of the year; and low density scenarios for $56 \%$ of the year. It appears that smaller 2 and $6 \mathrm{~m}$ gaps, as well as taller buildings, are just as effective as wider $10 \mathrm{~m}$ gaps, and shorter buildings.

This is a promising finding as it indicates less prominent changes to urban form (i.e. smaller increases in porosity) are required to enable effective natural ventilation, than was previously thought.

ACH's of $>20$ only occur during a small percentage $(<5 \%)$ of the year on some levels of the low density models. This does not appear to be an issue however, as natural temperatures within the passive models are already mostly 'comfortable' $\left(18-25^{\circ} \mathrm{C}\right.$, refer Section 7.1.3.1), and so high air change rates are not required to cool further.

These results indicate that given openable windows with at least $2 \mathrm{~m}$ of void beyond, ventilation criteria will be satisfied for around $50 \%$ of the occupied year. These results can be improved as they are based on a window openable area of only $5 \%$ of the floor area, so there is room for improvement in the design (refer Section 7.2.2.2).

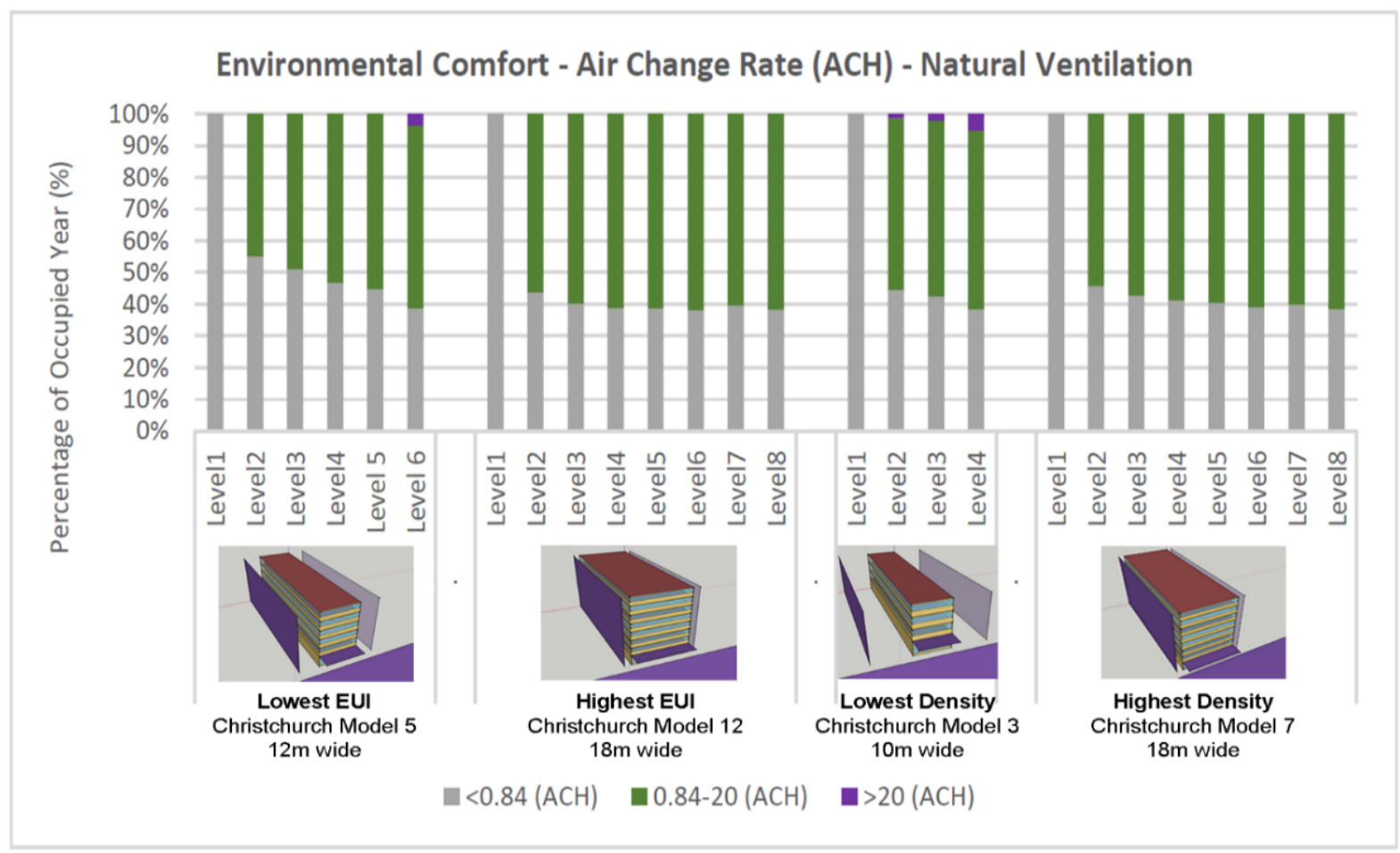

Figure 7.12. Natural ventilation performance - Air change rates for each selected passive scenario. 


\subsubsection{Environmental Performance Criteria 3 - Air Speed}

Section 4.3.1.2 identified any air movement faster than $0.3 \mathrm{~m} / \mathrm{s}$ could cause discomfort or annoyance but also found that occupants tend to be more forgiving in naturally ventilated buildings, and would tolerate air speeds of up to $2.0 \mathrm{~m} / \mathrm{s}$.

Figure 7.13 illustrates how much of the occupied year air speeds were: 'comfortable' $(<0.3 \mathrm{~m} / \mathrm{s})$, 'tolerable' $(0.3-2.0 \mathrm{~m} / \mathrm{s})$, or 'too fast' $(>2.0 \mathrm{~m} / \mathrm{s})$ for each of the selected passive scenarios. Results clearly show that at no point do any of the models experience excessive air speeds $(>2.0 \mathrm{~m} / \mathrm{s})$. Lowest density Model 3 experiences the highest air speeds but even this is 'comfortable' for over $90 \%$ (average) of the occupied year. Model 5 only reaches air speeds in excess of $0.3 \mathrm{~m} / \mathrm{s}$ on its top floor. These higher air speeds can be associated to the more extreme wind pressures present around the top of exposed (low density) buildings (refer Appendix D - UrbaWind Results). High density Models 7 and 12 do not experience air movement over $0.3 \mathrm{~m} / \mathrm{s}$. This was expected considering the low wind pressure differences associated with the high density urban forms. These results indicate natural ventilation would very little disturbance or discomfort to occupants through excessive air speeds.

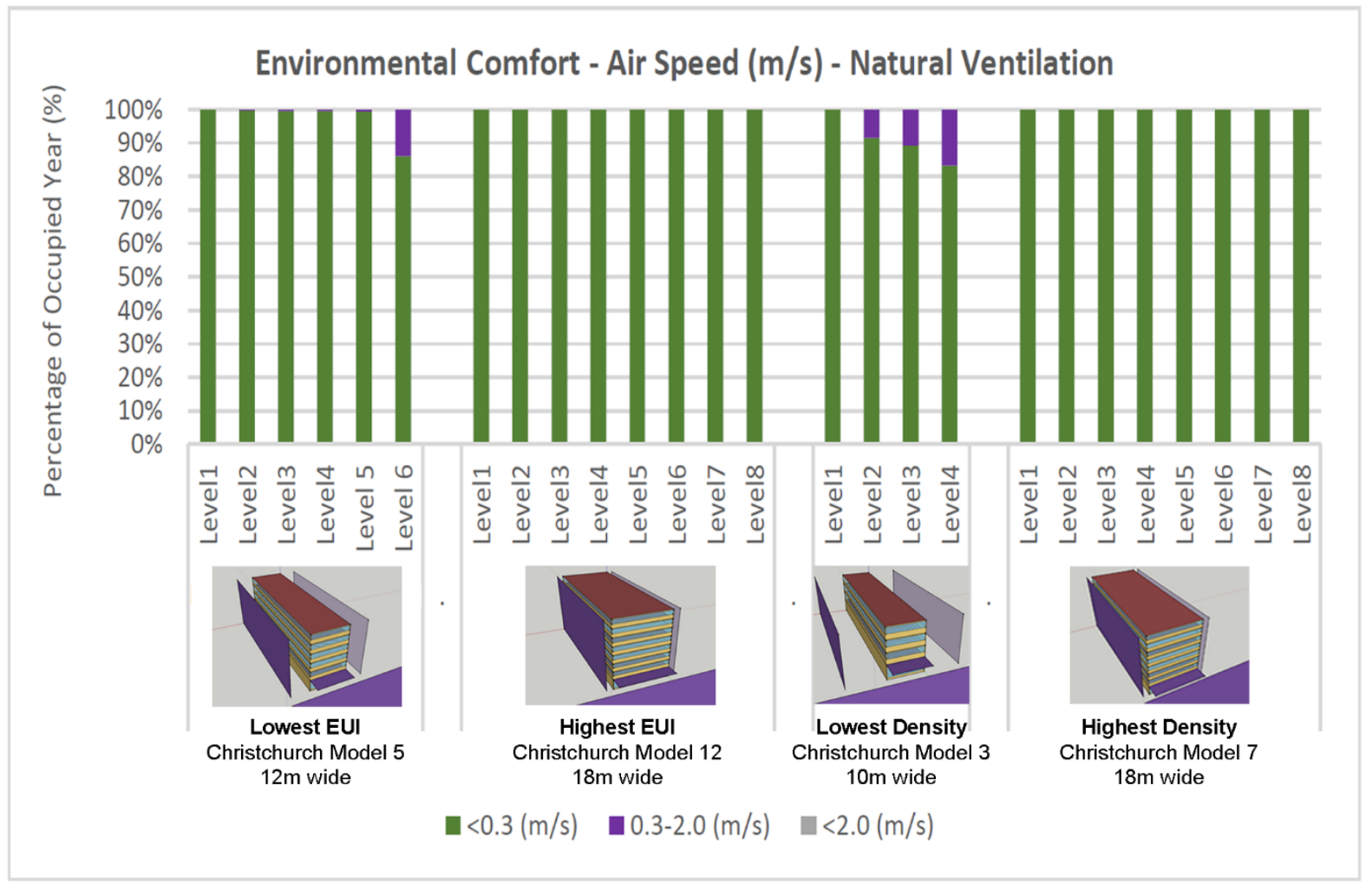

Figure 7.13. Natural ventilation performance - Air speed for each selected scenario

\subsubsection{Environmental Performance Criteria 4-Daylight Autonomy (DA)}

Daylight Autonomy (DA) describes the percentage of the occupied year a point reaches the $4001 x$ minimum threshold (refer Section 4.2.1.3). Figure 7.14 shows how the thinner floor plates and larger separation of buildings of Models 3 and 5 reach $4001 x$ for up to $100 \%$ of the year (orange-yellow); and that larger, closer buildings struggle to reach 400 lx for more than $10 \%$ (blue) of the occupied year. The flip-side of high DA values is that over-exposure is likely to be an issue (refer Section 7.1.3.5). 


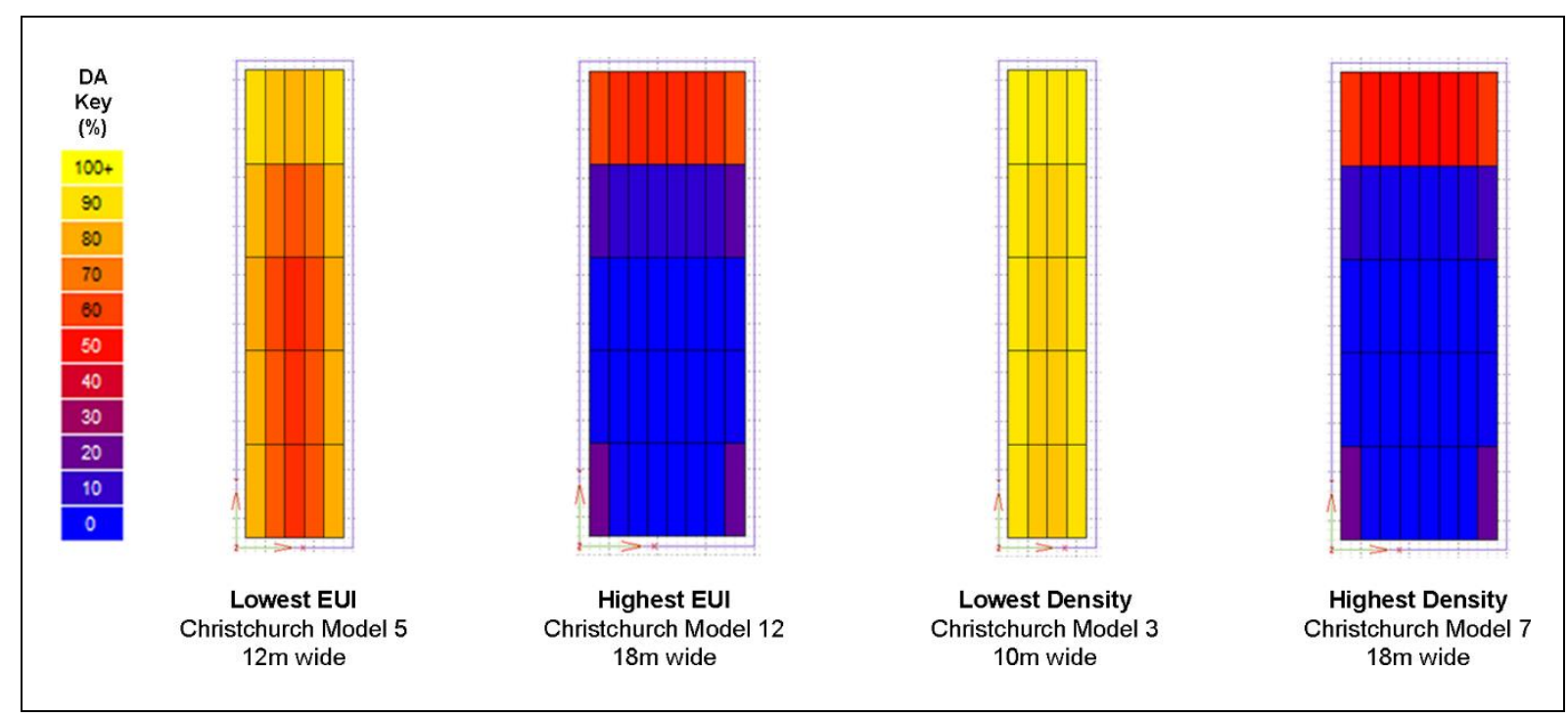

Figure 7.14. Daylight Autonomy (DA) for selected scenarios presented on Ecotect analysis grids

Beyond DA, this study also considers sDA (spatial Daylight Autonomy), which denotes the minimum coverage of space required to make daylighting feasible - in this case, $75 \%$ (refer Section 4.2.1.5).

Figure 7.15 combines DA and SDA to determine the portion of space that DA criteria is achieved for. Hours which both DA and SDA criteria are met are tabulated and stacked as either 'good' or 'preferred' daylighting. To be considered 'good daylighting', $>75 \%$ of grid points must reach $4001 x$ for at least $50 \%$ of the year. 'Preferred daylighting' is defined as $>75 \%$ of grid points reaching $400 \mathrm{~lx}$ for at least $75 \%$ of the year. Regardless of DA levels, if less than $75 \%$ of the space reaches $4001 x$, it will be considered poor daylighting and will not be tabulated, emphasizing how often the space is successfully day-lit. This sDA criteria (represented by the horizontal yellow line) addresses the point that daylighting is not successful if it does not cover the majority of the space.

Figure 7.15 shows that daylighting in Models 12 and 7 is poor, only $21 \%$ of the spaces reaching 400 lx. This illustrates how the high density urban forms do not allow enough daylight to penetrate the urban canyon and filter into the building spaces. The fact that results for these two scenarios are identical indicates that widening streets from $20 \mathrm{~m}$ to $30 \mathrm{~m}$ has no beneficial effect on daylight.

$100 \%$ of the space in Model 5 satisfies DA criteria. 50\% of the space receives 'good daylight' (400lx for $50-75 \%$ of the year) and the other $50 \%$ receives 'preferred daylight' (400lx for $>75 \%$ of the year). This is extremely good daylighting and explains the considerable electric lighting load reductions seen in Figure 7.4.

Even more impressive are the results seen for Model 3, which show $100 \%$ of the space reaches $4001 \mathrm{x}$ for over $75 \%$ of the occupied year. This is the best possible result under the selected DA and SDA criteria. However, such strong daylight may be detrimental to the buildings overall performance as it could incur both glare and solar gains. It is likely, in fact, that it is this over-exposure that makes Model 3 less energy efficient than Model 5, which benefits from shading of direct sunlight by closer, taller buildings.

These results support gaps between buildings as good mechanisms for delivering daylight. Further, they indicate $2 \mathrm{~m}$ gaps are insufficient; $10 \mathrm{~m}$ gaps are potentially too big, overexposing buildings; and that $6 \mathrm{~m}$ gaps could provide sufficient access to daylight but useful shading from sunlight. 


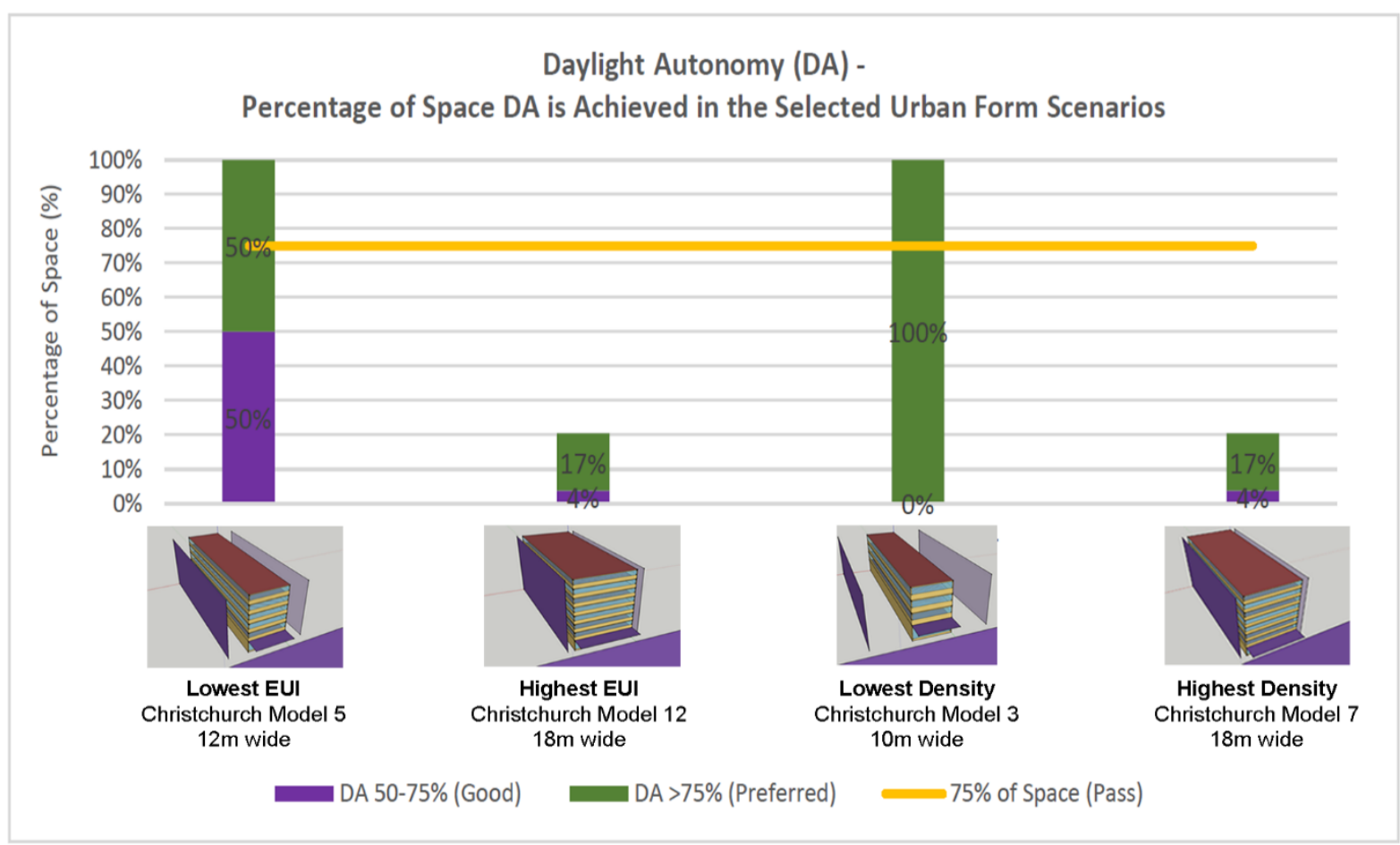

Figure 7.15. Daylight Autonomy (DA) and spatial Daylight Autonomy (sDA) performance for selected passive scenarios.

\subsubsection{Environmental Performance Criteria 5 - Maximum Daylight Autonomy (mDA)}

While high levels of daylight is beneficial for reducing artificial lighting loads, excessive light can cause glare and discomfort. The consequence of this is that daylight will likely be rejected through the use of blinds, and artificial lighting will be employed once again. Maximum Daylight Autonomy (mDA) tabulates instances when illuminances are greater than 4,000lx (refer Section 4.2.1.4). As with $\mathrm{DA}, \mathrm{mDA}$ analysis includes a spatial factor. If over-exposure occurs for more than $1 \%$ of the year, on more than $5 \%$ of the space, glare is likely to be an issue.

Figure 7.16 reports the percentage of space that mDA criteria are met for each scenario. In other words, the green ('comfortable') bars are times when over-exposure is not an issue. The yellow line represents the $95 \%$ spatial target.

As mentioned in the previous DA section, the high daylight levels present in Model 3 would likely result in considerable over-exposure. Here, all of the space experiences illuminances greater than $4,000 \mathrm{~lx}$ for more than $1 \%$ of the year (>mDA $1 \%$ ), meaning over-exposure is a substantial problem that could lead to occupants closing blinds permanently.

Solar shading devices such as overhangs and louvers have been identified as options that could help to alleviate these over-exposure issues (refer Section 6.2.3) these results are presented in Section 7.2.1.1.

As discussed in the previous section, it appears that urban form can also offer shading benefits. Higher density Model 5 , with its two extra floors and only $6 \mathrm{~m}$ gaps, is markedly better than Model 3 with $47 \%$ of the space avoiding glare. While this is still well below the performance criteria, it illustrates that the extra shading from surrounding buildings helps to limit exposure to direct sunlight - reducing glare issues and overheating even before specific shading devices are applied.

Models 7 and 12 perform well in terms of mDA, both cases avoiding over-exposure across $80 \%$ of their spaces. However, while $80 \%$ is a good return, it is still a fail according to the established criteria. Furthermore, these two scenarios performed poorly in terms of DA so did not pass either DA or mDA daylighting criteria. 


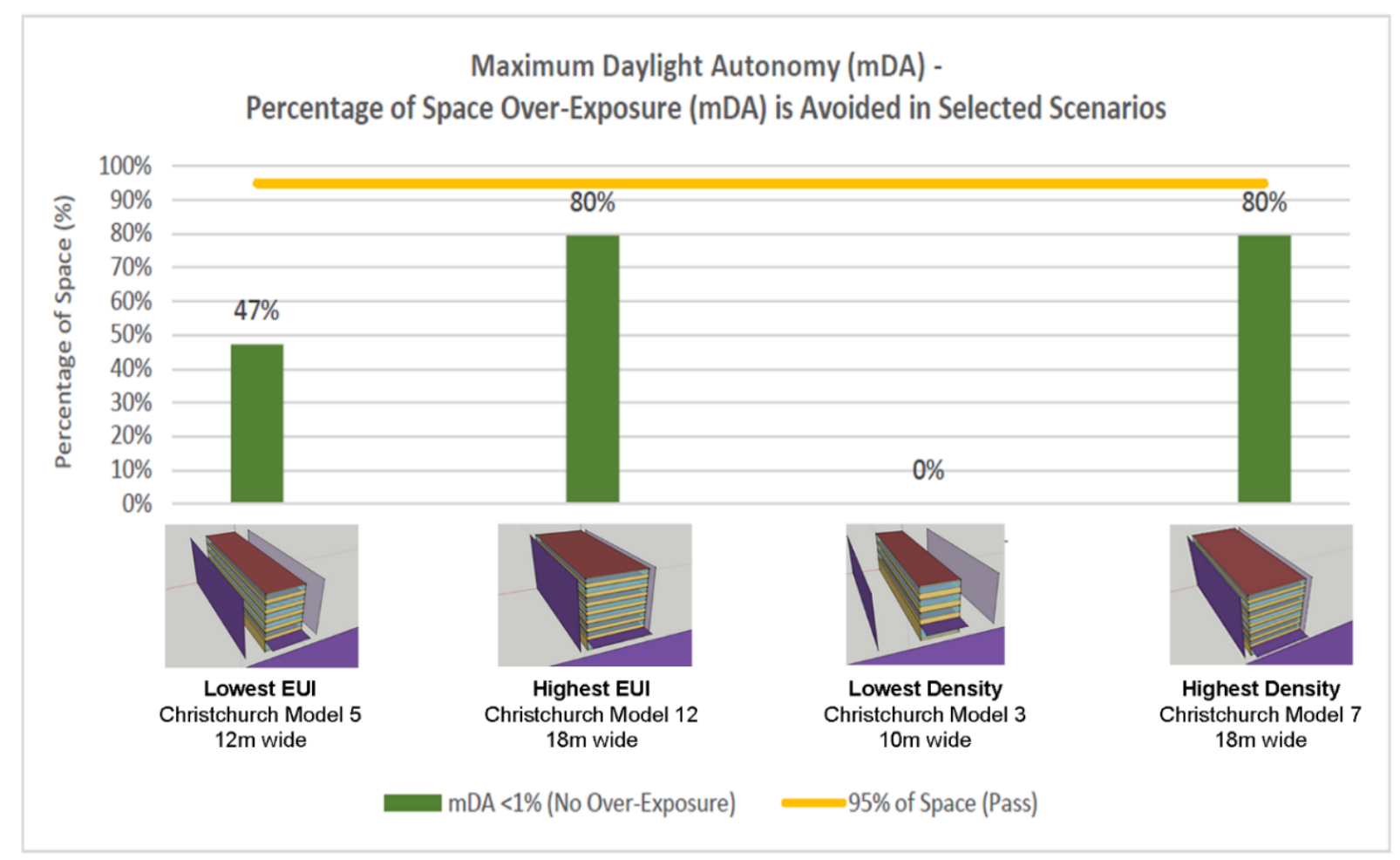

Figure 7.16. Maximum Daylight Autonomy (time and space over-exposure avoided) results for selected scenarios.

As was discussed in Section 4.2.1.4, mDA criteria must be demanding otherwise glare will occur and occupants will become uncomfortable. Development of daylighting systems and, in particular, solar shading systems aim to improve mDA results presented here. The results of these and other Building Design changes are reported in the following section. 


\subsection{Building Design for Improved Passive Performance}

Section 7.1 demonstrated that the provision of a porous urban form and windows could improve a building's energy performance by up to $48 \%$. The best urban form scenario - Model $5,12 \mathrm{~m}$ - was then taken and building design elements were tested to determine how much further performance could be improved- Section 7.2 presents these results.

\subsubsection{Building Designs Effect on Energy}

As with Urban Form, the effect of 'Building Design' is assessed for its effect on energy. This investigation is only applied to 'Model $5,12 \mathrm{~m}$ ' as it represents the highest potential for energy savings. Energy performance results of the building design are compared to each other as well as the original 'Model 5, 12m', which now acts as the baseline scenario.

\subsubsection{Daylighting Design - Energy Use Intensities (EUI's)}

The first stage of the Building Design investigation was a parametric analysis of the Daylighting Design parameters- WWR, glazing type and solar shading (refer Section 6.2).

Figure 7.17 presents the EUI resulting from each combination of the daylight design parameters. This graph shows that the original daylighting system, which consisted of a WWR of $50 \%$ (WWR 0.5 ); clear single layer of glazing (Tvis0.9); and no overhang $(\mathrm{OH} 0 \mathrm{~mm})$, performed well at $67.9 \mathrm{kWh} / \mathrm{m}^{2} /$ year.

The combination which performed most efficiently overall, at $65.7 \mathrm{kWh} / \mathrm{m}^{2} /$ year consisted of WWR 0.75 ; Tvis 0.73 (double glazing); and $\mathrm{OH} 750 \mathrm{~mm}$. It is expected that the large glazed area enables high levels of daylight, but the shading and increased insulative capacity of the double glazing limit heat transfer.

The worst combination, at $74.2 \mathrm{kWh} / \mathrm{m}^{2} /$ year consisted of WWR 0.25 ; Tvis 0.73 (double glazing); and $\mathrm{OH} 1,500 \mathrm{~mm}$, which is likely to be poorly day-lit due to the small windows and large overhangs.

Overall, the daylight system alterations only had minor effects on energy consumption, increasing EUI by up to $6.3 \mathrm{kWh} / \mathrm{m}^{2} /$ year $(9.2 \%)$, or decreasing it by up to $2.2 \mathrm{kWh} / \mathrm{m}^{2} /$ year $(3.3 \%)$, when compared to the original 'Model 5, $12 \mathrm{~m}$ '.

Following is a breakdown of the results for each of the three Daylighting Design parameters.

\section{Daylighting Design Parameter 1: Window to Wall Ratio (WWR)}

WWR - the size of a window relative to its wall - appears to be significant. Figure 7.17 shows that the smallest glazed area of $25 \%$ does not perform as well as the larger WWR's. Only a single WWR 0.5 iteration is less efficient than all WWR 0.25 iterations. This is likely to be because $25 \%$ is not large enough to deliver sufficient daylight to the space. WWR's of $50 \%$ and $75 \%$ appear to perform similarly on average, although $50 \%$ WWR $\left(66.6-68.9 \mathrm{kWh} / \mathrm{m}^{2} /\right.$ year $)$ is slightly better than $75 \%$ WWR (65.7 - $70.3 \mathrm{kWh} / \mathrm{m}^{2} /$ year). The difference is likely to be due to greater thermal transfer into and out of the space through the larger glazed surface.

\section{Daylighting Design Parameter 2: Glazing Type}

Glazing Type - the material properties of glass - did not generate any conclusive patterns. At a WWR of $50 \%$, double glazing (Tvis 0.73 ) performed marginally better than clear glass (Tvis 0.9 ), which was slightly better than reflective glass (Tvis 0.76 ). For the $25 \% \mathrm{WWR}$, clear glass combinations were the best and double glazing the worst, indicating translucency, not thermal properties, is the preferred glazing characteristic for small windows. This then reverses for the 75\% WWR.

Ultimately, double glazing (when combined with $750 \mathrm{~mm}$ overhangs and $75 \%$ WWR) was the best performer, as it maximizes diffuse daylight but minimizes direct sunlight and thermal transfer. 
However, this system realized only a small $3.3 \%\left(2.2 \mathrm{kWh} / \mathrm{m}^{2} /\right.$ year $)$ improvement over the original daylighting combination (clear glass and 50\% WWR) plus $750 \mathrm{~mm}$ overhangs, and would cost significantly more for larger, double glazed windows.

\section{Daylighting Design Parameter 3: Solar Shading (Overhangs)}

Solar shading - external devices designed to limit direct sunlight incident on the windows - had a clear effect. As expected, scenarios consisting of small windows (WWR0.25) performed better with no overhangs, maximizing daylight available to the restricted apertures.

Conversely, large WWR 0.75 windows were more efficient when overhangs were present- although $1,500 \mathrm{~mm}$ overhangs were not as effective as smaller $750 \mathrm{~mm}$ overhangs. In fact this was a pattern with all WWR's and glazing types- in all situations $1,500 \mathrm{~mm}$ overhangs produced a higher EUI than a $750 \mathrm{~mm}$ overhang in an identical situation. This indicates that there is an optimum point around $750 \mathrm{~mm}$ where overhangs are sufficient to minimize solar heat gains and impact on daylight is minimized. Maximum Daylight Autonomy (mDA) results, presented in Section 7.2.2.5, will illustrate the effect of overhangs on visual comfort.

For the following investigation of 'natural ventilation and thermal design' it was intended that only the most effective daylighting design system - WWR 75\%, double glazing and $750 \mathrm{~mm}$ overhangs would be considered. However, the degree of change required to realize performance improvements is also a factor, and so the original daylight system (plus $750 \mathrm{~mm}$ overhangs) will also be taken forward. The inclusion of this 'basic' daylighting design scenario enables an analysis into the effectiveness of passive design at its most simple, inexpensive manifestation. Therefore, natural ventilation and thermal design will be tested using two iterations of 'Model 5, 12m':

- 'Daylight 1' - WWR 0.5, Tvis 0.9, overhang 750mm (basic system); and

- 'Daylight 2' - WWR 0.75, Tvis 0.73, overhang 750mm (best system) 


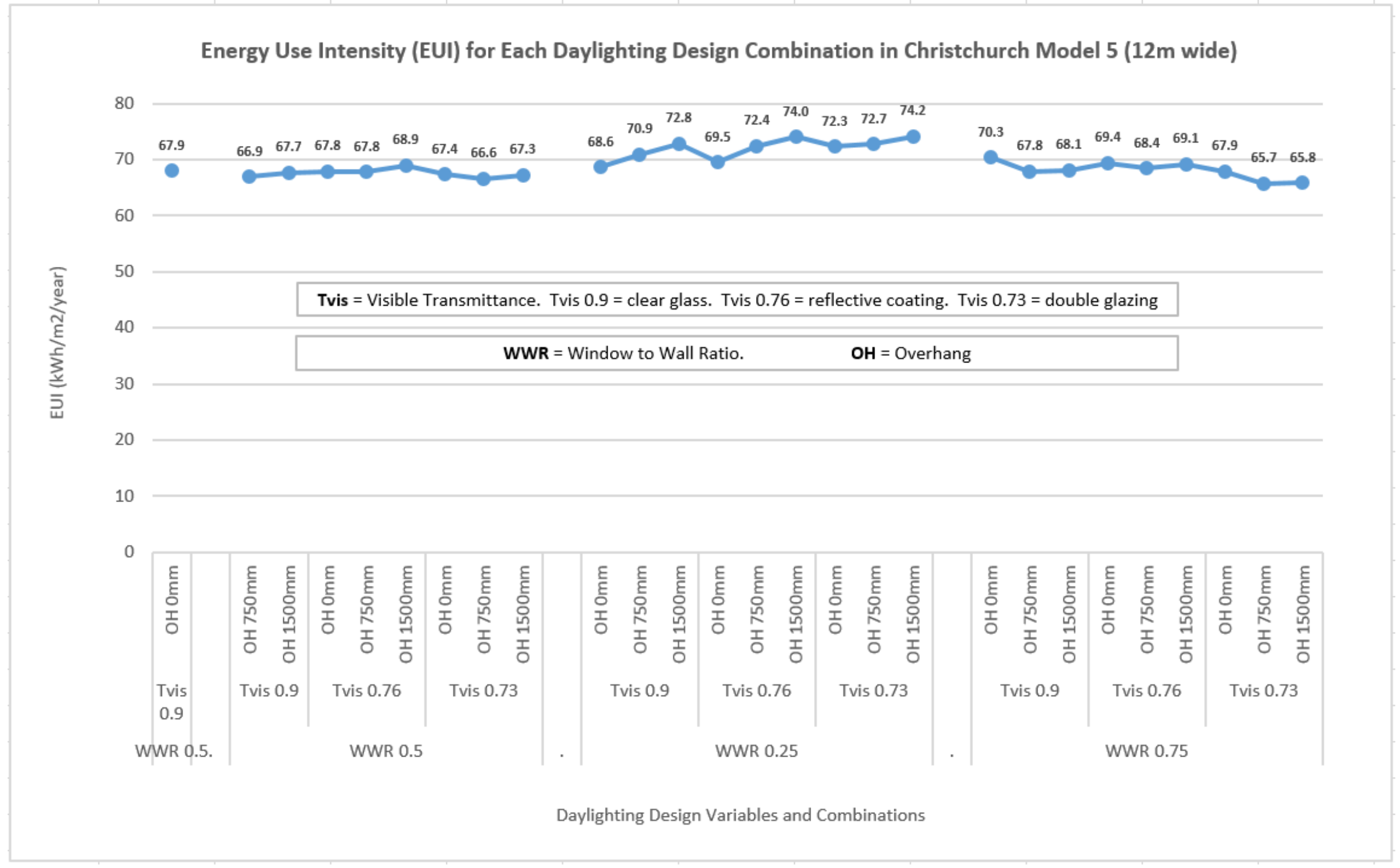

Figure 7.17. EUIs for each Daylighting Design scenario/combination tested 


\subsubsection{Ventilation and Thermal Design - Energy Use Intensities (EUI's)}

The second stage of the Building Design investigation focused on the Ventilation and Thermal Design parameters - Construction Type, Roof Insulation, Wall Insulation and Window Openable Area. This parametric analysis was conducted in GenOpt using 'discrete' variations of the parameters (refer Section 6.1).

Ventilation and thermal design variations were tested on two urban form scenarios.

Firstly, 'Model 5, 12m' consisting of both 'Daylight 1' and then 'Daylight 2' systems developed in the previous section is tested and compared to the original 'Model $5,12 \mathrm{~m}$ ' to determine how much of an effect ventilation and thermal design changes had.

Secondly, 'Model 0 ' is also optimized to determine how much a non-passive building could be improved. The models tested in this section are summarized and referred to as:

Model 0, 20m - Original Baseline

Model 0, 20m-Optimized Baseline

Model 5, 12m - Original Best Urban Form

Model 5, 12m - Daylight 1 Optimized

Model 5, 12m - Daylight 2 Optimized

Table 7.1 presents the Ventilation and Thermal Design variations that were identified as 'optimal' through the GenOpt process. These results are technically not 'optimal' as they are reached using non-discrete variables rather than linearly tested 'discrete' variables. However, the term 'optimized' is used to indicate the optimal solution, of those tested, has been reached (refer Section 6.1).

\begin{tabular}{|l|l|l|l|l|}
\hline Scenario & Construction Type & $\begin{array}{l}\text { Roof } \\
\text { Insulation }\end{array}$ & $\begin{array}{l}\text { Wall } \\
\text { Insulation }\end{array}$ & $\begin{array}{l}\text { Window Openable Area: } \\
\text { Percentage of floor area; } \\
\text { (and Absolute) }\end{array}$ \\
\hline Model 0- Baseline - Original & $\begin{array}{l}\text { Concrete } \\
\text { (insulation inside) }\end{array}$ & $\mathrm{R}-1.9$ & $\mathrm{R}-1.2$ & 0 \\
\hline Model 0- Baseline - Optimized & $\begin{array}{l}\text { Concrete } \\
\text { (insulation outside) }\end{array}$ & $\mathrm{R}-0$ & $\mathrm{R}-0$ & 0 \\
\hline Model 5, 12m - Original & $\begin{array}{l}\text { Concrete } \\
\text { (insulation inside) }\end{array}$ & $\mathrm{R}-1.9$ & $\mathrm{R}-1.2$ & $5 \%\left(15 \mathrm{~m}^{2}\right)$ \\
\hline Model 5, 12m - Daylight 1 & $\begin{array}{l}\text { Concrete } \\
\text { (insulation inside) }\end{array}$ & $\mathrm{R}-1.9$ & $\mathrm{R}-1.2$ & $5 \%\left(15 \mathrm{~m}^{2}\right)$ \\
\hline Model 5, 12m - Daylight 1- Optimized & $\begin{array}{l}\text { Concrete } \\
\text { (insulation outside) }\end{array}$ & $\mathrm{R}-5.7$ & $\mathrm{R}-3.6$ & $10 \%\left(30 \mathrm{~m}^{2}\right)$ \\
\hline Model 5, 12m - Daylight 2 & $\begin{array}{l}\text { Concrete } \\
\text { (insulation inside) }\end{array}$ & $\mathrm{R}-1.9$ & $\mathrm{R}-1.2$ & $5 \%\left(15 \mathrm{~m}^{2}\right)$ \\
\hline Model 5, 12m - Daylight 2- Optimized & $\begin{array}{l}\text { Concrete } \\
\text { (insulation outside) }\end{array}$ & $\mathrm{R}-5.7$ & $\mathrm{R}-3.6$ & $10 \%\left(30 \mathrm{~m}^{2}\right)$ \\
\hline
\end{tabular}

Table 7.1. 'Optimal' Ventilation and Thermal Design parameters for selected baseline and optimized scenarios.

Figure 7.18 presents the EUI results for each of these combinations. It shows that the ventilation and thermal parameters had next to no impact in improving energy consumption, at least for the passive buildings. In both cases (Daylight 1 and 2) only a 1\% decrease in EUI was realized. In comparison, the non-passive baseline realized a $21 \%$ reduction ( 136 down to $107 \mathrm{kWh} / \mathrm{m}^{2} /$ year). Following is a breakdown of the results for each of the four Ventilation and Thermal Design parameters.

\section{Ventilation and Thermal Design Parameter 1: Construction Type}

Construction Type - the primary 'frame' of the building - saw conclusive results. From the initial 'concrete with internal insulation' construction, all scenarios 'optimized' to 'concrete with external insulation'. 
Timber was also trialled but found not to be as effective. This is not a surprising result as concrete provides a 'thermal inertia' (timber does not), which abates temperature swings, helping to maintain a consistent and comfortable temperature. Exterior insulation supports this by encasing the thermal mass, protecting it from the outdoor environment. Interior insulation effectively rejects the thermal benefits a concrete construction offers.

\section{Ventilation and Thermal Design Parameter 2: Roof Insulation}

Results for Roof insulation were also clear. For both passive Models, the highest tested insulation value - R-5.7 ( $3 x$ building code minimum) - produced best efficiency. The roof surface is critical to limiting solar gains and convective heat losses. Tripling insulation to R-5.7 provides more resistance to heat transfers and therefore facilitates better environmental and energy performance.

This is not the case for the non-passive Model 0 however. Here, insulation levels dropped to zero for best energy performance. It is likely that, to mitigate the considerable overheating in the unventilated building (refer Figure 7.9), GenOpt exploited heat losses through the buildings surfaces by minimizing thermal resistance ( $\mathrm{R}$-value). This would reduce reliance on mechanical cooling and result in the lower EUI seen in Figure 7.18. Section 7.2.1.3 reports the energy end-use breakdown to address this.

\section{Ventilation and Thermal Design Parameter 3: Wall Insulation}

Wall insulation reacted exactly the same as roof insulation. For passive scenarios it maximized to R3.6 (triple building code) to maximize control over heat exchange between indoors and outdoors. However, while maximizing insulation levels (in roof and walls) may be the most effective energy conservation option, the effect this had was to the value of less than $1 \%$. Such a small impact is likely due to the large glazed areas (WWR's of $50 \%$ and $75 \%$ ) in these scenarios - meaning insulation is only applied to 50 or $25 \%$ of the envelope anyway. So although performance has been improved, the degree of that improvement in terms of operational energy savings, may not necessarily justify the extra capital cost associated with more insulation.

Model 0 was again optimized to zero insulation; reinforcing the notion the building is trying to eject excess heat.

\section{Ventilation and Thermal Design Parameter 4: Window Openable Area}

For both Daylighting Design scenarios, the Window Openable Area determined to be the most effective was double its original size. For Daylight Design 1, where the WWR was 50\%, the openable percentage of that glazed area doubled from $20 \%$ to $40 \%$ - meaning $20 \%$ of the entire façade is openable. Similarly, the Openable Area of Daylight Design 2 (WWR 75\%) also doubled in size, from $13 \%$ to $26 \%$ - $20 \%$ of total facade.

Considering window openable area was also tested at triple original size ( $3 x$ code minimum) but not preferred, these results show that an optimal openable area exists- around $20 \%$ of the façade, or $10 \%$ of the floor area. At this point, enough fresh air can be introduced to the space to ventilate and cool, but not so much that mechanical heating spikes. A more sensitive optimisation study would reveal this optimum point. According to these results, an openable window area equal to $10 \%$ of the floor area may be a more effective requirement than the building code's $5 \%$

While the energy effect of this doubling was minimal, the effect on IAQ could be valuable. Environmental performance areas are assessed in Section 7.2.2 following. 


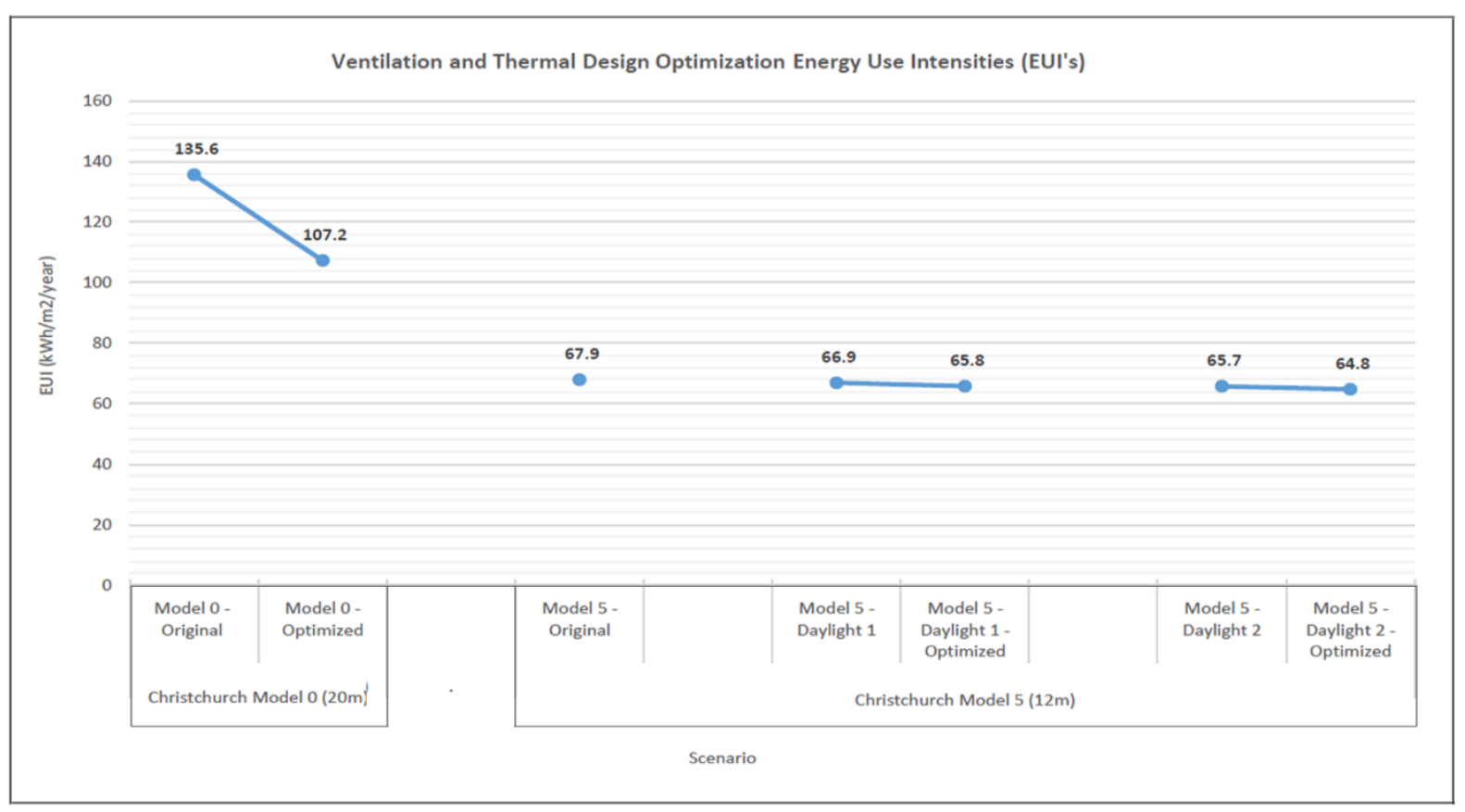

Figure 7.18. Final EUIs for selected baseline and optimized scenarios.

\subsubsection{3 'Daylighting Design' and 'Ventilation and Thermal Design' - Energy End-uses}

Figure 7.19 presents the energy end-use breakdown of the original and optimized Models. It shows how the considerable cooling loads in 'Model 0 ' are largely dissipated in 'Model 0 Optimized' by around $60 \%$ (195,000 down to $78,000 \mathrm{kWh}$, average across all zones). This ratifies the point made in the previous sections about how zero insulation allows some excess heat to be ejected from the building, reducing need for energy intensive cooling. Another change in energy consumption is a slight rise in heating loads on the top floor of 'Model 0 Optimized', due to greater convective heat losses through the uninsulated roof.

While the $21 \%$ overall energy reduction $\left(136 \mathrm{kWh} / \mathrm{m}^{2} /\right.$ year down to $107 \mathrm{kWh} / \mathrm{m}^{2} /$ year) between 'Model 0 ' and 'Model 0 Optimized' is significant (approaching the GreenStar EUI benchmark for offices of $105 \mathrm{kWh} / \mathrm{m}^{2} \mathrm{yr}$ ) it should not be recommended. The building design that produced this reduced energy consumption depends on uncontrolled, almost 'accidental' heat losses through walls. Furthermore, a party-walled building depends on a neighbouring building to regulate thermal transfer between that party-wall. If there is no adjacent thermal zone (e.g. one building 7 storeys, the neighbouring building only 3 - no adjacent zone on levels 4 and up), considerable heat transfer will occur between indoors and outdoors through the poorly constructed party-wall. Lastly, the fact remains that this space would still depend on mechanical heating, cooling, ventilation and lighting and would have none of the benefits of a connection with the outside world.

Figure 7.19 also presents the two final optimized scenarios - 'Model 5, Daylight 1', and 'Model 5, Daylight 2'. Both these models display extremely low HVAC use with heating, cooling and fans each consuming infinitesimally small amounts of energy. From the original 'Model 0 ', cooling loads in particular have diminished to only $1 \mathrm{kWh} / \mathrm{m}^{2} /$ year. This is a significant finding. Such minute HVAC dependency means that the HVAC system could be removed completely from the building. This would save a considerable amount of capital cost which could be reinvested in more financially rewarding, environmentally friendly natural ventilation technologies (e.g. automated openable windows). Focusing design on natural ventilation and thermal aspects means the building is more resilient and better equipped to maintain comfort through situations like power-cuts.

Section 7.2.2 examines the environmental comfort performance of these scenarios. 


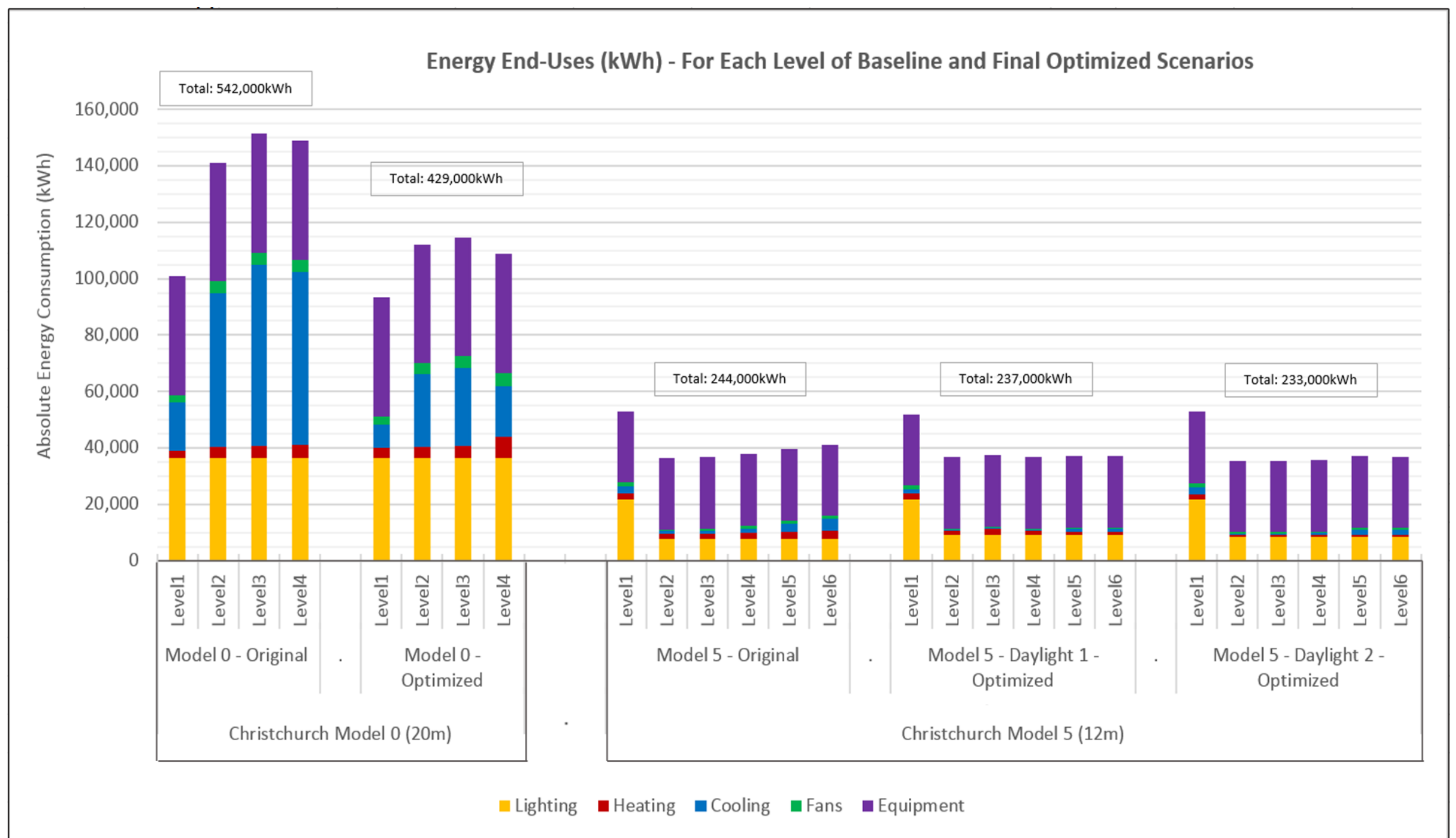

Figure 7.19. Final Energy End-uses for optimized scenarios with comparison against corresponding originals. 


\subsubsection{Building Designs Effect on Comfort}

The five environmental performance criteria addressed in the Urban Form investigation Temperature, air change rates, air speed, Daylight Autonomy and maximum Daylight Autonomy - are again assessed. To demonstrate overall changes, only the 'original' and 'optimized' models addressed in the previous energy sections are discussed here.

\subsubsection{Environmental Performance Criteria 1 - Temperature}

Figure 7.20 presents indoor temperatures for each of the five original and optimal scenarios without any HVAC system included. It identifies two significant findings.

Firstly, overheated hours have been reduced by $41 \%$ ( $86 \%$ down to $45 \%$, average across all levels) from 'Model 0 ' to 'Model 0 Optimized'. This has been affiliated with the removal of thermal insulation, which allows more of the excess heat to be released from spaces.

Secondly, the difference between the original Model 5 and the two optimized versions is smallreflecting the minimal energy reductions already presented. However, the 'Daylight 2 Optimized' building has developed to a point where comfortable temperatures are reached - naturally - for $99 \%$ of the occupied year, on all levels. This is a product of the improved control its thermal envelope offers. High thermal resistance in the roof, walls and windows (Insulated Glazing Units - 'double glazing') minimizes heat transfer through the building's surfaces; $750 \mathrm{~mm}$ overhangs reduces direct sunlight incident on the windows and associated solar heat gains; and openable windows allow excess heat to be released when needed. This is a very powerful result which confirms that HVAC equipment is not required if the building is designed well. Even the very simple 'Daylight 1 Optimized' model, which has identical thermal specifications as 'Daylight 2 Optimized' but with smaller, clear glazed windows, is capable of delivering thermally comfortable conditions for $90 \%$ of the occupied year.

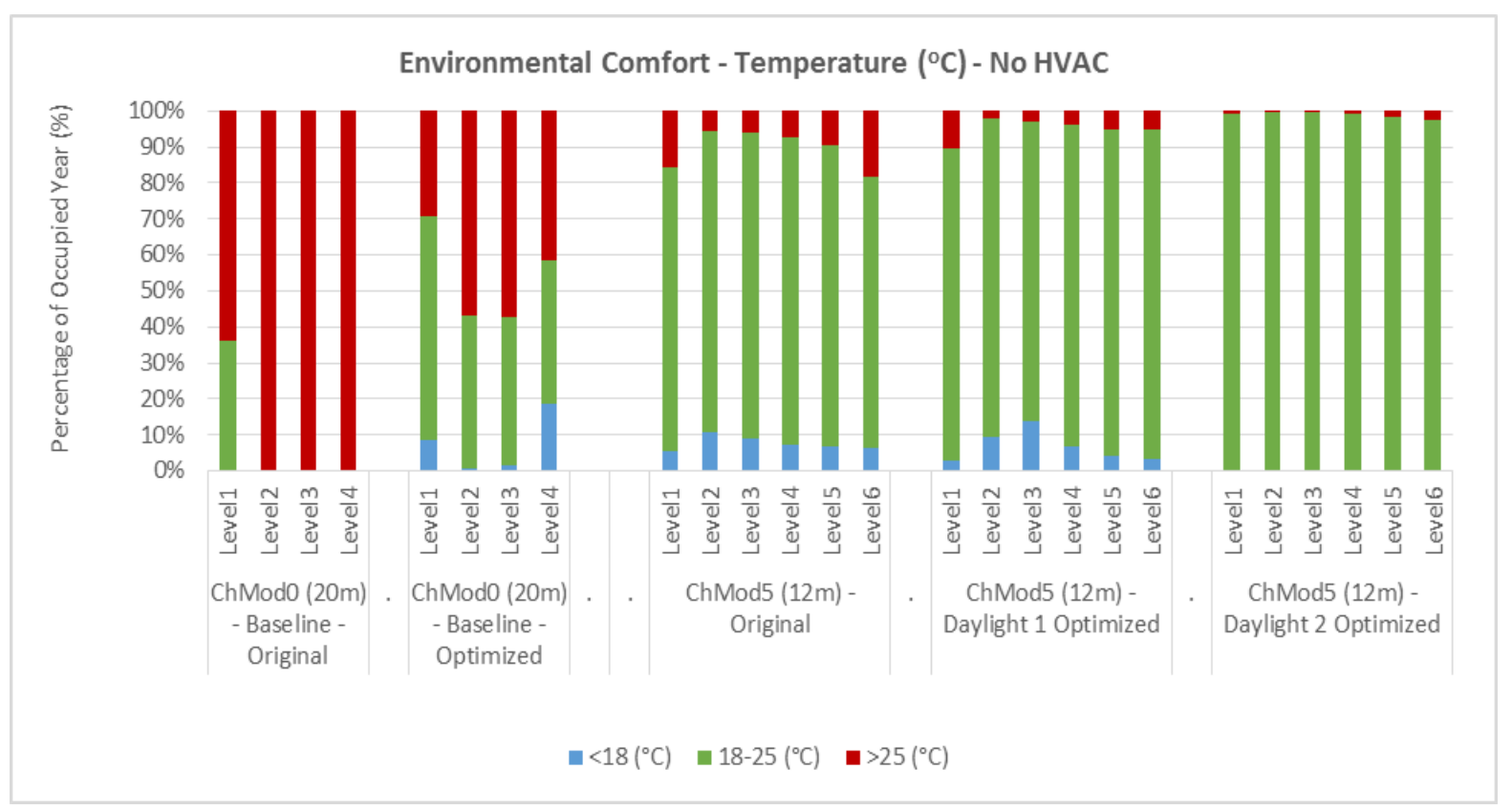

Figure 7.20. Natural (no HVAC) thermal performance for selected baseline and optimized scenarios. 


\subsubsection{Environmental Performance Criteria 2 - Air Change Rates}

One of the most evident short-comings of the passive buildings in the Urban Form investigation was the ability to deliver the minimum required air changes. Figure 7.13 showed how all four selected urban form scenarios only achieve the minimum ACH's for between $40-65 \%$ of the occupied year. It was expected that by enlarging the openable portion of the windows, more fresh air could be delivered to spaces. However, despite GenOpt doubling Window Openable Area from $5 \%$ of the floor area to $10 \%$, minimum air change rates are not markedly improved between the original 'Model 5, $12 \mathrm{~m}$ wide' and 'Daylight 1 Optimized'. Comparatively, 'Daylight 2 Optimized' (openable area also doubled) is improved by an average of $22 \%$ (44\% up to $68 \%$, average across all naturally vented levels). This improvement cannot simply be associated to the doubling of the openable window area as this is the same absolute area as 'Daylight 1 Optimized' (refer Appendix B.4 for window area calculations). Therefore something else must be affecting the volume of air that is introduced. It is possible that the more stable and cooler indoor temperatures in 'Daylight 2 Optimized' were more often within the $15^{\circ} \mathrm{C}$ indoor-outdoor temperature difference within which venting can occur (refer Section 4.3.2.1). This would've enabled windows to open wider and more often than 'Daylight 1 Optimized', resulting in higher ACH's. The oenable portion of windows could be increased more to further improve air change rates, but this evidently had an adverse effect on energy consumption and was overridden as a solution by GenOpt. Again, more sensitive analysis of window openable area may be able to further improve performance.

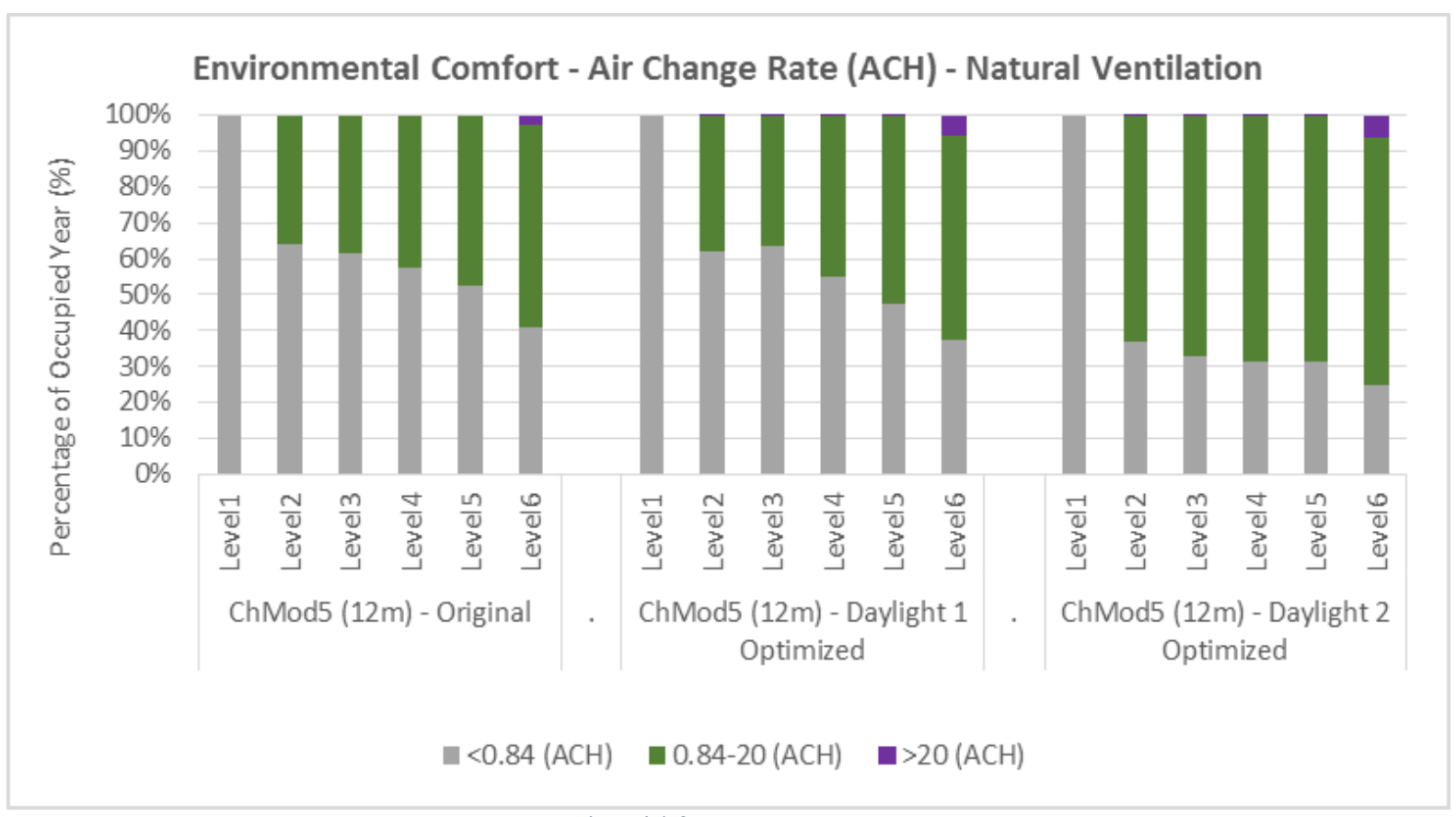

Figure 7.21 Air change rates (ACH's) for selected baseline and optimized scenarios.

\subsubsection{Environmental Performance Criteria 3-Air Speed}

As in the Urban Form scenarios, air speed is not an issue. For both optimized buildings only the top floors experienced any air speeds in the 'Tolerable' bracket of $0.3-2.0 \mathrm{~m} / \mathrm{s}$ (purple bars). At no point does any level of either optimized building experience 'Uncomfortable' air speeds $(>2.0 \mathrm{~m} / \mathrm{s})$. There is little difference between the original Model 5 and either of the two optimized models despite the doubling of openable window area for both. This indicates excessive air movement is not an issue for naturally cross ventilated spaces. 


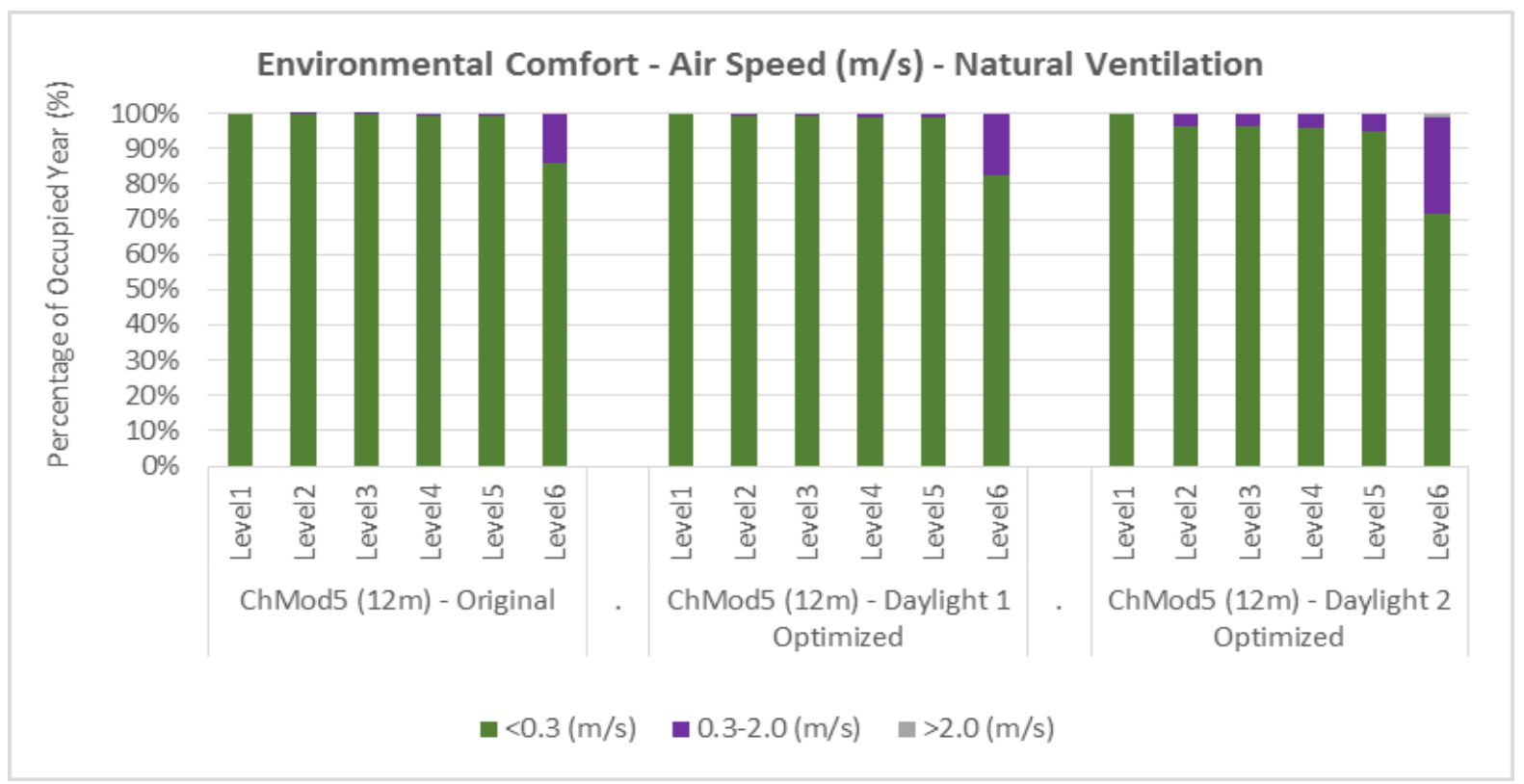

Figure 7.22 Air speeds (ACH's) for selected baseline and optimized scenarios.

\subsubsection{Environmental Performance Criteria 4 - Daylight Autonomy}

Figure 7.23 shows that DA - the percentage of the occupied year a point in a space achieves $>400 \mathrm{~lx}-$ has diminished in both selected daylighting scenarios. The original Model 5 , which consisted of $50 \%$ WWR, clear glass and no overhang, achieved DA criteria for $100 \%$ of the space. This has been reduced to only $78 \%$ of the space with the addition of a $750 \mathrm{~mm}$ overhang in the 'Daylight 1 ' scenario. 'Daylight 2', which consists of a $75 \%$ WWR, double glazing and a $750 \mathrm{~mm}$ overhang also experiences a decline DA, down to $83 \%$ of the space (due mostly to the same overhang addition) but not as drastically due to the larger window area. While neither Daylight Design 1 or 2 appear impressive in comparison to the original Model 5 DA performance, they do both achieve the minimum spatial (SDA) requirement of $75 \%$ of the space (refer Section 4.2.1.5). Additionally, the purpose of some of the daylight design changes, especially the overhangs, was to reduce overexposure, addressed in the following section.

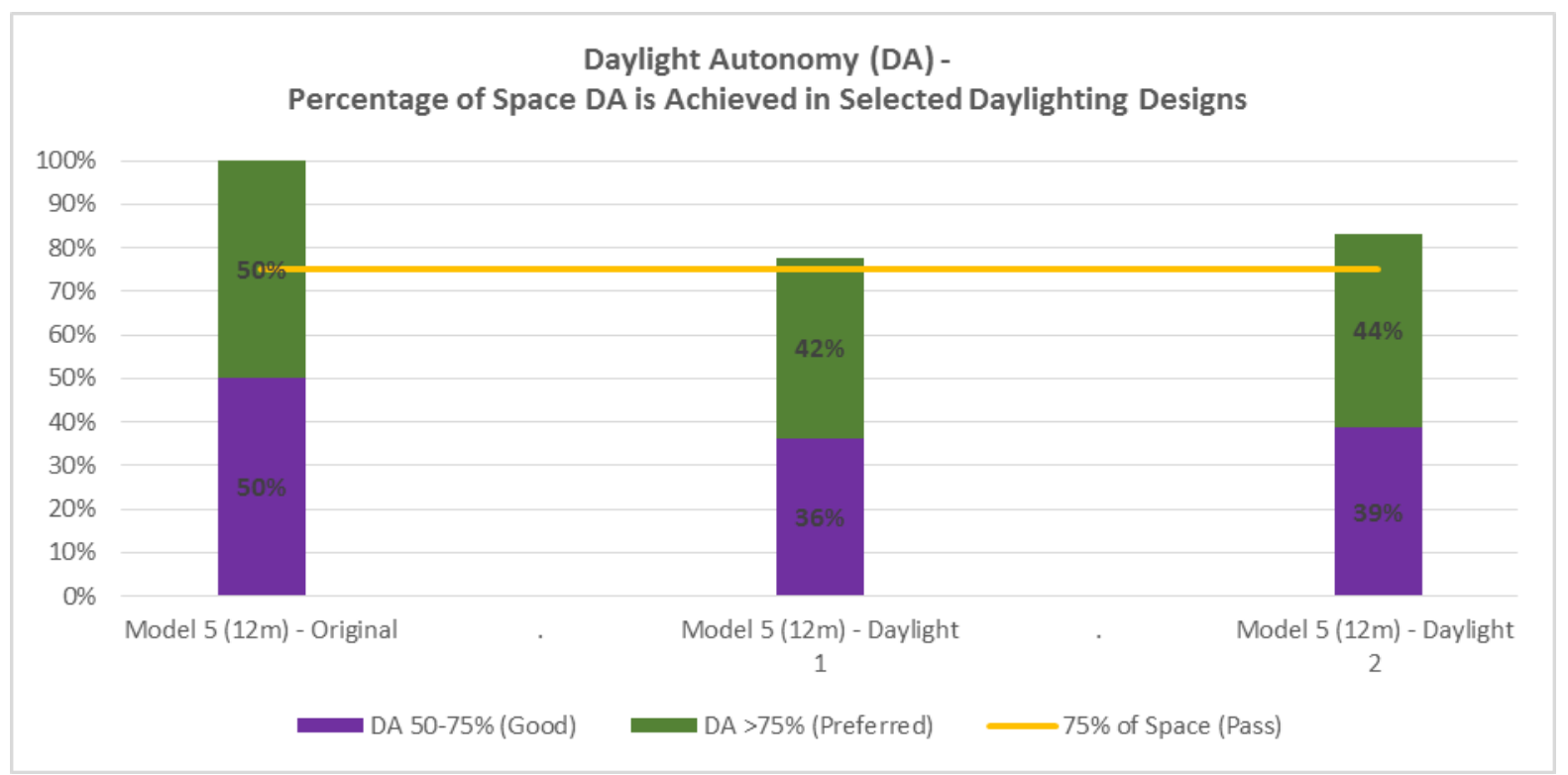

Figure 7.23 Daylight Autonomy (DA) and spatial Daylight Autonomy (sDA) performance for optimized scenarios. 


\subsubsection{Environmental Performance Criteria 5 - Maximum Daylight Autonomy}

Figure 7.24 illustrates the value of the overhangs in reducing over-exposure to daylight (mDA). Only $47 \%$ of the original Model 5 space passed mDA criteria $(>4,0001 x$ for no more than $1 \%$ of the occupied year, across $95 \%$ of the space). This is increased to $64 \%$ with the inclusion of overhangs in Daylight 1. Daylight 2 is also improved, but larger windows (75\% WWR) limit this improvement.

Ultimately, neither scenario meets the demanding mDA criteria. More appropriate overhang sizes could enhance performance however. For example, glare is most prominent along the northern perimeter, so larger overhangs would be of benefit here. Conversely, glare was not such an issue along the east and west perimeters so overhangs could be reduced here, improving DA but having little impact on mDA. Alternative shading devices like external louvers or meshes could also deliver better results.

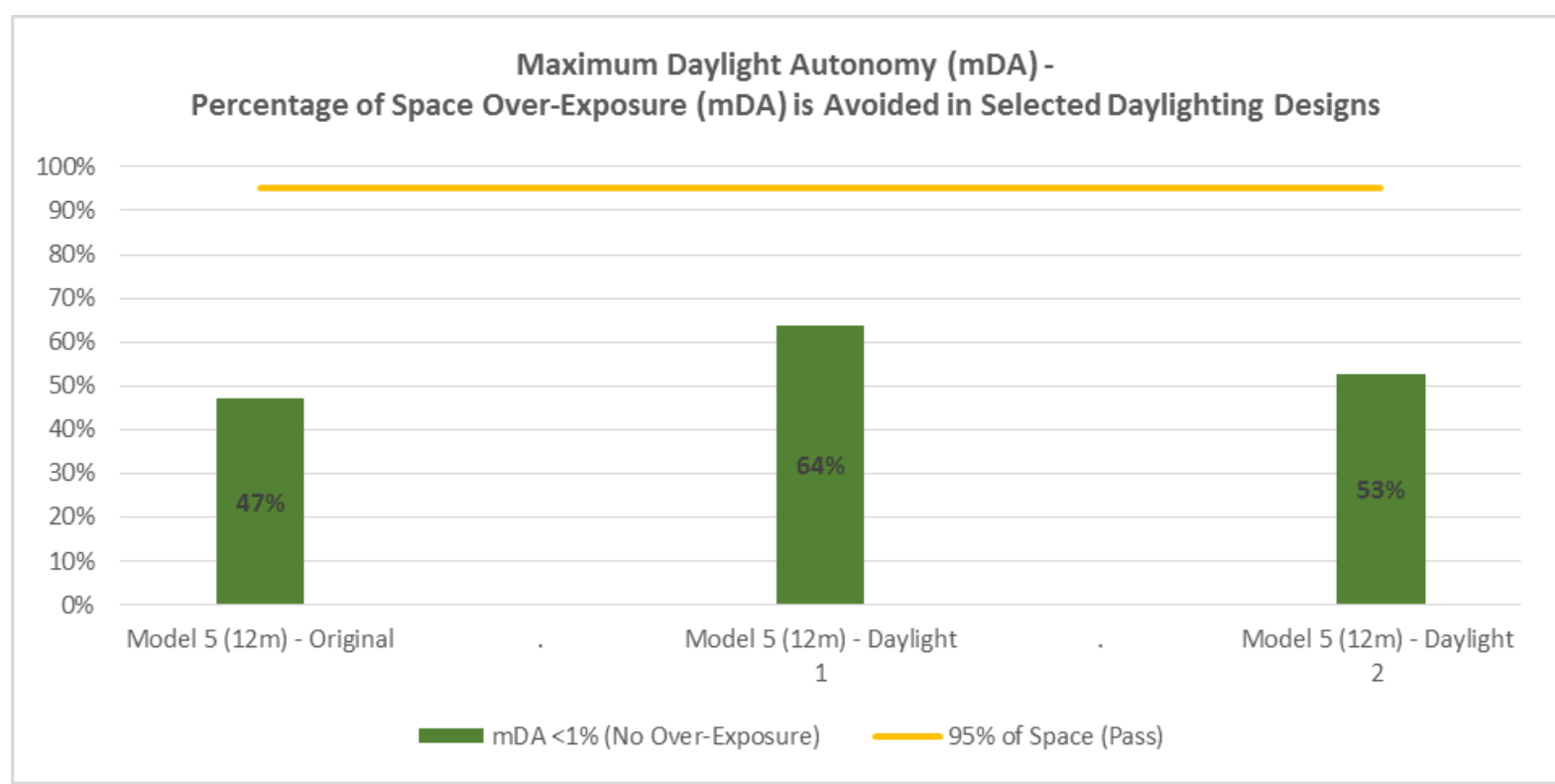

Figure 7.24 Maximum Daylight Autonomy (time and space over-exposure avoided) performance for optimized scenarios. 
Urban Form and Passive Design for High Performance Buildings in the Christchurch Rebuild 


\section{Chapter 8: Conclusion}

This research aimed to determine which changes to urban form and building design were most significant in achieving high-performance buildings, with minimal impact on density in central city Christchurch.

Using the concept of passive design - delivering comfortable indoor environments naturally - the thesis explored a fundamental issue of town planning - How to secure access to daylight and fresh air for all buildings.

Daylighting is a commonly employed energy conservation technique, enabling artificial lighting savings of up to $80 \%$ (Ministry for the Environment, 2008). Natural ventilation is not as frequently utilized but has equally significant potential as daylighting, with the ability to save up to $79 \%$ on cooling energy (Brager, et al., 2007). Increased access to daylight and fresh air also improves occupant satisfaction with their working environment, which can lead to reduced absenteeism and increased productivity (Sustainability Victoria, 2008).

There is no shortage of literature surrounding passive design and benefits in regard to the building; but less information exists concerning the urban environment and how the city's form affects a building's performance.

Large buildings shade other buildings from access to daylight and interrupt wind flow. These sheltering effects diminish the ability for simple openable windows to deliver daylight and fresh air to building spaces.

If urban planning laws do not mandate an urban form that ensures every building will have access to sun and wind, then daylighting and natural ventilation are not likely to be effective, or even possible.

Currently, Christchurch's urban planning laws prioritize maximisation of profitable floor area over environmental and energy efficiency, and consequently do not facilitate high-performance buildings. The result is that buildings are built to the full width of their property leaving no opportunity for access to daylight and fresh air.

Right now, as the central city rebuild begins, Christchurch has an opportunity to reformulate urban planning laws to ensure every building has sufficient access to daylight and fresh air.

Using a parametric style of investigation, significant urban form and building design variables were separately tested to determine their effect on building performance. Performance was assessed in three areas: energy consumption, indoor comfort and density.

EnergyPlus provided the primary energy and thermal simulations, Radiance/Daysim were used for reliable daylight calculations and analysis; and UrbaWind accounted for the effect of urban form on wind pressures for natural ventilation.

In terms of Urban Form, tests found that small, simple changes enabled significant improvements in building performance.

The 'non-passive' Baseline scenario - 'Model 0' - which only had access to the outdoors on its streetfacing façade, performed at a typical New Zealand office building Energy Use Intensity (EUI) of 
between 128-136 $\mathrm{kWh} / \mathrm{m}^{2} /$ year. In comparison passive scenarios ranged between 68$81 \mathrm{kWh} / \mathrm{m}^{2} /$ year (averaging $78 \mathrm{kWh} / \mathrm{m}^{2} /$ year). This is a substantial reduction of between 37 and $48 \%$.

Separating buildings was by far the most effective change tested in this research; the effects of other urban form changes such as building height and road width were comparatively insignificant.

Separating buildings by as little as 2 meters and incorporating openable windows to ventilate spaces naturally and deliver daylight, was enough to realize these energy reductions. The ability to ventilate spaces naturally through the opening of windows contributed the most significant reduction, decreasing mechanical cooling loads by as much as $92 \%$. Increasing gaps to $6 \mathrm{~m}$ enabled artificial lighting energy savings of up to $60 \%$ through daylighting; but provided enough shade to minimize solar heat gains of surrounding buildings. $10 \mathrm{~m}$ gaps offer little improvement over $6 \mathrm{~m}$ gaps.

Assuming a $20 \mathrm{~m}$ wide property, a $2 \mathrm{~m}$ separation would incur a floor area reduction of only $10 \%$. If this was to be applied to 4 storey tall buildings, uniformly across the CCB, only 4.4 CCB Blocks (out of 15 available) would be required to meet the projected demand for office space $\left(260,000 \mathrm{~m}^{2}\right)$. In the same scenario, $6 \mathrm{~m}$ wide gaps ( $30 \%$ of $20 \mathrm{~m}$ wide property) would still easily satisfy the density demand, requiring only 5.3 CCB Blocks.

In terms of building design, development from the initial minimum building code standards used in the urban form investigation, yielded minimal performance improvements.

- The most effective daylighting design changes - increasing WWR from $50 \%$ to $75 \%$, switching to Low-E double glazing and adding $750 \mathrm{~mm}$ overhangs - only reduced EUls by a further $1 \%$.

- The most effective thermal envelope changes - increasing insulation to $3 x$ code minimum and openable area of windows to $2 x$ code - also only realized a further $1 \%$ improvement.

The final best case scenario, 'Model 5, 12m - Daylighting 2 Optimized' - had an EUI of $64.8 \mathrm{kWh} / \mathrm{m}^{2} /$ year - a $50.2 \%$ reduction from the original 'Model $0,12 \mathrm{~m}$ ' baseline equivalent.

Daylight Autonomy performance was good in both the final daylight design scenarios, achieving the required $400 \mathrm{~lx}$ for $100 \%$ of the occupied year across at least $75 \%$ of the 'Model $5,12 \mathrm{~m}$ wide' space. However, overexposure remained an issue even in the most developed daylight design scenario where only $64 \%$ of the space passed maximum Daylight Autonomy criteria.

Direct sunlight can be a significant barrier to successful daylighting as it causes glare which can lead to occupants closing blinds and daylighting being forfeited. Daylighting systems, in particular shading devices, would need to be further developed to avoid this issue.

Concern over the frequency at which passive buildings can deliver comfortable indoor environments has been identified as a barrier to natural ventilation in particular. However results revealed that with the use of automated window opening systems and strict venting criteria, comfortable temperatures $\left(18-25^{\circ} \mathrm{C}\right)$ could be maintained for over $98 \%$ of the occupied year - without HVAC assistance. As well as enabling overheated air to be released from indoor spaces, openable windows were able to supply the required volume of fresh air to spaces for up to $74 \%$ of the occupied year. Excessive air speeds were not an issue.

These findings indicate if a buildings project funds targeted natural ventilation and daylighting systems, energy intensive HVAC systems would not be required, making buildings more naturally comfortable, energy efficient and resilient. 
In regard to the research aim, the thesis found that urban form has significantly more effect on building performance than building design does; and that separating buildings was the most effective urban form change.

It was found that, through this more porous urban form, a naturally ventilated and daylit building could perform up to $50 \%$ more efficiently than a building in a conventional compact urban form.

This thesis has proven that simple and minor changes to urban form and building design can produce the high performance buildings Christchurch desires.

If the demonstrated benefits of passive buildings are to be realised the CCC needs to consider modifying urban design regulations to facilitate a porous urban form in the CCB. 


\subsection{Artist's Impression of Proposed Urban Environment}
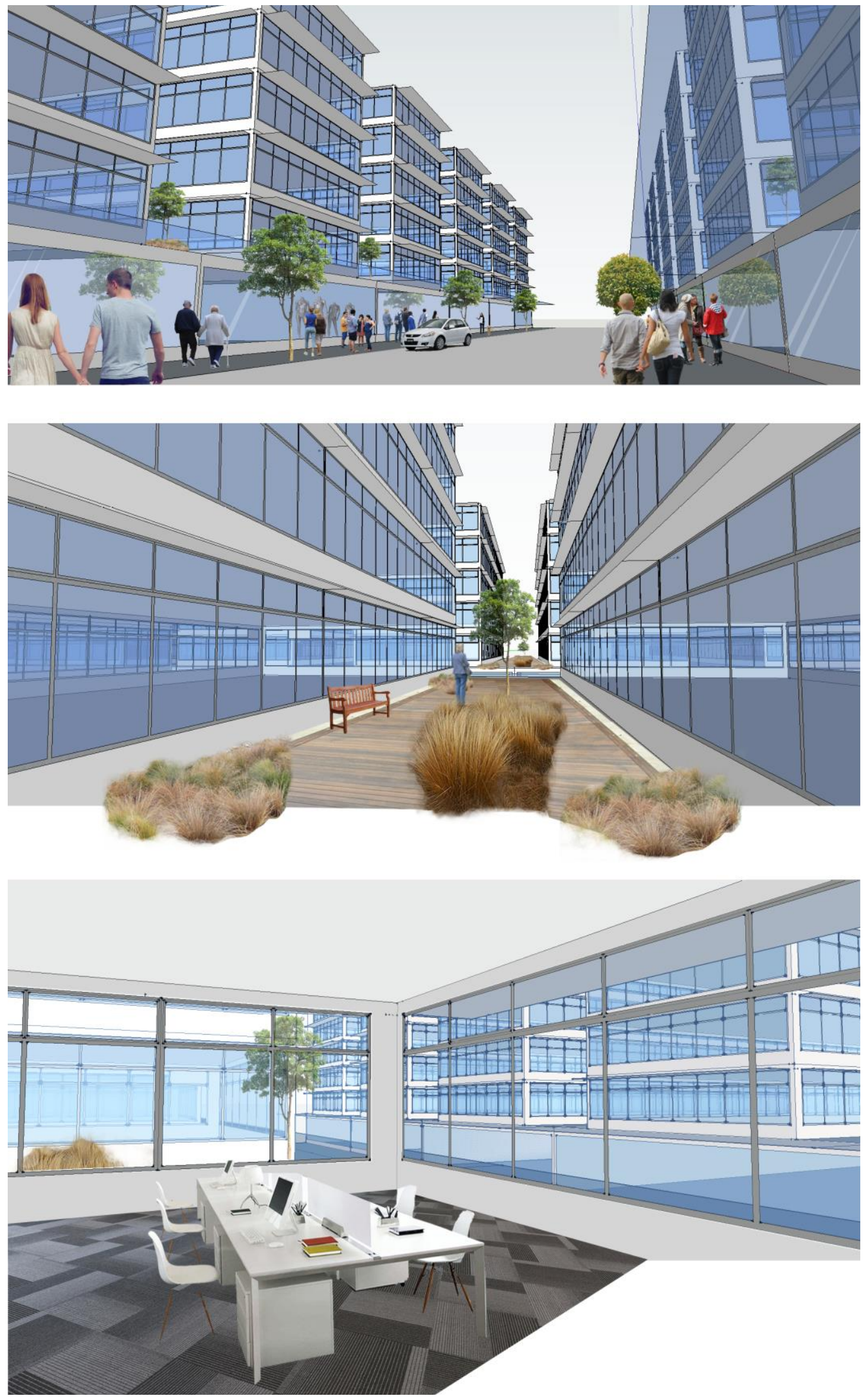

Figure 8.1 Artist impression of passive urban form and building design. 


\subsection{Future Research}

1) While this work demonstrated small gaps between buildings would be hugely beneficial for building performance, it was not clear exactly how small gaps could be. $2 \mathrm{~m}$ separations enabled effective natural ventilation, but $6 \mathrm{~m}$ gaps were required for daylighting benefits. It is likely there is an optimum separation distance between 2 and $6 \mathrm{~m}$ that would provide equally beneficial access to daylight and fresh air as a $6 \mathrm{~m}$ gap and would increase NLA. A sensitivity analysis could be a next step from this more rigid parametric study.

2) An investigation into comfort of the outdoor environment as a result of the porous urban form proposed by this research. Of particular interest would be the gaps between buildings on the roof of the Ground floor. It was this separation of upper floors that enabled the performance benefits but the gap does leave an awkward outdoor space in terms of inhabitation. The 'artist's impression' presented in the previous section (middle image) suggests the space could be used as a courtyard type function for employees of the adjacent buildings. However, the conditions and comfort of this type of space are unknown and would need to be assessed. 
Urban Form and Passive Design for High Performance Buildings in the Christchurch Rebuild 


\section{Works Cited}

2030 Palette, 2013. Side Daylighting. [Online]

Available at: http://blog.2030palette.org/swatch-profile-side-daylighting/

[Accessed 02 2014].

Advanced Lighting Guidelines, 2010. Daylighting. [Online]

Available at: $\underline{\text { http://algonline.org/index.php?daylighting-strategies }}$

[Accessed 02 2014].

Ali-Toudert, F. \& Mayer, H., 2006. Numerical study on the effects of aspect ratio and orientation of an urban street canyon on outdoor thermal comfort in hot and dry climates. Building and Environment, 02, pp. 94-108.

Anon., 1990. NZS 4303:1990 - Ventilation for Acceptable Indoor Air Quality, Wellington: Standards New Zealand.

Architectural Association Environment and Energy Programme, 2010. Comfort Ventilation. [Online] Available at: https://www.educate-sustainability.eu/kb/content/comfort-ventilation [Accessed 1401 2014].

Architectural Energy Corporation, 2006. Daylighting Metric Development Using Daylight Autonomy Calculations in the Sensor Placement Optimization Tool, Boulder, Colorado: Architectural Energy Corporation.

ASHRAE, 2004. ASHRAE Standard 90.1:2004 - Energy Standard for Buildings Except Low-Rise Residential Buildings, Atlanta: ASHRAE.

Autodesk, 2011. Sustainability Workshop: Wind Ventilation. [Online] Available at: http://sustainabilityworkshop.autodesk.com/buildings/wind-ventilation [Accessed 02 2014].

Bayleys Realty Group, 2013. Commercial/Industrial Property Research: Christchurch, Christchurch: Bayleys Research.

Bellia, L., De Falco, F. \& Minichello, F., 2013. Effects of solar shading devices on energy requirements of standalone office buildings for Italian climates. Applied Thermal Engineering, 14 05, pp. 190-201.

Beltran, L. et al., 2012. Energy and Daylight Performance of Angular Selective Glazings, Oak Ridge: Oak Ridge National Laboratory.

Bishop, R. \& Isaacs, N., 2012. BEES Interim Report - Year 5: Energy Use Outliers, Porirua: BRANZ.

Boyce, P. R., 2003. Human Factors in Lighting. Second ed. London and New York: Taylor and Francis Group.

Brager, G., Borgeson, S. \& Lee, Y., 2007. Summary Report: Control Strategies for Mixed-mode Buildings, Berkeley: University of Berkeley: Centre for the Built Environment .

BRANZ, 2012. BEES Buildings. [Online]

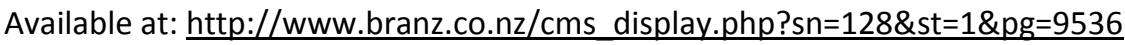

[Accessed 03 2014].

BRANZ, n.d. level: Passive Design. [Online]

Available at: http://www.level.org.nz/passive-design/

[Accessed 02 2014].

Brown, P., 2010. Passive and Active Design, s.I.: Atkins.

Canterbury Earthquake Recovery Authority (CERA), 2013. Good progress in CBD land purchases. [Online] Available at: http://cera.govt.nz/news/2013/good-progress-in-cbd-land-purchases

[Accessed 1012 2013].

Castelton, H., Stovin, V., Beck, S. \& Davison, J., 2010. Green roofs; building energy savings and the potential for retrofit. Energy and Buildings, 42(10), pp. 1582-1591.

CBRE and Lincoln University, 2012. The Impacts of the Canterbury Earthquake on the Commercial Office Market, Auckland: CBRE Research and Consulting. 
Change, C. \& Meroney, R., 2003. THe effect of surroundings with different separation distances on surface pressures on low-rise buildings.. Journal of Wind Engineering, Volume 91, pp. 1039-1050.

Charleson, A., 2008. Seismic Design for Architects. First ed. Oxford: Architectural Press: Elsevier.

Chen, Q., 2008. Ventilation performance prediction for buildings: A method overview and recent applications. Building and Environment, 27 05, pp. 848-858.

Christchurch City Council, 2000. Chirstchurch City Centre - 40 years of change, traffic, planning 1959-1999, Christchurch: Christchurch City Council.

Christchurch City Council, 2010. Policy on Structures on Roads 2010. [Online]

Available at:

http://www.ccc.govt.nz/thecouncil/policiesreportsstrategies/policies/groups/streetsroads/index.aspx [Accessed 08 2013].

Christchurch City Council, 2011. draft Central City Plan, Christchurch: Christchurch City Council.

Christchurch City Council, 2013. Christchurch City Plan Online. [Online]

Available at: http://www.cityplan.ccc.govt.nz/NXT/gateway.dll?f=templates\&fn=default.htm

[Accessed 0912 2013].

CIBSE, 1999. Good Practice Guide 237: Natural ventilation in non-domestic buildings: A guide for designers, developers and owners, London: CIBSE.

CIBSE, 2006. CIBSE Guide A: Environmental Design, Norwich: Chartered Institution of Building Services Engineers; Page Bros Ltd.

Collins, B., 1976. Review of the psychological reaction to windows. Lighting Research and Technology, Volume 8, pp. 80-88.

Compagnon, R., 2001. Radiance: A simulation tool for daylighting systems, Fribourg: University of Applied Sciences of Western Switzerland.

Costola, D., Blocken, B. \& Hensen, J., 2009. Overview of pressure coefficient data in building energy simulation and airflow network programs. Building and Environment, 12 02, pp. 2027-2036.

Creswell-Wells, T., 2012. BEES Interim Report: Christchurch Urban Form and Energy, Porirua: Building Research Association New Zealand (BRANZ).

Czeisler, C. A. et al., 1980. Human sleep: Its duration and organization depend on its circadian phase. Science, 12, pp. 1264-7.

Department of Building and Housing, 2011. Compliance Document for New Zealand Building Code: Claues G4 Ventilation, Wellington: Department of Building and Housing.

Department of Building and Housing, 2011. Compliance Document for New Zealand Building Code: Clause H1 Energy Efficiency., Wellington: Department of Building and Housing.

Department of Building and Housing, 2012. New Zealand Building Code - Clauses C1-C6: Protection from Fire, Wellington: Department of Building and Housing.

Didone, E. \& Pereira, O., 2011. Integrated Computer Simulation for Considering Daylight when Assessing Energy Efficiency in Buildings. Sydney, International Building Performance Simulation Association.

EnergyPlus, 2012. Input Output Reference, California: Lawrence Berkeley National Laboratory.

Ernst \& Young, 2012. CERA Christchurch Central City Commercial Property Market Study, Christchurch: CERA.

Farley, K. \& Veitch, J., 2001. A room with a view: A review of the effects of windows on work and well-being, Ottawa: National Research Council Canada.

FLUENT, 2011. CFD Online-Convergence. [Online]

Available at: http://www.cfd-online.com/Forums/fluent/90281-convergence.html

[Accessed 1710 2013]. 
Fort, N., 2013. Slide Share- Development and eco-construction project example, MeteoDyn. [Online] Available at: http://www.slideshare.net/meteodyn2/example-natural-airventilationen [Accessed 1710 2013].

Galasiu, A. \& Reinhart, C., 2008. Current daylighting design practice: A survey. Building Research and Information, 36(2), pp. 159-174.

Ghiaus, C. et al., 2006. Urban environment influence on natural ventilation potential. Building and Environment, Volume 41, pp. 395-406.

Givoni, B., 1994. Passive Low Energy Cooling of Buildings. First ed. Hoboken, New Jersey: John Wiley and Sons, Inc.

Glass Technology, 2013. Understanding Insulating Glass Units. [Online]

Available at: http://www.ppgresidentialglass.com/window glass/understanding IGU.aspx

[Accessed 04 2014].

Gough, A., 2013. 'Lively' new plans for Christchurch 'Strip'. [Online]

Available at: http://www.stuff.co.nz/business/rebuilding-christchurch/8481478/Lively-new-plans-for-

Christchurch-Strip

[Accessed 2903 2013].

Gratia, E. \& De Herde, A., 2003. Design of low energy office buildings. Energy and Buildings, 35(5), pp. $473-991$.

Hensen, S., 2013. Open Front Structure Wind Pressure Design. [Online]

Available at: http://seblog.strongtie.com/2013/02/open-front-structure-wind-pressure-design/

[Accessed 08 2013].

Hernandez, C. R., 2006. Thinking parametric design: Introducing parametric Gaudi. Design Studies, Volume 27, pp. 309-324.

Heschong, L., Lee, E. \& Mardaljevic, J., 2009. Daylight metrics and energy savings. Lighting Research and Technology, Volume 41, pp. 261-283.

Honeywell, 2008. Insulation Energy Savings: Key Issues and Performance Factors. [Online]

Available at: http://www.sealsprayed.com/docs/insulation energy savings.pdf

[Accessed 02 2014].

Hunter, C., Boyce, P. \& Howlett, O., 2003. The Benefits of Daylight through Windows, New York: Lighting Research Centre.

Ibarra, D. \& Reinhart, C., 2009. Daylight Factor Simulations - How close do simulation beginners really get?. Glasgow, IBPSA.

Illuminating Engineering Society, 2012. Approved Method: IES Spatial Daylight Autonomy (sDA) and Annual Sunlight Exposure (ASE), New York: Illuminating Engineering Society of North America.

Jakubiec, J. \& Reinhart, C., 2011. DIVA 2.0: Integrating daylight and thermal simulations using Rhinoceros 3D, Daysim and EnergyPlus. Sydney, International Building Performance Simulation Association.

Johnson, R. et al., 1984. Glazing energy performance and design optimistation with daylighting. Energy and Buildings 6, pp. 305-317.

Kleiven, T., 2003. Natural Ventilation in Buildings: Architectural concepts, consequences and possibilities, Trondheim: Norwegian University of Science and Technology.

Knowles, R., 2003. The solar envelope: Its meaning for energy and buildings. Energy and Buildings, 35(1), pp. 15-25.

Lam, J. \& Li, D., 1999. An analysis of daylighting and solar heat gor cooling-dominated office buildings. Solar Energy, 01 03, pp. 251-262.

Lawrence Berkeley National Laboratory, 2013. Getting Started with EnergyPlus, Berkeley, CA: US Department of Energy. 
Lenoir, A., Cory, S., Donn, M. \& Garde, F., 2013. Optimisation methodology for the design of solar shading for thermal and visual comfort in tropical climates. Chambery, France., 13th Conference of International Building Performance Simulation Association.

Leyronnas, P. \& Dupont, G., 2009. UrbaWind study cases- Validation File, Nantes, France: MeteoDyn.

LoVerso, V. \& Reinhart, C., 2010. A rules of thumb-based design sequence for diffuse daylight. Lighting Research and Technology, 05 01, pp. 7-31.

McIntosh, J., 2011. The Indoor Air Quality in 35 Wellington Primary Schools During the School Day, Wellington: Victoria University of Wellington.

Mead, D., 2011. Understanding Glare: Design Methods for Improving Comfort. Perkins+Will Research Journal, 3(1), pp. 46-51.

Meek, C., 2013. Automated and Manual Solar Shading and Glare Control: A Design Framework for Meeting Occupant Comfort and Realized Energy Performance, Seattle: University of Washington: Department of Architecture.

Mendell, M. \& Smith, A., 1990. Consistent Pattern of Elevated Symptoms in Air-conditioned Office Buildings: A Reanalysis of Epidemiologic Studies. Am J Public Health, 80(10), pp. 1193-1199.

Meteodyn, U., 2013. Youtube - Tutorial 1 the basics of creating a project with the CFD software. [Online] Available at: https://www.youtube.com/watch?v=LjMYc4tyk24

[Accessed 07 2013].

Metro GlassTech, 2006. Catalogue and Reference Guide. 6 ed. Auckland: Metropolitan Glass \& Glazing Ltd..

Ministry for the Environment, 2006. Value Case for Sustainable Building in New Zealand, Wellington: Ministry for the Environment.

Ministry for the Environment, 2008. Passive Solar Design Guidance, Wellington: Ministry for the Environment. Ministry of Business Innovation and Employment, 2014. Energy data and modelling: Prices: Data tables for prices. [Online]

Available at: http://www.med.govt.nz/sectors-industries/energy/energy-modelling/data/prices

[Accessed 04 2014].

Mora, M., 2010. Quantitative Vs. Qualitative Research - When to Use Which. [Online]

Available at: http://www.surveygizmo.com/survey-blog/quantitative-qualitative-research/

[Accessed 2711 2013].

Muehleisen, R. \& Patrizi, S., 2013. A new parametric equation for the wind pressure coefficient for low-rise buildings. Energy and Buildings, Volume 57, pp. 245-249.

Myers, G., Reed, R. \& Robinson, J., 2008. Investor Perception of the Business Case for Sustainable Office BUildings: Evidence from New Zealand. Kuala Lumpur, 14th Annual Pacific Rim Real Estate Society Conference 2008.

National Institue of Building Sciences, 2012. Daylighting. [Online]

Available at: http://www.wbdg.org/resources/daylighting.php

[Accessed 01 2014].

New Zealand Government, 2014. The Christchurch Rebuild - Gaining Momentum. [Online]

Available at: http://www.scoop.co.nz/stories/PA1404/S00301/the-christchurch-rebuild-gaining-

momentum.htm

[Accessed 05 2014].

New Zealand History Online, 2011. Christchurch earthquake kills 185. [Online]

Available at: http://www.nzhistory.net.nz/page/christchurch-earthquake-kills-185

[Accessed 09 2013].

New Zealand Planning Institute, 2013. Pre and Post Quake Aerial Photography of Christchurch. [Online] Available at: http://www.planning.org.nz/Story?Action=View\&Story id=1743

[Accessed 1812 2013]. 
Nielsen, M., Svendsen, S. \& Jensen, L., 2011. Quantifying the potential of automated dynamic solar shading in oddice buildings through integrated simulations of energy and daylight. Solar Energy, 05, 85(5), pp. 757-768.

NZGBC, 2013. Measuring Productivity in Green Buildings. [Online]

Available at: http://www.nzgbc.org.nz/index.php?option=com content\&view=article\&id=398:measuringproductivity-in-green-buildings\&catid=56: general-news\&ltemid=259

[Accessed 02 2014].

OPUS, 2011. OPUS Building Structures PIN Workshop. Christchurch, OPUS International Consultants.

Oxford Dictionaries, 2013. metric. [Online]

Available at: http://www.oxforddictionaries.com/definition/english/metric

[Accessed 3110 2013].

Ramponi, R. et al., 2011. Evaluation of wind-driven ventilation in building energy simulation: Sensitivity to pressure coefficients.. Lausanne, CISBAT.

Reardon, C., 2013. Passive Design: Thermal Mass. [Online]

Available at: http://www.yourhome.gov.au/passive-design/thermal-mass

[Accessed 04 2014].

Reinhart, C., 2012. Radiance-Daysim: Daylight Autonomy Benchmarks. [Online]

Available at: http://www.radiance-online.org/pipermail/radiance-daysim/2012-October/000023.html [Accessed 0611 2013].

Reinhart, C. F. \& LoVerso, V. R., 2010. A rules of thumb-gased design sequence for diffuse daylight. Lighting REsearch and Technology, Volume 42, pp. 7-31.

Reinhart, C. \& Walkenhorst, O., 2001. Validation of dynamic RADIANCE-based daylight simulations for a test office with external blinds.. Energy and Buildings, Issue 33, pp. 683-697.

Roberti, J. \& Helm, N., 2011. Towards Building Better Cities, Porirua: BRANZ.

Rogers, Z., Mardaljevic, J. \& Reinhart, C., 2006. Dynamic daylight performance metrics for sustainable building design. LEUKOS, 3(1), pp. 7-31.

Rowland, J. \& Moor, M., 2006. Urban Design Futures. Nwe York: Routledge.

Santamouris, M., 2006. Environmental Design of Urban Buildings: An Integrated Approach.. First ed. London: Earthscan.

Satwiko, P., Locke, N. \& Donn, M., 1998. Reproducing the real pressure coefficient using a computational fluid dynamics program- 'How close is close enough?'. [Online]

Available at: http://www.victoria.ac.nz/cbpr/projects/natural-ventilation-p1.aspx

[Accessed 1610 2013].

Shrestha, S. \& Maxwell, G., 2011. Emperical Validation of Building Energy Simulation Software EnergyPlus. Sydney, 12th Conference of International Building Performance Simulation Association.

Sibanda, N., 2009. Quantitative Research, Wellington: Victoria University of Wellington.

Standards New Zealand, 1990. NZS 4303: 1990 - Ventilation for Acceptable Indoor Air Quality, Wellington: Standards Association of New Zealand.

Standards New Zealand, 2006. AS/NZS 1680.1:2006 - Interior and Workplace Lighting: General principles and recommendations, Wellington: Standards New Zealand.

Stang, P., Cady, R., Batenhorst, A. \& Hoffman, L., 2001. Workplace Productivity. Pharmacoeconomics, 19(3), pp. 231-244.

Stewart, K., 2008. New Zealand Building Code Clause G7. Compliance Assessment Tool: Development and Implementation, Wellington: Victoria University of Wellington.

Stromann-Andersen, J. \& Sattrup, P., 2011. The urban canyon and building energy use: Urban density versus daylight and passive solar gains. Energy and Buildings, 10 04, pp. 2011-2020.

Sullivan, J., 2013. Tubular Daylighting Devices and People, Wellington: Victoria University of Wellington. 
Sustainability Victoria, 2008. 500 Collins St case study. [Online]

Available at: http://www.sustainability.vic.gov.au/Services-and-Advice/Business/Smarter-Resources-SmarterBusiness/Energy-efficient-office-buildings/Case-studies/500-Collins-St

[Accessed 09 2013].

Teixeira, J., Lomba, R., Teixeira, S. \& Lobarinhas, P., 2012. Application of CFD tools to optimize natural building ventilation design. In: B. Murgante \& e. al., eds. Computational Science and its Applications - ICCSA 2012.

Berlin: Springer Berlin Heidelberg, pp. 202-216.

TERI University, 2010. Development of Building Regulations and Guidelines to Achieve Energy Efficiency, Vienna: TERI University; and Renewable Energy and Energy Efficiency Parternship (REEEP)..

The Dominion Post, 2012. Green shows true colours in global crunch era. Commercial Property, 25 09, p. B6.

The Scottish Government, 2007. Section 3: Concept Design. [Online]

Available at: http://www.scotland.gov.uk/Publications/2007/02/28144045/4

[Accessed 03 2014].

The Society of Light and Lighting, 2002. Code for Lighting, Oxford: Butterworth Heinemann.

The Treasury, 2013. 2013 Budget: Supporting the rebuilding of Christchurch. [Online]

Available at: http://www.treasury.govt.nz/budget/2013/speech/06.htm

[Accessed 11 2013].

Thomas, R., 2007. ESI Support- Has your simulation converged?. [Online]

Available at: http://support.esi-cfd.com/esi-users/convergence/

[Accessed 1710 2013].

Tian, W., Tian, Z. \& Love, J., 2008. Window to wall ratios and commercial building environmental control in cold climates. Canada, 33rd Annual Conference of the Solar Energy Society of Canada \& 3rd Canadian Solar Building Research Network Conference,.

Tokyo Polytechnic University, 2007. Aerodynamic Database of Non-Isolated, Low-Rise Buildings. [Online] Available at: http://www.wind.arch.t-kougei.ac.jp/info center/windpressure/grouplowrise/mainpage.html [Accessed 01 2014].

Tzempelikos, A. \& Athienitis, A., 2005. The effect of shading design and control on building cooling demand. Santorini, Passive and Low Energy Cooling for the Built Environment.

U.S Department of Energy, 2011. Building Energy Software Tools Directory. [Online] Available at: http://apps1.eere.energy.gov/buildings/tools directory/alpha list.cfm [Accessed 2811 2013].

Walker, A., 2010. National Institute of Building Sciences: Whole building design guide- Natural ventilation. [Online]

Available at: http://www.wbdg.org/resources/naturalventilation.php

[Accessed 2210 2013].

Webby, M. \& Hoare, C., 2012. The Emergence of Christchurch. ArchitectureNZ, 02, pp. 25-34.

Wetter, M., 2008. GenOpt - A Generic Optimization Program. User Manual, Berkeley, California: Lawrence Berkeley National Laboratory.

World Health Organisation, 1985. Environmental Health: Health Impact of Low Indoor Temperatures, Copenhagen: Worl Health Organisation (WHO). 
Urban Form and Passive Design for High Performance Buildings in the Christchurch Rebuild 


\section{Appendix A: Robustness Tests}

\section{A.1. Robustness Test 1 - Analysis Grid Detail}

\section{Purpose}

To determine whether low detail analysis grids provide a sufficient level of daylighting information.

\section{Method}

Compare Daylight Autonomy (DA) data and resulting artificial lighting energy from a model with a high detail analysis grid, to an identical model with a low detail analysis grid.

\section{High Detail Grid}

$1 \mathrm{~m} \times 1 \mathrm{~m}$ grid points based on NZS1680 recommendations and discussion in Section 4.2.1.7. Equates to 441 grid points (9x49). Refer Figure A.1.1 - left grid.

\section{Low Detail Grid}

$2 \times 10 \mathrm{~m}$ grid points. $2 \mathrm{~m}$ X-direction intervals sufficient to test the $2 \mathrm{~m}$ building width increments; $\mathrm{Y}$ direction intervals not significant because daylight is uniform along the buildings length due to constant building separation distance $-10 \mathrm{~m}$ spacing's. Equates to 30 grid points (5x6) (grid on right).

\section{Results}

Annual daylighting simulations were performed in Radiance/Daysim between the hours of 8am-6pm (occupied hours). Figure A.1.1 depicts DA results (same criteria as established in Section 4.2.1.3) and Table A.1.1 summarizes findings.

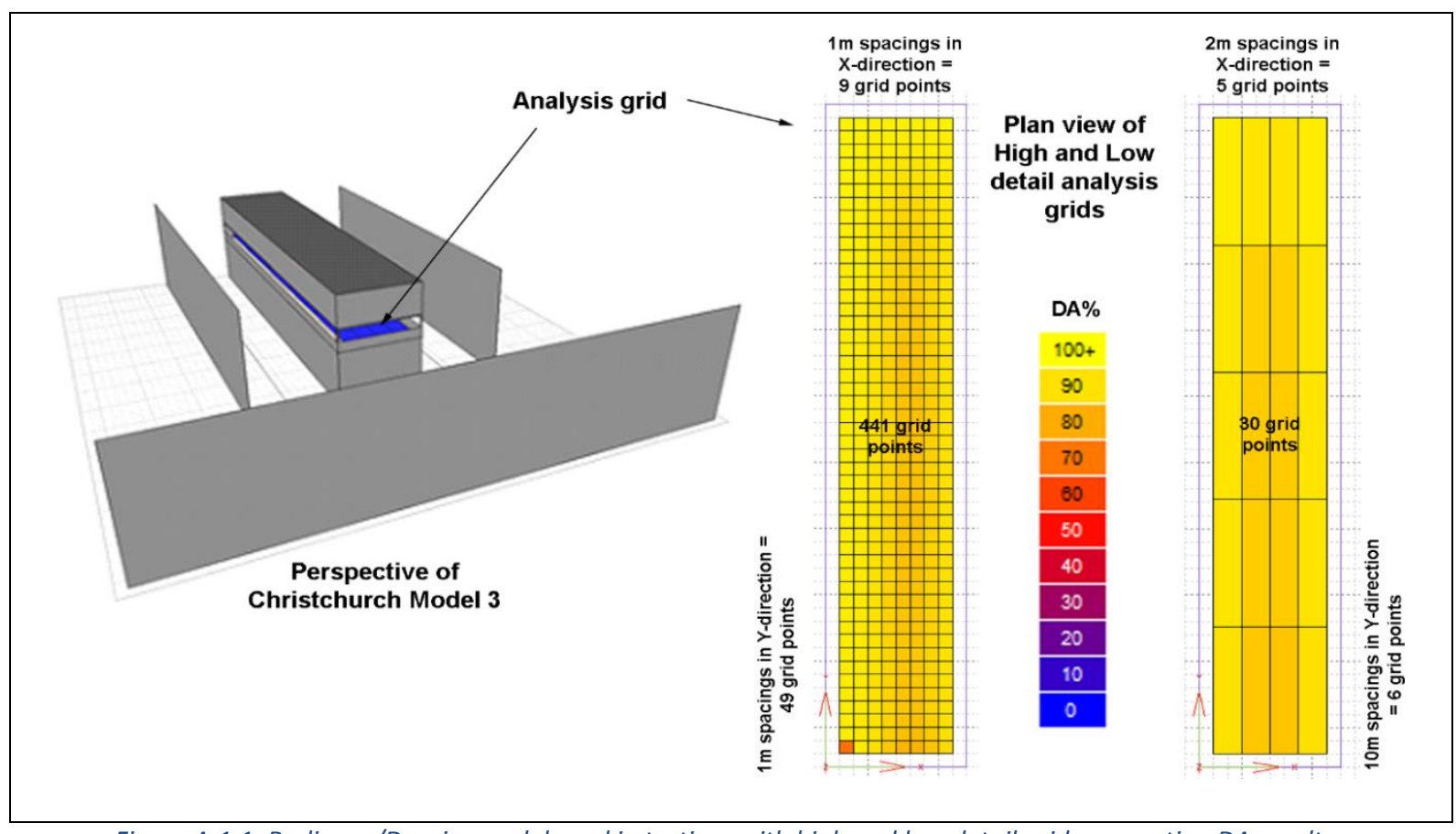

Figure A.1.1. Radiance/Daysim model used in testing; with high and low detail grids presenting DA results. 


\begin{tabular}{|l|l|l|l|}
\hline \multicolumn{4}{|c|}{ Daylighting Autonomy Results (single level) (DA, \%) } \\
\hline & High Detail Model & Low Detail Model & Percentage Difference (\%) \\
\hline Average DA & $90 \%$ & $89 \%$ & $<1 \%$ \\
\hline Minimum DA & $80 \%$ & $79 \%$ & $<1 \%$ \\
\hline
\end{tabular}

Table A.1.1. Daylight Autonomy differences between high and low detail analysis grids.

Using the method described in Section 4.2.3 daylighting data was plugged into corresponding EnergyPlus models to determine artificial lighting loads. Figure A.1.2 depicts the EnergyPlus model and settings.

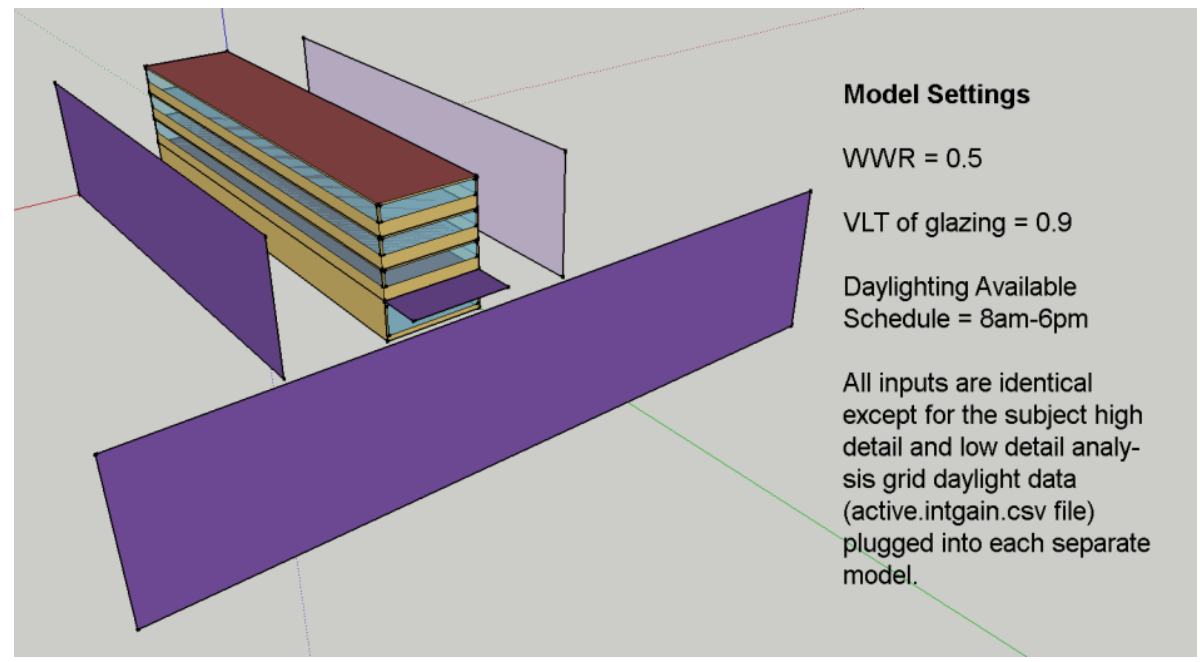

Figure A.1.2. EnergyPlus model and design specifications.

\begin{tabular}{|l|l|l|}
\hline \multicolumn{3}{|c|}{ Annual Lighting Energy Consumption (single level) (kWh) } \\
\hline High Detail Model & Low Detail Model & Percentage Difference (\%) \\
\hline 3,566 & 3,544 & $<1 \%$ \\
\hline
\end{tabular}

Table A.1.2. Resulting lighting energy consumption results produced by the high and low detail models.

\section{Findings}

- DA results show negligible difference $(<1 \%)$ between the high and low detail grids.

- Resulting artificial lighting energy consumption differences are also negligible $(<1 \%)$.

- Simulation time of the low detail model was around half of the high detail model.

Low detail grids produce near identical daylighting data as the high detail grid but takes half the time to do so. 


\section{A.2. Robustness Test 2 - Analysis Grid Frequency (across storeys)}

\section{Purpose}

To determine whether daylight analysis grids are required on every level of the subject building, or whether a single representative grid/level is sufficient- and, if so, which level.

\section{Method}

Compare the energy consumption of a building that consists of daylight analysis grids on each storey ('All Levels'), to an identical building with only a single, representative grid applied to all levels ('Representative Level').

Daylight levels are calculated in Radiance/Daysim and results are integrated into EnergyPlus where supplementary electric lighting loads are calculated (refer Robustness Test 3 and Section 4.2.3 for details on this method). The method is repeated twice- once for lowest density 'Model 3' and again for highest density 'Model 7' to ensure results are analogous across all urban densities (refer Section 5.4 for Urban Form models).

\section{All Levels - Model 3}

The same 'Model 3' and low detail analysis grid from Robustness Test 1 is used, with the grid moved to each upper level, as displayed in Figure A.2.1. Daylight results for each level are integrated with its corresponding level of the corresponding EnergyPlus model (Figure A.2.2) to generate lighting energy consumption data. This is the more robust method and is therefore the baseline.

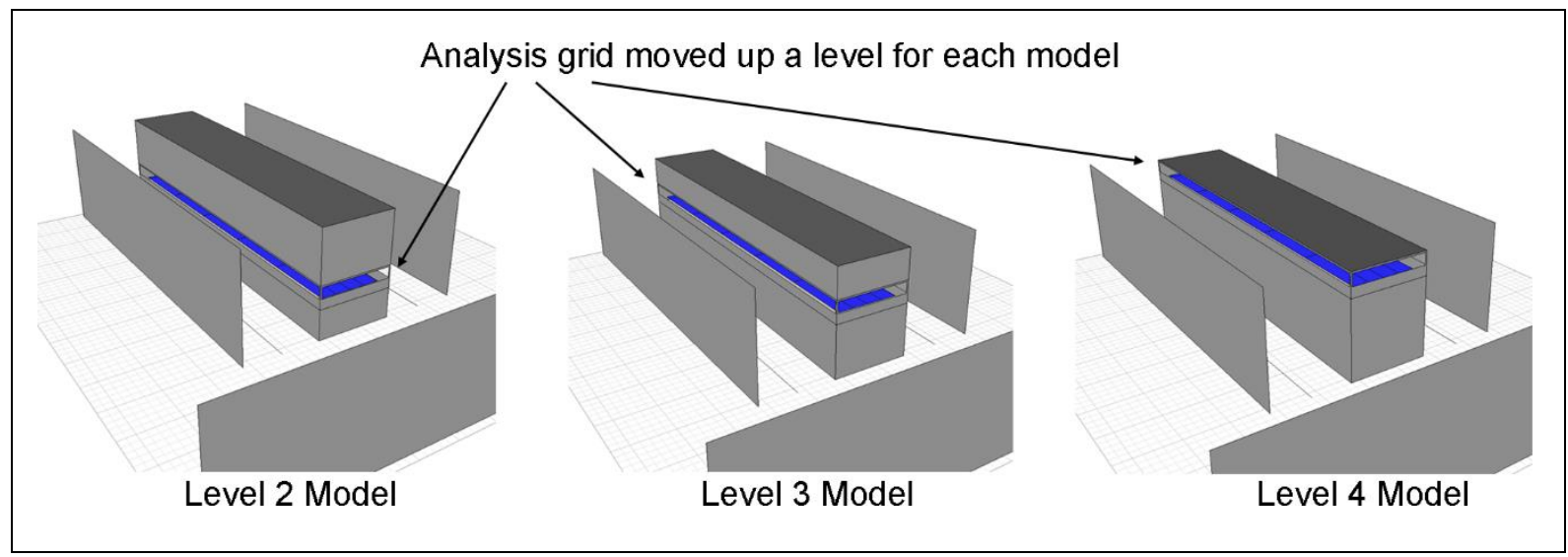

Figure A.2.1. Daysim models with analysis grid on each level.

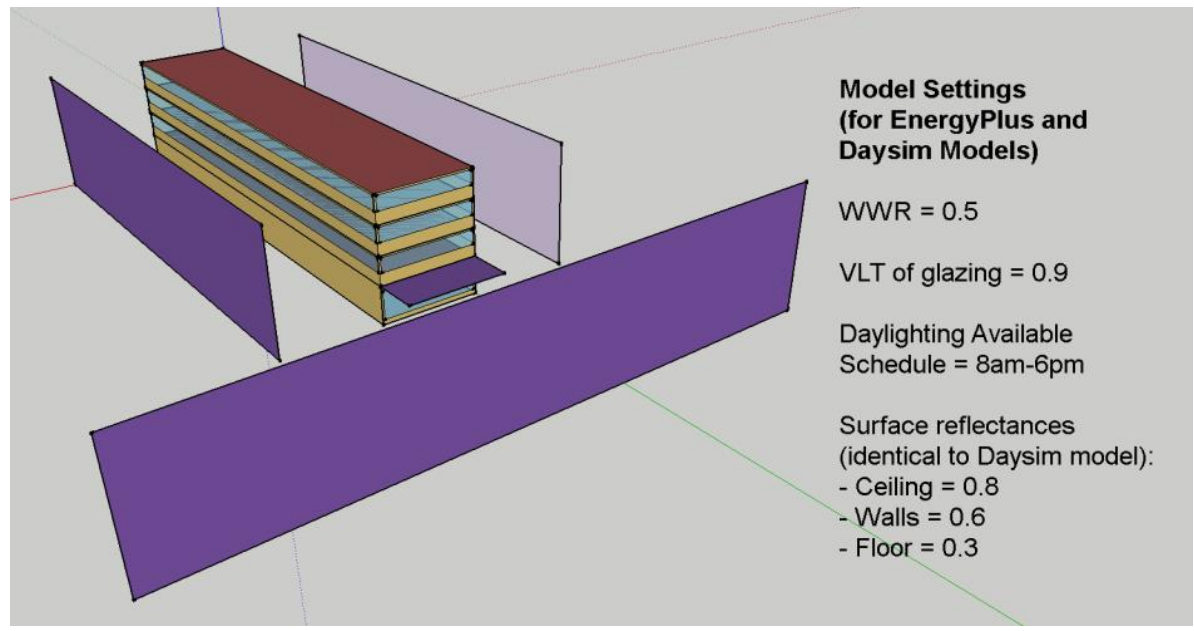

Figure A.2.2. Model 3 EnergyPlus model and design specifications. 


\section{Representative Level - Model 3}

The representative grid method calculates artificial lighting energy for the entire building, based on a single daylighting grid/level. This method is repeated three times using daylighting calculations for each of the three upper levels of the Daysim model.

\section{Results - Model 3}

Figure A.2.3 shows that when daylight and corresponding energy consumption is calculated individually for each level, a total of $22,000 \mathrm{kWh}$ is consumed across the building (red baseline).

In comparison, the Representative Level varies (depending on the level used for daylight calculations) but only by $\pm<1,000 \mathrm{kWh}$ - less than $5 \%$. When using the mid-height level 3 as representative, the difference from the baseline is less than $1 \%$. Time to conduct the 'Representative Level' method was less than half that of the full 'All Levels' method.

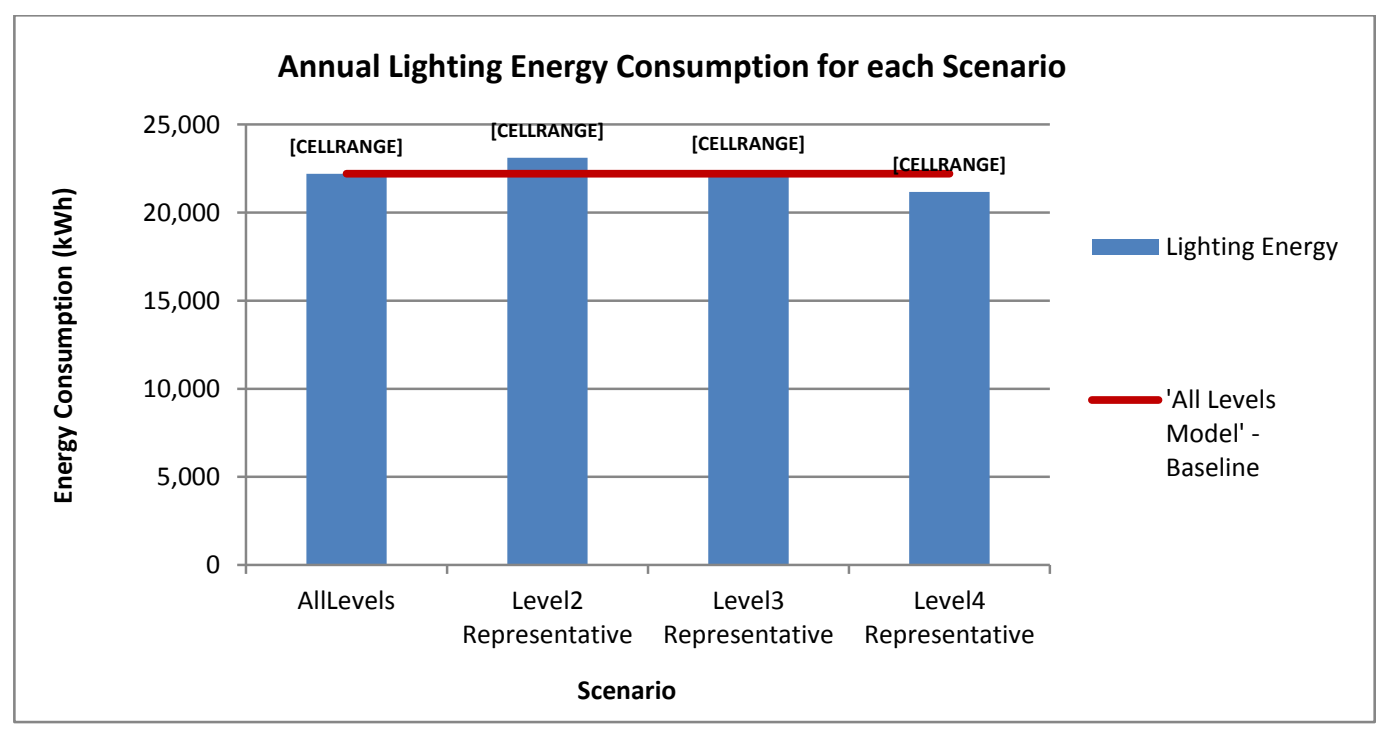

Figure A.2.3. Model 3 Lighting energy results

\section{All Levels - Model 7}

Same method used as for 'Model 3 - All Levels'. Figure A.2.4 shows the daylighting analysis grid applied to levels 2-8; Figure A.2.5 shows the corresponding EnergyPlus model.

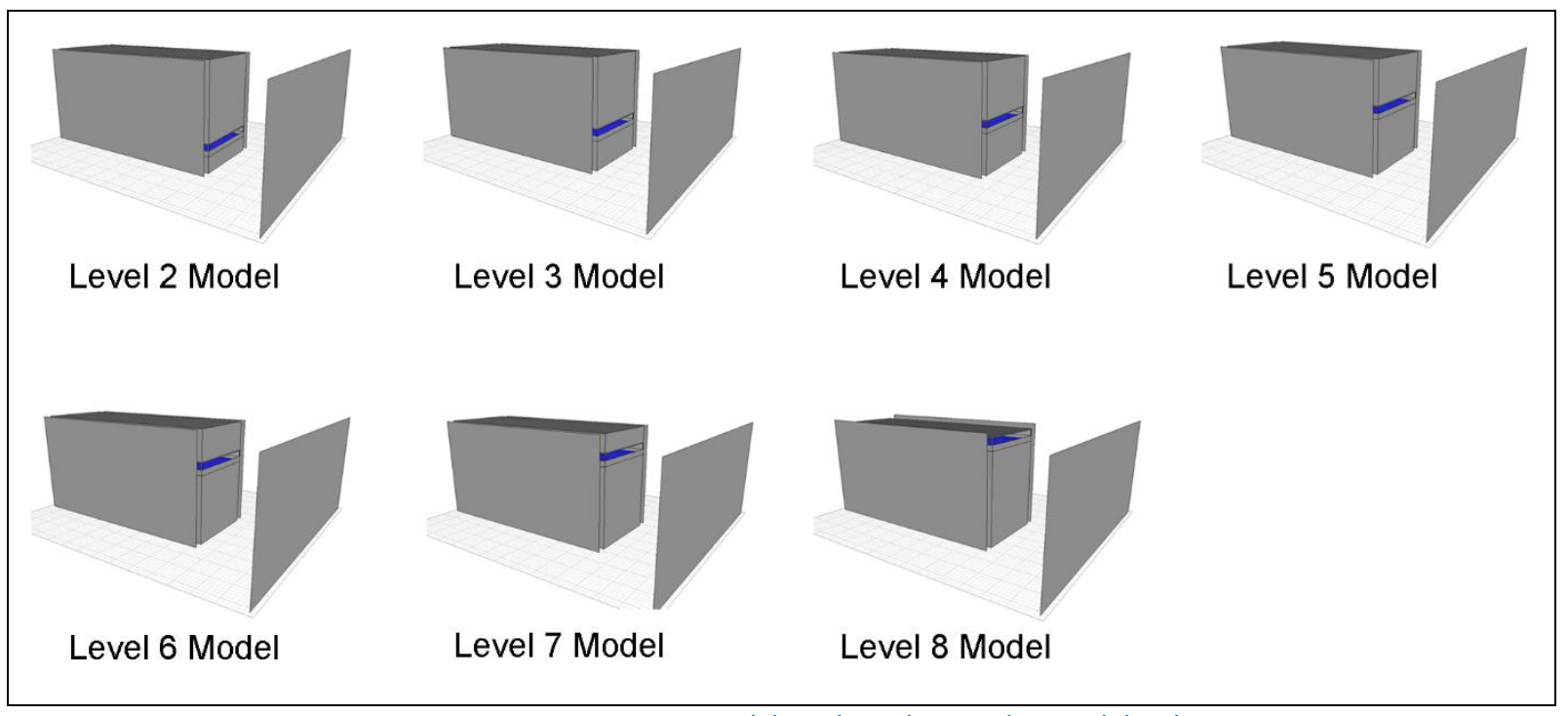

Figure A.2.4. Seven Daysim models with analysis grid on each level. 


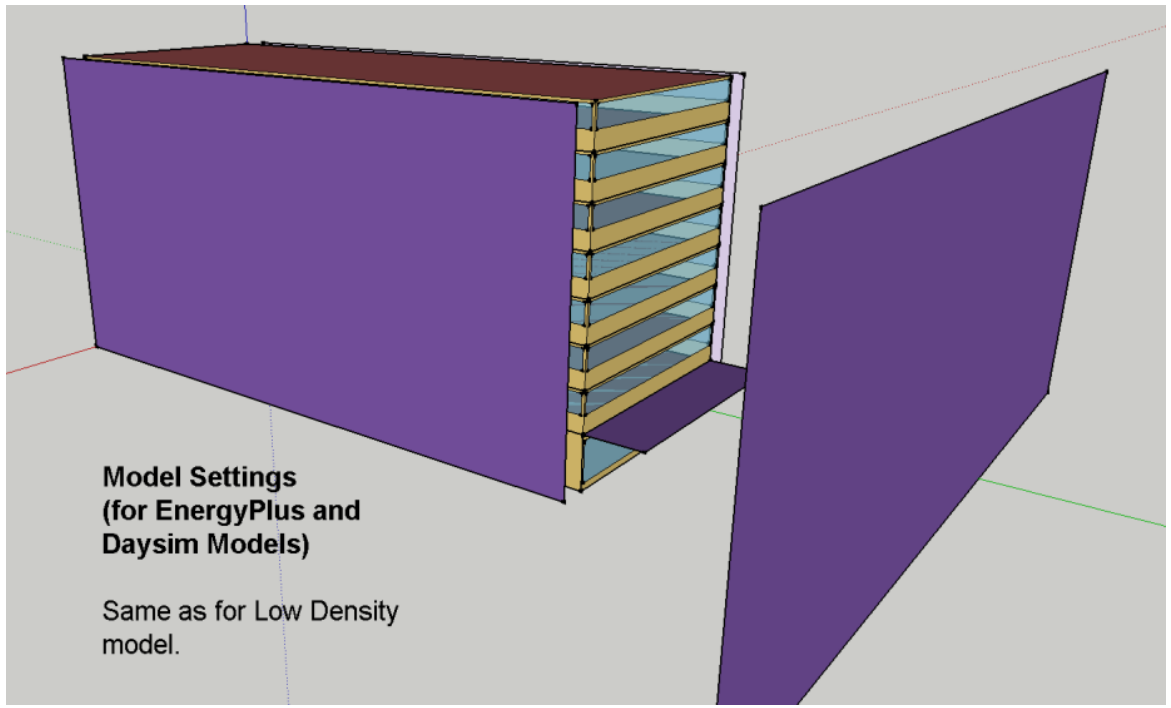

Figure A.2.5. Model 7 EnergyPlus model

\section{Representative Level - Model 7}

Same method used as for 'Representative Level - Model 3'.

\section{Results - Model 7}

Figure A.2.6 shows that when daylight and corresponding energy consumption is calculated individually for each level, a total of $154,000 \mathrm{kWh}$ is consumed across the building (red baseline).

The graph shows that Levels 2-6 would all slightly over-estimate lighting energy loads if used as representative levels by $5-11 \%$; whereas Level 7 slightly under-estimates by $4 \%$, and Level 8 grossly under-estimates by $42 \%$ lighting energy requirements.

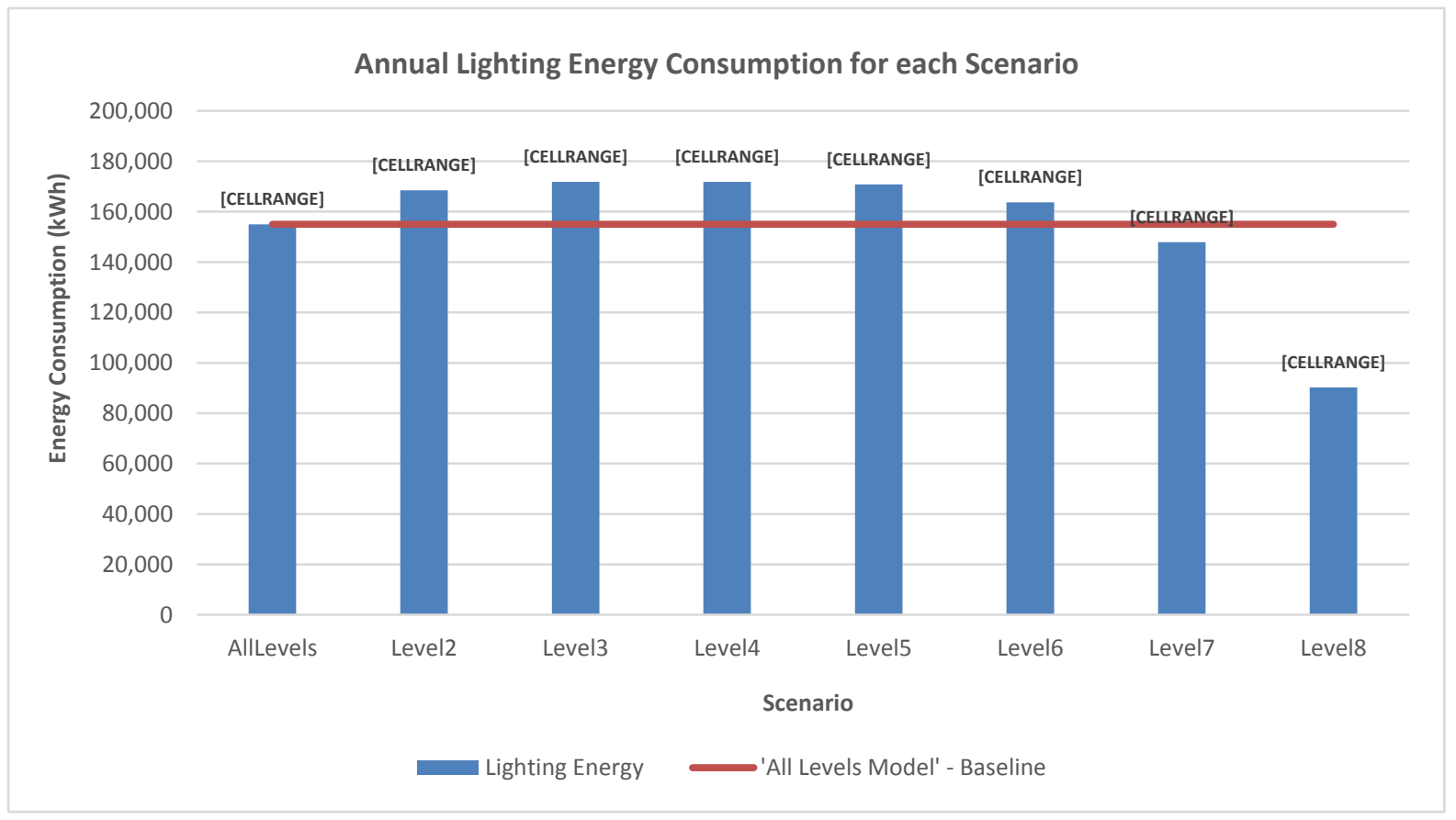

Figure A.2.6. Model 7 Lighting energy results 
Figure A.2.7 shows how lighting energy consumption differences translate to small total building consumption discrepancies. Levels 2-6 over-estimate total energy by 3-6\%; Level 7 under-estimates by $2 \%$; and Level 8 under-estimates by a substantial $23 \%$. Clearly, Level 8 enjoys very high levels of daylight at the top of the urban fabric which are not representative of the rest of the building and therefore cannot be considered as a representative level. Although Level 7 appears the most accurate, it also produces 'generous' results which would cause misleading performance improvements. Of the remaining scenarios, Level 6 produces the most accurate results at only $4 \%$ difference from the baseline. The difference between this and Level 5 however is only an insignificant $1 \%$. Therefore, as the mid-height storey, Level 5 will be adopted as the representative level for 8-storey Models 7, 8 and 9 in testing.

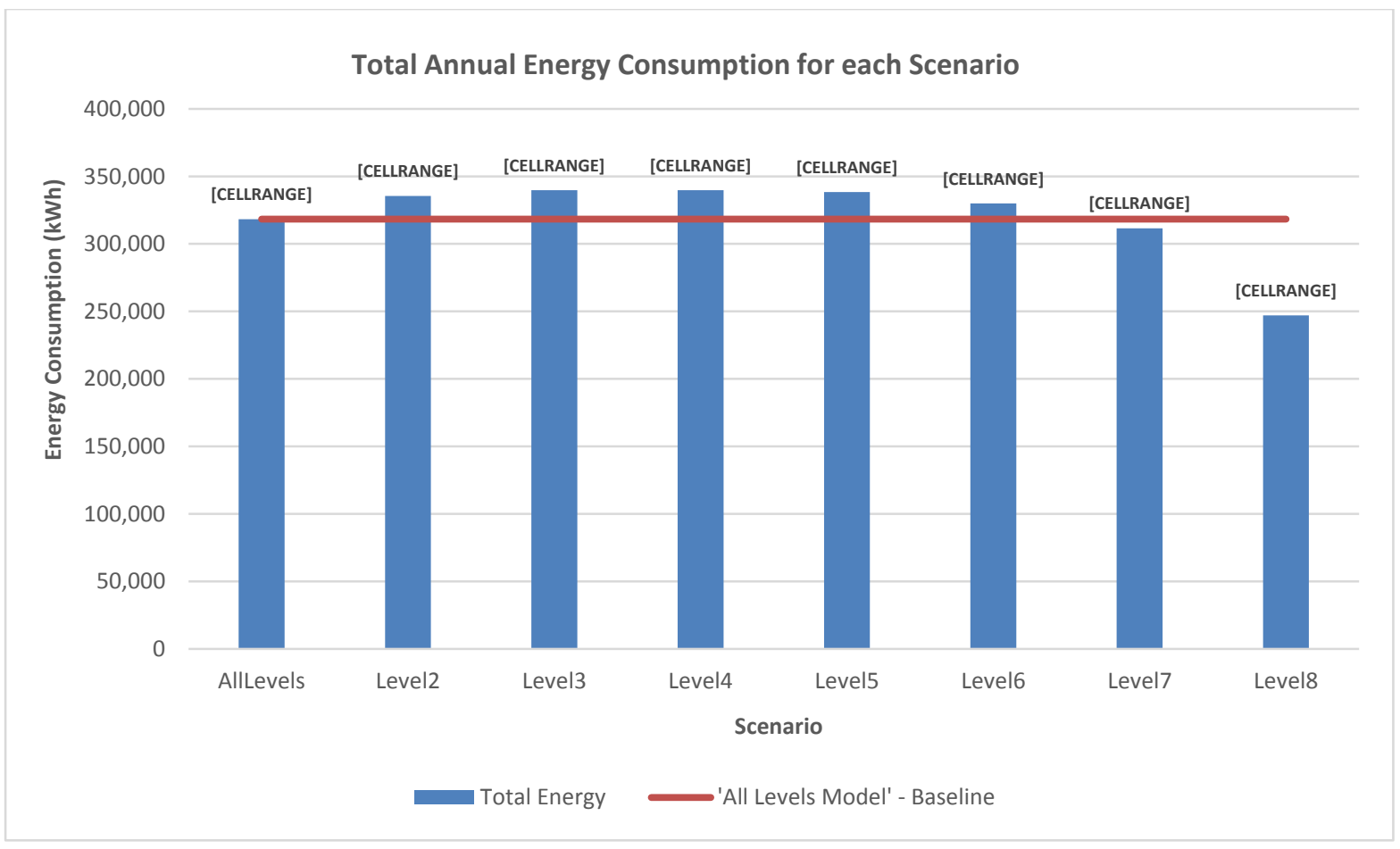

Figure A.2.7. Model 7 Total energy consumption

\section{Findings}

- In all tested scenarios it was found that the use of a single level for daylighting calculations could adequately (within 5\% of the detailed 'All Levels' baseline model) 'represent' daylight and resulting energy consumption when applied to all (passive) levels of the building.

- In all cases, the mid-height level will be used as the 'Representative' daylighting level to the rest of the building - i.e. Level 3 for 4 -storey scenarios; Level 4 for 6 -storey scenarios; and Level 5 for 8-storey scenarios.

The mid-height rule was assumed to be true for medium density 6-storey scenarios as an average of the low density 4-storey and high density 8-storey scenarios tested here. 


\section{A.3. Robustness Test 3 - Daylight Calculation Methods}

\section{Purpose}

To determine the most appropriate method of calculating daylight for the study.

\section{Method}

- 'Model 3' will be simulated four times, three using a different method of calculating daylight; and the fourth using only artificial lighting- to demonstrate the effect each method has on energy savings potential.

- Method 1 uses EnergyPlus as the daylight calculation engine; Method 2 uses Radiance/Daysim at 'low scene complexity' (detail); Method 3 again uses Radiance/Daysim but with 'high scene complexity'.

\section{Method 1: No Daylight}

'Model 3'. Lighting density $12 \mathrm{~W} / \mathrm{m}^{2}$. Lighting schedule $8 \mathrm{am}-6 \mathrm{pm}$. Settings identical for all models. This baseline uses purely artificial lighting as to demonstrate how much energy savings are possible through daylighting.

\section{Method 2: EnergyPlus Daylight Calculations}

EnergyPlus' 'Split-flux' method reads daylight levels at a sensor in the centre of each zone/level. For each zone/level, it then reduces supplementary artificial lighting density to deliver the desired $4001 x$.

Method 2 aims to quantify by how much EnergyPlus' 'split-flux' algorithm underestimates daylight and overestimates supplementary artificial lighting as a result (refer Section 4.2.2.1 discussion). Results will be measured against the more robust Radiance methods following.

\section{Method 3: Low Complexity Radiance/Daysim Daylight Calculations}

Radiance uses the 'Reverse Ray-tracing' algorithm which is widely regarded as the most accurate method of predicting daylight levels available (refer Section 4.2.2.2).

Radiances 'Low complexity' setting limits the 'bounces' of light off surfaces, enabling quicker simulation times than the 'High complexity' setting.

Daysim then relays Radiances daylight calculations through its 'artificial lighting reduction' report which can be referenced by EnergyPlus to modify electric lighting density according to present daylight levels. This report consists of hourly fractions denoting how much electric lighting can be reduced - e.g. 0.2 indicates lighting density would be modified from $100 \%\left(12 \mathrm{~W} / \mathrm{m}^{2}\right)$ down to $20 \%$ $\left(2.4 \mathrm{~W} / \mathrm{m}^{2}\right)$.

\section{Method 4: High Complexity Radiance/Daysim Daylight Calculations}

The third method tested employs the same process as 'Method 3' but specifies the 'High complexity' scene setting. 'High complexity' allows more reflections off surfaces which enables light to travel further, maximizing its effect. This setting is more representative of realistic light behaviour (and so acts as the baseline in this test) but requires longer simulation times.

\section{$\underline{\text { Results }}$}

Figures A.3.1 and A.3.2 present the Daysim and EnergyPlus models (Model 3) used for this test. For the Radiance/Daysim based methods, only a single analysis grid was used on the middle floor of the building ( $3^{\text {rd }}$ floor out of 4 floors- Ground floor not considered for daylighting). This is an approach that has been adopted throughout the study and is proven to generate reliable results in Robustness Test 2. 


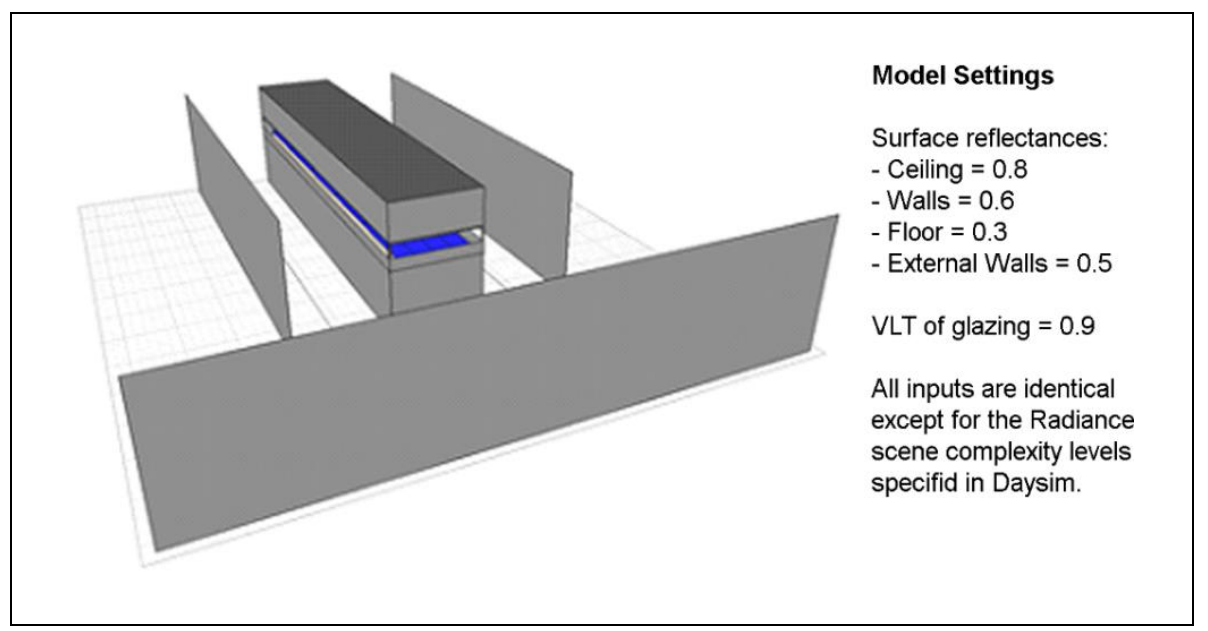

Figure A.3.1. Daysim model used in the test.

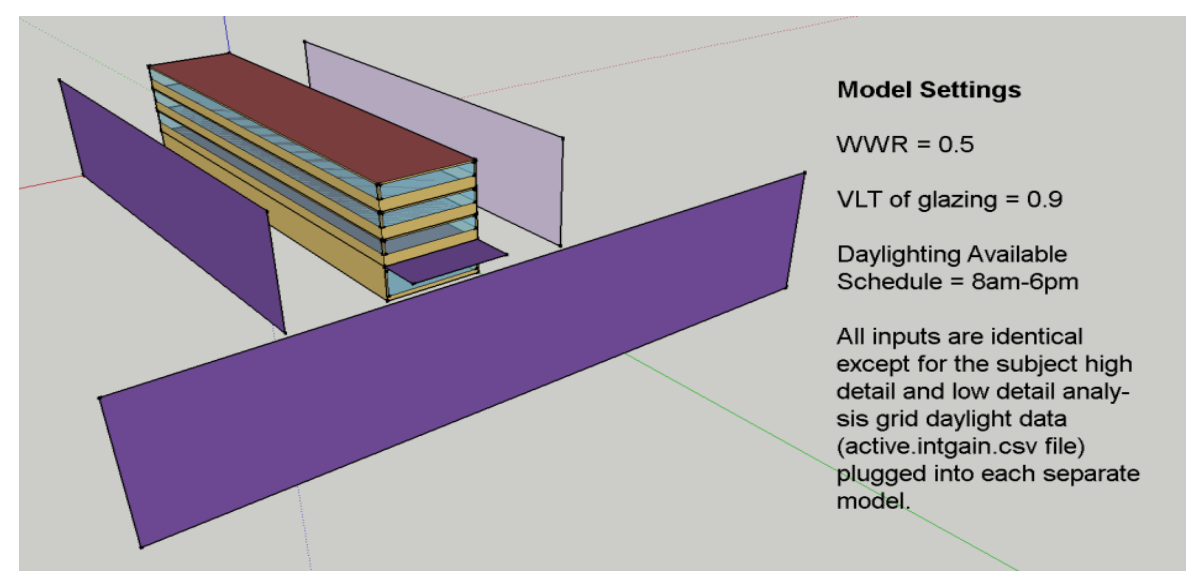

Figure A.3.2. EnergyPlus model and settings used in the test.

\begin{tabular}{|l|l|l|l|l|}
\hline \multicolumn{5}{|c|}{ Lighting Energy Predicted by Each Daylight Calculation Method and Difference to Baseline } \\
\hline & $\begin{array}{l}\text { Radiance, High } \\
\text { Detail (Baseline) }\end{array}$ & $\begin{array}{l}\text { Radiance, Low } \\
\text { Detail }\end{array}$ & EnergyPlus & No Daylight \\
\hline $\begin{array}{l}\text { Energy Consumption } \\
\text { (kWh) }\end{array}$ & 22,332 & 22,534 & 28,118 & 46,800 \\
\hline $\begin{array}{l}\text { Difference from } \\
\text { Baseline (\%) }\end{array}$ & - & $+<1 \%$ & $+26 \%$ & NA \\
\hline $\begin{array}{l}\text { Difference from ‘No } \\
\text { Daylight’ (\%) }\end{array}$ & $-53 \%$ & $-52 \%$ & $-40 \%$ & - \\
\hline
\end{tabular}

Table A.3.1. Comparison of Lighting energy consumption resulting from each daylighting method.

\section{Findings}

- EnergyPlus daylight calculations overestimate lighting energy by $26 \%$ compared to the 'Radiance High Detail' baseline.

- 'Radiance Low Detail' is within 1\% difference of 'Radiance High Detail'.

- According to Radiance, lighting energy can be reduced by $52 \%$ (46,800 down to $22,332 \mathrm{kWh}$ ). In comparison to the more reliable Radiance method, the $26 \%$ divergence in lighting energy calculations generated by EnergyPlus is excessive. Therefore, Radiance's low detail, which differed by $<1 \%$ from high detail settings will be used as the daylighting engine.

'Robustness Test 3 ' has also demonstrated that substantial lighting energy savings - over $50 \%$ - can be realized through the use of daylighting. 


\section{A.4. Robustness Test 4-Wind Angle Increment (WAI) Frequency}

\section{Purpose}

To determine required Wind Angle Increment (WAI) frequency for natural ventilation calculations.

\section{Background}

EnergyPlus uses the closest specified $\mathrm{Cp}$ value between the actual wind angle of incidence (according to the weather file) and the subject surface 'outward normal' $\left(90^{\circ}\right.$ to the surface) and adjusts weather file data based on that coefficient.

For a north facing façade example, if $\mathrm{Cp}$ values have been specified for every $45^{\circ}$, a wind angle of $89^{\circ}$ (in the weather file) will be applied to the $45^{\circ} \mathrm{Cp}$ value (because it is the first increment towards north); whereas a wind angle of $91^{\circ}$ would be applied to the $90^{\circ} \mathrm{Cp}$ value (because this is now the first increment towards north). Common WAl's used in similar studies include $90^{\circ}, 45^{\circ}, 30^{\circ}$, and $10^{\circ}$ (Costola, et al., 2009). $10^{\circ}$ is the smallest increment possible in EnergyPlus.

Every WAI requires a separate, time intensive CFD calculation in UrbaWind. Computations are conducted by the kind people at Meteodyn so should be limited as much as possible, but not so far as to compromise the accuracy of natural ventilation calculations.

\section{Method}

- Using UrbaWind, generate wind pressure coefficient $(C p)$ data for each level of each façade of an identical high detail WAI $\left(10^{\circ}\right)$ and a low detail WAI $\left(45^{\circ}\right)$ model ('Model $\left.3^{\prime}\right)$.

- Apply Cp data for each WAI to two separate EnergyPlus models and generate air change rate and energy consumption data.

- Compare results to determine whether faster low detail WAls produce reliable results compared to high detail WAls.

Figure A.4.1 presents 'Model 3 ' in its full urban environment as simulated in UrbaWind (with the EnergyPlus equivalent inset). Only east and west facades/windows were specified for venting (cross ventilation, refer Section 4.3.2). Table A.4.1 presents the $C p$ values generated by UrbaWind for the $10^{\circ}$ and $45^{\circ}$ WAls. UrbaWind outputs can be found in Appendix D.

\section{$\underline{\text { Results }}$}

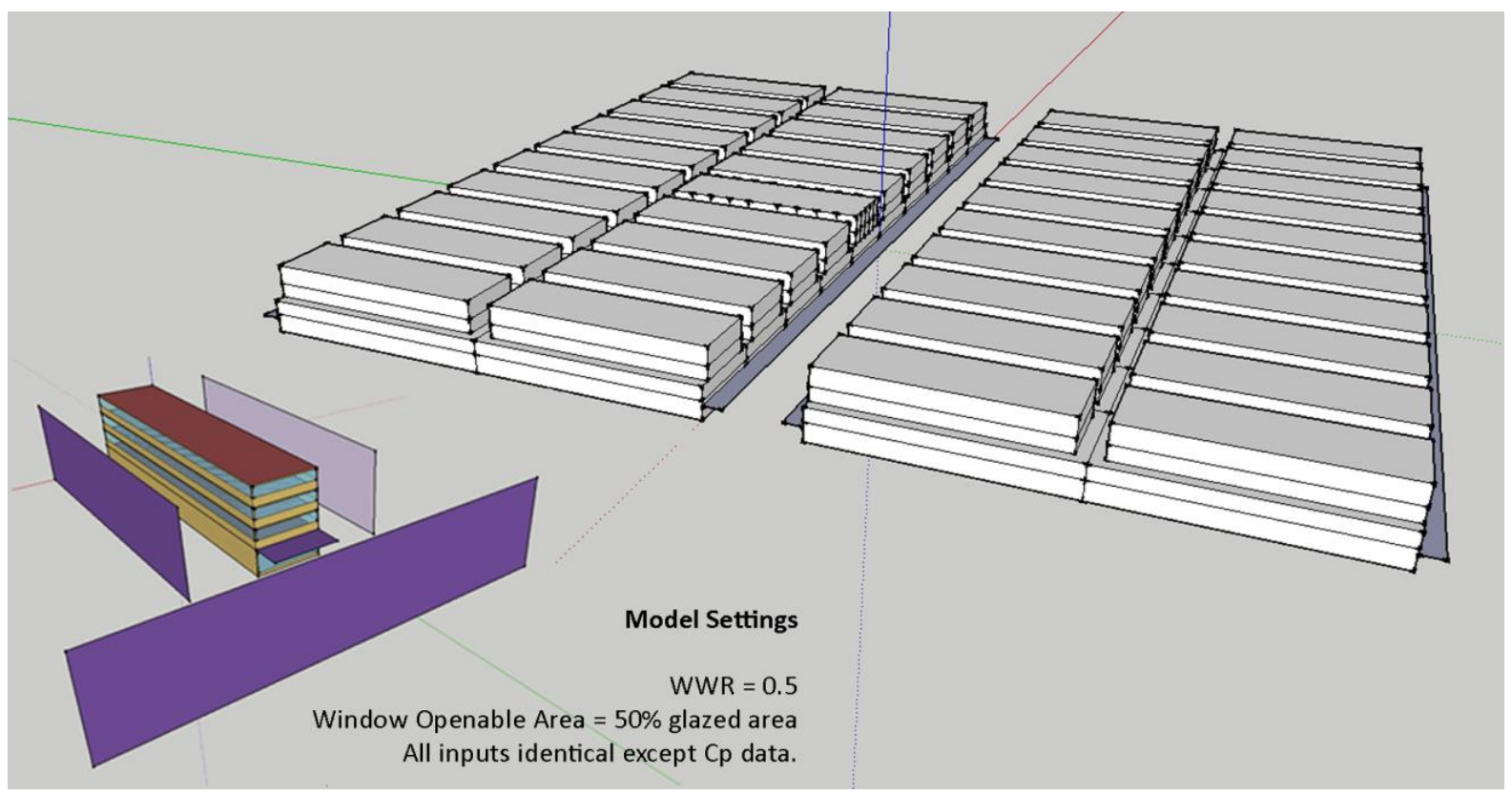

Figure A.4.1. EnergyPlus model and design specifications. 


\begin{tabular}{|c|c|c|c|c|c|c|c|c|c|c|c|c|}
\hline \multicolumn{13}{|c|}{ Wind Pressure Coefficients for Model 3 at Wind Angle Increments of $10^{\circ}$ and $45^{\circ}$} \\
\hline & \multicolumn{6}{|c|}{$10^{\circ}$ Increments } & \multicolumn{6}{|c|}{$45^{\circ}$ Increments } \\
\hline & \multicolumn{3}{|c|}{ West Facade } & \multicolumn{3}{|c|}{ East Façade } & \multicolumn{3}{|c|}{ West Facade } & \multicolumn{3}{|c|}{ East Façade } \\
\hline WAI & L2 & L3 & L4 & L2 & L3 & L4 & L2 & L3 & L4 & L2 & L3 & L4 \\
\hline $0^{\circ}$ & -0.2 & -0.2 & -0.2 & -0.2 & -0.2 & -0.2 & -0.2 & -0.2 & -0.2 & -0.2 & -0.2 & -0.2 \\
\hline $10^{\circ}$ & -0.2 & -02 & -0.15 & -0.2 & -0.2 & -0.2 & & & & & & \\
\hline $20^{\circ}$ & -0.15 & -0.15 & -0.15 & -0.15 & -0.15 & -0.15 & & & & & & \\
\hline $30^{\circ}$ & -0.15 & -0.15 & -0.1 & -0.2 & -0.2 & -0.2 & & & & & & \\
\hline $40^{\circ}$ & -0.1 & -0.1 & -0.1 & -0.2 & -0.2 & -0.3 & & & & & & \\
\hline $45^{\circ}$ & & & & & & & -0.1 & -0.1 & -0.05 & -0.2 & -0.2 & -0.3 \\
\hline $50^{\circ}$ & -0.15 & -0.15 & -0.1 & -0.2 & -0.2 & -0.2 & & & & & & \\
\hline $60^{\circ}$ & -0.1 & -0.1 & -0.05 & -0.3 & -0.3 & -0.3 & & & & & & \\
\hline $70^{\circ}$ & -0.1 & -0.1 & -0.05 & -0.3 & -0.3 & -0.3 & & & & & & \\
\hline $80^{\circ}$ & -0.05 & -0.05 & -0.05 & -0.3 & -0.3 & -0.3 & & & & & & \\
\hline $90^{\circ}$ & -0.05 & -0.05 & 0 & -0.3 & -0.3 & -0.3 & -0.05 & -0.05 & 0 & -0.3 & -0.3 & -0.3 \\
\hline $100^{\circ}$ & -0.1 & -0.1 & 0 & -0.3 & -0.3 & -0.3 & & & & & & \\
\hline $110^{\circ}$ & -0.1 & -0.1 & -0.05 & -0.3 & -0.3 & -0.3 & & & & & & \\
\hline $120^{\circ}$ & -0.1 & -0.1 & -0.1 & -0.3 & -0.3 & -0.3 & & & & & & \\
\hline $130^{\circ}$ & -0.1 & -0.1 & -0.1 & $\begin{array}{l}-0.3 \\
\end{array}$ & $\begin{array}{l}-0.3 \\
\end{array}$ & -0.3 & & & & & & \\
\hline $135^{\circ}$ & & & & & & & -0.15 & -0.15 & -0.1 & -0.3 & -0.3 & -0.3 \\
\hline $140^{\circ}$ & -0.1 & -0.1 & $\begin{array}{l}-0.1 \\
\end{array}$ & -0.3 & -0.3 & -0.3 & & & & & & \\
\hline $150^{\circ}$ & -0.15 & -0.15 & -0.1 & -0.3 & -0.3 & -0.3 & & & & & & \\
\hline $160^{\circ}$ & -0.15 & -0.15 & -0.15 & -0.2 & -0.2 & -0.2 & & & & & & \\
\hline $170^{\circ}$ & -0.2 & -0.2 & -0.2 & -0.2 & -0.2 & -0.2 & & & & & & \\
\hline $180^{\circ}$ & -0.2 & -0.2 & -0.2 & -0.2 & -0.2 & -0.2 & -0.2 & -0.2 & -0.2 & -0.2 & -0.2 & -0.2 \\
\hline
\end{tabular}

Table A.4.2 shows that $45^{\circ}$ WAls would result in slightly higher air change rates than the more detailed $10^{\circ}$ WAls but only by $5 \%$. Table A.4.3 shows that this equates to $9 \%$ less HVAC energy consumption. $9 \%$ could be considered a significant inaccuracy, but when put in context of the overall building energy consumption (includes lighting and equipment loads) that difference deflates to be within $1 \%$ between each model (refer Table A.4.4).

\begin{tabular}{|l|l|l|}
\hline \multicolumn{3}{|c|}{ Air Change Rates Results (ACH's averaged across all levels) } \\
\hline $10^{\circ}$ Wind Angle Increments (ACH) & $45^{\circ}$ Wind Angle Increments (ACH) & Difference (\%) \\
\hline 3.77 & 3.97 & $+5 \%$ \\
\hline
\end{tabular}

Table A.4.2. Air Change Rates for $10^{\circ}$ and $45^{\circ}$ Wind Angle Increments (WAIs).

\begin{tabular}{|c|c|c|c|}
\hline \multicolumn{4}{|c|}{ Energy Consumption Results (kWh) } \\
\hline Energy End-Use & $10^{\circ}$ WAl's (kWh) & $45^{\circ}$ WAl's (kWh) & Difference (\%) \\
\hline Heating & 5,429 & 4,758 & $-12 \%$ \\
\hline Cooling & 14,225 & 13,442 & $-6 \%$ \\
\hline Fans & 4,701 & 3,945 & $-16 \%$ \\
\hline Total HVAC & 24,355 & 22,146 & $-9 \%$ \\
\hline
\end{tabular}

Table A.4.3. Heating Ventilation and Air Conditioning (HVAC) energy consumption for $10^{\circ}$ and $45^{\circ}$ WAIs. 


\begin{tabular}{|l|l|l|}
\hline \multicolumn{3}{|c|}{ All End-uses Energy Consumption Results } \\
\hline $10^{\circ}$ Wind Angle Increments (kWh) & $45^{\circ}$ Wind Angle Increments (kWh) & Difference (\%) \\
\hline 125,917 & 126,744 & $+<1 \%$ \\
\hline
\end{tabular}

Table A.4.4. Total building energy consumption for $10^{\circ}$ and $45^{\circ}$ WAls.

\section{Findings}

- Neither air change rates (5\%) nor overall energy consumption $(<1 \%)$ were significantly affected by the less frequent Wind Angle Increments.

- This, in addition to the need to minimize CFD computation time, warrants the use of the lower detail $45^{\circ}$ wind angle increments in testing. 


\section{A.5. Robustness Test 5 - Surrounding Buildings Effect on Natural Ventilation}

\section{Purpose}

To quantify the effect surrounding buildings have on $\mathrm{Cp}$ values and the resulting natural ventilation performance.

\section{Method}

- Using the Tokyo Polytechnic University Aerodynamics Database (TPU database), build an 'Isolated Model' and a 'Non-Isolated Model' (identical model with surrounding urban forms).

- Apply Cp data for each scenario to two separate EnergyPlus models and generate air change rate and energy consumption data.

- Compare results to determine how much effect urban form has on natural ventilation predictions.

\section{Isolated Model and Cp Values}

The unrealistic Isolated Model (no surrounding urban form) selected from the TPU Database was $16 \mathrm{~m}$ wide, $24 \mathrm{~m}$ long and $18 \mathrm{~m}$ high - similar width and height dimensions to the tested Christchurch Models (refer Figure A.5.1).

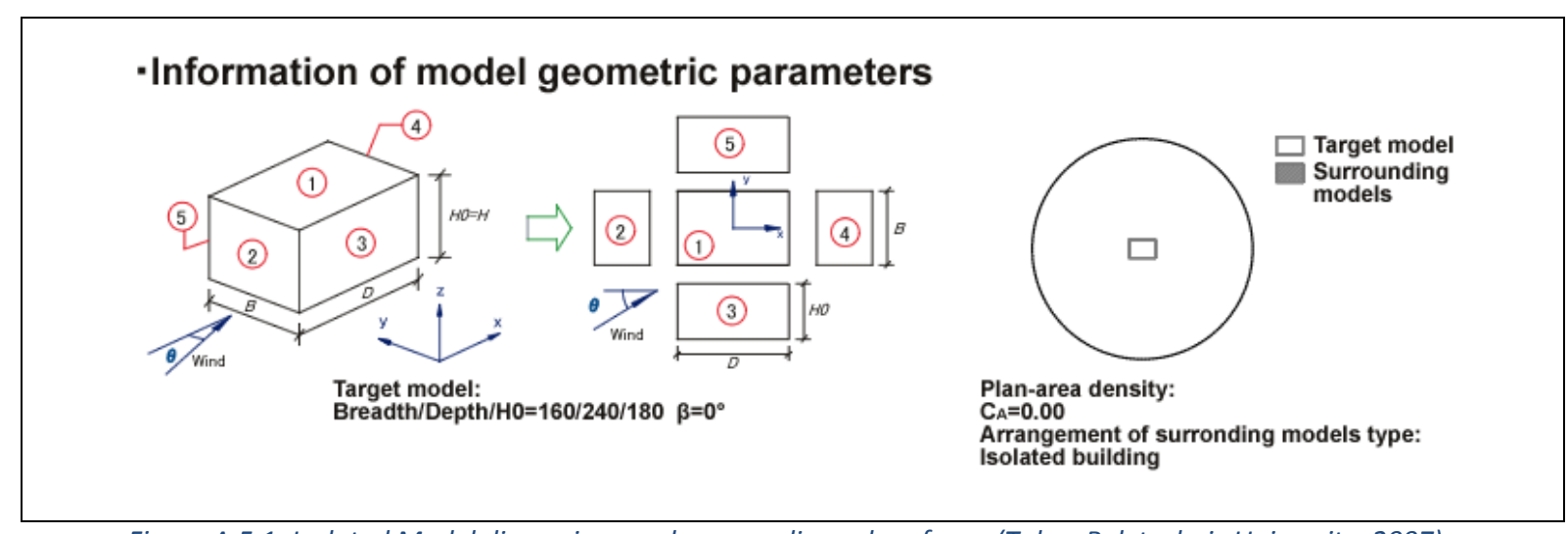

Figure A.5.1. Isolated Model dimensions and surrounding urban form. (Tokyo Polytechnic University, 2007).

Figure A.5.2 shows the $\mathrm{Cp}$ data for the western (surface 3, left) and eastern (surface 5, right) facades specified for natural cross ventilation in this study (refer Section 4.3.2).
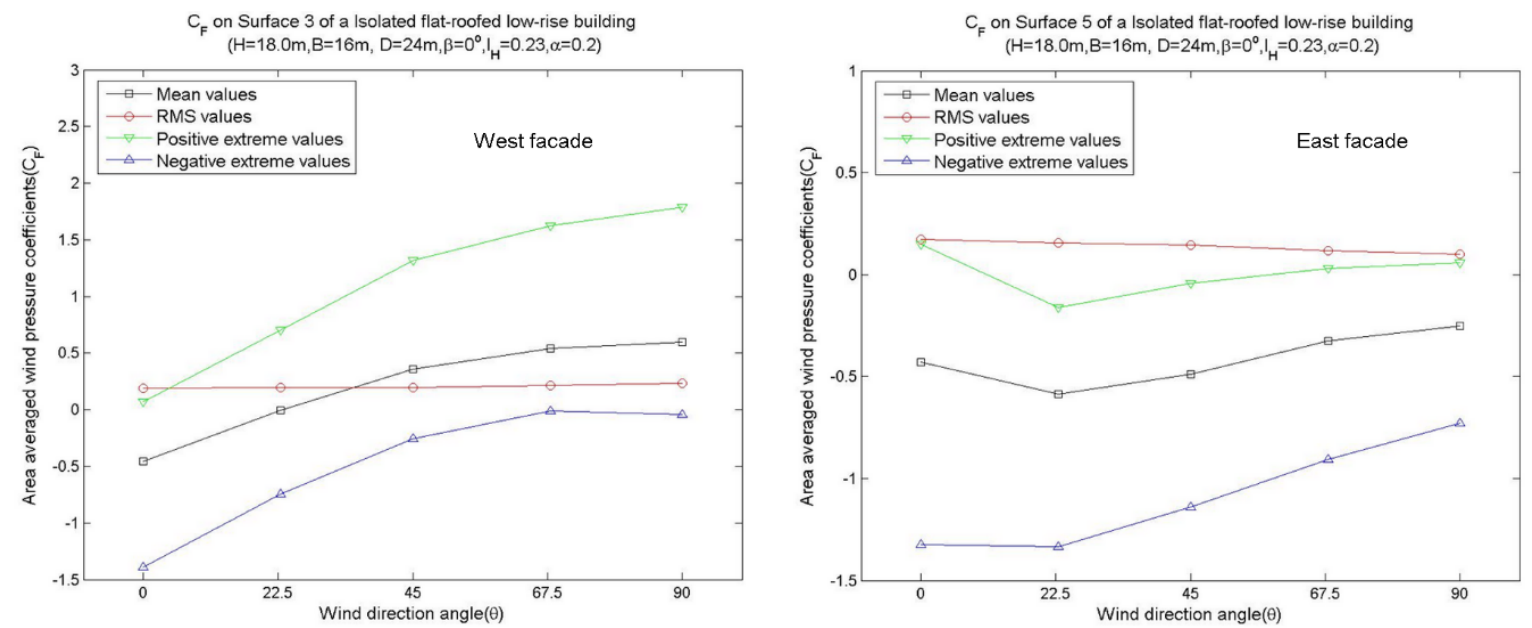

Figure A.5.2. Cp 'Mean values' (black line) generated by TPU Database for east and west facades of an 'Isolated' building. (Tokyo Polytechnic University, 2007). 
The data presented in Figure A.5.2 above is summarised into Table A.5.1 below and plugged into the EnergyPlus model.

\begin{tabular}{|l|l|l|l|l|l|}
\hline \multicolumn{7}{|c|}{ Isolated Model Cp Values } \\
\hline Surface & Cp at $0^{\circ}$ & Cp at 22.5 & Cp at $45^{\circ}$ & Cp at 67.5 & Cp at $90^{\circ}$ \\
\hline Surface 3 (West) & -0.5 & -0.1 & 0.4 & 0.5 & 0.6 \\
\hline Surface 5 (East) & -0.5 & -0.6 & -0.5 & -0.3 & -0.3 \\
\hline
\end{tabular}

Table A.5.1. Summary of Cp values for east and west facades of the Isolated Model for each wind direction.

\section{Non-Isolated Model and Cp Values}

Using the same isolated model from the Tokyo Database, a surrounding urban form was applied according to the TPU process seen in Figure A5.3. Figure A5.4 presents the Non-Isolated Model. This inclusion of surrounding buildings make the 'Non-Isolated Model' more realistic than the isolated model, and therefore represents the baseline.

Density $=\mathrm{C}_{\mathrm{A}}=$ (building area) / (area of site) $=(\mathrm{bd}) /(\mathrm{BD})$
$\begin{aligned} & \text { Where: } \\ & \mathrm{b}=\text { bredth of building } \\ & \mathrm{d}=\text { depth of building } \\ & \mathrm{B} \text { and } \mathrm{D}=\text { distance between adjacent points on buildings }\end{aligned}$
$\begin{aligned} & \text { Assumptions: } \\ & \mathrm{b}=15 \mathrm{~m} \text { based on early indications that CCB properties in } \\ & \text { Christchurch are } 20 \mathrm{~m} \text {; and that } 5 \mathrm{~m} \text { of that } 20 \mathrm{~m} \text { will become void, or } \\ & \text { the gap between buildings. } \\ & \mathrm{d}=50 \mathrm{~m} \text { or half a block deep. } \\ & \mathrm{B} \text { and } \mathrm{D}=\text { assumed to be } \mathrm{b} \text { and } \mathrm{d} \text {, respectively, plus the aforemen- } \\ & \text { tioned } 5 \mathrm{~m} \text { gap. }\end{aligned}$
$\begin{aligned} & \text { Therefore: } \\ & \mathrm{C}_{\mathrm{A}}=(\mathrm{bd}) /(\mathrm{BD})=(15 \times 50) /(20 \times 55)=0.68\end{aligned}$
Urban density setting selected $=0.6$

Figure A.5.3. Urban density calculations and graphic. (Tokyo Polytechnic University, 2007).

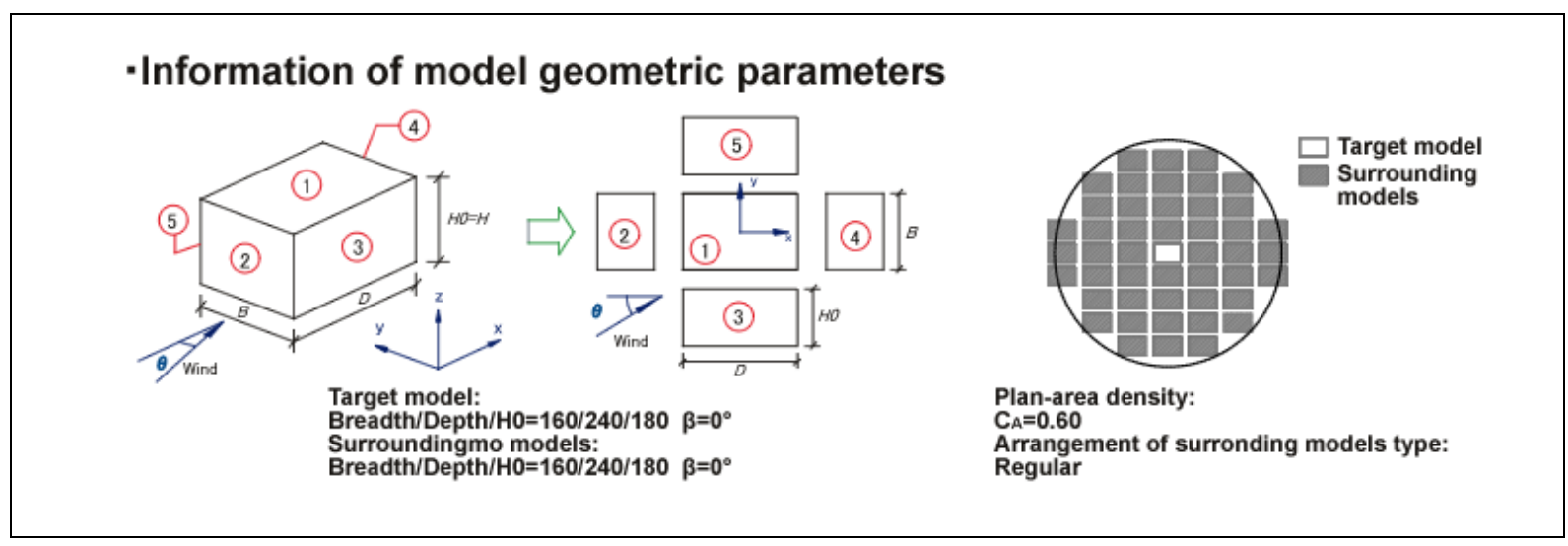

Figure A.5.4. Non-Isolated Model dimensions and surrounding urban form. (Tokyo Polytechnic University, 2007). 
Figure A.5.5 presents the $\mathrm{Cp}$ values generated for East and West facades of the Non-isolated model.

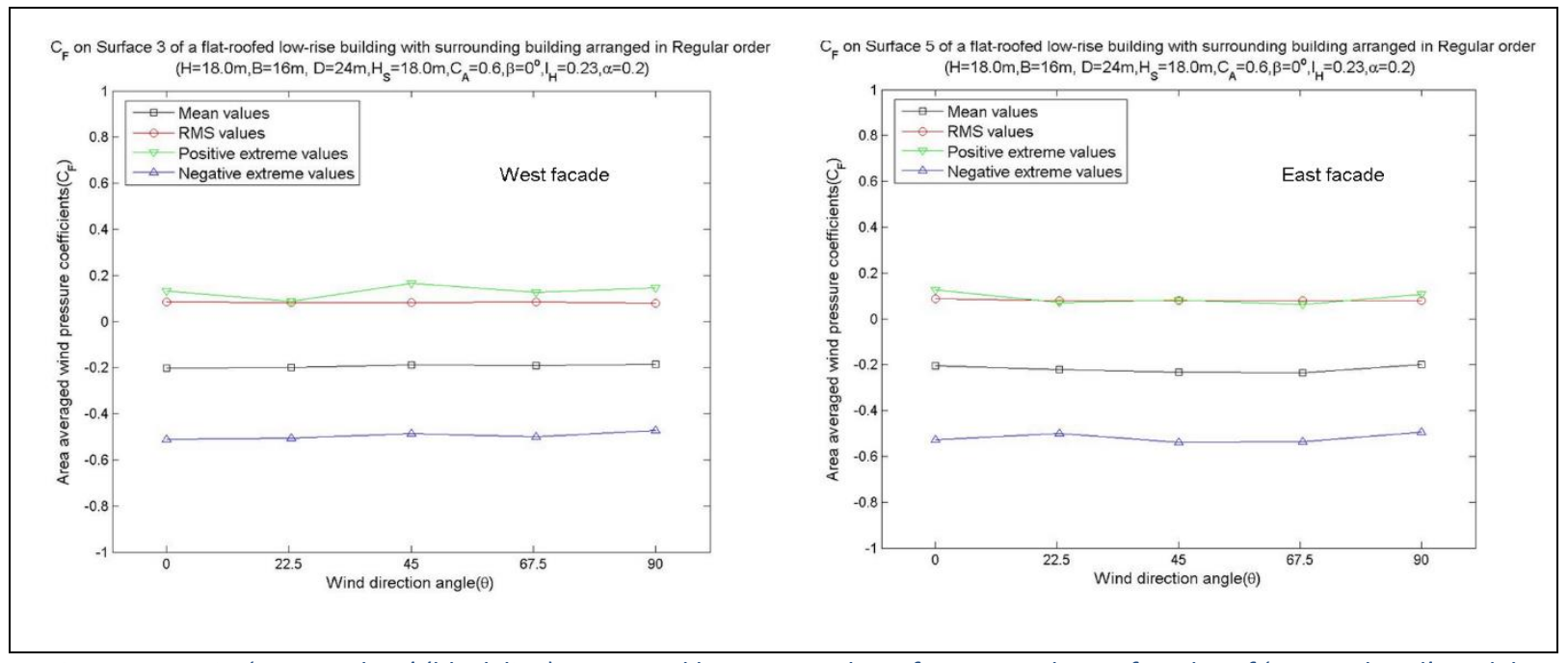

Figure A.5.5. Cp 'Mean values' (black line) generated by TPU Database for east and west facades of 'Non-Isolated' model. (Tokyo Polytechnic University, 2007).

The data presented in Figure A.5.5 above is summarised into Table A.5.2 below and plugged into the EnergyPlus model.

\begin{tabular}{|l|l|l|l|l|l|}
\hline \multicolumn{7}{|c|}{ Non-Isolated Model Cp Values } \\
\hline Surface & $\mathrm{Cp}$ at $\mathbf{0}^{\circ}$ & $\mathrm{Cp}$ at 22.5 & $\mathrm{Cp}$ at $45^{\circ}$ & $\mathrm{Cp}$ at $67.5^{\circ}$ & $\mathrm{Cp}$ at $90^{\circ}$ \\
\hline Surface 3 (West) & -0.2 & -0.2 & -0.2 & -0.2 & -0.2 \\
\hline Surface 5 (East) & -0.2 & -0.2 & -0.2 & -0.2 & -0.2 \\
\hline
\end{tabular}

Table A.5.2. Summary of Cp values for east and west facades of the Non-Isolated Model for each wind direction.

\section{$\underline{\text { Results }}$}

The $\mathrm{Cp}$ values presented in Tables A.5.1 and A.5.2 were entered into two corresponding EnergyPlus models (refer Figure A.5.6) and simulated to produce air change rate (Table A.5.3) and HVAC energy consumption data (Table 5.4).

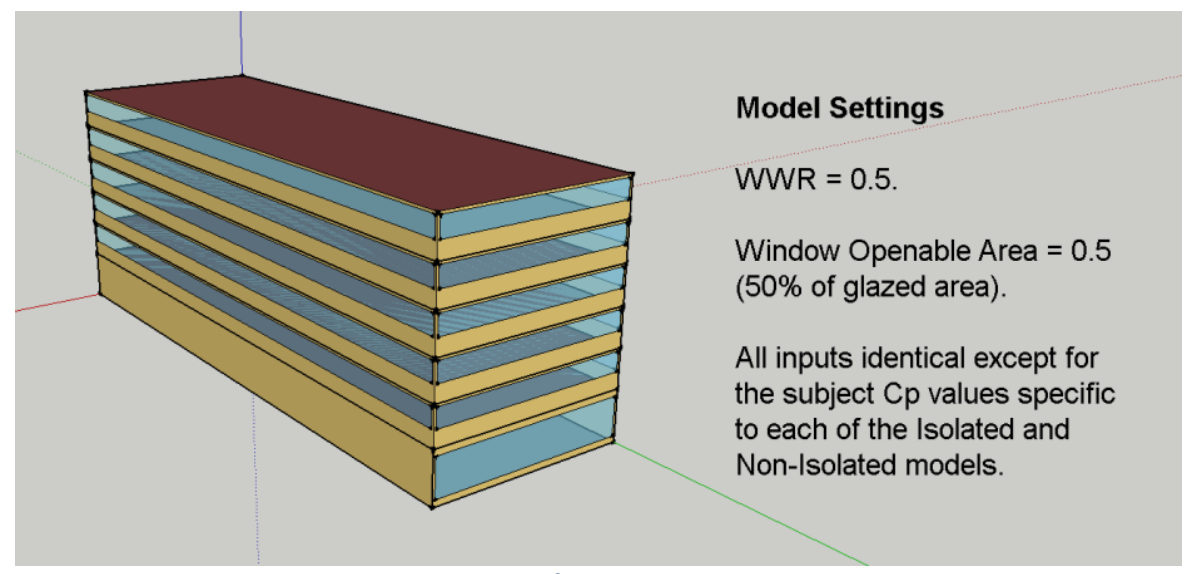

Figure A.5.6. EnergyPlus model used for both isolated and Non-Isolated scenarios. 


\begin{tabular}{|l|l|l|}
\hline Non-Isolated Model (ACH) & Isolated Model (ACH) & Difference (\%) \\
\hline 3.48 & 6.53 & $+54 \%$ \\
\hline
\end{tabular}

Table A.5.3. Air Change Rates for both isolated and Non-isolated models

\begin{tabular}{|l|l|l|l|}
\hline \multicolumn{4}{|c|}{ Energy Consumption Results } \\
\hline Energy End-Use & Non-Isolated Model (kWh) & Isolated Model (kWh) & Difference (\%) \\
\hline Heating & 437 & 2,624 & $+600 \%$ \\
\hline Cooling & 15,820 & 15,409 & $-3 \%$ \\
\hline Fans & 17,407 & 7,795 & $-55 \%$ \\
\hline TOTAL & 33,664 & 25,828 & $-23 \%$ \\
\hline
\end{tabular}

Table A.5.4. Heating Ventilation and Air Conditioning (HVAC) energy consumption for Isolated and Non-Isolated Models.

\section{Findings}

- Cp values of the 'Non-Isolated Model' are of lower amplitude and variability than the 'Isolated Model', reflecting the interrupted wind-flow caused by the surrounding buildings.

- Air change rates are grossly overestimated in the 'Isolated Model', 54\% higher than the 'Non-Isolated Model' baseline.

- Higher ACH's result in a $23 \%$ underestimation of total HVAC energy consumption in the unrealistic 'Isolated Model'.

The omission of surrounding buildings in the calculation of wind pressure data and natural ventilation effectiveness has a significant impact on reliability of results, generating energy differences of up to $23 \%$ when compared to the more realistic 'Non-Isolated Model'. Robustness Test 5 has demonstrated the importance of including urban form in simulations in this study. 


\section{A.6. Robustness Test 6 - Validation of UrbaWind}

\section{Purpose}

To determine whether the Cp values generated by UrbaWind are accurate and reliable.

\section{Method}

- $\quad$ Build an UrbaWind model identical to the Tokyo Polytechnic University (TPU) 'Non-Isolated Model' used in Robustness Test 6.

- $\quad$ Generate Cp values through both tools - TPU Model (baseline) and UrbaWind.

- Compare absolute Cp values and effect on air change rates and HVAC energy consumption in corresponding EnergyPlus models.

\section{Background}

This test was devised because existing validation of UrbaWind wind pressure (Cp) data is not conclusive.

The TPU Database provides $\mathrm{Cp}$ data for a range of building size and urban form scenarios. This data is produced through wind-tunnel tests and so is accurate (Tokyo Polytechnic University, 2007) and can be used as a reliable baseline for comparisons to be made against.

\section{Tokyo Polytechnic University (TPU) Aerodynamics Database Model (TPU Model)} Same TPU 'Non-Isolated Model' used in Robustness Test 5 - 16m wide, 24m long, 12m high; urban density 0.6 (refer Figure A.6.1).

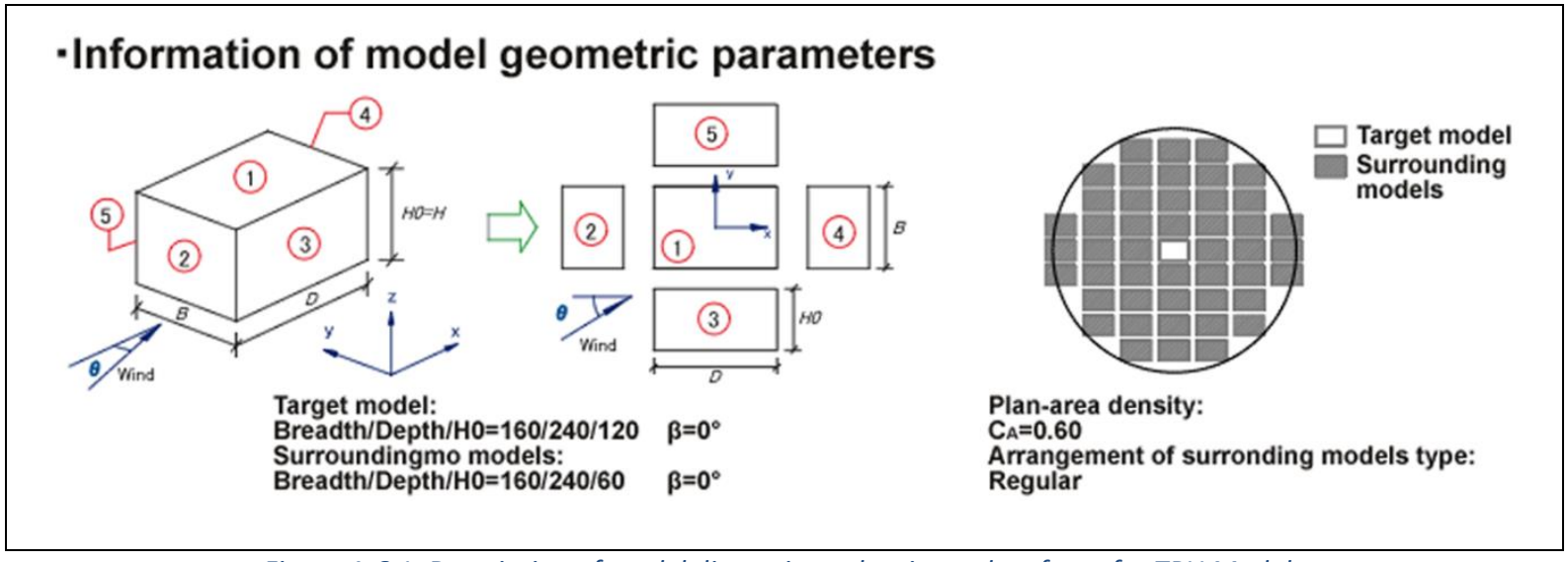

Figure A.6.1. Description of model dimensions, density and surfaces for TPU Model.

(Tokyo Polytechnic University, 2007).

Figure A.6.2 presents the 'Mean' Cp values (black lines) on each building surface (roof and four sides) for wind angles $0,22.5,45,67.5$ and $90^{\circ}$ (only wind angles available on database) associated with the selected model. 

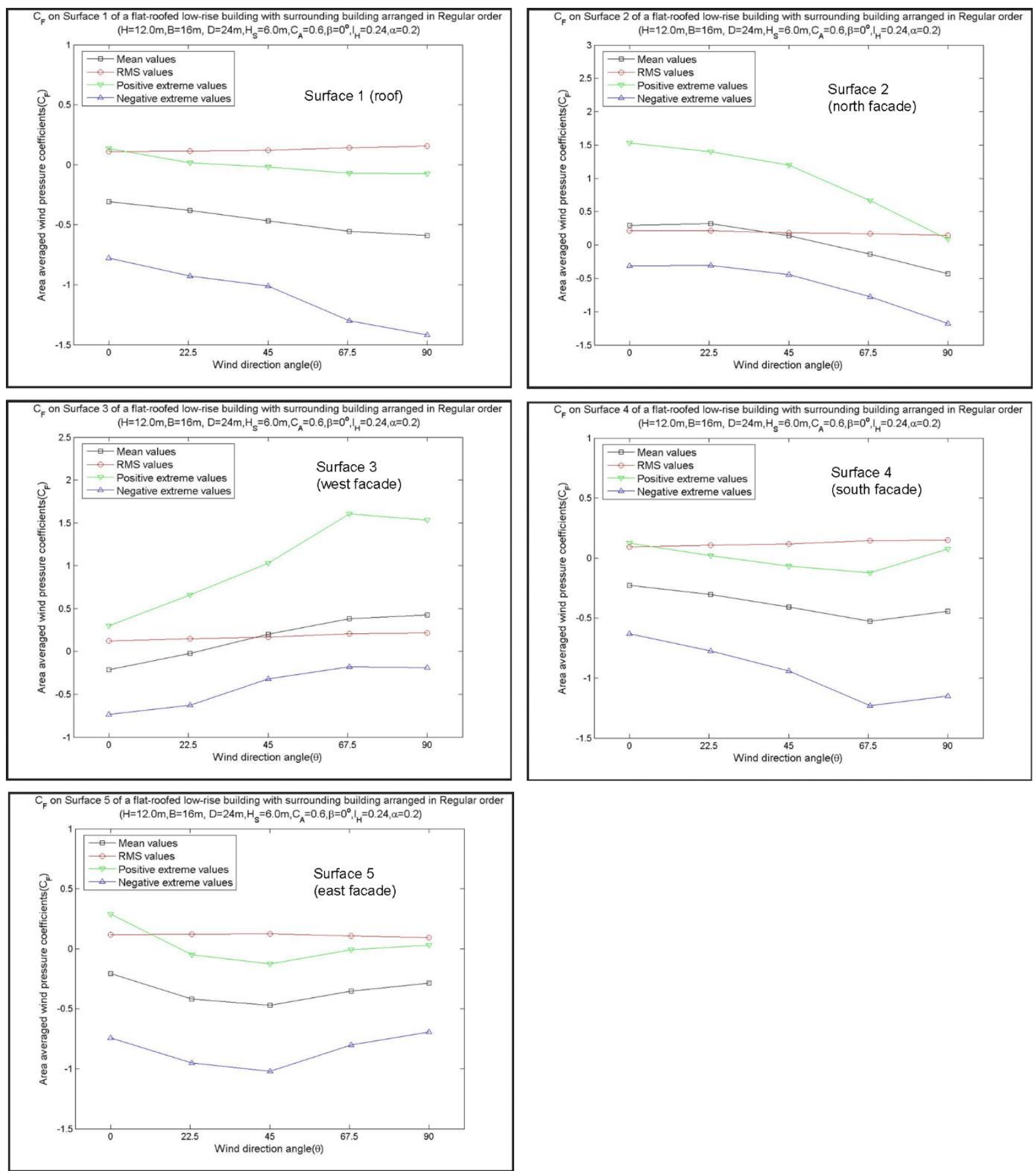

Figure A.6.2. Wind Pressure Coefficient (Cp) data for each surface at each wind angle (Focus: Mean Cp's - black line). (Tokyo Polytechnic University, 2007).

\section{UrbaWind Model}

The UrbaWind (software explained in Section 4.3.2.5) model created was identical to the TPU Model to ensure analogous results (refer Figure A.6.3). Figure A.6.3 also presents the computational domain and the Wind Pressure Coefficient scale applied. 


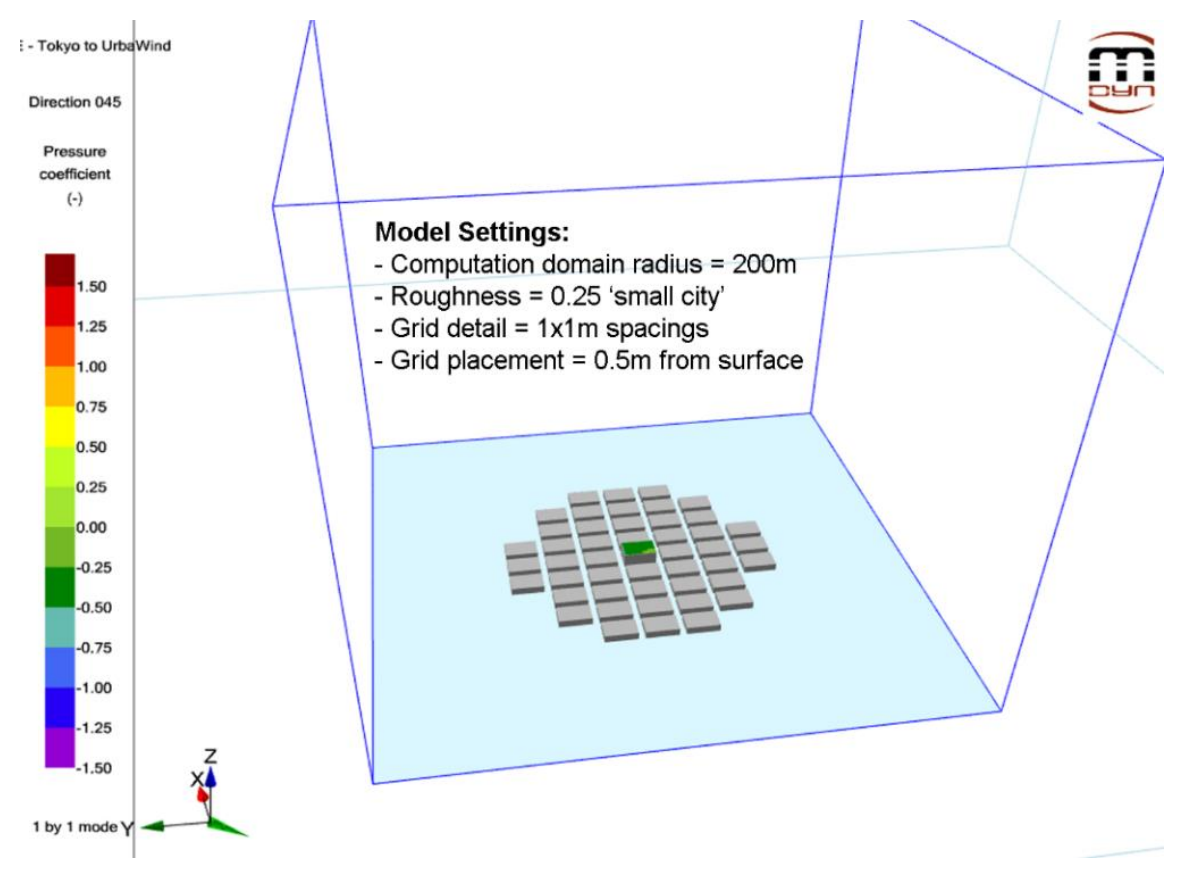

Figure A.6.3. Screenshot of the UrbaWind model, domain and Cp scale. (Author).

Figure A.6.4 presents colour renders of the $C p$ values generated by UrbaWind calculations on each building surface (roof and four sides) for wind angles $0,22.5,45,67.5$ and $90^{\circ}$.

\begin{tabular}{|c|c|c|c|c|c|c|}
\hline Wind Angle & $0^{\circ}$ & $22.5^{\circ}$ & $45^{\circ}$ & $67.5^{\circ}$ & $90^{\circ}$ & Cp Key \\
\hline $\begin{array}{l}\text { Surface } 1 \\
\text { (roof) }\end{array}$ & (missing) & -0.3 & & -0.5 & & $\begin{array}{l}1.50 \\
1.25\end{array}$ \\
\hline $\begin{array}{l}\text { Surface } 2 \\
\text { (north facade) }\end{array}$ & (missing) & 0.3 & 0 & -0.2 & & 0.50 \\
\hline $\begin{array}{l}\text { Surface } 3 \\
\text { (west facade) }\end{array}$ & (missing) & -0.2 & 0.1 & 0.3 & 0.4 & 0.00 \\
\hline $\begin{array}{l}\text { Surface } 4 \\
\text { (south facade) }\end{array}$ & (missing) & -0.5 & & & & -0.75 \\
\hline $\begin{array}{l}\text { Surface } 5 \\
\text { (east facade) }\end{array}$ & (missing) & -0.5 & & & & -1.50 \\
\hline
\end{tabular}

Figure A.6.4. Cp data represented as colour renders on each surface at each wind angle. (Author). 


\section{Results}

The data identified in Figures A.6.2 and A.6.4 are represented in Figure A.6.5 which compares the two sets of $\mathrm{Cp}$ data for each wind angle on each building surface.
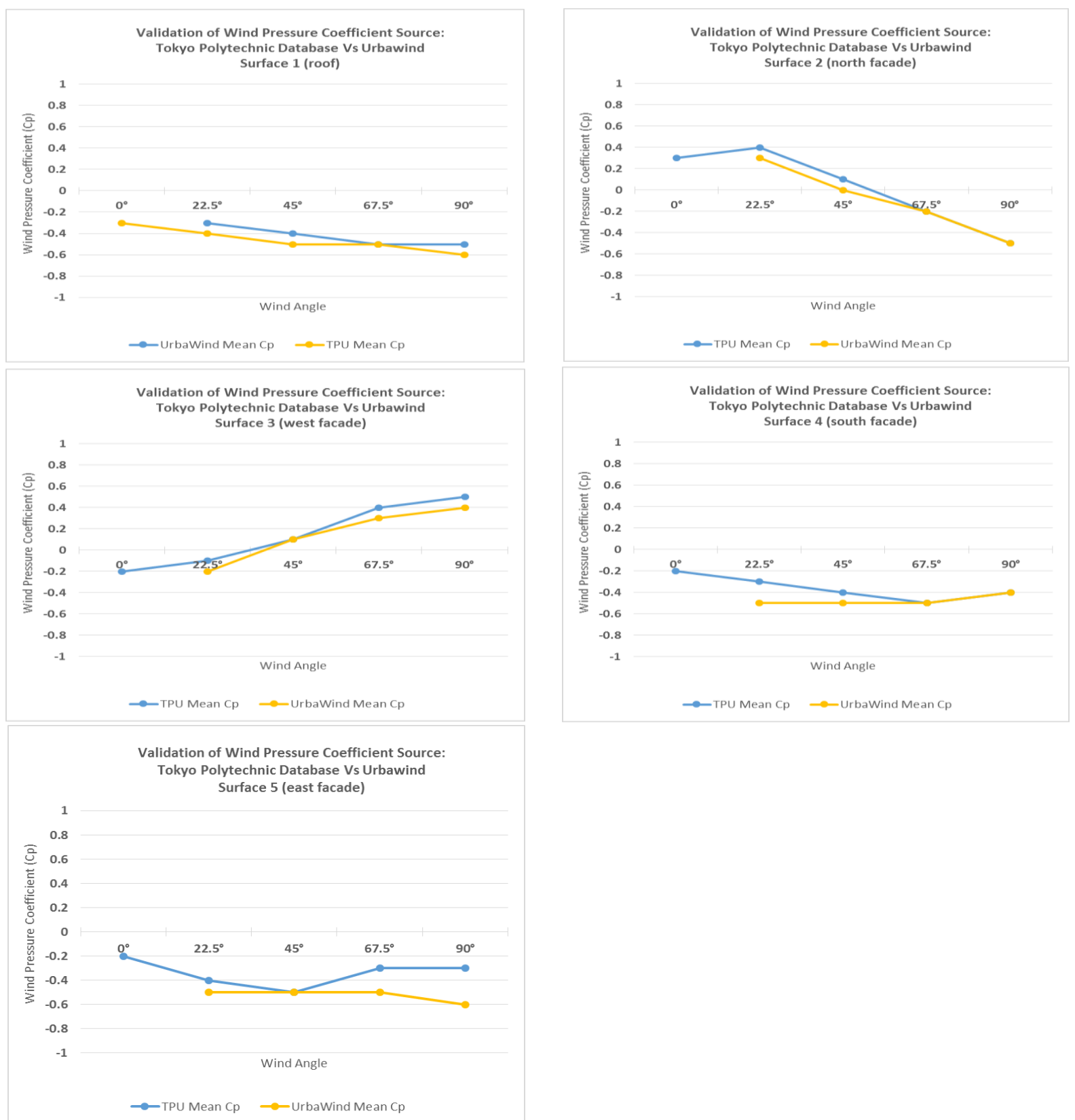

Figure A.6.5. (All 5 graphs- one for each surface). Comparison of accuracy between TPU and UrbaWind Cp values. (Author).

Absolute $\mathrm{Cp}$ values presented in Figure A.6.5 indicates $\mathrm{Cp}$ data generated by UrbaWind is similar to TPU generated values for surfaces 1,2 and 3 but deviate more for surfaces 4 and 5 . UrbaWind seems to consistently produce greater magnitude negative values than the wind-tunnel based data.

Analysis would benefit from the $0^{\circ}$ wind angle $\mathrm{Cp}$ values which would complete the trend lines, clarifying the patterns of the UrbaWind data but was omitted due to (my) user error in setting up the models.

In terms of resulting natural ventilation performance, Table A.6.1 shows that an EnergyPlus model using the UrbaWind $\mathrm{Cp}$ values produces air change rates within $2 \%$ that of a TPU based model. 
Resulting HVAC energy consumption is within $1 \%$ confirming UrbaWind is a reliable wind pressure and $\mathrm{Cp}$ data source for this study.

\begin{tabular}{|l|l|l|}
\hline \multicolumn{3}{|c|}{ Air Change Rates Results (ACH's averaged across all levels) } \\
\hline TPU Model ACH) & UrbaWind Model (ACH) & Difference (\%) \\
\hline 5.52 & 5.64 & $2 \%$ \\
\hline
\end{tabular}

Table A.6.1. Air change rates and difference between TPU and UrbaWind models.

\begin{tabular}{|l|l|l|l|}
\hline \multicolumn{5}{|c|}{ Energy Consumption Results } \\
\hline Energy End-Use & TPU Model (kWh) & UrbaWind Model (kWh) & Difference (\%) \\
\hline Heating & 4057 & 4035 & $<1 \%$ \\
\hline Cooling & 21996 & 21807 & $<1 \%$ \\
\hline Fans & 3981 & 3959 & $<1 \%$ \\
\hline Total HVAC & 30035 & 29802 & $<1 \%$ \\
\hline
\end{tabular}

Table A.6.2. Energy Consumption by Energy End-use (HVAC systems only) for both TPU and UrbaWind models.

\section{Findings}

Despite some UrbaWind generated $\mathrm{Cp}$ values not matching the Tokyo Polytechnic University wind tunnel calculated values, the infinitesimal differences in resulting air change rates and HVAC energy indicates UrbaWind is accurate enough to produce reliable wind pressure data for this study. 


\section{Appendix B: Calculations and Other Material}

\section{Appendix B.1 - Plot Ratio Calculations (individual property density analysis)}

\begin{tabular}{|c|c|c|c|c|c|c|c|c|c|}
\hline Scenario & $\begin{array}{l}\text { Building } \\
\text { Width }(\mathrm{m})\end{array}$ & \begin{tabular}{|l|} 
Building \\
Length $(\mathrm{m})$
\end{tabular} & $\begin{array}{l}\text { Number } \\
\text { of Levels }\end{array}$ & $\begin{array}{l}\text { Total Floor Area } \\
\text { per Property }\left(\mathrm{m}^{2}\right)\end{array}$ & $\begin{array}{l}\text { Gap between } \\
\text { Buildings }(m)\end{array}$ & $\begin{array}{l}\text { Required Property } \\
\text { Width }(\mathrm{m})\end{array}$ & \begin{tabular}{|l} 
Property \\
Length $(\mathrm{m})$
\end{tabular} & $\begin{array}{l}\text { Total Property } \\
\text { Land Area }\left(\mathrm{m}^{2}\right)\end{array}$ & Plot Ratio \\
\hline \multirow{6}{*}{$\begin{array}{c}\text { Christchurch } \\
\text { Model } 0\end{array}$} & 10 & 50 & 4 & 2000 & 0 & 10 & 50 & 500 & 4.0 \\
\hline & 12 & 50 & 4 & 2400 & 0 & 12 & 50 & 600 & 4.0 \\
\hline & 14 & 50 & 4 & 2800 & 0 & 14 & 50 & 700 & 4.0 \\
\hline & 16 & 50 & 4 & 3200 & 0 & 16 & 50 & 800 & 4.0 \\
\hline & 18 & 50 & 4 & 3600 & 0 & 18 & 50 & 900 & 4.0 \\
\hline & 20 & 50 & 4 & 4000 & 0 & 20 & 50 & 1000 & 4.0 \\
\hline \multirow{5}{*}{$\begin{array}{c}\text { Christchurch } \\
\text { Model } 1\end{array}$} & 10 & 50 & 4 & 2000 & 2 & 12 & 50 & 600 & 3.3 \\
\hline & 12 & 50 & 4 & 2400 & 2 & 14 & 50 & 700 & 3.4 \\
\hline & 14 & 50 & 4 & 2800 & 2 & 16 & 50 & 800 & 3.5 \\
\hline & 16 & 50 & 4 & 3200 & 2 & 18 & 50 & 900 & 3.6 \\
\hline & 18 & 50 & 4 & 3600 & 2 & 20 & 50 & 1000 & 3.6 \\
\hline \multirow{5}{*}{$\begin{array}{c}\text { Christchurch } \\
\text { Model } 2\end{array}$} & 10 & 50 & 4 & 2000 & 6 & 16 & 50 & 800 & 2.5 \\
\hline & 12 & 50 & 4 & 2400 & 6 & 18 & 50 & 900 & 2.7 \\
\hline & 14 & 50 & 4 & 2800 & 6 & 20 & 50 & 1000 & 2.8 \\
\hline & 16 & 50 & 4 & 3200 & 6 & 22 & 50 & 1100 & 2.9 \\
\hline & 18 & 50 & 4 & 3600 & 6 & 24 & 50 & 1200 & 3.0 \\
\hline \multirow{5}{*}{$\begin{array}{c}\text { Christchurch } \\
\text { Model } 3\end{array}$} & 10 & 50 & 4 & 2000 & 10 & 20 & 50 & 1000 & 2.0 \\
\hline & 12 & 50 & 4 & 2400 & 10 & 22 & 50 & 1100 & 2.2 \\
\hline & 14 & 50 & 4 & 2800 & 10 & 24 & 50 & 1200 & 2.3 \\
\hline & 16 & 50 & 4 & 3200 & 10 & 26 & 50 & 1300 & 2.5 \\
\hline & 18 & 50 & 4 & 3600 & 10 & 28 & 50 & 1400 & 2.6 \\
\hline \multirow{5}{*}{$\begin{array}{l}\text { Christchurch } \\
\text { Model } 4\end{array}$} & 10 & 50 & 6 & 3000 & 2 & 12 & 50 & 600 & 5.0 \\
\hline & 12 & 50 & 6 & 3600 & 2 & 14 & 50 & 700 & 5.1 \\
\hline & 14 & 50 & 6 & 4200 & 2 & 16 & 50 & 800 & 5.3 \\
\hline & 16 & 50 & 6 & 4800 & 2 & 18 & 50 & 900 & 5.3 \\
\hline & 18 & 50 & 6 & 5400 & 2 & 20 & 50 & 1000 & 5.4 \\
\hline \multirow{5}{*}{$\begin{array}{l}\text { Christchurch } \\
\text { Model } 5\end{array}$} & 10 & 50 & 6 & 3000 & 6 & 16 & 50 & 800 & 3.8 \\
\hline & 12 & 50 & 6 & 3600 & 6 & 18 & 50 & 900 & 4.0 \\
\hline & 14 & 50 & 6 & 4200 & 6 & 20 & 50 & 1000 & 4.2 \\
\hline & 16 & 50 & 6 & 4800 & 6 & 22 & 50 & 1100 & 4.4 \\
\hline & 18 & 50 & 6 & 5400 & 6 & 24 & 50 & 1200 & 4.5 \\
\hline \multirow{5}{*}{$\begin{array}{l}\text { Christchurch } \\
\text { Model } 6\end{array}$} & 10 & 50 & 6 & 3000 & 10 & 20 & 50 & 1000 & 3.0 \\
\hline & 12 & 50 & 6 & 3600 & 10 & 22 & 50 & 1100 & 3.3 \\
\hline & 14 & 50 & 6 & 4200 & 10 & 24 & 50 & 1200 & 3.5 \\
\hline & 16 & 50 & 6 & 4800 & 10 & 26 & 50 & 1300 & 3.7 \\
\hline & 18 & 50 & 6 & 5400 & 10 & 28 & 50 & 1400 & 3.9 \\
\hline \multirow{5}{*}{$\begin{array}{c}\text { Christchurch } \\
\text { Model } 7\end{array}$} & 10 & 50 & 8 & 4000 & 2 & 12 & 50 & 600 & 6.7 \\
\hline & 12 & 50 & 8 & 4800 & 2 & 14 & 50 & 700 & 6.9 \\
\hline & 14 & 50 & 8 & 5600 & 2 & 16 & 50 & 800 & 7.0 \\
\hline & 16 & 50 & 8 & 6400 & 2 & 18 & 50 & 900 & 7.1 \\
\hline & 18 & 50 & 8 & 7200 & 2 & 20 & 50 & 1000 & 7.2 \\
\hline \multirow{5}{*}{$\begin{array}{c}\text { Christchurch } \\
\text { Model } 8\end{array}$} & 10 & 50 & 8 & 4000 & 6 & 16 & 50 & 800 & 5.0 \\
\hline & 12 & 50 & 8 & 4800 & 6 & 18 & 50 & 900 & 5.3 \\
\hline & 14 & 50 & 8 & 5600 & 6 & 20 & 50 & 1000 & 5.6 \\
\hline & 16 & 50 & 8 & 6400 & 6 & 22 & 50 & 1100 & 5.8 \\
\hline & 18 & 50 & 8 & 7200 & 6 & 24 & 50 & 1200 & 6.0 \\
\hline \multirow{5}{*}{$\begin{array}{c}\text { Christchurch } \\
\text { Model } 9\end{array}$} & 10 & 50 & 8 & 4000 & 10 & 20 & 50 & 1000 & 4.0 \\
\hline & 12 & 50 & 8 & 4800 & 10 & 22 & 50 & 1100 & 4.4 \\
\hline & 14 & 50 & 8 & 5600 & 10 & 24 & 50 & 1200 & 4.7 \\
\hline & 16 & 50 & 8 & 6400 & 10 & 26 & 50 & 1300 & 4.9 \\
\hline & 18 & 50 & 8 & 7200 & 10 & 28 & 50 & 1400 & 5.1 \\
\hline $\begin{array}{l}\text { Christchurch } \\
\text { Model } 10 \\
\end{array}$ & 10 & 50 & 4 & 2000 & 10 & 20 & 50 & 1000 & 2.0 \\
\hline $\begin{array}{l}\text { Christchurch } \\
\text { Model } 11 \\
\end{array}$ & 14 & 50 & 6 & 4200 & 6 & 20 & 50 & 1000 & 4.2 \\
\hline $\begin{array}{l}\text { Christchurch } \\
\text { Model } 12 \\
\end{array}$ & 18 & 50 & 8 & 7200 & 2 & 20 & 50 & 1000 & 7.2 \\
\hline \multirow{5}{*}{$\begin{array}{l}\text { Christchurch } \\
\text { Model } 13\end{array}$} & 10 & 50 & 4 & 2000 & NA & NA & NA & NA & NA \\
\hline & 12 & 50 & 4 & 2400 & NA & NA & NA & NA & NA \\
\hline & 14 & 50 & 4 & 2800 & NA & NA & NA & NA & NA \\
\hline & 16 & 50 & 4 & 3200 & NA & NA & NA & NA & NA \\
\hline & 18 & 50 & 4 & 3600 & NA & NA & NA & NA & NA \\
\hline
\end{tabular}

Table B.1. Plot ratio calculations 


\section{Appendix B.2 - Hectares and CCB Blocks Calculations (CCB density analysis)}

\begin{tabular}{|c|c|c|c|c|c|c|c|c|c|c|}
\hline Scenario & $\begin{array}{l}\text { Building } \\
\text { Width }(\mathrm{m})\end{array}$ & \begin{tabular}{|l} 
Total Floor \\
Area per \\
Property (m2) \\
\end{tabular} & \begin{tabular}{|l|}
$\begin{array}{l}\text { Projected Floor } \\
\text { Area Demand } \\
\left(\mathrm{m}^{2}\right)\end{array}$ \\
\end{tabular} & \begin{tabular}{|l} 
Properties Needed \\
to Achieve \\
Projected Demand
\end{tabular} & \begin{tabular}{|l|} 
Land Area \\
per \\
Property \\
\end{tabular} & $\begin{array}{l}\text { Land Area Needed } \\
\text { for those Properties } \\
\text { Including Street }(\mathrm{m} 2)\end{array}$ & $\begin{array}{l}\text { Hectare } \\
\left(\mathrm{m}^{2}\right)\end{array}$ & \begin{tabular}{|l|} 
Hectares \\
Required at this \\
density (ha)
\end{tabular} & $\begin{array}{l}\text { CCB Block } \\
\text { Size (m2) }\end{array}$ & \begin{tabular}{|l|}
$\begin{array}{l}\text { Translated } \\
\text { to CCB } \\
\text { Blocks }\end{array}$ \\
\end{tabular} \\
\hline \multirow{6}{*}{$\begin{array}{l}\text { Christchurch } \\
\text { Model } 0\end{array}$} & 10 & 2,000 & 266,000 & 133 & 600 & 79,800 & 10,000 & 8.0 & 20,000 & 4.0 \\
\hline & 12 & 2,400 & 266,000 & 111 & 720 & 79,800 & 10,000 & 8.0 & 20,000 & 4.0 \\
\hline & 14 & 2,800 & 266,000 & 95 & 840 & 79,800 & 10,000 & 8.0 & 20,000 & 4.0 \\
\hline & 16 & 3,200 & 266,000 & 83 & 960 & 79,800 & 10,000 & 8.0 & 20,000 & 4.0 \\
\hline & 18 & 3,600 & 266,000 & 74 & 1080 & 79,800 & 10,000 & 8.0 & 20,000 & 4.0 \\
\hline & 20 & 4,000 & 266,000 & 67 & 1200 & 79,800 & 10,000 & 8.0 & 20,000 & 4.0 \\
\hline \multirow{5}{*}{$\begin{array}{l}\text { Christchurch } \\
\text { Model } 1\end{array}$} & 10 & 2,000 & 266,000 & 133 & 720 & 95,760 & 10,000 & 9.6 & 20,000 & 4.8 \\
\hline & 12 & 2,400 & 266,000 & 111 & 840 & 93,100 & 10,000 & 9.3 & 20,000 & 4.7 \\
\hline & 14 & 2,800 & 266,000 & 95 & 960 & 91,200 & 10,000 & 9.1 & 20,000 & 4.6 \\
\hline & 16 & 3,200 & 266,000 & 83 & 1080 & 89,775 & 10,000 & 9.0 & 20,000 & 4.5 \\
\hline & 18 & 3,600 & 266,000 & 74 & 1200 & 88,667 & 10,000 & 8.9 & 20,000 & 4.4 \\
\hline \multirow{5}{*}{$\begin{array}{c}\text { Christchurch } \\
\text { Model } 2\end{array}$} & 10 & 2,000 & 266,000 & 133 & 960 & 127,680 & 10,000 & 12.8 & 20,000 & 6.4 \\
\hline & 12 & 2,400 & 266,000 & 111 & 1080 & 119,700 & 10,000 & 12.0 & 20,000 & 6.0 \\
\hline & 14 & 2,800 & 266,000 & 95 & 1200 & 114,000 & 10,000 & 11.4 & 20,000 & 5.7 \\
\hline & 16 & 3,200 & 266,000 & 83 & 1320 & 109,725 & 10,000 & 11.0 & 20,000 & 5.5 \\
\hline & 18 & 3,600 & 266,000 & 74 & 1440 & 106,400 & 10,000 & 10.6 & 20,000 & 5.3 \\
\hline \multirow{5}{*}{$\begin{array}{c}\text { Christchurch } \\
\text { Model } 3\end{array}$} & 10 & 2,000 & 266,000 & 133 & 1200 & 159,600 & 10,000 & 16.0 & 20,000 & 8.0 \\
\hline & 12 & 2,400 & 266,000 & 111 & 1320 & 146,300 & 10,000 & 14.6 & 20,000 & 7.3 \\
\hline & 14 & 2,800 & 266,000 & 95 & 1440 & 136,800 & 10,000 & 13.7 & 20,000 & 6.8 \\
\hline & 16 & 3,200 & 266,000 & 83 & 1560 & 129,675 & 10,000 & 13.0 & 20,000 & 6.5 \\
\hline & 18 & 3,600 & 266,000 & 74 & 1680 & 124,133 & 10,000 & 12.4 & 20,000 & 6.2 \\
\hline \multirow{5}{*}{$\begin{array}{l}\text { Christchurch } \\
\text { Model } 4\end{array}$} & 10 & 3,000 & 266,000 & 89 & 720 & 63,840 & 10,000 & 6.4 & 20,000 & 3.2 \\
\hline & 12 & 3,600 & 266,000 & 74 & 840 & 62,067 & 10,000 & 6.2 & 20,000 & 3.1 \\
\hline & 14 & 4,200 & 266,000 & 63 & 960 & 60,800 & 10,000 & 6.1 & 20,000 & 3.0 \\
\hline & 16 & 4,800 & 266,000 & 55 & 1080 & 59,850 & 10,000 & 6.0 & 20,000 & 3.0 \\
\hline & 18 & 5,400 & 266,000 & 49 & 1200 & 59,111 & 10,000 & 5.9 & 20,000 & 3.0 \\
\hline \multirow{5}{*}{$\begin{array}{l}\text { Christchurch } \\
\text { Model } 5\end{array}$} & 10 & 3,000 & 266,000 & 89 & 960 & 85,120 & 10,000 & 8.5 & 20,000 & 4.3 \\
\hline & 12 & 3,600 & 266,000 & 74 & 1080 & 79,800 & 10,000 & 8.0 & 20,000 & 4.0 \\
\hline & 14 & 4,200 & 266,000 & 63 & 1200 & 76,000 & 10,000 & 7.6 & 20,000 & 3.8 \\
\hline & 16 & 4,800 & 266,000 & 55 & 1320 & 73,150 & 10,000 & 7.3 & 20,000 & 3.7 \\
\hline & 18 & 5,400 & 266,000 & 49 & 1440 & 70,933 & 10,000 & 7.1 & 20,000 & 3.5 \\
\hline \multirow{5}{*}{$\begin{array}{l}\text { Christchurch } \\
\text { Model } 6\end{array}$} & 10 & 3,000 & 266,000 & 89 & 1200 & 106,400 & 10,000 & 10.6 & 20,000 & 5.3 \\
\hline & 12 & 3,600 & 266,000 & 74 & 1320 & 97,533 & 10,000 & 9.8 & 20,000 & 4.9 \\
\hline & 14 & 4,200 & 266,000 & 63 & 1440 & 91,200 & 10,000 & 9.1 & 20,000 & 4.6 \\
\hline & 16 & 4,800 & 266,000 & 55 & 1560 & 86,450 & 10,000 & 8.6 & 20,000 & 4.3 \\
\hline & 18 & 5,400 & 266,000 & 49 & 1680 & 82,756 & 10,000 & 8.3 & 20,000 & 4.1 \\
\hline \multirow{5}{*}{$\begin{array}{c}\text { Christchurch } \\
\text { Model } 7\end{array}$} & 10 & 4,000 & 266,000 & 67 & 720 & 47,880 & 10,000 & 4.8 & 20,000 & 2.4 \\
\hline & 12 & 4,800 & 266,000 & 55 & 840 & 46,550 & 10,000 & 4.7 & 20,000 & 2.3 \\
\hline & 14 & 5,600 & 266,000 & 48 & 960 & 45,600 & 10,000 & 4.6 & 20,000 & 2.3 \\
\hline & 16 & 6,400 & 266,000 & 42 & 1080 & 44,888 & 10,000 & 4.5 & 20,000 & 2.2 \\
\hline & 18 & 7,200 & 266,000 & 37 & 1200 & 44,333 & 10,000 & 4.4 & 20,000 & 2.2 \\
\hline \multirow{5}{*}{$\begin{array}{c}\text { Christchurch } \\
\text { Model } 8\end{array}$} & 10 & 4,000 & 266,000 & 67 & 960 & 63,840 & 10,000 & 6.4 & 20,000 & 3.2 \\
\hline & 12 & 4,800 & 266,000 & 55 & 1080 & 59,850 & 10,000 & 6.0 & 20,000 & 3.0 \\
\hline & 14 & 5,600 & 266,000 & 48 & 1200 & 57,000 & 10,000 & 5.7 & 20,000 & 2.9 \\
\hline & 16 & 6,400 & 266,000 & 42 & 1320 & 54,863 & 10,000 & 5.5 & 20,000 & 2.7 \\
\hline & 18 & 7,200 & 266,000 & 37 & 1440 & 53,200 & 10,000 & 5.3 & 20,000 & 2.7 \\
\hline \multirow{5}{*}{$\begin{array}{c}\text { Christchurch } \\
\text { Model } 9\end{array}$} & 10 & 4,000 & 266,000 & 67 & 1200 & 79,800 & 10,000 & 8.0 & 20,000 & 4.0 \\
\hline & 12 & 4,800 & 266,000 & 55 & 1320 & 73,150 & 10,000 & 7.3 & 20,000 & 3.7 \\
\hline & 14 & 5,600 & 266,000 & 48 & 1440 & 68,400 & 10,000 & 6.8 & 20,000 & 3.4 \\
\hline & 16 & 6,400 & 266,000 & 42 & 1560 & 64,838 & 10,000 & 6.5 & 20,000 & 3.2 \\
\hline & 18 & 7,200 & 266,000 & 37 & 1680 & 62,067 & 10,000 & 6.2 & 20,000 & 3.1 \\
\hline Model 10 & 10 & 2,000 & 266,000 & 133 & 1300 & 172,900 & 10,000 & 17.3 & 20,000 & 8.6 \\
\hline Model 11 & 14 & 4,200 & 266,000 & 63 & 1300.0 & 82,333 & 10,000 & 8.2 & 20,000 & 4.1 \\
\hline Model 12 & 18 & 7,200 & 266,000 & 37 & 1300.0 & 48,028 & 10,000 & 4.8 & 20,000 & 2.4 \\
\hline \multirow{5}{*}{$\begin{array}{c}\text { Christchurch } \\
\text { Model } 13\end{array}$} & 10 & 2,000 & NA & NA & NA & NA & 10,000 & NA & NA & NA \\
\hline & 12 & 2,400 & NA & NA & NA & NA & 10,000 & NA & NA & NA \\
\hline & 14 & 2,800 & NA & NA & NA & NA & 10,000 & NA & NA & NA \\
\hline & 16 & 3,200 & NA & NA & NA & NA & 10,000 & NA & NA & NA \\
\hline & 18 & 3,600 & NA & NA & NA & NA & 10,000 & NA & NA & NA \\
\hline
\end{tabular}




\section{Appendix B.3 - Minimum Air Change Rate Calculations}

\begin{tabular}{|c|c|c|c|c|c|c|c|c|c|c|c|c|c|}
\hline $\begin{array}{l}\text { Space } \\
\text { Width }(\mathrm{m})\end{array}$ & \begin{tabular}{|l|} 
Space \\
Length $(\mathrm{m})$
\end{tabular} & \begin{tabular}{|l|} 
Space \\
Area $\left(\mathrm{m}^{2}\right)$
\end{tabular} & \begin{tabular}{|l|} 
Space \\
Height $(\mathrm{m})$ \\
\end{tabular} & $\begin{array}{l}\text { Space } \\
\text { Volume }\left(\mathrm{m}^{3}\right)\end{array}$ & $\begin{array}{l}\text { Minimum Air Flow } \\
\text { (L/s/person) }\end{array}$ & \begin{tabular}{|l|} 
Space per \\
Person $\left(\mathrm{m}^{2}\right)$
\end{tabular} & \begin{tabular}{|l|} 
Total \\
People
\end{tabular} & \begin{tabular}{|l|} 
Minimum Air \\
Flow (L/second)
\end{tabular} & $\begin{array}{l}\text { Seconds in } \\
\text { an Hour }\end{array}$ & $\begin{array}{l}\text { Minimum Air } \\
\text { Flow (L/hour) }\end{array}$ & $\begin{array}{l}\text { Litres } \\
\text { in } \mathrm{m}^{3} \\
\end{array}$ & $\begin{array}{l}\text { Convert } \\
\text { to } \mathrm{m}^{3} \\
\end{array}$ & \begin{tabular}{|l|} 
Air Changes per \\
Hour (ACH)
\end{tabular} \\
\hline 10 & 50 & 500 & 3 & 1,500 & \begin{tabular}{r|}
10 \\
\end{tabular} & 10 & 50 & 500 & 3,600 & $1,800,000$ & 1,000 & 1,800 & $\begin{array}{r}0.83 \\
\end{array}$ \\
\hline 12 & 50 & 600 & 3 & 1,800 & 10 & 10 & 60 & 600 & 3,600 & $2,160,000$ & 1,000 & 2,160 & 0.83 \\
\hline 14 & 50 & 700 & 3 & 2,100 & 10 & 10 & 70 & 700 & 3,600 & $2,520,000$ & 1,000 & 2,520 & 0.83 \\
\hline 16 & 50 & 800 & 3 & 2,400 & 10 & 10 & 80 & 800 & 3,600 & $2,880,000$ & 1,000 & 2,880 & 0.83 \\
\hline 18 & 50 & 900 & 3 & 2,700 & 10 & 10 & 90 & 900 & 3,600 & $3,240,000$ & 1,000 & 3,240 & 0.83 \\
\hline
\end{tabular}

Table B.3.Air change rate calculations

- $\quad$ Minimum Air Flow rate of 10 Litres/second/person obtained from (Anon., 1990).

- Space per Person was assumed to be $10 \mathrm{~m}^{2}$ based on maximum density for office space. Maximum density was used as it represents the worst case scenario - requiring more demanding air change rates to be achieved. This created a more challenging ventilation criteria. 


\section{Appendix B.4 - Window Openable Area Calculations}

\begin{tabular}{|c|c|c|c|c|c|c|c|c|c|c|}
\hline \multicolumn{11}{|c|}{ For WWR of $50 \%$, each building width } \\
\hline $\begin{array}{l}\text { Space } \\
\text { Width }(\mathrm{m})\end{array}$ & \begin{tabular}{|l|} 
Space \\
Length $(\mathrm{m})$
\end{tabular} & $\begin{array}{l}\text { Space } \\
\text { Area }\left(\mathrm{m}^{2}\right)\end{array}$ & $\begin{array}{l}\text { x\% (of Floor } \\
\text { Area ) }\end{array}$ & $\begin{array}{l}\text { Floor Area } \\
\left(\mathrm{m}^{2}\right)\end{array}$ & $\begin{array}{l}\text { Across Two } \\
\text { Sides }\left(\mathrm{m}^{2}\right)\end{array}$ & $\begin{array}{l}\text { Window } \\
\text { Height }(\mathrm{m})\end{array}$ & $\begin{array}{l}\text { Window } \\
\text { Length }(\mathrm{m})\end{array}$ & $\begin{array}{l}\text { Glazed Area } \\
\text { per Side }\left(\mathrm{m}^{2}\right)\end{array}$ & $\begin{array}{l}\text { Openable Area } \\
\text { of Window (\%) }\end{array}$ & $\begin{array}{l}\text { Openable Area } \\
\text { of Window }\left(\mathrm{m}^{2}\right)\end{array}$ \\
\hline 10 & 50 & 500 & $5 \%$ & 25 & 12.5 & 1.5 & 50 & 75 & 17 & 12.5 \\
\hline 12 & 50 & 600 & $5 \%$ & 30 & 15 & 1.5 & 50 & 75 & 20 & 15 \\
\hline 14 & 50 & 700 & $5 \%$ & 35 & 17.5 & 1.5 & 50 & 75 & 23 & 17.5 \\
\hline 16 & 50 & 800 & $5 \%$ & 40 & 20 & 1.5 & 50 & 75 & 27 & 20 \\
\hline 18 & 50 & 900 & $5 \%$ & 45 & 22.5 & 1.5 & 50 & 75 & 30 & 22.5 \\
\hline
\end{tabular}

Table B.4.Window openable area calculations - urban form scenarios

\begin{tabular}{|c|c|c|c|c|c|c|c|c|c|c|}
\hline \multicolumn{11}{|c|}{ For WWR of $50 \%, 0$, code, double code, tripple code $\%$ of floor space } \\
\hline $\begin{array}{l}\text { Space } \\
\text { Width }(\mathrm{m})\end{array}$ & $\begin{array}{l}\text { Space } \\
\text { Length }(\mathrm{m})\end{array}$ & $\begin{array}{l}\text { Space } \\
\text { Area }\left(\mathrm{m}^{2}\right)\end{array}$ & $\begin{array}{l}\text { x\% (of Floor } \\
\text { Area ) }\end{array}$ & $\begin{array}{l}\text { Floor Area } \\
\left(\mathrm{m}^{2}\right)\end{array}$ & $\begin{array}{l}\text { Across Two } \\
\text { Sides }\left(\mathrm{m}^{2}\right)\end{array}$ & \begin{tabular}{|l|} 
Window \\
Height $(\mathrm{m})$
\end{tabular} & \begin{tabular}{|l|} 
Window \\
Length $(\mathrm{m})$
\end{tabular} & $\begin{array}{l}\text { Glazed Area } \\
\text { per Side }\left(\mathrm{m}^{2}\right)\end{array}$ & $\begin{array}{l}\text { Openable Area } \\
\text { of Window (\%) }\end{array}$ & $\begin{array}{l}\text { Openable Area } \\
\text { of Window }\left(\mathrm{m}^{2}\right)\end{array}$ \\
\hline 12 & 50 & 600 & $0 \%$ & 0 & 0 & 1.5 & 50 & 75 & \#DIV/0! & \#DIV/0! \\
\hline 12 & 50 & 600 & $5 \%$ & 30 & 15 & 1.5 & 50 & 75 & 20 & 15 \\
\hline 12 & 50 & 600 & $10 \%$ & 60 & 30 & 1.5 & 50 & 75 & 40 & 30 \\
\hline 12 & 50 & 600 & $15 \%$ & 90 & 45 & 1.5 & 50 & 75 & 60 & 45 \\
\hline 12 & 50 & 600 & $20 \%$ & 120 & 60 & 1.5 & 50 & 75 & 80 & 60 \\
\hline
\end{tabular}

Table B.5.Window openable area calculations - thermal and ventilation design scenarios, WWR50\%

\begin{tabular}{|c|c|c|c|c|c|c|c|c|c|c|}
\hline \multicolumn{11}{|c|}{ For WWR of $75 \%, 0$, code, double code, tripple code $\%$ of floor space } \\
\hline \begin{tabular}{|l|} 
Space \\
Width $(\mathrm{m})$
\end{tabular} & \begin{tabular}{|l|} 
Space \\
Length $(\mathrm{m})$
\end{tabular} & $\begin{array}{l}\text { Space } \\
\text { Area }\left(\mathrm{m}^{2}\right)\end{array}$ & \begin{tabular}{|l}
$x \%$ (of Floor \\
Area )
\end{tabular} & $\begin{array}{l}\text { Floor Area } \\
\left(\mathrm{m}^{2}\right)\end{array}$ & $\begin{array}{l}\text { Across Two } \\
\text { Sides }\left(\mathrm{m}^{2}\right)\end{array}$ & \begin{tabular}{|l} 
Window \\
Height $(\mathrm{m})$
\end{tabular} & \begin{tabular}{|l|} 
Window \\
Length $(\mathrm{m})$
\end{tabular} & $\begin{array}{l}\text { Glazed Area } \\
\text { per Side }\left(\mathrm{m}^{2}\right)\end{array}$ & $\begin{array}{l}\text { Openable Area } \\
\text { of Window (\%) }\end{array}$ & $\begin{array}{l}\text { Openable Area } \\
\text { of Window }\left(\mathrm{m}^{2}\right)\end{array}$ \\
\hline 12 & 50 & 600 & $0 \%$ & 0 & 0 & 2.25 & 50 & 112.5 & \#DIV/0! & \#DIV/0! \\
\hline 12 & 50 & 600 & $5 \%$ & 30 & 15 & 2.25 & 50 & 112.5 & 13 & 15 \\
\hline 12 & 50 & 600 & $10 \%$ & 60 & 30 & 2.25 & 50 & 112.5 & 27 & 30 \\
\hline 12 & 50 & 600 & $15 \%$ & 90 & 45 & 2.25 & 50 & 112.5 & 40 & 45 \\
\hline 12 & 50 & 600 & $20 \%$ & 120 & 60 & 2.25 & 50 & 112.5 & 53 & 60 \\
\hline
\end{tabular}

Table B.6. Window openable area calculations - thermal and ventilation design scenarios, WWR75\%

Minimum Openable Window Area of 5\% of the space's floor area obtained from Section 1.2.2 of 'Clause G4 - Ventilation' of the New Zealand Building Code (Department of Building and Housing, 2011). 


\section{Appendix B.5 - EnergyPlus Constructions}

\begin{tabular}{|c|c|c|c|c|c|c|c|c|c|c|c|c|c|}
\hline Field & Obji & $0 \mathrm{bi2}$ & $0 \mathrm{~b} \mathrm{j}^{3}$ & $0 \mathrm{bi} ; 4$ & $0 \mathrm{~b} ; 5$ & $0 \mathrm{~b} ; \overline{6}$ & $0 \mathrm{bi7}$ & $0 \mathrm{~b} ; 8$ & $06 i^{9}$ & 0bilo & obil1 & obil2 & $0 \mathrm{~b} ; 13$ \\
\hline Name & Groundfloor & 1.0 & 2.0 & 3.0 & 11.0 & 12.0 & 13.0 & 21.0 & 22.0 & 23.0 & 31.0 & 320 & 33.0 \\
\hline Outside Layer & Soil & Stone/Motar & Timberiweatherboards & Stone/Mottar & MetaProfile & MetaProfile & MetaProfile & CarpetPad & CarpetPad & CarpetPad & Plasterboard12mm & Plasterboard $12 \mathrm{~mm}$ & Plasterboard12mm \\
\hline Layer 2 gaver & Membrane & 1.2 & 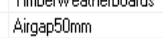 & ReinforcedConcrete2000mm & $\begin{array}{l}\text { Metariroule } \\
\text { Membrane }\end{array}$ & $\begin{array}{l}\text { Medirinouie } \\
\text { Membrane }\end{array}$ & $\begin{array}{l}\text { Mitarlenie } \\
\text { Membrane }\end{array}$ & ReinforcedConcrete $200 \mathrm{~mm}$ & Sheathing $12 \mathrm{~mm}$ & ReinforcedConcrete2000mm & ReinforcedConncetere200mm & TimberFrame900mm & ReinforcedConcrete $200 \mathrm{~mm}$ \\
\hline Layer 3 & ReinforcedConcrete200mm & ReinforcedConcrete $200 \mathrm{~mm}$ & Membrane & 1.2 & Sheathing $12 \mathrm{~mm}$ & Sheasthing $12 \mathrm{~mm}$ & Sheathingir $12 \mathrm{~mm}$ & Plasterboard12mm & Timberf Fames0 $00 \mathrm{~mm}$ & Plastebboard12mm & CarpetPad & Sheathing12mm & CarpelPad \\
\hline Layer 4 & CarpetPad & Plasterboard12 $2 \mathrm{~mm}$ & TimberFiame90mm & Plasterboard12 $2 \mathrm{~mm}$ & Airgap50mmm & Airgap $50 \mathrm{~mm}$ & Airgap50mm & & Plasterboard12 $2 \mathrm{~mm}$ & & & CarpetPad & \\
\hline Layer 5 & & & 1.2 & & Membrane & Membrane & Membrane & & & & & & \\
\hline Layer 6 & & & Plasterboard12mm & & 1.9 & Timberframe90mm & ReinforcedConcrete200mm & & & & & & \\
\hline Layer 7 & & & & & ReinforcedConcrete200mm & & & & & & & & \\
\hline Layer 8 & & & & & Plasterboard12mm & Plasterboard12mm & Plasterboard 12mm & & & & & & \\
\hline Layer 9 & & & & & & & & & & & & & \\
\hline Layer 10 & & & & & & & & & & & & & \\
\hline
\end{tabular}

Table B.7.EnergyPlus Constructions

\begin{tabular}{|l|l|l|}
\hline \multicolumn{3}{|c|}{ Construction Names and Types } \\
\hline 1.0 & Wall & Concrete with insulation inside \\
\hline 2.0 & Wall & Timber with insulation in framing cavity \\
\hline 3.0 & Wall & Concrete with insulation outside \\
\hline 11.0 & Roof & Concrete with insulation inside \\
\hline 12.0 & Roof & Timber with insulation in framing cavity \\
\hline 13.0 & Roof & Concrete with insulation outside \\
\hline 21.0 & Inter-Ceiling & Concrete \\
\hline 22.0 & Inter-Ceiling & Timber \\
\hline 23.0 & Inter-Ceiling & Concrete \\
\hline 31.0 & Inter-Floor & Concrete \\
\hline 32.0 & Inter-Floor & Timber \\
\hline 33.0 & Inter-Floor & Concrete \\
\hline Numbered (integers) Constructions required for GenOpt process. \\
\hline
\end{tabular}

Table B.8 Construction names. 


\section{Appendix B.6 - Christchurch City Plan Road Sizes}

Obtained from: Christchurch City Plan Online: Volume 3: Part 8 Special Purpose Zones: Appendix 2 'Roading hierarchy standards'.

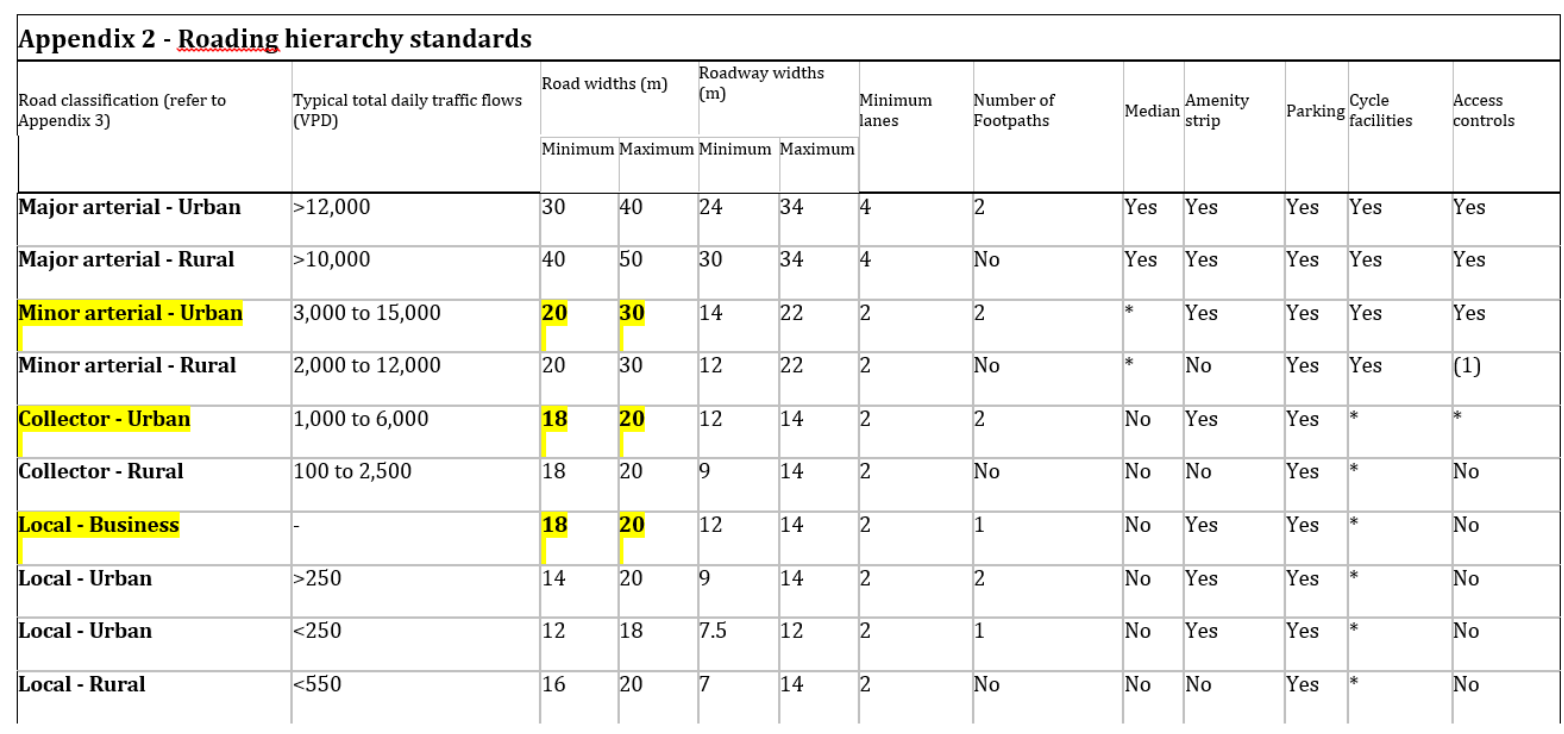

Table B.9.Christchurch street types. 


\section{Appendix B.7-EnergyPlus Occupancy Schedule}

Screen shot of a Model idf (EnergyPlus) file displaying the Occupancy Schedule settings.

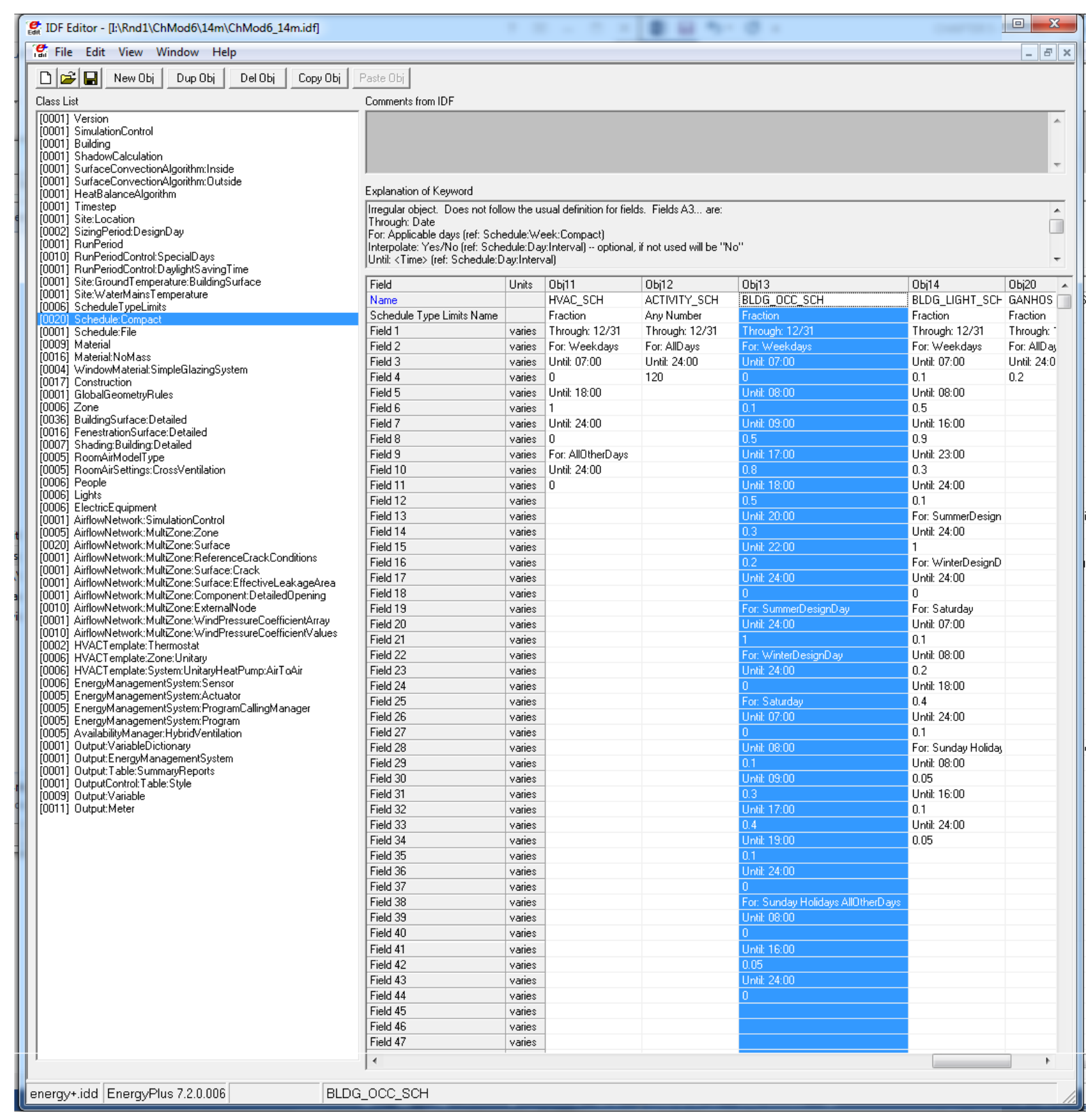

Figure B.1.EnergyPlus occupancy schedule 


\section{Appendix B.8 - Central City Business zone (CCB) Area and Block Calculation}

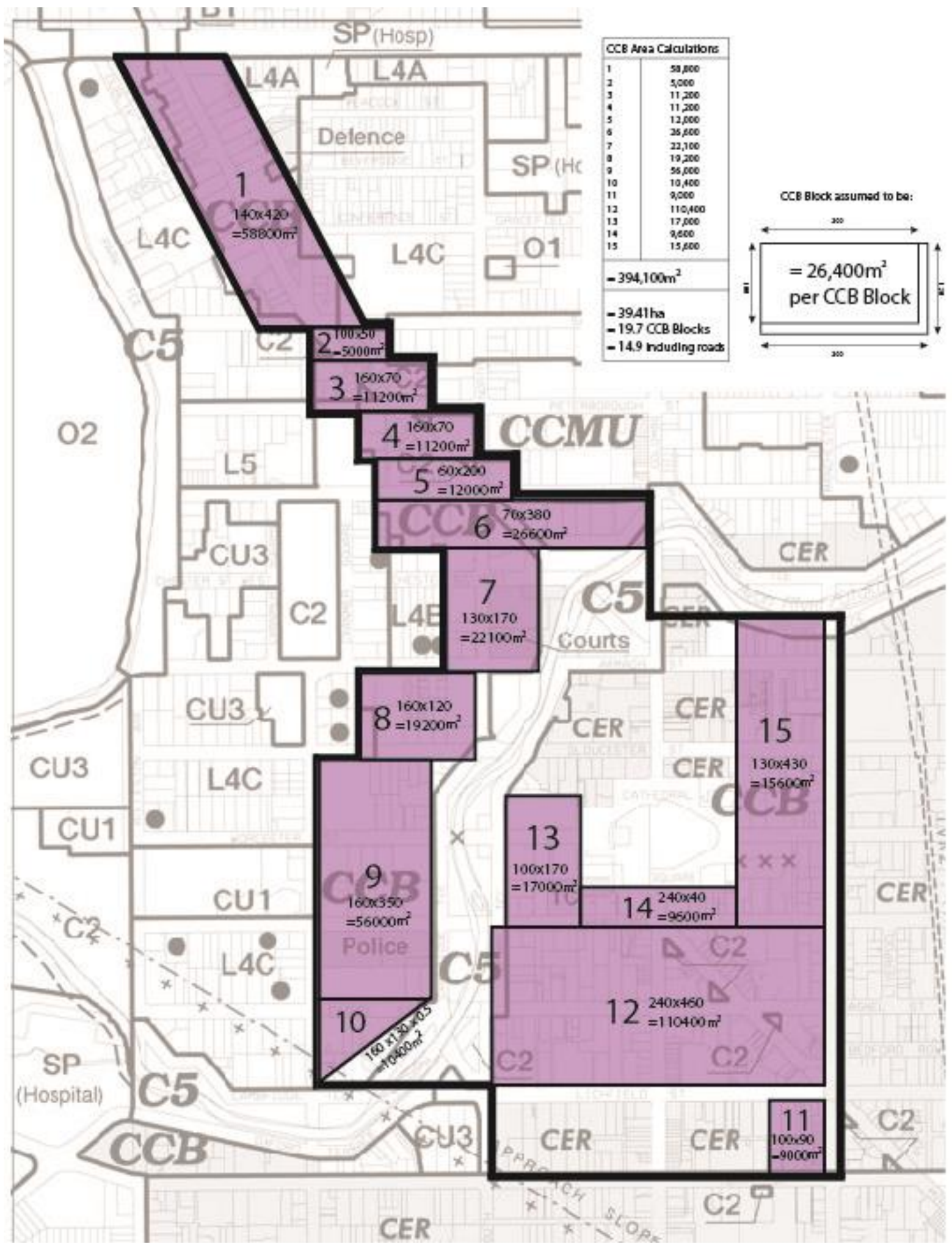

Figure B.2.CCB area and block calculations. 


\section{Appendix C: Christchurch Architects Survey}

\section{Questionnaire - Architecture NZ Magazine}

\section{Participant Information Sheet}

Title of Project: Urban Form for Passive Buildings and Density in the Christchurch Rebuild.

Researcher: Tavis Creswell-Wells - Masters of Building Science (specialising in Sustainable Engineering Systems) student at Victoria University of Wellington.

Urban form is the physical manifestation of a city's infrastructure. Usually, the existing urban form of a city restricts a building's access to solar and fresh air amenities. As a result, the solar energy, daylight and natural ventilation amenities, and hence overall sustainability, of a new building are innately limited. However, in Christchurch, there is an opportunity to create a new urban form in a way that minimises impact on each building's access to these fundamental amenities, while still retaining acceptable density (for individual buildings, and across the central city).

The aim of my research is to develop an urban form that enables ALL buildings to have adequate access to these amenities while also providing projected demand for floor area, in the four avenues central city zone.

This surveys purpose is to maximise the relevance of the computer models I will be creating for the study.

The questions in the survey aim to identify typical and extreme architectural design patterns for Christchurch's central city commercial buildings, based on current local practice.

There will be no attempt to critique designs, merely to identify current general architectural patterns.

All data gathered in this study will stay anonymous, unless you (the architectural firm) would prefer the data you provide to be recognized within the study. All survey forms will be destroyed following completion of the study.

I would like to thank you in advance for your participation. Your feedback will help me to form a reliable representation of commercial architectural practices in the rebuild and increase credibility of this research.

At the beginning of the survey you will be asked to confirm:

a) You have read this document

b) If you would like copy of the survey response data (at the conclusion of the survey).

c) If you would like a copy of the completed thesis (at the conclusion of the survey).

It is also possible that findings from the research form a journal (e.g. 'Energy and Buildings') article.

If you have any questions or would like to receive further information about the project, please contact me at wellstavi@myvuw.ac.nz or my supervisor, Dr Michael Donn at michael.donn@vuw.ac.nz.

Best regards,

Tavis Creswell-Wells (Masters of Building Science candidate, Victoria University of Wellington)

Signed:

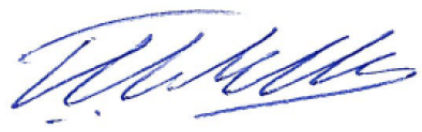

Date: $29 / 11 / 2013$ 


\section{Consent to Participate in Research}

Date: $29 / 11 / 2013$

Title of Thesis Project: Urban Form for Passive Buildings and Mixed-use Intensification in the Christchurch Rebuild.

This form explains your rights as a participant in this survey and research. Please read and familiarize yourself with the following points prior to beginning the survey.

$\checkmark \quad$ I have been given and have understood an explanation of this research project ('Participation Information Sheet').

$\checkmark \quad$ I have been given an opportunity to ask questions about the research.

$\checkmark \quad$ I understand that my answers to the survey can stay entirely anonymous, OR, can credit the architectural firm responsible for the design of that reported building- whichever option we as the firm prefer.

$\checkmark \quad$ I understand that I will have an opportunity to check the transcripts of the survey before publication.

$\checkmark \quad$ I understand that the data I provide will not be used for any other purpose outside of this thesis; the Architecture NZ magazine article; and Architecture NZ's sister publication 'Progressive Building'; or released to others without our written consent.

$\checkmark \quad$ I understand that I have the opportunity (at end of survey) to ask for a summary of the results of this research when it is complete.

$\checkmark \quad$ I understand that we may withdraw ourselves (or any information we have provided) from this project (before data collection and analysis is complete) without having to give reasons or without penalty of any sort.

If you agree to these terms and are happy to take the survey, please highlight 'Yes' below. This will indicate (anonymously) your consent to participate in the survey.

I agree to take part in this research? (Please highlight 'Yes' if consent given) Yes / No 


\section{Notes for Answering the Survey}

The following questions aim to identify architectural patterns in central city commercial buildings being built in the Christchurch rebuild.

- $\quad$ To this end, the questionnaire should be answered only for central city commercial buildings that have been built; have gained consent and are under construction; or, at the very least, be in the final stages of design development.

- $\quad$ Please report one building per questionnaire form. If you or your firm have multiple built or to be built projects, please fill out separate forms for each building.

- $\quad$ Finally, if it is possible and appropriate, please attach 1-2 perspective drawings/renders of the building for presentation.

The questionnaire consists of 17 questions and is expected to take around 10 minutes to complete.

Please read the grey 'notes' below each question to help you answer it appropriately.

Then, simply erase the orange examples and enter your answer.

\section{GENERAL QUESTIONS:}

What firm designed the subject building? (OPTIONAL)

Firm:

What is the subject buildings address?

Address: 
BUILDING FORM QUESTIONS:

\section{Question 1:}

What is the building typology for each floor?

\begin{tabular}{|l|l|}
\hline Ground floor & e.g. retail \\
\hline First floor & e.g. office \\
\hline Second floor & Etc. \\
\hline Third floor & \\
\hline Fourth floor & \\
\hline Sixth floor & \\
\hline Seventh floor & \\
\hline Eighth floor & $\begin{array}{l}\text { Note: Typology being: Office, Residential, Retail, Hospitality, or Other (please specify). } \\
\text { If there are multiple typologies on a floor, use predominant type. Please specify an answer for } \\
\text { each floor of the building (as this question also informs building height). }\end{array}$ \\
\hline \multicolumn{2}{|l}{ Comments: }
\end{tabular}

\section{Question 2:}

What is the Ground Floor finished ceiling height for this building?

Floor to finished ceiling Height (m): e.g. $4.5 \mathrm{~m}$

Note: Please answer to nearest $0.1 \mathrm{~m}$. This question refers to 'floor to finished ceiling', not 'floor to ceiling structure' or 'FFL to FFL'.

Comments:

\section{Question 3:}

What is the Upper Floors (First Floor and above) finished ceiling height for this building?

Floor to finished ceiling Height (m): e.g. $3.6 \mathrm{~m}$

Note: Please answer to nearest $0.1 \mathrm{~m}$. This question also refers to 'floor to finished ceiling', not 'floor to ceiling structure' or 'FFL to FFL'.

Comments:

\section{Question 4:}

What is the width of this building?

Building width (m): e.g. $15 \mathrm{~m}$

Note: Please answer to nearest meter. If building width varies, please specify the width at the street front edge.

Comments:

\section{Question 5:}

What is the width of the property this building sits on?

Property width (m): e.g. $18 \mathrm{~m}$

Note: Please answer to nearest meter. If property width varies, please specify the width at the street front edge.

Comments: 


\section{BUILDING CONSTRUCTION QUESTIONS}

External Walls:

Question 6:

What is the primary external wall construction type of this building?

Construction type: E.g. Steel frame, polystyrene insulation, timber sheet cladding, GIB interior lining.

Note: Include- structure, insulation, external cladding and internal lining layers if possible/ appropriate.

Comments:

\section{Question 7:}

What level of insulation does this building have in the external walls?

Insulation level (R-value): e.g. R2.2

Note: If it varies from wall to wall, please specify the overall 'target' insulation level (e.g. code minimum; or, BASE tool minimum; or, any other number).

Comments:

Roof:

Question 8:

What is the primary roof construction type of this building?

Construction type: E.g. Concrete floor-plate, Pink-batts insulation, Concrete roof tiles, GIB interior lining.

Note: Include- structure, insulation, external cladding and internal lining layers if possible/ appropriate.

Comments:

\section{Question 9:}

What level of insulation does this building have in the roof?

Insulation level (R-value): e.g. R2.8

Note: If it varies from wall to wall, please specify the overall 'target' insulation level (e.g. code minimum; or, BASE tool minimum; or, any other number).

Comments:

Floor:

Question 10:

What is the primary floor construction type of this building?

Construction type: e.g. concrete slab on ground

Note: Simply choose the general construction type, either-concrete slab on ground; or, raised timber on piles; or, other (please specify).

Comments:

\section{Question 11:}

What level of insulation does this building have in the floor? Insulation level (R-value): e.g. code minimum

Note: If it varies from across roof sections, please specify the overall 'target' insulation level (e.g. code minimum; or, BASE tool minimum; or, any other number).

Comments:

Window to Wall Ratio (WWR):

Question 12:

What is the typical WWR level (excluding party walls) on Ground Floor facades for this building? 
WWR (\%): e.g. $60 \%$

Note: Round WWR's to nearest 10\%. All facades will be assumed to have uniform WWR.

Comments:

Question 13:

What is the typical level of WWR (excluding party walls) on Upper Floor (First Floor and above) facades for this building?

WWR (\%): e.g. 40\%

Note: Round WWR's to nearest 10\%. It will be assumed that all upper levels have identical

WWR's.

Comments:

\section{Windows:}

Question 14:

What is the glazing type used in this building?

Glazing type: e.g. $6 \mathrm{~mm}$ thick, clear, low-E, double glazed, with argon gas infill.

Note: Please include all of the following properties that apply- Glass thickness, glass colour, glass coating, number of layers of glazing, gas fill between glazing layers.

Comments:

Question 15:

What is the window frame type used in this building?

Frame type: e.g. aluminium/steel

Note: Please choose from the following categories- 'Timber/plastic/PVC'; or, 'Aluminium/Steel';

or, 'Aluminium/Steel thermally broken'.

Comments:

Solar Shades:

Question 16:

Does this building employ any of the following solar shading devices?

\begin{tabular}{|l|l}
\hline External louvers & e.g. North façade only
\end{tabular}

External fins e.g. None

Internal blinds

e.g. East and West facing windows

Note: If devices are used, please indicate which façade direction/orientation they are used on.

Comments:

Ventilation:

Question 17:

What is the ventilation type used in this building?

Ventilation type: e.g. Mixed-mode automatically opened windows

Note: Please choose from the following- '100\% Mechanically ventilated'; or, '100\% Naturally ventilated'; or, 'Mixed-mode [mixture of natural and mechanical ventilation] manually opened windows'; or, 'Mixed-mode automatically opened windows'.

Comments:

Questionnaire Complete.

Thank you for your participation!

Information

If you would like a copy of the findings of this survey, and/or a copy of the completed thesis, please contact me atwellstavi@myvuw.ac.nz or rangitokomo@hotmail.com 


\section{Appendix D: UrbaWind Results}

Appendix D presents the Urban Form models simulated in UrbaWind (CFD software) to produce Wind Pressure Coefficient $(\mathrm{Cp})$ data to be integrated into EnergyPlus models for natural ventilation calculations. For each of the 13 Urban Form models, geometry and resulting $\mathrm{Cp}$ rendering for east and west (venting) facades at each tested wind angle $\left(0,45,90,135,180^{\circ}\right)$ is identified.

Models seen in the following images include two floors of continuous frontage (Ground and first floors). This was changed to just the ground floor after CFD simulations were conducted (refer Section 5.2.5). $\mathrm{Cp}$ data from the second floor was then applied to the first floor to adjust for this change, rather than re-simulating.

Model 0 is not represented here as its side facades are not exposed to the outdoors and so there is no opportunity for cross ventilation, and no need for wind pressure data. 


\section{Christchurch Model 1:}

4 levels ( $14 \mathrm{~m}$ ) tall; $2 \mathrm{~m}$ gap between buildings; 2 levels continuous frontage; $20 \mathrm{~m}$ wide road.
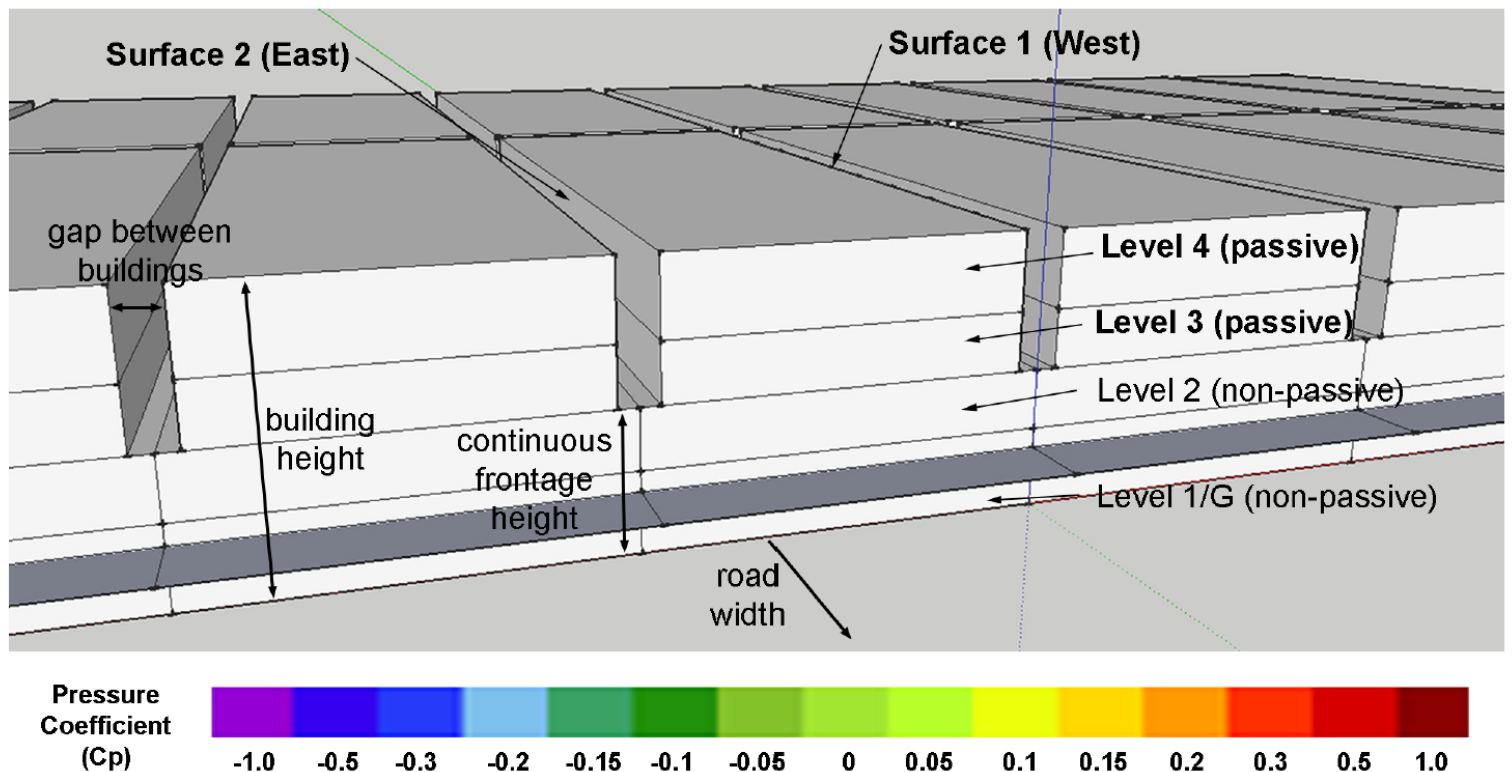

north end

Level 4: average $C p=-0.2$

Level 3: average $\mathrm{Cp}=-0.2$

Surface 1 (West): $0^{\circ}$ wind angle

\begin{tabular}{|l|}
\hline Level 4: average $C p=-0.1$ \\
\hline Level 3: average $C p=-0.15$ \\
\hline
\end{tabular}

Surface 1 (West): $45^{\circ}$ wind angle

\begin{tabular}{|l|}
\hline Level 4: average $C p=-0.1$ \\
\hline Level 3: average $C p=-0.15$ \\
\hline
\end{tabular}

\section{Surface 1 (West): $90^{\circ}$ wind angle}

\begin{tabular}{|c|}
\hline Level 4: average $\mathrm{Cp}=-0.15$ \\
\hline Level 3: average $\mathrm{Cp}=-0.15$ \\
\hline
\end{tabular}

Surface 1 (West): $135^{\circ}$ wind angle

\begin{tabular}{|c|}
\hline Level 4: average $C p=-0.2$ \\
\hline Level 3: average $C p=-0.2$ \\
\hline
\end{tabular}

Surface 1 (West): $180^{\circ}$ wind angle 


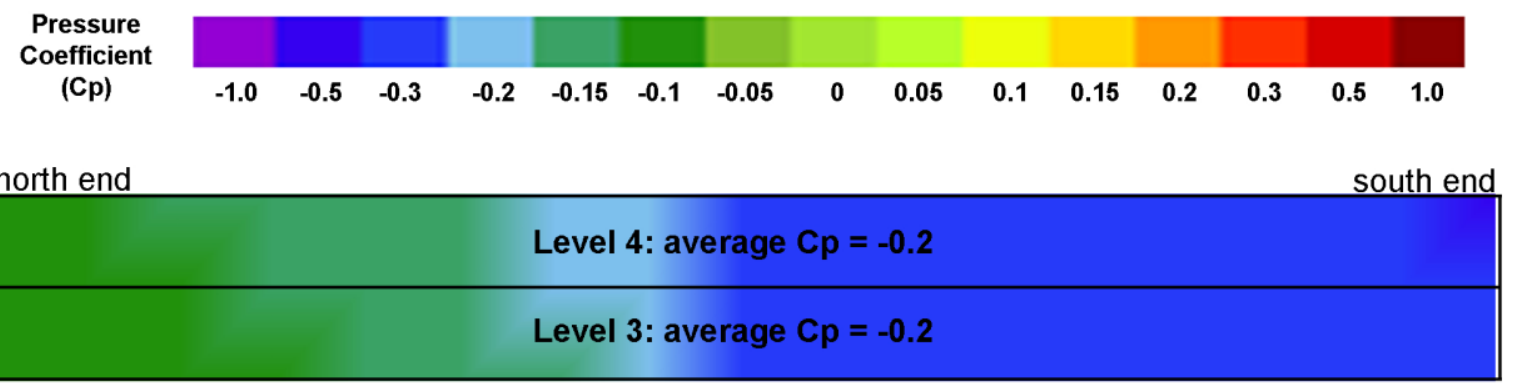

Surface 2 (East): $0^{\circ}$ wind angle

\begin{tabular}{|l|}
\hline Level 4: average $\mathrm{Cp}=-0.3$ \\
\hline Level 3: average $\mathrm{Cp}=-0.15$ \\
\hline
\end{tabular}

Surface 2 (East): $45^{\circ}$ wind angle

Level 4: average $\mathrm{Cp}=-0.3$

Level 3: average $\mathrm{Cp}=-0.1$

Surface 2 (East): $90^{\circ}$ wind angle

\begin{tabular}{|c|}
\hline Level 4 : average $\mathrm{Cp}=-0.2$ \\
\hline Level 3: average $\mathrm{Cp}=-0.15$ \\
\hline
\end{tabular}

Surface 2 (East): $135^{\circ}$ wind angle

\begin{tabular}{|c|}
\hline Level 4: average $\mathrm{Cp}=-0.2$ \\
\hline Level 3: average $\mathrm{Cp}=-0.2$ \\
\hline
\end{tabular}

\section{Surface 2 (East): $180^{\circ}$ wind angle}

NOTE: Cp's for wind angles 225,270 and $315^{\circ}$ are assumed to be the same as those identified for angles 135,90 and $45^{\circ}$ (respectively) at the same level on the opposite side of the building. This is because the model is symmetrical on the north-south axis, so these wind directions will have the same results. For example, a $45^{\circ}$ wind will have the same pressure on the eastern facade as a $315^{\circ}$ wind will have on the western facade, and so they can be substituted without having to conduct another CFD computation.

\begin{tabular}{|l|cccccccc|}
\hline \multicolumn{10}{|c|}{ Model 1 Cp Summary } \\
\hline & \multicolumn{1}{|c|}{$\begin{array}{l}\text { Wind Angle (from North) } \\
\mathbf{0}^{\circ}\end{array}$} & $\mathbf{4 5}^{\circ}$ & $\mathbf{9 0 ^ { \circ }}$ & $\mathbf{1 3 5}$ & $\mathbf{1 8 0 ^ { \circ }}$ & $\mathbf{2 2 5}^{\circ}$ & $\mathbf{2 7 0 ^ { \circ }}$ & $\mathbf{3 1 5}^{\circ}$ \\
\hline $\begin{array}{l}\text { Surface 1 (West) } \\
\text { Level 3 } \\
\text { Level 4 }\end{array}$ & -0.2 & -0.1 & -0.1 & -0.15 & -0.2 & -0.15 & -0.1 & -0.15 \\
$\begin{array}{l}\text { Surface 2 (East) } \\
\text { Level 3 } \\
\text { Level 4 }\end{array}$ & -0.2 & -0.1 & -0.1 & -0.15 & -0.2 & -0.2 & -0.3 & -0.3 \\
\hline
\end{tabular}




\section{Christchurch Model 2:}

4 levels $(14 \mathrm{~m})$ tall; $6 \mathrm{~m}$ gap between buildings; 2 levels continuous frontage; $20 \mathrm{~m}$ wide road.

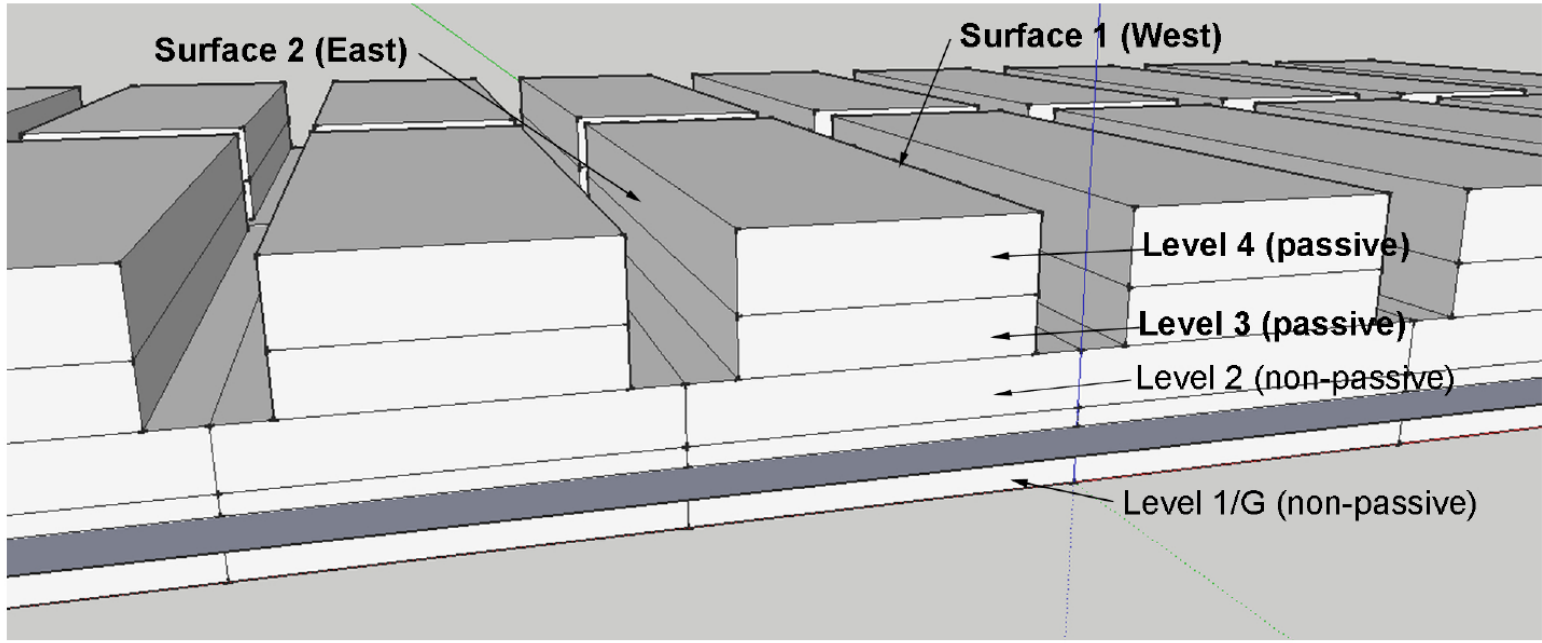

Pressure

Coefficient

(Cp)

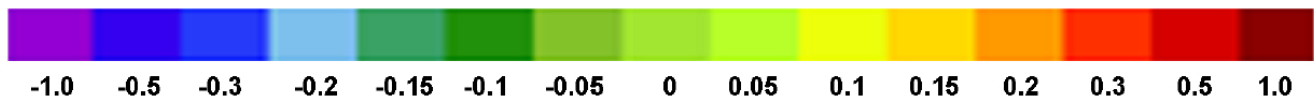

north end south end

Level 4: $\mathrm{Cp}=-\mathbf{0 . 2}$

Level 3: $\mathrm{Cp}=-0.2$

Surface 1 (West): $0^{\circ}$ wind angle

Level $4: C p=-0.1$

Level 3: $C p=-0.15$

Surface 1 (West): $45^{\circ}$ wind angle

Level 4: Cp $=-0.05$

Level 3: $C p=-0.15$

Surface 1 (West): $90^{\circ}$ wind angle

Level 4: $C p=-0.15$

Level 3: $C p=-0.2$

Surface 1 (West): $135^{\circ}$ wind angle

Level 4: $\mathrm{Cp}=-\mathbf{0 . 2}$

Level 3: $C p=-0.2$

Surface 1 (West): $180^{\circ}$ wind angle 


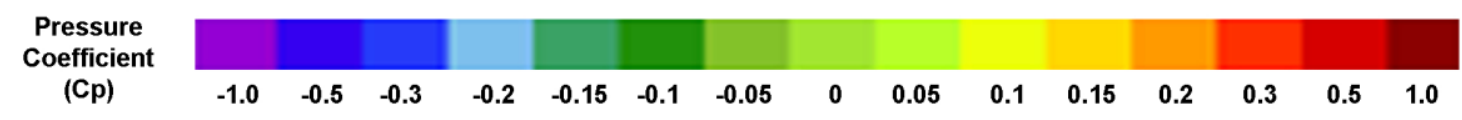

north end south end

Level 4: average $\mathrm{Cp}=-0.2$

Level 3: average $\mathrm{Cp}=-0.2$

Surface 2 (East): $0^{\circ}$ wind angle

\begin{tabular}{|c|}
\hline Level 4: average $\mathrm{Cp}=-0.3$ \\
\hline Level 3: average $\mathrm{Cp}=-0.15$ \\
\hline
\end{tabular}

Surface 2 (East): $45^{\circ}$ wind angle

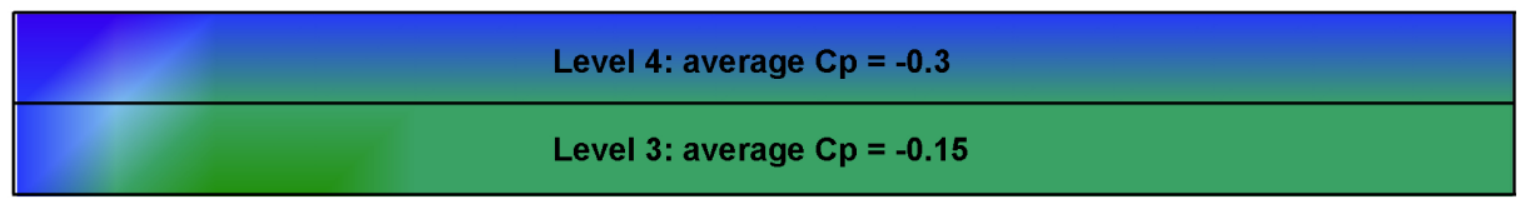

Surface 2 (East): $90^{\circ}$ wind angle

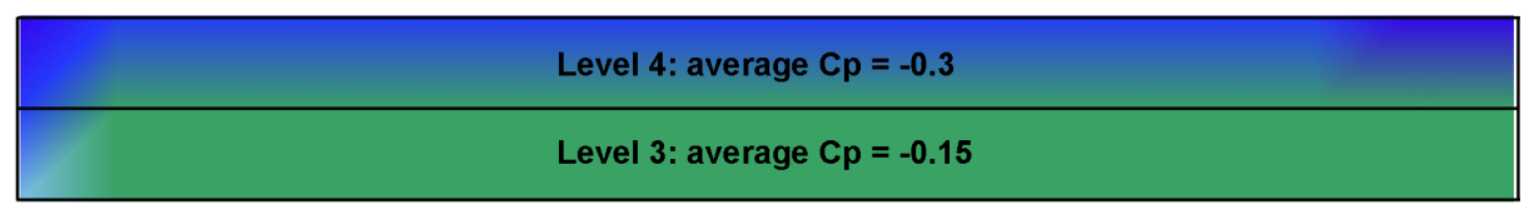

Surface 2 (East): $135^{\circ}$ wind angle

\begin{tabular}{|c|}
\hline Level 4: average $\mathrm{Cp}=-0.2$ \\
\hline Level 3: average $\mathrm{Cp}=-0.2$ \\
\hline
\end{tabular}

\section{Surface 2 (East): $180^{\circ}$ wind angle}

NOTE: Cp's for wind angles 225,270 and $315^{\circ}$ are assumed to be the same as those identified for angles 135,90 and $45^{\circ}$ (respectively) at the same level on the opposite side of the building. This is because the model is symmetrical on the north-south axis, so these wind directions will have the same results. For example, a $45^{\circ}$ wind will have the same pressure on the eastern facade as a $315^{\circ}$ wind will have on the western facade, and so they can be substituted without having to conduct another CFD computation.

\begin{tabular}{|l|llllllll|}
\hline \multicolumn{10}{|c|}{ Model 2 Cp Summary } \\
\hline & $\begin{array}{l}\text { Wind Angle (from North) } \\
\mathbf{0}^{\circ}\end{array}$ & $\mathbf{4 5}^{\circ}$ & $\mathbf{9 0 ^ { \circ }}$ & $\mathbf{1 3 5 ^ { \circ }}$ & $\mathbf{1 8 0}^{\circ}$ & $\mathbf{2 2 5}^{\circ}$ & $\mathbf{2 7 0}^{\circ}$ & $\mathbf{3 1 5}^{\circ}$ \\
\hline $\begin{array}{l}\text { Surface 1 (West) } \\
\text { Level 3 }\end{array}$ & -0.2 & -0.15 & -0.15 & -0.2 & -0.2 & -0.15 & -0.15 & -0.15 \\
Level 4 & -0.2 & -0.1 & -0.05 & -0.2 & -0.2 & -0.3 & -0.3 & -0.3 \\
Surface 2 (East) & & & & & & & & \\
Level 3 & -0.2 & -0.15 & -0.15 & -0.15 & -0.2 & -0.2 & -0.15 & -0.15 \\
Level 4 & -0.2 & -0.3 & -0.3 & -0.3 & -0.2 & -0.2 & -0.05 & -0.1 \\
\hline
\end{tabular}




\section{Christchurch Model 3:}

4 levels (14m ) tall; $10 \mathrm{~m}$ gap between buildings; 2 levels continuous frontage; $20 \mathrm{~m}$ wide road.
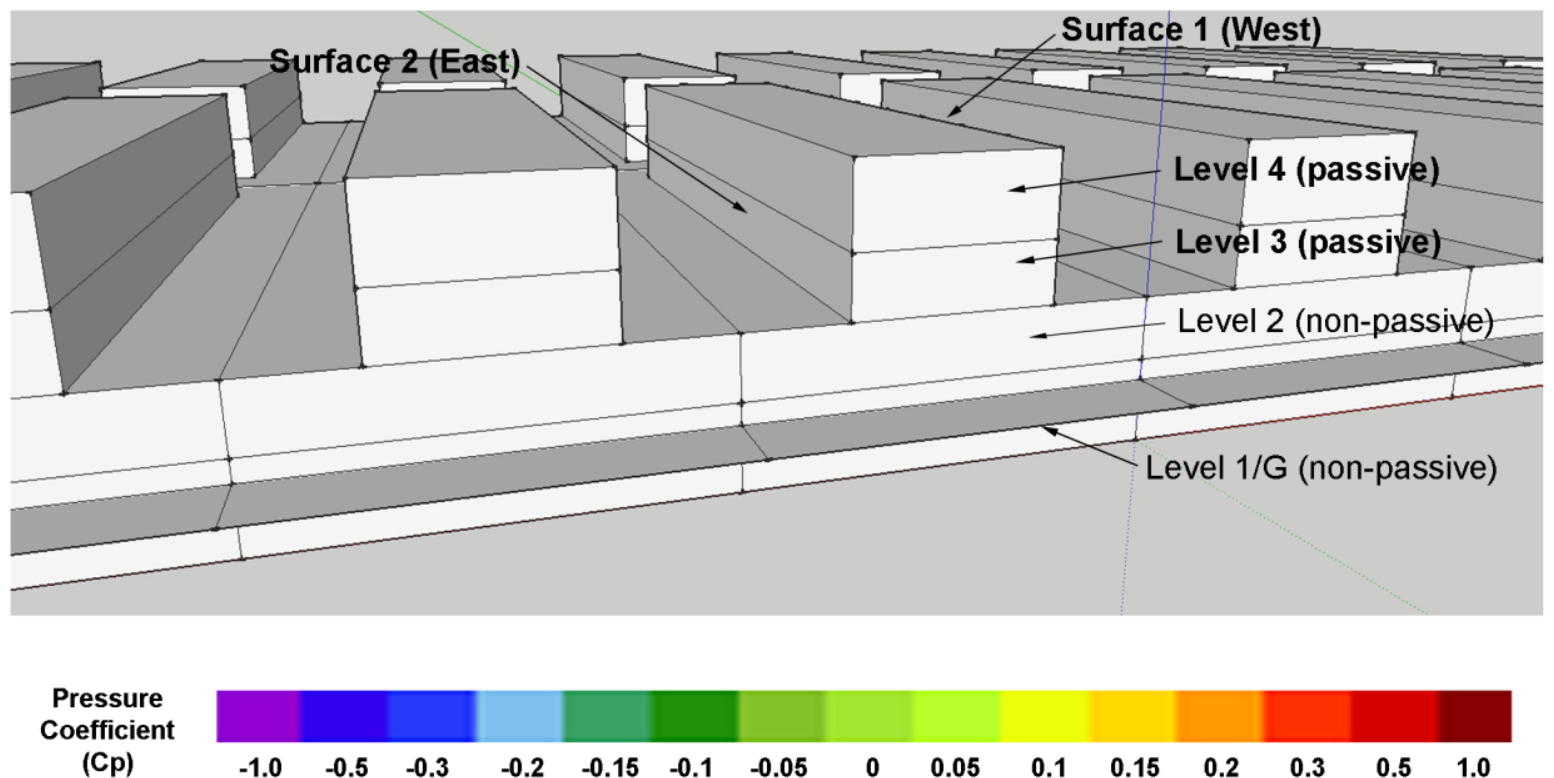

north end south end

\begin{tabular}{|c|}
\hline Level $4:$ average $\mathrm{Cp}=-0.2$ \\
\hline Level 3: average $\mathrm{Cp}=-0.2$ \\
\hline
\end{tabular}

Surface 1 (West): $0^{\circ}$ wind angle

Level 4: average $C p=-0.05$

Level 3: average $C p=-0.1$

Surface 1 (West): $45^{\circ}$ wind angle

\begin{tabular}{|l|}
\hline Level 4: average $\mathrm{Cp}=0$ \\
\hline Level 3: average $\mathrm{Cp}=-0.05$ \\
\hline
\end{tabular}

\section{Surface 1 (West): $90^{\circ}$ wind angle}

\begin{tabular}{|c|}
\hline Level 4: average $\mathrm{Cp}=-0.1$ \\
\hline Level 3: average $\mathrm{Cp}=-0.15$ \\
\hline
\end{tabular}

Surface 1 (West): $135^{\circ}$ wind angle

\begin{tabular}{|c|}
\hline Level 4: average $\mathrm{Cp}=-0.2$ \\
\hline Level 3: average $\mathrm{Cp}=-0.2$ \\
\hline
\end{tabular}

Surface 1 (West): $180^{\circ}$ wind angle 


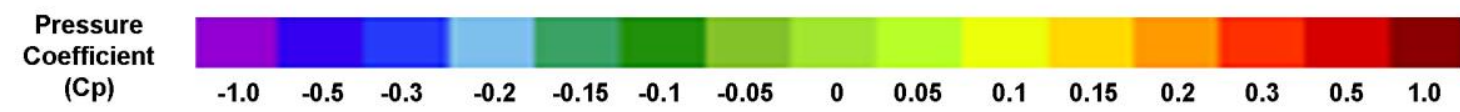

north end

Level 4: average $\mathrm{Cp}=-0.2$

Level 3: average $\mathrm{Cp}=-\mathbf{0 . 2}$

\section{Surface 2 (East): $0^{\circ}$ wind angle}

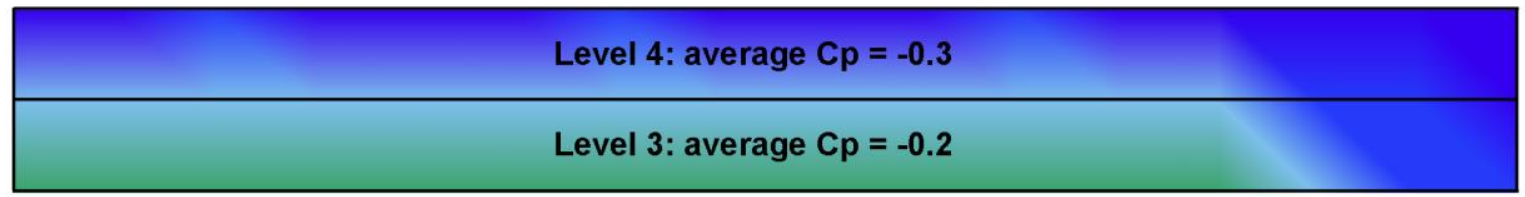

Surface 2 (East): $45^{\circ}$ wind angle

Level 4: average $C p=-0.3$

Level 3: average $\mathrm{Cp}=-0.15$

Surface 2 (East): $90^{\circ}$ wind angle

Level 4: average $\mathrm{Cp}=-0.3$

Level 3: average $\mathrm{Cp}=-0.2$

Surface 2 (East): $135^{\circ}$ wind angle

\begin{tabular}{|c|}
\hline Level 4: average $\mathrm{Cp}=-0.2$ \\
\hline Level 3: average $\mathrm{Cp}=-0.2$ \\
\hline
\end{tabular}

Surface 2 (East): $180^{\circ}$ wind angle

NOTE: Cp's for wind angles 225,270 and $315^{\circ}$ are assumed to be the same as those identified for angles 135,90 and $45^{\circ}$ (respectively) at the same level on the opposite side of the building. This is because the model is symmetrical on the north-south axis, so these wind directions will have the same results. For example, a $45^{\circ}$ wind will have the same pressure on the eastern facade as a $315^{\circ}$ wind will have on the western facade, and so they can be substituted without having to conduct another CFD computation.

\begin{tabular}{|c|c|c|c|c|c|c|c|c|}
\hline \multicolumn{9}{|c|}{ Model 3 Cp Summary } \\
\hline & \multicolumn{8}{|c|}{ Wind Angle (from North) } \\
\hline & $0^{\circ}$ & $45^{\circ}$ & $90^{\circ}$ & $135^{\circ}$ & $180^{\circ}$ & $225^{\circ}$ & $270^{\circ}$ & $315^{\circ}$ \\
\hline \multicolumn{9}{|l|}{ Surface 1 (West) } \\
\hline Level 3 & -0.2 & -0.1 & -0.05 & -0.15 & -0.2 & -0.3 & -0.3 & -0.2 \\
\hline Level 4 & -0.2 & -0.05 & 0 & -0.1 & -0.2 & -0.3 & -0.3 & -0.3 \\
\hline \multicolumn{9}{|l|}{ Surface 2 (East) } \\
\hline Level 3 & -0.2 & -0.2 & -0.3 & -0.3 & -0.2 & -0.15 & -0.05 & -0.1 \\
\hline Level 4 & -0.2 & -0.3 & -0.3 & -0.3 & -0.2 & -0.1 & 0 & -0.05 \\
\hline
\end{tabular}


Christchurch Model 4:

6 levels $(20 \mathrm{~m}$ ) tall; $2 \mathrm{~m}$ gap between buildings; 2 levels continuous frontage; $20 \mathrm{~m}$ wide road.
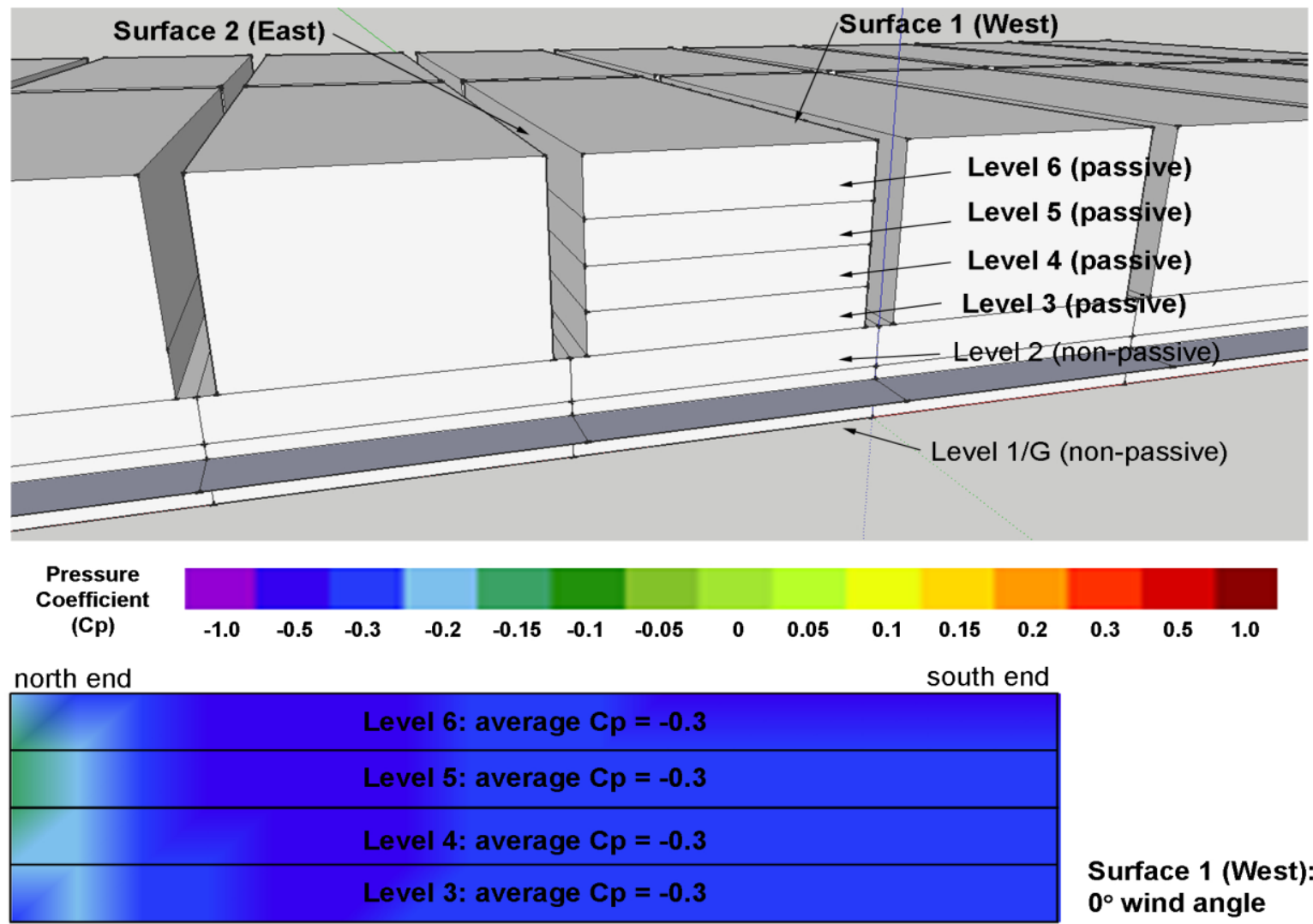

Surface 1 (West): $0^{\circ}$ wind angle

\begin{tabular}{|l|}
\hline Level 6: average $C p=-0.15$ \\
\hline Level 5: average $C p=-0.2$ \\
\hline Level 4: average $C p=-0.2$ \\
\hline Level 3: average $C p=-0.2$ \\
\hline
\end{tabular}

Surface 1 (West): $45^{\circ}$ wind angle

\begin{tabular}{|l|}
\hline Level 6: average $C p=-0.2$ \\
\hline Level 5: average $C p=-0.2$ \\
\hline Level 4: average $C p=-0.2$ \\
\hline Level 3: average $C p=-0.2$ \\
\hline
\end{tabular}

Surface 1 (West): $90^{\circ}$ wind angle

\begin{tabular}{|l|}
\hline Level 6: average $C p=-0.3$ \\
\hline Level 5: average $C p=-0.3$ \\
\hline Level 4: average $C p=-0.3$ \\
\hline Level 3: average $C p=-0.3$ \\
\hline
\end{tabular}

Surface 1 (West): $135^{\circ}$ wind angle

\begin{tabular}{|l|}
\hline Level 6: average $C p=-0.2$ \\
\hline Level 5: average $C p=-0.2$ \\
\hline Level 4: average $C p=-0.2$ \\
\hline Level 3: average $C p=-0.2$ \\
\hline
\end{tabular}


south end

north end

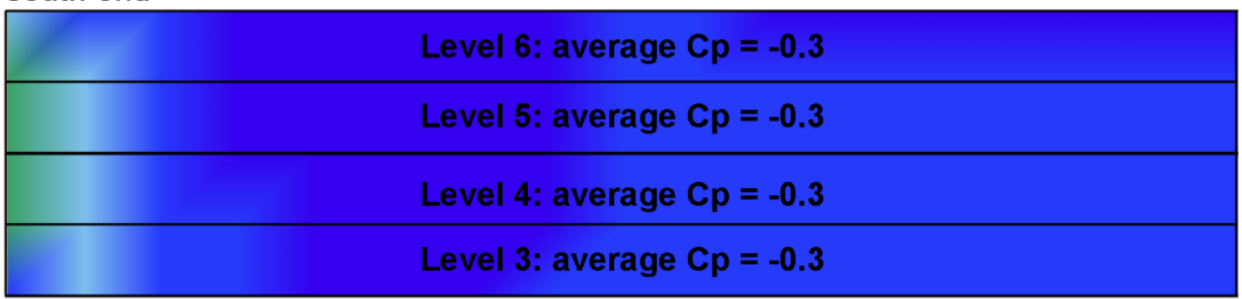

Surface 2 (East): $0^{\circ}$ wind angle

\begin{tabular}{|l|}
\hline Level 6: average $C p=-0.3$ \\
\hline Level 5: average $C p=-0.2$ \\
\hline Level 4: average $C p=-0.2$ \\
\hline Level 3: average $C p=-0.2$ \\
\hline
\end{tabular}

Surface 2 (East): $45^{\circ}$ wind angle

\begin{tabular}{|l|}
\hline Level 6: average $C p=-0.2$ \\
\hline Level 5: average $C p=-0.15$ \\
\hline Level 4: average $C p=-0.15$ \\
\hline Level 3: average $C p=-0.15$ \\
\hline
\end{tabular}

Surface 2 (East): $90^{\circ}$ wind angle

\begin{tabular}{|l|}
\hline Level 6: average $C p=-0.3$ \\
\hline Level 5: average $C p=-0.2$ \\
\hline Level 4: average $C p=-0.2$ \\
\hline Level 3: average $C p=-0.2$ \\
\hline
\end{tabular}

Surface 2 (East): $135^{\circ}$ wind angle

\begin{tabular}{|c|}
\hline Level 6: average $C p=-0.3$ \\
\hline Level 5: average $C p=-0.2$ \\
\hline Level 4: average $C p=-0.2$ \\
\hline Level 3: average $C p=-0.2$ \\
\hline
\end{tabular}

Surface 2 (East): $180^{\circ}$ wind angle

\begin{tabular}{|l|llllllll|}
\hline \multicolumn{8}{|c|}{ Model 4 Cp Summary } \\
\hline & \multicolumn{7}{|l|}{ Wind Angle (from North) } \\
& $\mathbf{0}^{\circ}$ & $\mathbf{4 5 ^ { \circ }}$ & $\mathbf{9 0 ^ { \circ }}$ & $\mathbf{1 3 5 ^ { \circ }}$ & $\mathbf{1 8 0 ^ { \circ }}$ & $\mathbf{2 2 5}^{\circ}$ & $\mathbf{2 7 0}^{\circ}$ & $\mathbf{3 1 5}^{\circ}$ \\
\hline Surface 1 (West) & & & & & & & & \\
Level 3 & -0.3 & -0.2 & -0.2 & -0.3 & -0.2 & -0.2 & -0.15 & -0.2 \\
Level 4 & -0.3 & -0.2 & -0.2 & -0.3 & -0.2 & -0.2 & -0.15 & -0.2 \\
Level 5 & -0.3 & -0.2 & -0.2 & -0.3 & -0.2 & -0.2 & -0.15 & -0.2 \\
Level 6 & -0.3 & -0.15 & -0.2 & -0.3 & -0.2 & -0.3 & -0.2 & -0.3 \\
Surface 2 (East) & & & & & & & & \\
Level 3 & -0.3 & -0.2 & -0.15 & -0.2 & -0.2 & -0.3 & -0.2 & -0.2 \\
Level 4 & -0.3 & -0.2 & -0.15 & -0.2 & -0.2 & -0.3 & -0.2 & -0.2 \\
Level 5 & -0.3 & -0.2 & -0.15 & -0.2 & -0.2 & -0.3 & -0.2 & -0.2 \\
Level 6 & -0.3 & -0.3 & -0.2 & -0.3 & -0.3 & -0.3 & -0.2 & -0.15 \\
\hline
\end{tabular}




\section{Christchurch Model 5:}

6 levels $(20 \mathrm{~m}$ ) tall; $6 \mathrm{~m}$ gap between buildings; 2 levels continuous frontage; $20 \mathrm{~m}$ wide road.
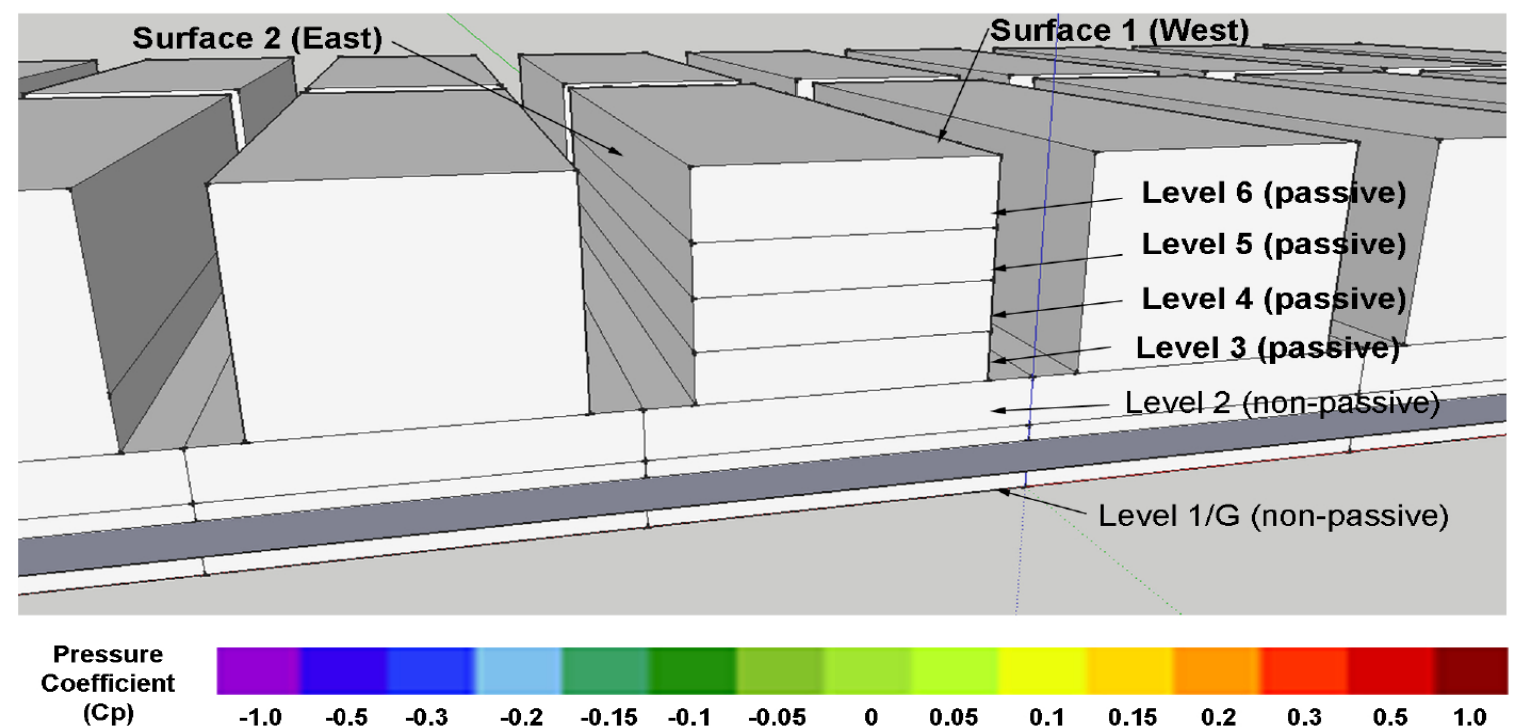

\begin{tabular}{|l|}
\hline Lerth end \\
\hline Level 6: average $C p=-0.3$ \\
\hline Level average $C p=-0.2$ \\
\hline Level 3: average $C p=-0.2$ \\
\hline
\end{tabular}

south end

\begin{tabular}{|l|}
\hline Level 6: average $C p=-0.15$ \\
\hline Level 5: average $C p=-0.2$ \\
\hline Level 4: average $C p=-0.2$ \\
\hline Level 3: average $C p=-0.2$ \\
\hline
\end{tabular}

Surface 1 (West): $0^{\circ}$ wind angle

\begin{tabular}{|l|}
\hline Level 6: average $C p=-0.15$ \\
\hline Level 5: average $C p=-0.2$ \\
\hline Level 4: average $C p=-0.2$ \\
\hline Level 3: average $C p=-0.2$ \\
\hline
\end{tabular}

Surface 1 (West): $45^{\circ}$ wind angle

\begin{tabular}{|l|}
\hline Level 6: average $C p=-0.2$ \\
\hline Level 5 : average $C p=-0.3$ \\
\hline Level 4: average $C p=-0.3$ \\
\hline Level 3: average $C p=-0.3$ \\
\hline
\end{tabular}

Surface 1 (West): $90^{\circ}$ wind angle

Surface 1 (West): $135^{\circ}$ wind angle

$$
\begin{aligned}
& \text { Level 6: average } C p=-0.3 \\
& \text { Level 5: average } C p=-0.3 \\
& \text { Level 4: average } C p=-0.3 \\
& \text { Level 3: average } C p=-0.3
\end{aligned}
$$


south end

north end

\begin{tabular}{|l|}
\hline Level 6: average $C p=-0.3$ \\
\hline Level 5: average $C p=-0.2$ \\
\hline Level 4: average $C p=-0.2$ \\
\hline Level 3: average $C p=-0.2$ \\
\hline
\end{tabular}

Surface 2 (East): $0^{\circ}$ wind angle

\begin{tabular}{|l|}
\hline Level 6: average $C p=-0.3$ \\
\hline Level 5: average $C p=-0.2$ \\
\hline Level 4: average $C p=-0.2$ \\
\hline Level 3: average $C p=-0.2$ \\
\hline
\end{tabular}

Surface 2 (East): $45^{\circ}$ wind angle

\begin{tabular}{|l|}
\hline Level 6: average $C p=-0.3$ \\
\hline Level 5: average $C p=-0.2$ \\
\hline Level 4: average $C p=-0.2$ \\
\hline Level 3: average $C p=-0.2$ \\
\hline
\end{tabular}

Surface 2 (East): $90^{\circ}$ wind angle

\begin{tabular}{|l|}
\hline Level 6: average $C p=-0.3$ \\
\hline Level 5: average $C p=-0.2$ \\
\hline Level 4: average $C p=-0.2$ \\
\hline Level 3: average $C p=-0.2$ \\
\hline
\end{tabular}

Surface 2 (East): $135^{\circ}$ wind angle

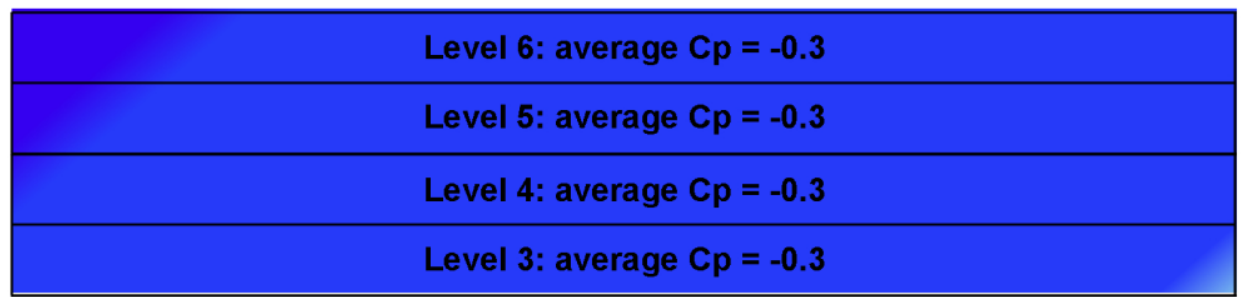

Surface 2 (East) $180^{\circ}$ wind angle

\begin{tabular}{|l|cccccccc|}
\hline \multicolumn{8}{|c|}{ Model 5 Cp Summary } \\
\hline & $\begin{array}{l}\text { Wind } \\
\mathbf{0}^{\circ}\end{array}$ & $\mathbf{4 5} \mathbf{4 5}^{\circ}$ & $\mathbf{9 0 ^ { \circ }}$ & $\mathbf{1 3 5 ^ { \circ }}$ & $\mathbf{1 8 0}^{\circ}$ & $\mathbf{2 2 5}^{\circ}$ & $\mathbf{2 7 0 ^ { \circ }}$ & $\mathbf{3 1 5}^{\circ}$ \\
\hline Surface 1 (West) & & & & & & & & \\
Level 3 & -0.2 & -0.2 & -0.2 & -0.3 & -0.3 & -0.2 & -0.2 & -0.2 \\
Level 4 & -0.2 & -0.2 & -0.2 & -0.3 & -0.3 & -0.2 & -0.2 & -0.2 \\
Level 5 & -0.2 & -0.2 & -0.2 & -0.3 & -0.3 & -0.2 & -0.2 & -0.2 \\
Level 6 & -0.3 & -0.15 & -0.15 & -0.2 & -0.3 & -0.3 & -0.3 & -0.3 \\
Surface 2 (East) & & & & & & & & \\
Level 3 & -0.2 & -0.2 & -0.2 & -0.2 & -0.3 & -0.3 & -0.2 & -0.2 \\
Level 4 & -0.2 & -0.2 & -0.2 & -0.2 & -0.3 & -0.3 & -0.2 & -0.2 \\
Level 5 & -0.2 & -0.2 & -0.2 & -0.2 & -0.3 & -0.3 & -0.2 & -0.2 \\
Level 6 & -0.3 & -0.3 & -0.3 & -0.3 & -0.3 & -0.2 & -0.15 & -0.15 \\
\hline
\end{tabular}




\section{Christchurch Model 6:}

6 levels $(20 \mathrm{~m}$ ) tall; $10 \mathrm{~m}$ gap between buildings; 2 levels continuous frontage; $20 \mathrm{~m}$ wide road.

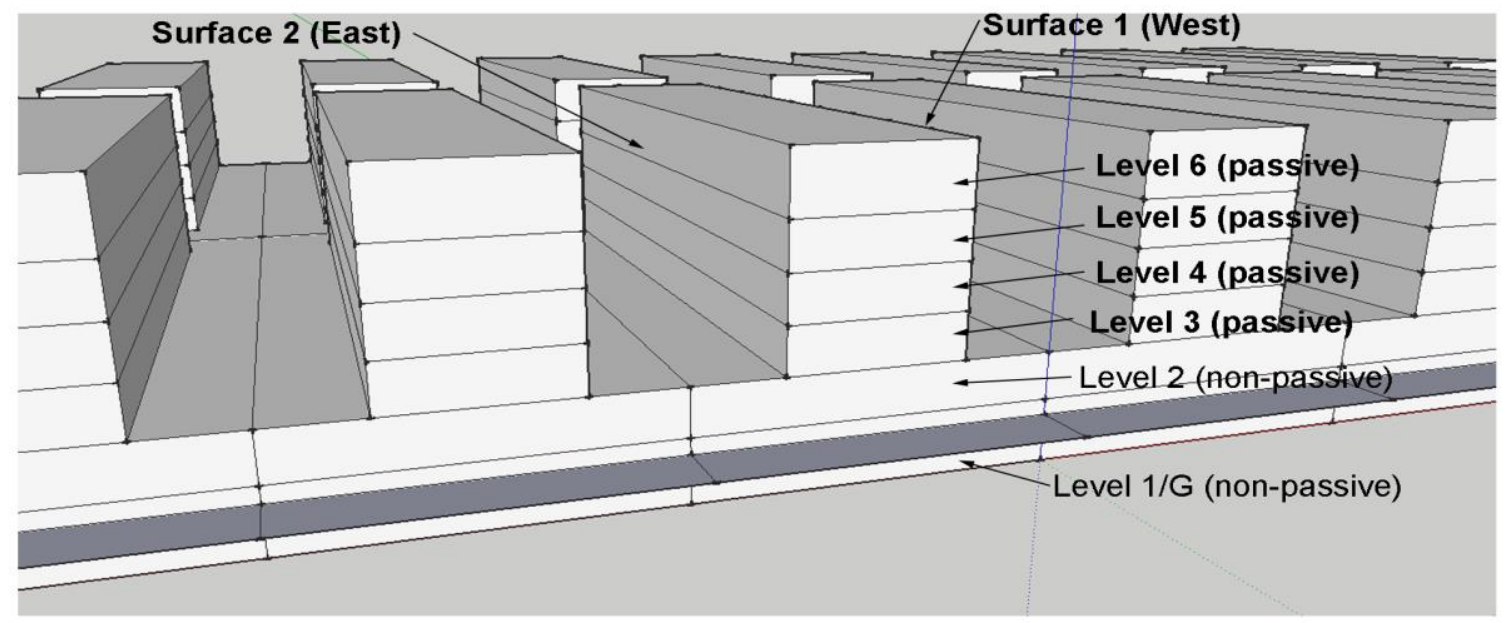

Pressure

Coefficient

(Cp)

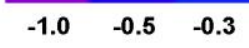

$-0.2$

$-0.15-0.1 \quad-0.05$

0.05

0.1

$0.15 \quad 0.2$

$\begin{array}{lll}0.3 & 0.5 & 1.0\end{array}$

north end

Level 6: average $C p=-0.2$

Level 5: average $\mathrm{Cp}=-\mathbf{0 . 2}$

Level 4: average $C p=-0.2$

Level 3: average $C p=-0.2$

Surface 1 (West):

$0^{\circ}$ wind angle

\begin{tabular}{|l|}
\hline Level 6: average $C p=-0.15$ \\
\hline Level 5: average $C p=-0.2$ \\
\hline Level 4: average $C p=-0.2$ \\
\hline Level 3: average $C p=-0.2$ \\
\hline
\end{tabular}

Surface 1 (West): $45^{\circ}$ wind angle

\begin{tabular}{|l|}
\hline Level 6: average $C p=-0.15$ \\
\hline Level 5: average $C p=-0.2$ \\
\hline Level 4: average $C p=-0.2$ \\
\hline Level 3: average $C p=-0.2$ \\
\hline
\end{tabular}

Surface 1 (West): $90^{\circ}$ wind angle

\begin{tabular}{|l|}
\hline Level 6: average $C p=-0.2$ \\
\hline Level 5: average $C p=-0.3$ \\
\hline Level 4: average $C p=-0.3$ \\
\hline Level 3: average $C p=-0.3$ \\
\hline
\end{tabular}

Surface 1 (West): $135^{\circ}$ wind angle

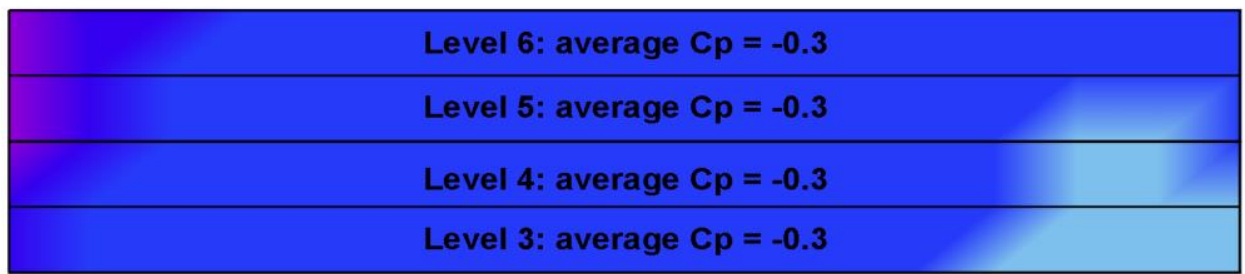

Surface 1 (West): $180^{\circ}$ wind angle 


\begin{tabular}{|c|}
\hline Level 6: average $C p=-0.2$ \\
\hline Level 5: average $\mathrm{Cp}=-0.2$ \\
\hline Level 4: average $C p=-0.2$ \\
\hline Level 3: average $C p=-0.2$ \\
\hline Level 6: average $C p=-0.3$ \\
\hline Level 5: average $C p=-0.3$ \\
\hline Level 4: average $C p=-0.3$ \\
\hline Level 3: average $C p=-0.2$ \\
\hline Level 6: average $C p=-0.3$ \\
\hline Level 5: average $C p=-0.3$ \\
\hline Level 4: average $C p=-0.2$ \\
\hline Level 3: average $C p=-0.2$ \\
\hline Level 6: average $C p=-0.3$ \\
\hline Level 5: average $C p=-0.3$ \\
\hline Level 4: average $C p=-0.3$ \\
\hline Level 3: average $C p=-0.2$ \\
\hline Level 6: average $C p=-0.3$ \\
\hline Level 5: average $C p=-0.3$ \\
\hline Level 4: average $C p=-0.3$ \\
\hline Level 3: average $C p=-0.3$ \\
\hline
\end{tabular}

Surface 2 (East): $45^{\circ}$ wind angle

Surface 2 (East): $90^{\circ}$ wind angle

Surface 2 (East): $135^{\circ}$ wind angle

Surface 2 (East): $180^{\circ}$ wind angle
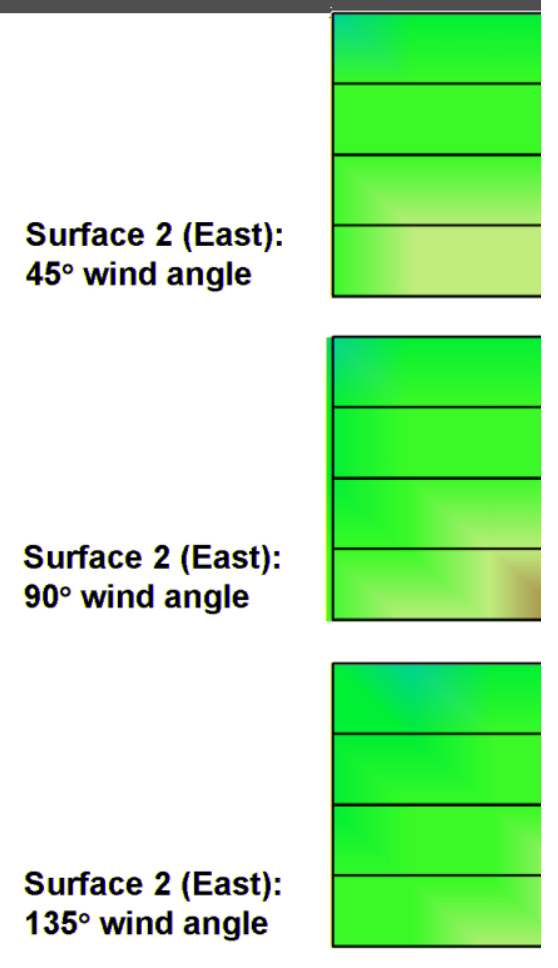

\begin{tabular}{|c|c|c|c|c|c|c|c|c|}
\hline \multicolumn{9}{|c|}{ Model 6 Cp Summary } \\
\hline & \multicolumn{8}{|c|}{ Wind Angle (from North) } \\
\hline & $0^{\circ}$ & $45^{\circ}$ & $90^{\circ}$ & $135^{\circ}$ & $180^{\circ}$ & $225^{\circ}$ & $270^{\circ}$ & $315^{\circ}$ \\
\hline \multicolumn{9}{|l|}{ lest) } \\
\hline & -0.2 & -0.2 & -0.2 & -0.3 & -0.3 & -0.2 & -0.2 & -0.2 \\
\hline & -0.2 & -0.2 & -0.2 & -0.3 & -0.3 & -0.3 & -0.2 & -0.3 \\
\hline & -0.2 & -0.2 & -0.2 & -0.3 & -0.3 & -0.3 & -0.3 & -0.3 \\
\hline & -0.2 & -0.15 & -0.15 & -0.2 & -0.3 & -0.3 & -0.3 & -0.3 \\
\hline \multicolumn{9}{|l|}{ ast) } \\
\hline & -0.2 & -0.2 & -0.2 & -0.2 & -0.3 & -0.3 & -0.2 & -0.2 \\
\hline & -0.2 & -0.3 & -0.2 & -0.3 & -0.3 & -0.3 & -0.2 & -0.2 \\
\hline & -0.2 & -0.3 & -0.3 & -0.3 & -0.3 & -0.3 & -0.2 & -0.2 \\
\hline & -0.2 & -0.3 & -0.3 & -0.3 & -0.3 & -0.2 & -0.15 & -0.15 \\
\hline
\end{tabular}

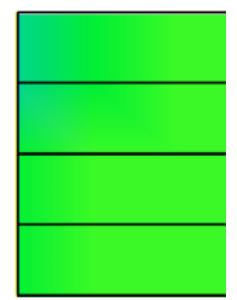

Surface $1(\mathrm{M}$

Level 3

Level 4

Level 5

Level 6

Surface 2 (E Level 3 Level 4

Level 5

Level 6 
Christchurch Model 7:

9 levels ( $28 \mathrm{~m}$ ) tall; $2 \mathrm{~m}$ gap between buildings; 2 levels continuous frontage; $20 \mathrm{~m}$ wide road.
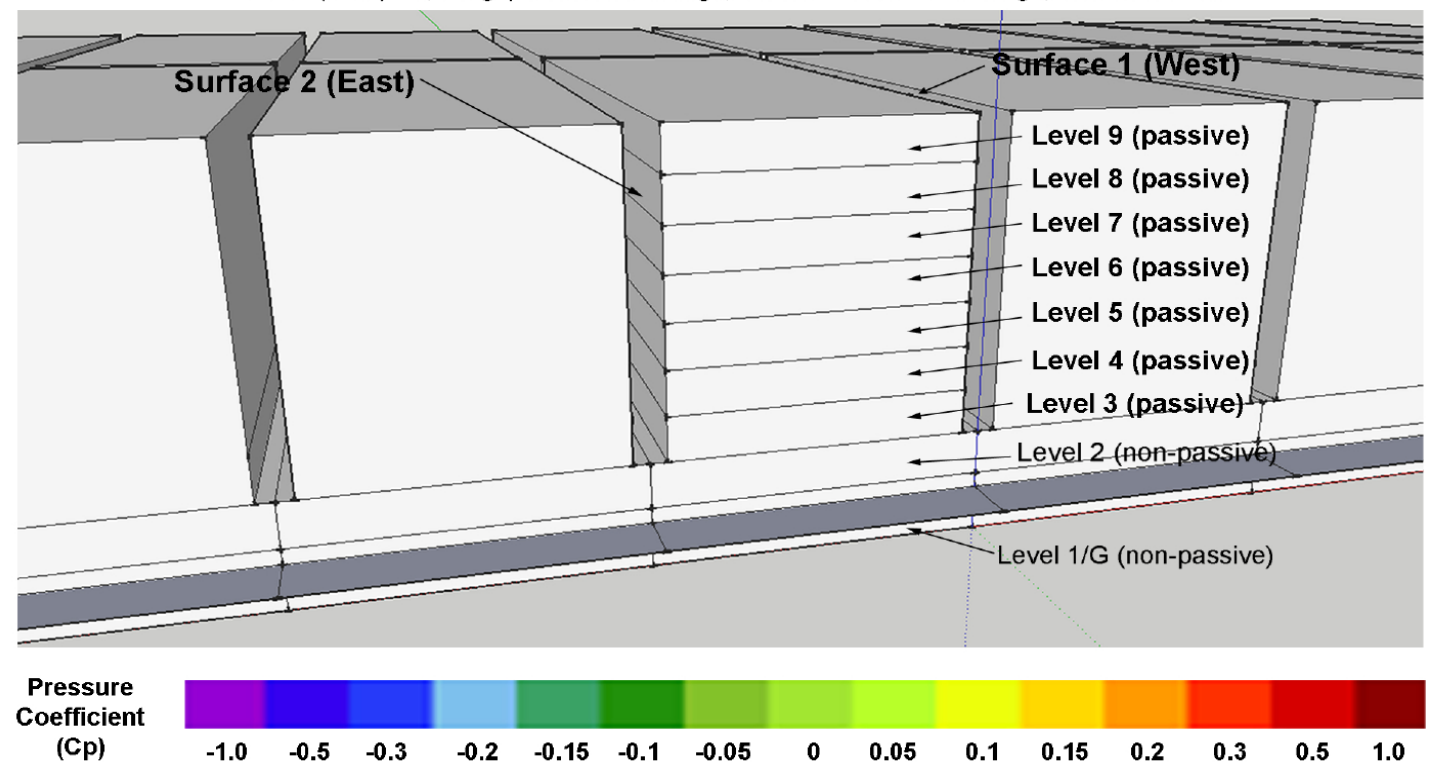

\begin{tabular}{|c|c|}
\hline Lorth end & South end \\
\hline Level 8: average $C p=-0.3$ \\
\hline Level 7: average $C p=-0.3$ \\
\hline Level 6: average $C p=-0.3$ \\
\hline Level 5: average $C p=-0.3$ \\
\hline Level 4: average $C p=-0.3$ \\
\hline Level 3: average $C p=-0.3$ \\
\hline
\end{tabular}

Surface 1 (West) Level 3: average $C p=-0.3$

$0^{\circ}$ wind angle

\begin{tabular}{|c|}
\hline Level 9: average $C p=-0.3$ \\
\hline Level 8: average $C p=-0.3$ \\
\hline Level 7: average $C p=-0.3$ \\
\hline Level 6: average Cp $=-0.3$ \\
\hline Level 5: average $C p=-0.3$ \\
\hline Level 4: average $C p=-0.3$ \\
\hline Level 3: average $C p=-0.3$ \\
\hline
\end{tabular}

Surface 1 (West): $45^{\circ}$ wind angle

\begin{tabular}{|c|}
\hline Level 9: average $C p=-0.3$ \\
\hline Level 8: average $C p=-0.3$ \\
\hline Level 7: average $C p=-0.3$ \\
\hline Level 6: average $C p=-0.3$ \\
\hline Level 5: average $C p=-0.3$ \\
\hline Level 4: average $C p=-0.3$ \\
\hline Level 3: average $C p=-0.3$ \\
\hline
\end{tabular}

Surface 1 (West): Level 3: average $\mathrm{Cp}=-0.3$

$90^{\circ}$ wind angle

\begin{tabular}{|c|}
\hline Level 9: average Cp $=-0.3$ \\
\hline Level 8: average Cp $=-0.3$ \\
\hline Level 7: average Cp $=-0.3$ \\
\hline Level 6: average Cp $=-0.3$ \\
\hline Level 5: average Cp $=-0.3$ \\
\hline Level 4: average Cp $=-0.3$ \\
\hline Level 3: average Cp $=-0.3$ \\
\hline
\end{tabular}

Surface 1 (West): $135^{\circ}$ wind angle

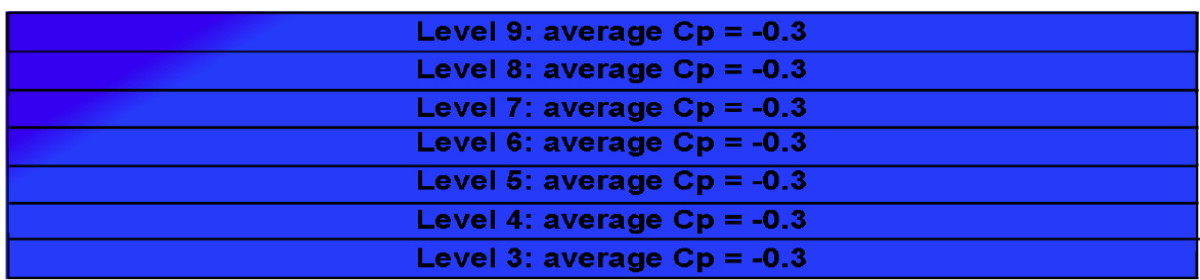

Surface 1 (West): $180^{\circ}$ wind angle 
south end

north end

\begin{tabular}{|c|}
\hline Level 9: average $C p=-0.3$ \\
\hline Level 8: average $C p=-0.3$ \\
\hline Level 7: average $C p=-0.3$ \\
\hline Level 6: average $C p=-0.3$ \\
\hline Level 5: average $C p=-0.3$ \\
\hline Level 4: average $C p=-0.3$ \\
\hline Level 3: average $C p=-0.3$ \\
\hline
\end{tabular}

Surface 2 (East):

$0^{\circ}$ wind angle

\begin{tabular}{|c|}
\hline Level 9: average $C p=-0.3$ \\
\hline Level 8: average $C p=-0.3$ \\
\hline Level 7: average Cp $=-0.3$ \\
\hline Level 6: average Cp $=-0.3$ \\
\hline Level 5: average $C p=-0.3$ \\
\hline Level 4: average Cp $=-0.3$ \\
\hline Level 3: average Cp $=-0.3$ \\
\hline
\end{tabular}

Surface 2 (East):

$45^{\circ}$ wind angle

\begin{tabular}{|c|}
\hline Level 9: average $C p=-0.3$ \\
\hline Level 8: average $C p=-0.3$ \\
\hline Level 7: average $C p=-0.3$ \\
\hline Level 6: average Cp $=-0.3$ \\
\hline Level 5: average $C p=-0.3$ \\
\hline Level 4: average Cp $=-0.3$ \\
\hline Level 3: average $C p=-0.3$ \\
\hline
\end{tabular}

Surface 2 (East): $90^{\circ}$ wind angle

\begin{tabular}{|c|}
\hline Level 9: average $C p=-0.3$ \\
\hline Level 8: average $C p=-0.3$ \\
\hline Level 7: average $C p=-0.3$ \\
\hline Level 6: average Cp $=-0.3$ \\
\hline Level 5: average Cp $=-0.3$ \\
\hline Level 4: average Cp $=-0.3$ \\
\hline Level 3: average $C p=-0.3$ \\
\hline
\end{tabular}

Surface 2 (East): $135^{\circ}$ wind angle

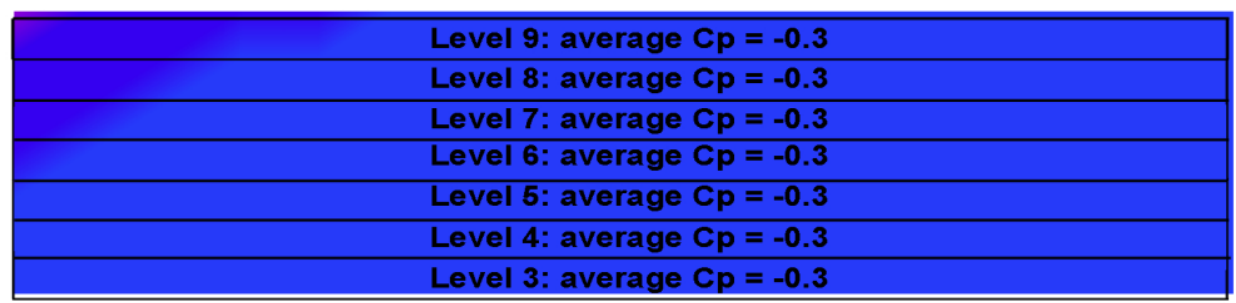

Surface 2 (East): $180^{\circ}$ wind angle

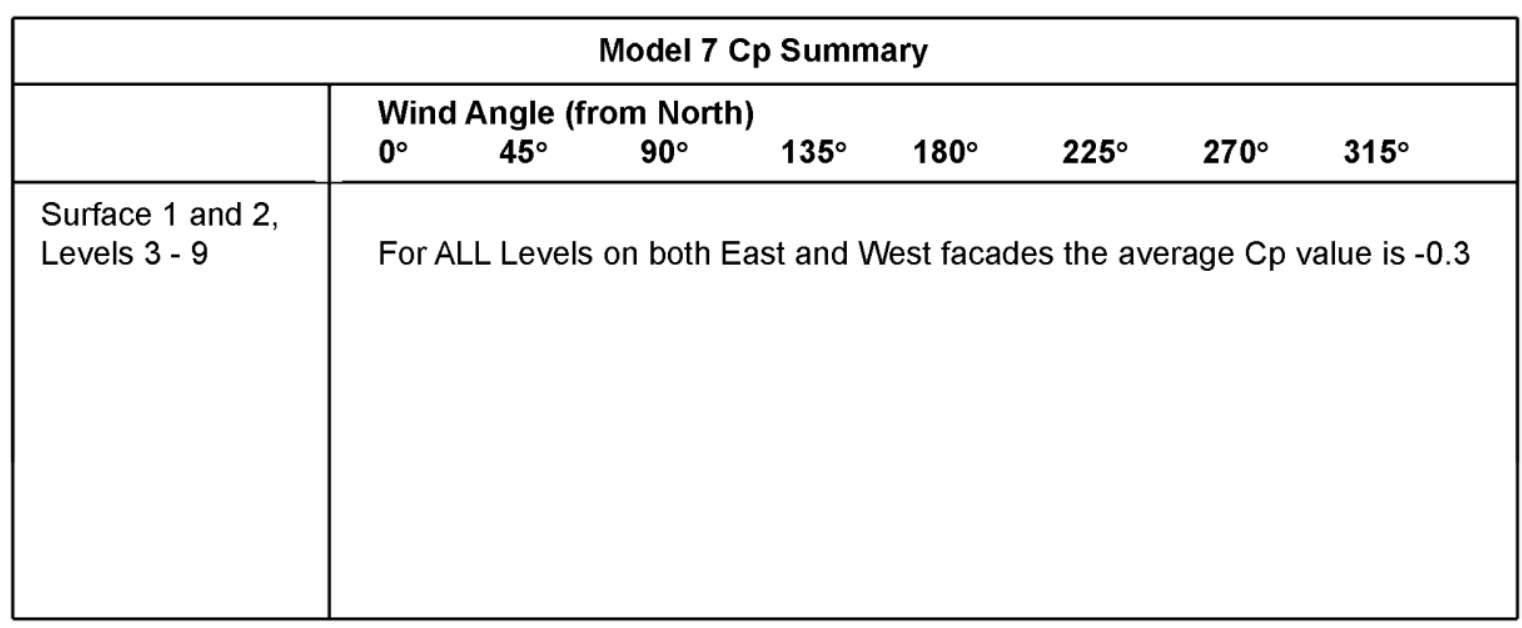


Christchurch Model 8:

9 levels $(28 \mathrm{~m}$ ) tall; $6 \mathrm{~m}$ gap between buildings; 2 levels continuous frontage; $20 \mathrm{~m}$ wide road.
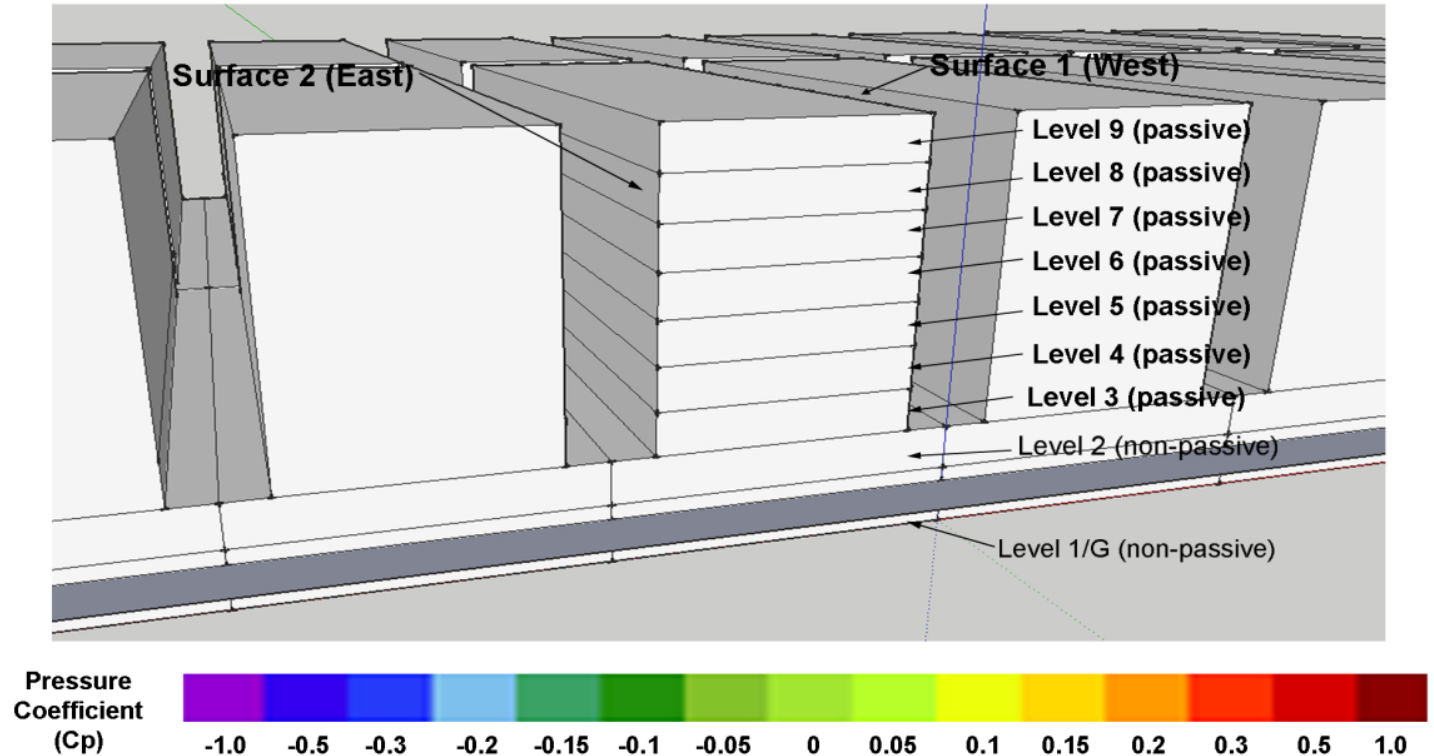

\begin{tabular}{|c|c|}
\hline Level 9: average $C p=-0.3$ & south end \\
\hline Level 8: average $C p=-0.3$ \\
\hline Level 7: average $C p=-0.3$ \\
\hline Level 6: average $C p=-0.3$ \\
\hline Level 5: average $C p=-0.3$ \\
\hline Level 4: average $C p=-0.3$ \\
\hline Level 3: average $C p=-0.3$ \\
\hline
\end{tabular}

Surface 1 (West): $0^{\circ}$ wind angle

\begin{tabular}{|c|}
\hline Level 9: average Cp $=-0.3$ \\
\hline Level 8: average Cp $=-0.3$ \\
\hline Level 7: average Cp $=-0.3$ \\
\hline Level 6: average Cp $=-0.3$ \\
\hline Level 5: average Cp $=-0.3$ \\
\hline Level 4: average Cp $=-0.3$ \\
\hline Level 3: average Cp $=-0.3$ \\
\hline
\end{tabular}

Surface 1 (West): $45^{\circ}$ wind angle

\begin{tabular}{|c|}
\hline Level 9: average $C p=-0.2$ \\
\hline Level 8: average $C p=-0.3$ \\
\hline Level 7: average $C p=-0.3$ \\
\hline Level 6: average $C p=-0.3$ \\
\hline Level 5: average $C p=-0.3$ \\
\hline Level 4: average $C p=-0.3$ \\
\hline Level 3: average $C p=-0.3$ \\
\hline
\end{tabular}

Surface 1 (West): Level 3: average $C p=-0.3$ $90^{\circ}$ wind angle

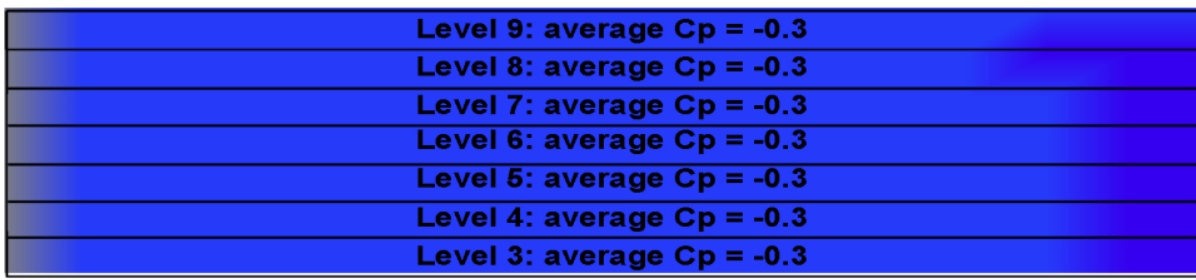

Surface 1 (West): $135^{\circ}$ wind angle

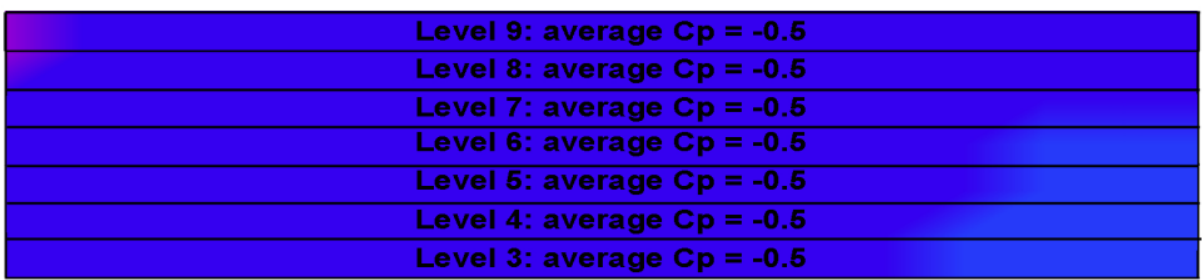

Surface 1 (West) $180^{\circ}$ wind angle 
south end

north end

\begin{tabular}{|c|}
\hline Level 9: average $C p=-0.3$ \\
\hline Level 8: average $C p=-0.3$ \\
\hline Level 7: average $C p=-0.3$ \\
\hline Level 6: average $C p=-0.2$ \\
\hline Level 5: average $C p=-0.2$ \\
\hline Level 4: average $C p=-0.2$ \\
\hline Level 3: average $C p=-0.2$ \\
\hline
\end{tabular}

Surface 2 (East): $0^{\circ}$ wind angle

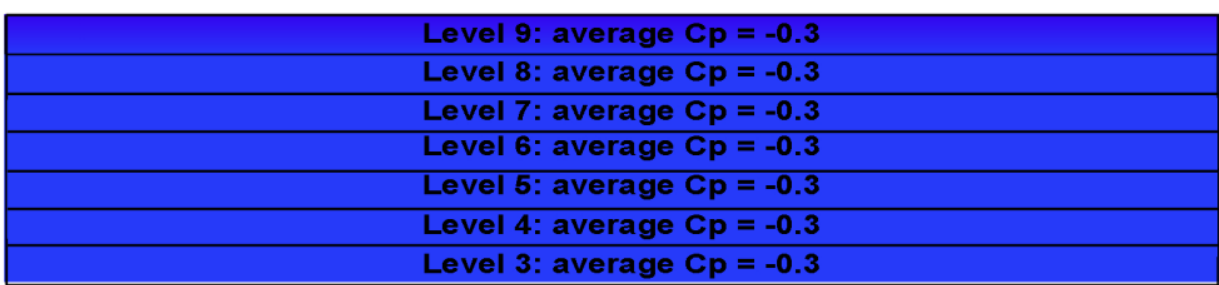

Surface 2 (East): Level 3: average $C p=-0.3$

$45^{\circ}$ wind angle

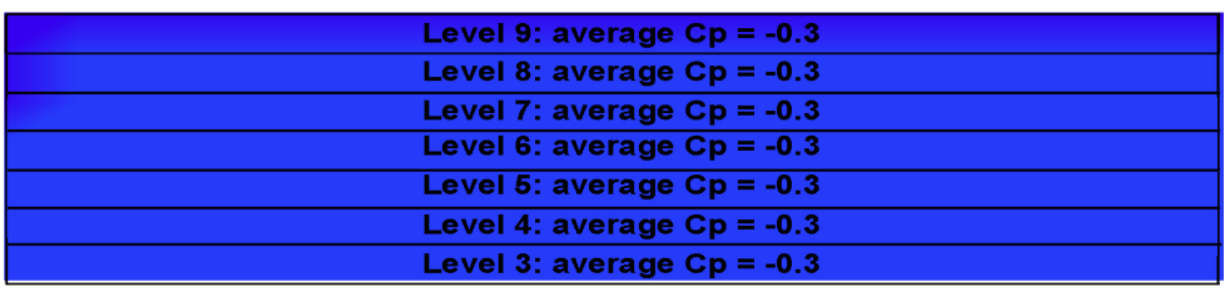

Surface 2 (East): $90^{\circ}$ wind angle

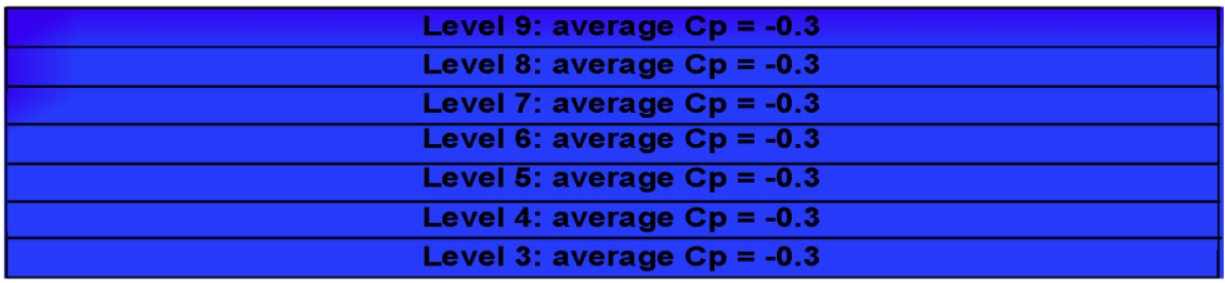

Surface 2 (East): $135^{\circ}$ wind angle

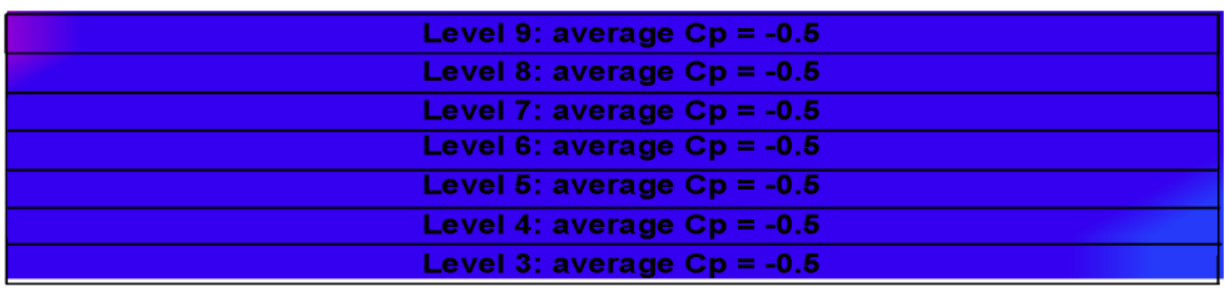

Surface 2 (East): $180^{\circ}$ wind angle

\begin{tabular}{|c|c|c|c|c|c|c|c|c|}
\hline \multicolumn{9}{|c|}{ Model 8 Cp Summary } \\
\hline & \multicolumn{8}{|c|}{ Wind Angle (from North) } \\
\hline & $0^{\circ}$ & $45^{\circ}$ & $90^{\circ}$ & $135^{\circ}$ & $180^{\circ}$ & $225^{\circ}$ & $270^{\circ}$ & $315^{\circ}$ \\
\hline \multicolumn{9}{|l|}{ Surface 1} \\
\hline Level 3 & -0.3 & -0.3 & -0.3 & -0.3 & -0.5 & -0.3 & -0.3 & -0.3 \\
\hline Level 4 & -0.3 & -0.3 & -0.3 & -0.3 & -0.5 & -0.3 & -0.3 & -0.3 \\
\hline Level 5 & -0.3 & -0.3 & -0.3 & -0.3 & -0.5 & -0.3 & -0.3 & -0.3 \\
\hline Level 6 & -0.3 & -0.3 & -0.3 & -0.3 & -0.5 & -0.3 & -0.3 & -0.3 \\
\hline Level 7 & -0.3 & -0.3 & -0.3 & -0.3 & -0.5 & -0.3 & -0.3 & -0.3 \\
\hline Level 8 & -0.3 & -0.3 & -0.3 & -0.3 & -0.5 & -0.3 & -0.3 & -0.3 \\
\hline Level 9 & -0.3 & -0.3 & -0.2 & -0.3 & -0.2 & -0.3 & -0.3 & -0.3 \\
\hline \multicolumn{9}{|l|}{ Surface 2} \\
\hline Level 3 & -0.2 & -0.3 & -0.3 & -0.3 & -0.5 & -0.3 & -0.3 & -0.3 \\
\hline Level 4 & -0.2 & -0.3 & -0.3 & -0.3 & -0.5 & -0.3 & -0.3 & -0.3 \\
\hline Level 5 & -0.2 & -0.3 & -0.3 & -0.3 & -0.5 & -0.3 & -0.3 & -0.3 \\
\hline Level 6 & -0.2 & -0.3 & -0.3 & -0.3 & -0.5 & -0.3 & -0.3 & -0.3 \\
\hline Level 7 & -0.3 & -0.3 & -0.3 & -0.3 & -0.5 & -0.3 & -0.3 & -0.3 \\
\hline Level 8 & -0.3 & -0.3 & -0.3 & -0.3 & -0.5 & -0.3 & -0.3 & -0.3 \\
\hline Level 9 & -0.3 & -0.3 & -0.2 & -0.3 & -0.5 & -0.3 & -0.3 & -0.3 \\
\hline
\end{tabular}


Christchurch Model 9:

9 levels $(28 \mathrm{~m}$ ) tall; $10 \mathrm{~m}$ gap between buildings; 2 levels continuous frontage; $20 \mathrm{~m}$ wide road.

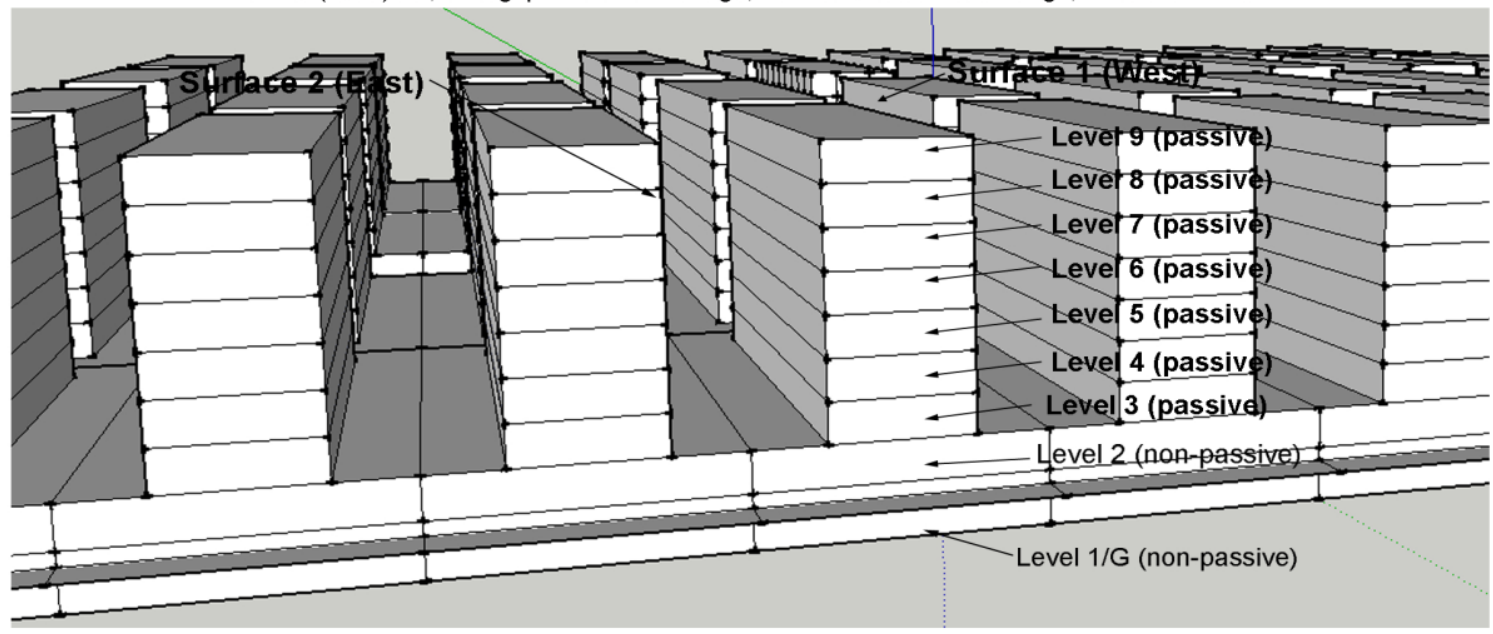

Pressure Coefficient

(Cp)

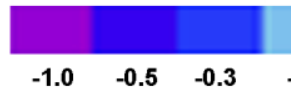

north end

\begin{tabular}{|l|}
\hline Level 9: average $C p=-0.3$ \\
\hline Level 8: average $C p=-0.3$ \\
\hline Level 7: average $C p=-0.3$ \\
\hline Level 6: average $C p=-0.3$ \\
\hline Level 5: average $C p=-0.3$ \\
\hline Level 4: average $C p=-0.3$ \\
\hline Level 3: average $C p=-0.3$ \\
\hline
\end{tabular}

Surface 1 (West): $0^{\circ}$ wind angle

Level 9: average $\mathrm{Cp}=-0.3$

Level 8: average $C p=-0.3$

Level 7: average $C p=-0.3$

Level 6: average $C p=-0.3$

Level 5: average $C p=-0.3$

Level 4: average $C p=-0.3$

Level 3: average $C p=-0.3$

Level 9: average Cp $=-0.2$

Level 8: average $C p=-0.3$

Level 7: average $\mathrm{Cp}=-0.3$

Level 6: average $\mathrm{Cp}=-0.3$

Level 5: average $C p=-0.3$

Level 4: average $C p=-0.3$

Level 3: average $C p=-0.3$

Level 9: average Cp $=-0.3$

Level 8: average $C p=-0.3$

Level 7: average $C p=-0.3$

Level 6: average $C p=-0.3$

Level 5: average $C p=-0.3$

Level 4: average $C p=-0.3$

Level 3: average $C p=-0.3$

Level 9: average $C p=-0.5$

Level 8: average $C p=-0.5$

Level 7: average $\mathrm{Cp}=-0.5$

Level 6: average $C p=-0.5$

Level 5: average $C p=-0.5$

Level 4: average $\mathrm{Cp}=-0.5$

Level 3: average $C p=-0.5$
Surface 1 (West):

Surface 1 (West): $90^{\circ}$ wind angle

Surface 1 (West): $135^{\circ}$ wind angle

Surface 1 (West): $180^{\circ}$ wind angle $45^{\circ}$ wind angle 
south end

north end

\begin{tabular}{|l|}
\hline Level 9: average Cp $=-0.3$ \\
\hline Level 8: average $C p=-0.3$ \\
\hline Level 7: average Cp $=-0.3$ \\
\hline Level 6: average Cp $=-0.2$ \\
\hline Level 5: average Cp $=-0.2$ \\
\hline Level 4: average Cp $=-0.2$ \\
\hline Level 3: average Cp $=-0.2$ \\
\hline
\end{tabular}

Surface 2 (East): $0^{\circ}$ wind angle

\begin{tabular}{|c|}
\hline Level 9: average Cp $=-0.3$ \\
\hline Level 8: average Cp $=-0.3$ \\
\hline Level 7: average Cp $=-0.3$ \\
\hline Level 6: average Cp $=-0.3$ \\
\hline Level 5: average Cp $=-0.3$ \\
\hline Level 4: average Cp $=-0.3$ \\
\hline Level 3: average Cp $=-0.3$ \\
\hline
\end{tabular}

Surface 2 (East): $45^{\circ}$ wind angle

\begin{tabular}{|c|}
\hline Level 9: average $C p=-0.3$ \\
\hline Level 8: average $C p=-0.3$ \\
\hline Level 7: average $C p=-0.3$ \\
\hline Level 6: average Cp $=-0.3$ \\
\hline Level 5: average Cp $=-0.3$ \\
\hline Level 4: average $C p=-0.3$ \\
\hline Level 3: average $C p=-0.3$ \\
\hline
\end{tabular}

Surface 2 (East): $90^{\circ}$ wind angle

\begin{tabular}{|l|}
\hline Level 9: average Cp $=-0.3$ \\
\hline Level 8: average Cp $=-0.3$ \\
\hline Level 7: average Cp $=-0.3$ \\
\hline Level 6: average Cp $=-0.3$ \\
\hline Level 5: average Cp $=-0.3$ \\
\hline Level 4: average Cp $=-0.3$ \\
\hline Level 3: average Cp $=-0.3$ \\
\hline
\end{tabular}

Surface 2 (East): $135^{\circ}$ wind angle

\begin{tabular}{|l|}
\hline Level 9: average Cp $=-0.5$ \\
\hline Level 8: average Cp $=-0.5$ \\
\hline Level 7: average Cp $=-0.5$ \\
\hline Level 6: average Cp $=-0.5$ \\
\hline Level 5: average Cp $=-0.5$ \\
\hline Level 4: average Cp $=-0.5$ \\
\hline Level 3: average Cp $=-0.5$ \\
\hline
\end{tabular}

Surface 2 (East): $180^{\circ}$ wind angle

\begin{tabular}{|c|c|c|c|c|c|c|c|c|}
\hline & \multicolumn{7}{|c|}{ Model 9 Cp Summary } & \multirow[b]{3}{*}{$315^{\circ}$} \\
\hline & \multicolumn{5}{|c|}{ Wind Angle (from North) } & \multirow[b]{2}{*}{$225^{\circ}$} & \multirow[b]{2}{*}{$270^{\circ}$} & \\
\hline & $0^{\circ}$ & $45^{\circ}$ & $90^{\circ}$ & $135^{\circ}$ & $180^{\circ}$ & & & \\
\hline Surface 1 & & & & & & & & \\
\hline Level 3 & -0.3 & -0.3 & -0.3 & -0.3 & -0.5 & -0.3 & -0.3 & -0.3 \\
\hline Level 4 & -0.3 & -0.3 & -0.3 & -0.3 & -0.5 & -0.3 & -0.3 & -0.3 \\
\hline Level 5 & -0.3 & -0.3 & -0.3 & -0.3 & -0.5 & -0.3 & -0.3 & -0.3 \\
\hline Level 6 & -0.3 & -0.3 & -0.3 & -0.3 & -0.5 & -0.3 & -0.3 & -0.3 \\
\hline Level 7 & -0.3 & -0.3 & -0.3 & -0.3 & -0.5 & -0.3 & -0.3 & -0.3 \\
\hline Level 8 & -0.3 & -0.3 & -0.3 & -0.3 & -0.5 & -0.3 & -0.3 & -0.3 \\
\hline Level 9 & -0.3 & -0.3 & -0.2 & -0.3 & -0.2 & -0.3 & -0.3 & -0.3 \\
\hline Surface 2 & & & & & & & & \\
\hline Level 3 & -0.2 & -0.3 & -0.3 & -0.3 & -0.5 & -0.3 & -0.3 & -0.3 \\
\hline Level 4 & -0.2 & -0.3 & -0.3 & -0.3 & -0.5 & -0.3 & -0.3 & -0.3 \\
\hline Level 5 & -0.2 & -0.3 & -0.3 & -0.3 & -0.5 & -0.3 & -0.3 & -0.3 \\
\hline Level 6 & -0.2 & -0.3 & -0.3 & -0.3 & -0.5 & -0.3 & -0.3 & -0.3 \\
\hline Level 7 & -0.3 & -0.3 & -0.3 & -0.3 & -0.5 & -0.3 & -0.3 & -0.3 \\
\hline Level 8 & -0.3 & -0.3 & -0.3 & -0.3 & -0.5 & -0.3 & -0.3 & -0.3 \\
\hline Level 9 & -0.3 & -0.3 & -0.2 & -0.3 & -0.5 & -0.3 & -0.3 & -0.3 \\
\hline
\end{tabular}


Christchurch Model 10:

4 levels $(14 \mathrm{~m})$ tall; $10 \mathrm{~m}$ gap between buildings; 2 levels continuous frontage; $30 \mathrm{~m}$ wide road.
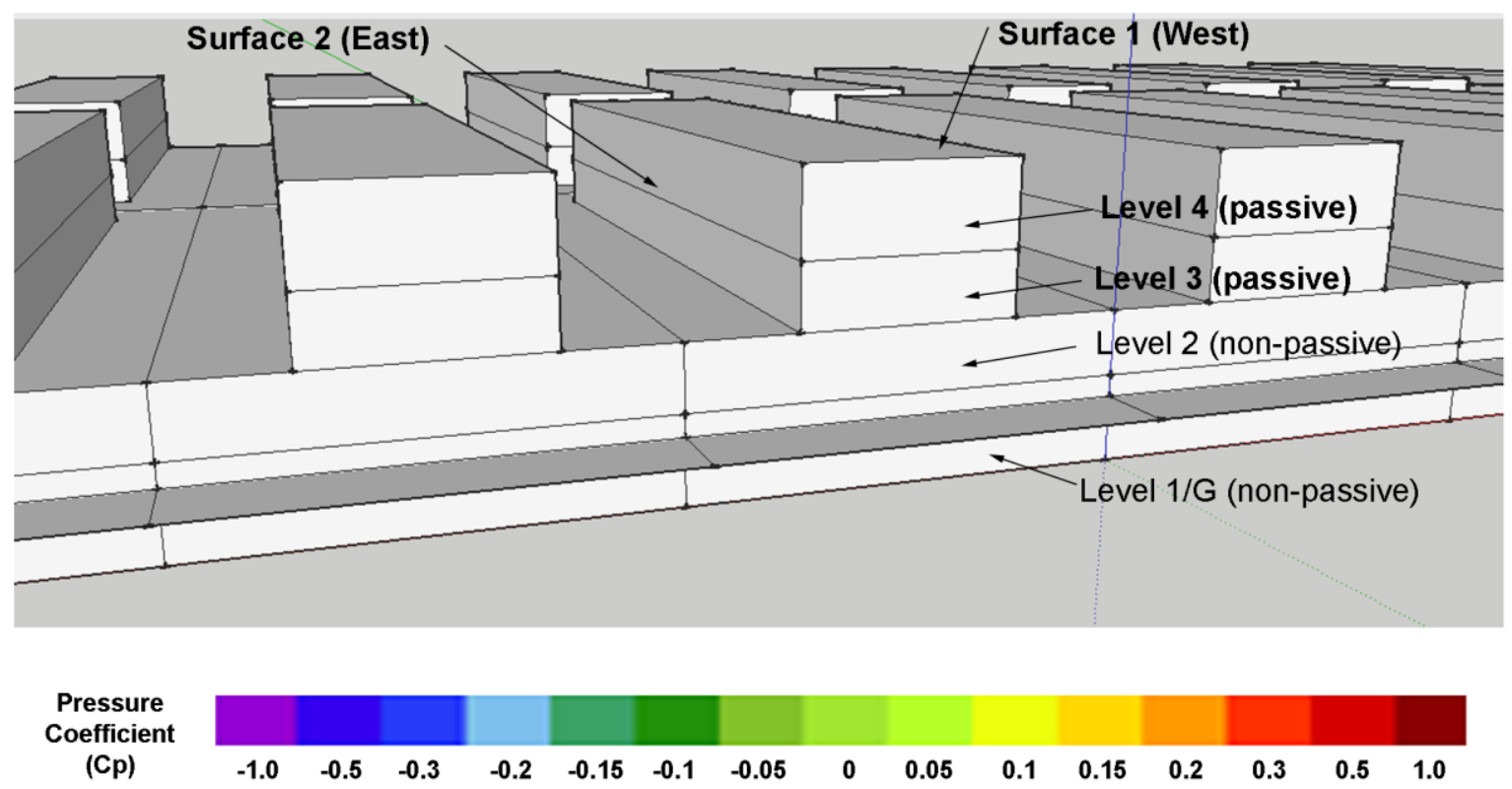

north end south end

Level 4: average $\mathrm{Cp}=-0.2$

Level 3: average $\mathrm{Cp}=-\mathbf{0 . 2}$

Surface 1 (West): $0^{\circ}$ wind angle

Level 4: average $C p=-0.1$

Level 3: average $\mathrm{Cp}=-0.1$

Surface 1 (West): $45^{\circ}$ wind angle

Level 4: average $\mathrm{Cp}=-0.1$

Level 3: average $\mathrm{Cp}=-0.1$

Surface 1 (West): $90^{\circ}$ wind angle

\begin{tabular}{|c|}
\hline Level 4: average $\mathrm{Cp}=-0.15$ \\
\hline Level 3: average $\mathrm{Cp}=-0.15$ \\
\hline
\end{tabular}

Surface 1 (West): $135^{\circ}$ wind angle

Level 4: average $\mathrm{Cp}=-0.2$

Level 3: average $\mathrm{Cp}=-0.2$

Surface 1 (West): $180^{\circ}$ wind angle 


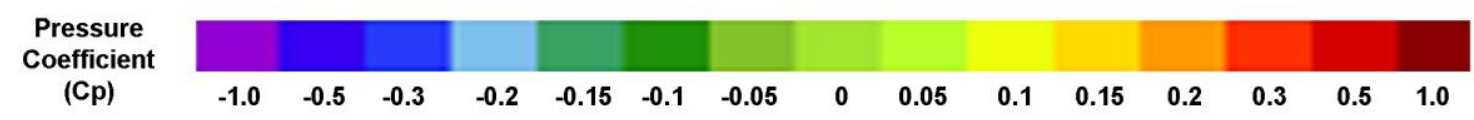

north end south end

Level 4: average $C p=-0.2$

Level 3: average $\mathrm{Cp}=-0.2$

Surface 2 (East): $0^{\circ}$ wind angle

Level 4: average $\mathrm{Cp}=-0.3$

Level 3: average $\mathrm{Cp}=-0.2$

Surface 2 (East): $45^{\circ}$ wind angle

Level 4: average $\mathrm{Cp}=-0.3$

Level 3: average $C p=-0.1$

Surface 2 (East): $90^{\circ}$ wind angle

\begin{tabular}{|c|}
\hline Level 4: average $\mathrm{Cp}=-0.15$ \\
\hline Level 3: average $\mathrm{Cp}=-0.2$ \\
\hline
\end{tabular}

Surface 2 (East): $135^{\circ}$ wind angle

Level 4: average $C p=-0.2$

Level 3: average $\mathrm{Cp}=-0.2$

Surface 2 (East): $180^{\circ}$ wind angle

\begin{tabular}{|c|c|c|c|c|c|c|c|c|}
\hline \multicolumn{9}{|c|}{ Model $10 \mathrm{Cp}$ Summary } \\
\hline & \multicolumn{8}{|c|}{ Wind Angle (from North) } \\
\hline & $0^{\circ}$ & $45^{\circ}$ & $90^{\circ}$ & $135^{\circ}$ & $180^{\circ}$ & $225^{\circ}$ & $270^{\circ}$ & $315^{\circ}$ \\
\hline \multicolumn{9}{|l|}{ Surface 1 (West) } \\
\hline Level 3 & -0.2 & -0.1 & -0.1 & -0.15 & -0.2 & -0.2 & -0.1 & -0.2 \\
\hline Level 4 & -0.2 & -0.1 & -0.1 & -0.15 & -0.2 & -0.15 & -0.3 & -0.3 \\
\hline \multicolumn{9}{|l|}{ Surface 2 (East) } \\
\hline Level 3 & -0.2 & -0.2 & -0.1 & -0.2 & -0.2 & -0.15 & -0.1 & -0.1 \\
\hline Level 4 & -0.2 & -0.3 & -0.3 & -0.15 & -0.2 & -0.15 & -0.1 & -0.1 \\
\hline
\end{tabular}


Christchurch Model 11:

6 levels $(20 \mathrm{~m})$ tall; $6 \mathrm{~m}$ gap between buildings; 2 levels continuous frontage; $30 \mathrm{~m}$ wide road

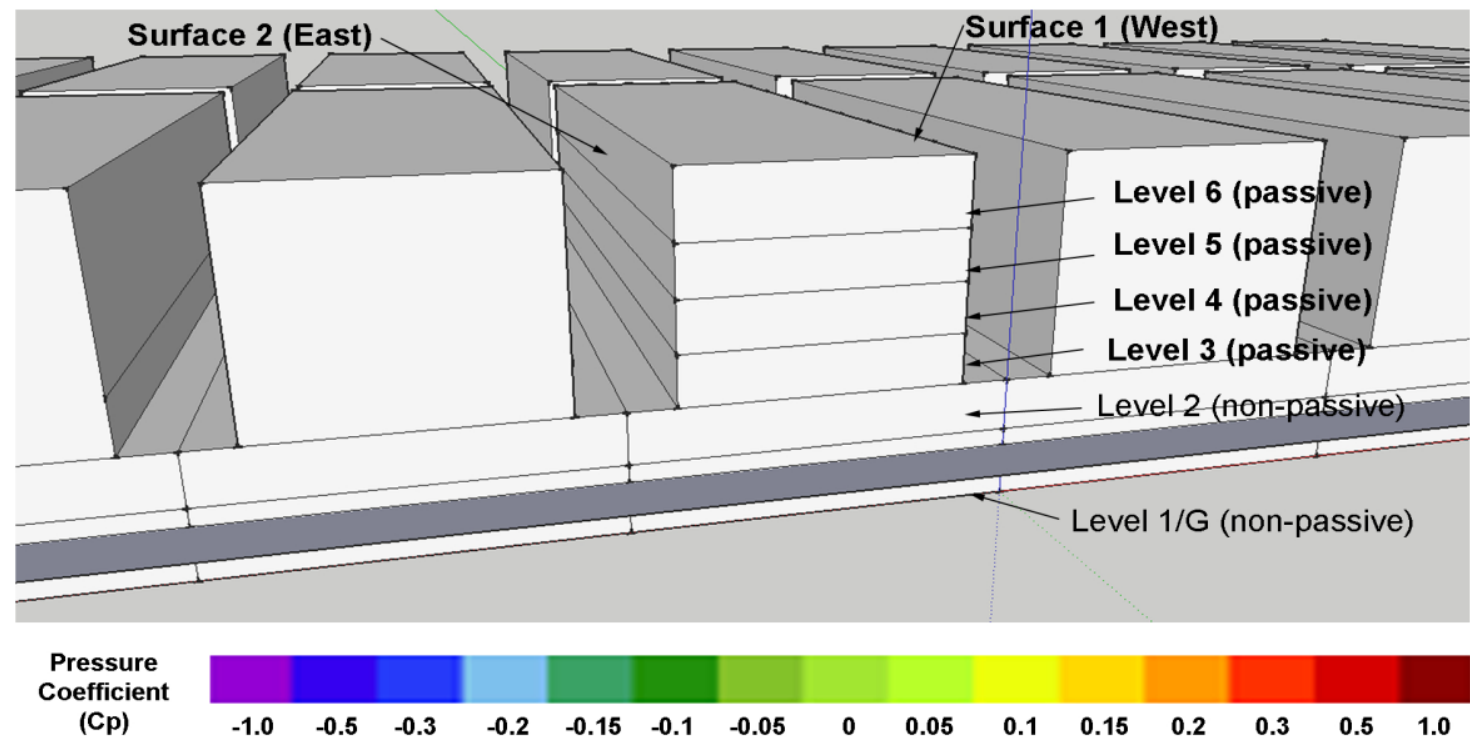

north end

south end

\begin{tabular}{|l|}
\hline Level 6: average $C p=-0.3$ \\
\hline Level 5: average $C p=-0.2$ \\
\hline Level 4: average $C p=-0.2$ \\
\hline Level 3: average $C p=-0.2$ \\
\hline
\end{tabular}

Surface 1 (West): $0^{\circ}$ wind angle

\begin{tabular}{|l|}
\hline Level 6: average $C p=-0.15$ \\
\hline Level 5: average $C p=-0.2$ \\
\hline Level 4: average $C p=-0.2$ \\
\hline Level 3: average $C p=-0.2$ \\
\hline
\end{tabular}

Surface 1 (West): $45^{\circ}$ wind angle

\begin{tabular}{|l|}
\hline Level 6: average $C p=-0.2$ \\
\hline Level 5: average $C p=-0.2$ \\
\hline Level 4: average $C p=-0.15$ \\
\hline Level 3: average $C p=-0.15$ \\
\hline
\end{tabular}

Surface 1 (West): $90^{\circ}$ wind angle

\begin{tabular}{|l|}
\hline Level 6: average $C p=-0.2$ \\
\hline Level 5: average $C p=-0.2$ \\
\hline Level 4: average $C p=-0.2$ \\
\hline Level 3: average $C p=-0.2$ \\
\hline
\end{tabular}

Surface 1 (West): $135^{\circ}$ wind angle

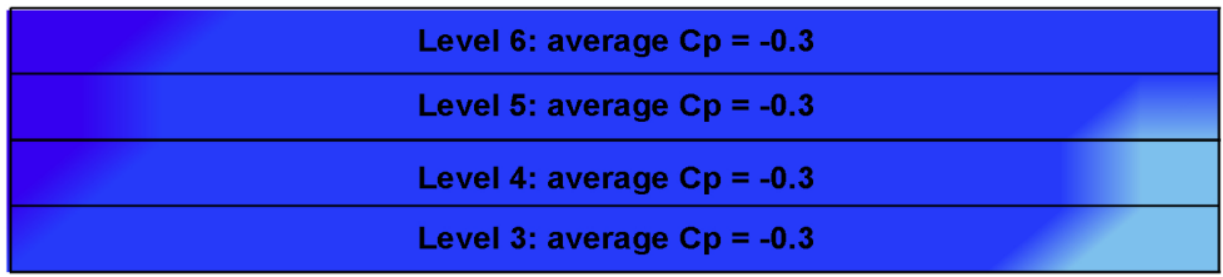

Surface 1 (West): $180^{\circ}$ wind angle 
south end

north end

\begin{tabular}{|l|}
\hline Level 6: average $C p=-0.2$ \\
\hline Level 5: average $C p=-0.2$ \\
\hline Level 4: average $C p=-0.2$ \\
\hline Level 3: average $C p=-0.2$ \\
\hline
\end{tabular}

Surface 2 (East):

$0^{\circ}$ wind angle

\begin{tabular}{|l|}
\hline Level 6: average $C p=-0.3$ \\
\hline Level 5: average $C p=-0.2$ \\
\hline Level 4: average $C p=-0.2$ \\
\hline Level 3: average $C p=-0.2$ \\
\hline
\end{tabular}

Surface 2 (East): $45^{\circ}$ wind angle

\begin{tabular}{|l|}
\hline Level 6: average $C p=-0.3$ \\
\hline Level 5: average $C p=-0.2$ \\
\hline Level 4: average $C p=-0.15$ \\
\hline Level 3: average $C p=-0.15$ \\
\hline
\end{tabular}

Surface 2 (East): $90^{\circ}$ wind angle

\begin{tabular}{|l|}
\hline Level 6: average $\mathrm{Cp}=-0.3$ \\
\hline Level 5: average $\mathrm{Cp}=-0.2$ \\
\hline Level 4: average $\mathrm{Cp}=-0.2$ \\
\hline Level 3: average $\mathrm{Cp}=-0.2$ \\
\hline
\end{tabular}

Surface 2 (East): $135^{\circ}$ wind angle

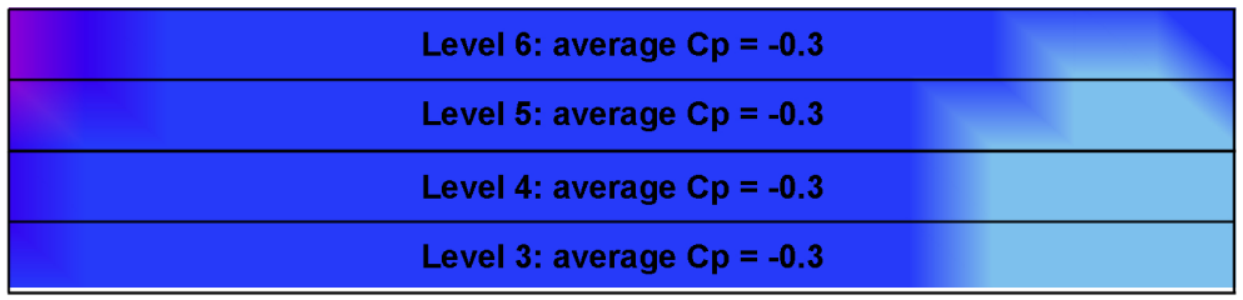

Surface 2 (East) $180^{\circ}$ wind angle

\begin{tabular}{|l|llllllll|}
\hline \multicolumn{8}{|c|}{ Model 11 Cp Summary } \\
\hline & \multicolumn{7}{|l|}{ Wind Angle (from North) } \\
& $\mathbf{0}^{\circ}$ & $\mathbf{4 5 ^ { \circ }}$ & $\mathbf{9 0}^{\circ}$ & $\mathbf{1 3 5}^{\circ}$ & $\mathbf{1 8 0}^{\circ}$ & $\mathbf{2 2 5}^{\circ}$ & $\mathbf{2 7 0}^{\circ}$ & $\mathbf{3 1 5}^{\circ}$ \\
\hline Surface 1 (West) & & & & & & & & \\
Level 3 & -0.2 & -0.2 & -0.15 & -0.2 & -0.3 & -0.2 & -0.15 & -0.2 \\
Level 4 & -0.2 & -0.2 & -0.15 & -0.2 & -0.3 & -0.2 & -0.15 & -0.2 \\
Level 5 & -0.2 & -0.2 & -0.2 & -0.2 & -0.3 & -0.2 & -0.2 & -0.2 \\
Level 6 & -0.3 & -0.15 & -0.2 & -0.2 & -0.3 & -0.3 & -0.3 & -0.3 \\
Surface 2 (East) & & & & & & & & \\
Level 3 & -0.2 & -0.2 & -0.15 & -0.2 & -0.3 & -0.2 & -0.15 & -0.2 \\
Level 4 & -0.2 & -0.2 & -0.15 & -0.2 & -0.3 & -0.2 & -0.15 & -0.2 \\
Level 5 & -0.2 & -0.2 & -0.2 & -0.2 & -0.3 & -0.2 & -0.2 & -0.2 \\
Level 6 & -0.2 & -0.3 & -0.3 & -0.3 & -0.3 & -0.2 & -0.2 & -0.15 \\
\hline
\end{tabular}




\section{Christchurch Model 12:}

9 levels (28m ) tall; $2 \mathrm{~m}$ gap between buildings; 2 levels continuous frontage; $30 \mathrm{~m}$ wide road.
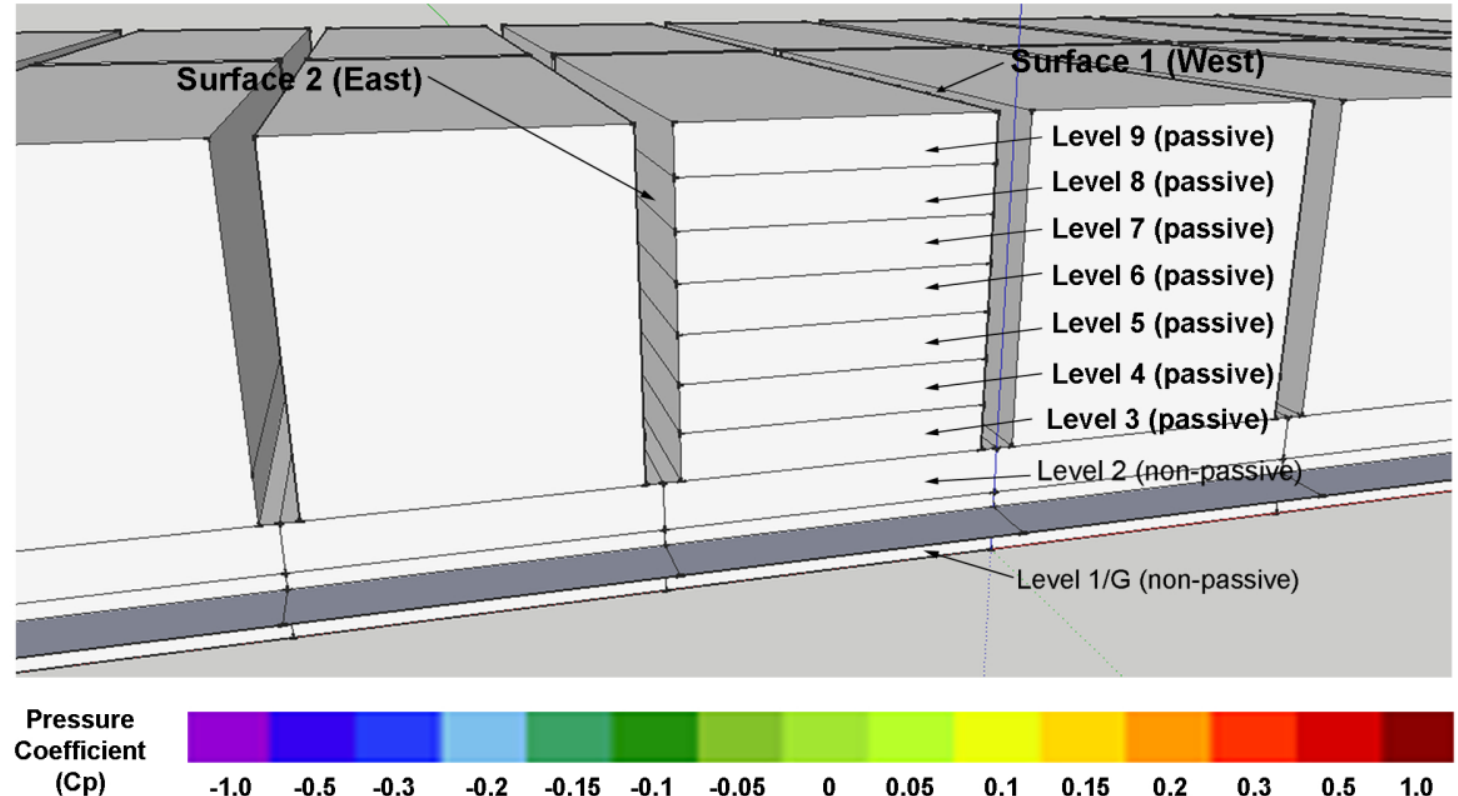

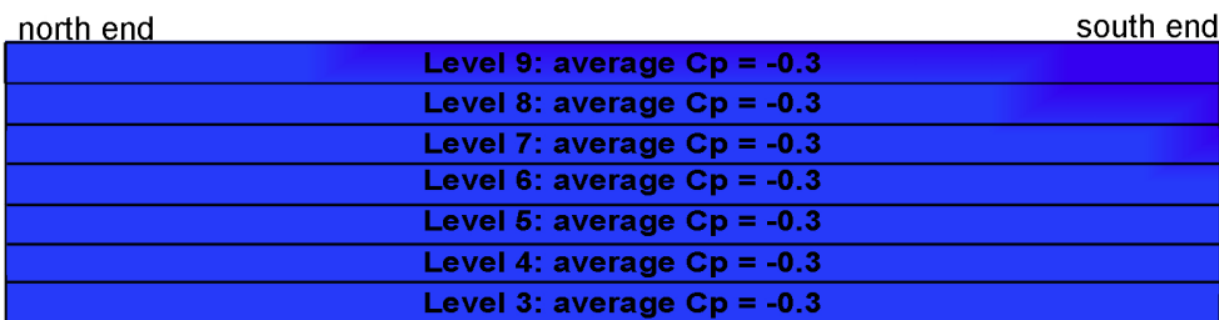

\begin{tabular}{|l|}
\hline Level 9: average $C p=-0.3$ \\
\hline Level 8: average $C p=-0.3$ \\
\hline Level 7: average $C p=-0.3$ \\
\hline Level 6: average $C p=-0.3$ \\
\hline Level 5: average $C p=-0.3$ \\
\hline Level 4: average $C p=-0.3$ \\
\hline Level 3: average $C p=-0.3$ \\
\hline
\end{tabular}

Level 9: average $\mathrm{Cp}=-0.3$

Level 8: average $\mathrm{Cp}=-0.3$

Level 7: average $\mathrm{Cp}=-\mathbf{0 . 3}$

Level 6: average $\mathrm{Cp}=-0.3$

Level 5: average $\mathrm{Cp}=-0.3$

Level 4: average $\mathrm{Cp}=-0.3$

Level 3: average $\mathrm{Cp}=-0.3$

\section{Level 9: average $\mathrm{Cp}=-0.3$}

Level 8: average $\mathrm{Cp}=-0.3$

Level 7: average $\mathrm{Cp}=-0.3$

Level 6: average $\mathrm{Cp}=-0.3$

Level 5: average $\mathrm{Cp}=-0.3$

Level 4: average $\mathrm{Cp}=-\mathbf{0 . 3}$

Level 3: average $\mathrm{Cp}=-0.3$

\begin{tabular}{|c|}
\hline Level 9: average $C p=-0.3$ \\
\hline Level 8: average $C p=-0.3$ \\
\hline Level 7: average $C p=-0.3$ \\
\hline Level 6: average $C p=-0.3$ \\
\hline Level 5: average $C p=-0.3$ \\
\hline Level 4: average $C p=-0.3$ \\
\hline Level 3: average $C p=-0.3$ \\
\hline
\end{tabular}

Surface 1 (West): $0^{\circ}$ wind angle

Surface 1 (West): $45^{\circ}$ wind angle

Surface 1 (West): $90^{\circ}$ wind angle

Surface 1 (West): $135^{\circ}$ wind angle 


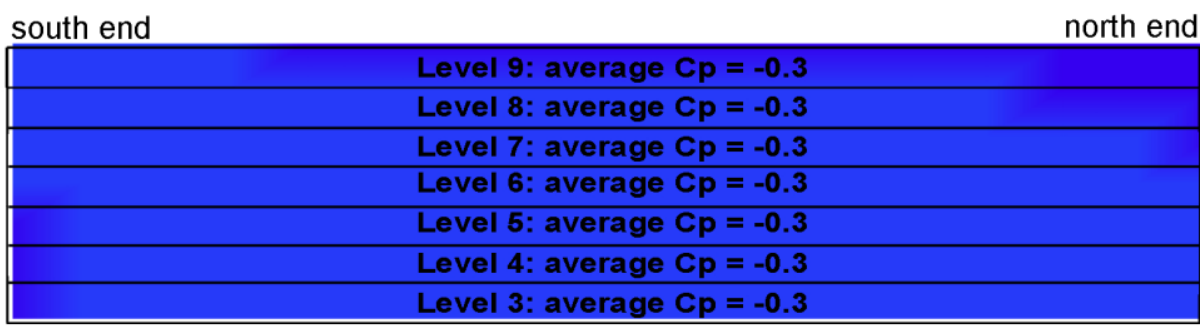

Surface 2 (East): $0^{\circ}$ wind angle

\begin{tabular}{|c|}
\hline Level 9: average $C p=-0.3$ \\
\hline Level 8: average $C p=-0.3$ \\
\hline Level 7: average Cp $=-0.3$ \\
\hline Level 6: average Cp $=-0.3$ \\
\hline Level 5: average Cp $=-0.3$ \\
\hline Level 4: average Cp $=-0.3$ \\
\hline Level 3: average Cp $=-0.3$ \\
\hline
\end{tabular}

Surface 2 (East): $45^{\circ}$ wind angle

\begin{tabular}{|c||}
\hline Level 9: average $C p=-0.3$ \\
\hline Level 8: average $C p=-0.2$ \\
\hline Level 7: average $C p=-0.2$ \\
\hline Level 6: average $C p=-0.2$ \\
\hline Level 5: average $C p=-0.2$ \\
\hline Level 4: average $C p=-0.2$ \\
\hline Level 3: average $C p=-0.2$ \\
\hline
\end{tabular}

Surface 2 (East): $90^{\circ}$ wind angle

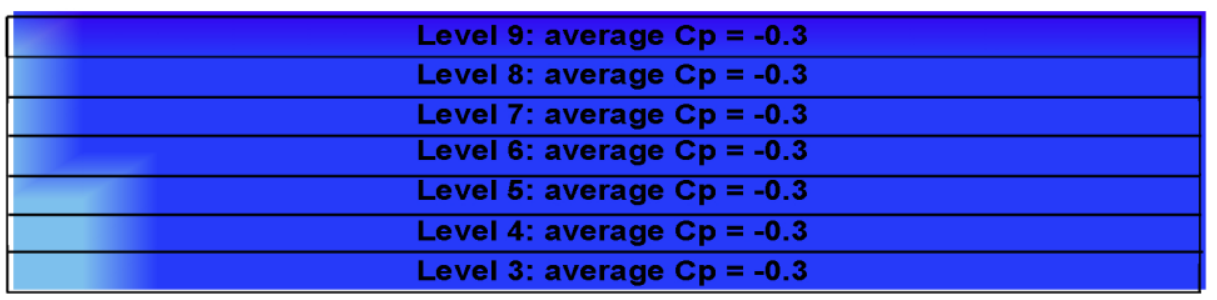

Surface 2 (East): $135^{\circ}$ wind angle

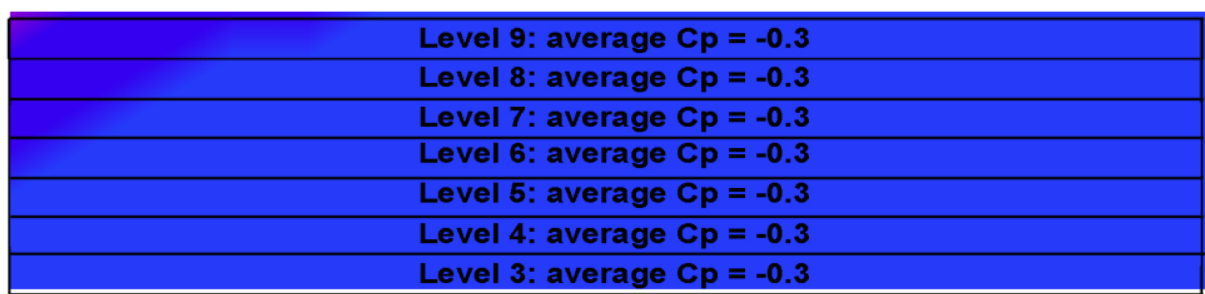

Surface 2 (East): $180^{\circ}$ wind angle

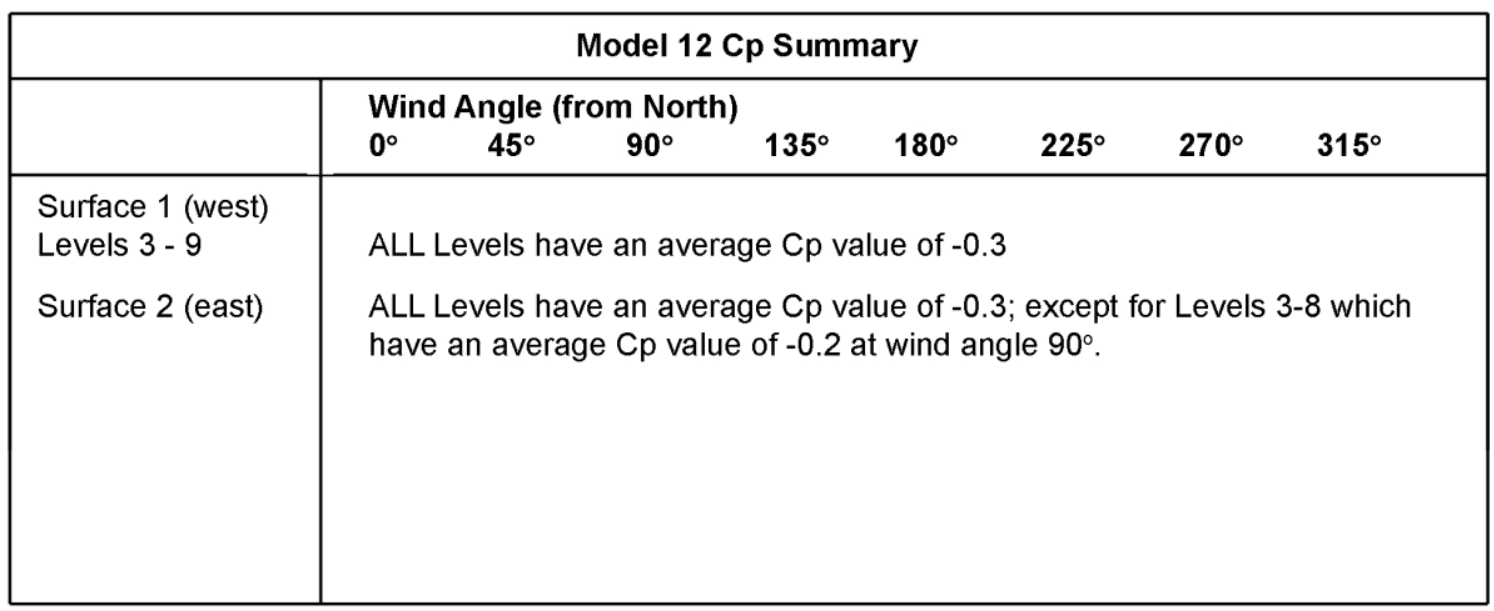




\section{Christchurch Model 13:}

4 levels (14m ) tall; no surrounding buildings (isolated).
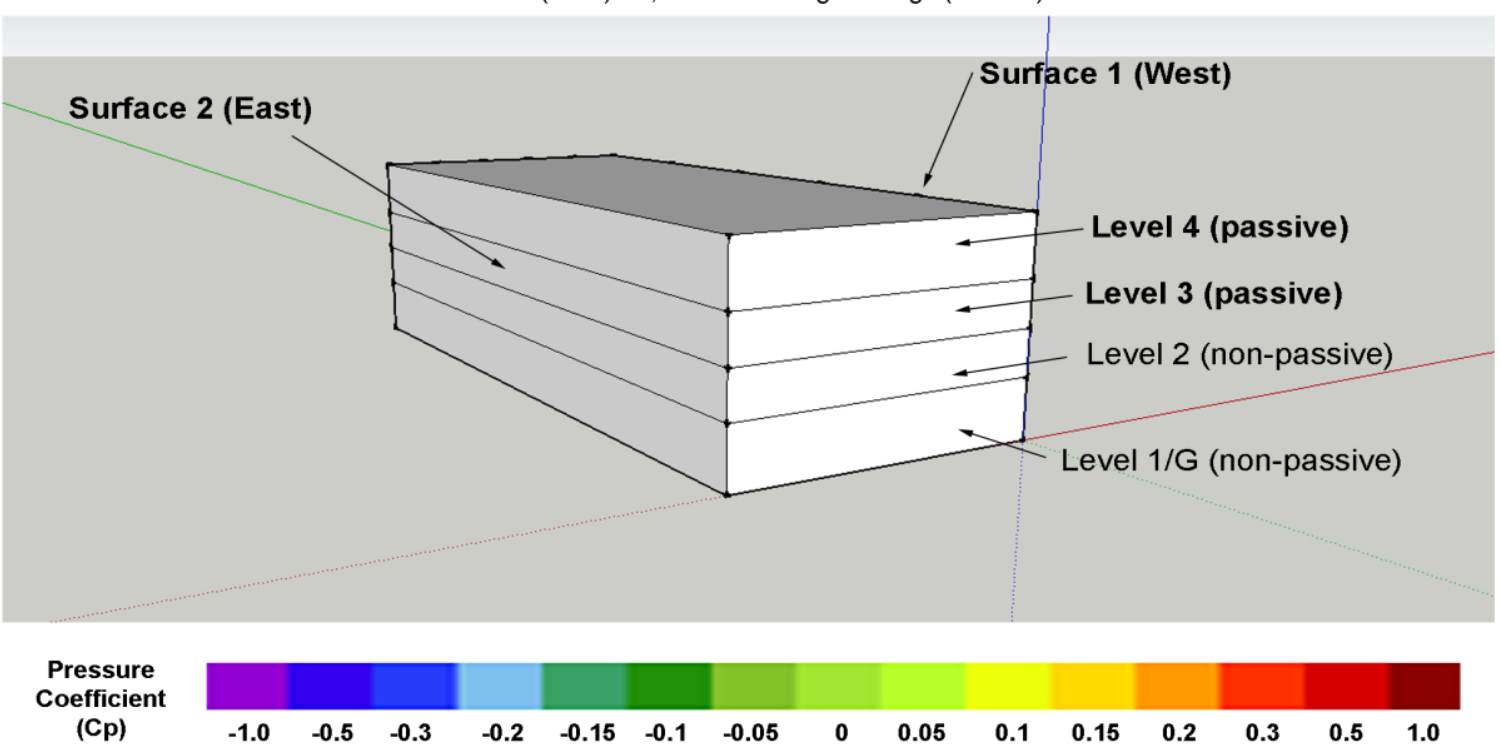

north end

south end

\begin{tabular}{|l|}
\hline Level 6: average $C p=-0.2$ \\
\hline Level 5: average $C p=-0.2$ \\
\hline Level 4: average $C p=-0.2$ \\
\hline Level 3: average $C p=-0.2$ \\
\hline
\end{tabular}

Surface 1 (West):

$0^{\circ}$ wind angle

Level 6: average $\mathrm{Cp}=0.3$

Level 5: average $\mathrm{Cp}=0.3$

Level 4: average $\mathrm{Cp}=0.3$

Level 3: average $\mathrm{Cp}=0.5$

Surface 1 (West): $45^{\circ}$ wind angle

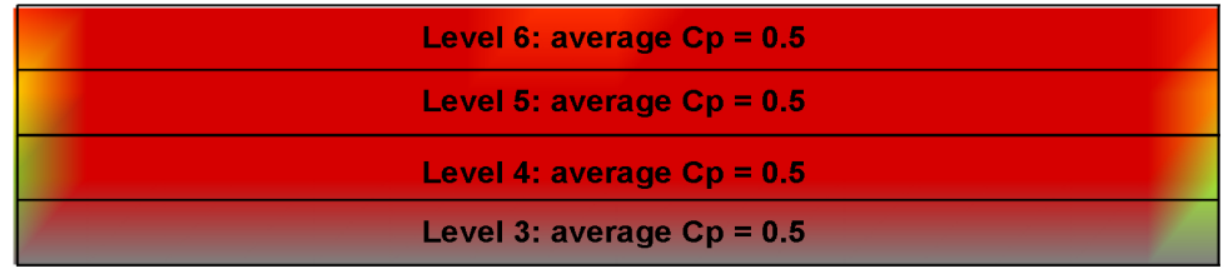

Surface 1 (West): $90^{\circ}$ wind angle

\begin{tabular}{|l|}
\hline Level 6: average $C p=0.2$ \\
\hline Level 5: average $C p=0.3$ \\
\hline Level 4: average $C p=0.3$ \\
\hline Level 3: average $C p=0.5$ \\
\hline
\end{tabular}

Surface 1 (West): $135^{\circ}$ wind angle

\begin{tabular}{|l|}
\hline Level 6: average $C p=-0.2$ \\
\hline Level 5: average $C p=-0.2$ \\
\hline Level 4: average $C p=-0.2$ \\
\hline Level 3: average $C p=-0.2$ \\
\hline
\end{tabular}




\begin{tabular}{|l|}
\hline Level 6: average $\mathrm{Cp}=-0.2$ \\
\hline Level 5: average $\mathrm{Cp}=-0.2$ \\
\hline Level 4: average $\mathrm{Cp}=-0.2$ \\
\hline Level 3: average $\mathrm{Cp}=-0.2$ \\
\hline
\end{tabular}

Surface 2 (East): $0^{\circ}$ wind angle

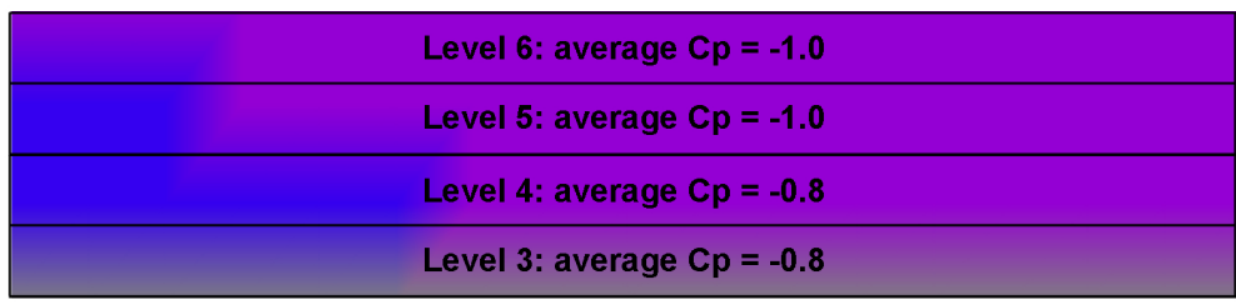

Surface 2 (East): $45^{\circ}$ wind angle

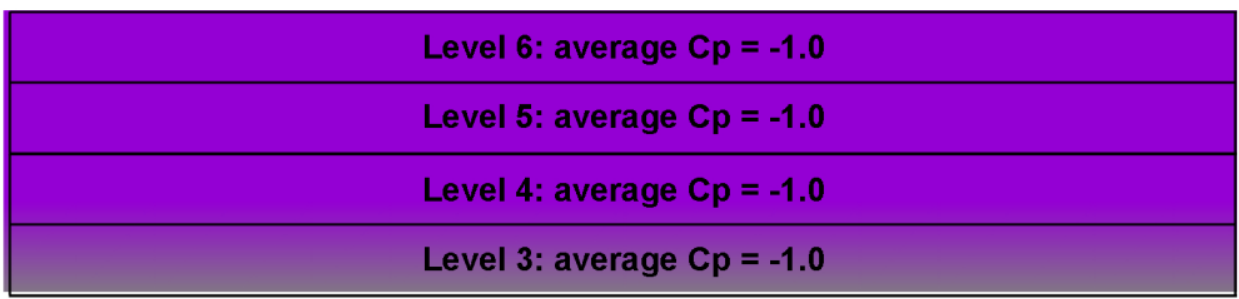

Surface 2 (East): $90^{\circ}$ wind angle

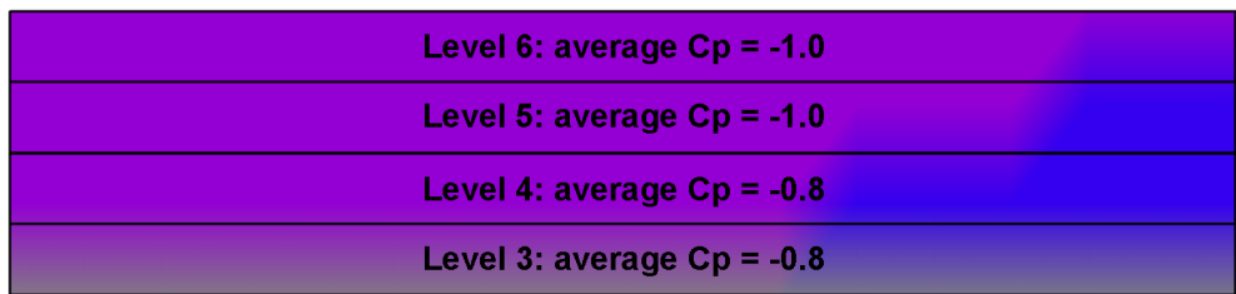

Surface 2 (East): $135^{\circ}$ wind angle

\begin{tabular}{|l|}
\hline Level 6: average $C p=-0.2$ \\
\hline Level 5: average $C p=-0.2$ \\
\hline Level 4: average $C p=-0.2$ \\
\hline Level 3: average $C p=-0.2$ \\
\hline
\end{tabular}

Surface 2 (East): $180^{\circ}$ wind angle

\begin{tabular}{|l|cccccccc|}
\hline \multicolumn{8}{|c|}{ Model 13 Cp Summary } \\
\hline & \multicolumn{7}{|c|}{ Wind Angle (from North) } \\
& $\mathbf{0}^{\circ}$ & $\mathbf{4 5 ^ { \circ }}$ & $\mathbf{9 0 ^ { \circ }}$ & $\mathbf{1 3 5}$ & $\mathbf{1 8 0 ^ { \circ }}$ & $\mathbf{2 2 5}^{\circ}$ & $\mathbf{2 7 0}^{\circ}$ & $\mathbf{3 1 5}^{\circ}$ \\
\hline Surface 1 (West) & & & & & & & & \\
Level 3 & -0.2 & 0.5 & 0.5 & 0.5 & -0.2 & -0.8 & -1.0 & -0.8 \\
Level 4 & -0.2 & 0.3 & 0.5 & 0.3 & -0.2 & -0.8 & -1.0 & -0.8 \\
Level 5 & -0.2 & 0.3 & 0.5 & 0.3 & -0.2 & -1.0 & -1.0 & -1.0 \\
Level 6 & -0.2 & 0.3 & 0.5 & 0.2 & -0.2 & -1.0 & -1.0 & -1.0 \\
Surface 2 (East) & & & & & & & & \\
Level 3 & -0.2 & -0.8 & -1.0 & -0.8 & -0.2 & 0.5 & 0.5 & 0.5 \\
Level 4 & -0.2 & -0.8 & -1.0 & -0.8 & -0.2 & 0.3 & 0.5 & 0.3 \\
Level 5 & -0.2 & -1.0 & -1.0 & -1.0 & -0.2 & 0.3 & 0.5 & 0.3 \\
Level 6 & -0.2 & -1.0 & -1.0 & -1.0 & -0.2 & 0.2 & 0.5 & 0.3 \\
\hline
\end{tabular}


Urban Form and Passive Design for High Performance Buildings in the Christchurch Rebuild 